UNIVERSIDADE DE SÅO PAULO

ESCOLA DE COMUNICAÇOESE ARTES

\title{
TRÊS CENTROS CULTURAIS NA CIDADE DE SÃO PAULO
}

\author{
ROBERTO CENNI
}

DISSERTAÇÃO DE MESTRADO

Orientador: Prof. Dr. José Teixeira Coelho Netto.

\author{
$S A ̃ O P A U L O$ \\ 1991
}




\section{TFES CENTRQS CULTUFAIS}

DA CIDADE DE SAD PAULO

Roberto Cenni

DISSERTAÇAD DE MESTRADO

Orientador: Frof.Dr. José Teixeira Coelho Netto

ESCOLA DE COMUNICACYES E ARTES

UNIVERSIDADE DE SAD PAULO

SAO PAULO - 1991 
Esta dissertação é dedicada as pessoas que por meio do seu trabalho contribuem para a produçăn, a difusăo e a compreensăo dos elementos culturais. 
Agradeço a colaboraçăo de

Jose Teixeira Coelho Netto

Lúcia Vianna Lacourt

Monica Aliseris

e também a

Laura Figueira de Aguiar

Maria Christina Barbosa de Almeida

Marilia Ansarah

Mar1lia Xavier Cury

Meire Inevaso

Paulo Vasconcelos

Vanda Teixeira

bem como a todos os que concederam entrevistas e contribuiram com dados e informaçôes. 


\section{RESUMO}

o presente trabatho teve como proposta pesquisar os tress espacos da

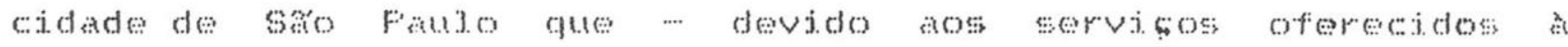
populaso a diversidade e dinamismo das atividades propostas -... majs ten atuado com as caractersteas de contros culturats.

o Contro Culturat Sáo Fauto foj concebido para ser uma grande biblioteca pubitca e teve oseu projeto adaptado a um centro culturat que visava multiplas atividades. E um depertamento que

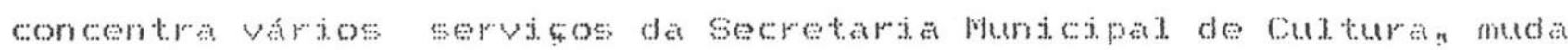
seus dirigentes e chefes de divisos periodicamente re recte mutos jovens: que vao estudar na bibliotecan

o Museu l..sar segat. foi constitudo para abrigar e divulgar a obra desse artista tendo sido criado por iniciativa de sua fantija ma casa em que moravam fum do acervo possus apesar de suas pequenas dimensoms uma biblioten esecializad e areas que oferecem propostas participativas aos frequentadores. 0 museu conta com antigos funcionarios para desenvolvor mas atividadese sempre sorreu por problemas de falta de verbas: mesmo apos sua

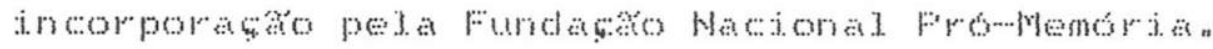

o 650 o uma institujero privada que visa a atendimento do

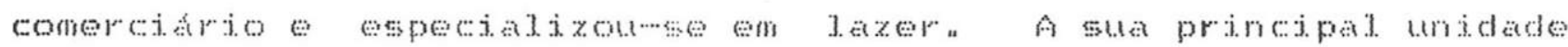

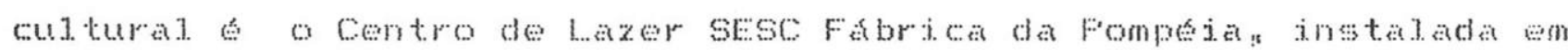
uma antiga fabrica inglesa restarada Em seu jnscjo realizou propostas de vanguarda hoje atua como un complexo en gue as atividades esportivas as preocupacoss assistenciaje juntaramsen a átrea cul turaln.

De cada um dos centros foi descrito o seu historico a as: reatizaços, a arquitetura a estrutura organizacional e como se estabelecen as relasoes entre os funcionstoss o centro e os frequentadores. Fosteriormente foran feitos estudos comparativos entre os trtes centros procurandowse anajisar como lidam com os elementos artaticos e cuturats a contribujo gue oferecem a panorama cul tural da cidade. 


\section{ABSTRACT}

This treatise sets out to examine three sites in the wity of saro Faulo that due to the servides offered to the poputation and the diversity and dynamism of the activitiess proposed have assumed the roll of culturat centress.

The outural contre of Saro faulo was intended to be a public J.jorary but was adapted into a cultural center with the obiective of offering a diversity of communal activities " Various services of the Municipal ministry of culture are contred heren the directors and departmental supervisers are changed periodicany and many young people use the centre to study in its 1ibrary.

The Lasar segall Musum founded on the initiative of his family in his old home was established to house and bring prominence to the

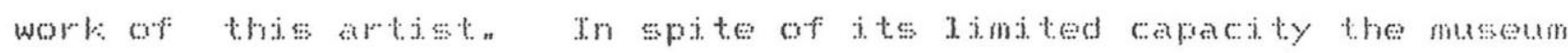
offers a speciatized library and activities for the publice as well as a display of the coldection. The musum has had the same stary for many years. $x t$ has al ways suffered from financial diffictities which have not improved since it became part of the Nationat Foundation Fromeremoria.

SESC is a private institution that caters for employers in the commercial field offering lejsure facilitiesn Its man cultural unit is the sfes Fomperia l.ejsure centre which was set up in a renovated finglish factory" at first the l...isure centre of fered many innovative productions of shows and theatren but today the sports activities and subsidized publice services and amenitios have been added to the culturat pursutis.

Descriptions are given of each of the centress their aims achievements: architecture, planning structure and how relationships between the staff, the centre and the publice are established. Finally the three centres were compared and analized to see how they deal. with the cultural and artistic elements and to evaluate the contribution they offer in the cutcurat panorama of the eity. 


\section{INDICE}

Fáglina

1. INTRDDUCFAO | " |

2. CENTRO CULTURAL SAO PAULO

2.1. A Construgso do Centro cuturat sa Fauto " " " " " " "

2.2. Frojeto Arquitetonico e Intencess na criaço do cosf on

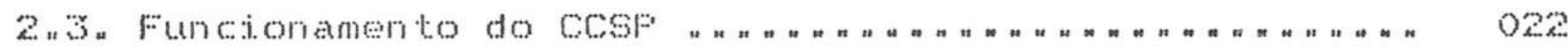

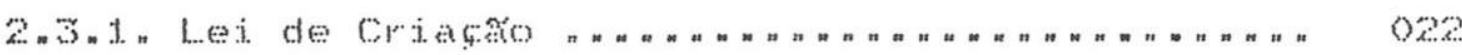

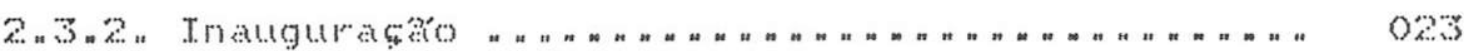

2.

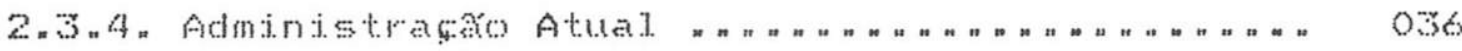

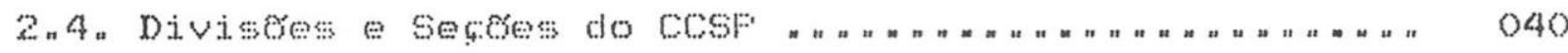

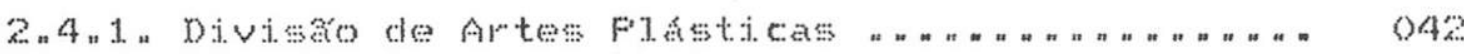

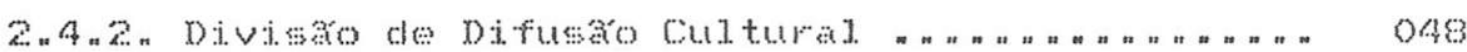

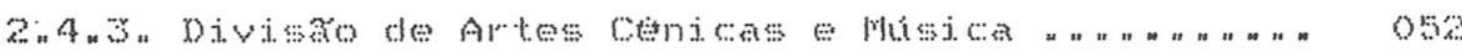

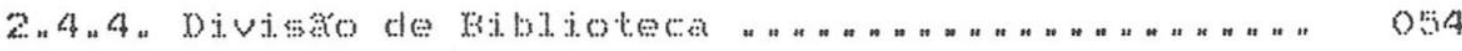

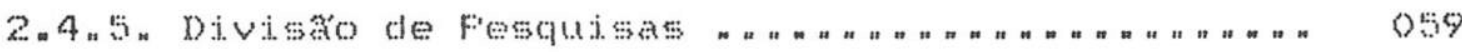

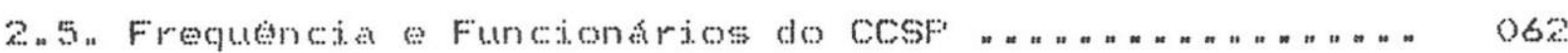

3. MUSEU LASAR SEGALL

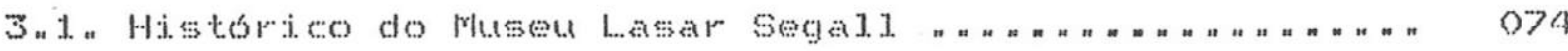

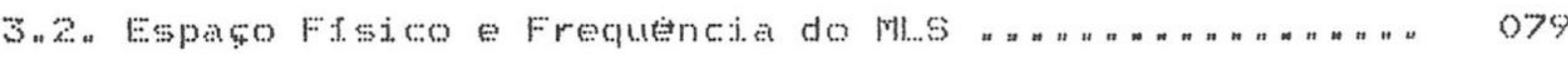

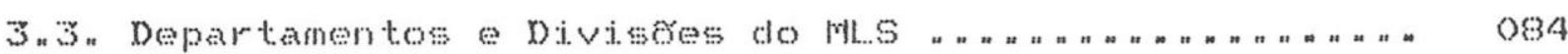

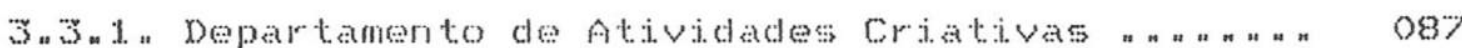

3.3.2. Departamento de Biblioteca Tenny Klabin Segall o98

3.

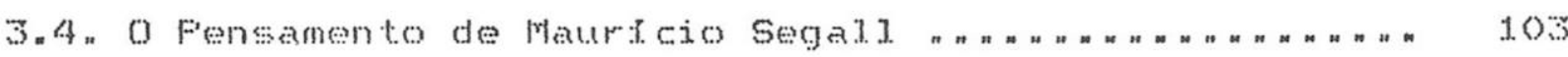

4. CENTRO DE LAZER SESC FABRICA DA POMPEIA " . " n " . " n " n " " " " "

4.1. "Ferspetivas para una Velha Fabrica " " " " n " " " " " " " " " 116

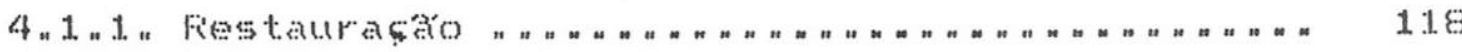

4, 1.2. Thauguraçes 
4.2. Expectativas e Reatizaçes do ClsfF " " " " " " " " n " " " " " 125

4.2.1. O Rue se Esperava da Fomperia n n " n " " " n " " " n " " 125

4.2.2. O Que Foi Feito na Fompeia " " " " " " " " " " " " " " " " 134

4.2. 3. Mudaças Adininistrativas " " " " " " " n " " " " " " " " " " 137

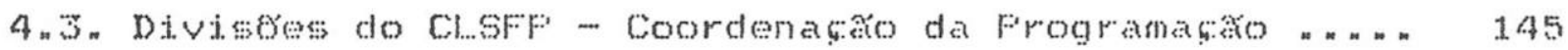

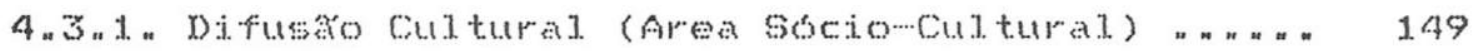

4. 3n "2. Teatro/Choperia (Area Sociowcut turat) " " " " " " 161

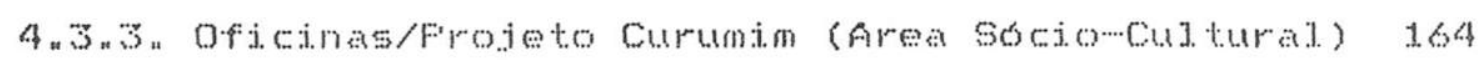

4.4 " Frequencia Funcionários do Cl.sFF " " " " " " " " " " " " " " " 168

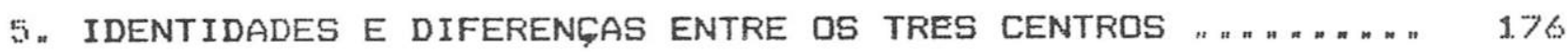

5 . 5 . Concest tos

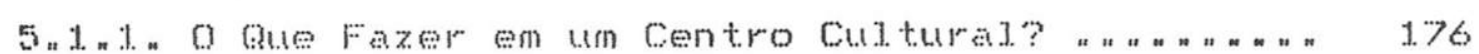

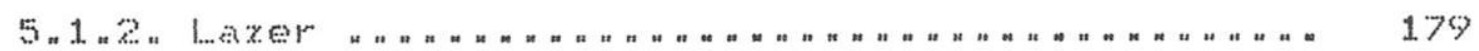

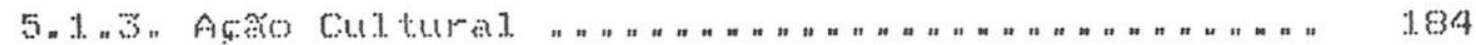

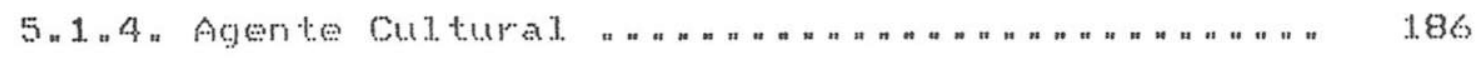

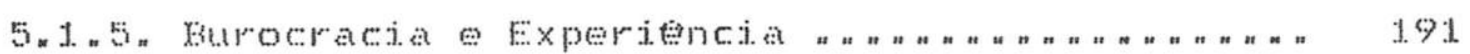

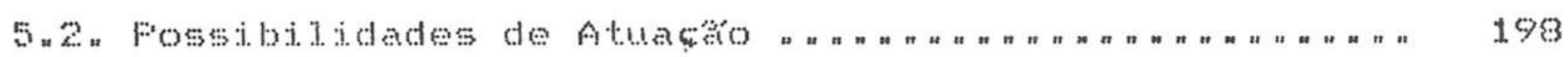

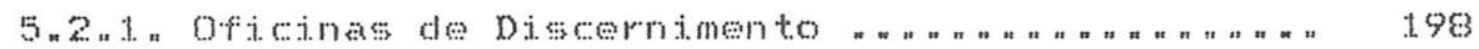

5 2.

$5.2,3$. Atividades Corporais nos Centros " " " " " " " " " " 208

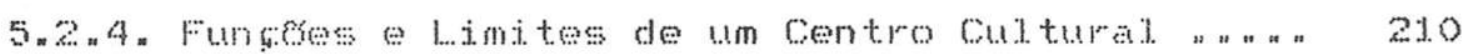

5. 3. Caractertsticas dos Centros Fescutisactos " " " " " " " " " " " 214

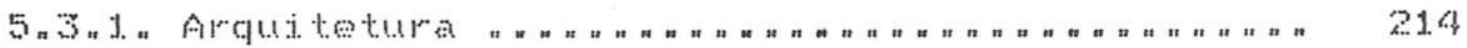

5,3 .

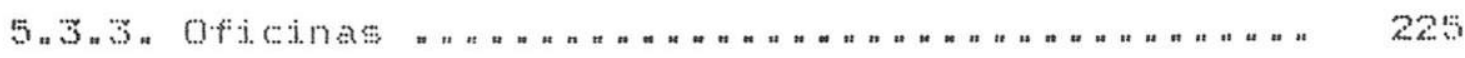

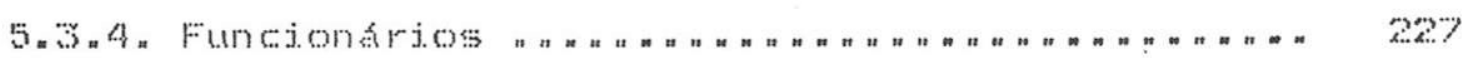

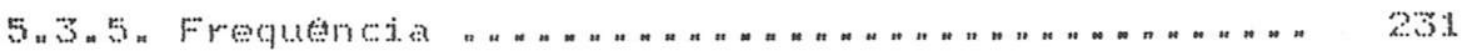

5 "3.6. Consequencias do Frano Brasil. Novo " " " " " " " " 233

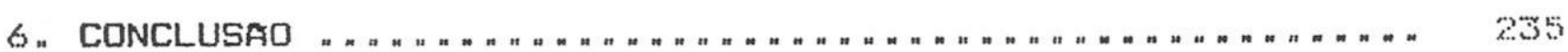

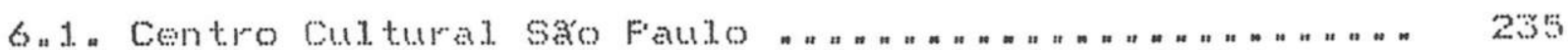

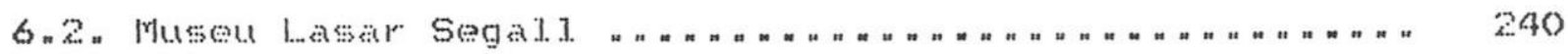

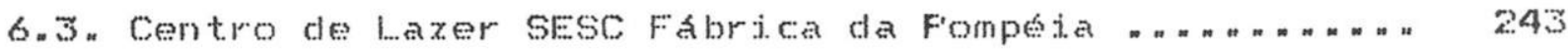




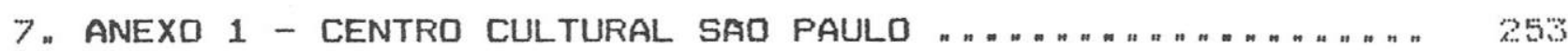

7. 1. Arquitetura

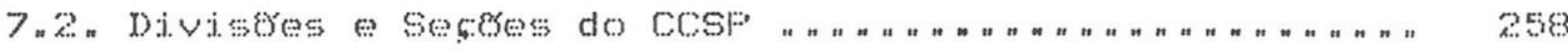

7 "

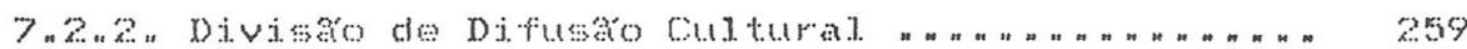

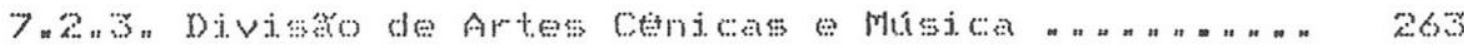

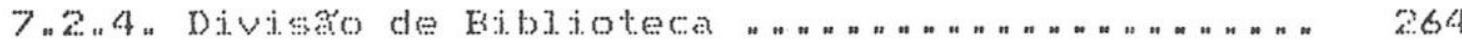

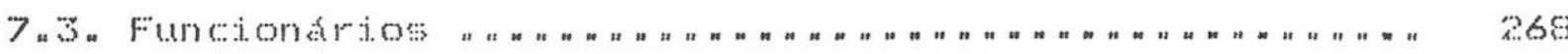

7.4, Entrevistas e Dados Bibliograficos " " " " " " " " " n n " " " " 270

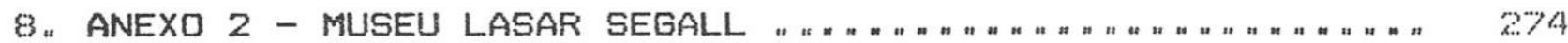

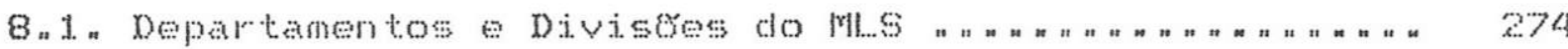

8.1.1. Deparkmento de Atividades Criativas " " " " " " 274

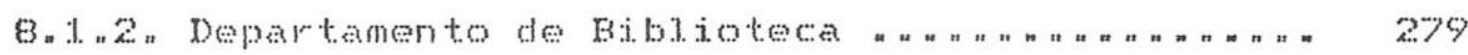

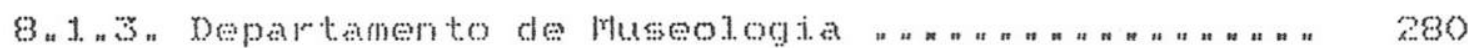

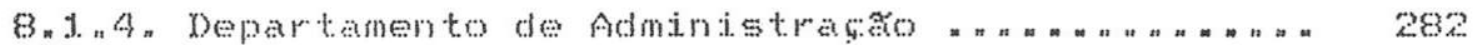

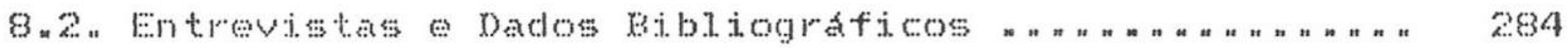

9. ANEXO 3 - CENTRO DE LAZER SESC FABRICA DA POMPEIA " " " " a " "

9,1 ,

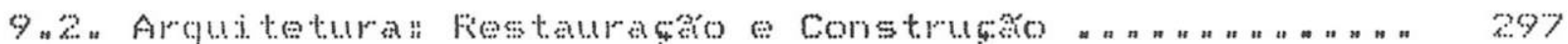

9.

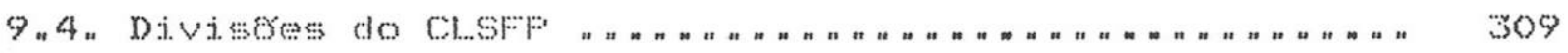

9.4.t. Coordenacto das Atividades de Apoio

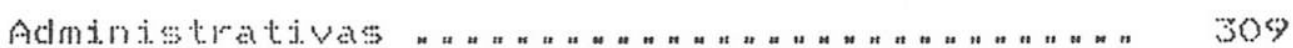

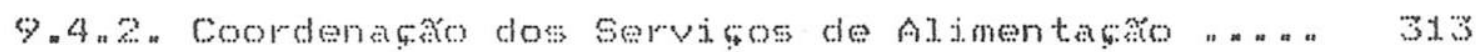

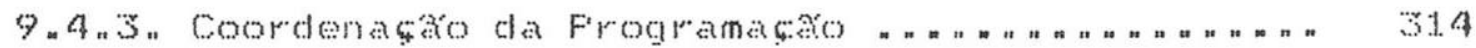

9.5 "Entrevistas Dados bibliograficos " n " " " " " " " " " " " " 325

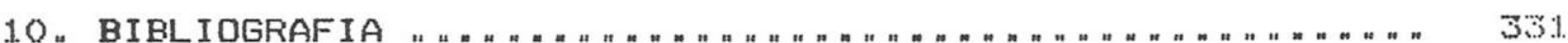




\section{INTRODUÇAO}

A dissertaço de mestrado "Tres centros culdurajs da cidade de sac Fato" tem como objetos de pesquisa o centro cultural sacs Faujo, o Museu Lasar Segaje o Centro de Lazer SESC Fabrica da Fompeia por terem se caracterizado como os principais centros culturais da cidaden

For centro cultura. entende-se o lugar que oferece optoses tajs como consulas e leituras en una bibliotecan apreciaço de exposiscesn atividaces do setor de oficinas exibicho de filmes e videos; audicho de misicas e registros sonorosa apresentacoses de espetaculos - enfim, un espaşo que abrigue e possibilite essa diversidade de expressoses de forma a propiciar uma circulasio dintanica da cultura No centro sempre esta acontecendo algo que atrat as pessoas a as convida a ir verificar as varias propostas elaboradas pelos agentes culturats - que nás deveriam apenas preparar atividades mas também estimular a relasac dos frequentadores com os elementos culturats.

A cidade de Sá Faulo tem poucos centros culturais perifericos "Ha varios Jocais que trabalham especificanente com uma ou outra das possibijidades acima citadasy oficinas que oferecem cursos episodicos com o programa e periodo préfixados! e alguns musus quen eventuamente -- dependendo de quem os esta dirigindo - atuan cono centros culturais en deterninadas epocas; voltando depois as exposiches do acervo ou mostras temporariasi estes espacos náso participan portanto do carater de múlipia atuaça dos centros de culturan

O:s tres centros estudados diferem bastante quanto as; instalaços, especificidades e orgros administrativos a que respondern. 
o Centro Cultural. São faulo localizawe num predio projetado para abrigar inicialmente una grande biblioteca públican E! portanto, una biblioteca-centro cultural. e 0 seu espaço foi. construtclo especificamente para promover contatos culturais o que naso ocorreu com os outros dojs centros, que foram adaptados de antigas construçes n Fertence a prefeitura paulistana e foi. institufo por le.j. como sendo um departamento da secretaria Munisipal de Cultura de Sao Frato.

o Museu Lasar segall surgiu de uma iniciativa particular da famlita Segall t tendo sido posteriornente incorporado pela Funclagáa

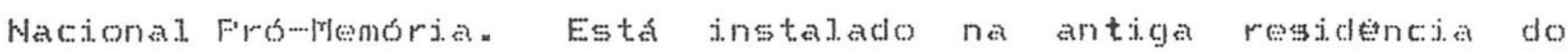
artiata, onde mantem o acervo de obras de Segalin en como propose diversas atividadess culturaisy constitui-mesem um museu-centro cul. turat.

O Centro de Lazer SESC Fabrica da Fompeia esta no espaco restaurado de una antiga fábrica de geladeiras e tambores. E: un centro de lazer cultural e pertence ao Serviso social do comercio.

Frocurou-se mostrar o que e cada un dos centros em suas varias instancias: o passado (historico da implantacaso e realizacses culturats), a instalaço flsica (descriço da arquitetura e de seus espacos" equipamentos " problemas funcionais) " a estrutura oficial. de organizaço (regimento interno, lej. de criaço, organograma) a forma de funcionamento (definişo administrativa! recursos disponfveis)! a atuaţo politica (diretrizes atuass discurso instituciona1), as op̣oss culturais (programas de atividacless womo se lida con a cultura e o que se pretende) e a relaçáco com as pessoas (tratamento dado aos funcionarios, o que estes pensam da instituisar como se caracteriza a frequencia).

No caso do Centro Cultural Sá Faulo "foran estudados a sua construşa e os problemas advindos da năo finalizaço da obran que deran origem a sua historia tortuosa polemica que ocupou as manchetes de jornats: os sonhos dos arquitetos e a realidade do predio construjọ as idealizaçes de Mário Chamie de que, pelo 
menos entre as paredes deste centro culturat, as pessoas estivessem mais proximas e pudessem ter iguais oportunidades os varios servicos culturajs prestados pela prefeitura que passaram a ser reunidos no centro $e$ a forma pela qual este se relaciona administrativamente com a secretaria Municipal de Culturan

o Museu Lasar Segall, que se distingue pela coneiliaşo de tress áreas basicas -- a bibjojotecan o museut que abriga o acervo de segall e as atividades de centro cultural - exaninado na sua atuaço como espaco experimental e nas inovacyes que trouxe a anbito cujturad da cidaden As preocupacoss museologicas, a valorizaço da reflexaco as diretrizes presentes nas ideias concepses de Muricjo segaj. deternjom a atuaţo do museu. devendowe tanbon destacar a sua condicho de liberdade apesar de

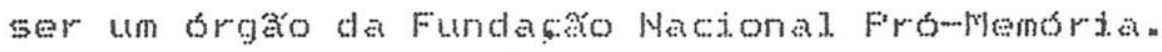

Descreveuse o que o 0 SESC - Serviço Sociat do Comercio -... suas metas e modo de aço para melhor se compreender o centro de Lazer SESC Fabrica da Fompeja Tendo jniciado shas atividades como un espaco que mostrava e promovia diversas mandestaçes cuturats do que se considerou no infeio dos anos 80 a vanguarda paulistana, brasileiran e mesmo internacionat nas areas de teatro. dança musica eartes plasticas percebe-we hoje a maior presença do carater assistencial. neste centro. Faralelamente a programasa cultural desenvolven se projetos de atendimento de publicos espectficos (crianças e idosos) n atividades esportivasu serviços de a imentaço a aço de todo un complexo administrativo para receber o grande púbij.co que se espera.

Nas pesquisas foram utilizados os documentos de cada instituison seus textos e publicacoes nos casos do centro Cultural Săo Faujo (que năo tem praticamente nada em ternos de registros) e do SESC Fabrica da Fompeia (o SESC so dispere de textos teoricos do que se pretendia fazer, sem relatorios das experiencias realizads nessa unidades o trabalo foi desenvolvido principalmente atraves das noticias de iornais e revistas e das entrevistas com funcionarios de cliversos setores. A base da 
pesquisa foi o organograma de cada instituiço, eixo sobre o qual se define seu funcionamento, sendo tambern o elemento mats concreto para se ingressar nas vicissitudes de cada espaço. o Museu Lasar Segat1 possui maior definisaco dada por seu regimento interno e Centro Cultural sáo Faulo tem suas metas determinadas pela lej de criaça, sendo que partes destes dois documentos for am reproduzidas no transcorrer da dissertaşo.

A arquitetura foi bastante considerada por se constituir num fator deterninante do que e conveniente ser realizado en cada centro. Este trabatho pretendeu verificar como se pensa a cultura e como ela apresentada e processada nas tres instituigoss, procurandome analisar a atuaçáo geral de cada centro e sua importancia para a cicladen os dados a as infornaceses utilizada foram obtidos en estatisticas feitas pelos proprios centros nas entrevistas reatizadas com agentes cuturais e atraves da observaço - diante da inexistencia de outros partotros cientificos para se avaliar a prática culturaj. "Fosteriormente." realizouse o estudo comparativo entre as intençes o os discursos" as condiçes as praticas dos tres centros em questan

A constataço da necessidade de estudar a a tuacho dos centros culturais de sao faulo e o que possibilitam ao publico frequentador deve-se a notoria inexistincia de pesquisas e andises teoricas nesta area. A historia da criago e das realizaçes destes centros é, na maioria das vezes" de dificil acesso devido ao grande descaso pela memoria e a falta de registros de suas vivencias. Tal atituce e perigosa pois pernite que a experiencia se desvaneça, levando consigo o registro do que foi. empenhado: a atuaşa dos participantes e o conhecimento adquirido.

Se os centros cuturats nao foram pesquisadosn a aço cultural, ou seja, as formase os conteldos da pratica cultural, foram menos ainda. E importante refletir sobre a maneira como a proposta culural. mediada pelos agentes culturais, pode acontecer para os frequentadores de un centros e se este tem a jutencán de desenvolver atividades que possan trazer subsidios que colaborem 


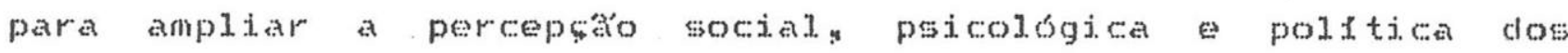
individuos . Fortanto "tornawse necessario saber o que se considera açáco cultural. o que foi ativado durante o processo e qual o motivo de realizalas senclo estas questers debatidas junto as: possibilidades de atuagáo dos centros culturajis a bibliografia apontada no final colaborou para este estudo e como se trata de un tema interdisciplinar, contou-se com conceitos nas areas de pedagogia, fitosofian organtzaçá institucional e pos modernidaden entre outros n(*)

(")nota: A dissertaçato foj iniciada en setenbro de 1989 e terninada en fevereiro de 1991. Este perfodo foi usado nas pesquisas, nos estudos e na redaço. As pesquisas no Centro cultural sa Paulo e entrevistas a funcionários foran realizadas principalaente durante os aeses de outubro e noveabro de 1989 ; 0 trabalbo no kuseu Lasar Segall concentrou-se nos aeses de noveabro e dezeabro de 1989 a no Centro de Lazer SESC Fábrica da Poapeia ea aaio e junho de 1990. As audanças da politiea institucional on as substituigóes de funcionários entrevistados ocorridas apos este periodo foran pouco consideradas. 
2. CENTRO CULTURAL SAD PALLD

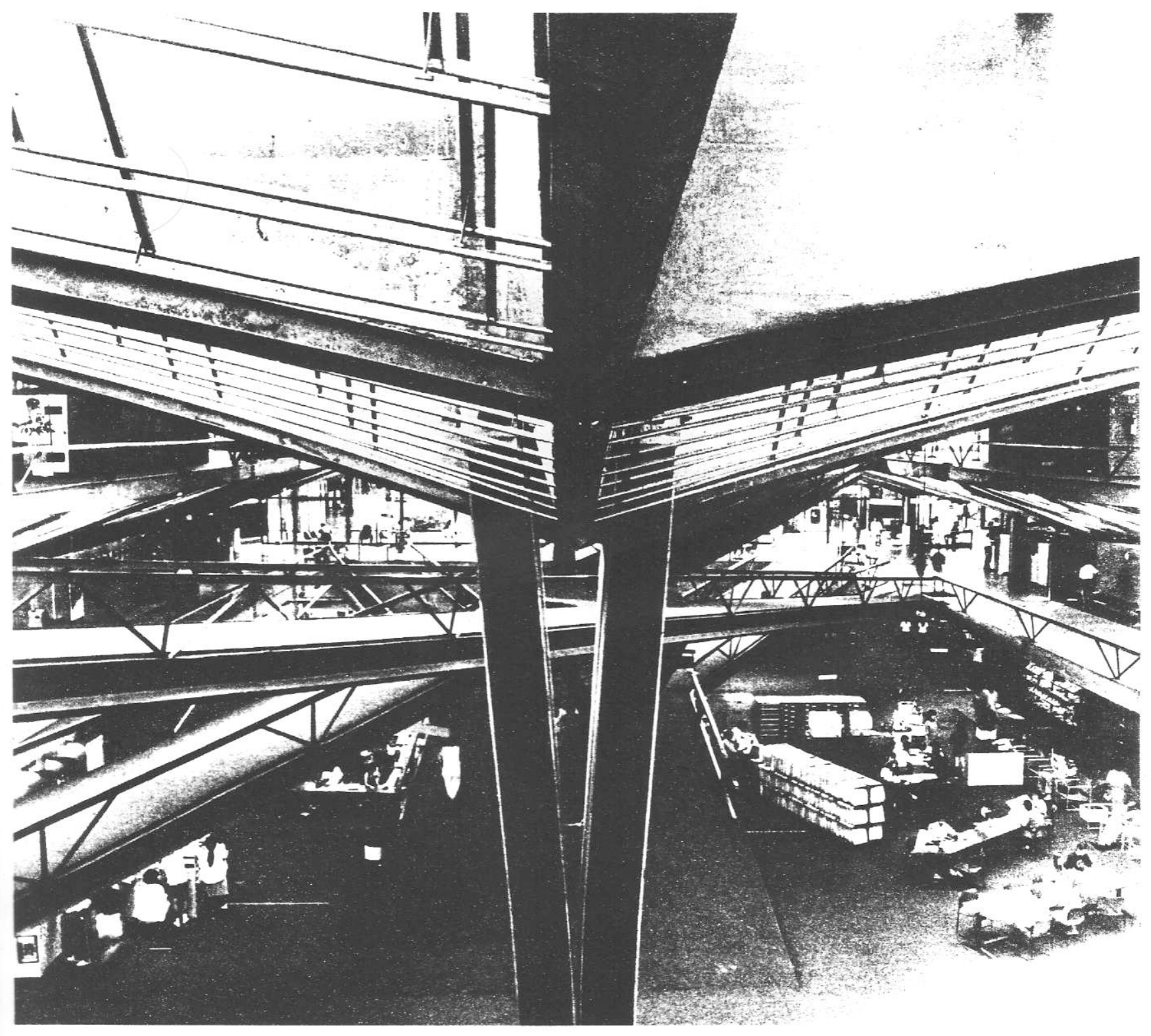

Rampas de acesso, rua interna e biblioteca

(Foto - Joơ Mussolin) 


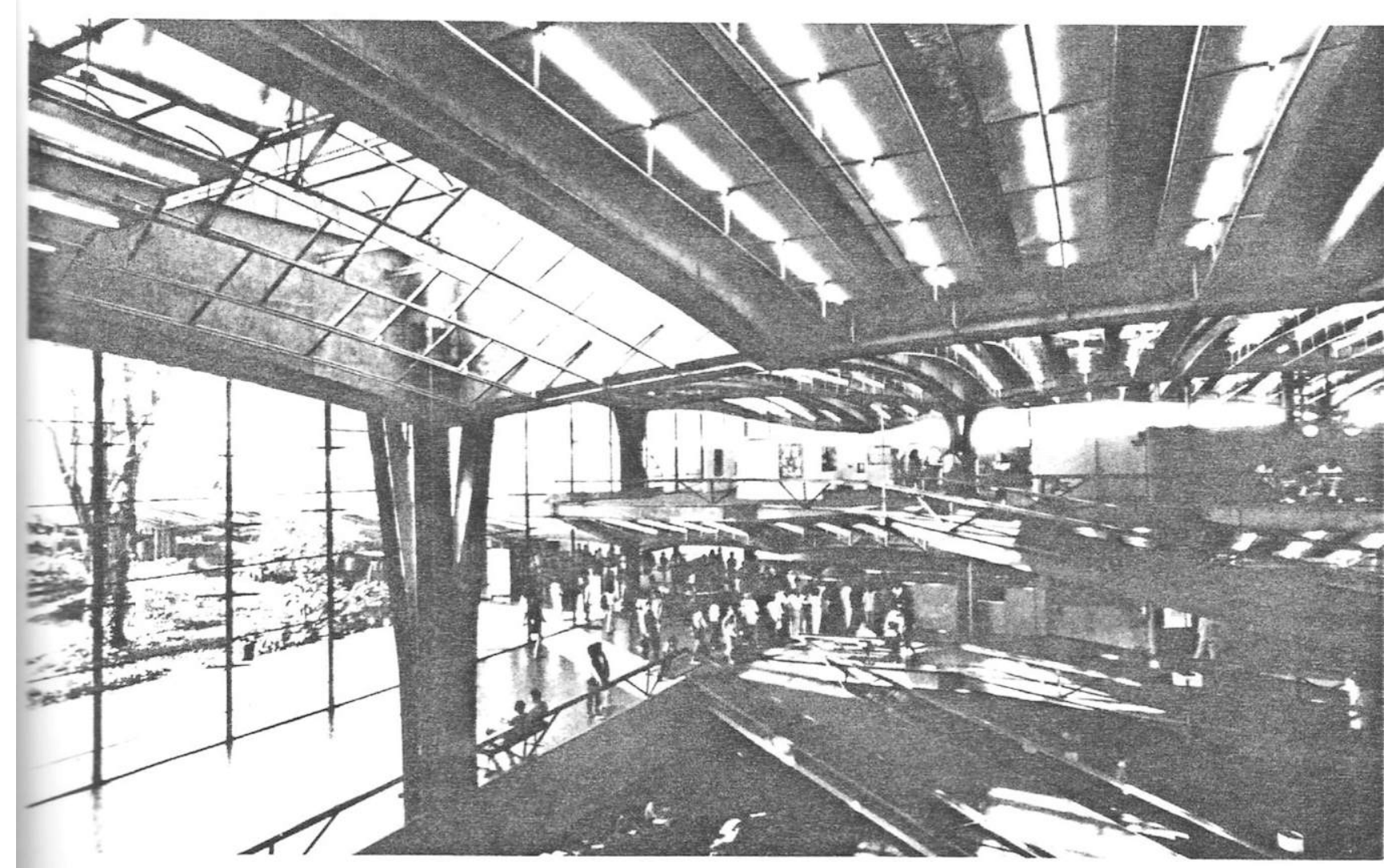

Fila para a biblioteca na rua interna; acima um dos espaços da Divisăo de Artes Plásticas. 


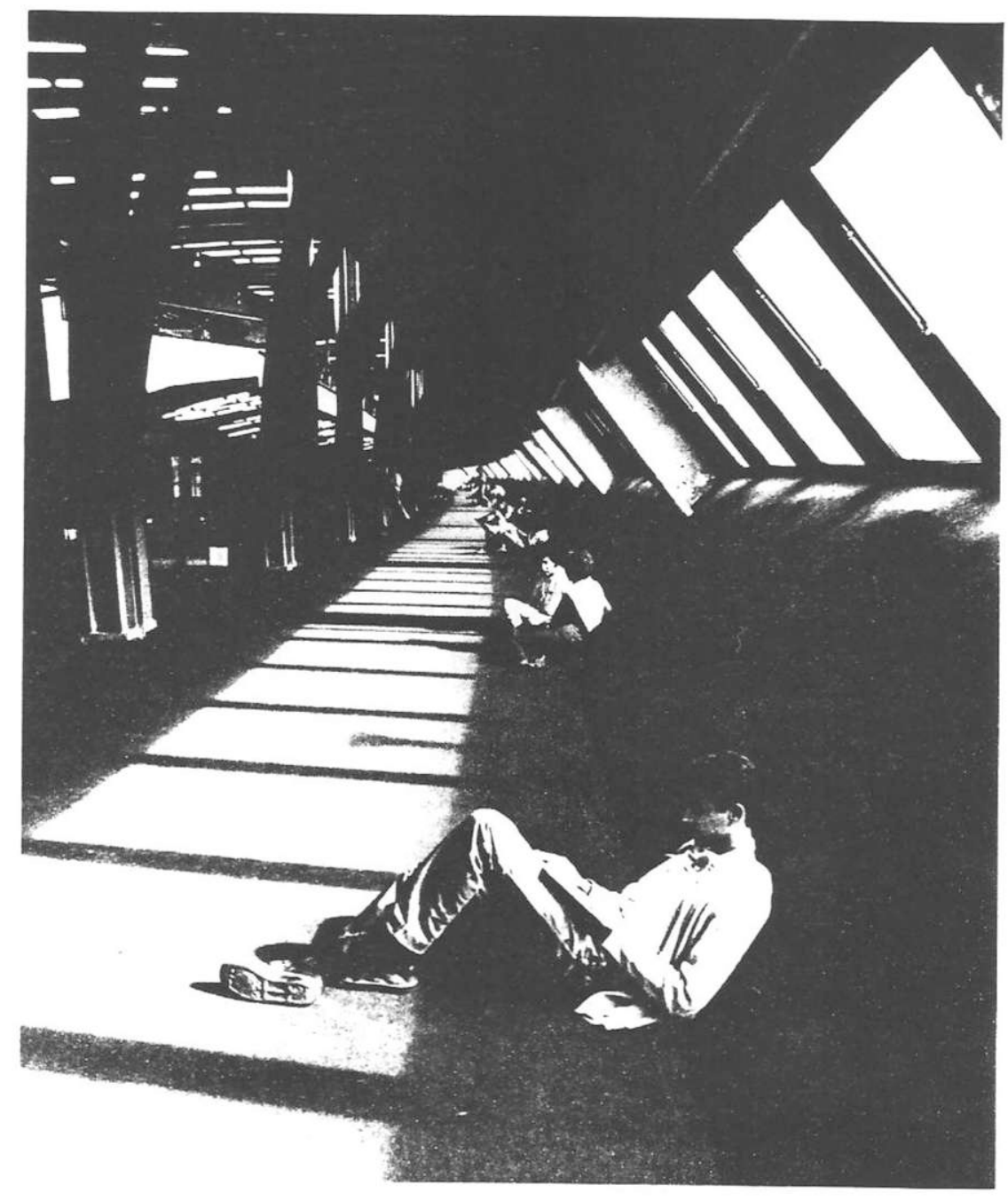

Jovens estudando 


\subsection{A Construçăo do Centro Cultural săo Paulo}

o vale do rio Itororo teve sua ocupaço joniciada com fazendas quilombos: locais de açottes de escravos e pequenas chacaras, sendo posteriormente aberta a avenida 23 de Maion Na encosta do vale havia casas de grandes quintajs com frente para a rua vergueiro. en cujo leito subterraneo foi construfdo o metró.

Na administraço de Miguel Colassuono surgiu o Frojeto Vergueiro (jutho de 1973), una tentativa de reurbanizaço da area resultante das desapropriacoes efetuadas pela companhia do Metropolitano de sao faulo para a construgáde sua linha norte-sul. Contando com uma area de 300.000 metros quadrados o terreno apresentava un grande desnlvej entre a rua verguejo e a avenida az de Maio e, segundo o projeto da Elufe -.. Empresa Munipa de Urbandzanon ali. serian construfdos um complexo de torres de escritorios notejs e un shopping conter, sendo o espaço restante destinado a construço de uma gigantesca biblioteca publica municipal e de alguns próclios comerciass "Naquela ocasiá o prazo previsto para o termino das obras era de cinco anos.

Dois anos depois o entao prefeito de Sao Faulo olavo setubal a resolveu cancelar o projeto vergueiron que ja havia sido posto em concorrencia publica por achar que o projeto naro atendia as: necessidades da cidade. Setubal optou por manter a construço da bibliotecan com a exiguncia de que so\% da area fosse reservada ao verde, mas a desistencia de se realizar o projeto vergueiro resultou num pedido de indenizatán do Consorcio frounb que havia vencido a concorrencian eque acabou por ganhar a causa.

Em 1976, foj aberta uma concorrencia para o projeto da biblioteca pela Secretaria Mnicipal de Cultura (a Sllc havia sido criada no ano anterior atraves de um desdobramento do Departamento de Cultura da Secretaria de Educaços que era dirigida por sabato Magaldi. Venceu o concurso o arquiteto Eurico Frado Lopes. tambem idealizador do rearcado de Finheiros. 
No local, alen da biblioteca, seriam instalados o Departamento do Fatrimonio Histórico e o Departamento de Informages e Documentaça Artistica -.- IDAFT" A capacidade prevista era de dojs; milheses de volumes; distribuldos por varias areas de conhecimento, cada una contando com sua propria sala de leitura. Alem dos; livros, ela contaria com recursos de mutimeios para informacto.

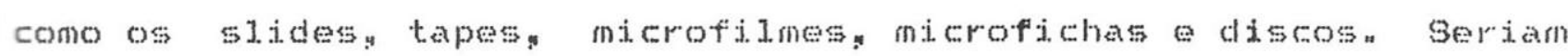
tamberm construtdos dois auditorios, um deles destinado k apresentaço de grandes espetaculos e áreas de vitrines para exposiçess.

Todo esse primeiro projeto, entretanto, foi considerado dispendioso pela administraço setubaly que pediu ao arquiteto Eurico Frado Lopes una adequaço as possibilidades da prefeitura As obras comeşaran en 1978 e prosseguiram até o final da administraço setubal, en juho de 1979, realizando-se neste perfodo os servịos de terraplenagem e as fundaçes basticas.

Na administraço do prefeito fieynato de Barros a o secretario municipal de cultura máro Chanie resolveu reformular o projeto. visando adapta-1o a um centro cultural mutidisciplinar, apoiandose mo dus justificativas basicasa a localizato privilegiada a as enormes proporpos de un ediffeio quen se destinado apenas a funçio de biblioteca" teria excessiva capacidade ociosan

Foi constitufda una comissáo para estudar as modificaçes clo prédio en maio de 1980, que propos o cancelamento da área da biblioteca circulante -.. quase un terço da area destinada a construçá -.. o que possibilitaria, com certas modificaçes de carater arquitetonicon a construçó do cinema municipat. do teatro de arena e de un espaç para recitais e concertos sinfonicos A As areas reservadas à estocagen de volumes seriam transformadas ern atelierse oficinas de artesanato aprendizagern, enquanto a area do teatro italiano daria lugar para salas pspeciais de ensaio a area das exposiçes de livros e documentos ligados ao livro seria redimensionada para uma multiplicidade de opṣyes - artes plásticas" simposioge exposiçes em geral. Femodelado e reconceitudo" o 
projeto passaria a ter 12 mil. metros quadrados de area para atividades culturats espectficas - o triplo da area anteriormente prevista - capacidade para un públito de vinte inil pessoas por dia. segundo Chanie, que se referiu as modtficagres como "un conceito atulizado de centro de atividades culturaia diversificacas, o que, por si. so, corresponde a una multiplicaço de demanda e interesses em relaçăo ao ediffcio".

Fara o financiamento do empreenclimento fez-3e un emprostimo junto a Caixa Econtionica Estadual que garantiu a construço pois a verba inicialmente obtida se destinara apenas aos movimentos de terra fundacoses.

A execuço da obra coube a secretaria de servicos e obras -.. SSO, ey desce as primeiras estavaçes, a construgso do centro Cultural Sä Faulo ficou a cargo da SADE -.. Sul Americana de Engenharia $S$ An g que havia vencido as duas licitaçes fejtas para a obra, recebendo a coordenaça técnica e administrativa do projeto. bem como a responsabilidade de fornecimento e montagem das estruturas metalicas instalages santarias edetricas a SADE nobi.i.izou seus desenhistas e projetistas, a obra saiu do controle de Eurje Frado Lopess apesar da firma construtora ter contratado o escritorio do arquiteto.

Durante a execuça das fundaçes, inidiada em janeiro de 1979 e na qual foram removidos mais de duzentos mil metros cubicos de terra (o que provocou un desnivel da orden de 15 metros entre a rua Vergueiro a av. 23 de Maio). o talude da Vergueiro passou a se constituir en problema delicado no que se referia a estabilidade. A soluço para resolver o muro de arrimo, com extensáo aproximada de $400 \mathrm{~m}$ de comprimento ao longo da rua Vergueirog foi executar una cortina de concreto, atirantada contra placas de ancoragem. conforme explicasco do engenheiro da Maubertec Engenharia $E$ projetos Ltda " responsavel pelos calculos estruturais da obran 
A construçáo do Centro Cultural Sáo Faulo foi programada em duas etapas distintas Na prineju foram fetos movimentos de terra, fundaçes, estruturase muros de arrimo. Na segunda, obras de complementaço. No periodo do primeiro contrato com a SADE. terminado em meados de 1981, menos da metade da edificaşio havia sido erguidan

Com relaço ao sistema construtivon para viabilizar as formas pretendidas pejo projeto arquitetonico do cosp foram pesculisados e empregados diversos materiais como concreto acon vidro acrsicon tijolo tecidon Como a obra bastante diferenciada e apresenta estruturas mistas, foran feitas inumeras inovacess, modificandowse muitas vezes os conceitos tradicionais de execucaron for exemplo" sa conhecidas as técnicas para o levantamento de una estrutura de concreton assim como para uma de aço mas náso no caso dos dojs materiats trabalhando juntos E a estrutura do Centro cul tural Gá Faulo compreendeu tanto pilares de concreto como de aço enquanto nas vigas aconteceu a composiço dos dois materiats " Fra necessario una grande precisáo no concreto para acompanhar o aço usinado, pois os partmetros de erro admissfvej para as estruturas de concreto sáo muto diferentes dos concebiveis para as estruturas metalicas o que obrigou equipes inteiras a se aclaptaren! como as pecas deverian trabalhar juntass tamberm o seu posicionamento deveria ter alta precisaso para que se acoplasem perfeitamenten associando-me assim o trabalho do metalurgico ao do pedreiro.

Segundo depoimento de engenheiros da SADE a obra correspondet. a um trabalo artesanal, nada seriadoy exigindo da construtora o dominio de novas ternicas muto especticas desde a fabricacko ate a implantaçáo das peças na obra. Nomalmente os elementos metalicos uti.izaclos na construço civil sáo retos " porem na obra foram executadas colunas e vigas com trechos retos e curvos: havendo enta a necessidade de concordancias num comportamento individual totalmente sem regra de formaça - tanto que para o detalhamento foi necessario se recorrer ao computador. 0 aco empregado, de precisaso milimetrica, serviu como stuporte do concreto armado, funcionando associado a ele, economizando as formas de 
madedra garantindo a exatidao das linhas e a suavidade das curvas sem comprometimento das estruturass o que seria impraticavel visualmente com o uso do concreto no processo tradicional. Alsm disso, era necessario que as colunas fossem esbeltas, para uma ocupaça monima da area dos andares.

De acordo com informactes da construtora, foram confeccionados cerca de 1.500 tipos de vigas diferentes, 100 tipos de pilares, 12 tipos de escadas metalicas (helicoidatse retas) e 2 tipos de rampas (em forma de $X \in Y$ ).

Na maioria dos casos as vigas de aço cumpriram funço estetica e estrutural e em outros apenas garantiran a forma mas; invariavelmente o aço aliviou as estruturas provisorias do cimbramento sendo esta una das mais importantes inovaçoses segundo a SADE. OS pilares tem aspectos diferentes, mas cumprem a mesma funço na estruturatso grandes ou pequenos dependendo de sua concepsáno no projeto assumindo uma tonica particular a cada

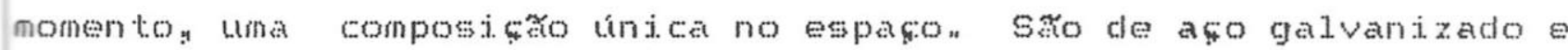
sustentam as tres lajes: o piso $80 b_{y}$ que constitui praticamente una rua interna o piso 810, da pinacoteca, que forma tanbem uma grande área externa ajardinada o nIvel. que cobre a pinacoteca subindo aos niveis superiores; o numero de pilares diminui. sucessivamente" as cargas de piso saco menores e aparecem os grandes vazios os grandes Vásos. Segundo Dario Eloi Cabral engenheiro responsável. pela obran assim se criou " un sistema estrutural en que cada pega cumpre un papel. diferentes representando um personagem e respondendo, em dimensoes; formato, e trabaliho estruturat. ao elenco das emoçeses que escolhemos para cada área".

Havia una aparente contradiça entre a industrializaço a a adoça das formas variaveju náo repetitivas caracteristicas da produço artesanal. Fara atender a esta estrutura foram usadas as técnicas de caldeiraria pesada, na qual oito metalurgicosy rabalhando en una fábrica na periferia de sáo fauloy prepararan as toneladas de peças metalicas que garantiram as dimensobes e deram forma suporte para toda a estrutura mista, fincluindowise a o 
gigantesco pilar central, que apresenta forte parentesco com o tronco de algumas velhas arvores preservadas bem no meio da constructo. Essas arvores comperem un pequeno iardion semelhante aos que adornavan tantas casas antigas la están reunidas mangueirasa tipunas, pitangueiras, Jabuticabeiras e araucarias Adiante desse jardion esta o nucleo da construçon onde rampas metaljos cruzam o espaço! ligando as diversas áreas.

Ao final da obra o engenheiro Darjo Elot Cabral comentaria que a ténica construtiva foi pesquisada e completada ra propria

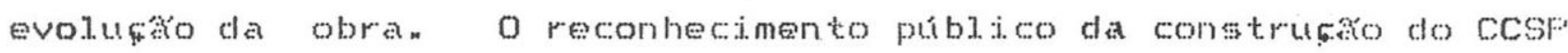
adveio con o premio "Faulo Fragoso 1982" outorgado pela ABCEM -Associaçao Brasiledra dos Construtores de Estruturas Metalicas.

Chegaram a ser reundos 2.000 operarios trabalhando para a conclusa da obra no canteiro que avançava por 300 metros a partip do Viaduto Beneficoncia Fortuguesa entre a rua Vergueiro a a avenida 23 de Maio. A largura da edificacto era de 55 metros em media: totalizando una area construfda de 46.500 metros quadrados. No conjunto foran consumidos 20 mi.t metros cubjcos de concreto armado e cerca de 2000 toneladas de açon

\subsection{Projeto Arquitetonico e Intençôes na Criaçăa do Centro Cultural Săo Paulo}

o projeto da época de olavo setubaly que planejava a criaca de uma nova biblioteca central na faixa de terreno da rua vergueiro, pretendia solucionar a obsolesctencia funcional. volunterica da Eiblioteca Central Mario de Andraden Sem a necessaria renovaço em termos de biblioteconomia e com o inevitave]. crescimento de seu acervo que náo contou com um escoanento atraves clas bibliotecas ranaisy a Mario de fndrade tornou-se inapelavelmente ultrapassada. Inaugurada en 1942. concebida para 350.000 volumes" na época do projeto da fiua Vergueiro ja estava com 800.000 volumes e recebendo uma frequencia 
diaria de 2.000 pessoas. o que significava un publico tres vexes maior que o previsto para suas dimensegs.

Em busca da soluçá do problema criou-se uma comissán que reunia especialistas am biblioteconomia e arquitetos responsaveis pelo novo projeto. Até se chegar a um consenso entre os participantes da comissác passou-we um bom tempo. May Broolin Negráo, diretora do Departamento de Bibliotecas Fublicas nfoi a Europa a fin de participar de conferencias e visitas em predios de bibliotecas públicass e depois disto transcorreram mais dois anos de elaboraço, com inumerass discussoess

A enfase a leitor a uso do livro, ao inves da importatia desmesurada ao proprio acervo bibliograficon seria a grande

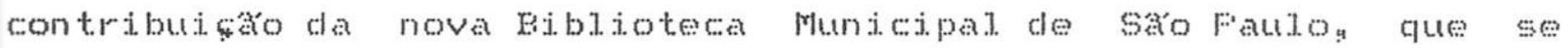
pretendia bem distante de un "depossto de livros" "

Diferenciando-se da Biblioteca Mario de fndrade onde o leitor penetra por una enorme porta deixa seus documentos na portaria se subnete a un ritua para alcangar o livro desejacto a nova biblioteca permitiria o contato direto com o acervo procuraria facilitar ao máximo a relaço livro/lejtor.

E sabido que no Erasil. os que frequentam a biblioteca publika såo aqueles que năo tem dinheiro para comprar ljuros preocupaço para com a nova biblioteca era a de que ela ná fosse apenas usada na leitura funcional dos estudantess mas motivasse a ledtura de lazer: procurando desenvolve-wa enquanto hábito cul tural. .

Osis arquitetos tinham a jeleia cle dotar a biblioteca de um restaurante, para que o usurio náo precisasse deixar o predio duranteseu perlodo de consultane acreditavam que deveria se aceitar naturamente as eventuais perdas de livros, considerando-me que nada e perene. Sobre eventuajs dificuldades com o crescimento do acervo ao longo dos anos; o documento resultante do trabalho da comissáso afirmava que, como se fosse un organismo vivo, o ediffeio 
deveria ter um programa de crescimenton de forma a preservar sua undade funcional- -estetica nas diversas fases de sua vida biti.

- projeto do CCSF: realizado pelo escritorio do arquiteto Eurico Frado Lopes e tendo como comator Luiz Benedito Castro Telites, resultou num predio baixon que explora a imensidao dos espaços longitudinais en seus quatro pavimentosy os quais se adequaram exatamente a forma de talude do terreno que caracteriza a topografia da regiăo. o conjunto massivo de concreto e aço acaba por se assemelhar, de acordo com alguns observadores, a um portentoso porta-aviges.

Segundo Eurico Frado Lopes, as modificaçes solicitadas no desenvolvimento do projeto foran a este adequadas atraves do trabalho de técnicos do escritorio de arquitetura que realizaram estudos! entrevistas p pesquisas ate consolidarem um programa funcional: "Examinamos extensa bibliografia sobre o tema Centro cultural." devoramos livros sobre bibliotecasy inclusive publicaços da ow como o nosso, dimensionamos as areas en relacho aos usuarios: levantamos dados sobre eles e montamos os objetivos no sentido de facilitar ao máximo o encontro do usuario como edificio".

Desde o indicio, quando os arquitetos viram o local destinado a execusaro do projeto que contava com un grande pomar que restara do fundo do quintal de uma antiga residencian a intenço de preservar as caracteristicas da área e combina-las harmonicamente com a obra ficou firmemente decidida como havia tamberm o intutito de se atender a un publico bastante heterogtneo "afastou-se logo a ideia da construçấo de una única entrada com hati portas de cristate portaria. Foran criadas cinco opçes de acesso ao cCsF" sendo que todas estas entradas estäo voltadas para a rua verguedron onde se pode chegar pela avenida Faulista, pela avenida 23 de Maiog pela propria rua Verguejro ou pela linha norte-sul do metro, situando-se o centro entre as estaçoses Faralso e Vergueiro. 
" Nos procuramos reproduzir no CCSF o clima paulista - explica Eurico Frado Lopes - como se expressa, inclusive, nas varias utilizaços do aço e no estilo art-nouveau das estaços de trens, no viaduto Santa Ifigenja e em outros locajs" "A relaço como exterior foi cuidadosamente pensaday de acordo com os arquitetos! poiss alem da agressividade da pajsagem urbana havia o problema da conservaçáo das obras e dos objetos de arte a serem expostos. Numa cidade marcada por altos edificicos que escalam o horizontes o ccsfo distinguewse hoje pela solusto longitudinal de surs vastas dependenciass sendo composto por imensos espacos vazados para: conforne dizem seus projetistas" quebrar a rigidez do concreto do ạo utidizados. Esses espacos foran planejados para pernitir a entrada de luz natural. o reconhecimento dos prédidos da cidade e das avenidas que correm paralelas ao ediffcio e a visao do jardim interno.

o CCSF e atravessado nos seus 300 metros de extensáo por una rua interna que da acesso a todas as dependencias e proporciona a visaso de todas as funçes, numa transpartncia que "segundo os arquitetos, incita a participaço: o proprio espaço se programa como que convidando o usuarjo a participar das atividades ali. desenvolvidas, dispensando os simbolos visuais para a orientaço. Todas as dependencias do predio sac fechadas por grandes paredes de vidro e contam com aberturas predominantemente zenitajs e verticais para entrada de luz com minima entrada de calor a luz natural 6 captada por domos de acritico justalados en extensas areas na cobertura de alguns niveis e pelo emprego preferencial do vidro como elemento defechanento. Nessa rua interna ha escadas que conduzer as plateias dos teatros cinema e auditorio que estáso localizados no pavimento abaixon e rampas de acesso que descem levando a biblicoteca e a discoteca (em forma de $Y$ ) e sobem para a Pinacoteca Municipal. (en forma de $x$ ) ; caninhandowse pela rua interna no sentido da estagko Verguejo do Metrts chega dos teatross que presta se tambern a exposiches e espetáculos y e na 
outra extremidade desta rua esta localizados os ateliers de artes plásticicaş „(2)

0 ponto de partida para a idealizaço do CCSP foi o de possibilitar ao público que percorresse o ediflcio a nog̣o do todo, em funçáo da transpartencia e horizontalidade, e a percepço da relaçáco multidisciplinar entre os espaços. o escritório de arquitetura empenhou-se em năo permitir situaçes arquitetenicas que trouxessem a compartimentaças pois segundo Luis Telles, a arquitetura nåo deve projetar o ranço cristalizado das pessoas, favorecendo a jgrejinhas e panelas.

- arquiteto Eurico Frado Lopes planejou e fez tudo transparente" porem Fernando Lemos, o segundo diretor do ccsF": sentiu a necessidade de usar cortinas de pano bege cru para poder contar com certas areas isoladas" Segundo o argut teto houve a preocupacso de se trabalhar com um minimo de determinacos fixas: "Assimy no se encontram salas restritas e definidas as definiços funcionais săo feitas por setores ou por blocos " De tal maneira o préclio permite troca de funçess e reformulaca do layout. pois há pontos de luz, som etelefonia seguidamente em todos os pisos. Mesino com toda esta versatilidade, coerente com o multiuso dos espaços proposto pelo secretario da cultura existe no predio um respeito mituo para com o usuario e para com a obra. Frocuranos construir un centro cultural que funcione plenanenten que seja receptivo" bonito e confortavel".

"O que se visava - continua o arquiteto - era atender a comunidade como um todo en termos do que a gente julga anseios popularess impedindo a inibiço, evitando qualquer bloqueio na circulaşo, pernitindo facilidade de acesso a qualquer area do edificio e optando por solugbes funcionais de utilizaço dos espaços" .

(2)obs.: Maiores informaçర్s sobre o projeto arquitetonico do CCSP poden ser obtidas no Anexo 1, que tanben conté as plantas dos pisos. 
Definidas as linhas fundamentais da proposta, os arquitetos precoparamse em despertar no individuo a vontade cle participar da cultura. "Foi. constiente a procura de un espaço lúdjeo, sensual. curvilfneo, de luminosidade suave, de sonoridade amena, sem perder a perspectiva da atmosfera do lugar" disse Eurjo Frado Lopes" "Visamos total liberdade no tratamento do teto no uso das curvase noutros elementos que nos pernitiram chegar a una concepsaso estruturat que podia variar conforme a necessidade de cada arean mas mantendo a unidade funcionaly da mesma forma que a ossatura de um organismo vivo. Nosso projeto é diverso daguele que repete un mesmo formaton impondo uma estrutura repetitiva a todas as areas do edificio, clesconsiderando a personalidade de cada área " "Wossa ideia era a de fazer uma obra popular aberta transparente jovem, que pudesse emocionar as pessoas atraves de seus diferentes espaços e tomamos o cuidado de dosar muto bem as coisas para que o predio náo perdesse as proporceses do corpo humano" "Era preciso pesquisar materiais e varias vezes a reuniá de materiais conhecidos resultou numa opsăo nova e eficientẹ foram usados na ornamentaço o aço: o concreto: o vidro e o tijolo: e o tecido (suedine) , que e un elemento delicado como a pele e reflete a luz. entrou como contraponto desta linguagem conforme o plano de arquitetura suavizando a força do aço e a dureza do concreto. Foram utilizadas tiras de tecido encobrindo as Juzess favorecendo assim una superficie com uma sinuosidade e leveza de formas que acompanhavan o ambiente.

o escritório de arquitetura também foi o responsácel pelo desenho dos moveis "dos ladrithos que revestem o cháon dos tecidos que cobrem os tetos" determinando toda a decoraça interna do edificio na mesma linguagem do projeto arquitettonicog a partir do desenho dos moveis da bibliotecan criados de acordo com o lay-out. de orientaça radial foi projetado coerentemente todo o mobiliário do CCSF: sempre com a preocupaça de náo quebrar o espaço, de tal forma que os móvejs pudessem funcionar individualmente ou aos grupos, possibilititando arranjos, forşando passagens e desenhando circulaşeses. 
A intengáa dos arquitetos era a de envolver o usuarion descle a entrada do predion com un espaço dinatrico, determinado pelo proprio desenho arquitetonico: o piso com diferentes tons de verde formava desenhos abstratosy os pilares de aço colorjo de azut intenso combinavam com as vigas, desenhando curvas suaves; nunca repetidas, a luz naturat brincava com jogos de claro e escuro as árvores; redimensionavan o espaço, quebrando o comprimento do presio. A marca inconfundivel do CCSF para o visitante comun sáo os pilares de aço. que apresentam tamanhos irregulares e foran constidufdos do chapas soldadas.

o logotipo do CCSF" que e a representaga de una juncro de curvas, foi criaclo por Enitie Chanie, esposa do secretario de cultura. Segundo ela " " " depois de minha primeira visita as obras do centro: os estudos da marca que eu vinha desenvolvendo foram para o lixo. Fermaneceram na minha visaso as belfssinas estruturas e a partir delas criej. a marca e o logotipo" "En certo monento de sua historias porenn o Centro culturat. Sáo Fauto resolveu trocar este logotipo. passando a usar duas longas barras horizontais e parale as e colocando dentro da primeira delas o seu nome e na segunda o logotipo anterior miniaturizado. Enilie Chamie entrou com um processo para que voltasse o seu logotipoy o que conseguiu na época da administraço de Tanio Quadros.

Fara Mario Chamie o novo centro serviria principalmente para unificar a vida cultural de Sao Faulo, oferecendo o necessario "ponto de confluencia" para uma metropole culturalmente desmembrada que possura suas atividades culturais fragnentadas e dispersas por vários lugares. "Vamos ter una concentraço multiplicada de atividades culturais e artfsticas de modo permanente" explicava o secretario da cultura. "Na historia de Sá Faulo, tivemos um Iugar assim a partir de 1.91. no Teatro Municipal E isso deu na Semana de 22. Depois, na decada de 30, houve a Universidade de sáo Frato. Agora, na decada de 80, quen sabe o que obteremos com o centro Cultural ?" 
"Hoje as grandes cidades se ressentem de un polo culturat de carater popular "Un museu isoladon uma bibilotecas un teatron săo naturamente editistas seletivosn mas, quando se cria uma ligatom entre eles: a pessoa pode sentir mais prazer en usufruir

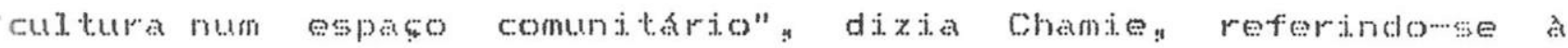
Discoteca Municipaly gue na epoca se instalava num espaco emprestado no predio da administraso fiegionat da l...pan e "que muito pouca gente conhece" "

En 1982, Sá Fato possufa aproximamente 8,5 milhess de habitantesy a mator parte deles espraiada pela periferiane o cosm tinha a ambiço de estar a disposiço de todos eles " "A populaço da cidade de sao Faubo a mais heterogthea do pass. Wák comundades com habtos culturats totalmente diferentes uns dos outrose o cosf podeser o ponto de convergencia desses usose costumes cuturais " Ferceberse que a pretenso era a de prestar um servigo as varias cidades que coabiavan dentro de saro ralou todas elas segundo as teses de Chamien encontrarian un lugar de expressăo de unificasanon

Diante da mut.jpijeidade de usos permitida pelo projeton os arquitetos acreditavan que o centro cuturat. sa Frato poderia receber 15.000 pessoas por diag reunindo un púbicico disperso por centenas de galerias, exposiçoes e museus alom dos apreciadores de todo qualquer tipo de arten Isto implicava na existencia de um restaurante cujo funcionamento seria de acordo com as apresentaçes artisticas e os perfodos de mator afutuncia ao estudo e pesquisan de un barzinhon com horario mas els aticon para o ponto de encontro, depois do cinema ou do showg sendo estes lowais previstos no projeto.

Os frequentadores poderian fazer cursos regulares nas diversas areas artisticas dos laboratorios de criatividaden que seriam dotados do instrumental necessario. No laboratório de músican por exemplo, alem de instrumentos como o piano! pretendianse ter o equipamento necessario para pesquisas eletroacusticas e mesmo para 
realizar gravaços. "Uma das caracteristicas desse contro de cultura -.. garantia chamie - sera sua funcaco produtora g náo de simples vitrina una vez que tamben expora os trabalhos eriados em seus laboratorios" .

A comparaço do CCSF com o Beabourg parisiense era inevitave1. o Centro Georgess Pompidou, com sua arquitetura em tubose estruturas aparentes, constitutame num grande polo do atraço na capital francesa fazendo a junco mul tidiscipinar da informaçon da cultura e das artes a len de ter um museu de arte. As intençes do CCsF: assimg muto se aparentavan com o modelo frances: Mas enquanto o Beaubourg parisiense sobe alto ge agressivo, o nosso centro e achatado, submergido en seu espigáo.

"E por i.sso que o COF náo pode ser confundido como sendo o Georges Fompidou brasileiro": dizia Furico Frado Lopesn "0 Pompidou tem un enfoque arquitetonico que privilegia as fachadas. impoeme a cidade caracterizando una especie de show de tecnologia e pouca relaço com a atividade. e agui se pretende um funcionamento mais ativo participante procurando despertar o que acontece numa construço năo departanentalizada" "

Foucos dias antes da inauguraço do cosf relatava com orgutho a carta que acabava de receber do diretor do Centro beorges Fompidou Tean chaude oroeshens" para quen o congenere paulista era apaxonante e en certos aspectos superior ao universalimente conhecido Beaubourg.

\subsection{Funcionamento do CCSP}

\subsubsection{Lei de Criaçăo}

o Centro cultural Sá Faulo foi idealizado para ser um departamento autonomo da secretaria micipal de cultura com dotaça orşamentaria proprian 
A 6 de mado de 1982 o prefeito Feynado de Barros sancionou e promulgou a lei nr. 9467" ja aprovada pela Camara Municipal, criando o CCSF "Fublicada no Diario oficial do Munictpio a 7 de maion a lei cletermina em seus artigos a competencian a composicá administrativa a a atonomia orsamentaria daquele departamento" definindo como objetivos do CCSF":

a) Flemejar, promorer, incentivar e documentar as criacses

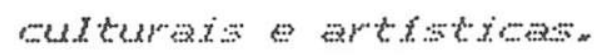

b) Remir e orgendar una inframestrutura de informaxpes sobreo conhecimento humano.

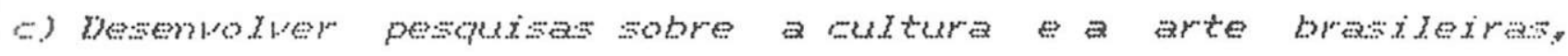

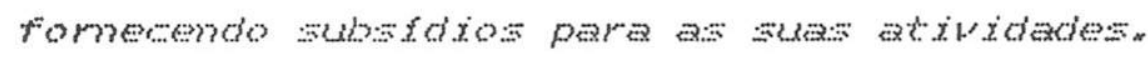

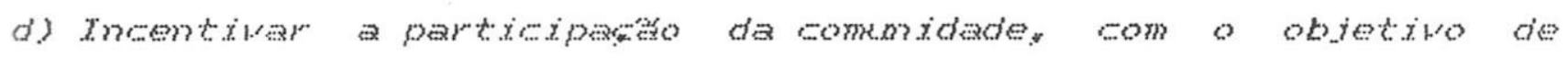

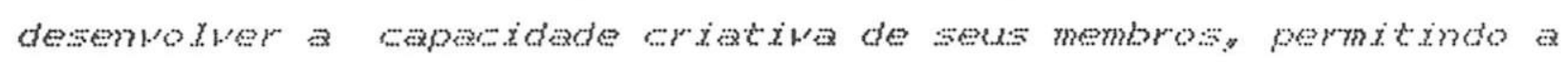

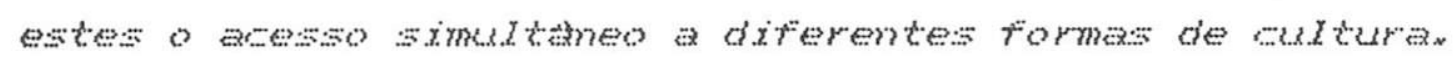

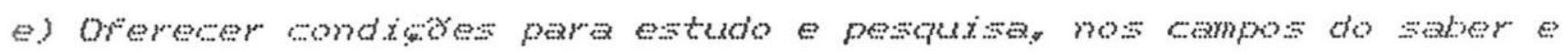

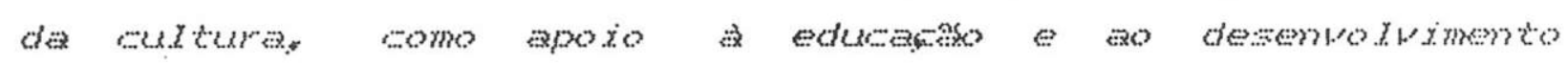
cientition temologicon

A prefeitura no pensava na epoca em aumentar seu quadro de funcionarios com a abertura do centro cultural. Saro Fauto devido aos grandes gastos já acumulas pela sua construçós. os bibliotecarios e o pessoal administrativo e tecnico seriam remanejados de outros locaiss porem algumas contratacess especticicas se fazian necessarias.

\subsubsection{Inauguraço}

No dia 13 de maio de 1982 o Centro Cultural. Sá Faulo foi inaugurado incompleto, apos 2 anos, 10 meses e 1 dia de construcho, para que o prefeito Feynaldo de Barros pudesse presidir a cerimonia antes de afastarne do cargo, a fim de disputar o governo do estado pela legenda do FDS. Até agosto de 1981 menos da metade da 
gigantesca obra estava feita como noticiaram os jornats porsm a partir daquela data inversoes macisas de recursos dos cotres ouncipais permitiram uma "violenta aceleraço do projeto" na

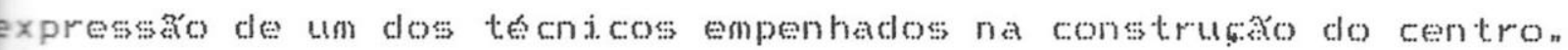

Tanto Feynaldo de Barros como Máto Chamie vinham procurando hegar que o cosf estava sendo inaugurado antes do tempo por questors elejtoraisn Feynato de Barros afirmava que o mass importante. "as obras civis" "estavam prontas chamie alegava que parte a ser inaugura era uma especie de "jinframetrutura" das que serian conclutess "dentro de uns dois ou tres meses" "

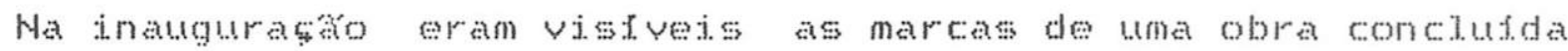
as pressas segundo os jornatsi os carpetes estavam estirados no chă mat. 1avado, as pastithas do piso eran arrancadas com novimentos bruscos dos pess.

Finguanto esperava pelo prefeito chanie se jiritou com a insistencia dos reporteres sobre a apressada inauguraca da obran Frisando que o nome do novo centro o "Centro cutturat sa fauto" "e na "Centro Cultural do Verguedro" ou "de Sá Faulo" (z) "Chamie alegava que seria un desrespeto a populacho esperar para entregar - centro concluto, pois alduns setores ja estavam em condiges de funcionamento. "A inauguraça năo provoca qualquer probleman o Centro cuturat tem varios setores autonomos Nos estamos entregando nove unjdades hojea un teatro para 450 lugares. un cinema municipala auditorjog un teatro de arena para 5 so pessoas. area de exposibses de artes plasticas discotecan una pinacoteca com 1,800 obras, un foyer e un jardin interno. Dentro de uns dois ou tres meses nos ja teremos un acervo catalogado suficiente para inaugurar a biblioteca" "explicou chamie "defendendo a criaça do CCSF" "Una cidade como Sao Fauto precisa de um centro culturat como

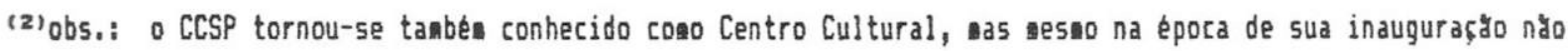
o único da cidade, pois já existia o Centro Cultural Jabaquara, tabén pertencente a SMC e inaugurado en 1980 , aléa do SESC Fábrica da Ponpeia já ter aberto extra-oficialnente ao público alguns de seus setores. 
essen de facil acesso a moradores de todas as regibes da cidace n " as pessoas se enganan quando pensem gue a cutura os unabra de linha de montagen! ou $\$$ una obra acabada. A cultura vive de suas

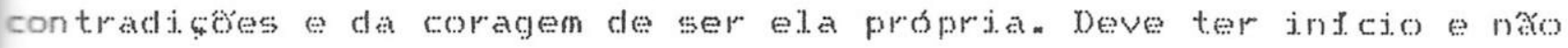
ter medo da rota a cumprir" "

Em seu discurson o secretario de custura disse que a construça do espaço aconteceu porque percebeu-se que "da fraticén Desvairada entre o dardim da Luz a Avenida Faudistan nos restava

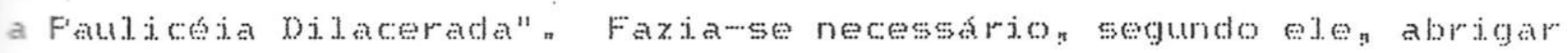
num so espaço cutura popular e cutura erudita e todo tipo de mantestamo cuturat de grupos ou comundades as mass diversas.

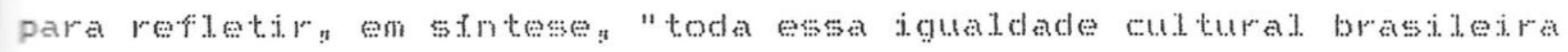
que of feita justamente de diferenças" "

Foran distribufos cartoes postais com a foto do centro Culturat. Saro Fato folhetos que continham a ilustrasko dos diversos pisos e dos servisos oferecidos além da programaca inauguras. ede dois pequenos textos? um de Feynato de barrose outro de Mrio Chamien este acui reproduzidon

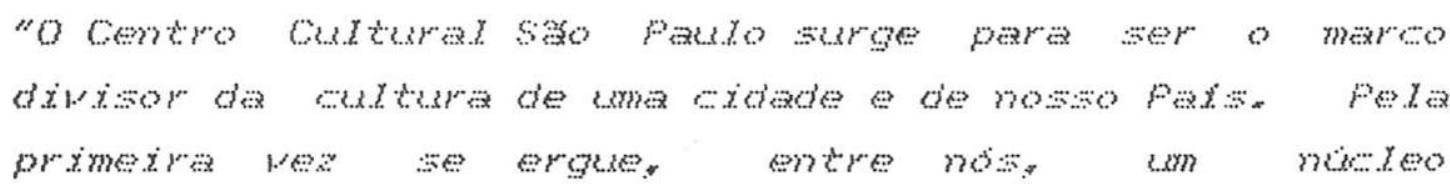

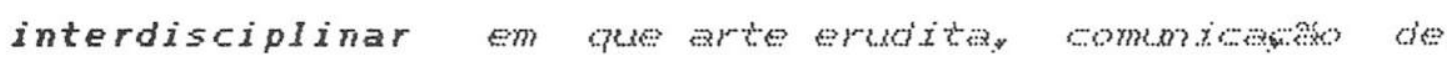

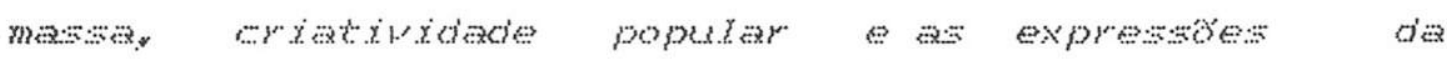

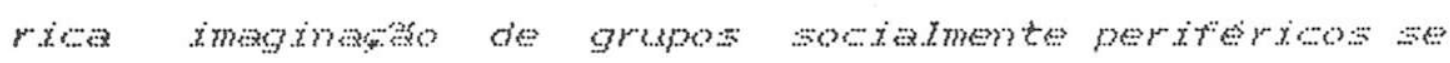

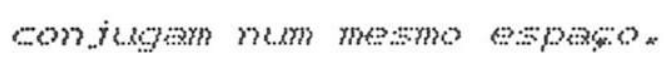

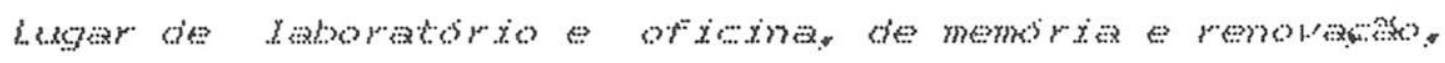

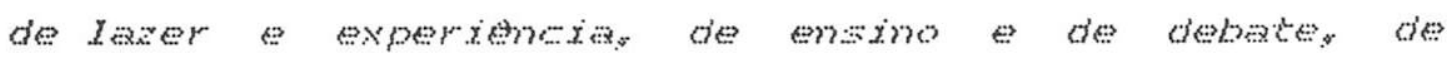

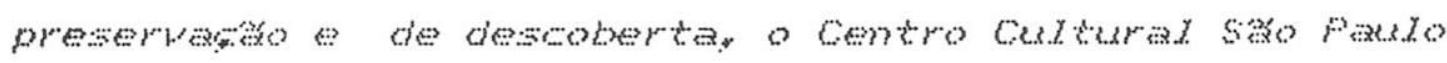

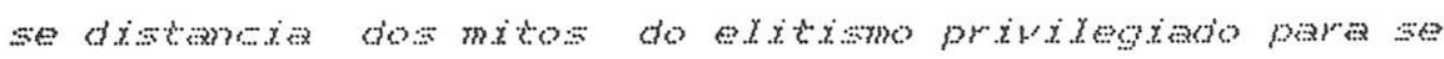
aproximer dis condises reats do nowo pow en refletir a

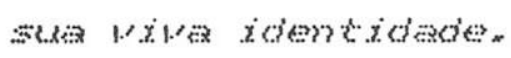




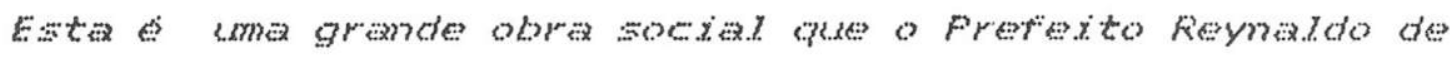

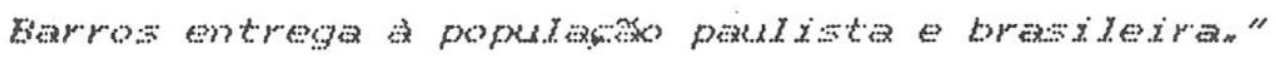

\title{
Mistio Chexplis
}

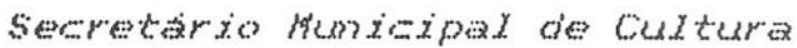

o arquiteto Eurico Frado Lopes, estranhamente, naro teve o seu nome citado en nenhum dos discursos e nem mesmo impresso no folleto distributo aos presentes na solenidace de inauguraço. Wotou-se que os tijolos aparentes da parede lateraly no piso inferiory traxian as initiais Fu em lembranga a nome do entáno prefeito da cidade.

Na abertura do CosF foi apresentado o 10 modulo da exposicao "Semana de $22 /$ semana de 32" trazendo obras do periodo de 1922 a 1942 e devendo permanecer por tress mesess dando posteriormente lugar aos outros dois modulos que cobririam os 40 anos restantes. o auditorion o teatrog o teatro de arena e o cinema programaram, para a primeira semana de atividadess debates, encontros culturajs.s espetaculos e filmes sempre buscando un paratelo a mostra "semana 22/Semana 82".

Em entrevista que concedeu a jomalistas poucos dias antes da inauguraço chamie afirmava que depois que assumiu a smo os planos de construsaro da biblioteca foram mudados completanente. sendo que a obra ficou aparentemente menor" "menos majestosa" se se transformou num centro cultural, a exemplo do Georges fompiclou e do recem-inaugurado na época "Barbican center" en Londres" "Com o nosson havera apenas tres centros culturais nessa linha em todo o mundo. Mesino o Lincoln Centery de Nova York, náo e tao pluricut turat como os de sao Faulon londres e Faris" "Acrescentou também que no cCs: serian cobraclos apenas os espetaculos teatraisu ao contrario de Faris e Londres onden segundo chamie, o simples acesso ja era pagon 
Algumas pessoas se manifestaram nos jornats sobre a criaço do CCSF" Fietro Maria Bardi achava que a cidade deveria ter un grande centro de difusaro cultural. e disse que, ern principion "este se baseia no modelo que propusemos en 1947 e conduzimos..- com a vali.osa contribujho da Frefejtura no no ruseu de Arte" "

Fara o entao jornalista Torge da Cunha Lima a obray anda que de grandes proporçes; se justificava inteiramente" "clescle que nâo se transforme num twFs das artes oficias" ${ }^{2}$ E achava que a estrutura do centro deveria ser de una fundaço" "que se constitua com representantes dos meios culturajs de representantes da sociedade civit en todos os ntveisu e deve ser fiscalizado por curadores de i. i.bada reputaço sensibilidade"

o professor Carlos Guitherme Mota pronunciou-se da seguinte manejra: "Wăo creio que seja oportuna a crtica suspirosa a obran numa terra en que se faz tao pouco pela cutbura Ela deriva de um projeto que fo melhor que o sistema pos-1964 conseguiu articular" A critica a se fazer seria a de que esse projeto na foi. sufieientemente discutido pelos diversos segmentos da sociedade" " Carlos Mota nato acreditava que a dispersa geografica fosse mais positiva ou mais democratican "ate porque tem havido muita socializaço da ignorancia, un certo social-wobrismo' que certas esquerdas adoram. For outro lado. a concentraça desse centro pluricultural pode reforsar as tendencias autoritarias sempre presentes nas ideologias culturats brasileiras" .

0 arquiteto Carlos Lemos acreditava que a juventuce universitaria e alouns poucos interessados na aprimoracho cultural. "todos da ciasse media ascendente" iriam lucrar bastante com esse complexo cultural n mas o povo nao. 


\subsubsection{Problemas}

No oitavo dia apos sua inaugumaton o Centro Cultural sao Paulo foi submetido a primeira forte chuva e năo resistiun Goteiras infiltraçes de agua surgiram em toda a extensao do predion enquanto um grupo de funcionarics tentava em vaco conter com rodos as aguas que se infituravam atraves dos vidros laterais pelo acesso principat de entrada na rua vergueiro e pela porta que dá para a Finacotecan Nesta areag a sgua da chuva vinda da rua entrava livrementen cobrindo parte do carpete verde-musgo e atingindo os paineis onde estavam expostas obras dos mas fanosos artistas brasileiros " o corre-corre foi geral a ate que se ergueu uma mureta para impedir a inundacto. Alguns funcionarjos removian mesas e estantes de un lado para o outroy en busca dos poucos metros quadrados de teto sem infiltracso de agua e opersios que ainda trabalhavan no acabamento da obra estendian lona plastica nos locais das goteiras Tamberm o piso inferior acabou sendo atingido

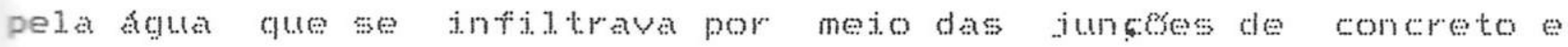
ferro, das tubulacoes hidraulicasn

o diretor do Cos" Ficardo ontake dizia que o tato das obras terem sido aceleradas para permitir a inauguraso antes da safda cio prefeito "nato tem nada a ver com as goteira" "contudo a opiniáo de un grupo de operarios que trabalhava no acabanento da construsa era bastante diferenteg afirmando que "isso aqui foi feito a toque de caxa eso podia dar no que deun Nos trabalhamos aqui vinte quatro horas por dia e sempre assion quern tem pressa come crú quente" " Segundo os operarios. cerca de cem homens ainda trabalhavam na parte de hidrálica, alvenaria e eletricidade do précli.ion.

Suando se manifestou a respeito marjo chanie chegou a inventar una fabuia "Tnauguramos uma goteja na fita vergueiron Mas descobrimos gue a goteira náso estava funcionando bem. Entán. depois de una pesquisa exaustivan vimos que o motivo desse mau funcionamento era o centro cultural que "entá, consertanos para que a goteira passasse a funcionar sem problemas" referindo-se 
ironicamente ao espaço dado pelos jornais a inundaga so sof ida pelo cent.ron

Ds operarios realizaram trabalhos de calafetaços nos pontos majs eriticos do teto, com mastite, que é un complexo resultante da mistura de Varios materiajs os problemas do CCSF poremn eram inúneros e ficaran evidenciados quando un grupo de musicos eruditos apresentou-se em una das salas e reclanou da inexistencia de tratamento acustico no local" cujas paredes de tijolos permitem o vazamento de som impossibilitando eventos paralelos n Tamberm foram apontados o barulho dos passos nas escadarias de ferroy a trepidaço causada pela passagem do metro, a falta de iluminaço nas escadarias a falta de entrada esada para os musicose desaparecimento de objetos no camarims dentre outras constataçes de menor importancian

Os jornats tamberm aproveitaram para fazer as suas listas de criticas e nelas constava a dificuldade de estacionamenton pois nao ha mutos espaços por perto e varios trechos sáo proibidos a as pasti.has do piso de entrada que eran perigosamente escorregadiase já se tinham soltado em alguns lugares, a ausencia de un bar dentro do centron que acabava favorecendo a permanencia de ambutantess o ajardinamento precario, a falta de grades de protecho en lugares onde o desnlvel. 6 acentuadon a ventilaço preckria, a ausencia de lixeiras, etc.

Os dirigentes do CCSF diziam ter recebido o predio daquela forma e que dependian de verba para consertar mas era preciso movimentar o espaço apesar dos problemas. para que ele naco morresse. Segundo afirmavam năo era facil fazer tudo no messo tempon colocar o centro a serviso dos artistas " receber a comunidade, tentar conseguir a verba para a reforma " "

No ano seguinte a inauguraço do cosf o prefeito da cidace era Mario Covas: a secretaria de cultura estava com Fabio Magalhases e o Centro Cultural Sao Faulo era dirigido por Fernando Lemos, que prestou a seguinte declaraçáno aos jornais: 
"Ruando assumimos a direçáso do CCSF avisamos a imprensa que estavamos; herdando una obra da qual discordamos integralmenten A soluçso que encontramos foi utilizar o nosso preparo politio w intelectual. para faxer esse espaso funcionar como e possivel. para que daqui a pouco alguem năo venha com a icleia maluca de transformar is so aqui. numa outra rodoviaria. Estamos arcando com esse abacaxi: essa obra inacabada que foi inaugurada por motivos politicosn que temos levado en frente usando ate do prestigio pessonl para conseguir de empresas materiatis necossarios para montar uma exposiço. Forque dinheiro năo ternos e estamos entre tres secretarias de Estado - a de obrasy a de Finangas e a de Cultura - sen a possibilidade de intervir nas obras e nos equipamentos por causa dos contratos assinados com a administraşo anterior " " Nós estamos pagando por uma obra errada e as criticas 50 ajudam a destruir o esforgo que temos feito acpi. dentron com a ajuda de profissionais que poderian estar ganhando o triplo en outros lugares, mas que estás aqui. batalhando para fazer

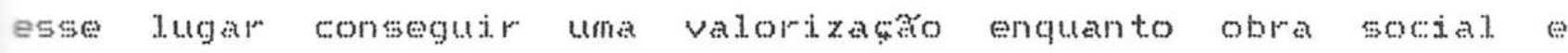
culturaln Ciaroy nós estabelecemos as nossas prioridades y entre elas está o tratamento acustico dos teatrosy as cabines cle projeçon as bibliotens infantis e de brajlde e o restauranten que nos traria un retorno imediato de dinheiron com 500 funcionarios trabalihando agui. nen lanchonete temos a que existia fechou porque o contrato expirou e no era posstvel. renova-lo nas condiços en que funcionava"

Com a inauguraço do CCSF nasceu um desentendimento que se tornou cronico e progressivo entre os empreiteiros da obra e a prefeitura A coordenaşo tecnica e administrativa pertencia a SADE: gue cuidou de toda parte metalica da obran on a rotodo Engenharia $S_{n} A_{n}$ foi a responsavel pelas estruturas de concreton sendo que estas duas empresas contrataran as outras firmas para

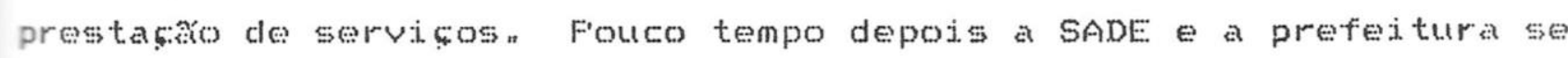
incompatibilizaran de tal maneira que o orgão publico processou a SADE por nấo ter concluldo a obra esesta a prefeitura por falta de pagamento sendo que no periodo sob júdice năo se poderia realizar nenhuma reforma devendo-se para tanto esperar o veredicto dos 
julzes. Forem toda a infrawestrutura de instalaseses so era do conhecimento da construtora e o simples ligar e desligar o quadro de luz cabia a seus funcionarios, que tinham náo apenas o dominto da situaça elotirica mas de tudo que deveria funcionar no ccsfo. .

Em setembro de 1984, cinco meses apos a morte de Eurico friraclo Lopes num acidente automobilistico (tendo sido seu corpo velado na biblioteca do CCSF')! o arquiteto l.uiz Telles foi chamado para a realizacko de obras de emergtencia que visavam a segurança do edificioe do usuariog providencia esta tomada no periodo da direşo de Jose cerado Martins de oliveira. Wá se sabia. entretantoy ate onde os projetos coincidian com a sua realizaço. ou seja se as plantas especificaçes havian sido respeitas nas 1.inhas eletricas" hidraulicas e nos condutores de ar condicionado: pois o escritorio de arquitetura de Eurico Frado Lopes náo acompanhou a execuça da obran Luiz Telles procurou realizar esquemas aproximativos da realidade do cCsF e buscou solucoses alternativas: como a abertura dos caixilhos para ventilasa cruzadas substituindo o ar condicionado.

Durante a administraço de Tose Geraldo Martins de oliveiran o assistente tecnico da direço para assuntos de arquitetura lrurilo de lorais Seixas! afirmoü "Wada seguiu una norma tecmica perfeita. o piso de pastilha ou piso de vidrotily foi muto mal assentado! o predio s todo modulado em 6y25 m, cada viga mede 6,25 me nesses eixos deveria ter pelo menos una junta de dilataçă mas

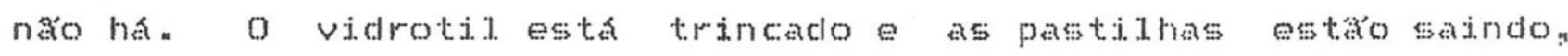
pojsy alén do mau assentamento na epoca possivelinente andaram sobre as pastilhas recem colocadas. O acabamento foi mal feito a parte de concoretagen tambern náo foi rigorosa er alguns lugares a forma se abriu e está meio defeituosa. Mas isso náo cai náo tern perigo de estroçar ". " A parte de encanamentos já deu vazamentos e un predic com apenas 3 anos naco deveria sofrer esse tipo de problema, mujas tubulaçes estáo sem bolsas. Tudo foi. feito as pressas, sem um minimo de capricho. E um projeto muito boniton um projeto super audacioso, de grande valor arquitetonicon além de ser uma obra muito caran Fenas foi mat cuidada a execuçă alem da 
pressa por motivos politicosa o que seria feito em um ano demoraram menos de quatro meses ... 0 centro so pode ser considerado concluldo quando o piso da avenida 23 de Maio estiver pronto" "

o pertodo sob júdice terminou em novembro de 1988; quando o departamento judiciario da prefeitura liberou o centro. apos o transcorrer de processos de majs de 1 .200 paginas; que foram se expandindo em pastas auxiliares. Hoje, un ano aposs há a possibilidade de se mexer nos espaços mas faltam recursos; Luiz Telles ja foi novamente chamado para assessorar a continuidade das obras necessarias e constituiuse uma equipe de arquitetos para

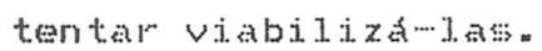

Os problemas persistiram ao longo das administractose como passar do tempo alguns ate pioraram devido a falta de manutenços pois, como se sabes o prédio ven funcionando en estado deficitario desce sua inauguraço. As caxilharias onde estáo assentadas as grandes paredes de vidro, nao foram devidamente vedadas e permitem a passagen da agua os telhados" formados por telhas de anianto e mólulos de acrilico transparente "sofrem do mesmo problema muta agua passa pelas frestas abertas nos encaixesy encuanto as calhas nao tem capacidade suficiente de escoamento e contribuem para a infiteraso. Ate ha pouco o telhado năo possuta passarelas que facilitassem sua manutençă, e nos reparos acabavam-se quebrando majs telhas a a jua tamben escorre por entre a estrutura metalica o concreto aneaçando as coleçes do acervo que saco cobertas com plasticos pretos, numa medida paliativa para salvar livros, revistasediscosn so nas obras de impermeabilizatso do telhado, juntas de dilataça e lajes que apresentam varjas fissurasy a prefeitura teria que gastar uma verdadeira fortuna.

Os problemas congenitos de acústica nos auditorios continuam até hojeg o tratamento terno-actistico sob as telhas ná foi feito, portanto năo há defesa contra o calor e o ruldo"e e enorme o barulho da chuva nas telhas de cimento anianto. O projeto original previa a colocaço de grande quantidade de vegetaço para reduzir a incidencia de calor mas nada disso acabou sendo feito. 
Ha vários tipos de equipamentos, alem da usina do sistema central de arwcondicionado abandonados no primeiro piso, transformado num imenso poráo.

A tubulasáo do sistema de ar condicionado foi espalhada pelo predio intejro e a sala que guarda o equipamento alemáco assemedhase a casa de máquinas de um navion mas nunca funcionou. o ar condicionado deveria ocupar todas as dependencias do ccsF" completar todos os espaços quando se conta com un grande volume de ar a temperatura varia pouco e o trabalho do sistema depois do ar resfriado seria apenas de manutenço "a Forem segundo os arquitetos" e diffcil. fazer funcionar algumas partes de forma estanque quando foram ideatizadas dentro de um todo que se complementa. A prefejtura pagou o projeto, realizado pela Termoplan e posteriomente instalado pela cebec, que acabou falindo. A questacicou em litigio en en 1984, foi chamada a chimatec para a investigasáo. Normalmente os prédios de concretoe vidro vivem de ar condicionado" a ausencia desse equipamento no ccsp faz com que os funcionarios suem a ponto de tirar a camisa" o calor chega ate a abir barrigas nos sandufches de acritico usados nas montagens de exposicoses e e insuportavel permanecer embaxo dos módulos de acrilicon A presenca do ar condicionado serviria tambem para evitar que o acervo fosse atacado por inicroorganismos existentes no ar exterior.

o projeto de telefonia previsto teria equipamento para 300 ramais mas essa central telefonica nă pode ser conectada porque nă foram completadas as tubulatess teleftnicas do prédioy e a Telesp recusoume a instalar osistema precariamente. o ccsp pacava as prestacoes mensais sem poder usar o equipamento, que a Telesp năo vende, apenas aluga, e a soluço temporaria utilizada foi. a de se dispor linhas com algumas extensoses pelo centro, que sempre estao ocupadas.

o projeto inicial previa a instalaşa de doze elevadores, sendo oito panoraticos. Estäo em funcionamento seis: os dois elevadores ao lado da Pinacoteca, que transportam os cegos e 
funcionarios e que sáo utilizados tambem para se chegar ao primeiro piso, os dojs montawargas, que server ao teatro de arenay os doj: elevadores da cozinha que nẫo esta ativada.

Até hoje náo funcionam o restaurante, o bar/lanchonete; o laboratorio fotografico, o laboratório serigrafico, a biblioteca infanto-juveni1, os laboratórios musicass a cabine de correio e telegrafos e o estacionamento que estavam previstos inicialmente. .

Wo pensar dos arquitetos deveria haver una comunjocaşo total do espaçon sempre aberto a circulaçes, porem a realidade nå permite isso. o piso superiory destinado exclusivamente ks exposicoses de artes plasticas esta sendo utilizaco clescle a inauguraça pela equipe administrativan que tentou criar um espaco exclusivo atraves do ergumento de uma barricada de biombos " Devese isto ao fato do piso da avenida 23 de Maio náo estar conciufdo. no podendo abrigar o que the havia sido destinado -... os escritorios das diversas divisoss tecnicas e a area da diretoria. Acabou por ser usado como deposito de tudo o que foi retirado do Teatro Municipal na epoca de sua reforma e la ainda continuam empilhados" numa grande montanha com mais de cinco metros de altura os teloes pintados em pano dobrados! e outros elementos cenograficos pontilhados por pulgas. Esse espaco năo tem janelas nem refrigeraço de ar. náo se vet a luz do sol " e segundo os funcionarios, "cria-se musgo la embaixo, junto a poejra aos ratos e as baratas que habitam o lugar." Ha mutos pontos de vazamento pela avenida 23 de Maio, com buracos de salda do prédiog e a noite a ronda e realizada por tres ou quatro vigias que náo permanecen no 10 cal.

o roubo 6 um dos mass difteeis problemas que as administraçes enfrentan no cCsF" favorecido pela situaçăo do prédion todo aberto para fora e interligado entresj. Na ho há lugar para guardar-se bbjetose tudo some das gavetas, nao se podendo deixar de trancar nem um copo ou a escova com a pasta de dentes. Fouba-se tudo: pessoas entram pela avenida 23 de Maio e arrancam os reatores das lampadas instaladas neste piso e ate se chegou a fagrar um homem 
com um saco cheio de cabos de refletores; pertencentes ao Teatro Municipal - perseguido, largou o saco e fugiu. Alguns equipamentos de cozinha ná uti.i.zacios, como a maquina de frios sumiram de uma sala trancada durante fidmagens realizadas no local.

0 espaco das oficinas apresenta vazamentos entre os vidros. 0 maior deles é perto do extintor de inctindio, pois nă ha un vidro com o recorte necessario para vedar essa abertura, e e comum o desaparecinento de varios materiais de trabalho. Fecentemente roubaram trets máquinas de escrever da administraço e um aparelho de telefones o que causou desconfianca entre os proprios funcionarios: na primeira quinzena de outubro de 1989 cortaran levaram parte do cabo do pararaios.

A área acima da construcho deveria ser ajardinada e aberta ao publico: na epoca da inauguraço o local apresentava esculturas, portem a escada vermelha de metal que the da acesson ao lado do jardima esta joterditada por uma corda amarrada. Mesmo assimu alguns casaj:s de namorados sobem pelas laterais do predio e meninos escalan a rampa branca a direjta do centro apoiamse depoja nos ferros e chegan at parte superior" onden segundo se comenta" "a molecada faz mistrias". Nesta regiáo venta muto, e vento tanben entra pelas aberturas do predion chegando a formar correntes que balançan os pesados painesis pendurados nos corredores internos n

o aspecto do Centro Cultural. Sac Faulo năo nada convidativo. Fraticamente todas as janelas basculantes que dao vista para a avenida 23 de Maio estäo quebradas com vidros trincados e 0 sistera de abrir/fechar emperrado, sendo que mutos dos vidros quebrados en vários pontos do CCSF foram substitusdos por tapumes de madeira pintada ha pequenos nucleos que servem como deposito de cadeiras e elementos cenicos semi-abandonados e cantos vedados ao publico que guardam bugigangas, fazendo com que o conjunto se assemelhe a uma favela. 
o prédio inteiro a vado pelo seu lado dired to sendo que as entradas saso ferhadas por tapumes horizontais, que substituen as portas no perfodo noturno, numa tentativa de impedir a acomodasco de alguns indigentes que procuram se encostar pelas brechas do CCSSF:

As colunas de aço na esta todas pintadas com o azul profundo que lhes caberia as junçes de vidro/acolconereton de diffeit. ajuste com certos recortes apresentam reentrancias abertas que abrigan uma sujeira de acesso complicado para os 1.impadores. 0 mosatco verde do chäo esta bastante desfigurado sofrendo diversas

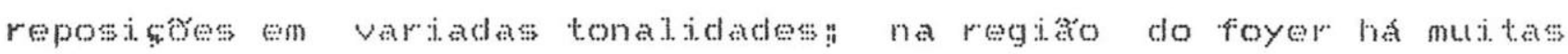
marcaços feitas com fita crepe que nao foran tiradas al grossejo cimento usado para remendar os buracos das pastilhas fug id dias.

Segundo um dos vigitantes, o predio do cosf "f meio mole" e apresenta una sinfonia de mumurios que se manifestam durante: a not.e. As emendas das colunas no cha saco feitas com borrata para possibilitar os novimentos do predion mas ha regibes - a area do foyer, principalnente -- em que a dilataço náo é contida e se levantam placas inteiras de pastilnas soltando estalidos caractertsticos" Esse fentmeno mats frequente no tempo de calor: quando tamberm o reboque das juntas chega a cair. o aco as veres dá fortes estouros" principalmente nas escadas enquanto as lampacias fluoresentes fazen seus tiques costumeirosn

\subsubsection{Administraçă Atual}

No intejo de 1989, Luiza Erundina - candidata do Fátido dos rrabalhadores, o FT a.- assumiu a prefeitura de sa Faulo e escolheu para a Secretaria Municipal de Cultura a filosofa Marilena chaui que por sua vez nomeou faulo sergio finheiro para a diresao do CCSF" Forkm o pretendido diretor ja era professor da Universidade de Săo Fato e époibida a acumulaço de cargos publicos. Faulo Sergio Frinheiro ná chegou a assumir a nomeaço foi invalidada, 


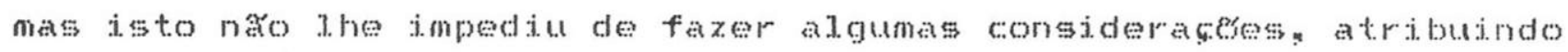
a situaçio do CCsF a "inciuria" e a "megalomania" dos antigos governantes municipais. "O CCSF e un caso exemplar de dexmandos" We le se concentran todas as taras administrativas do autoritarismo brasileiro" afirmou Faulo sergio Finheiron apontando a desproporsa entre a qualidade dos servicos prestados a comundade - ao contribuinte " a quantidade de funcionarios que havia no ccsp no finat da administraçá do prefeito Janio Buadros" Diante do absurdo or camento para resolver os problemas fisicos do predioy adequando assim aos seus propositos de animasio culturat. posicionou-se dizendo que "o custo do acabamento do prétio e da reforma socialmente discutivel, devemos promover um amplo debate. com a participaço de toda a secretaria e da sociedace" "

o professor de filosofia Tose Americo Motta Fessanha veio a ocupar o cargo de diretor do CCSF en marso de 1989 e adotou como um dos pontos fundamentais de sua gestaon segundo suas palavras a obietivo de intensificar a refiexa interna externa do gue cutcura e ampliar sua difusăo democratica Enfrentou de infeio problemas eletricos pois as instaleses foram mat feitas e apresentavan fiacos desprotegidas o gambiarms que superaquecian devido a capacidade de carga insuricienten ocasionando riscos de acidente. Depois de una pane nas jnstalaceses, os peritos do corpo de bombeiros interditaram tras satas de espetaculos e inicioume un processo de reforma bu buck de una nova adequasto dos espacos Fetiraramse cadedras para aumentar o espaco de circulasos trocaramse os carpetes inflamaveis as safdas foram sinalizadas os extintores revisadosy mas a solucio definitiva das dificuldaces eletricas ná parece estar proximan pois ate dezembro de 1989 aconteciam problemas com os disiuntores, ocasionando en alguns dias o fechamento do cosf.

Outra prioridade dessa administraço é colocar a cozinha em funcionamento pensandowse en algo como uma escola de refeiçes, patrocinada pela secretaria de Abastecimenton mas isto so podera acontecer depois de o plano passar pela camara Municipal e ser aprovado mediante decreto. O restaurante do cCsF nunca funcionou e 
o bar está parado desde 1983, pois atuava de maneira illegal por ter sido instadacio sem concorencian

A atual. equipe de arquitetos orientados por Luz Telles passa por algums dificuldades - no term clinheiro sequer para comprar um compasso -.. mas a intença e fazer un redimensionamento de tudo num

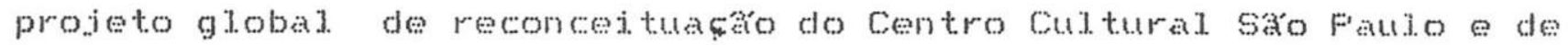

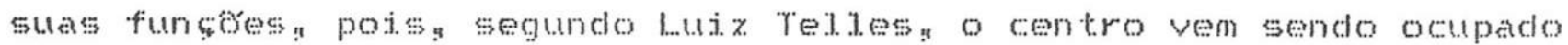
por pessoas que naso se dignam a entender a proposta do projoto. e mutos dentro de un escuma de funcionalismo publico váto tomando o espaco para si. Segundo o arquiteto "pelo menos agora temos un diretor que sabe o que e um centro cutural" thembrando-se de alguns diretores antigos com quem manteve contaton

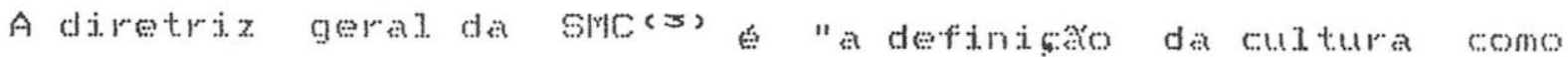
direito do cidada" e todos os seus orgas deven estar interligados e participando de grandes projetos vinculados a cidadania cultural. Isto significa segundo a sectetaria Marilena Chat "que a populapso tenha assegurado o direito de acesso aos bens cut turais! direito de produzir cultura edireito de participar das decisoms

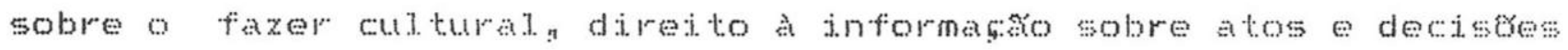

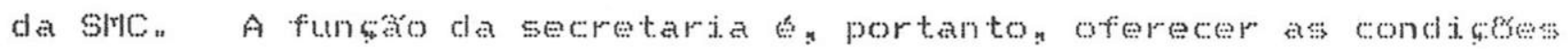
para gue estes direitos se tornem realidade p possibilitando alternativas ao teor autoritario e paternalista com que se tem tratado a culturan

Tajs intencoss implicam em algumas atitudes como a de que os projetos cuturais deven ser submetidos a previa aprovaciso pelo colegiado do cosf (que of fixo e composto pelos chefes das divisoess -. pretendewse tambern a inclusa de representantes dos frecuentadores) e pelo Colegiado da SmC (que muda sua composiça periodicamente) " Os objetivos da aprovaçáo pelo colegiado da secretariag conforme documento enviado as divisoes do ccsp (em

(3)obs.: neste capltulo fora incluidas inforabộes posteriores ao perfodo en que foi feita a pesquisa no CCSP, pois tratan-se de questores que definen a polftica da SMC. 
Dezembro de 1990) sâ os seguintes" amadurecimento das propostas atraves da discussáso coletiva compremeno pelo colegiado do contetio e das implicaceses do projeto proposto apropriaca da propostan se aprovada como projeto do conjunto da secretarian sem prejutzo das responsabilidades especticas sobre o mesmo; progranaço das atividades da secretaria como um conjunto articuladon integrado com a diretriz e as metas anuats

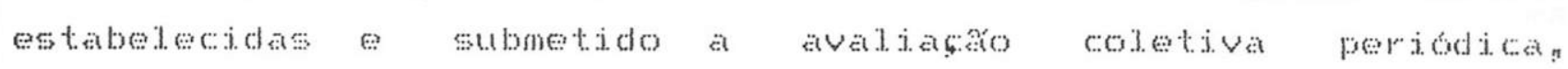

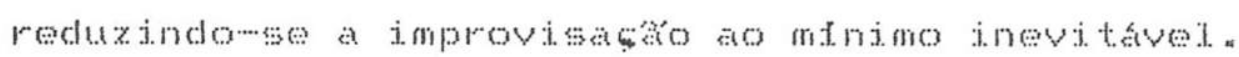

Estao previstas reundes mensats para discusso dos projetos a serem implementados no mes seguinte e pera avaliar a execuço dos projetos culturas aprovados anteriomente. segundo adouns funcionarios estas instancias de conselhos de cultura podem ter a intentaro de denocratizar mas dificutam e retardan a execuso ros projetos: os direitos dos cidadros saro apenas demagogia democratican

Fretendendo aunentar a receita na area culturata a swo concebeu una nova proposta orcamentarja anuat ques para vigorar" deve ser aprovada em votaço pela Camara munipal de vereatores. Foi apresentada a jdexa do Fundo de Cutura de tat forma que as rendas venham a reverter diretamente para as areas que as geraram naxo entrando no montante global para depois serem dadas frapes: minimas a culturan considerawe que as tentativas de muanga na estrutura iur idica so as bons qualidades desta geston

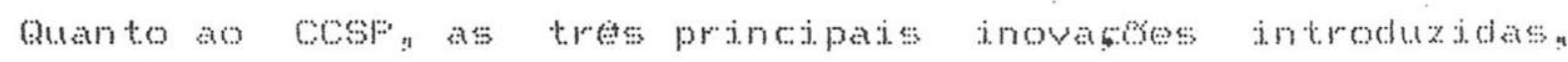

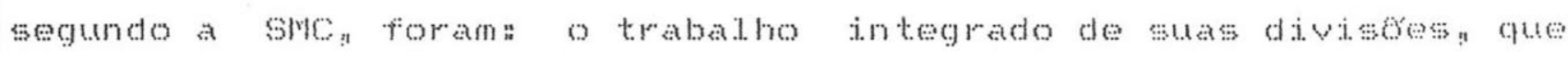
operan por projetos a centro cono prasa publica coberta e local de convivencia para os jovens: espaço de irraciagro das formes experimentats de rulturan abrigando essas expressoss no proprio centro ou desenvolvendowas en outros espacos como o wospitat do Servidor frublicon com a intengso de ajudar no processo teraptitico. creches, centros esportivos esindicatos)" 
Forem a nova administraço do FT na Secretaria Municipal de

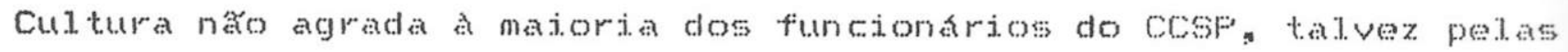
grandes expectativas alimentadas por todos segundo funcionarios simpatizantes do proprio partido! o FT apresenta o discurso de "recuperar a dignjace" mas repete uma pratica viciada de fazer polftica - e ciassista atua com muto democratismo e escolhe jucompetentes como administradoress E exemplificican com o "Frograma da Decharaço dos Direitos do Homen e do Cidadro" que foi concebidoe imposto pena secretaria micipal de cutura sem a preocupacso de se discutir com os tecnicos que acabaram tendo que trabalhar em algumas madrugadas para apronta-1o a tempon

\subsection{DivisB̈es e Seçôes do CCSP}

Conforme o seu organograman o CCSF t composto pelo gabinete do diretorn que recebe o apoio direto de tres secresin por seis grandes divisises.

Segundo Tose Americo Totta Fessanha o que lhe cabe como Diretor do cCsF o coordenar com os chefes das divisoses que compoem o colegiadon a realizacaro das metas do centro atraves de suas açes, tentando direciona-las para que tenham o melhor teor possivel. Como o cosf t una especie de laboratorio experimental de diferentes areas da secretaria Municipal de cultura que esta en estreita convivencia num mesmo local o diretor acha que deve haver trabalhos de integraşo dessas areas desenvolvendo se projetos dos quais participen varias divisoes e buscandowe uma sintonia com outros organismos da sle a abertura para a cidade.

As sectes ligadas a diretoria geral sáo as seguintes:

A Supervisao Coordenadora de Eventos, orgáo que reline a progranaço

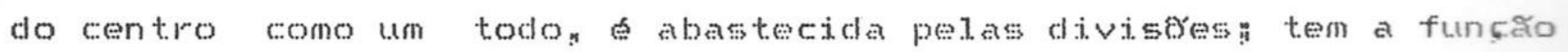
de realizar o mapa de uso dos locass e responde as cartas de sol.i.i. taçáco de espaços 


\section{CENTRO CULTURAL SAO PAULO}

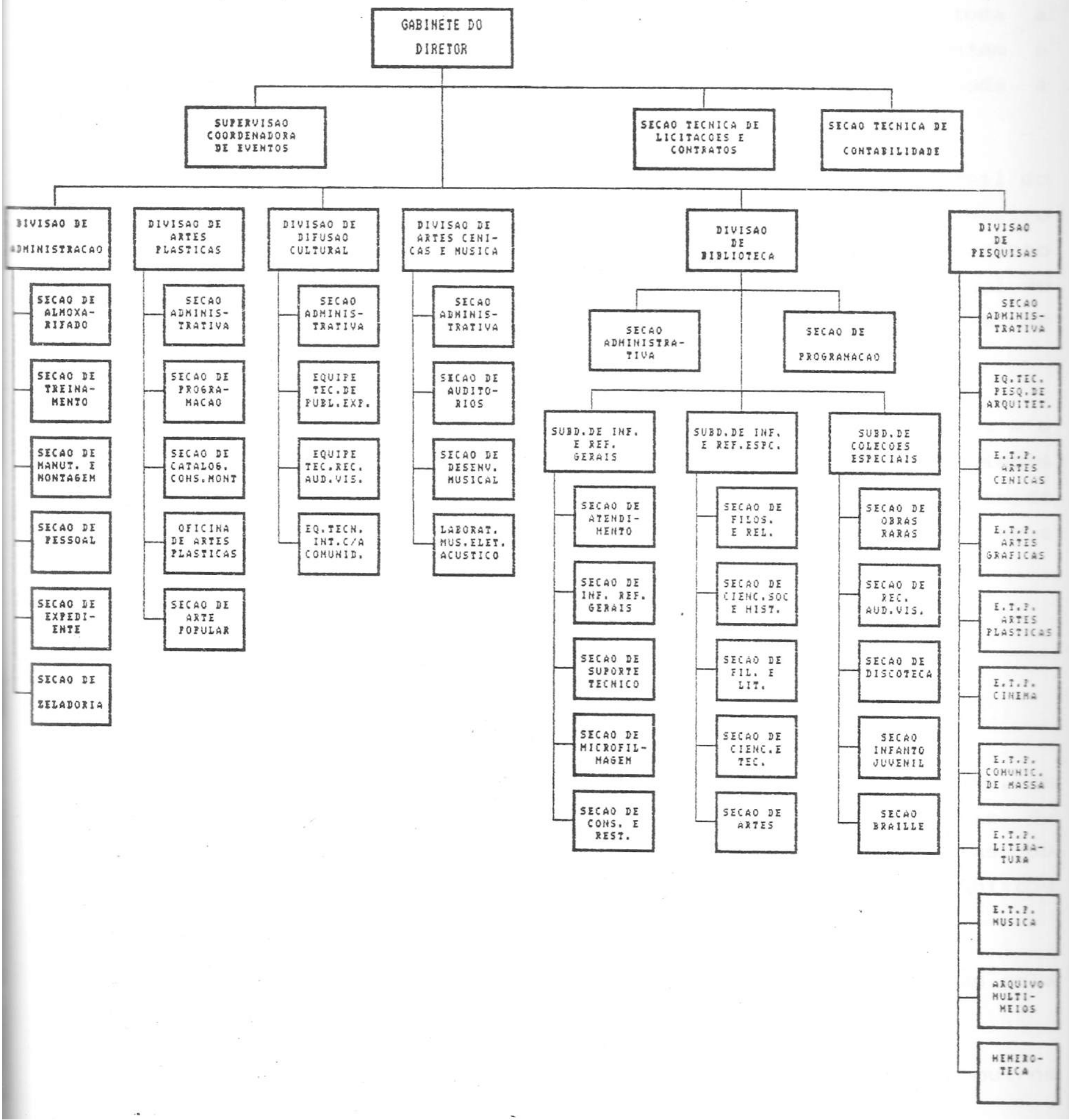


A Secaro Ténica de Licitacaes e Contratos que processa toda a parte de contratose licitasos do COFi as divisoses montam o processo e o encaninhan para esta seça que confere toda a documentacáo formaliza o contrato.

A Secaro Técnica de Contabilidade qu que controla a parte contabil. clo CCSF" cuida dos pagamentos e fornece informacoses sobre o dinheiro

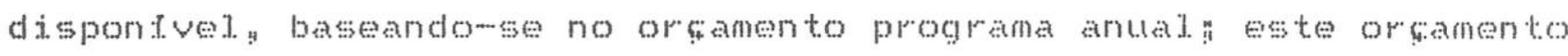
e obtido atraves de una previsao publikada no diario oficiad do Munictpione cujo sistema basico a ajstado pela secretaria de Finan

o COSF possui seis divisoes que reatizam as atividadeseo atendimento sendo una divisaso de aministrato o cinco divisom culturas. Fara cada una destas divisems ha una segro administrativa propria que cuida das questoes relativas aos seus funcionarios a (4)

\subsubsection{Divisă de Artes Plásticas}

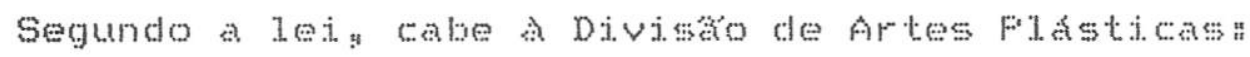

a) localizr. catalogar e preservary direta ou indiretanente as obras de artes plasticas pertencentes a patrimento da administracas recomendando, en casos especiais n regras de

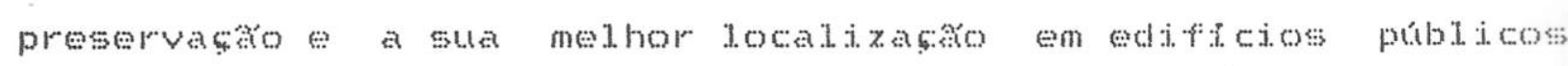
municipatis.

b) orientar: selecionar e avaliar as obras a seren adquiridas pela administra६̧宀o.

(i) programar e organiaar exposiçbes do acervo municipat outros eventos.

(4)obs.: a descriça das funçtes de cada una das 5eçtes que fazen parte do organograna do CCSP pode ser encontrada no Anexo 1. 
d) incentivar o exereicio das artes plasticass a partir do nivel de in in i. i.

e) reunir trabalhos e organizar coleçes de arte popular. principalmente da Fegiá Metropolitana de Săo Faulo.

f) Manter a Finacoteca Municipal.

A Divisaro de Artes Fisticas cujos escritorios espaco de exposicoses localizanse no piso 810 6 composta por quatro segess tecnicas e una administrativa.

Apesar de nao ter sido diretamente citada nos atributos da 1ei. que se procupa mats com o acervoy a secao de programasa w a responsavel pela definitso do que sera mostraco ao púbico e pela montagen das exposiseses.

A Sefao de Catalogafao, Conservacăo e Hontagem et chefician descle o seu inf obras do acervo da prefeitura que se encontran en predios publicos"s pois as Secretaris Municipais mantem obras de arte espathadas por suas unidades. As obras en logradouros publicos: como as

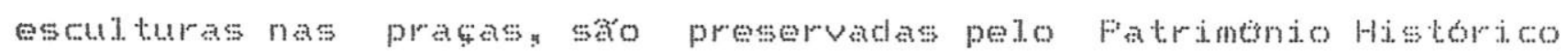
Mun i. tipat.

A chamada Finacoteca Muicipal possui. un acervo de 1 "700 obras, com pinturas de Franz Fost. Anita malfatti e Flavio de Carvatho entre outros sendo que 8o\% do seu montante saro obras sobre papel. Na decada de 50 houve un grande acrescimo de obras a acervo municipal gabato Magald adquiriu algumas peças durante sua gestáce na decada de 80 o acervo recebeu dongess a estando hoje estacionado. 
Na ppoca da inauguraço do CCSF" a ideia era a de reunir todo o acervo num cofre a ser instalado no piso da avenida 23 de Maio, senclo expostas 200 obras por vez no espaso destinado as mostras do acervo, logo na entrada do piso superior entre os dois paineis onde se encontra a estatua de Erecheret. Fretendiame possibilitar o acesso as obras para os visitantes do centron pois nos predios administrativos poucos ass viam. Forem. o CCSF nă apropriado para expor obras de arten porque os raios solares inciclem diretamente nelas a luz artificial fluorescente queima papel e estraga os pigmentosnge a umidace as danifican

Como o acervo naco foi reunido, o trabalho de Ana Guerra tem sido o de visitar as unidades, atualizar as fichas de catalogascon e. quando necessariog recorrer a especialistas esolititar verba para restauron

A Oficina de Artes Plasticas atende a comuniclade a partir de

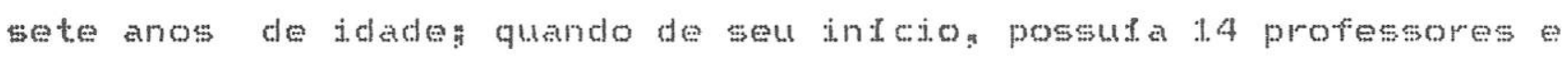
4 coordenadores: mas a divisa perdeu alguns cargos devido a remanejamentos feitos para cobrir fendas de pessoal no centro e atualmente conta com 8 professores e 1 coordenador, que 1á están há 6 anos

A atuagro da oficina se da en tres areas distintas: nos cursos para crianças adolescentes a adulos, nos quais se enfatiza a descoberta o desenvolvimento da lingugen plastica do desenho, da pintura e da esculturan na formaça e treinamento dos instrutores de arte das instituicoses da prefejtura atendendo as BI -.. Eibliotecas Infantowuvenis " Escolas Fublicas Municipats e unidades da FEBEM a nas atividades que nă tem continujdade sisteratica, como os ciclos de debates sobre artes plasticas as discusses sobre trabalhos de arte educaşa e a atividades de domingo como "Explorando Materiais" que desenvolve trabalhos com materiais espectficos (palitos de sorvete "papelós fios "etcn). 
Nos primeiros anos do CCSF, nas administraçes de Fernando Lemos o Jose berato de oliveiray houve eventos importantes realizados pela oficina fora do centro, como os "out-"doom" dos Direjtos das Criançs, feitos num dia en 11 escolas da prefeituran e as aulas nos domingos de manha na Frạa Dom Tose Gaspara que reuniran 400 criancas por dia e se constituiran no primeiro evento de massa com criancas em sá Faulo snesta epoca a responsavel pela seça era ma Cristina Fereju de filmeida)

o material o fornecido pe1o COSF mas e restrito consendido atraves de un diffej. processo. En novenbro de 1989 apenas 50 pessoas por dia frequentavam a oficina de artes fidsticast acreditase que por ma divulgată pretendewse chegar a atender 300 pessons ate a metade de 1990.

A quinta area da Divisáo de Artes Fusticas a sega de Arte Popuar que tem a frente Faulo Vasconcelos desce 1983. sondo que seus integrantes dedicanse ds atividades de levantanentos interferencias junto aos produtores de cultura os projetos externos comprenden pesquisas como nos folguedos populares de sa Faulo no contato con artistas autodidatas) e elaboraga de programas en bairos periferjos como as oficinas de bringuedos em escolas publicas), enquanto os internos fazem o levantamento a exposiça dos produtos dessa cutura popular para umapreciaco anditica fora do seu contexton

Ate 1985 as exposiceses foram descentralizadas sendo que as pesquisas geravan mostras que ná chegavam a cosfo fienina kat e cabriel. Borba diretores da divisáo na epoca tinhan certa resistencia a ceder os espaços nobres para se expor a cultura popular, vista cono conservadora. A partir de paulo Maranca o trabaliho da seço passou a ser mostrado no centron

Diz Faulo Vasconcelos que a todo governo e necessario montar um esquema de seduço para manter a area popular e lenbra da intenço de Gabriel Borba que enfeitiçado por richel foucaut segundo Faulo Vasconcelos -- mas com un pensamento progressista, 
pretendia trangformar a Seça de Arte Fopular em Seço de Arqueologia do Cotidiano, preocupado com a asorşáo da cultura da cidade.

A lei fala sobre a aquisiço de arte popular, porén nă ha lugar para se guardar nacla no CCSF a a sesa acaba realizando trabalhos com os acervos públicos municipais expondo entre outros temas, capas de discos e obras de 1.teratura de cordely resultantes de pesquisas nos acervos da propria biblioteca do centro. Fara esta seço realizar una mostra no nivel superior o espaco deve ser requisitado pela Divisáso de Biblioteca.

A proposta de a Sesco de Arte fopular pertencer ao Departamento de bibliotecas da Semetaria Municipad de Cutura agrada a Faulo Vasconcelos pois as bibliotecas ja existentes ficam i.hadasy sern programaço, en num processo de descentralizackon poderjam promover patestras, oficinas e exposiçes sobre arte

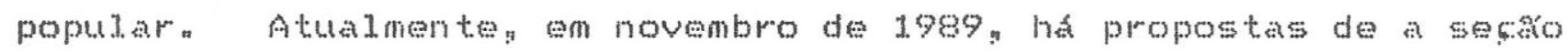
abastecer un espaço no metrt santa cectia e a passagem subter ranea da avenida Consolaço; ao lado do cinema Belas

As exposicoes realizadas pela Divisáo de Artes Fiasticas dependem das opcoes determinadas pelos seus diretores ern cada pertodo. A primeira diretora foi IIza Kawall Leal. Ferreiray durante a administraço de Ficardo ontake, que ficou pouco tempo! na epoca pretendiase construir salas para gravuras e salas para oficinas de arte. A sucessora de rlza Ferreira, durante a gestao de Fernando Lemos, foi a artista plastica lienina Katz, que se caracterizou por acentuada valorizaşa do consagrado, enquanto Gabriel Borbay professor da faU a diretor da divisáno no perfodo de

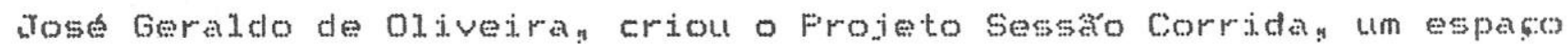
para iniciantes e artistas energentes que se apresentavam, sem qualquer seletaro, por curtos pertodos de tres a cinco dias.

Entre 1983 - 1985, sob a direçăo de Fenina Katz e Gabriel Eorba, o que se apresentou foi a produçáo contemportinea, e segundo alguns, elitista. Houve pesquisas que resultaram ern exposiçes 
como as de Livio fibramo, Flavio Tmperio e Vilanova Artigas, abertas por tress meses cada una com grandes repercussoses na imprensa o piso superior das exposiçesn ate o final de 1985 , era dividido em sete espacos ligados entre sis confrontando as linguagens e interesser que, segundo se pensava, perneavan a culdura da cidaden

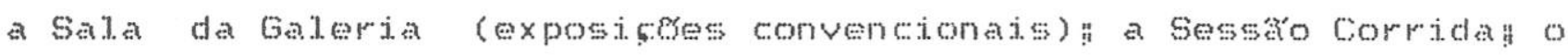
Sagua (acervo munitipal) a Grande Sala (artistas convidados) : 0 Espaco7 (reservado a outras seçess do Coff ou a instituipess fora dele) a Sala Expressa Nova (novos midiase performances) o Escritorio de Arte Fostal (pecas doadas por water zanini) " Ate entros expor no centro culturat sa froulo dava status as artes plasticas tiveran bastante forţa na programaço.

Com a chegada de Tanio Ruaros a prefeitura varios secretarios de cultura foran nomeados e o cosf teve cinco diretores: poren Faulo Maranea permaneceu como diretor da Divisas de Artes Fiaticas Durante este pertodo caju por terra a estrutura da exposiça pesquisada e todo o piso superior virou uma grande sesso corrida com uma invasa do novo inteiramente

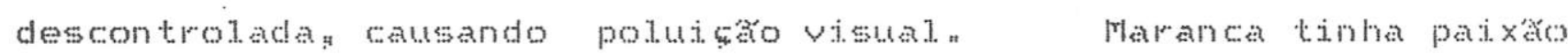
por papel e queria a rotatividade por exeelencian com novas exposiçes a cada 15 dias. De acordo com alouns comentarios a Divisa de Artes Fisticas virou uma feira de rabiscos s chegando a exibir as exposiçes de artes pidsticas wom mes n

A atual. responsavel. peio setor" Sonda salustein boldberg" demonstra nitida tendencia a arte contemporinea feita pelos jovens artistas da cidade reunindowos em mostras coletivas"

Os funcionarios da divisáo comentan que a imposiço de exposiços vem sendo um procedimento de todos os governos e desde o infejo ha certos problemas como a inexistencia de salas fechadas para guardar as obras de arte depois da exposicto. Essa falha faz com que as obras corran varios riscos. 


\subsubsection{Divisă de Difusă Cultural}

Esta divisáco atua principalmente nas ruas internas do patamar intermediario, nominado piso 806: e a area que reline o maior número de profissionats dentro do CCSF englobando a Sesáo Administrativa e tres equipes técnicas que prestam serviços as demais divisoss executam trabalios de atendimento a pubico e crian projetos independentes ou integrados as outras áreas do centro. Enfim. como dizem seus funcionarios, o que sobrou para se fazer acaba cando para a Divisáo de Difusào Culturaly tamben responsavel pela extroversaco de tudo o que e produzido no CCsF"

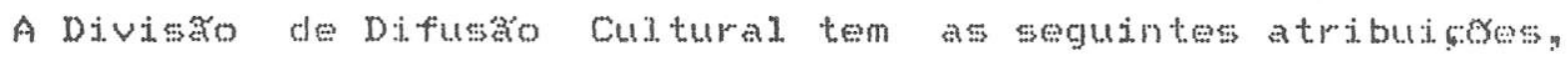
conforme a lei.

a) apoiar tecnicamente o registro de pesquisas realizadas pelo Centro Cul tural e elaborar o seu produto final.

b) produzir edifundir trabahos graficos a audiowisuats e outros" relativos a arte a cuturan

c) documentar as atividades do Centro Cultural sato Faulon

d) promover a participaça e a integraço da comunidade nas atividades desenvolvidas pelo Centro cultural.

o Setor de Radioatividade pertencente a Equipe Thenica de Fecursos Audiovisuais" realizou algunas das atividades que mais caracterizaran a atuaţo do CCSF e foi formato com a intenço cie se teriar un nucleo de producăo de trabalhos radioftnicos "Segundo Magaly do Fradon responsavel. pela Fadioatividade desde sua formaço f $_{0}$ linico setor fora da lei do CCSF" ná estando previsto nos seus estatutos. Nă existen portanton cargos para ele as atividades sao cobertas por pessoas vinculadas a outros setores e "sempre se da um jeito para conseguir dinheiro." 
A radio interna funcionou en carater declaradarnente experimental, com deficiencia das condiçes tecnitas de produço difusaso, de setembro de 1982 a novembro de 1983. ocupando un empaco

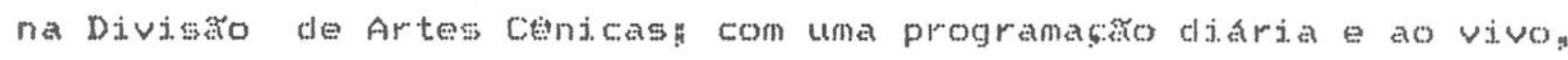
atraves de transmissa via caixas actsticas espalhadas pelos varios espaços do centro. veiculava internamente informasces da programaşo do CCSF e divulgava produçes dos grupos emergentes e independentes; apresentando musicas que nomalmente nas frequentavam as radios comerciais "A voz da radio era do volume do som ambiente norma. na biblioteca náo havia cajxas actisticas mas o som vazava do piso intermediario para baixo devido a estrutura do predio algumas pessoas chegaram a rectamar. A rádio interna parou porque o empenho dirigido para a sua existencia foi. encaminhado aos projetos pilotos desenvolvidos na radio USF"

Tamberm en novenbro de 1983 foi. fechada a lanchonetes único Jugar para se sentar de forma descompromissada no centro (ja que a biblicoteca implica em pesquisas e os teatros en ver apresentaçes). e que servia de ponte para a rádion pois as pessoas que se reuniam 1 a davam jeleias e pediam misicas. Sem a lanchonete os frequentadores circulam pelos espaçoss e nacoscutan do comeco ao fim os programas culturais Hoje os arquitetos estro estudando novos locais para reinstalar a radio.

o mais importante trabalho desenvolvido pela Fiadioatividacio deu-se quando " em jullo de 1984, passou a transmitir uma

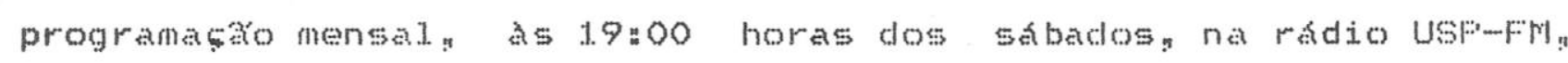
com a serie "Anos 60: a Década Explosiva" que durou ate julno de 1985 os programas continham as musicas os aspectos culturats dos filmes das pecas teatraise os acontecimentos polfticos que marcaram a epoca. A Fiadioatividade continua ate hoje com este mesmo horario na rádio USF desenvolvendo outros projetosn

A Fiadioatividade apresenta tanbem shows ao vivon desenvolveu programaços com a intenço de relembrar a vitalidade dos programas antigos de auditorio. com uma banda acompanhando ao vivo cantores: dançarinos, apresentadores, animatores; imitadores; jurados" 
poetas, mimicos p performaticos a magicos " Hoje realiza shows no teatro de arena con bandas emergentes que ainda náo gravarann na linha do reggae, rock funte e outros estilos, sendo as bandas escolhidas atraves de fitas de demonstraço.

Os integrantes da Divisáo de Difusáco cuturat recordam saudosos o pertodo de 1983 a 1985 quando havia un cuidado com a programasto e a imprensa recebia bem as propostas culturas Nessa opoca Jutio abe era o diretor da divisas assessorado por Vanda reixeiray ese discutia de tudo no centros com grande participaço publican Em abril. de 1984, por exemploy houve um clebate sobre a constituinte que reuniu 1,500 pessoss na sala Adoniman Babosan "0s eventos eram sempre acompanhados de seminarios buscando no debate com o publico leva-1o a uma formago mais ampla e a una reflexa mass profunda en mesmo com a politica de năo se dar certificados "comparecia muta genten

Havia o conselho de Frogramaça Geral do cosf " onde as propostas dos funcionarios e as vindas de fora eram analisadas por uma equipe formada petos diretores das divisoes pera supervisao coordenadora de eventom e pelas pessoas que apresentavan ow projetosg desta pratica resultou a Farede da Foesian um espaco aberto aos poetas gue inserevian previamente seus trabalhos eventos que ocuparam todo o centro e integraram as divisoes como o Frojeto Fathagada Fretendiane que certas exposicoss reatizadase tombadas pelo coff fossem mostradas en outros locas porem elas nă tinham sido concebidas com material apropriado para itinerar" normalinente eram produzidas tendo o actitico como suporten que risca e quebra com facilidade. o ideat seria enquadrarmse as imagens com vidro e aluminion necessitandowse porem de verba para $\operatorname{tanton}$

No final de 1985 preparoumse a "Expedicho Sá Faulo" " uma leitura da cidade atraves do Cosfa com o apoio do Tomat da Tarde, que estava completando a anos e realizou una serie de reportagens sobre o assunto durante una semana. Esperava-se que Fernando Henrique Cardoso ganhasse as elejocess para a prefeitura da cidade, 
mas com a vitoria de Tanio Ruaros; as 7.000 fotos pertencentes ao projeto acabaram não sendo mostradas.

As diversas mudangas de secretarios e de diretores do CCSP no governo de Tanio Ruadros acarretaram desanimon o centro sofreu um grande esvaziamento de técnicos sendo que as funcionários só da Divisa de Difusco culturat satran durante o periodo. o ambiente ná propiciava mas a participaso popular sentindowse a ruptura do uso mass democratico a desarticulaço dos movimentos do cosf.

Fara conseguir negociar a majora na camara ranio loteou a cidade, a assim o cosp transformouse em un espaco politico de Andrade Figueira, vereador do Fwox, conforme reportagens do jornal Folha de Saco faton A partir dat o periodico foi proibido pelo prefeito de ser comprado pelas unidades municipaisn A coordenatora de eventos do centro passou a ser a mulher de fndrade Figuedrä foram realizadas no espaço da Divisaco de Difusaro Cut tural exposiçes de pintura do rT Exerciton de pequenas fotos das fachadas de Centros Espiritas, e mostras fotograficas do tipo "reportagens de casanento" "com os nus censurados" segundo se comentas todas as coisas tidas como subversivas e pollemicas foram descartadas realizandowse exposicoses que náso colaboravam para aumentar a compreensso dos visitantes quanto as suas reatidades, nå levando portanto a nenhuma reflexáo -- eran vitrinas de variedades sem a menor consequencia. No meio da confusan as vezes aparecia alouna coisa razodvel. En 1987 pretendeumse reatizar uma exposiça dos cinco anos do cosf que náo chegou a acontecers pois seria baseada nos noticiarios da imprensa, esta praticamente não havia divulgado o centro naqueles ultimos dois anos.

Atualmenten a administraço de rose fmerico Motta Fessanha estat tentando algunas modificases na divisano como jigar a Fadioatividade diretamente ao Gabinete do Diretor" mas ainda năo há resultados efetivos " 


\subsubsection{Divisăo de Artes Cenicas e Música}

A le de determina que cabe a esta divisao:

a) planejar: coordenar, executar e controlar, nos espaços disponfveis do CCSF" as atividades artisticas relativas a música, canto dança, teatro e cinema " obietivando o seu desenvolvimento difusaro.

b) incentivar a pratica musicaly a partir do nfvel de ind ciacron

e) produzir executar montagens cenicas.

As quatro salas de espetaculos do CCSF apresentam as seguintes caracteristicas:

A Sala Tardel Fitho s utilizada para confertucias, debates. apresentacoes de musica erudita (possui. dois pianos de $1 / 4$ de cauda e um de armario) edança a sua lotaţo de 350 lugares apos a reforma do corpo de bombeirosn que retirou algumas cadeiras. Possui palco italiano, urdimento "black- out" g dojs camarins e uma cabine equipada com mesa de luz e corte de som. o cos atende as solicitaçes de companhis profissionais para esta salas que permanecen normalinente por um mess e executa projetos propritos como festivais mostras e oficinas " Nela ensaja o comal do cosfa criado en 1984.

O teatro de arena e chamado Sala Adoniran Barbosa! e promove shows de grupos musicais que se apresentam normalmente de quarta a domingon sendo que os menos conhecidos recebem o espaço apenas por dois dias e săo selecionados por fitas. Em 1984 e 1985 desenvolveu-se no local o projeto "de conversa em conversa" que ocorria quinzenalmente" reunindo grande público para conversar com pessoas de destaque na area cutural. Esta sala dispore de 750 lugares, possui. un camarim e o palco recebe i.tuminaçáo natural atraves de una cobertura de vidro. Os misicos normalmente peden para corcar com corda a regiáo próxima ao vidro que circunda a 
sala, pois, como é tudo aberto, o som escapa por cima, mas a corda evita que as pessoas vejam as apresentaşess.

A Sala Faulo Entio sales Gomes tem palco italiano, 91 cadeiras e 6 usada para teatro infantil. sendo realizados espetaculos para escolas as quintas e sextas-oreras. Originou-se de uma sala grandes do tamanho da Jardel Filho, que foi dividida ao meio, resultando tamberm na Gata Lima Barreton Essas tres salas possuem una cabine comum e sisterna de ar condicionado.

Todas as salas sáso equipadas orm some luz, de qualdade considerada de razodvel. a boa. Os equipamentos sáo oferecidos pe1o cosp: o que abaixa o preso dos ingressos cobrados! o centro noro recebe porcentagem de bilheteria nas apresentacoss dos grupose companhias a ha un teto maximo estipulado pela smc para o valor clos ingressos. Âlguns espetaculos tem entrata franca - quando o CCSF paga o cache requerido ou no caso de se apresentarem os compos estaveis da prefeitura na Sala Jarded Filho (orquestra sinfonica Toven, Corpo de Baile do Teatro Municipaly orquestra sinfonica Municipal, Coral. Faulistano e Quarteto de Cordas).

A billheteria náo vende ingressos antecipados para evitar a atuaço de cambistas $e$ o cCSF ná pode ficar com dinheiro porventura arrecadado e reverte-10 em beneficios para a divisao, pois se houvesse algum ganho: teria que ser encaninhado aos cofres públicos. Apenas se fosse una fundaço o cosf poderia receber a verba en seu próprio proveito.

A Sala t...ma Barreto o o unico coinema municipal da cidade, apresentando una sessao por dia e dispondo tamber de 9 ll lugares. $A$ preocupaçáo dos progranadores se da na srea de um cinema mais alternativo e como năo se alugan filmes ou eles sáo emprestados pelos consulados" com apresentaptes gratutas, ou estabelecern-se acordos com distribuidoras independentesy que ficam com a bilheteria. 
As salas devem apresentar seus eventos em horarios diserentes, pois ha vaxamento de som entre elas " Fortanton a Sala frulo Entio tem apresentaşes as 1500 horas; no teatro de arena ha ensaios para equatizaço de som a partir das 16 oo horas n com o show acontecendo as 20 no horas (18:00 horas aos clomingos) a a Gala l..ima Barreto proieta seus filmes as 19:00 horas (sendo que apenas o teatro de arena e o cinema podem trabahar juntos, pois seus espacos naso sac fronteiriços) e os espetaculos apresentactos na sala dardel Fitho sato sempre marcados para as atno horas.

Há muto se pretende fazer un tratamento actstico das salas a uma reforma "limpa" "como e chamada na qual devem ser trocadas as portas de vidro por outras acusticas (mais pesadas com enchimento de la de vidro) engrossadas as paredes divisorias de avenarian

Nos primeiros sete meses e meio de existencia do cosf foram realizados 508 eventos nas salas de espetaculon fis apresentacos abrangeram mísica popular música eruditan teatron dança teatro infantil y leitura dramática múcica pealizando-me palestras sobre diversos temas culturase cursos de teatro de danca e de nistoria da arte Fretendiase que essa diversificason inciusive quanto a generos n possibilitasse que o espaco pubitico do cosf estivesse aberto as diferentes camadas da poputaço em termos de idaden escolhes: gostos: visoes de mundo e niveis culturass e para facilitar a frequencia as pessoss de baxa renda os ingressos dos espetaculos eram baratos ou gratis na grande matoria das vezes.

\subsubsection{Divisă de Biblioteca}

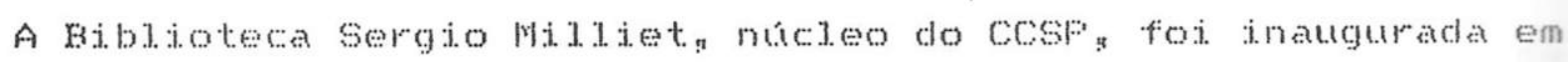
1983. Instalada no piso 801 g o espaco do centro que recebe mator pubidico apesar de náo permitir jovens com menos de 14 anos por adotar o sistema de consulta livre. o seu acervo náo é circulante. 
o Departamento de Bibliotecas Fublicas havia estabelecto um plano de compra de livros para formar o acervo gerall da biblifoteca do centro que estava sendo criado. Forem, com a inaugurage prematura apenas se transferiu parte do acervo de una das divisoss do departamento a kiblioteca Mário de Andracle que acabou cedendo ao ccse os livros editados a partir de 1960 (alguns livros foram repostos: mas permanece uma lacuna nos anos 60 e 70 no seu acervo) eas revistas do ano de 1980 en diante. Quando en 1975 ciriousse IDAFT -.- Departamento de Informaşo e Documentagro Artistican todos os livros de arte da Mrio de Andrade foran reundos no zo andar desta mesma biblioteca e passaram a pertencer a biblioteca de or te

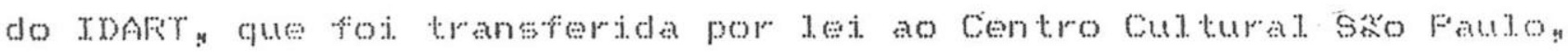
junto as seçes de beriodicos internacionats " A nova biblioteca estava entao sendo constituda por livros de arte que realmente passaram a lhe pertenerer pe pa transferencia de livros discos: demais pecas das quats o costera apenas depositarion cabendo este acervo ao Departanento de Bibliotecas Fúbicas! que se responsabilizaria também pela sua atualizaçou

A Jei. de criaço do Cosf determina o seguinte para a divisa de Biblioteca:

a) organizar e difundir informaçes relativas ao conhecimento humano.

b) reunir e preservar os registros de informacess qualquer que seja o seu suporte materiat. n

c) reatizar pescutsas bibliograficas, objetivando apoiar os ostudos de seus usuatios" en qualduer nfvel.

d) incentivar a formaça dos hábitos de leitura de utilizaço de informacton

(e) promover eventos. 
A entrada na biblioteca se dá através do piso 806 , onde há um local para se guardar todas as bolsas pastas e objetos das

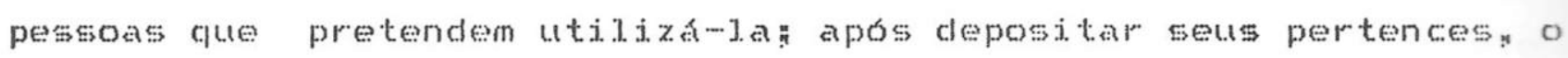
consulente desce uma rampa que o leva ate o piso inferior: chegando ao balcăo de informacres da biblioteca.

Na Sefáo de Discoteca esta instalada a "Discoteca Fublica Municipal. Oneyda Alvarenga", que de 1935 a 1968 ficou sob a responsabilidade desta pesquisadora orientada por Mario de Andrade. Inicialmente oneyda pretendia montar a discoteca somente com musica erudita, o que determinou una boa representaga nesta area, e promovia cursos com os discos do acervon A discoteca possui. documentos historites como o Arquivo da Falavra com discos que registraram as vozes dos brasileiros de diversas regibes durante o "Congresso Nacional da Lingua Falada" e as informaçes da "Missao de Fesquisa Folclorica" quen sob a tutela de Mario de Andrade, reuniu em 1938 musicologos e folcloristas para coletar o material musical de diversas regioes cujas gravacos for dopois passadas a discosi ha vitrinas na discoteca com pects recolnidas pela missano.

A discoteca sofreu oito mudanças desde sua criagro quando estava instalada na avenda krigadejo Luz fontonio foi despejada, pois a prefeitura de Fauto Matu náo pagou o aluguel. "Na inauguraço do Cosf foram levados alguns discos e partituras. ficando o resto na Divisáco de Discoteca e biblioteca de Múca no bairo da Lapa. Sendo una divisaro com seu acervo distribuido em oito seçes e cinco setoresn a discoteca possufa na epoca um orsanento proprio. com mais autonomia e com possibitidades de ampliaço de recursos, podendo até comprar discos importados". Com a transferencia para o centro cultural săo Fauto sofreu uma involusăo, pois de divisáso passou a seçon havendo a partir de entao poucas compras para o acervo algumas doaçes. A discoteca sofre problemas de operaço no CCSF devido ao sol e as goteiras. Segundo a chefe de seçon Tamico Shimizer, na l.apa a discoteca era mais frequentada por pesquisadores e no CCSF e mais procurada para lazer. 
o acervo da divisano é composto por 66.000 discos de 33 e 78

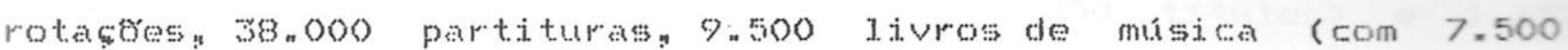
tftuloss e a hemerotecan os discos sáso cobertos com piastico preto para evitar o po e a poeira volume. Esses as vezes ressecam e quebram sominhos com facilidade "Sa na matoria jomportos pois a coleço abarca a época anterior a indústria fonografica no Brasil.

A musica popular que esta a disposiço é apresentada en 1.jstagens pelas quats o publico escolhe o que quer ouvir " sa organizadas por interprete por titulo o juteressado preenehe a requisiço a entrega no batco de atendimento onde uma funciondria lhe da un fone de ouvido com o mimero da tomada cue the coube coloca a obra solicitada no aparelho. Ha 26 fones de ouvido acoplados a 13 tocamdiscose 12 tapewers bas fitas do acervo sacom pequeno número, pojs estragan muto podendo ser readizadas aldums gravaçes para reproduzir os discos) " conta con duas máninas lavadoras de discos que tamberm secan mas

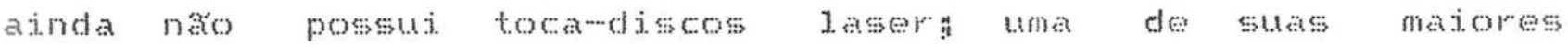
necessidades atuats ó poder contar com un conhecedor para avaliar seu acervo"

A discoteca 6 un dos pontos de mator juteresse do cosf "sendo frequentada por um publico fiel gue vai todos os dias há a restriço de se aceitar para cada pessoa apenas uma solicitaço de escuta por pertodon para se evitar abusos" "As fitas se formam porque mutos vern agui. para escutar misicas gue a todo momento o radio estat tocando -.. afirmou un asstuo frequentador logo no indejo do funcionamento da discoteca -.. Tsso o um absurdo. As pessoas deveriam saber tirar major proveito das opçes culturais da cicladen" Os musticos que procuram as partituras poden obtewas por emprestimo pelo pertodo de vinte dias a e os livros a a contrario do restante da bibliotecan nao sáo de livre acesso mas podern ser emprestados . 
A Biblioteca Sergio Militiet iniciou seu acervo com 50.000 livrose hoje conta com 60.000 (sendo 53.000 titulos) e 1.652 t.tulos de perjodjos isto sem se contar as segeses da subdivisao de Coleçes Especiais.

As estantes: mesas dos consulentes e demais pesas do mobiliario apresentan una estrutura de ferro vermetha que as carateriza e foran criadas especiamente para o centro cultural.

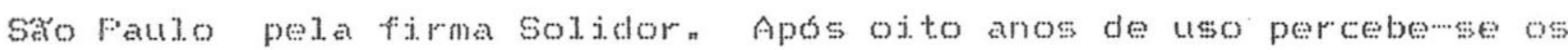
desgates e a necessidade de reposiço de alguns moveis a provocando comentarios de que o cos vai ficar velho antes de ge terminar de construir. o po da bibidoteca e retirado por uma firma limpadora - carpete concentra poeira e como tudo e fechado pocte ocasionar rinite e bronquite a ám da grande unidade no inverno das eternas gotedras: as vezes pessoas reciamarn de que e tudo devassado de nao terem privacidaden certas programaçes de cinema incomodam a bibliotecan e alouns funcionarios cijemse cansados por estarem sempre expostos ao puibitico.

Desde a inauguraço da biblioteca esta implantado o sistema do detector de roubos, que deve possivelmente ter evitado $70 \%$ das tentativas de furto. Há un arco de metal na rampa de safda da bibliotecan e caso um livro do acervo atravesse esse arco d acionado o alarne pela emissa de deterninada frequencia provocada por una chapinha magnetica escondida na capa dos livros a aguns frequentadores perebem o segredo e arrancan o miolo do livro, levando o consjo e dejxando as capas e o magnetico no banheiro. o acesso pelo elevador năo é permitido ao público porque 1á năo há um sistema de detectan alom dos roubos de livros constatase varias páginas arrantadas! en agressivas atitudes de dilapidacko e muti. açáo das obras do acervo público.

A biblioteca esta aberta a público treze horas por dias iniciando-se a preparacko duas horas antes do intcio de seu funcionamento; na divisao trabalham 44 bibliotecarias que cobrem todas as seçes durante todo o perfdon estando sempre presentes 3 funcionarios em cacla seçon A biblioteca náo abre aos domingos, 
embora a nova diretoria deseje estes funcionamenton

As bibliotentass atuan tambem como protessoras (pois mutos colegios

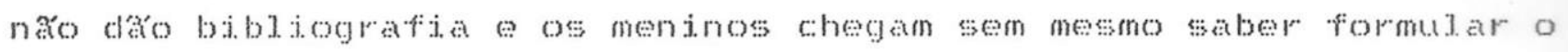
que guerems o costuman atender varias consultas por telefore. Os estudantes aparentemente gostan do espaso da bibliotecan pois

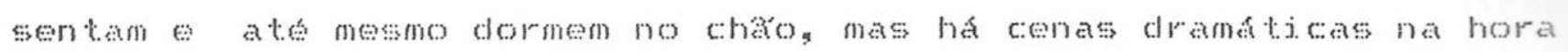
de fentr o xeroxy com pessons pedindo "uma espia pelo amor de Dews" e ate chorando porgue tem que entregar o trababtio logon

A frequencia da biblioteca varia de lo 500 a 3000 pessons por

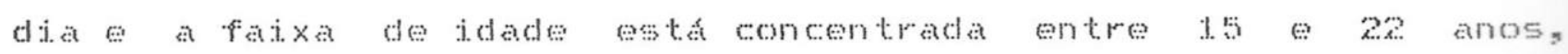

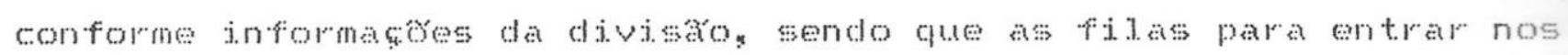

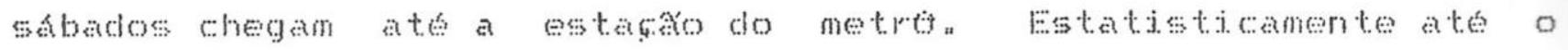

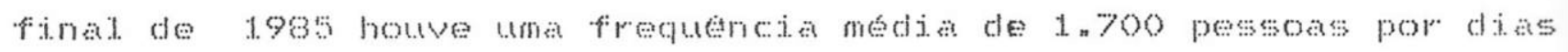

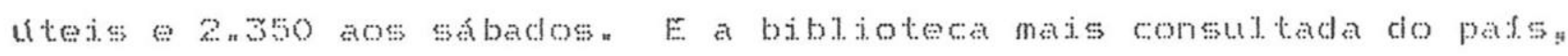

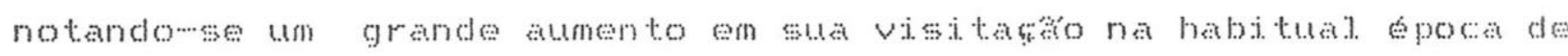

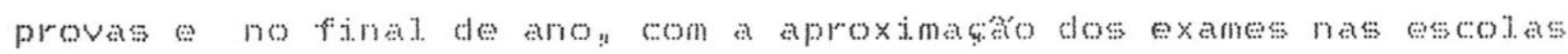
edos vestibuld ares

\subsubsection{Divisào de Pesquisas}

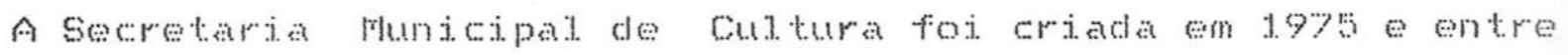

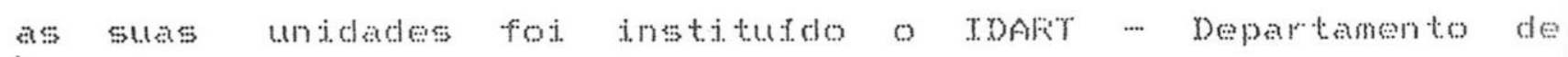

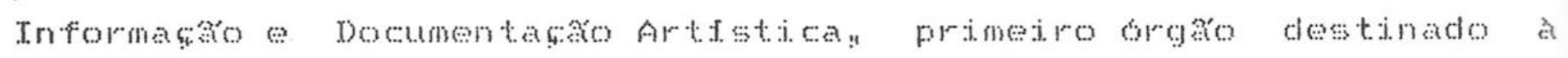
pesquisa e registro do fato cutural q buscando preservar para

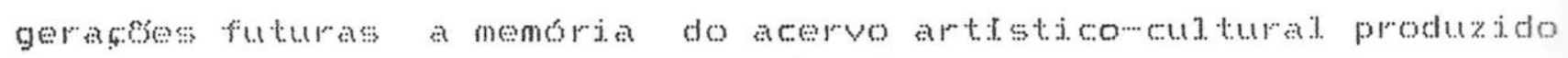

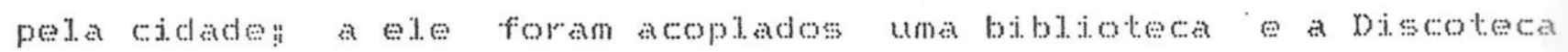
Municipal. A jofia era de se pensar a cuturan inciusive realizando diagnosticos quanto a caminhos necessidedes e novas tendencias e para tanto foram constitutas ojto equipes tecnicas

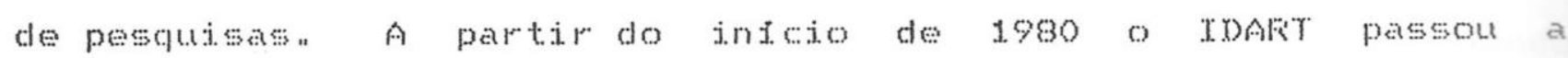
funcionar na casa das fistortas uma edificaşo cle caracterfstica ingless destinada d produço de gás que na vespera do seu cententrion no segundo semestre de 1989 , sofreu um inctudio e foi interditing ten 


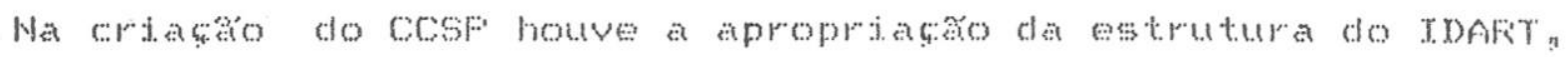

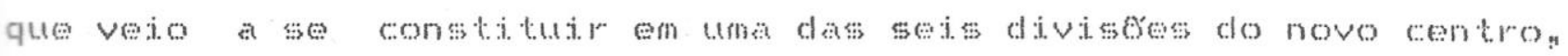
passando a se chamar divisao de pescussas segundo a leid a ela compete:

a) realizar pesquisas baseadas nas atividades do ocsfo outras

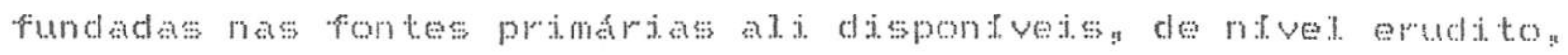
popular e de massan

b) propor atividades e programaçess apoiadas nas pesqujess realizadas

c) registrar informabes sobre a arte brasideira organizar os arquivos documentarios

d) promover eventos.

A incorporata causou algumas moditicagos como a perda de autonomian pois o TDeFr como departamento era una unidade

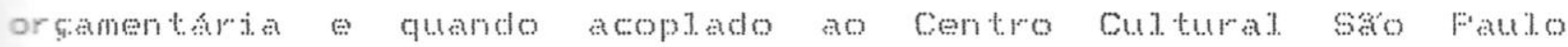
submetewse As suse condicoss pots o centro se constituta num nova e aglutinadora undade or mamentarian a grafica do roskt foi.

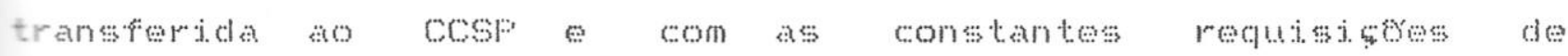

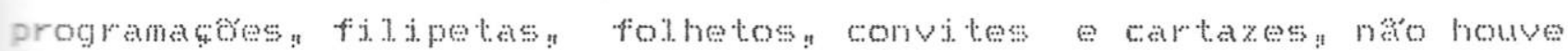
nais tempo para se tmprimir os trabalhos da Divisao de fesquisas

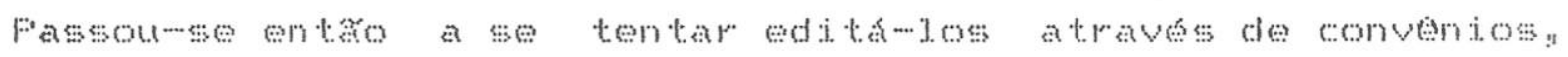

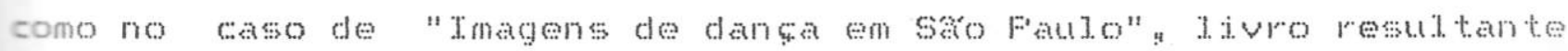
de un convenio com o THEsF" mas recianase de que o processo muito demoradon Na dpoca do TDART a tiragen de cada trtulo era de 2.000 exemplares a distributos pelas bibliotecas e entidades culturats de todo pats caso una pessoa se interessasse por alouma pesquisan deveria enviar ura carta de solicitatro en sendo considerada merecedora a receberian Wunca houve uma polftica de reedica mo mos titulos se esgotaram foram tamberm editados anuários sobre certos temas com a relaşa de tudo o que foi publicado sobre o assunto en jornats e periodicoss 


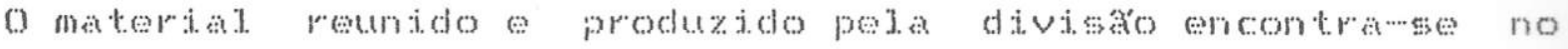

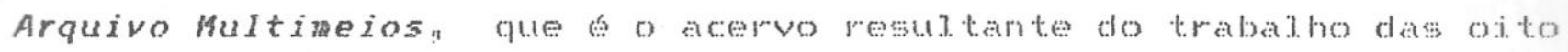
areas teconcas de pesquisas acrescido de doacess que ter por objetivo prineipal documentar de maneira sistematica os eventos

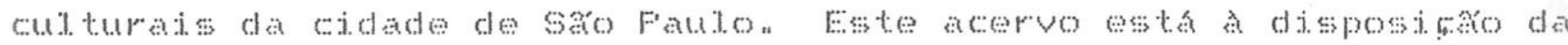
comudade deste 1979 e seis anos depois contava com 750 pesquisas tombadas e com 200 mil documentos sobre a producso cut turat da/na

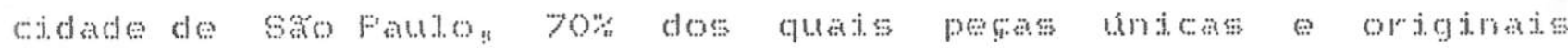
produzidas pela divisanon

A intença $\Leftrightarrow$ a de reunit a recuperar e preservar documentos com informases contidas sobre varjos suportes como jomats que sa agrupados na hemeroteca "filmes, pitas de audion fotos? textos

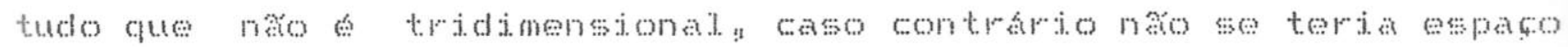

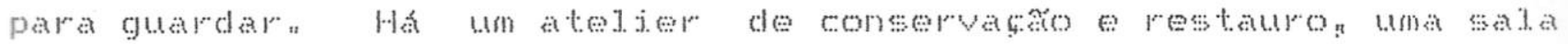

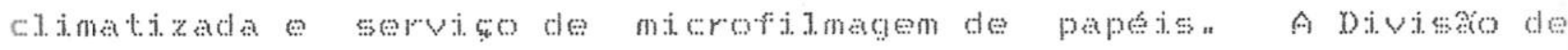

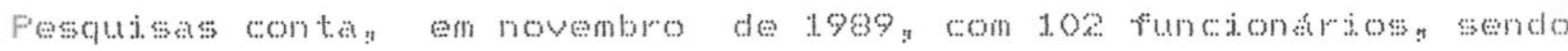
que mutas das pessons osta presentes deste a fundaço do rompta os pesquisadores trabalham com a coleta feita na fonten num processo de recolha exterman

Conforme a propria lej definen a Divisa de Fesquisas náso seria apenas un entro de menoria para colder e cutur a nowsa arte contemportnean mas deverian tambem extroverter o seu trabalno subsidiando a programąo do centro outurat sa Faton Este viria a ser o lugar da amostragem visual a cinetican conematogrática plastican como una grande viturina dos levantanentos fextos nas pesquisas da divisan Tsto porems esta longe de acontecer, porque năo existem vinculaçes reasse apenas esporadicamente produto de una pesquisa se transforma em exposisas como ocorreu,

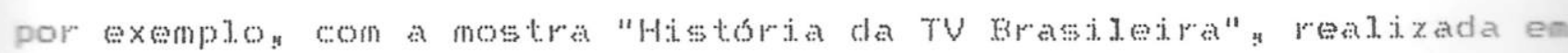
setembro de j.988. Nomalmente, a cada trese meses a Casa das Retortas organiza uma exposicko, apesar do seu espaço ser poucc adequatio. 


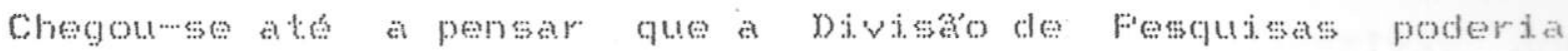

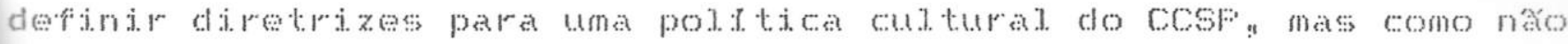

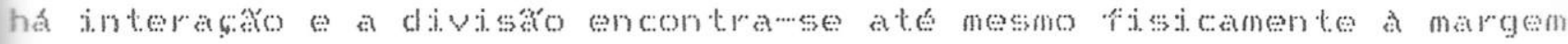
do entro, os seus funcionarios redigiram uma proposta a secretaria Municipat de cutura pedindo a volta as condiches do antigo roakt. Dentre as rejuindicacoes hat a de se obter uma possibilidade editoriat forten uma grafica propria significa poder imprimire

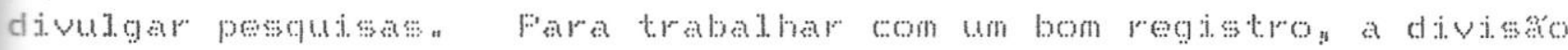
deveria ter videose fitmadoras porem mutas vexes ate ridmess fotograficos ato comprados com o dinheiro dos fun eionarios.

Seria desejavel. uma hamonia entre os agentes cuturats da Secretaria Municipal. de Cutura de tal maneira gue tudo posse

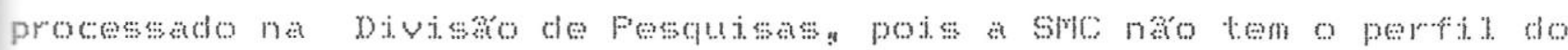
que realizou ate agora A Casa das Fetortas porenn no dispor de

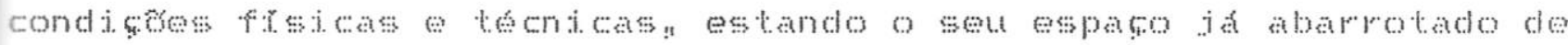

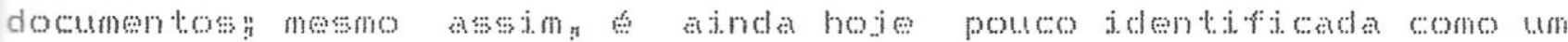

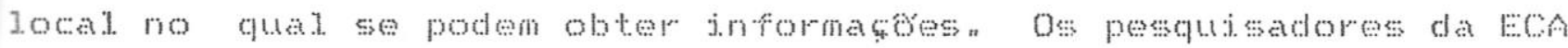
sáso seus tripicos usuatios

\subsection{Frequencia e Funcionários do CCSP}

o Centro culturat sa Faulo esta aberto a publico todos os dias da semana das 9 noo as $23 n 00$ homas sendo que so a bibliotera nao abre aos comingos e fecha as 22,00 horas os teatros normalmente apresentam espetaculos de quarta a domingo as exposiços estáno sempre abertas.

Segundo pesquisa encomendada pela Secretaria Municipat de Cutura reatizada com os usurtos do cosf no segundo semestre de 1989, o centro de mass frequentato nos dias de sabadon principalmente no periodo da manha encuanto que de segunda a

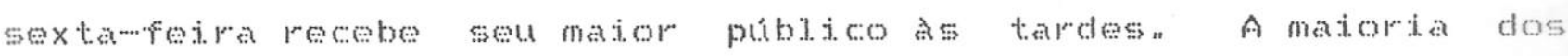
frequentadores conhece o centro ha mas de guatro anos náso tem

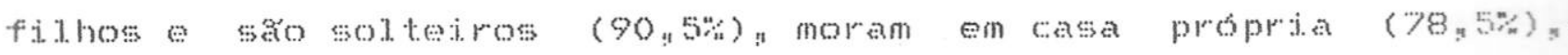

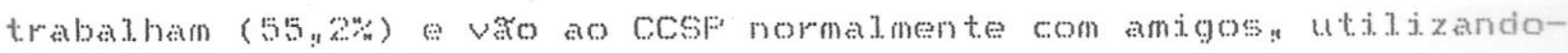




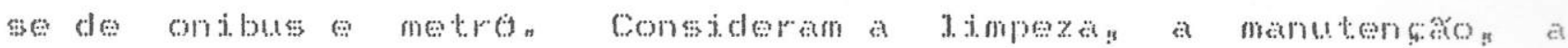

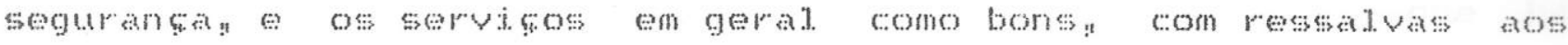

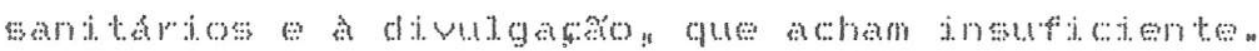

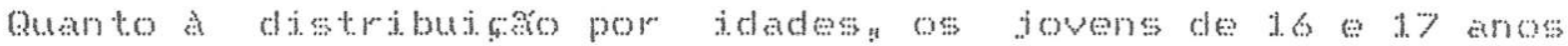

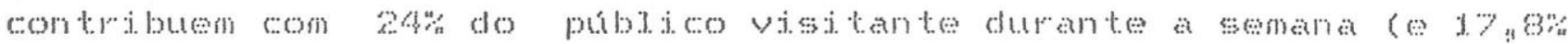

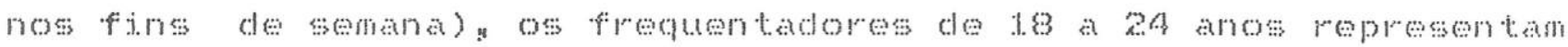

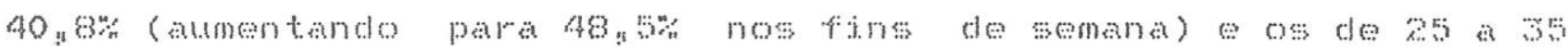

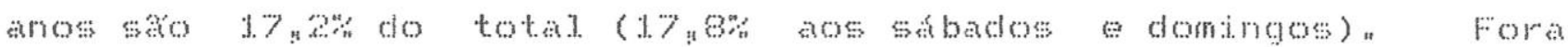

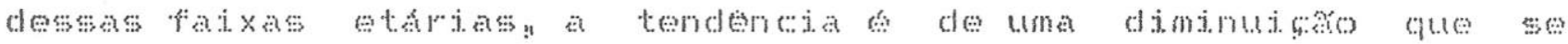
acentua quanto mats sm aproxima dos extremosy semdo muto pequena a

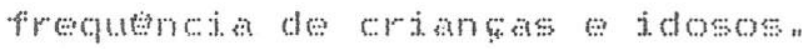

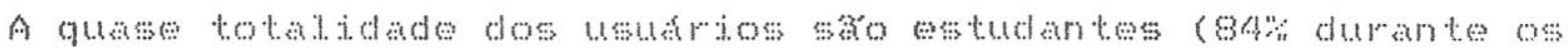

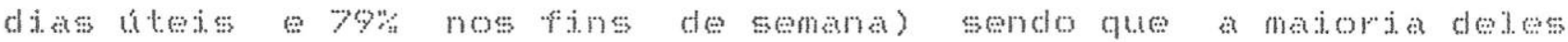

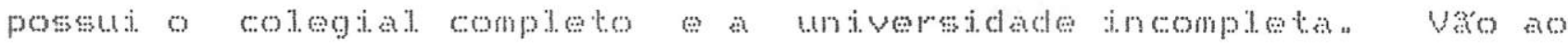

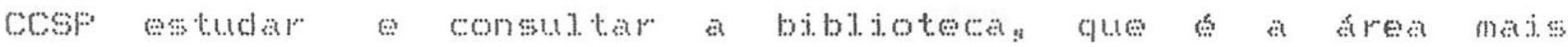

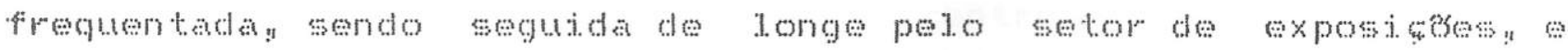

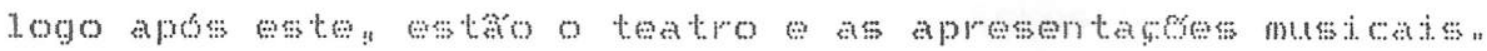

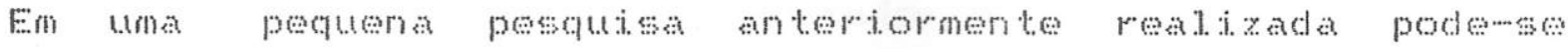

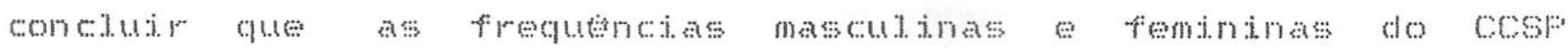

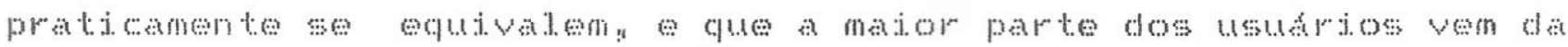
zona sul da sideden

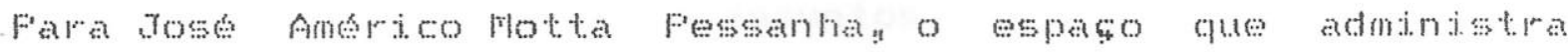

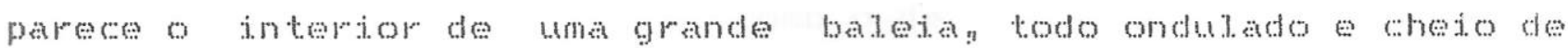

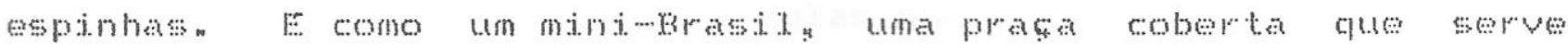

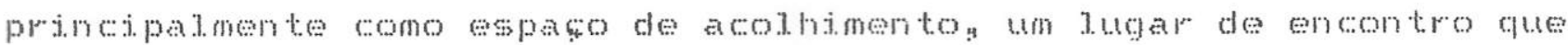

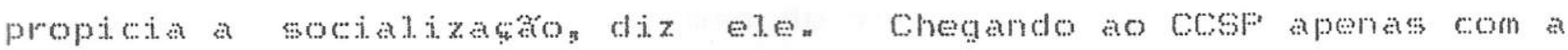

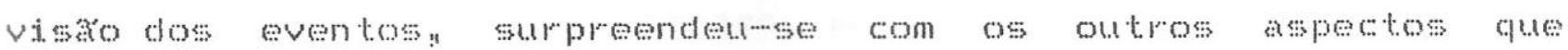
descobriu hoje afima que o cosfo muto mais do que pensavan

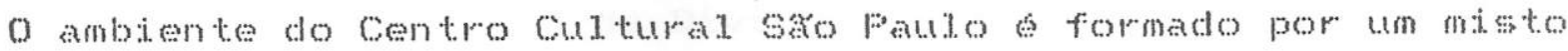

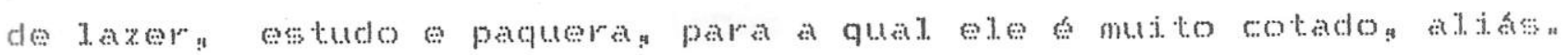
Hat sempre roisas acontecendo a revelia do sem funcionamento

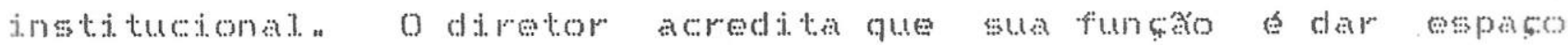


1egitimado para o COSF ser tudo isso e observa que ha bibliotecarias para dispor os livros em seus lugaress mas nám funcionarios para atender os frequentadores fal tando equipanento humano para cuidar do lado mats "marginald do centro"

Dentre os frequentadores ha pessose que moram emboladas

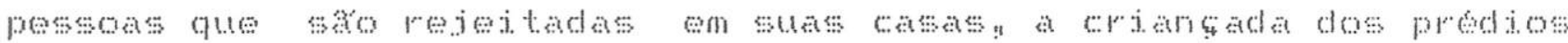
proximos que nato tem onde brincar e vai ao cos com seus skates

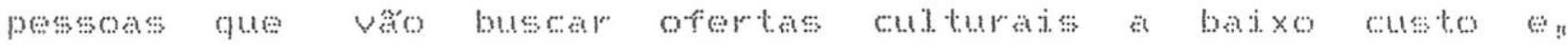
prineipatmente "estudantes n Estando o centro aberto o sempre vistrel. en suss dependencias um grande aftuxo de estudantes que se sentem descontrafos o suficiente para se esticarem no cho la ficarem exaninando sous materiats de estudo.

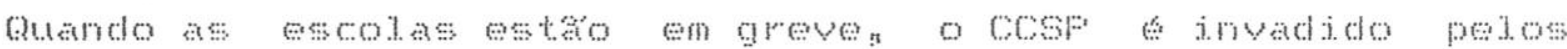
ahunos a se juntam em grupos espathados pelo centro sempre ha uma boa quantidade de japoneses vindos dos batros proximos a caregados de pastas e cadernos alem das pessoss que esta ostondo para

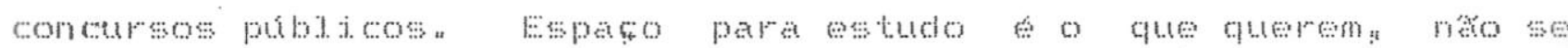
importando muto com as exposiços ou shows apresentados n

Mas nao apenas o estudo institucionalizado que ocupa o centro culturat sato faton pois encontramse grupos que se reunem para aprender os mas diversos assuntos como os esotericos os maticos ou ate mesmo casos cono o de un professor de ingles que nao tinha espaco com e dava autas numa mesinha.

o cosf definiu suas normas de funcionamento de uson porem a

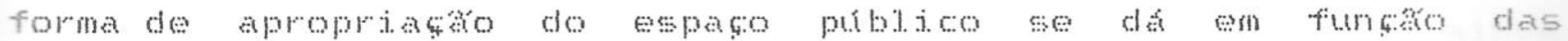
conventencias do usuraton prova disto 6 que acontecen num pequeno espaco localizado na rua interna do piso 806 proximo a

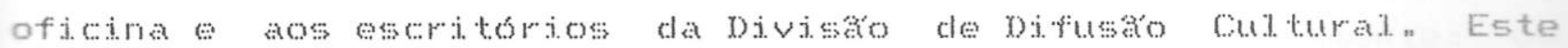

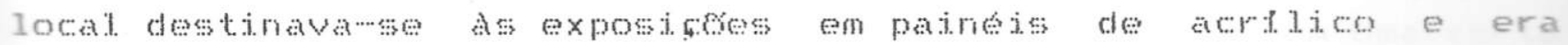
tamben wado para colocacto de mesas para apoiar salgadinhos e. copos nos coquetess de abertura de grandes eventos. No dia seguinte aos coguetisis porkm qualumer demora para recolher as 
mesas o e 1 as eran logo tomadas por estudantess que reagiam quando se tentava retitratas a

E.:xperimentouse dispor as mesas no espaç do foyer dos

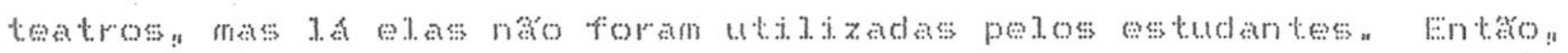
depois de certo tempon o local dos coqueteis dex ou de ser mats um espaco de exposicome as trinta mesas originamente adquiridas

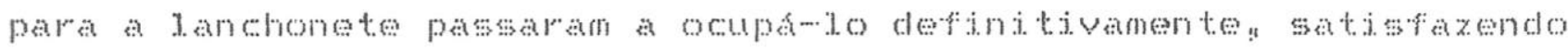
a demanda requeridan como a biblioteca na permite a entrada der 1.ivrose apostidas os estudates nas tinham onde estudar com seus materiass do que decorra a valorizaco das mesimbasn

Durate seu periodo de trabatho na divisá de difusa

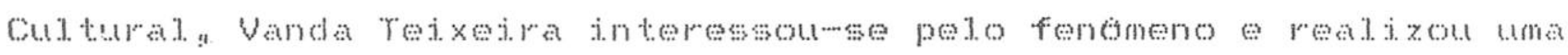
pescutsa com os usuririos das mesas verificando que todos se servem delas para estudar a qualduer dia a guaguer hora há procura 30\% dos entrevistados frequentam as mesas diarianenten sendo que mutitos tomam conhecimento dexas atraves de amigosn

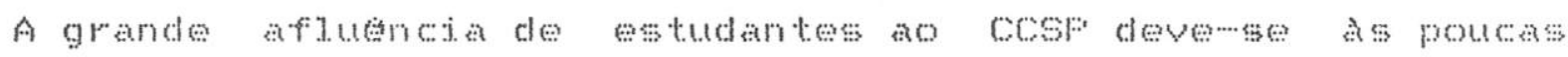
opsoses de locais para o estudo: que pode apenas ser realizado wm

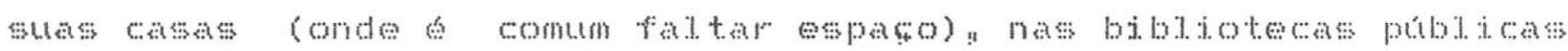
ou nas bibliotecas das faculdades que nao sto muto aprecindas por

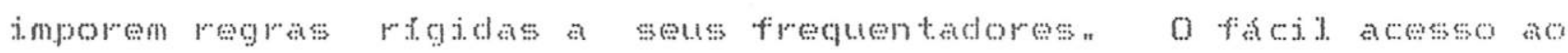
Centro culturat. Saro Fato of deterninante para a sua escolna ja que se situa entre duas estaçes de metro a matoria dos usuram mora en bajros servidos por este transporten

Frecupados en estudar os usurios das mesas náso desenvolvem grandes relacionamentos entre si. e segundo a pescutsay as mulheress de Is a 25 anos de jdate sko as mas presentes destacandowse anda

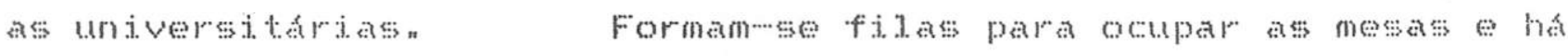
ate um mercado negro de venda dos seus espaços mast ha tamberm regrass de comportamento que se deriniram espontaneamenten om membros do grupo das mesas naso sao barubentos mantern uma certa 1. impera nâ so aproprian de mesas vazias com objetosn 


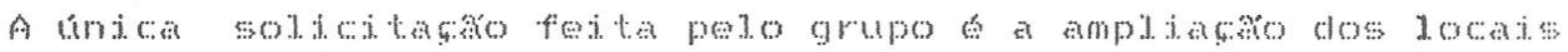

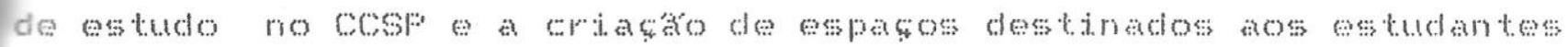

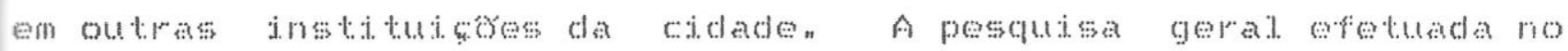

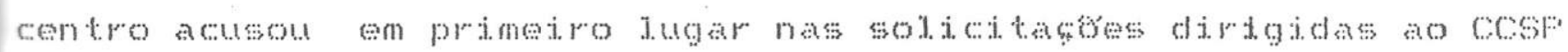

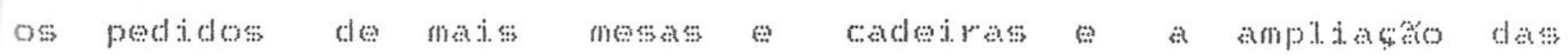
possibididades para ostudon

As optintos das pessons que tabaham no centro sato quase sempre coincidentes quanto aos idealizadores e diretores do cose

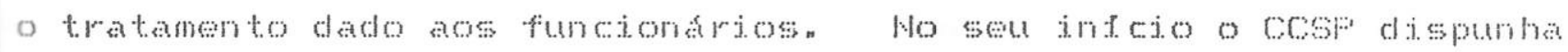
de verbas para faxer programatoss como e natura em qualquer local. que esta sendo lansado e pretende que as atenceses lhe sejam

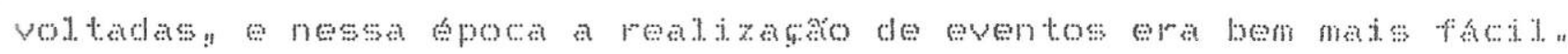
Mrio chamie era visto como un seminditador mas possibijitava certa autonomia as equpes deixandows a vontade para pensare dando forca para se executar pardo ontake foi quericto pelos funcionarios que o consideravam un homem de mut tas qualidadesn

Os diretores Fermando l..mos e Tose Gerado Martins de oldverma foram os primeiros herdeiros dos mutiplos problemas do centro

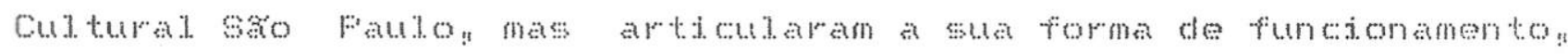
foram assessorados por bons propissionajs e realizaram eventos memoraveiss

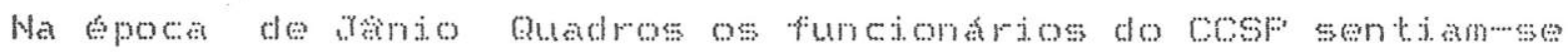

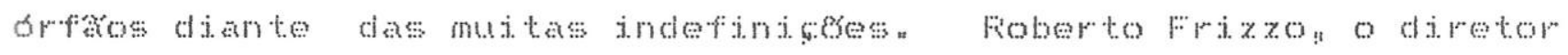
que mais tempo duroug era conhecido por chegar ao cosm com sua Mercedes Benz: e acabou colocando dinheriro do seu bolso para a "x

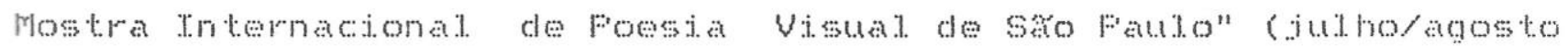

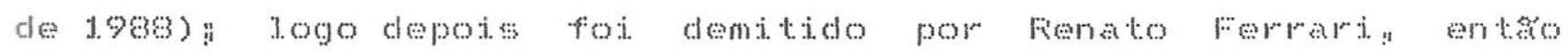
secretario municipal de culdura que nato hava aprovado o evento.

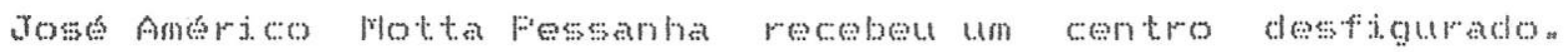

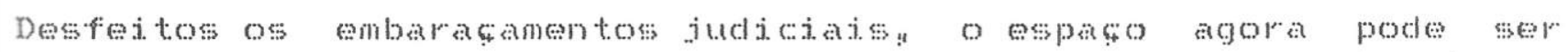

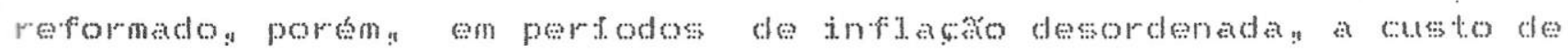
ouro. conseguira eje a menos ressuscitar as boas atividades do $\cos 5 ?$ 


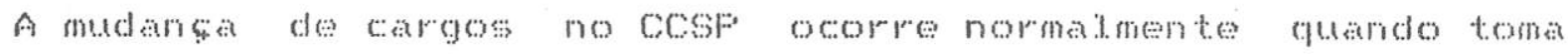

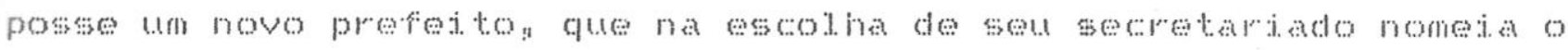

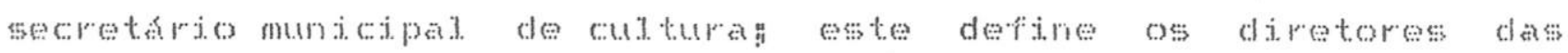

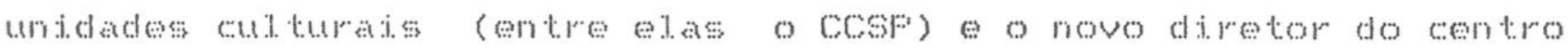

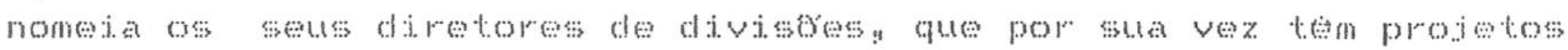

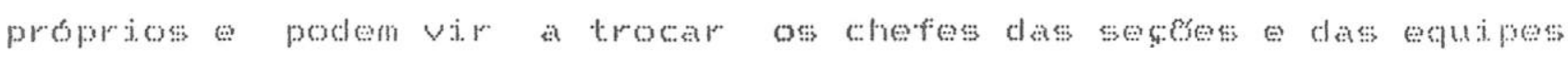
tecticicis ncs

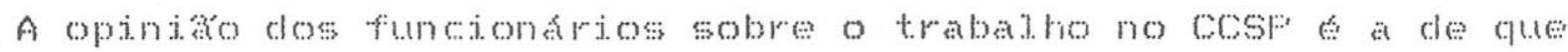

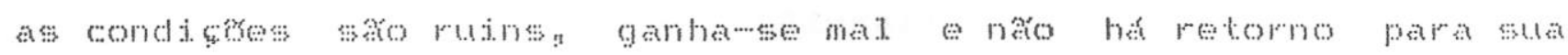

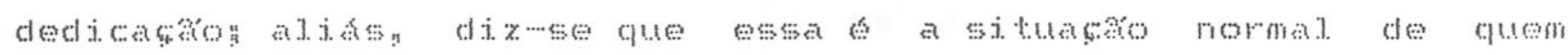
trabalin para a prefexturan aunto a possibididade de corescimento

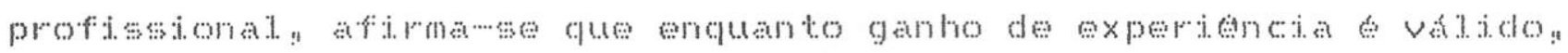

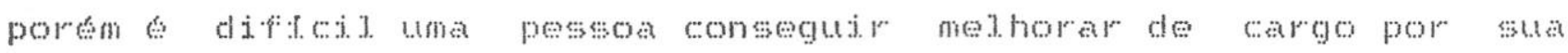

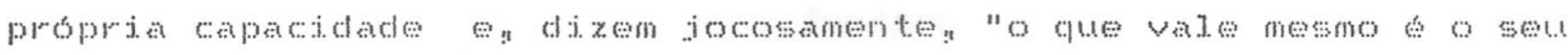

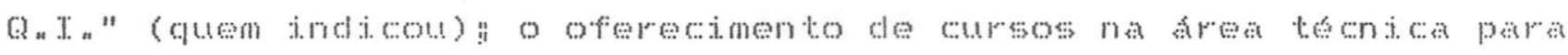

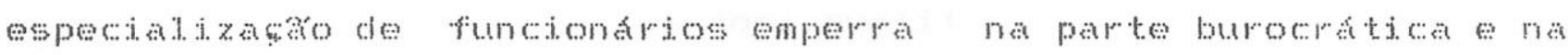

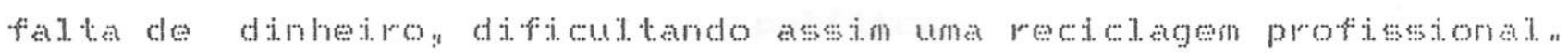
Normanente os funcionarios conseguen o oredito pelo traballo

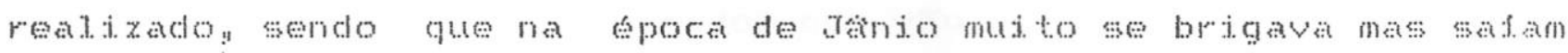

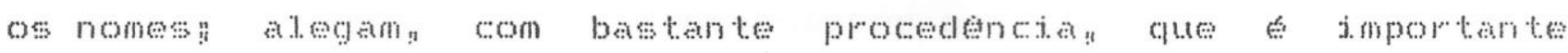

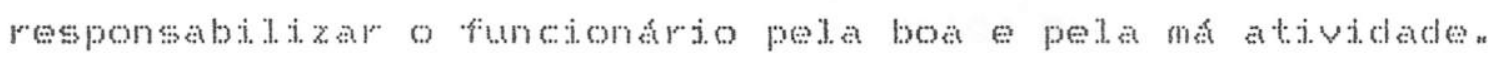

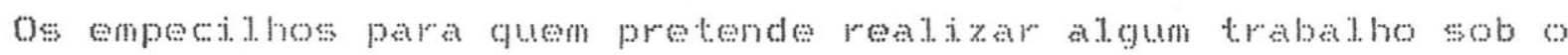

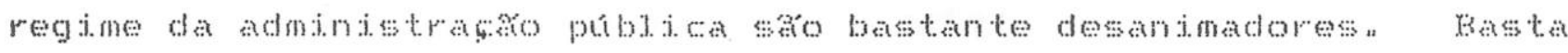

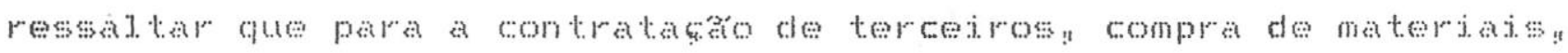

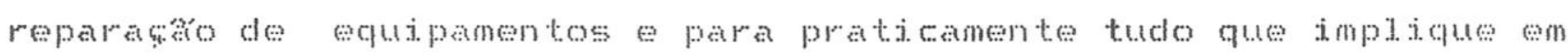
gastos o necesstrio se efetur um processo gue demora aproximadamente tres meses do comęo do pedido ato a obtença da

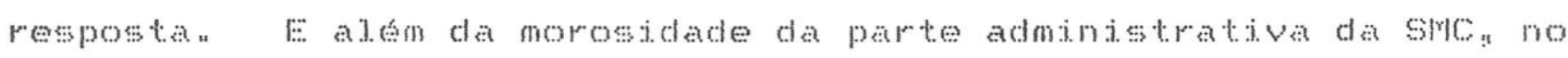
departamento jur dico tudo o motivo de obstrugro parese haver um

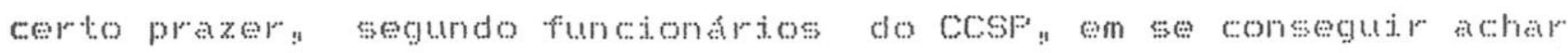

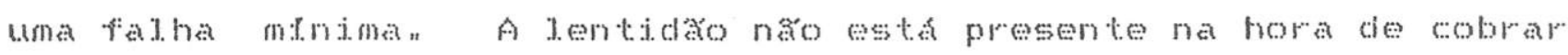

(s)obs,: as informaçôes sobre as Seçtes Adninistrativas e sobre as categorias de funcionários do CCSP estào no Anexo 1. 


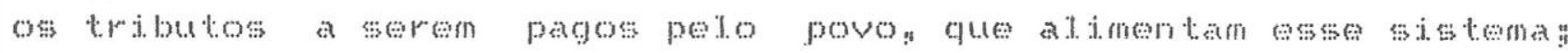
ta. funcionamento ó evidentementen denowo tanto a un contro

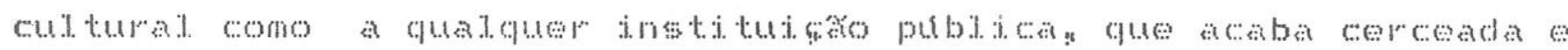
incapar de atur de forma efetivan

En sua opocan Fernando hemos defendia a ide ia dese tentar

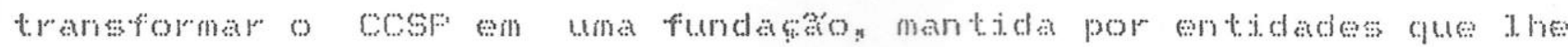
possibititariam recursos propriose a independencia das poteticas

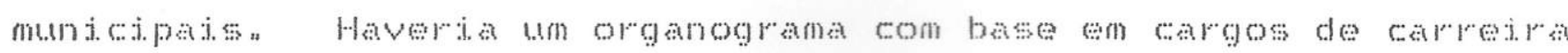
(como pesquisador e agente cultural) gue possibilitaria uma asconsto pois atuamente apenas os funcionaros eretivos tam caminhos para evolute os comissionados naso tom nem uma avaliago do trabatho gue reatizamn

Comentawse que o cose possui funcionarios inexperientes sendo

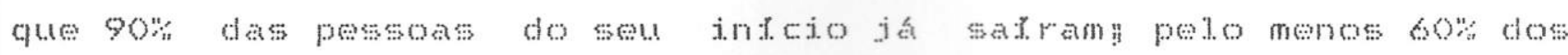
cargos ocupados so comissionados qualificativo dado por dirotomes

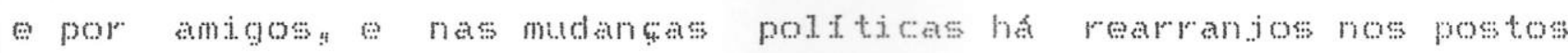

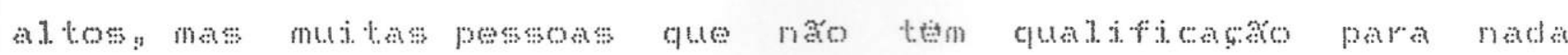

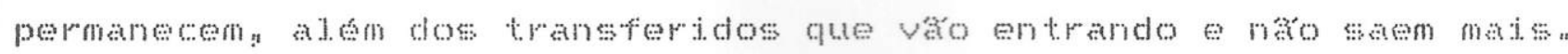

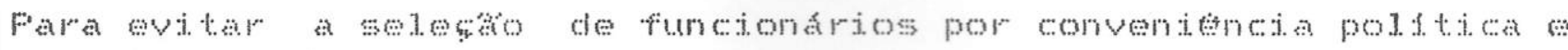
por amizade poder-wewa adotar a antiga proposta de abrir concurso para todos os cargos do Contro cultura] Saro faulon

Atuamente o cof conta com aproximadamente 600 funcionsios

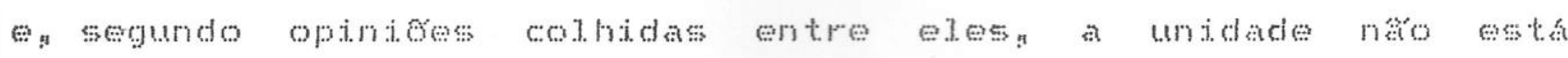
inchada considerandowe que o trabalho se estende por sete dias da

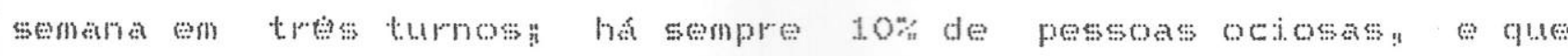
sempre continuarso assim "porque en serviço publico isso acontece" comentam. Fortm as determatcess da nova diretoria para que certos setomes do cosf trabahem para toda a secretaria munipal de cultura causa poltmican os funcionarios destes setoress artimam que

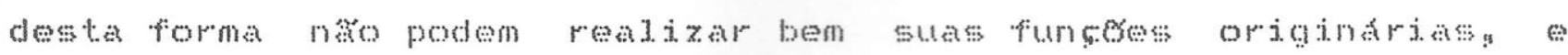
outros achan que havia certa ociosidaden 


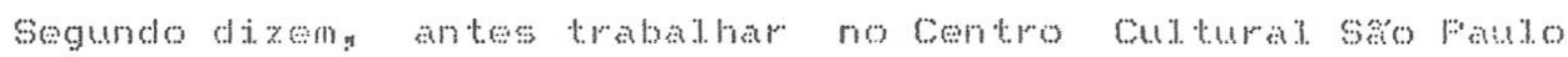
era motivo de orguthon e hoje descluatifican 


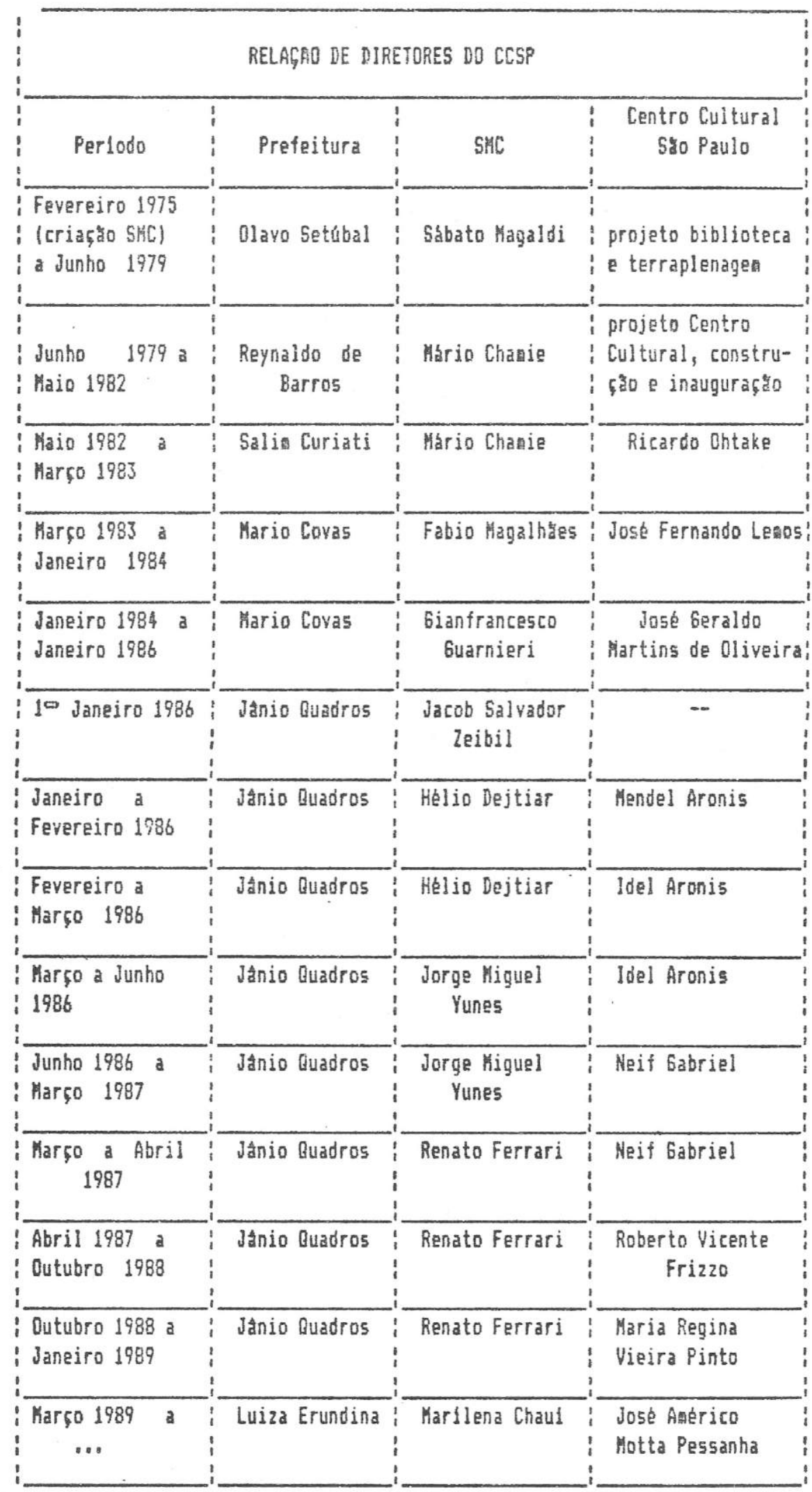


3. MUSEU LASAR SEgALL

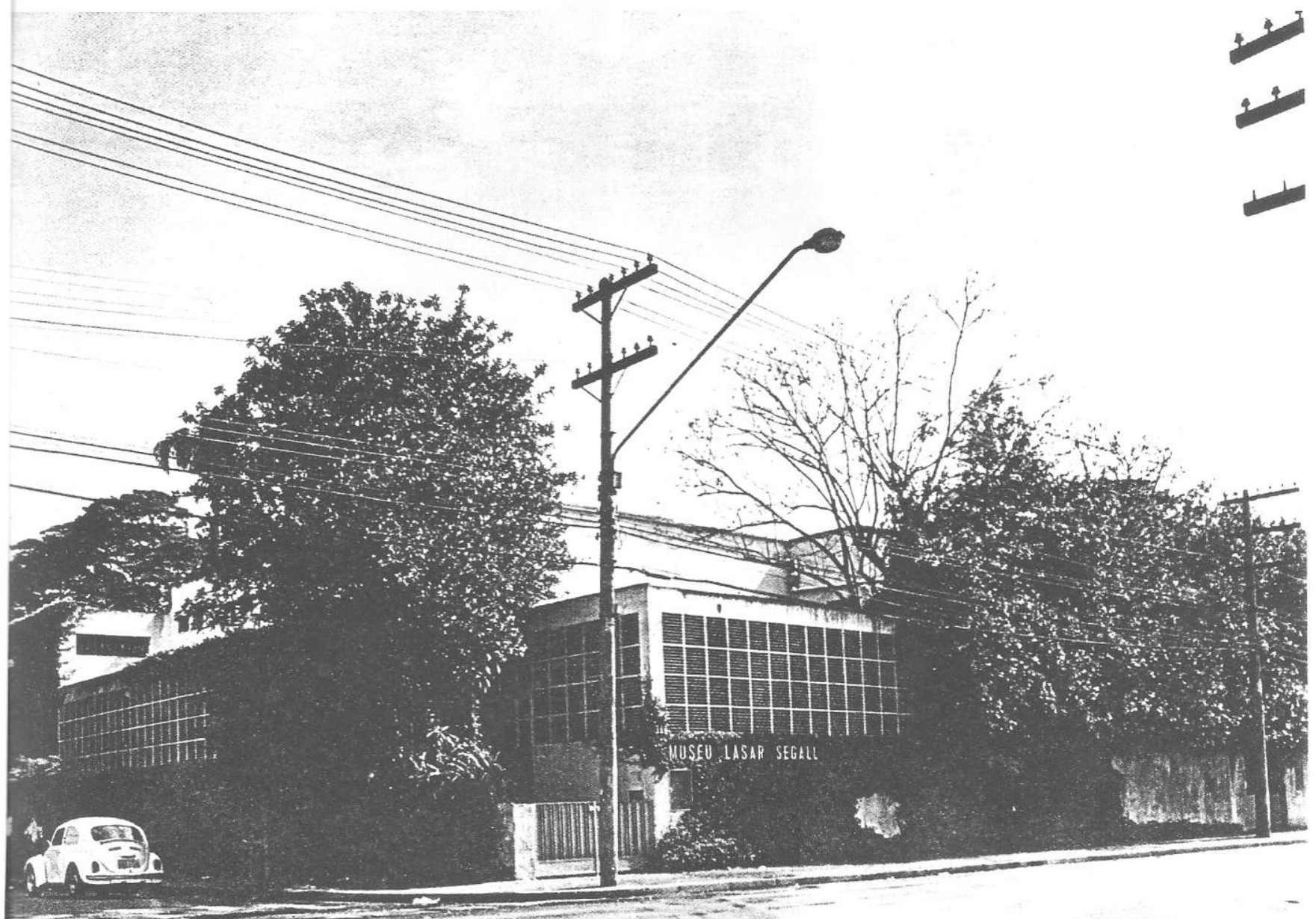

C.

Sede do museu, no bairro de Vila Mariana 


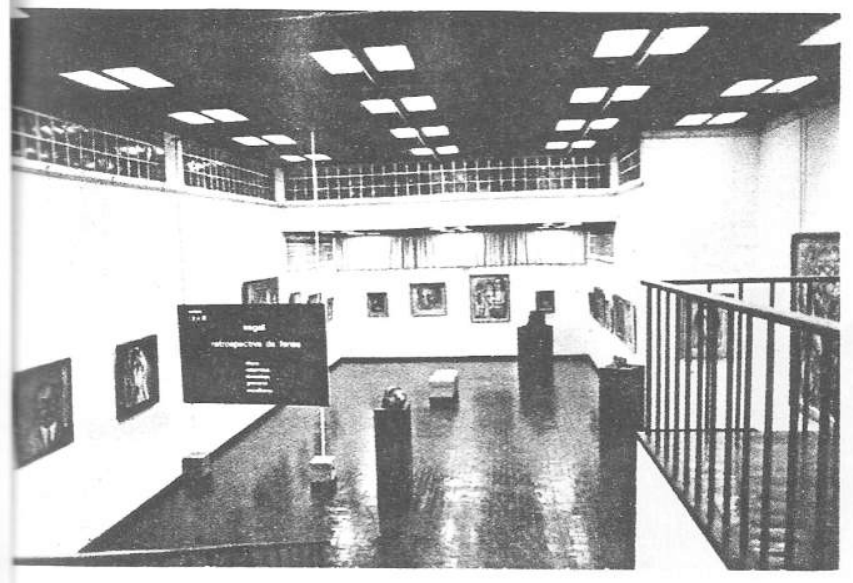

Vista parcial da principal sala de exposiçoes

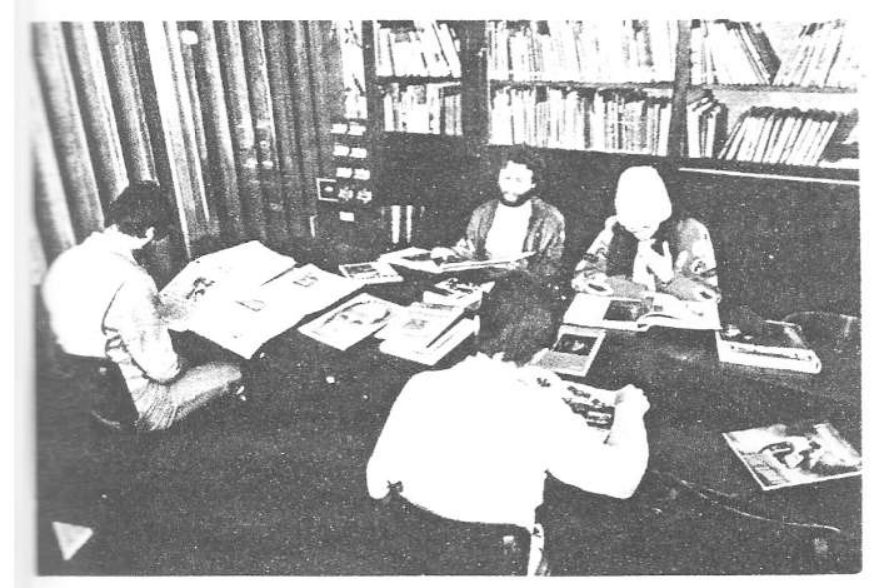

Biblioteca - sala de consultas e leitura

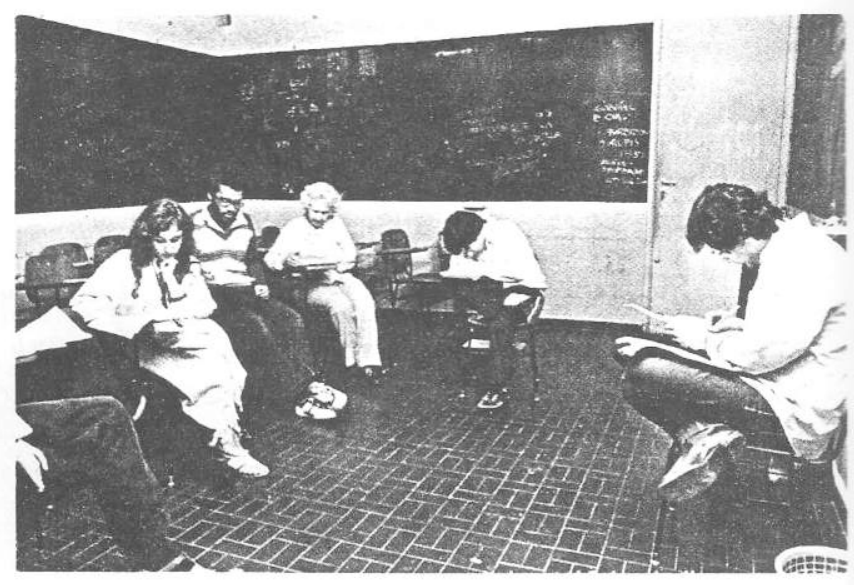

Sala para cursos e laboratorio de linguaqea

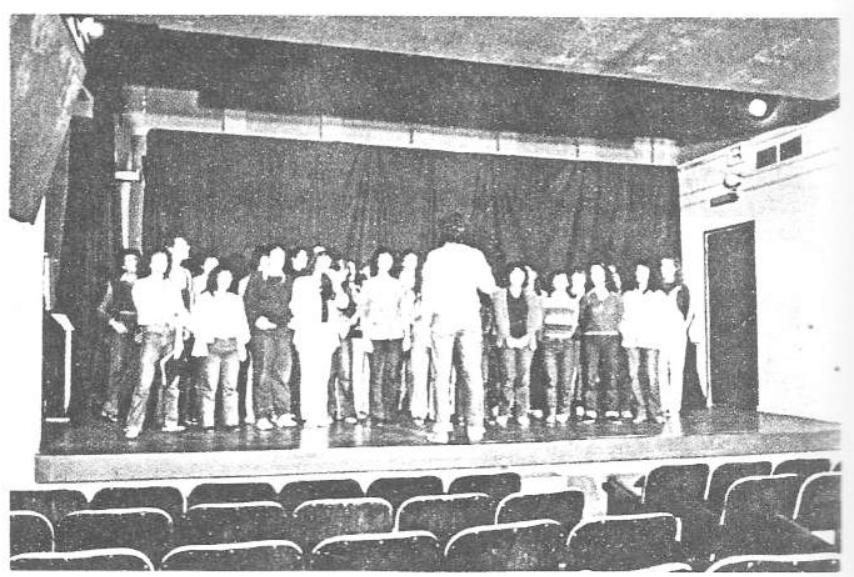

Auditorio con ensaio do coral do museu 


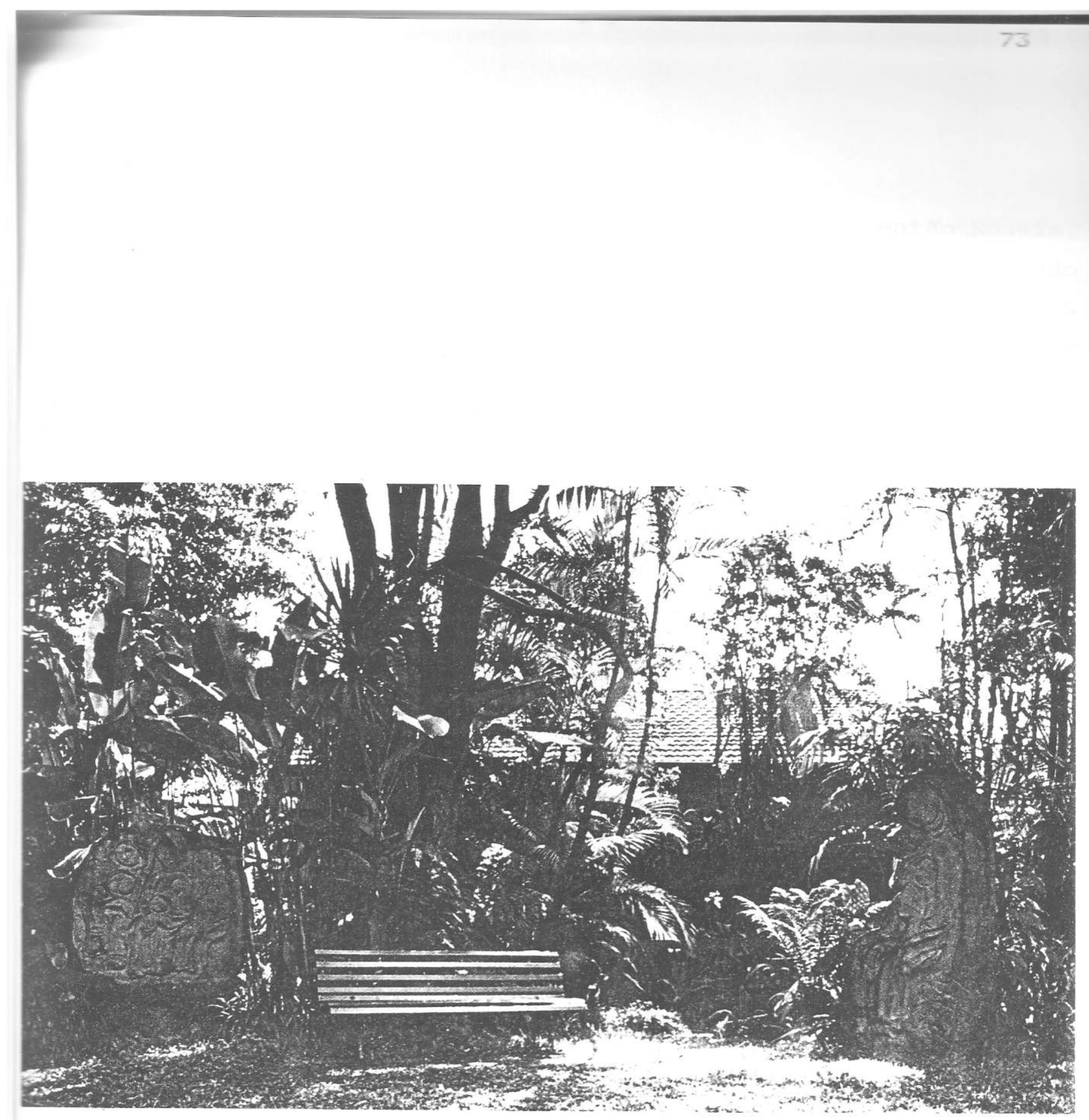

Jardim interno do museu, com reproduços de esculturas de Lasar Sega 11 . 


\subsection{Histórico do Museu Lasar Segall}

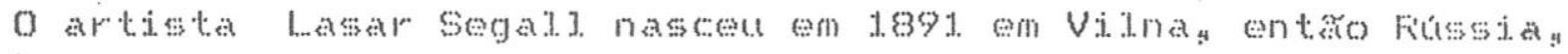

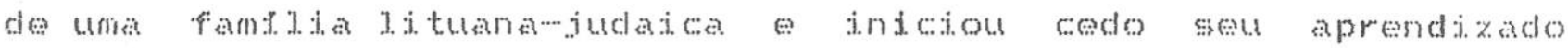

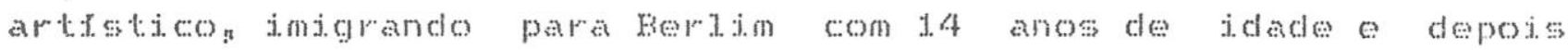
transferindowse para Dresden onde participou do importante movimento expressionista a Jemán Em 1913 vem ao Brasid e apresenta seus trabathos en sá Fauto mostrando as modernas tendencias

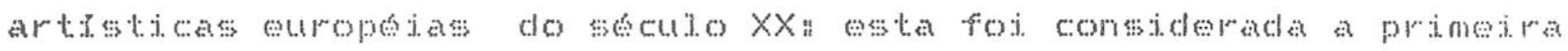

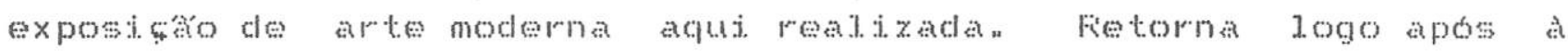
Alemanha onde permaneceria por 1.0 anos tendo sido confinado durante parte da Frimeira Guera mundia como cidadáo de pás hostitip durante apos o conflito reatizou diversas exposiches

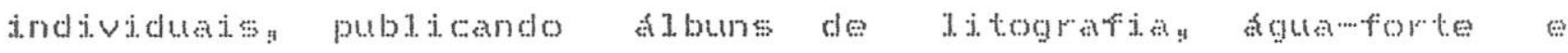
x.jogravura tornandowe conhecido na vida artigtica a lema.

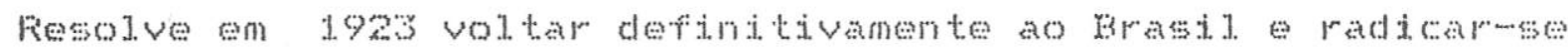
en sá fraton onde se naturatizou brasiletro e constituiu sua

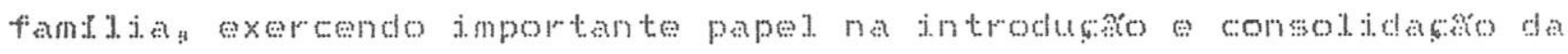
arte contemporsinea brasideira Fetornou poucas vezes a Furopa para mostrar seus trabalhos u Faleceu no ano de 1959 en sua

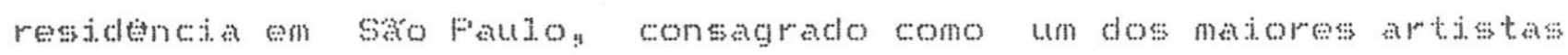
plasticos brasileiros mas praticamente esquecido na Furopa.

Nesta ocasian a mator parte de sua obra estava reunida em seu atedier pois o artista naso costuma vender seus trabalhos apesar de frequentemente presentear anigos com eles. Sua vilivan a escritora renny Klabin Segally dedicoume a divulgar o trabaho de Lasar segali. no exterior e a consolidar o acervou com vistas a futura fundaça de un museu, sendo que deste 196i realizava em sua casa mostras publicas do acervo do artista mpos o falectimento de

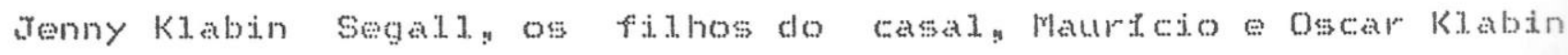
segali " resolveram destinar o jmovel onde residiram e trabalharam seus pats deste 1932 para a instalaço do Museu Lasar segall. Inicialinente foi construfda una casamata de concreto a prova de 
fogon poeira eluz, com temperatura e umidade relativas do ar controladas para poder abrigar o acervo de obass

Apos a dewiso de fundar o musen os irmasosegal dedicaran

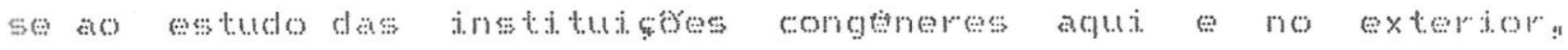
resolvencto optar pela forma de associatso civit sem fins lutrativos por ser a que majs correspondia aos objetivos de assegurar

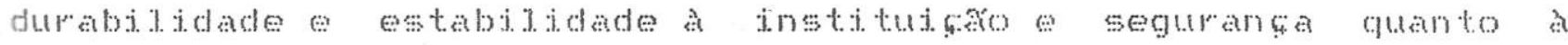

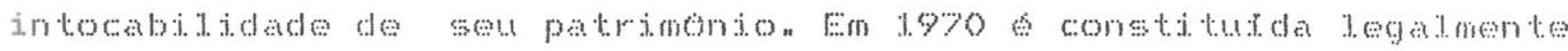

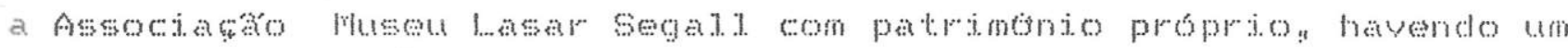
Conselho de curadores composto pelos descendentes consengutness

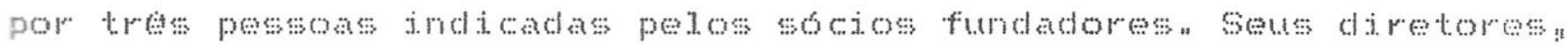

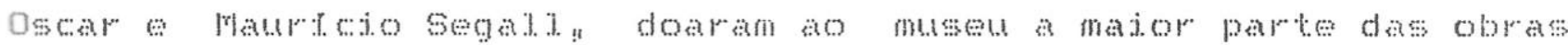
que herdaram alem de 13 , oon volumes para a bibliotema o predio sede do musen e todo o mobiliarion Colaboraran atinda com outros

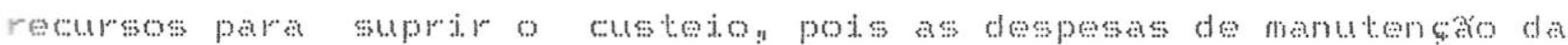
associacko serian cobertas pela renda de afugued de un edifferio om Santo Amaro que pertencia a fandia segall a sendo somadas a esta

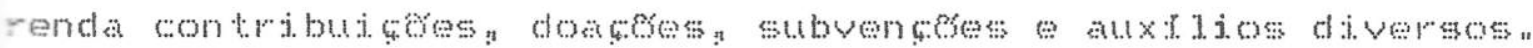

A associaço fod logo dectarada de utilidade publican mas ato 1973 o seu runcionamento era irregular atividades na conservano e divulgato da obra de basar segal.

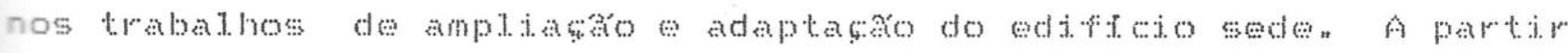
dessa data o museu abre regutarmente suas portas com uma proposta

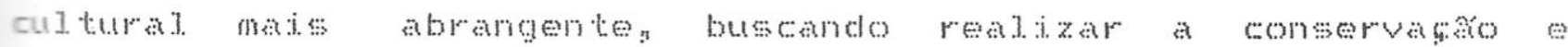
divulgaşo da obra do artista dentro de um quadro dinamiong com una funçáso social ativa "pretendendo ser um museu "vivo" " Tnicialmente este "vivo" foi compremdido como exteticon com varias coisas acontecendo ao mesmo tempo sem que se soubesse bem por que, resultando num espetáculo com funçso cultural indefind

Foi necessario ao museu descobrir a vocago gue the seria

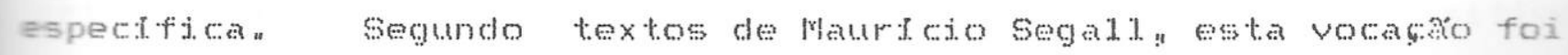

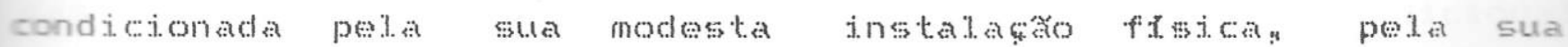

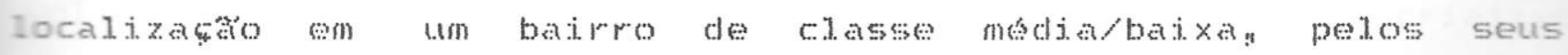
reduzidos recursos materiats e humanose pela situataro nacional de 


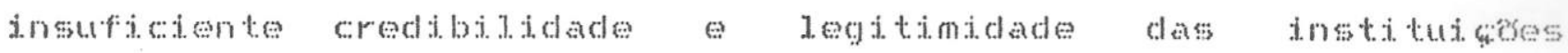
culturats que deterninaran a convenibncia de un museu comuntariog ondese pudesse equidibrar o carater universal da obra de Lasar Segat. a as condiços que delimitavam o funcionamento do museu,

Apos reatizar diversas exposices das obras de segald e de outros artistass variados cursos e projeçes cinematografisas o

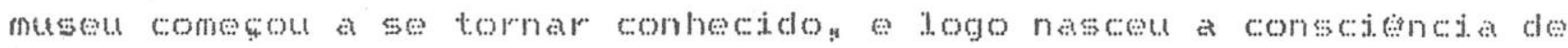
que era necessario a go que desse certa consistencta a esse todo. Neste momento, conforme relatam textos do museu, os cursos cutsuras ja tinham a tenctencia de se desviar do tradicional.

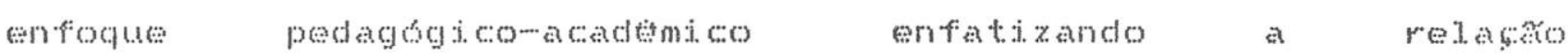
ensino/atividade enquanto as mostras adquirian un carater mais

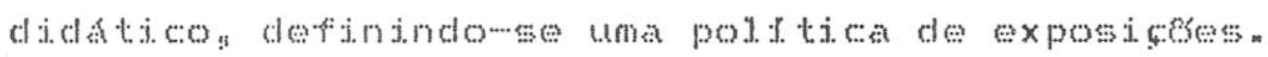

A preocupaço com uma sequencia de manifestapos que retratassem a reatidade artistica nacional e local era crescenten n

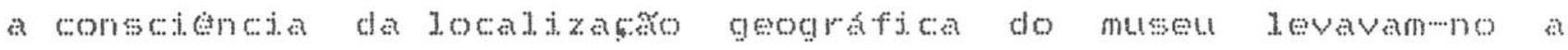
tentar trabalos com publicos nomalmente alhejos as atividades culturatis da cidaden Daf resularam os cursos de fotografian cineman redaço e artes visuajs, realizados em convenios com sindicatos operarios e escolas pobres do bajro procuravane náso partir de programas prewfixactos mas sim elabora-los juntamente com

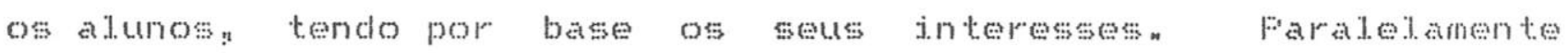

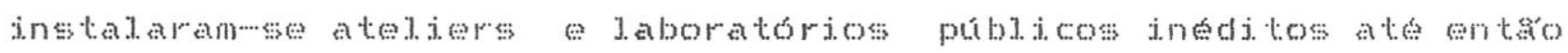
no pass que readizavan trabahos nas areas de artes visuasu fotografia "linguagem musican

En 1977, con experiencias vivenciadas as jofias mas ciarass preparou-se un primeiro documento intituido "Wna proposta para uma politica culturat do Museu Lasar segall." que defendia a necessidade de o museu ser tanto un centro de atividades quanto um centro de contemplackon foi tambem afirmada a necessidade de que os museus de arte passassen a ser instituigos voltadas ao desbloqueio sensitivo das pessoas: nao atraves de uma atitude diclatica traticional. voltacla ao jintejecto mas por meio do proprio exerefejo criativo dos seus frequentadores. A proposta era a de que coexistisseno 


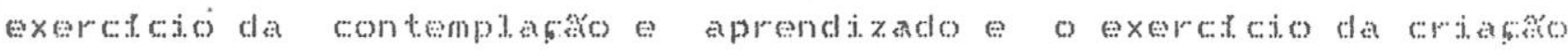
como manejera de sene; i. bi. j. idate

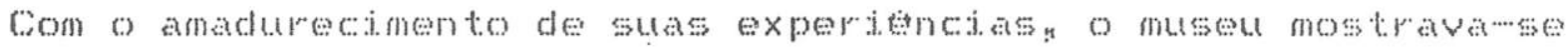
tanbem interessado em colaborar no surginento de outras

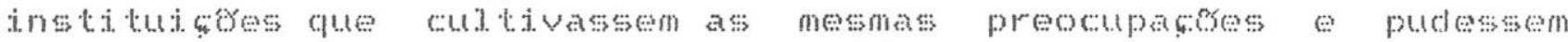

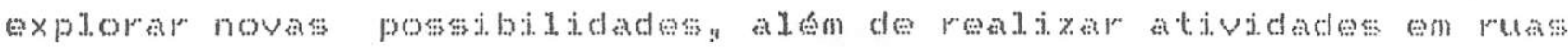

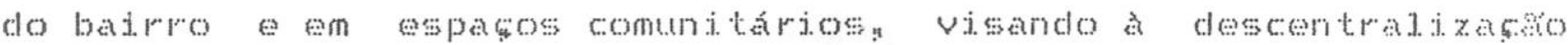

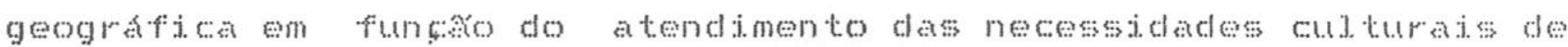

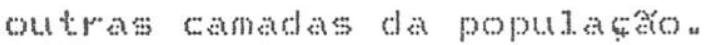

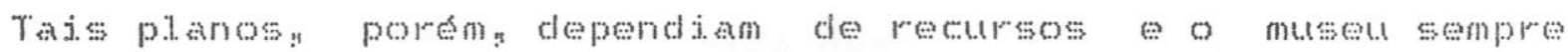

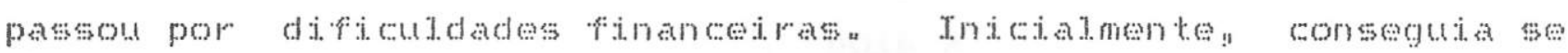
manter com a renda do ediftejo da Av Santo Amarom mas com o tempo

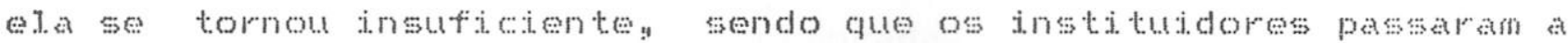
suplementar os fundos netessarios ate o final de $19 \% 5$ gundo o museu comega a receber subvenceses governamentais en todos os

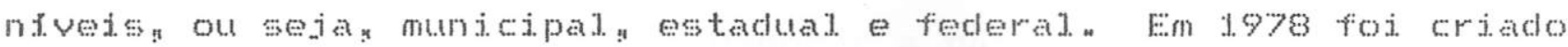
um corpo de socios contribuintes como semente para un projetada

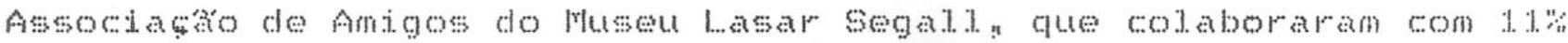
do organento total. daque anos sendo que as rendas proprias

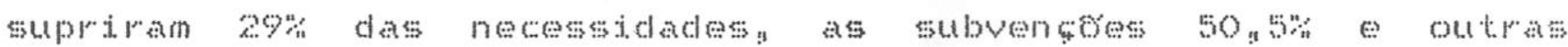
receitas 9, $9 \%$ Esta condiço de existencian com grande porcentagem

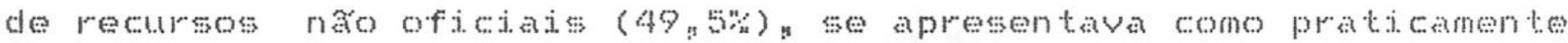

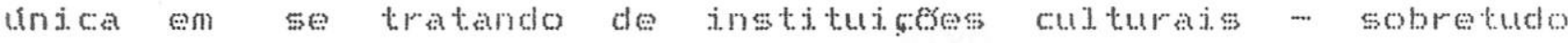

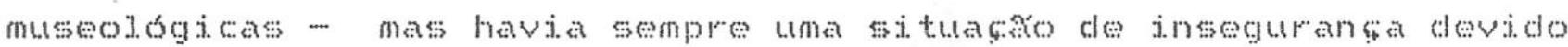

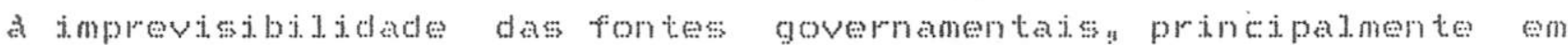

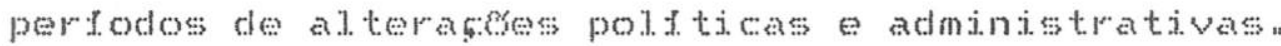

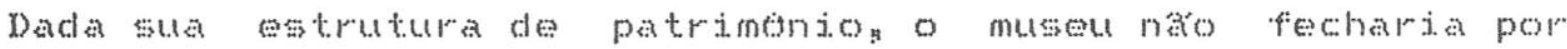
falta de recursos. Foderian a contragostog reduzir drasticanente suas atjuidades mas continuaria a atender seu objetivo estatutario

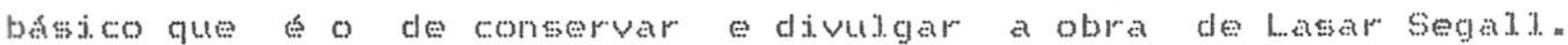

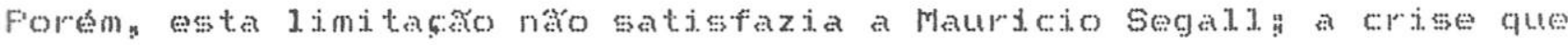
se injoiou en 1981. con o corte dos substojos governamentajs.

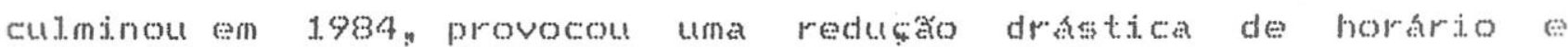




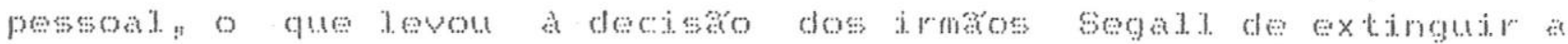

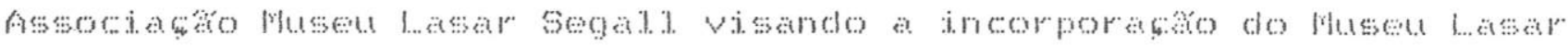

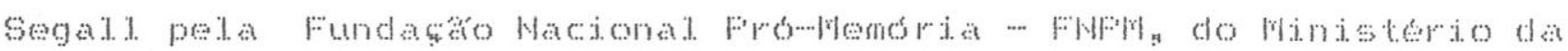

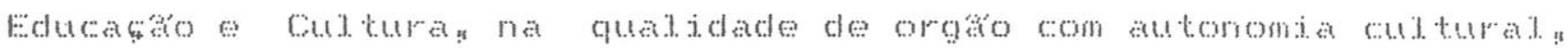

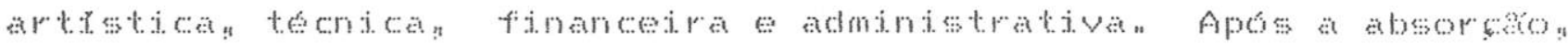
a estrutura de receita do museu foi bastante alteman cabendo

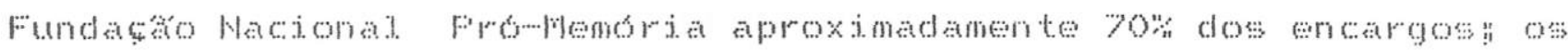
30\% restantes serian obtidos iunto a outras fontes oficiats

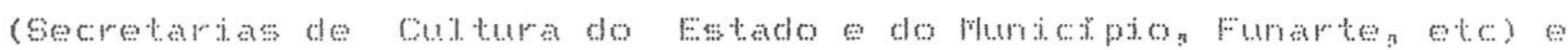
privadas.

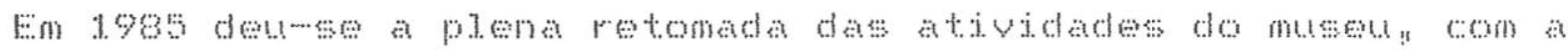
duplicacto de seus funcionarios pois a Assomiano musu l..tsar segall al terou seu quadro de pessoat obietivando novas perspectivas de trabatho antes de ser incorporada possibilitando assim a existencia do servico Educativon entre outras inovacess.

A incomporapo comequ a vigorar a partir de 31 de dexembro de 1984, realizada en carter irrevogked e irretratuvel mediante o cumprimento das condiçes especias de garatias oferendas a Conselho consutivo (antigo onselho ourar) do Museu l..sear segat.

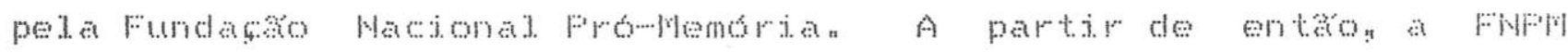

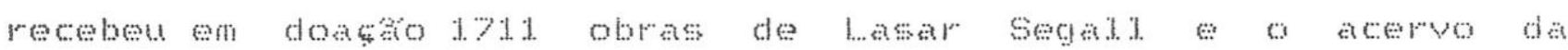
Bibliotem renny klabin Segaliz tendo sido fot to um contrato de

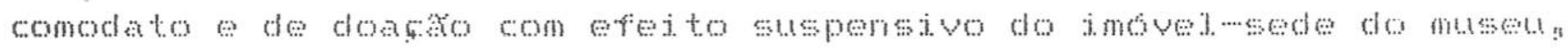

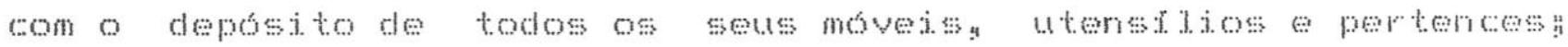
tudo isso devera passar defintivanote a propriedade da uniso se a absorcto me mantiver valida nos 25 anos decorentes da assinatura do contraton

o imovel segundo acordon devera ser usado pela fropl parat

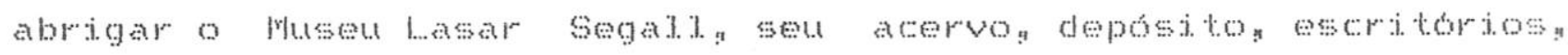
estudios a biblioteca e todos os departamentos necessarjos ao seu perfeito funeionamenton Sera achinistrado pelo conselho consultivo e pela diretoria do Mil..s na Finw de acordo com os termos de seu Fiegimento Interno. 
Sobre os funcionarios, deterninourse que o quadro tendeo

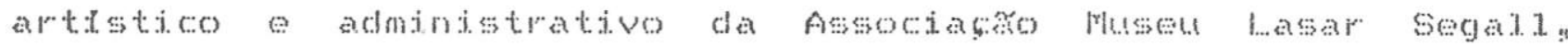
existente na data do infoio da vighoia da sua extingron com os respertivos salarios e jornadas de trabatho seria absorvido pela

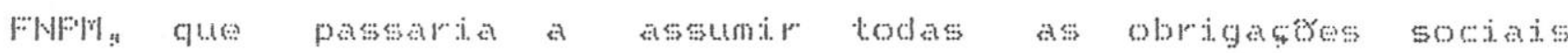

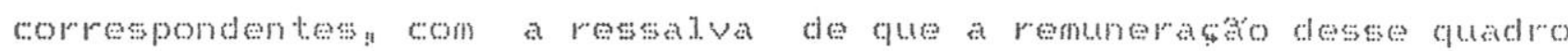
estivesse de acordo com a tabela salariat da Fwly os reajustes de salarios dos funcionarjos absorvidos se farian nas mesmas normas da

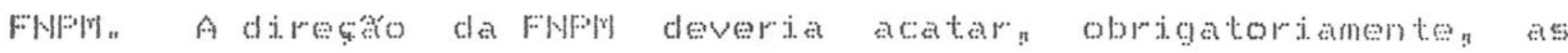
jndicacos da diretoria do rlls para a contratagros dispensan

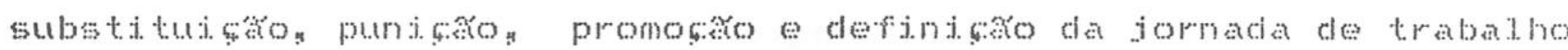
do pessont do museug berm como a estruturasio do seu quadro funcionaly tudo realizado de acordo com as nomas internas da Finlwn

\subsection{Espaço Físico e Frequencia do MLS}

o Museu Lasar segati o considerado una institugho de pequeno porte e trabatha com 64 funcionarios (41. em tempo integrat n 20 em tempo parcial e 3 colaboradores): que atendem a um público de aproximadamente 30,000 visitas por ano 0 musu esta aberto ao publico de terça a domingo na parte da tarden com algumas divisoses estendendo suas atividades no perfodo noturno as sextas e sabados: permanece fechado as segundas feiras mas abre nos feriados a no mes de janeiro oferece apenas as salas de exposigness que exibem normalimente retrospectivas da obra de segali.

o museu localizame no bairro de vila Mariana a aproximadanente $5 \mathrm{Km}$ do centro da ojdade a un quartedra de una grande avenida radial servida por varjos tonibus e pela linha nortewsul do metro cuja estaco mais proxima dista soo metros do museug nas redondezas encontramse quatro escolas pubijedse sete particulares de primetiro esegundo grassn

0 predio do museu tem una area total coberta de $1528 \mathrm{~m}^{2}$ brutoss distributa en dois planos: o espaço resultou da consolidaça de trtes residenctas genjuadas (em duas delas residia o 


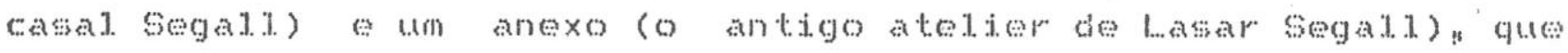
sofreram sucessivas reformas e ampliagos. A construmo ocupa 800 $m=$ ale un terpeno de area total de $1408 \mathrm{~m}^{2}$ a sendo o restante coberto

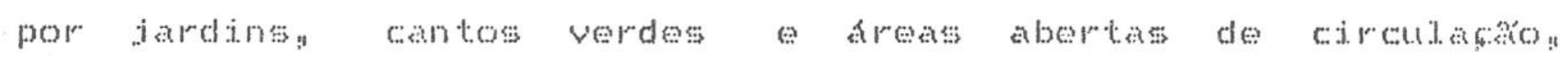
desenhados por segall e acessiveis ao púbitico.

As salas de exposicoss o auditorion o deposito do acervon anexo do atelier e algums instapos auxidiares que servem ao

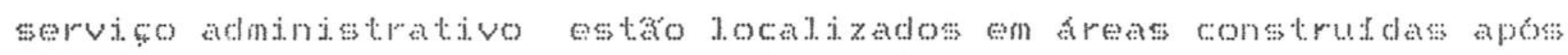
a morte de fenny kiabin Segalia apesar das reformas realizadas pelo casal. segall e das novas adaptacos gue visavam melhorar a funcionalidade do museu, o espaso manteve certas caratertsticas arquitetonicas do projeto basicon de 1931 a de Gregori. Warchavehikn pioneiro da arutetura modema no krasti. os tracos decorativos vivenciats do pintor foran mantidos de acordo com o posstuelu conservandowse antigas cores o moveisn havendo ate originais Bathas: os apetrechos artisticos usados por segall em suas atividades podem ser vistos na reconstitutio de seu atelier.

o visitante entra no museu atravess de un hall a servido por una

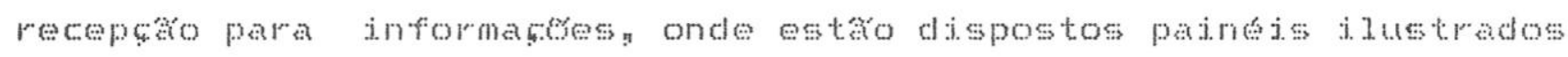
sobre a bra de segall. podewe adquirir publicacoes sobre o artistan o acesso ao museu gratujo para todas suas atjudades a logo na entrada o frequentador recebe o material informativo: constitufdo pelo boletim mensal. (stntese da atividade global do museu no mes) e os folnetos especticos sobre a programago cinematografican exposiches e cursos sendo este material impresso na grafica do museun

Ruase todos os espasos abertos ao publico estáco no primeiro pison Ass salas de exposiçes" bibliotecan auditorion sala de cursose cafoteria encontran-se nesse pison que tamberm abriga d grafica o almoxarifadon estando a direita do predio o ateliere

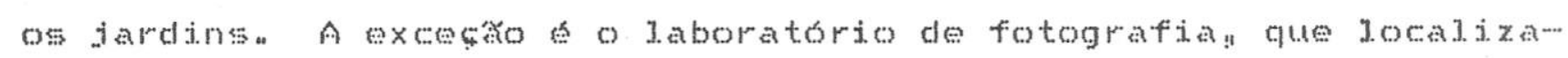


\$e no piso superior e possue um acesso proprio de independentes pois o restante do andar ocupado por escritorios administrativos n' 1 ,

Desede o indedo do funcionamento do Museu l.wsar Segati houve a preocupacáto se registrar com o mator numero posstrel de

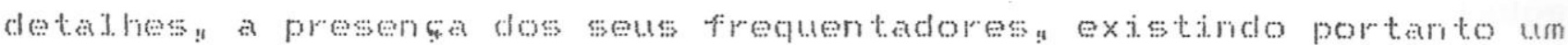
vasto materiat que possibitita pesquisas Empenhado on trabahar

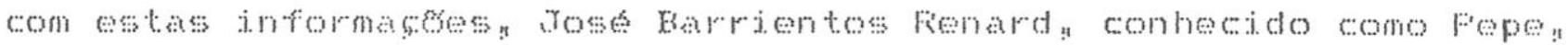

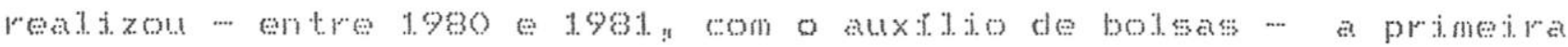
otapa da sua pesquisan Essa etapa provia o ostudo quantitativo da

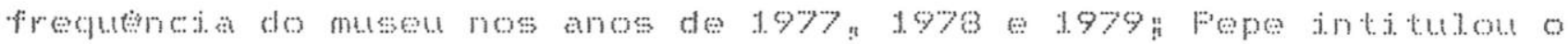

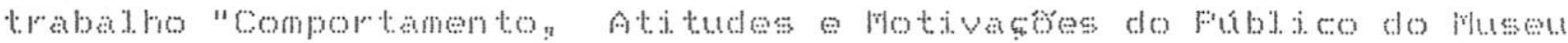

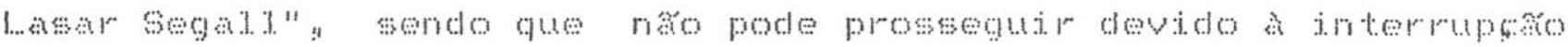
das bolsas, naso anasisando portanto o aspecto qualitativo dos frequentadorms

Waquela poca havia poucas pesquisas na area e eram difusas as

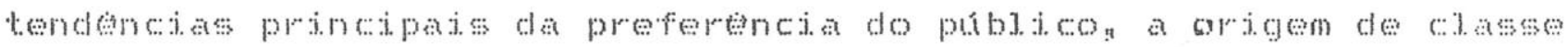
- nuvel educacional preciso dos visitantes dos museus gaterias salas de teatro de concertos ben como as raxos da indiferenca dos que por la nunca se aventuravan, fpesar desse traballo ia ter completado alguns anos nada mats foi elaborado sobre a frequencia

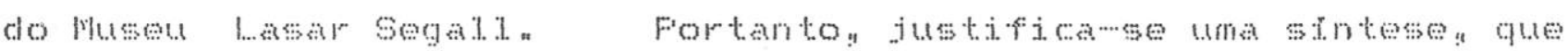
pock apontar aspectos sociologicos peculdares a populaço de sa Fato no que se refere ds suas rengeses com os eventos culturas a sua dispositan esperiatmente nos museus

Fot considerado frequentador habitual aquele que frequenta o musu quatro ou mass vezes ao ano e o eventual o que o visita menos vezes. No trienio estudado houve uma distribuigho homogthea sendo constatada a frequencia absoluta anut de siobo visitas n

(1)obs.: A planta do MLS no foi fornecida por questóes de segurança. 


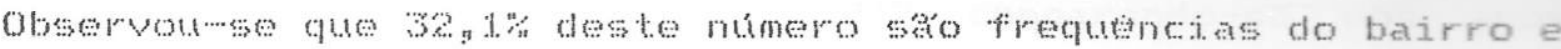

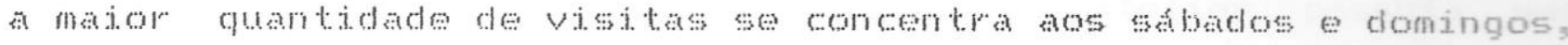

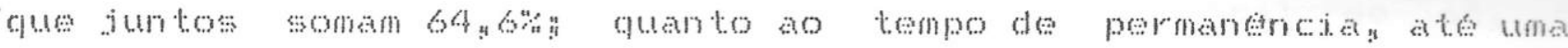

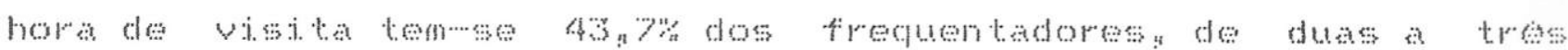

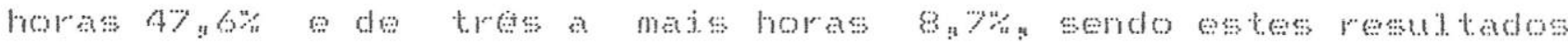

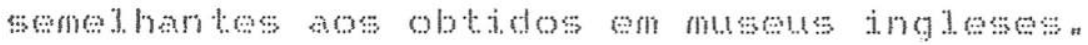

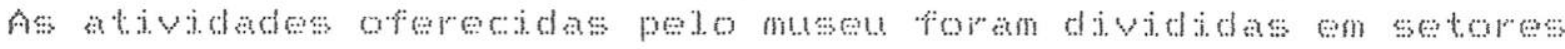

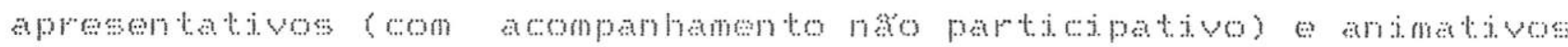

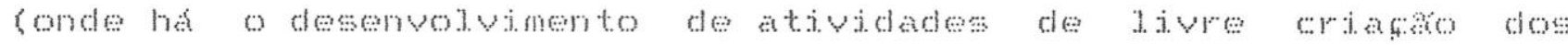

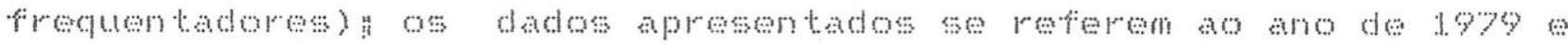

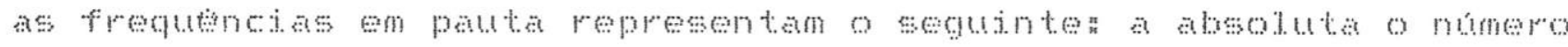

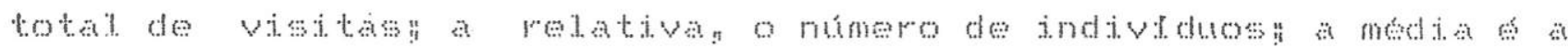

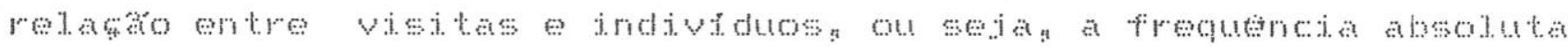

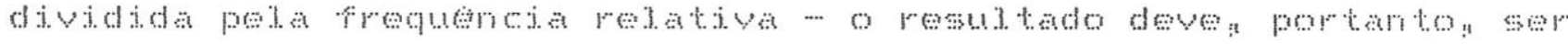
mator ou igunt a umn

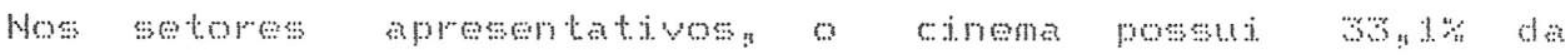

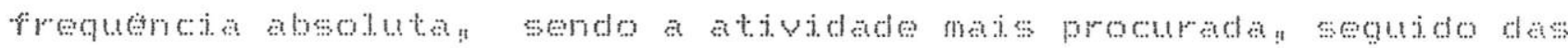
expos i

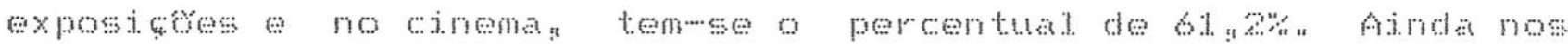

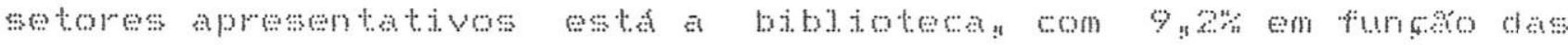

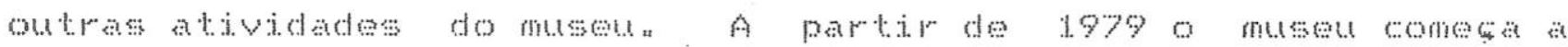

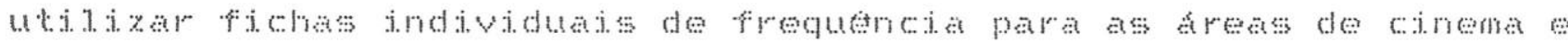

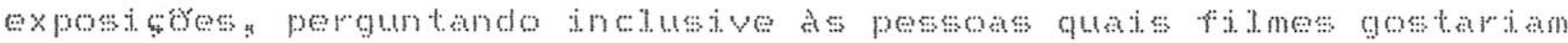
de $v e r$.

A rregundia absoluta no no de $19 \% 9$ nos

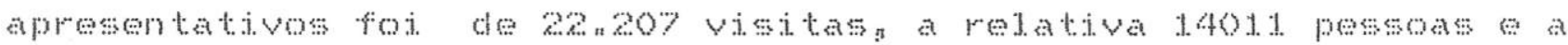

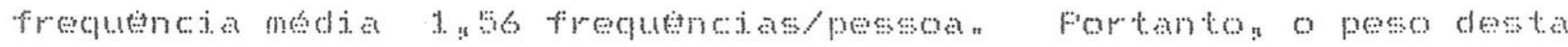

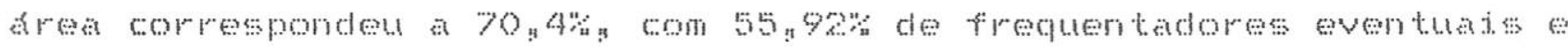
$14,42 \%$ do habitutis

Nos setores andmativos, o atelier permanente apresentat for $6 \%$

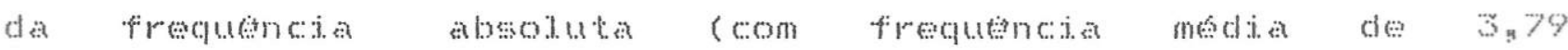

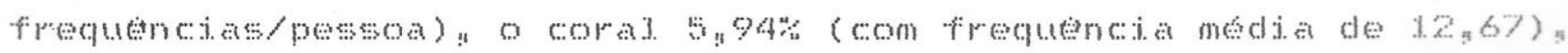

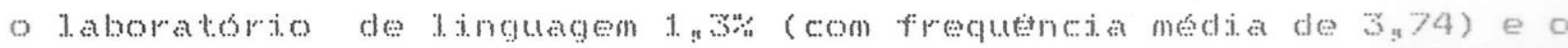


plantao fotografico 6, $3 \%$ (com 4,73 frequencias/pesson) " rodos os setores foran mats prowuracos an 1979 comparandows aos anos anteriores: nesta opoca estimavawe que o ateider possusa uma cidentela de 243 frequentadores habituats. 0 corat de 65,0 Iaboratorio de linguagen de 27 e plantato fotografico de 153.

A prequencia absoluta em 1979 nos setores animativos foi de 9. 342 freguencias a relativa 2.014 pessoas e a frequencia media 4,63 frequencias/pessoa o peso da area animava correspondeu a $29,6 \%$ sendo $6.56 \%$ de frequentadores eventuds o $2301 \%$ de habituatis.

Os setores apresentativos possuem uma ata frequencia absoluta e una batia frequencia median pelo contrarion os setoress animativos

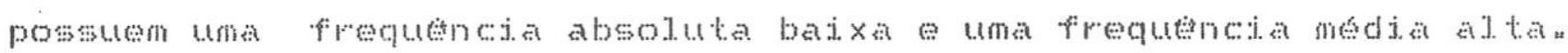
A frequencia media gerat do museu foj de 1 a 97 frequencias/pessona semelhante ao que se obteve para museus ingleses. observouse gue $90 \%$ das pessoss frequentavan especificamente os setores do museu mesmo os frequentadores habituass tinhan uma baixa frequencia intersetoriat fato este que contrariava a polftica cultura do museu que na pratica estimulava a intercomunicaso $a$ a interdis siplinariedade.

Os diferentes setores do museu possutan en 1979 una $w 1$ identela de 1 "001 frequentadores habituais (6a $24 \%$ do total de frequentadores): que perfizeram 11.828 frequencias ano (37.45\% do total. das frequencias), e una quantidade de 15.024 frequentadoress

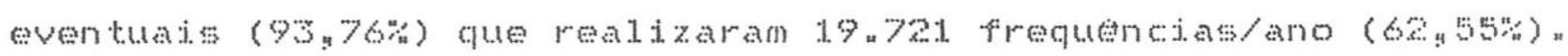

A frequencia absoluta por setores desde o intcio do musu Lasar segali. (1973) ate dezembro de 1988 ajuda a visualizar a escolha dos vistantes e usurios diante das atividades oferectass 
Exposi çoes;

Fon woses cinematogrations

xis.t. j. oteca

Cursos Diversos

Laboratorio Fotografico (intcio ern 76)

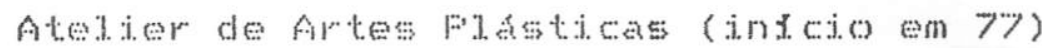

Laboratorio de l...inguagem (infeio en 78)

corat. (inteio em 78)
$1.07,1.00$

191.939

51.859

$25,40 \%$

18.983

47,161

7.898

$19.4 \% 9$

Total de Frequencias de 1973 a 1988 :::

$469,86 \%$

\subsection{Departamentos e Divisoes do Museu Lasar Segall}

Conforme o organograna, o Museu Lasar Segadi a admindatrado pelo Conselho Deliberativo e dirigido pelo diretor presidente diretor adiunto os departamentos divisoes seçes e setores sa di.rigidos por cheress

- Conselho DeIiberativo formado pelos antigos curadores da associacton que passaram a conselheiros consutivos acrescido de novos participantess o conselho e constitufdo por te membros" natos ou elettos" sao membros natos o presidente da Fundaso Nacional. Formeremoria o secretario da secretaria do Fatrinonio Historicoe Artistico Nacionaly e os descendentes consanguneos em 1.inh direta de Lasar segalin ate a segunda gerachon madores de 18 anosin os eletos saco en numero deseis e foran escolnidos entre personalidades de notoria dedicano a cultura e as artes. conselho Deliberativo atuanente e presidido por Oscar Klabin

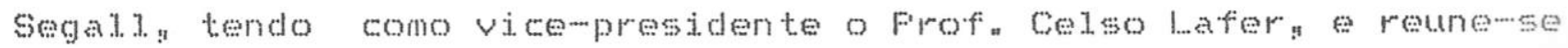
ordinaramente uma vez por semestre sendo a primeira reuniáo anual realizada no meio do ano a segunda no final ou indeio do ano seguinte 0 extrarcinarianente, quando os interesses do museu estiverem presentess 


\section{MUSEU LASAR SEGALL}

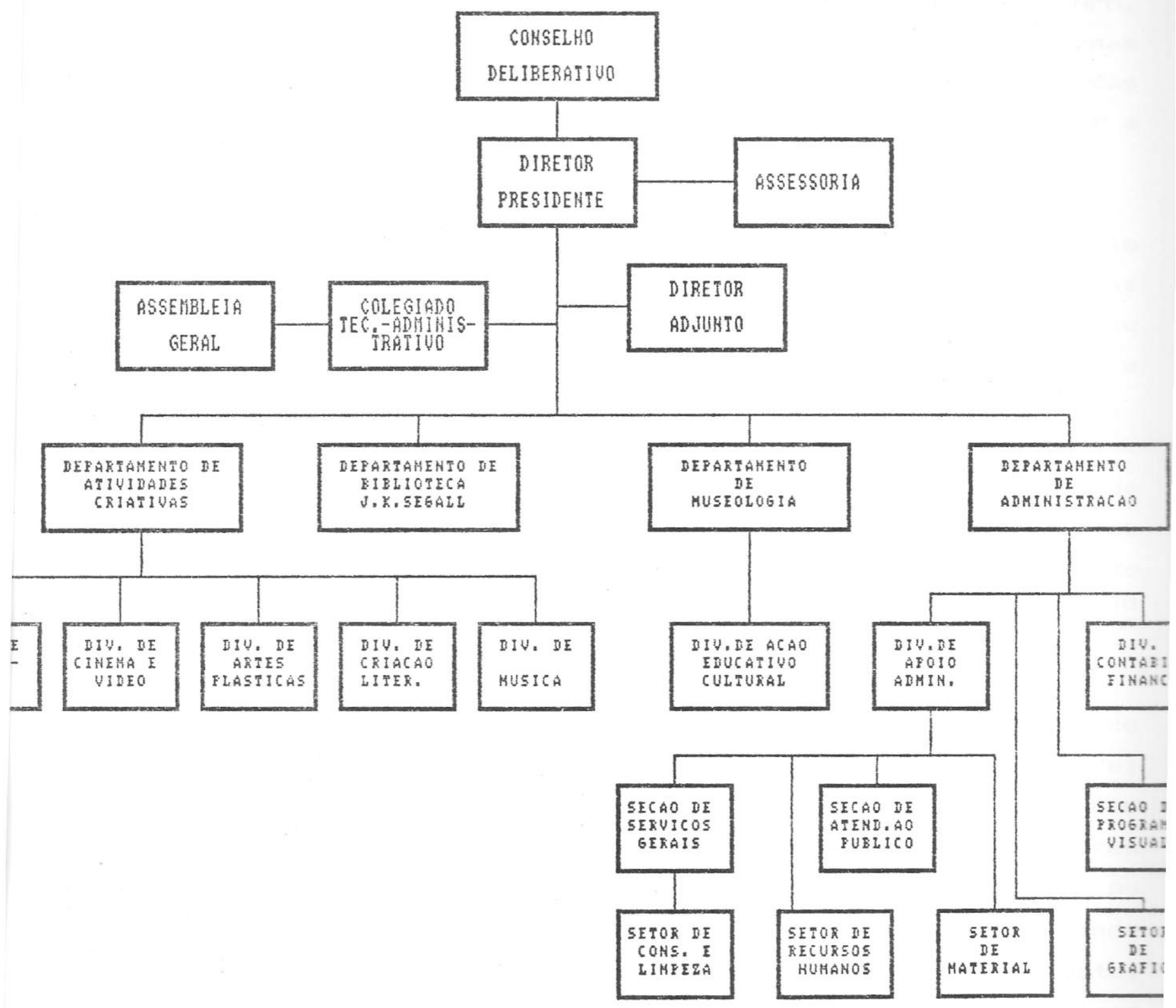




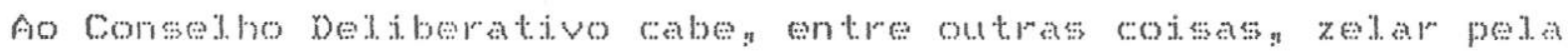
identidade culturat e pela autonomia do Museu l. asar segally aprovar a proposta de plano de trabalo ede orsanton os relatorios a as

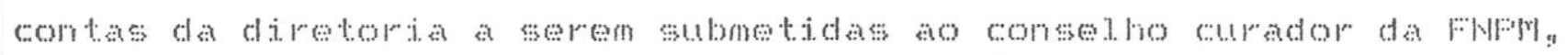

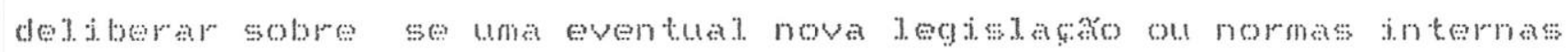
gerais da FNFr constitum na pratica um descumpimento das salvagurdas derindas no acordo entre as institubos eleger a di.retoria do museun

A diretoria 6 constitufda pelo diretor presidente e pelo diretor adjuto que tem cono competencia exemtar tocks as atividades de diresto a aministracto do rlls nos termos do seu regimento interno acatando as dectsess do conselno beliberativo as nomas cabtueis da FNH川 $(z)$

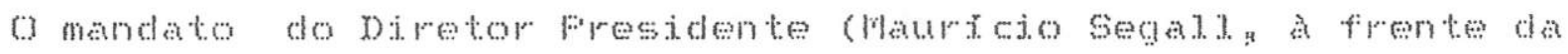

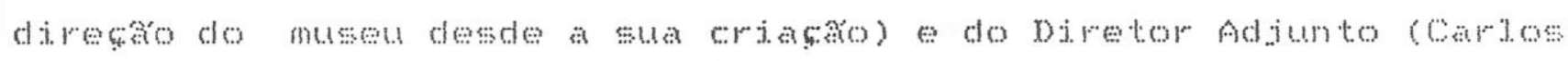
Wencle1 de Maghases) o de 3 anos sendo permitida a reconduço total ou pareial h vedada a acumatso dos cargos de presidente do conselho Deliberativo de diretor presidente do museun

o Colegiado Tecnico-Administrativo o un organismo de deliberatro coletiva que assessora a diretoria fe composto por dez

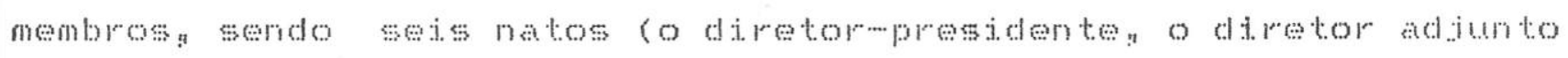
e os quatro cheres de departanentos) quaro indicados por estess dentre os funcionarios com tradiço na historia do musen As

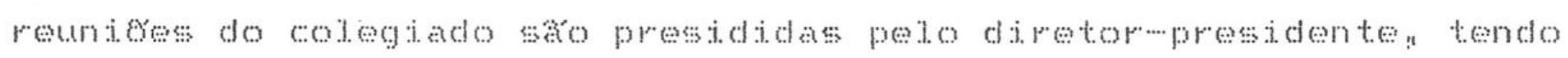
este o voto de gualidade quando ha matora a ser submetida a voto ao colegido compete o seguinte coomenar as atividades rotineiras do museu deliberar sobre a proposta de plano de trabalno

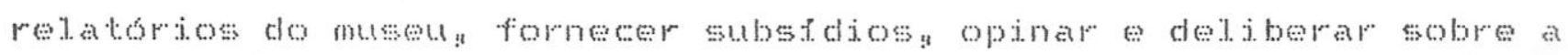

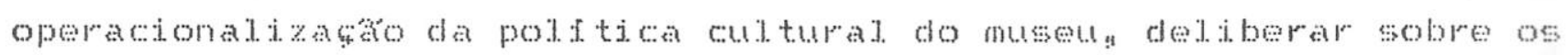

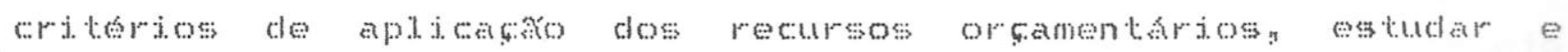

(2)obs.: maiores informaços sobre o que compete a cada instancia, bell cono detalhes sobre 05 departamentos e divisbes do MLS, poden ser obtidas no Anexo 2. 


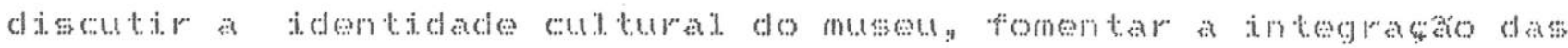

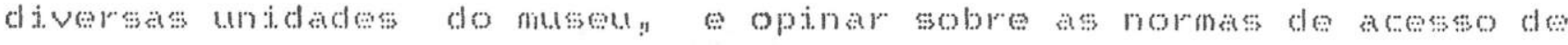

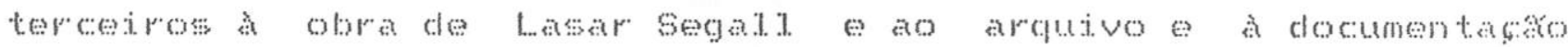
sobre o artitistin

A Assembléia Geral funciona como unidade auxidi ar do colegiato

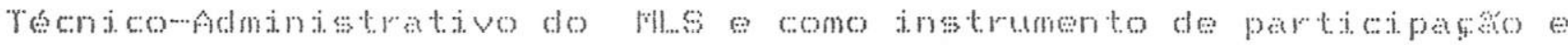

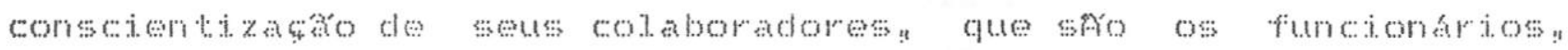

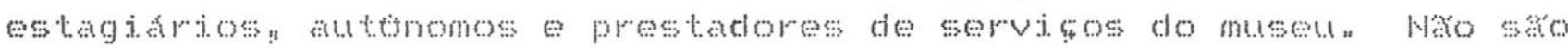

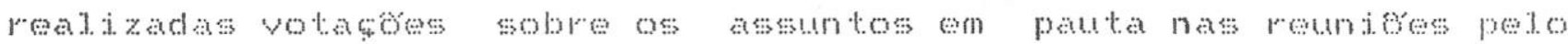

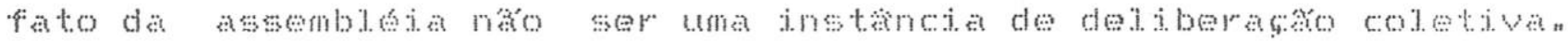

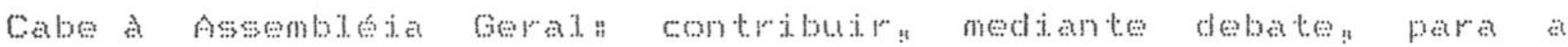

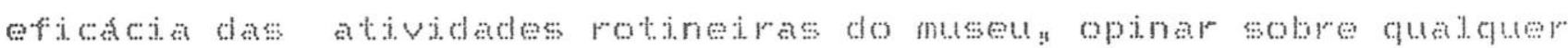

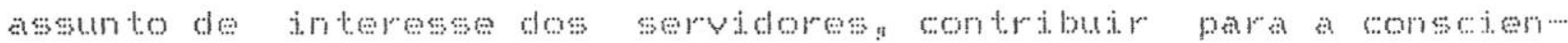

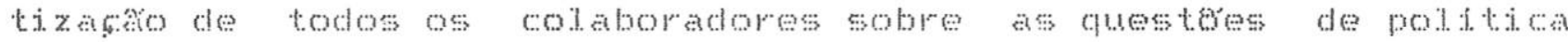

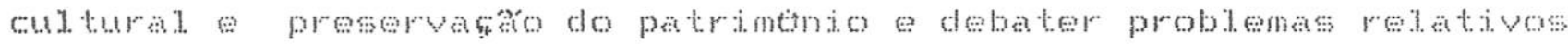

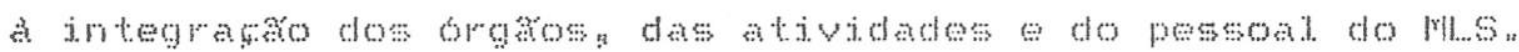

\subsubsection{Departamento de Atividades Criativas}

Este departamento foi formado a partir de experitencis a

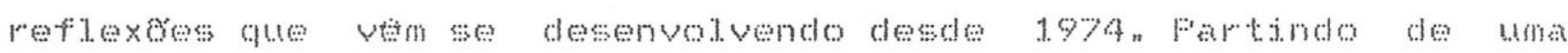

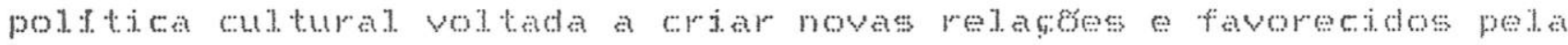

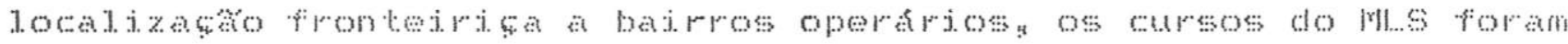

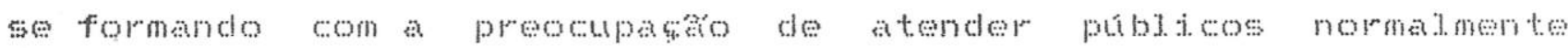

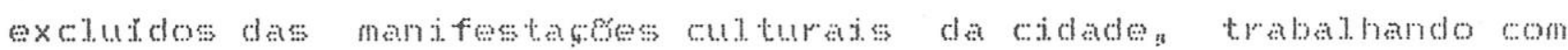

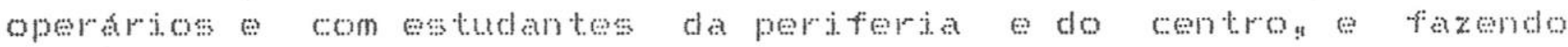

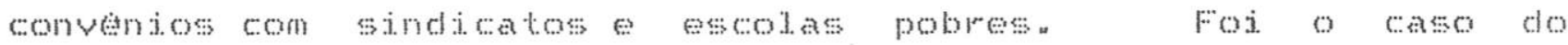

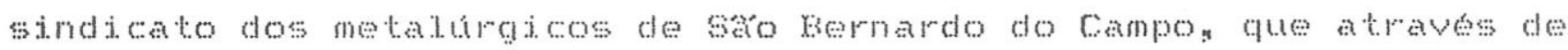

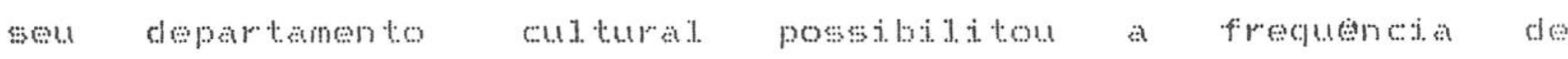

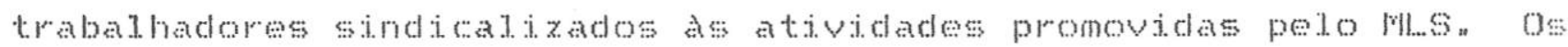

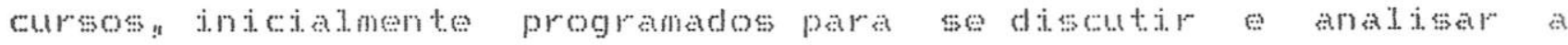

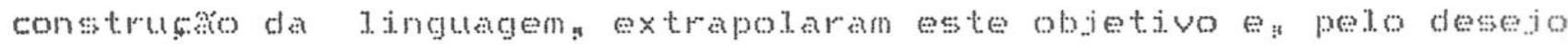

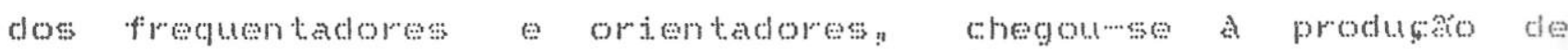

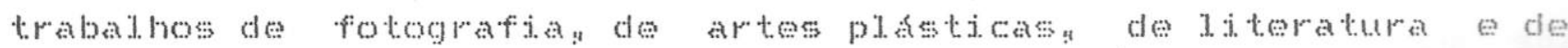
cinema Destes cursos se originou o nucleo de cinema no sindicato 
dos metalurgicos de sá Eernardos onde foram reatizados alguns

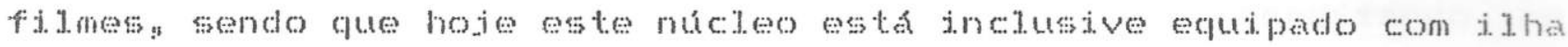
de edichon 0 conventos com escolas do barro deran a un grande número de estudantess carentes o acesso as atividades criativas a chance des pela primeira vex manter contato com a possibilidade de expressio de driand

Nesta fase o museu estabeleseu dois partmetros bastos para a

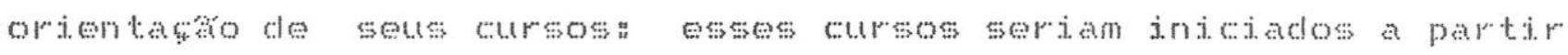
da constucho, pelos proprios frequentadores; de equipantos

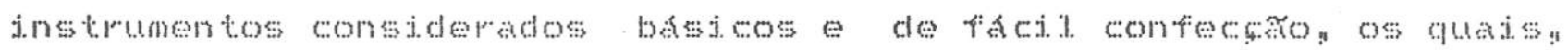

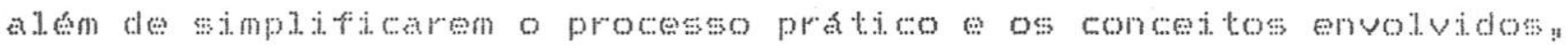
ajudavam a desmistificar o dessofisticar os exementos a a construcho da linguagem essa diversificaso de linguagens ser.a apresentada trabahada pelos frequentadores de maneira con iunta

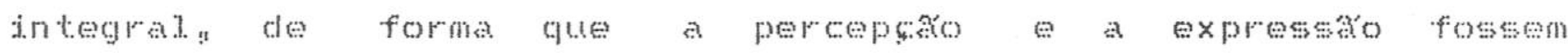
conoretizadas a partir de una experiencia vivida os cursos pela diversdade de suas propostas interessaran as pessons com mator potenciat crtatco de varios pontos da cidade, que vian no museu uma oportunidade de aprofundarem suas abordagen criativas. Este fato aliado a falta de pessoas para fazerem pontes do museu com os sindicatos a as escolas a teraran a frequencia dos cursos.

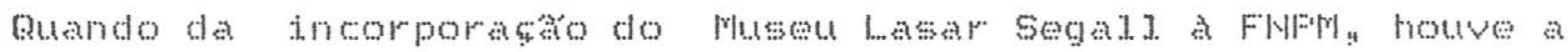
necessidade de se dar certa organicidade as diversas atividades criativas do museu originandowse o centro de fitividades oriativas - CAC nascido com una polf tica cuturat de bases ja derindas gue clava un periti. geral para todas as atividades. Waquele momento os objetivos do centro de Atividades criativas foram expostos por seu

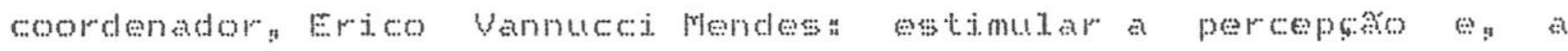
partir dat. a expressáo da sensibilidade de coda un desperta atraves de manifestepes criativas de origen plastica ou atraves da palavra escrita falada cantada utidizar a propria programaço como propulsora de discussess, provocasose seminariosi buscar o desenvolvimento de trabalihos em conjunto com entidades e instituiges cujos projetos e programasse fentificuen com sua propostay e consolidar o cologiado, orgá interno do cac integrado 


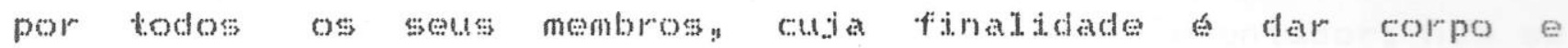

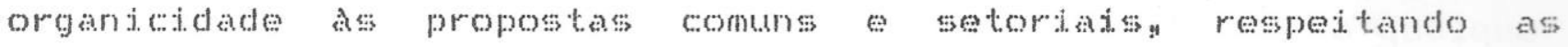

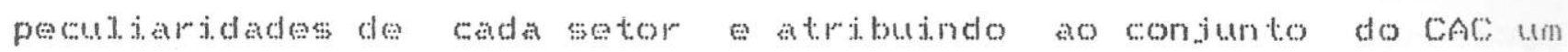

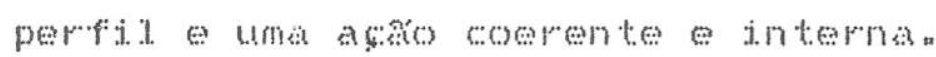

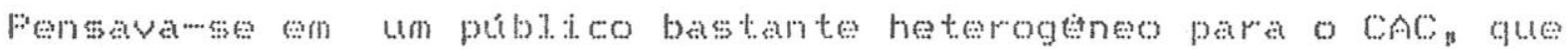
abrangesse pessons de qualquer camada social a partir dos lo anos

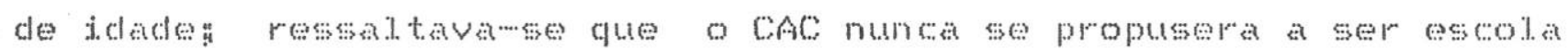

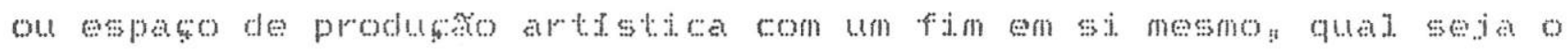
produto artaticos pois esse produto eran para efexto da proposta do musen fruto da abertura de un espaco onde as pessons experimentavan e desenvolvian mantesetasos proprias mouato trubalhavan sua nexessidae de expresesos gerandon portanto

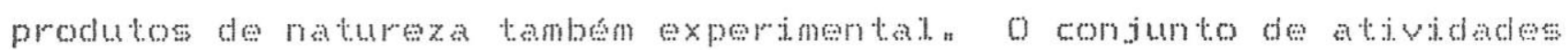

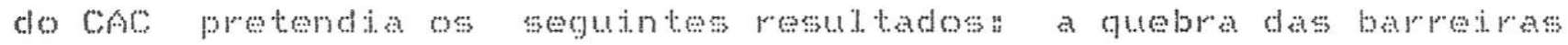

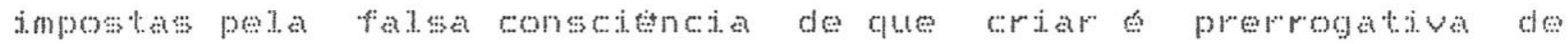
pessods esperiaton o desbloquedo dos processos interrompidos por

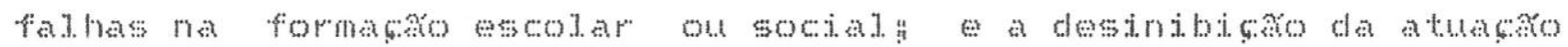

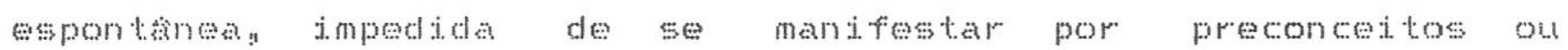
estertipos

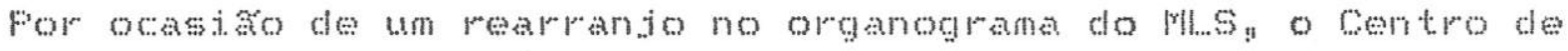

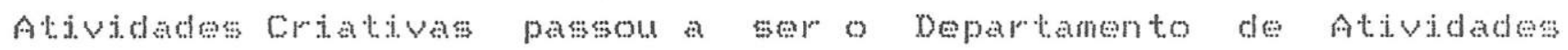

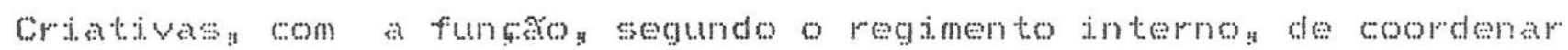

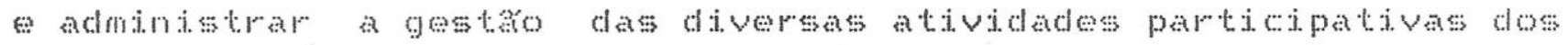

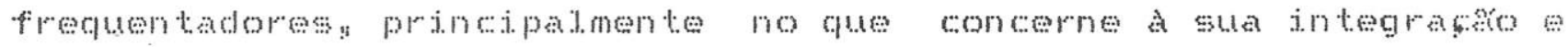

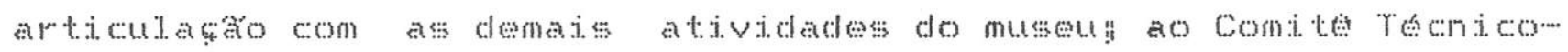

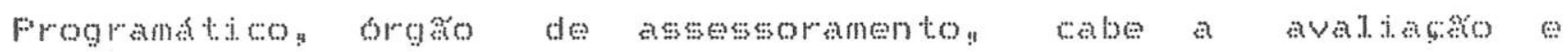
deliberstro coletiva referentes a uma polition culturato do

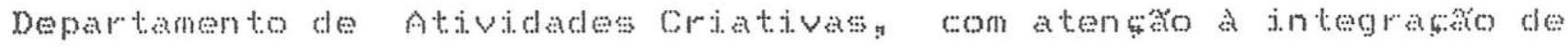

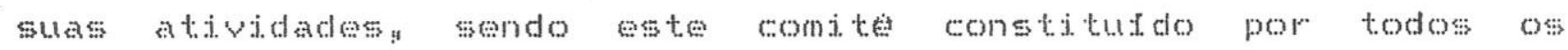

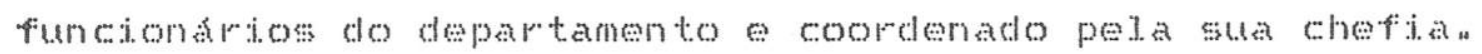

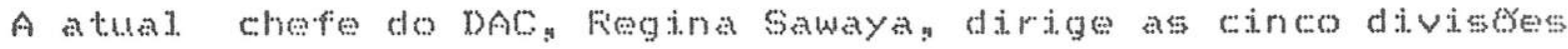
do seu departanento voltadas ao desenvolvimento expressivon que

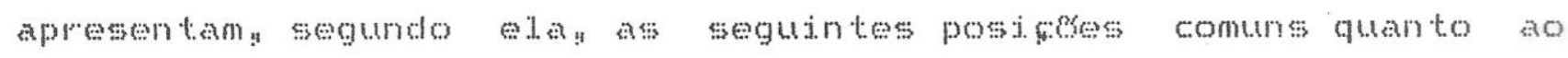

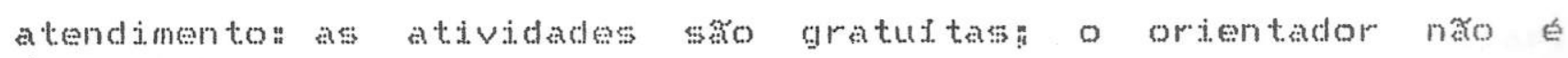


diretivo orienta a partir de um movimento do frequentadory náo se

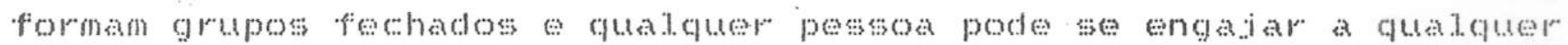
momentop o frequentador deve assumir seu processo de expressason sento nao ha nada que sustente este processo valorizar o processo - o produto ssegundo a opinta de fiegina sawaya e alguns orientadores), mas nato misturar o trabalho profissionat com o amador (dal natse fazerem exposicess dos frequentadores nas salas

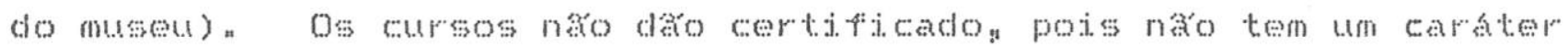
curricular de comeson mejo e fin.

Conforme o regimento interno compete a cada uma das divisosts pjanejar" coordenar" supervistonar: executar e avaliar an atividats participativas dos frequentadores do setor dos cursos das oficinas das palestras e realizar outras avidades aftns com a sua strean

A icha centula da Divisalo de fotografia a de oferecer o espaco para se utilizar a fotogratia como meio de expressa pessonal.

0: cursos nas escolas de fotografia ensinam mas a parte teconican e o museu procura atraves de varias atividades no setora dar una visa da fotografian discutindo fotografos ctassicose seus estilos atraves da projeço desides e da utilizaço dos bons recursos de sua bibliotecan nostrando as possibilidades de conteudo fotografico be buscando uma formacko cuturat para seus frequentadores.

O: "planteses fotograficos" saco horarjos em que o laboratorio esta aberto a qualduer frequentadora que pode marcar hora para uso gratuto: o materiat sensivel (filme e papel) lhe caben estando a sua disposiço os materiats equipantos minimos necessarios a revelackon ampliakso e secagem bem como un orientador para informaçes e comentarios Esta dinatmica fínica na cidaden o que provoca un grande numero de inscritos (cheganse a atender 15 pessoas por dia) e o desgaste do laboratorion devido a um comportamento por vezes unicamente utilitario - desejacse ampliar, 


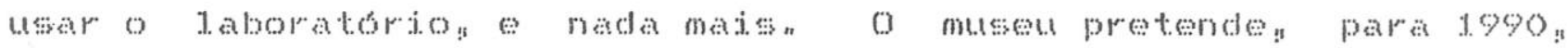
enfatizar o trabalho com os grupos de fotografian que levam ao desenvolvimento de ctrculos de amizade entre os participantesa por

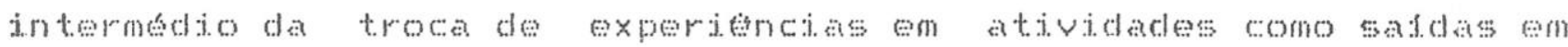

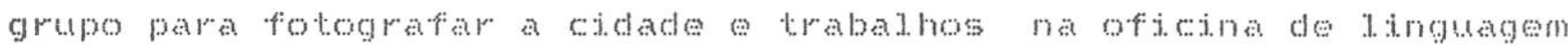

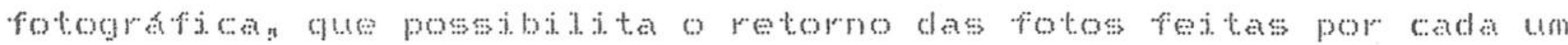

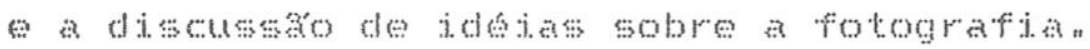

No folloto en que descreve as propostas do setor para o mo

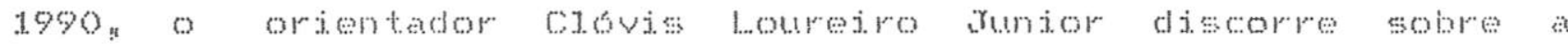

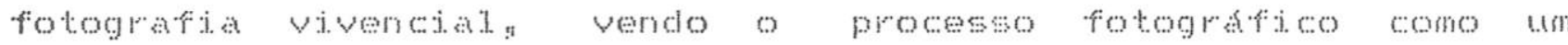
relacionamento dintmico com o mundo vistuely e com os aspetos

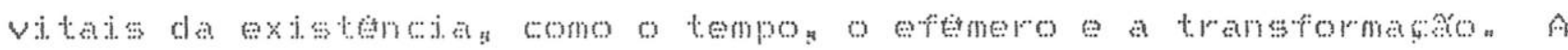

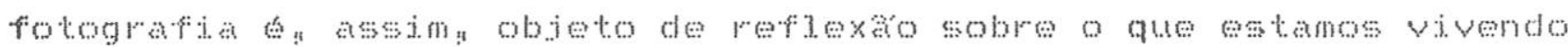
e que estanos perebendo agindo como uma especte de terntometro

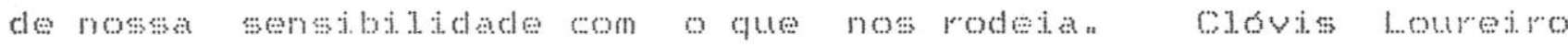
afirma gue "numa abordagen vivencial da fotografian o obetivo

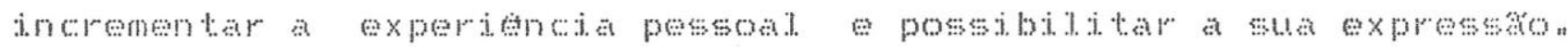

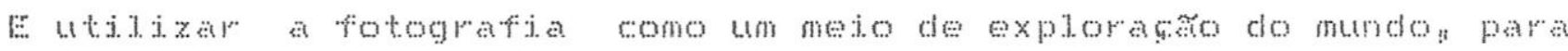

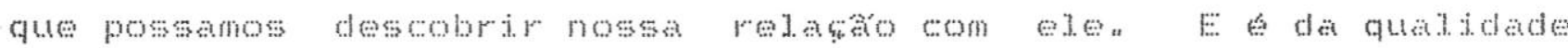
desse relacionamento que depende a qualidade da fotografia"

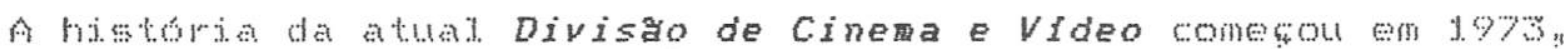

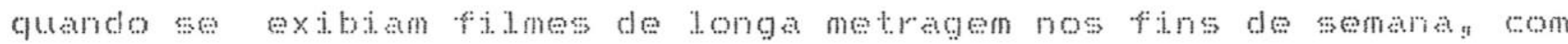

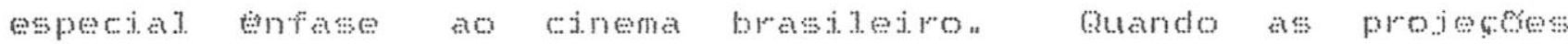

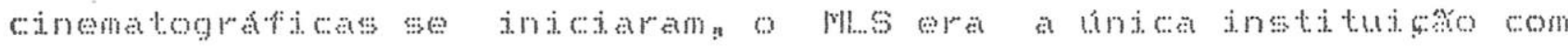

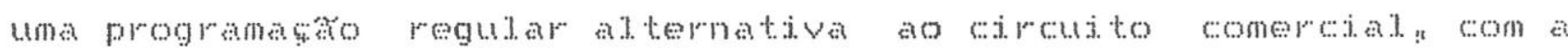

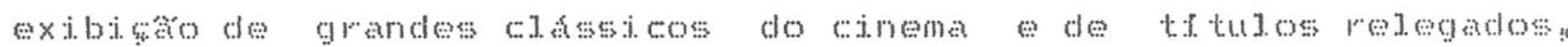

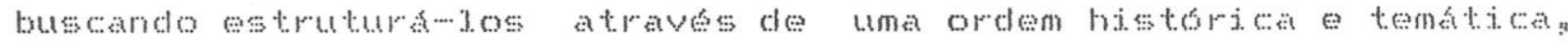
sendo que as outras poucas iniciativas do genero na cidade foran

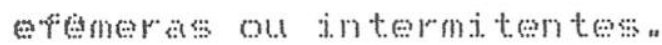

A programagro do musen tamborn ge caraterizava por valorizar o

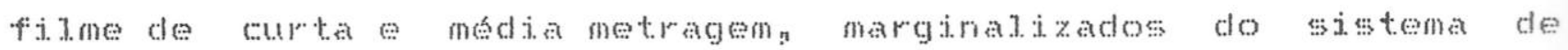

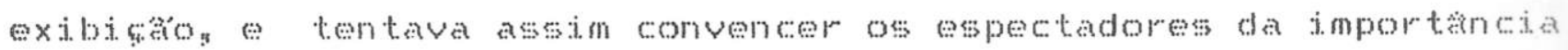

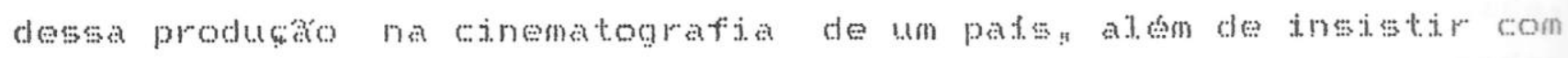
os longas nacionats. que ocupaum a metade da programaço da fopoca. 
Com o passar do tempo comeşou a se desenvolver na cidade un circuto de exibjoses de fjomes ditos "culturats" ou "de arte" curta por mewanisnos legats do Conselho wasonad de cinema --

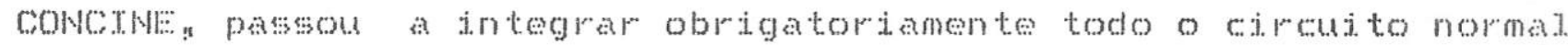
de exibican o mercado estava se abrindo aborondo a produs a de

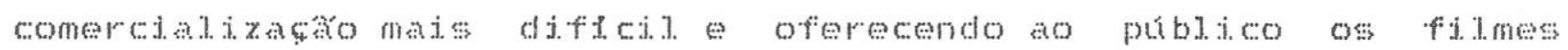
proprios das "sessoes especiais" "Foremp mesmo atualmente o cinema do mos apresenta un sistema diferente dos cineclubesa sendo ainda un dos poucos ospacos em sao paulo com entrada franca " For naw depender e naso contar com a bilheterian pode se arriscar mass. mostrando fidmes de rara exibiço, que sao normatinente enprestados por consudas a institujoses cuturats ou alugas das

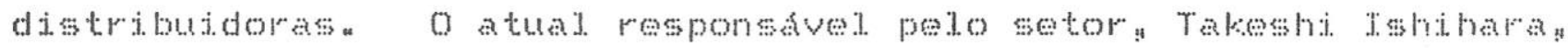
desenvolve a progranaso estudando a oferta dos acervos

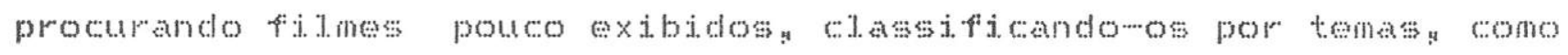
os direjtos humanos a ctasse trabahadoran ou por datas importantes que podem commspondse ao nascinento ou a morte de cineastas"

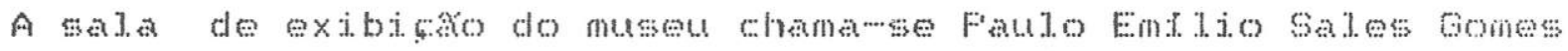
e possui. 120 lugares, muj tas vezes ocupados por un publico fiel. havendo mesmo rengiosos presentes todos os fins de semana filguns destes frequentadores se organizran e participaran de una experiencia inedita que se chanou oficina de frogramacton na qual. os grupos exaboram e executaran os projetos das mostras cinematograficas com a consequente pesqujar de fitimografian localizaşo de copias edicho de catalogos com a reprodusko de

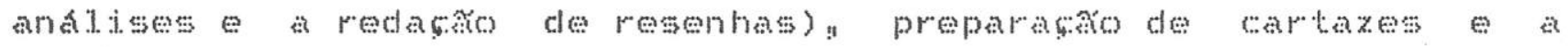
realizaço de todo o trabatho de and maso, baseados na estrutura do museu e na biblioteca especializada en cinena da oficina resultaram ciclos como o de ozuado candeiass o de fidmes

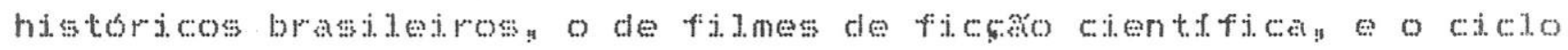
de Fassbinder" considerato o de menhor dintimican

o folheto mensal de programaşo da Divisano de Cinema nomalmente apresenta sinopses dos fithess com a ficha ténicas resumo do enredo e resenhas criticas (muitas vezess traduzidas 


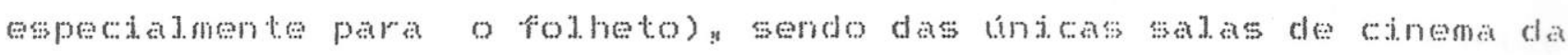
cidade a oferecer tal servison fis sessos de cinema comegan exatamente no horario previsto e terminantemente proibido entrar apos o juf cio da projeçon havendo as vezes pessoss inconformadas.

o museu dispoe de monitor e gravador de video usados eventualmente para mostrar obras produzidas originamente em video

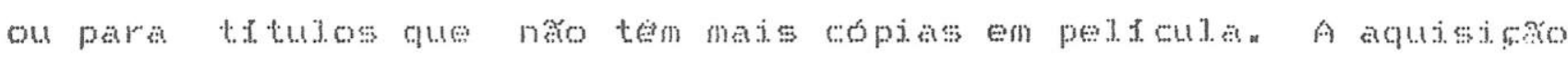
de noves equjementos possibilitaria a concertixaso do projeto de se realizar uma oficina de video, com a elaborabo de rotedros introdusa a linguagen aprendizagem dos rudimentos da duminaso da gravaston wen

Fortin o setor de cinema o o gue apresenta matores dificuldades dentro do musen a comesar pelo equpamento de projecto que estava em grande defasagm tecnologion diante das novas opses oferecidas nesta decaca na area do cimema ba comercial on Saro Faton A obsoluncia dos projetores acaretava constantese constrangedores problemas tecoicos impossibititando una quajdade minima de exibiço e motivando a recusa de emprestimos de filmes por parte de alduns cineasts o 0 ano de 1989 foj diverso na programata do museu que so trabalhou com a bitola $16 \mathrm{~mm}_{n}$ pots os projetores de 35 mo quebram naso valia a pena

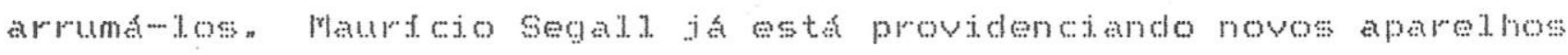
e os doara ao museun

A Divisao de Artes Plasticas possuj os espagos do antigo atelier de Segall onde saro reatizadas as atividades com desentro pintura, o anexo que fot construtcos destinaco a gravura em metal. (equipala com dus mesas e caja de breu) a d xilogravura a modelugm com argita e construso de objetos tridimensionats o trabaho com ditografia nato o reatizadon pois exige tanques e pedras sendo tudo necessarianente grande e pesado. No anexo hat uma estante com livros e equpantos que saso devidamente respeitados pelos frequntadoresy pedewe a estes que levern sua matrizess por uma questán de espaçon 


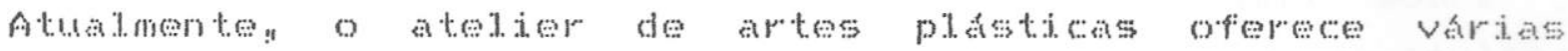

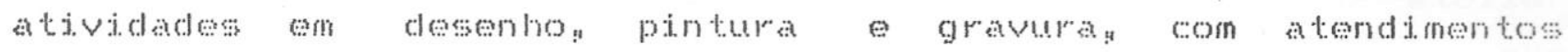
individuas (na parte da tarde) que visam ajudar o frequentador a

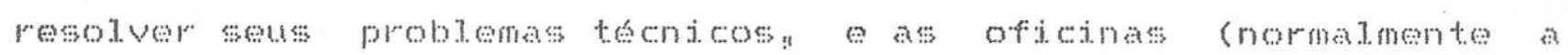
not te)

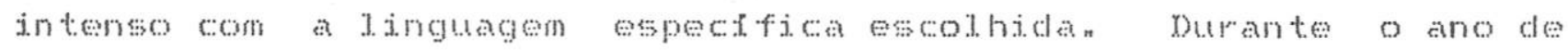

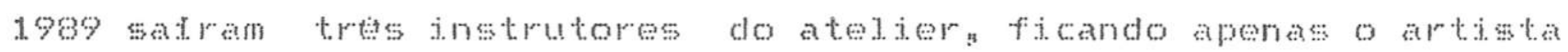

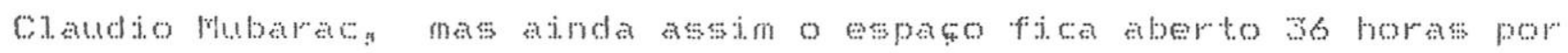
semana sendo o undo da cidade que funciona dewta maneiran

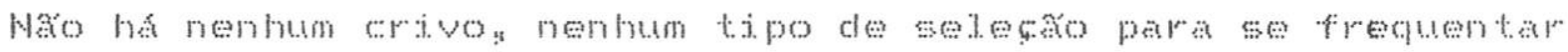

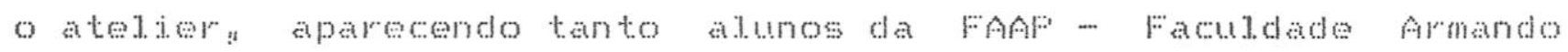

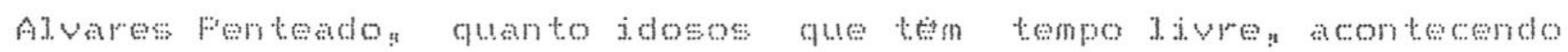

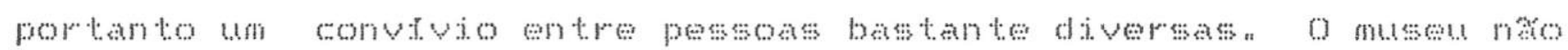

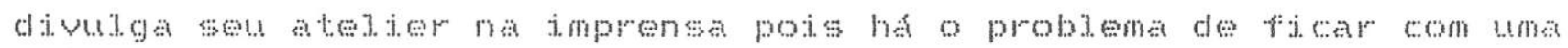

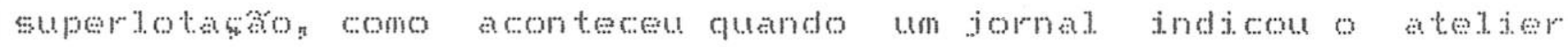
como um locat onde se poderia setudar pintura de grapan o que causou o apareximento de 68 senhoras querendo pintar casaros Ma

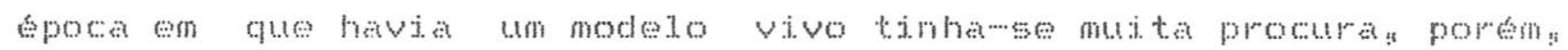

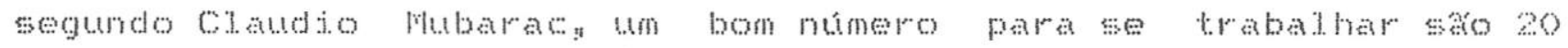

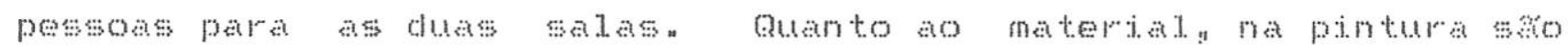

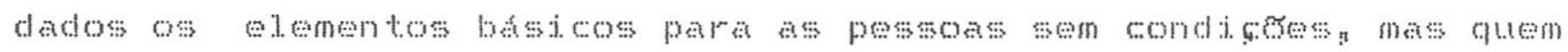

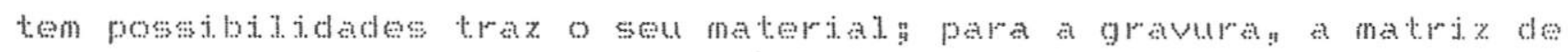

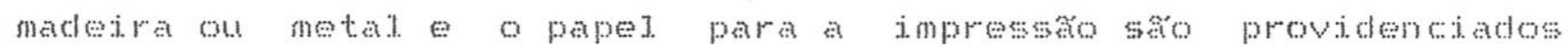

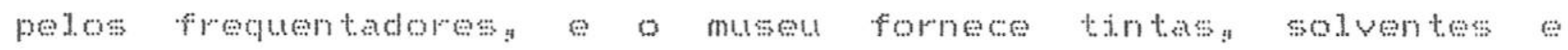

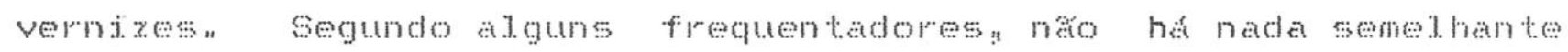

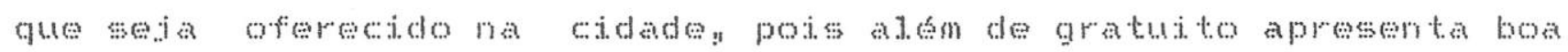

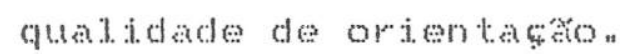

Enquato outras instituigres aplican planos concretos o museu

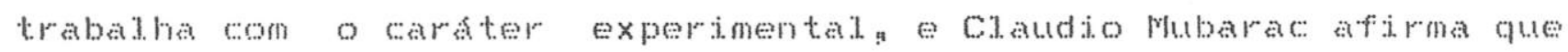

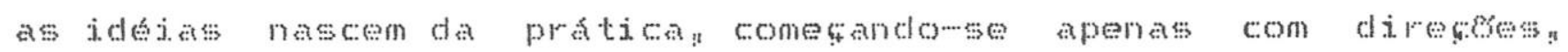

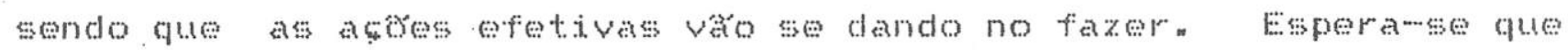
a arte seja vista como forma de investigatäo do mudo para wada un

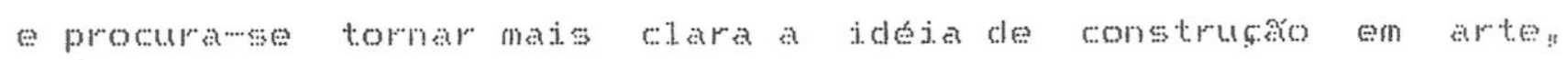

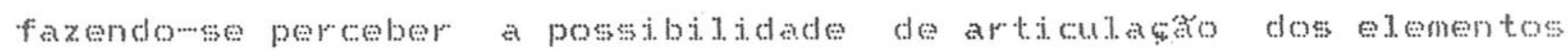
para produzir un significado ese obter uma fiudez que torna o 


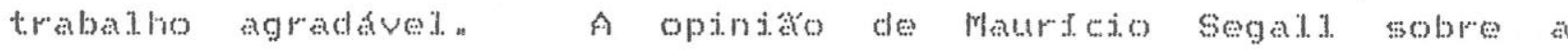
conventeneid de naso expor os trabathos resutantes do atelier basciane na intenço te nao causar expectativas nas pessons que poderiam comesar a trabalhar para este fim mas aloumas vezes saco realizadas pequenas exposiços nas paredes do ateder para mostrar - gue ceada un vem fazendon

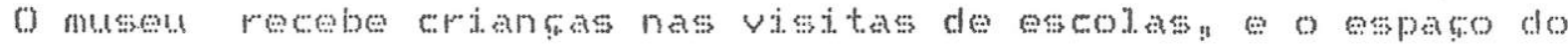

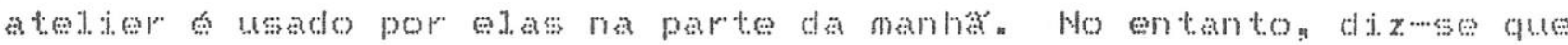
as atividades com criancas nás faxem parte da vocaso do musu, agewe dessa maneira para naso confundir os dois tipos de trabahon

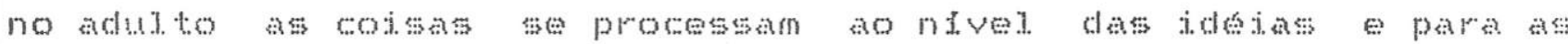

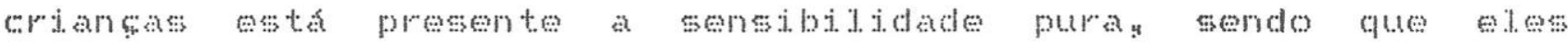

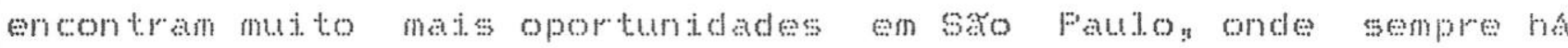
varias propostas de iniciaço artestica infantila do que os adolesentes ou adultos.

Eventudimente se consegue inserir cursos especiats que didan com processo oriativon com verba cedida pela flvm mas năo posstrej pagar ben esses professoresy que acabam aceitando encargo mas pela proposta de trabalo do museu. o proximo curso en vista por exemplon ira tratar de papel artesanal " Descle 1987 a gravura vern sendo a pretiea mase jotensa da area de artes plasticas a a inexistencia de un centro aberto para o estudo da gravura er sao prulo levou o museu a se omupar mas desta 1.inguagem mantendo os atendimentos abertos no atedier reatizando oficinas e cursos de gravuran tanto de formato basica cono de discussuro dos mejos graficosn

Dentre as propostas com a palavray a Divisao de Criagao Literaria promove debates e analises de textos de terceiros: mostrando lejturas possiveds sem toma-las como modelo. mo mesmo tempon estimula o redigir de forma individual ou coletiva a partir de temas conjuntamente escolnidos e discutidos os textos saco mimeografados e passam por nova analise coletivan sendo un dos objetivos o de se chegar a reatizar o ciclo jntegrat. que vai deste

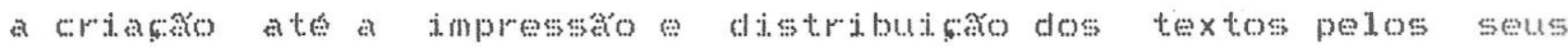




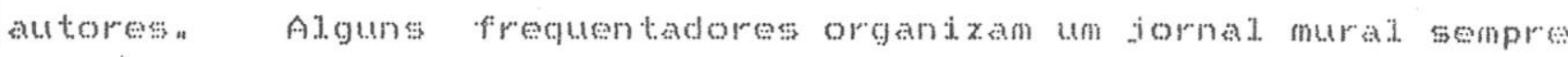
exposto na cafeteria do museu.

o. curso a aberto a quat quer interessado independentemente do seu grau de escolaridadea ha frequentadores que vern do lorubi. de Santo André da periferia e de santos: reunem analfabetose empregadas domesticas a professores universitarios. Segundo bison Fampazo. coordenador da divisán de oriago

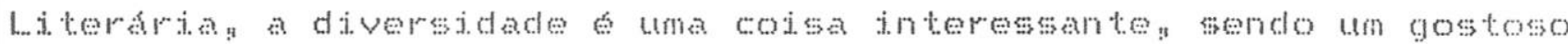
desafio testar o trabalho nesta circunstancian Ha tambern pessoas desestruturadas gue aparecem como quen busca terapa a que se ligan

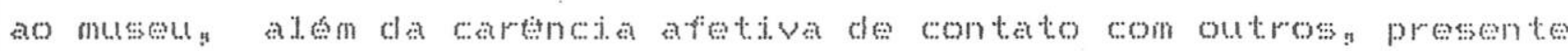
en todosin

A grande variedade de pessoas que se encontra nos cursos posstvel. grastas a facilidade do metris senclo que mutos frequentadores chegan por indicateses de outros alguns vâ ao museu somente para agueda atividade espectidan nem olhando para as expostices e outras propostas como natse pagan as pessons no se comprometem mutos năo aparecem majs porem os clue resolvem faxer o curso vao mestho formando grupos coesos que conviver t.e 1. exonann

Tnicialmente gitson Fampazo deparou com a dificuldade de conceber un lugar coletivo de produtividade textual desvinculado da empresa ou da escola en contraste por exemplon com o conjunto de praticas demarobas pela tradiço de un atelier de artes piasticas" com o decorrer das aulas foram aparecendo varios elementos u um carater de socializasaro atraves da producoso do texton que no momento de sua ciriaço be batante individual o prazer de praticar

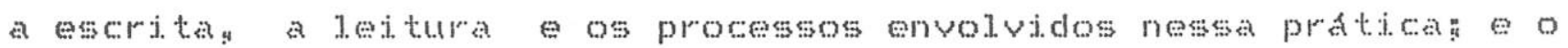
aprendizado de formas de texto a do caninho que se tern que percorrer entre a intenço e o ato de escrever

Considerandowse un educador, un professor no melhor sentido da palavran Gitason Fampazo confirma a existencia de um carater pedagogico nos cursos; mas sem a chatice da escola a havendo a 


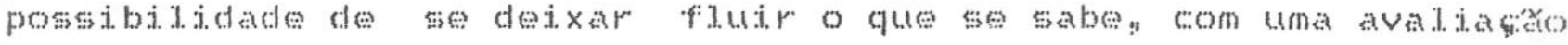

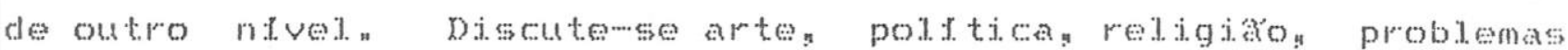

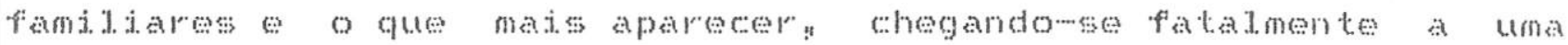
revisaro do processo de escolarizaço de cada un os cursos provocam

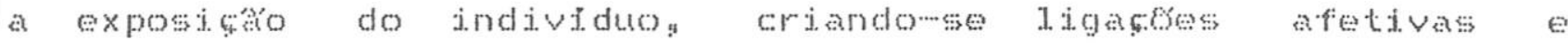

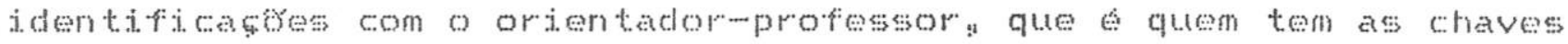

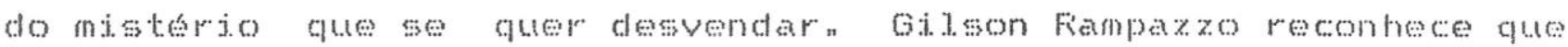

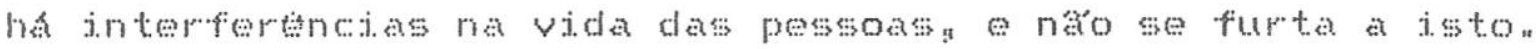

A Divisgo de Husica teve a criacho de seu coral em $197 \%$ por

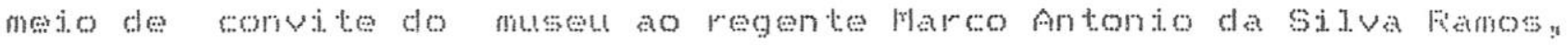
que organizava corats nos bairros perifericos da cidaden

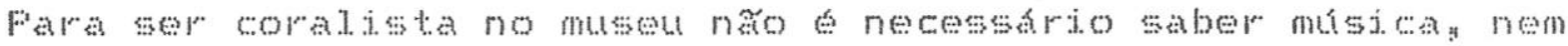
saber eantar ou ter boa voz sendo apenas feito um teste de

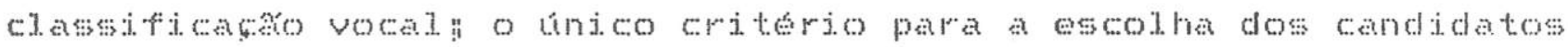

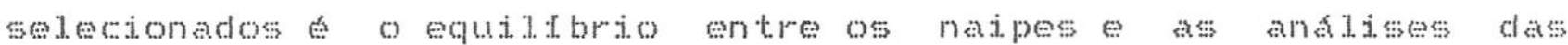

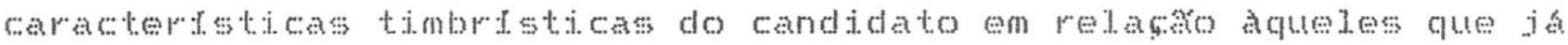
fazen parte do natpe onde ele devers ingressarn

O Corat do Musen l.. asar segall tem a preotupaço constante de educir o públicon atraves do tipo de escolha de repertorio da

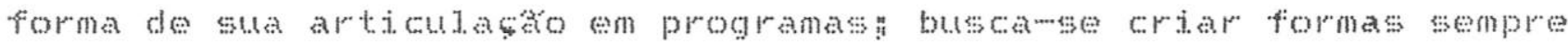
novas de envolvimento do publico com o que se passa no pal co para j.

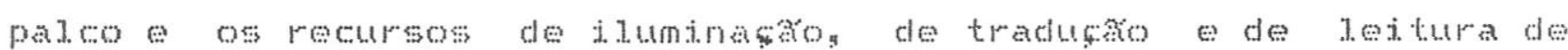

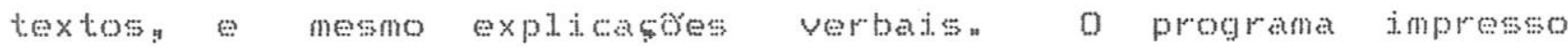
representa uma complementasto da apresentaço do corou sendo o guta do que se desenvolve no palco e podendo trazer certo tipo de informaţo que náto saberia ser veiculada de outra forma.

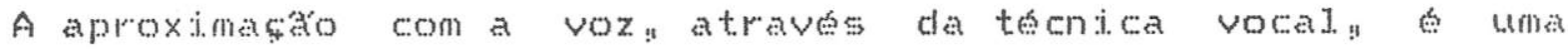
aproximasto to homem com seu corpoy e um certo comportamento corporal. o intelectual. vaj fazer surgir o bom instrumento vocal. 0 trabalo do coral. do museu esta construido de forma que o coralista possa ter suas potenoindidades desenvolvidas; seus conhecimentos de música de canto ampados progressivamente e uma intimidade 
crescente com a linguagem musidal buscancio favorecer a enofaco do grupo, componente basico do ato interpretativo no canto coral.

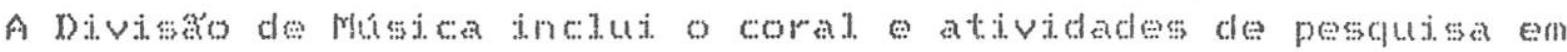
música, alen de promover cursos, eventos; palestras e debates na area die musica e principalmentes na área de musica vocal.

\subsubsection{Departamento de Biblioteca Jenny Klabin Segall}

De acordo con o regimento interno do Pll.s.s compete a este departamento pernitir e facilitar o acesso de estudantes professoress pesquisadores e publito en gerat ao seu patrintonio biblioteckro e zelar pelos acervos da bibliotecan mediane a utilizaço das nomas tocnicas de biblioteconomia documentacko A biblioteca existe oficialmente deste 1970 , com a eriack da

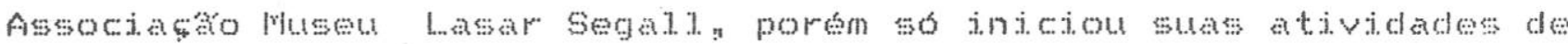
atendimento ao publico en 1.973. Fercebida a cartencia de un acervo especializado en cinema e teatro particularmente no caso brasileiro), criouse una biblioteca voltada a essas areas (incorporando também radion televisa e fotografia) que alom disso abriga toda a documentaco impressa sobre a vida e a obra de l...sar Gegali. Eata biblioteca recebeu o nome de renny Klabin segalla em homenagern aे esposa de Lasar segall e ideatizadora do museus tradutora para o portugues de elassicos da dramaturgia europera como ooethe : Facine molitere.

o acervo dos livros pertencentes a fantija segall constituiu o nucleo central da biblioteca que foi enriquecida com a compra de colectres e atraves de doages jmportantes como as de fnatol Fosenfeld e da Fundaço Cinemateca Brasileira sendo que esta ocorreu apos um inctudio no seu prediog parte do acervo de 1.juros, folhetos, roteiros e revistas chegou molhada ao museu, devido a aço dos bomberros. A biblioteca possui algumas obras rarase ate unicas no brasila como tractucoses ineditas para o portugues de pecas de teatro estrangeiras en geral doadas pelos proprios tradutoresg ha tamberm coletwens de peças de teatro 


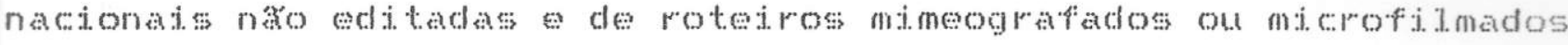
de fidmes nacionatis

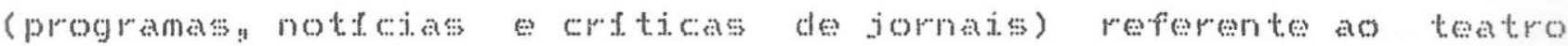

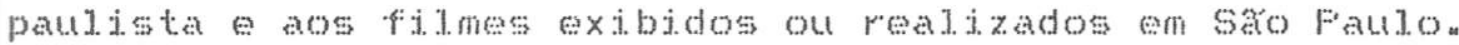

Atualmente o acervo que recebe atualizaces constantes,

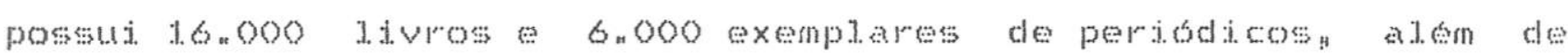
1. 000 folnetos, 900 fotografias de teatro e cinema 5000 programas de teatron 900 textos mimeografas 500 cartazes de cinema a hemerotecas que se concentra no cinema brasiteirow

o material permanente $e$ tombadon como os divros e moveis 0 que no acontece com os catalogosn revistas e follow biblioteca publica sistematicamente bibliografias e coletaneas de seu aervon distribuindo-as gratutamente a outras instituiges jinteressados

o espaco que a biblioteca ocupa corresponde a uma area de 160 $m=$ " com aproximadamente 1.000 metros linearess de estantesn A

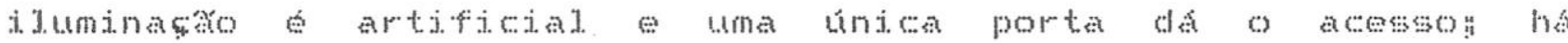
clispontveis vinte lugaress para consultas en mesas e sete pottronas e um sora para lejtura o controle de entrada fo foto atraves da assinatura de um livro, que fornece os dados uti.izados para os Ievantamentos estatisticos $\quad 0$ acesso as estantes o liven permitindo que o púb]ico tenha contato direto com o acervo possa ampliar sua escolna nenhum materia da biblioteca o circulanten mas existem facididades para a reproducto xerografica fotografica do material de interesse dos lejtores: a preco de custon

A Biblioteca Tenny kiabin Segall atende no perido da tarden funciona nos feriados, e das poucas que abrem nos fins de semana

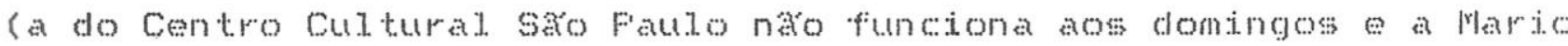
de fondracle alterna os domingos en que esta aberta) " o seu publicio e diversificadon comparecendo estudentes de primeiro grat (moradores do batro de outras localdades), alunos de cursos de comunicacess atores selecionando textos conografos programdores de cine-clubes, e pesquisadores brasileirose estrangeiros: por 


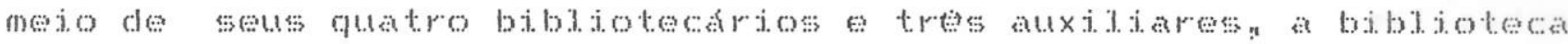
reatizan a pedido dos usuarios lovantamentos bibliograficos sobre assuntos espectiticos epresta atendimento por correspondencia ou por tel lerone"

\subsubsection{Departamento de Museologia}

Conforme determinaçes do regimento interno o Departamento de

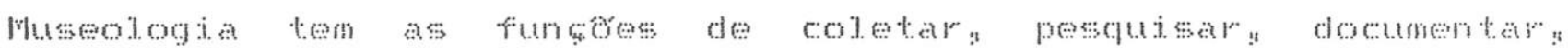
conservar" expor divulgar o acervo artsticon fotografico documentat do mis relacionado com a vida e obra de tasar segalla alem de pesqusar e documentar as obras de segald pertencentes a colectes de terentose promover exposiches temportrias de dutros

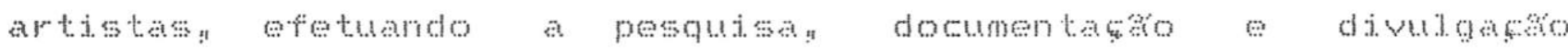
correspondentes:

Alem de se ocupar do acervo dos cubdas que ele demanda 0 Departamento de Meselogia constiturdo por un setor de programasa visual un setor de pesquise sobre a vida obra de

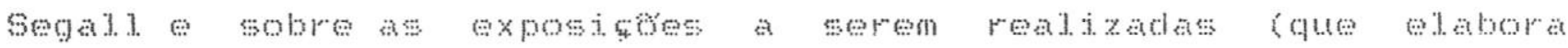
inclusive os textos para catalogos) e um setor educativo que contom a monitorian

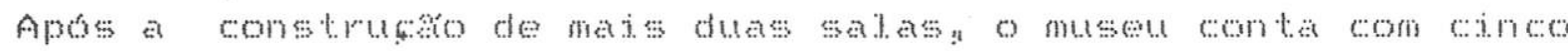

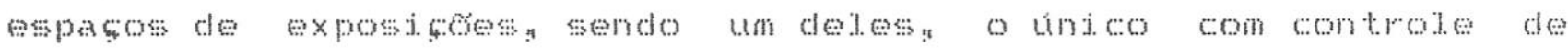
temperatura destinado a mostra permanente da grande pintura de

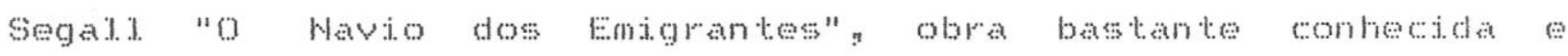
procurada pelos visitantes n As satas sao bem inuminadas com luz naturat. cimpedindowsen porem a incidencia direta dos ratos solares sobre ass obras expostass e a iluninato artiticiat o do tipo

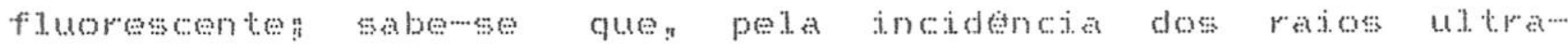
violetas nentuma das duss condiçes e favorave1, e projeto para instalacaro de luzes incandescentes aguarda possibilidades financeirasn Ha tambern una pequena area onde se apresentam permanentemente os materias equipanentosa utenstios e lives encontrados no atelier de Lasar segall. 
Enbora o me possua un acervo monograficon sá realizacas tamberm exposiceses de outros artistasn geralmente daqueles que

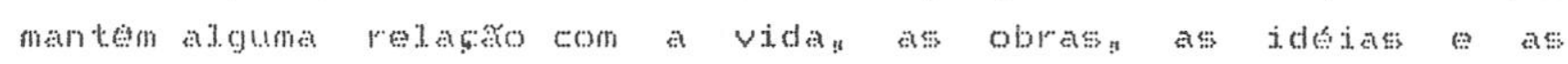
tematicas desenvolvidas pelo proprio segalln como os que colaborarm com o contexto expressionista entre os anos 100 os anos so: ou participaran do panorama artsticowculurat retrataram o ambiente paulistano da epocan Atuamentes com a joda de instatr o contro de oravura no museu ha uma enfase nesta 1.ingugen ereadizarase mostras de artistas que noo pertenceran a spoca de Segatin como Foty e Renina Katz. Momalmente as exposicoses fickm abertas durante un mes e meto mas por una questo de custos e para se ter mas tempo de elaboracho pensan wem mantew por dois meses e meion assim serian realizadas tres ou quatro exposicoses grandes por anon o que possibilitaria uma melhor conceptas e mats oportunidades de exploragro para o servigo

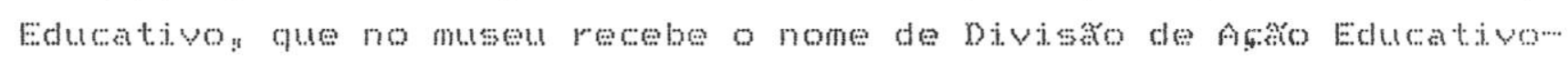
cult turat.

Comprendendows a museografia como a parte que lida com os problems tomicos de localizaton exposiço e conservacho das

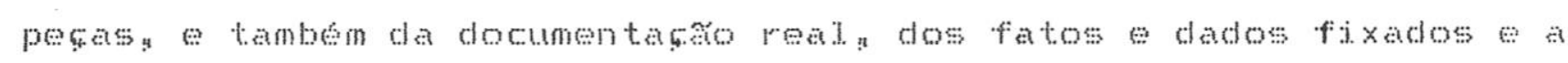
museologia como a andise reflexiva do fentemeno musegraficou preoupandome com a extensaso da vida do museu com o seu funcionamento e com a sua findidade o wuseu l...sar segali trabatha nos dois planos porton com un grande mpenho em desenvolver sem museologicamente Adotandowe oriterios de acordo com o perfit da instituişon as exposiços cada vez mas vem adquirindo aspectos didaticos năo forçosamente no sentido da apresentacho parale a de materiat escito ou graficon ou mesmo verbel para escidrecer as mostrass mas principalmente na propria definicho da polt tica de exposiçes desenvolveuse jnclusive un carater educativo para a vigitancian que ná ficaria so cuidandon mas poderia tambem fornecer informaţoss. 
A possibididade de avaliar o efed to das exposictes no publico preocupa sobremaneira Marelo mráijos chefe do departamento de Museologia, que sente dificutades em optar por una metodologa de

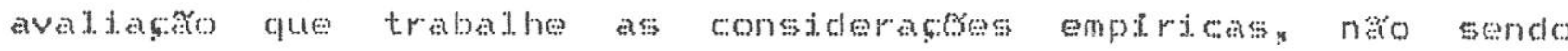
favoravel ao questionario dirigido ou aberto por achar que a pergunta cria expectativa nas pessoasn

Com a incorporaço do museu a FWry criaramse as condiches para a implantạ̧o da Divisăo de A६ăo Educativo-CulturaI possibilitando a concretizaço de projetos junto a escolas de 10 a 2o graus, pois anteriomente o museu prestava atendimento a grupos: de manetira assistomatican

De acordo com o regimento interno cabe a essa divisa

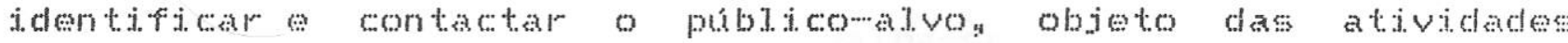
educativas desenvolvendo tendeas de divulgago espectifias para

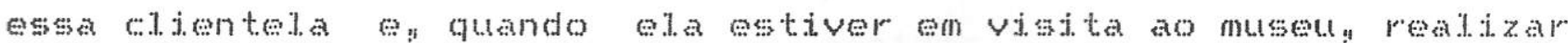
atividades pedagogies visando a melhor aprovetamento da potencialidade educacionat das obras do acervo das exposis rea i. i. zadas

Organizanse grupos de escolares na jelade de 7 a 18 anos com un máxo de 40 participantesn que sán atendidos por pessoas do servico educativo com formatro de arteweducarom depois do visitarem as exposiços os escolaress sa levados a registrar suas impressoses en atividades plasticas procurandome estimular a reflexaro sobre as semelhanças e diferenças entre os seus traballos pessoaise a obra do artistan Fara cada exposjoto ef feito un projeto educativo, como aconteceu por exemplo com "Foty I1ustraclor" quando as escolas do yo grau participaram de atividades ciriativas relacionadas no processo de ilustraço de textos 1.jerarios e realizaram pequenas gravuras para justor sous proprios textoss

Ha uma preocupaño crescente com a fungro pedagogia moderna

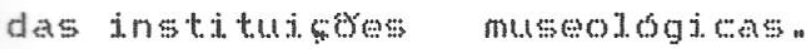
A formulacto estruturata e sistematizaço das atividades educativas cabem a um servico 


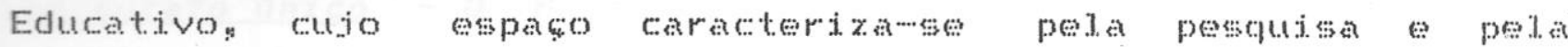

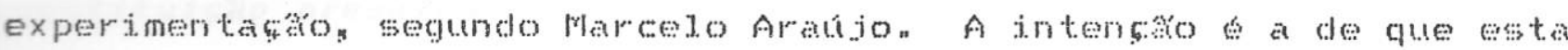

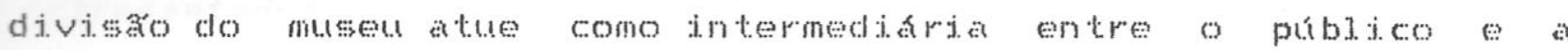

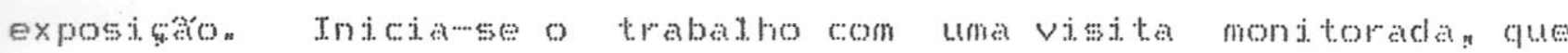
pretende colocar a pesson en contato com a exposichon procurando

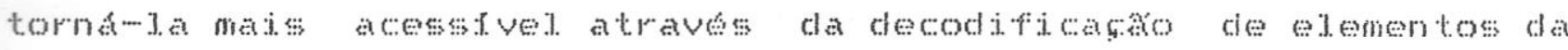

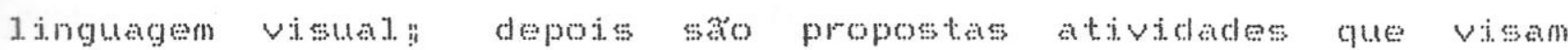
trabalnar a relaço da pesson com a exposictionon

Enquanto a escola privitegia o cognitivo e o explicativo centrandowse majs no verbal a ouseu pretende lidar com o judutivo

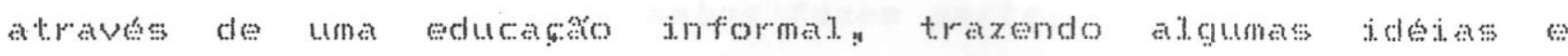
dejxando que as pessoas formen seus concettosn Desenvolvewe hoj

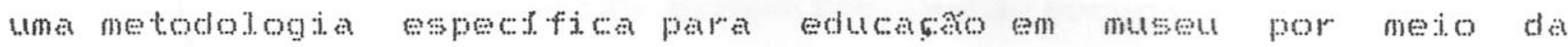
linguagen do objeton ou sejay trabalmawe o significado que o objeto tem pelo caminho afetivon partindo do elementos da pesso

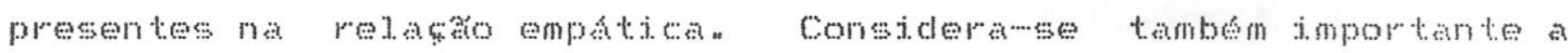

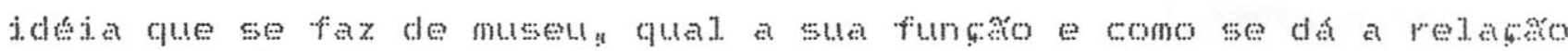

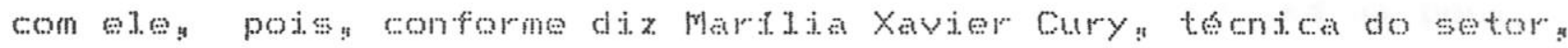

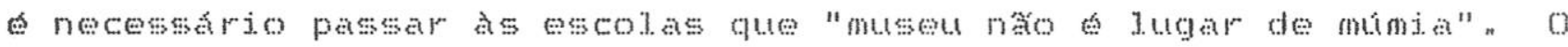

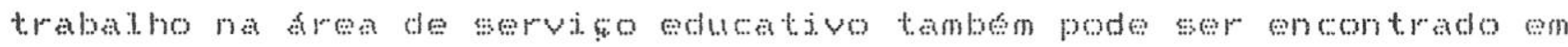

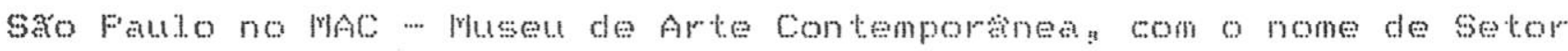

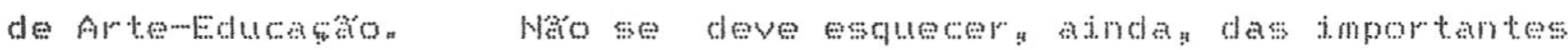
experiencias na formaţo deste tipo de atividade reatizadas quando

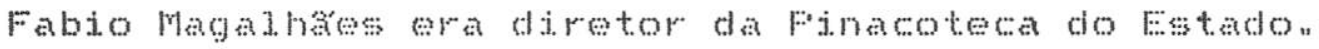

\section{4. o Pensamento de Mauricio Segall}

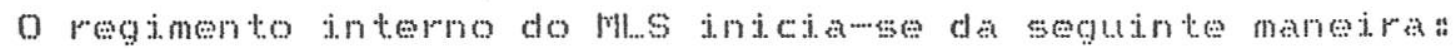

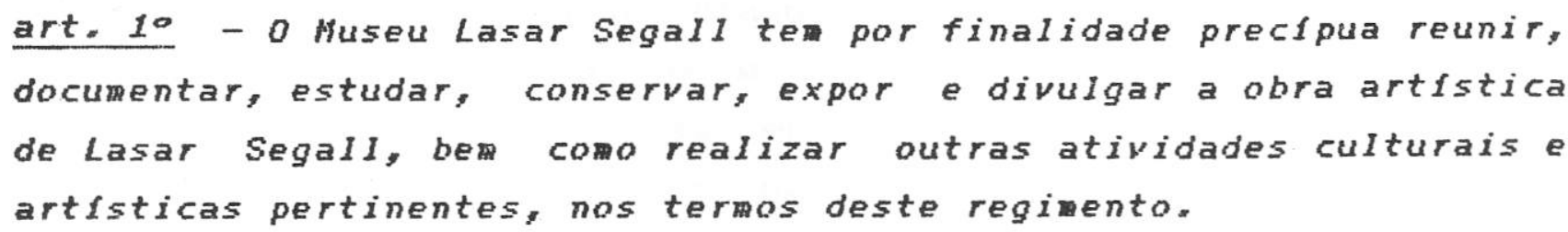


paragrafo único - O Museu lasar segall caracteriza-se como uma instituica preservadora da menoria e do patrimonio cultural, representados por seus acervos, sua historia e suas experiencias, $e$ geradora de producao artistico-cultural, orientada pela visa do papel dialetico da cultura nos processos sociais, pela convicfao de que o desenvolvimento do potencial expressivolcriativo do ser humano e elemento fundamental no processo de construfa da individualidade sensfvel e consciente, e pela adocalo de un conceito conterporaneo e dinarico de wuseologia em que todo o ser humano, ex sua relafalo com os objetos, independente de sua classe social e nfvel de formaço, e visto como um agente de transformacalo da realidade concreta da qual ambos fazex parte.

Nestas palavras estáso presentes as preocupactes de Mauriojo Segalin que tamben poden ser encontradas em artigosy participagess en debates palestras que vem proferindo e nas suas entrevistas diz possuir mais condiçes de lideranga hoje devido a experitoncia

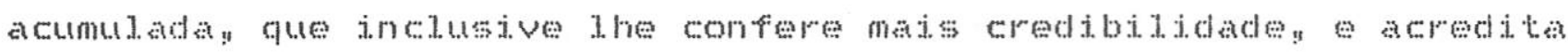
que pode realizar cortas coisas graças a sua permantenda na posicho de diretor do museun

A partir do documento concebido en 1977, quando se pretendia a definisto de una polftica culturat para o museug Marfeio segadit procurou sempre expressar seus pensanentos " Naqueda boca tentava... se formar algo que naco apenas un museu monografico conecandowe portanto, com uma ciareza pelo negativop a ideja de un centro a partir do qual a obra de segall seria irradiada em meio a outras atividades gerou inicidinente un aglomerado de coisas ao qualse tentou dar organicidade para que o museu năo se tornasse una grande colagem. Freservou-se sempre a possibilidade da passagem do contemplador passivo ao apreciador ativo com a intencán de tornar o ser humano mais completo e socialmente mais positivo" $A$ preocupaşo central a em suma era - e ainda é a de conservare divulgar a obra do artista e desenvolver as atividades citativas dos frequentadores do museu, como objetivo constante de inserir esse conjunto na realidade sociomecontonicowcultural que o cerca, proporcionando mais solidez a instituicko. 
Durante participacáo no seminario "O negro a escraviaso nos museus brastleiros" "Maurdeto Segall afirmou o seguintea "Como a cultura lida com a produço da conscitincia dos homens e com a auto... determinaço do seu cotidiano por decortencia ela se coloca no atmbito polfticon mas ha sempre uma tendencia de se atenuar ou anutar o significado do polftico nas instituigess culturais " " E. preciso por a nu a optro joologioa de cada musu e efetur uma politica coerente. Fois e preciso que o receptor da informato tenha conhecimento das premissas sobre as quais cada museu os

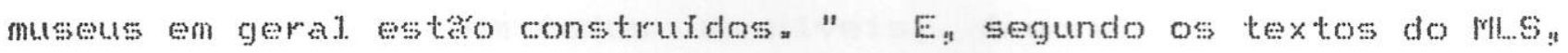
a sua polftica cultumat assume explicitamente a conceptao da arte da vida de l..asar segally acroditando na expressividade potencial de todo ser humano ${ }^{-}$tendo a arte como vinculo do homen com a consciencia 0 mundo "Tose Fenard" em sua pesquisa sobre o museu. diz que a intercomunicapa e anterdisciplinariedade sao os pontos basicos postulados pela polftica cutural do mils na conceptó da arte como una luta por recuperar a autonomia do cotidiano" cotidiano que sob as linhas de forca da hegenonia cultural. dominante aparece fragmentadon dividido e espalhaton com uma

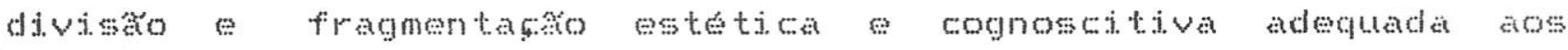
propositos dessa hegemonia.

For ontre as falas de Maurio sogaliotamse os pontos a que 1. atribui. maior importancian Un deles a a intença de combater o que frequentemente acontexe nos museus quando somente os privilegidos do saber eda cultura possuem os codjog necessarios para decifrar as mensagens e obter a fruitro estetica experimentando un sentimento de pertencer ao meiog oposto a sensacto de exclusaco experimentada pelos outros " A sua ideia é de que os museus deixem de ser "Templos das Musas" "e transformense en Casas do Fovon passando a intervir de forma ativa no processo

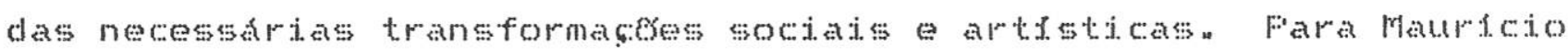

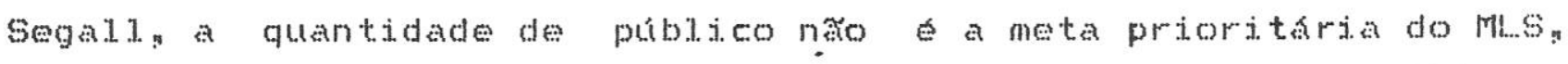
dando-se mais jomportancia a funçáso efucativa dipigida ao publico alvo com quen se quer trabalhar e estabelecenclo cono objetivo principal o de se chegar a relaço museuvida em substituigo a museu-escola 
Diante da questao da centrajzago da cutura posicionase contrario ao gigantismo de un beabourgn por exemplo: que romo diz, representa o desejo frances de ser o centro do mundo culturat, - sempre pensou no mis cono un modelo de descentralizasaro. Considera a principal fungró do rlt.s a de ser um museu piloto de tal. forma gue sua experiencia seja motivadora do surgimento de iniciativas semelhantes en outras instituiçes que atendam outros batros ou ate mesmo outras ciclades do interior ou de outros estados "Sua conviçso of a de que a descentratizaso de todos os eventos cuturais n em todos os niveisy e o unico caminho para o atendimento das necessidacies cuturajs de todos os segmentos da

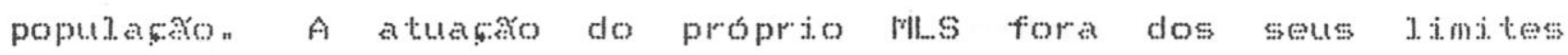
goograficos vem ocorrendo principalinente na presença de Maurio segali ou de representantes do museu en congressosy e na ajuda ss atividades oferecidas ao púbico quando da abertura do frarqu Modernista tambon localizado no bairro de Vila Mariana Esa construsaro foj projetada por warchavehikg expoente da arquitetura moderna e concunhdo (as suas mulheres eran irmass de Lasar Segall, expoente da arte moderna.

For outro laclo Maurtio segat dectara seus jomigos abertamenten esforsa se para combater a ameaça de massificaso imposta pelos meios de comunicasto, propondo una luta pela sua

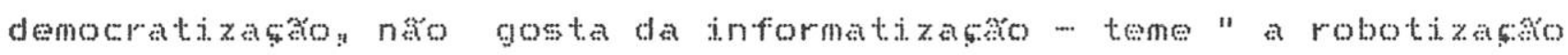
decompente do reinado absoluto da tecnologia que o seculo XXI aneaca para nossos fi.jhosa sendo que devenos fugir da tentagro tecnocratica "-- tem ojeriza a mareting cultural que trata a cultura como produto a ser consunido e confunde o aspecto mercadologico de suas lojas com educago

Seguindo-se por seu pensamento, para um museu gerar cultura to necessario trabahar com a sensibilizaço do indivfduo, sendo que este deve ser preparado e conscientizado para se tornar um agente ativo da realidade os aspectos fundanentais da atual museologiag presentes nos debates contemportaneos; tratam segundo suas

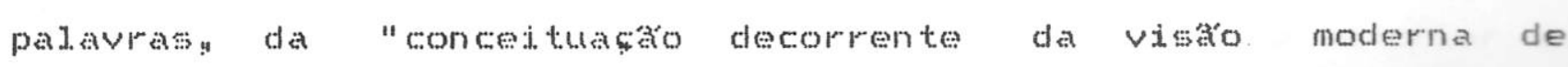
preservaçaco de patrimtonio culturalartistico centrada na funcao 
social. do objeto preservado sintetizada de forma mimplificada peja noţo: 'O passado a serviso do presente no preparo do futuro', que procura integrar os tres momentos no tempog e mais especificamente a preocupacko de que o espaco e o objeto preservados sejam 'usados' contemporaneante no processo de conscientizacho do indivfduo 0 seu 'uso' 6 defindo agui como j.nstrumento da esfera racionalsensibi.i.zadora econseidentizadora atraves do "pensar/emocionar" " Ou sejay o ben-widar do testemuno historicon lido este atraves do fituro da sensibilizato do individuo para a transformaşo da reatidade concera" "E prossegue, no mesmo texto preparado para o encontro de museologia

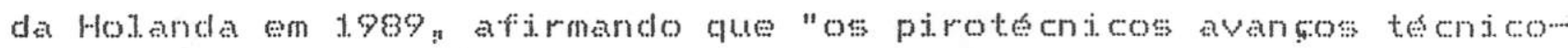
arquitetonicos da museogratia nâso sáno decorrentes dos necessarios avancos conceituas/filosoficos en nivel da museologian mas sim os substituen, mascarando sua inopertincia reat no enfrentar da modernidade" "

No dialogo entre frequentador e obra que deve ser carrogado

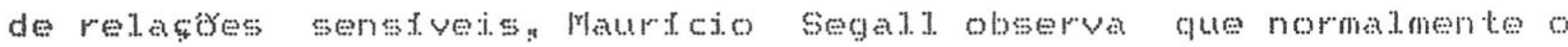
objeto tem prevalencia sobre o frequentador sendo que os dojs saco partes de un mesmo todo. Fara elen o conhecinento da realidade deve ser adguirido atraves da sensibididades pois o ato de emocionarse com manifestaçes artisticas torna as pessoas mais "sábias" - há una incorporaţo e esse novo conherimento vai. se sedimentandon

Ferguntado sobre o que se pode fazer para ativar a

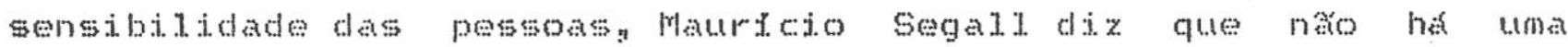
formula deve se experimentar: e como uma das principajs functest dos musess no terceiro mundo a a de colaborar na formacko da consciencia social, a tarefa jmediata gerian entán a de começar a programar o que experimentar e as metodologias a serem empregadas.

Procurando concentrar e documentar as reflexbes geradas no MLS idealizou-se o CEICA - Centro de Estudos Interdisciplinares em Expressoes Cuturaje Artisticas A Antencho era a de se criar um espaco interdisciplinar que trabalhasse as diferentes linguagense 
açes criativas decorrentes da pratica do museu lasar segati "e pesquisasse as atividades do publico frequentador estabelecendo criterios de analise experimental everificando os mectanismos de produçato reproduço simbolica da sociedade. En conformidade ao pensamento de l...sar Segall de que "devemos por todos os meios ao nosso alcanose tratar de langar uma ponte entre o pubidico e os artistas" " os funcionarios do pll.s irian pesquisar suas atividades encuanto agentes modificadoress mediadores de toda mensagen aço ou polftica cuturaln Forem o cETCA náo chegou a existir. permanecendo apenas o desejo de se constituir un orgáo para pensar sobre o museu e coordenar publicaçes sobre a sua producho intelectual.

Freocupato constante de Maurcio segall th a de que o museu nå vire uma empresan naso se transforme em negocio como vem acontecendo com certos museusy com a criasko de 10 ass restaurantes. Teme que a se promover a venda de objetosy essa funçon que deveria ser secundarian passe para o primeiro plaron sendo que quen compra nao estabelece vinculaço com o museu al em

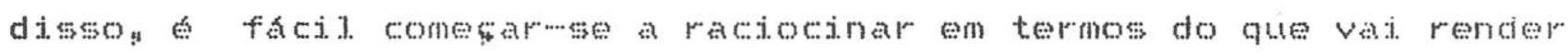
dinheiro. A desculpa de sempre fe a de que as iniciativas de vendas sao "en beneffcio do museu" diz Martejo segal. que acha gue os museus deven ser Jugares de resistencia alternativos " nám ceder

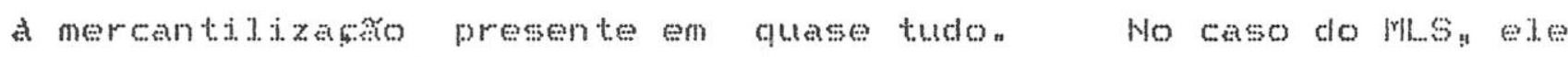
aprova apenas a venda de pecas que promovam a divalgagaso da obra de Lasar Segall. Acredita porem que os museus de hoje precisan se auto-sustentar: náo devendo mais ficar na dependencia do Estado "e exemplifica com o governo britanicon que pretende tirar o Estado de tudo privatizando ate mesmo o metrt. Fara tanto defende maior incentivo a iniciativa privada quando esta doa a museus. o que favoreceria a aça de mprestrios como Jose rindilim que tem interesse pela cultura e poderia aplicar maise se beneficiar mais diante de incentivos mais estimulantes penquanto a Lei Sarney dá "total liberdade" a iniciativa privada aplicar o seu dinheiron. 
Como a FNF sofre cortes de verba a as vezes so pocle manter os

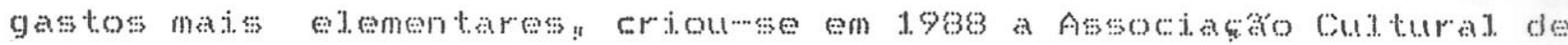

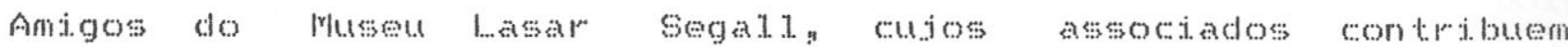
regularmente a fim de colaborar para o desenvolvinento das atividades do museu sendo que o conselho da associagáo pesolve o que sera fejto com a verba arrecadada os socios possuem descontos de $50 \%$ ma compra dos materiats vendidos pelo mas tatis como rejmpresses de gravuras de l.wsar segall e catalogos o podem deduzir suas contributçes de seu Tmposto de Fenda nos termos da

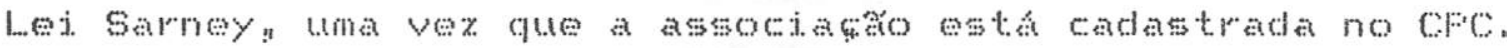

A construça de um predio no terreno ao lado do mil..s que ampliaria mo muto as possibilidades de atuatro do museu

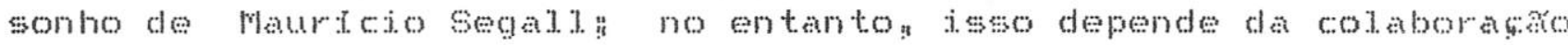
da iniciativa privada

Ass reunioes ocupan importante espaco dentro do processo de administracto desenvolvimento do Miss a possui funçes de assessoria e decisa junto a diretoriat discutindo questess como as solicitaces de emprestimo de obras do acervoy o contento conceitual para o projeto do centenario do nascinento de segalin o reforso das atividades de gravura e a suspensán da pintura no atelier aberto do museun A reunia gerah ou assembleia de funcionaros em princtpio naso deliberativa mas colabora para direcionar algumas resolucoes qualquer assunto pode ser colocado na pautan que obedece a uma certa ordem.

Esta reunia e oficial "faz parte do regimento interno tendo

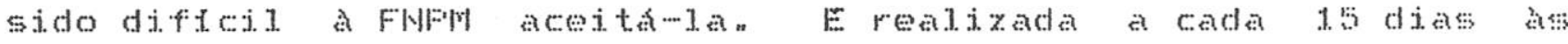

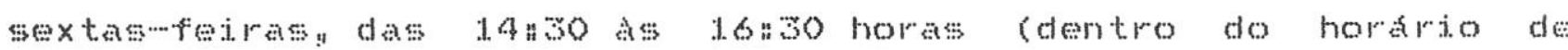
trabatho dos funcionarios para que todos comparectan) nesses dias

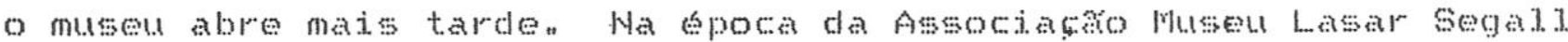
havia tamben reunioses gerais. poren eram mais esparmas As reunibes tem Iugar no auditorjo do museun os funcionarios e Maurcio segali sentamse mas catedras enquanto duas pessoas posicionarise no palco -.. o coordenador da reunico e o secretarion que $\Leftrightarrow$ responsavej. pela ata " os encarregados dessas duas funçes 
mudan toda reunison de tal forma que os proximos saso sorteados ao termino de cada encontro. 0 andanento da reuniáse da inicianente com a leitura da ata da reunia anterior: depois passame aos informes como acertos de pagmento e noticias da

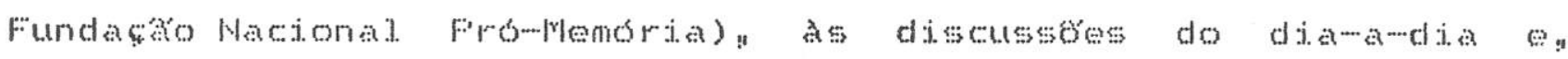
finalmente, as discussyess substantivas: no caso de se planejar uma festa interna por exemplo, conversawe sobre os objetivos da festa como vem se dando a confraternizaso dos functonarios do

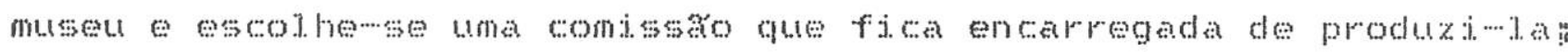
normalmente se discute quats so as prioridades do museu e se chega messo a questionar o porque de alouns terem hora marcada outros naso.

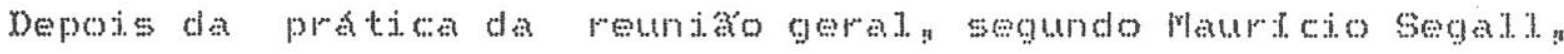
diminutu muto a conversa tipica dos corredoress permenda por intrigase fofocas esse processo coletivo de participacerom que se discute tudo leva a consciencia do que a instituisho de

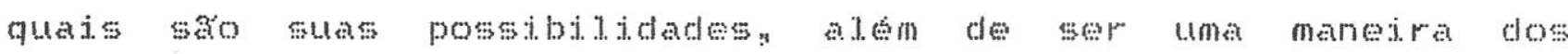
funcionarios saberem mais a respexto do museu em gerat ex estarem capacitacos a informar corretanente os usurios o museu consiciera que qualquer funcionario tem algo de positivo a contribuje a possibididade real. - a mesmo a necessidade - de eles participarem das decisos aumente ontusismo no trabaho e diminui a rotatho

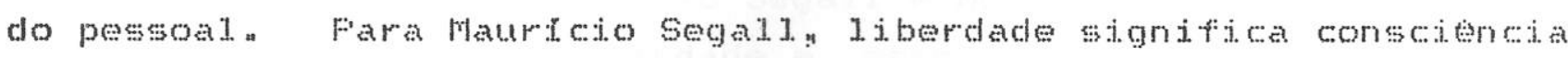
das aternativas e possibilidace de escolha atraves do exercteio cia sensibitidade. E jsso o que ele pretende que seja desenvolvido nas reunibes q que tambem evitam a alienacko dacueles que trabalham eso conhecen sua tarefa forem, fot prectiso persistir no esporso de prosseguir nas reunibes " pois "segundo o diretor normatimente se desiste na segunda tentativa a democracia e un processo dificil que lida com divergencias e diferenças.

- encarregado da Seçáco de Serviços Geraisa Dario Mata siriaco, acha que ha reunibes boas e outras "mujto chatas" mas existe o espaco para falar o que se pensan fato que náa acontece em outro lugary e "muita gente aprendeu muita coisa no museu" Admitido ha oito anos para fazer a limpezan este foi o lunco 


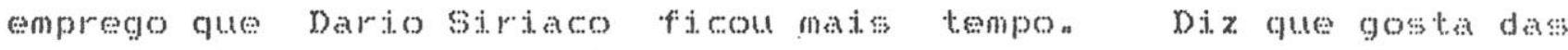

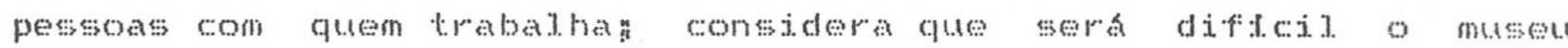

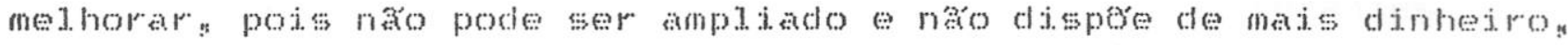
sendo pegueno mas aconcheganten Na verdaden o gue se perebe que os funcionsrios gostan do museu e falan dele com carinho.

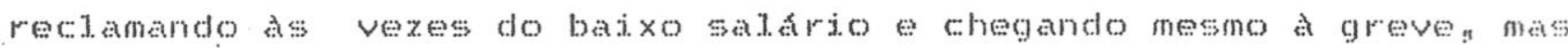

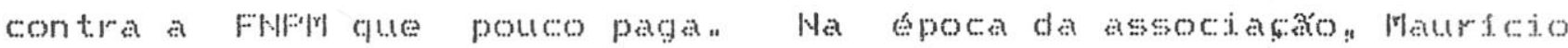
segal. andava nervoson com a despesa toda por sua contan mas

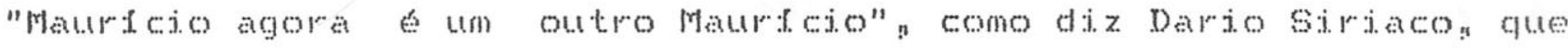

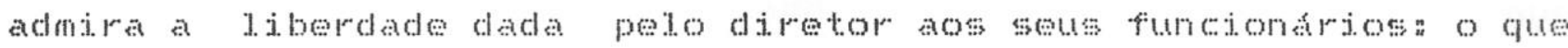
Vale a palavra de cada um - nä se exige sequer a apresentaço de un exame modico para justificar fat tas a

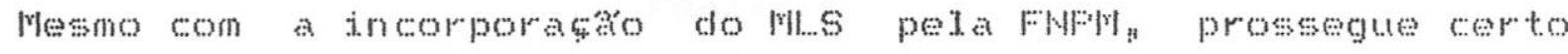

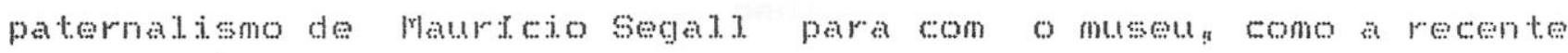
donço dos projotores de 35 mo o o pagamento da festa de fim de ano

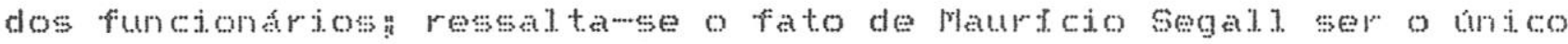
di.retor da Fromeremorja sem receber salurion

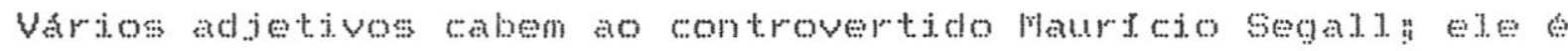
tido como democretico e autoritarion uma pessoa habil e jnteldgente com forte natureza personalista que se firma en alous pontos ex

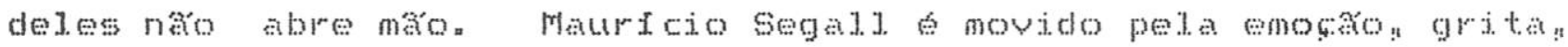
xingar क् crescer emotivö seu envolvimento afetivon ald ado ao otimismo gue o caraterizan tem ajudado o museu a continuar sobrevivendo e a

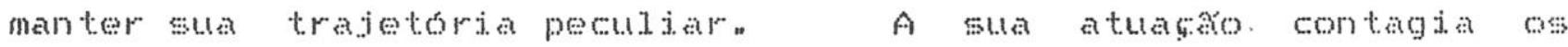

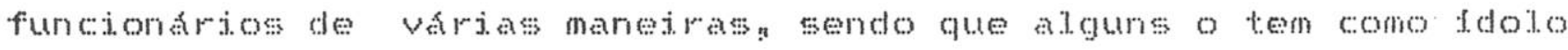

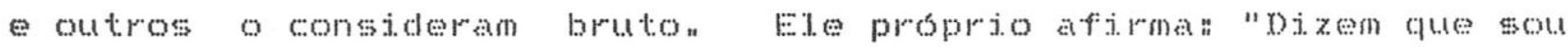

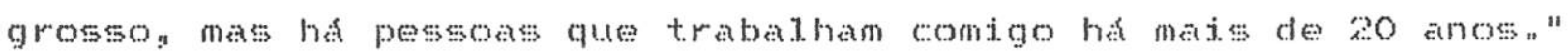

A habilidade sedutora de Maturio segall causa certa dificuldade para as pessoas que pretendem enfrentalo. E. de trazer efomentar discussess convicto de que por mejo de as os

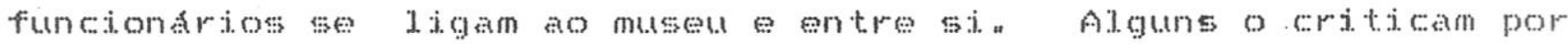
ngo admitir nenhum artiftejo para atratr pessos ou consegur dinheiron defendendo una musologia purista que năso estat de acordo 
com a realidade do pals, anda mats quando os museus de todo o mundo alugam seus espaços para eventos de firmas a contan com patrocinacores promovendo exposicoses possum restaurantes como forma de ganhar dinheiro de reunir as pessoas que se acostuman a programar lat seus encontros sociais n Rum o questiona diz que no Mi..s so se acimite mervir o alimento espiritual.

Wa vercaden Mauricio Segala vive um dileman poiss o funcionamento democratico que implantou no museu restringe as

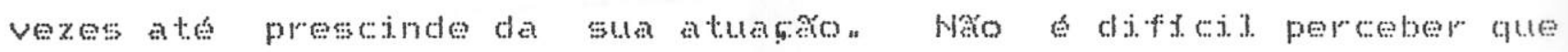
Maurtejo segast gostaria que todosn funcionaros e visitantess introjetassem a viessem a propagar a jmagem gue ele tom do seu muse -.. ao qual dedicou grande parte de sua vida - aborrecense quando se defronta com una realidade que sente como adversa esbravejando mas 1090 depois pedindo descupas en atitudes que externam seu espirito ambivalente.

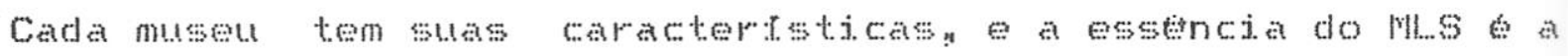

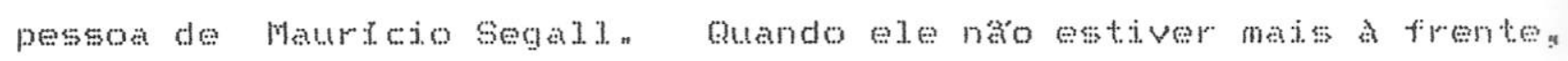
provavelonte o museu sera outro" Maurcio Segall porma no admite isson afirnando que ha pessons plenamente capacitadas a dar sequencia ao trabalho desenvolvido ate hoje. 
4. CENTRO DE LAZER SESC FABRICA DA POMPEIA

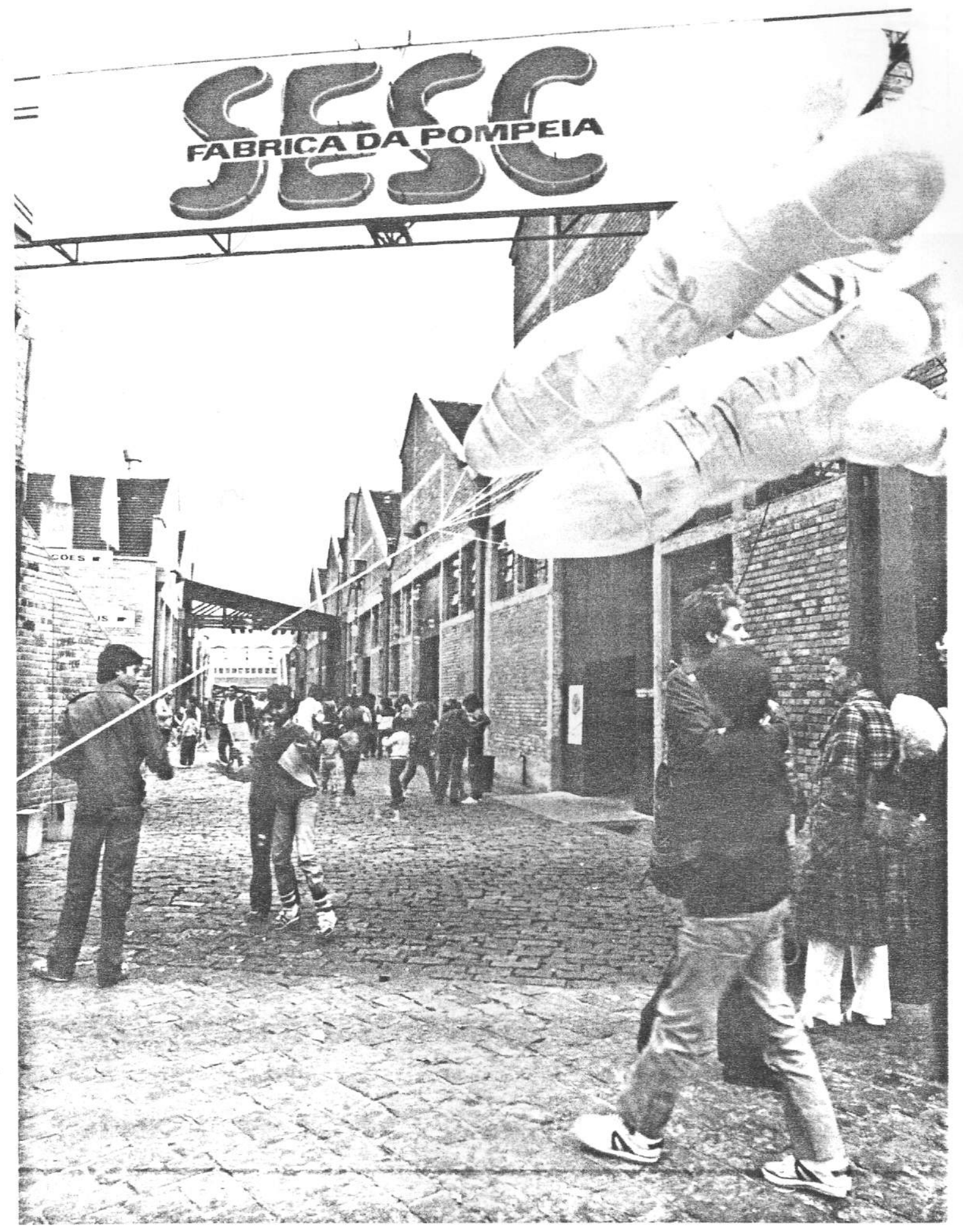

Entrada principal, com a rua interna e os galpôes culturais 


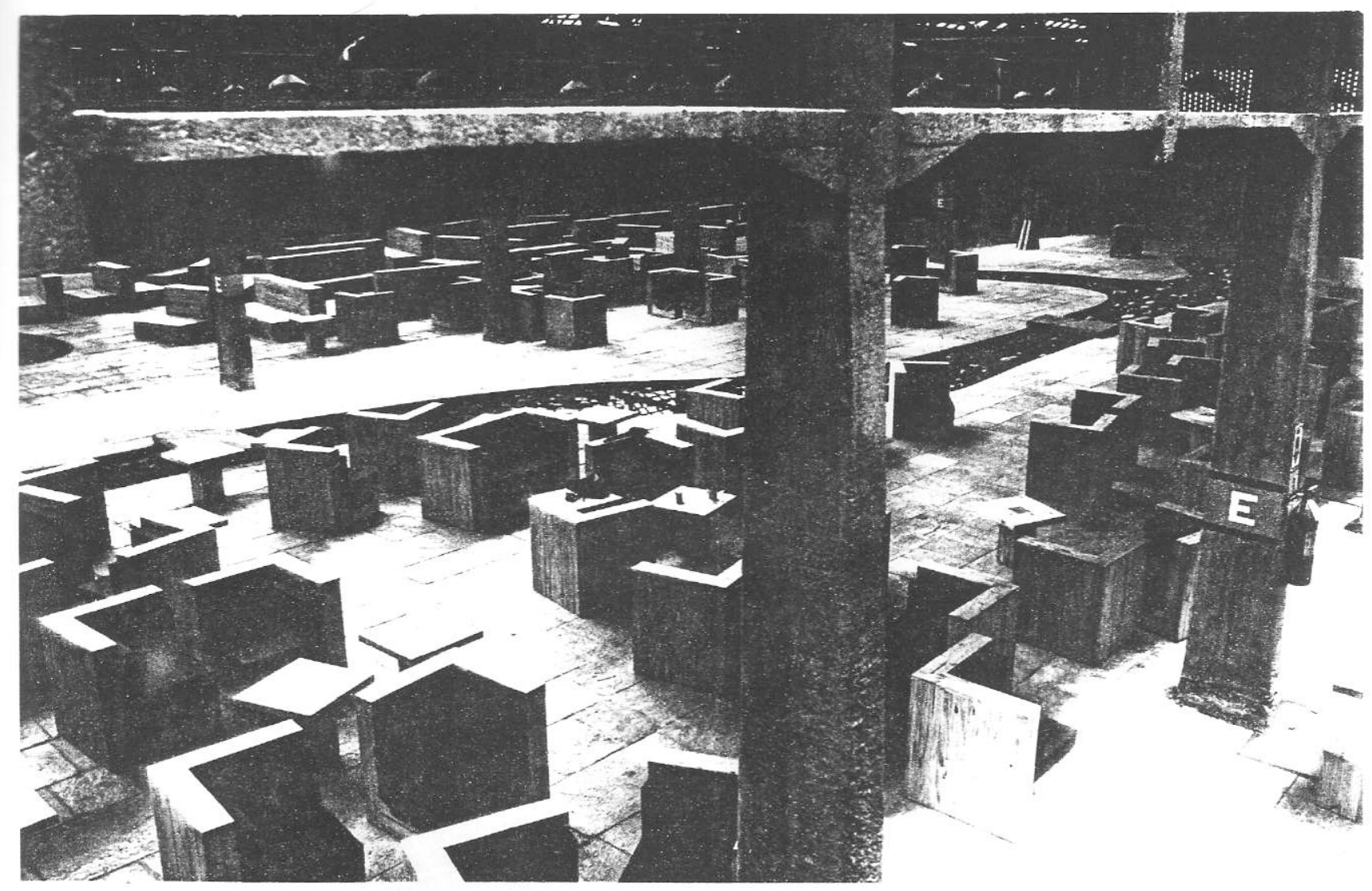

free de Convivencie 


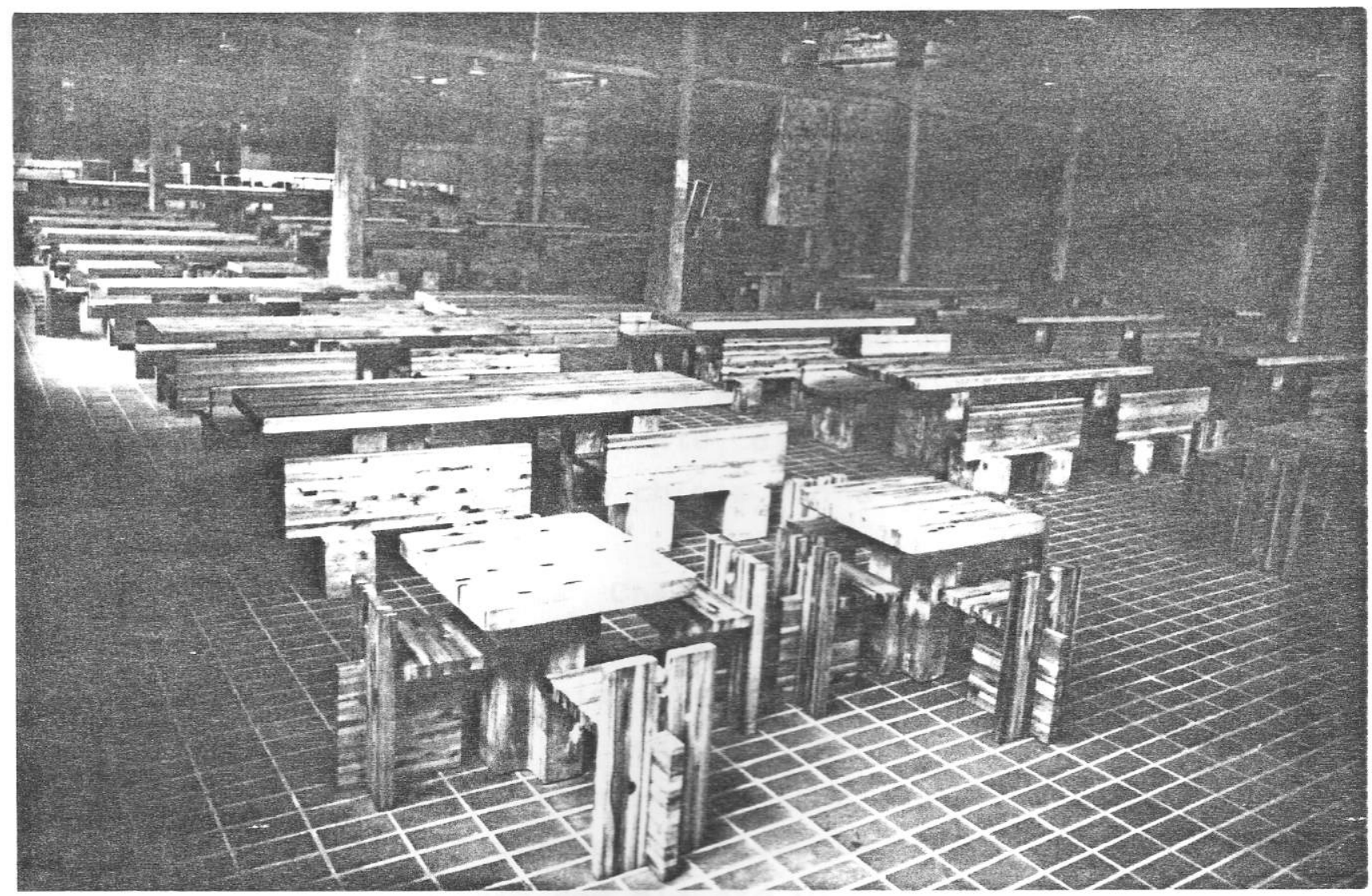

Restaurante e Choperia 


\subsection{Perspectivas para uma Velha Fábrica}

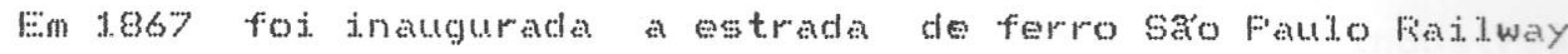

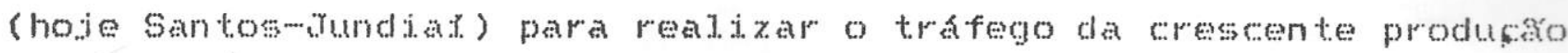
agricola principalmente a resultante da cultura cafeedran que vinha do interior do estado. os engenheiros inglesess vindos inicialonte para a construgho da estrada de ferron se adaptaram a regia perto das estapeses alugando e comprando easas ou chacaras ! - bairro da Lapa comecava a modificar a sua condicho de suburbano. Os britanicos tinham o tijolo aparente como pactro de construstio jndustriat. encontraran mutos oledros no lugary gue utilizavan o barro especiat do rio ritete assim surgim os primejros galpos fabris ao longo da ferrovian a regato foi tomando o aspeto de uma Manchester tropical.

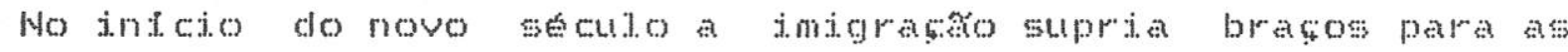
1.avouras do cafo paulista e para plantar as chacaras da periferia onsten escutavame frequentemente dialetos italianos nas ruas dessa regian onde a Saro Futo chique vinha buscar seus al inentos.

Os antigos terrenos da Chatcara banands pertencente ao bara do Eananat. (que da nome a rua limite do sesc wompeia) form comprados em 1911 no intejo da era dos loteamentos urbanos pei Companhia Urbano Fredial e passados a Daniel Heydenreich por

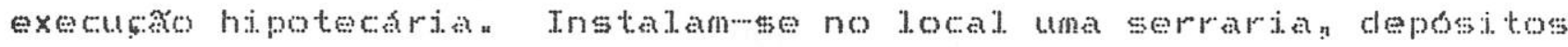
e gargons. sendo que Adolf Heydenreich: parente de Danida adquire a proprieclade e permanece com ela ate vir a falecer em 1933. rrotis anos depois a firma alema Maser \& Cia Ltdan compra o lote de sua viliva.

E.m 1938, baseando-se num projeto ingles importado, indeiouse a constructio da fabrica onde hoje se insta o centro de tarer $5 \mathrm{se}$

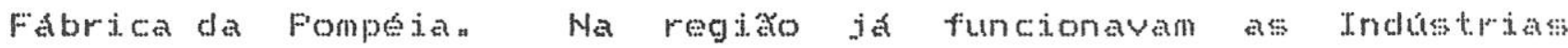
Feundas Francisco Matarazo, o Curture Franco Brasileiro a Trol entre outras. No ano seguinte a Maser muda sua razo social para Fabrica Nacional de Tambores acaba sendo desapropriada durante a 
segunda guerra com os Masser voltando a Alemanha os documentos e

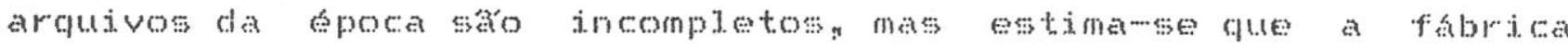
tenha sido leiloada en 1945, surgindo como proprieteria a rnduts.ja

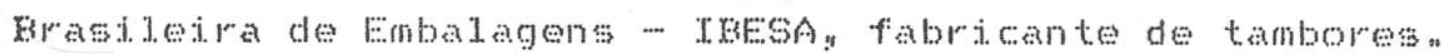

Fosteriomente a JBEsm recebeu en seu espaço a sinha de

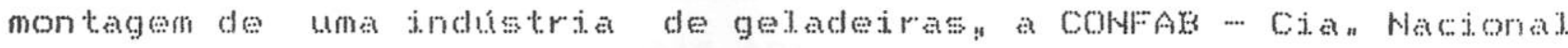
de Forjagen de Açon que fabricava a Gelomatic a querosene se depois eletrica alem de almoxarifados depositose garagens ate o final da decada de 60 era ben conhecida a fabrica de geladeiras junto ao antigo hargo da Fompéia ponto obrigatorio de linha de tonibus "e quen vinha do interior do estado passava forcosamente ao lado delan

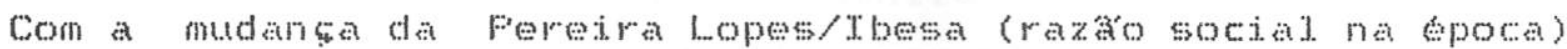

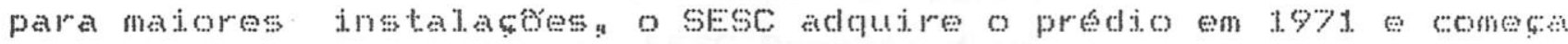
a utilizato improvisadamente em 1975, adaptando quaras esportivas, un pequeno teatron e espacos para cursos a atividaces de doningon Apesar da precariedade das instatacos a observavawe que o publico se sentia bem naqueles velhos espacos comegndo a surgir entan a ideta do restauro E apos quaro anos de uso adaptan, 5 sesc fecha as portas da fabrica com a deciso de recupera-ian

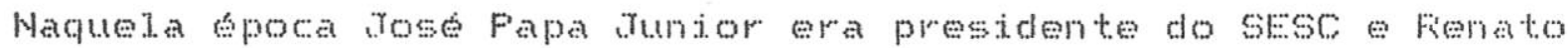
Fequixa o diretor regional. que havia visto a restauraca de conjuntos fabris em viagem recente a Europa $\cdots$ tendo assumido o cargo no intcio de 1976 apos fortes convuseses na institutanon o trabatho das unidades Moveis wnimos correspondia a $70 \%$ dos atendimentos do $5 \mathrm{se}$ a difusao repercusso das suas realizacoss nos jornass conferia força ao diretor da area porting como consequencia de rixas nas disputas pelo poder interno o sEsc optou pela desativaça do projeto unImos passando a atuar apenas nos seus espacos. A propria nomenciatura dos tecnicos foi posteriormente modificada passandomse de orientacor social, que era aque 1 que formava os grupos na comunidade, para animador culturat. o trabalno com o idoso foi o tunco trabalho social que permanecen . 
A presenga de Fento Fequixa foi determinante para o SESC, pojs imprimiu a entidade uma diretriz de funcionamento baseada no teorico de Jazer roffre Dumazedier - que vinha a sá Foulo dar

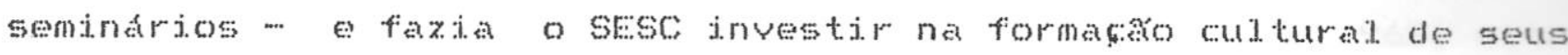

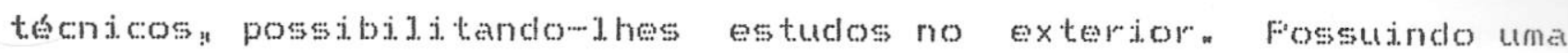

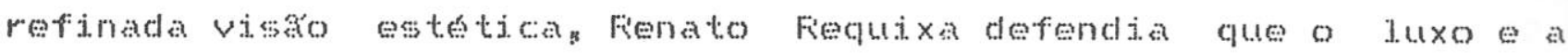
arte deverian ser possibilitados as pessons simples. a degando que o contato com una cutura mas aprimorada poderia muda-1as suas consideraçes oram feitas prineipalmente en defesa do centro Campestre de Interlagos (inaugurado em 1975), cuja sofisticacă, cliz.ians poderia afugentar as pessoas

Aproveitando sua condiço de estabilidade dentro do SESC. que The dava a garantia de uma alta indenizaca se fosse deritido: Fenato Fequixa ousava se impunha perante o presidente fapa Juniory comentase que o SESC Fompeita un resultado meritorio do seu arojo. Ein sua tpoca on ginasios de esporte foram usados para shows interestacuas de musica popular brasileiran criouse o Teatro Fixinguinha (uma quadra do sesc vilia wova que foi. transformada ein palco para MFes e foram realizadas as freiras de Culdura Fopular (en 1976 e 1977, no SESC Vila Hova), com a venda de pesas artesanajs comprasas por todo o pats pelos tenticos do sesc. sendo que parte das pecas foj separada para a constitusio de un acervo de arte popular. No campo das artes plasticas o SESC recebia a assessoria do Frof "Fintro Maria Bardin gue era bastante amigo de Fenato Fequixa e programava exposiços no centro Campestre com o acervo do MAsF - Muse de Arte de Sáo Fauton

\subsubsection{Restauraçăo}

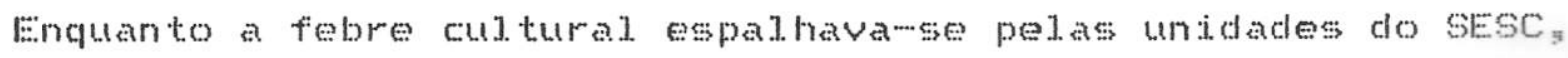
- arquiteto (faz questa do mascujino) Lina Bo bardi estava comesando o longo trabatho de restauracto da antiga fabricag considerado por mutos o mais fantastico projeto de sua carreira. Trazia en seu curriculo de realizaçess no pals o projeto de sua casa no Momubl. (uma caixa de vidro sustentada por delgados pilotis 
e escondida dentro de un pedaço de mata atjantican foi construfda em 1950 ali a arquteta vive ate hoje em companha de seu marido: o professor Bardig sua juma vinte gatos), o projeto do masF (ideadizado por Lina ko Bardi en 1957, e inaugurado en 1968, este prédio tomoume famoso pelo seu varo livre de 70 metros) e a restauraça do solar do Unháo (realizada em salvador em lgoz: transformando as edificạ̧⿻s seiscentistas num centro de cultura).

Wascida em Foma batizada nas dependeneia do Vaticanon a

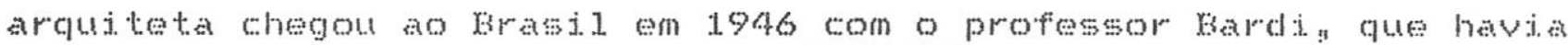
sido convidado para dirigir o futuro museu de frte de sáo fauto

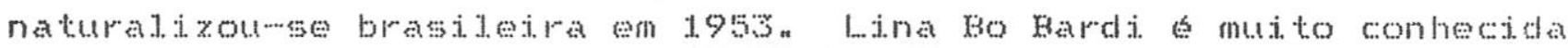
pelas suas dectaracoses desconcertantes g considerandows stalinista militarista e antifeminista ("a mulher e mis forte que o homern una criatura desamparada") nunca tirou ferias a ahando os domingos eferiados os piores dias na conta sua idade e diz nunca ter sido vaidosa, pois ja nasceu bonita.

Feito o estudo economico comparativo entre a construcko de un novo centro a restauracto da fabrica mostravase evidente a vantagem da conservaço dos gapoes, que era estimata em low do valor calculado pelo Servigo de Engenharia do SEsc para edificar una nova construçan cujo projeto seria de dulio Neves " o prazo previsto para a restauracto de Lina Bo Bardi era de un anon quatro vexes menor do gue o tempo que seria gasto para se erguer un novo centron Alem disto sustentavase a jobia que a permantencia da pajsagem urbana habitual. seria um fator de integraço comun tarka de vinculaça do individuo ao espaçog do ponto de vista culturat. alegouse que derrubar e construire substituir una cut tura por outra desvalorizando a que desaparece e supervalorizando a que surge, encuanto reciciar e somar culturas simul. taneanen t.e n

Fara o trabatho de restauro da fabrica e construcso do predio esportivo, l...ina Bo Bardi. teve a colaboraça de dois arputetos assistentes, Marcelo Carvatho Ferraz e Andre Vainer, e dos engenheiros do SESC, Antonio Carlos Martineli e Luis Octavio 


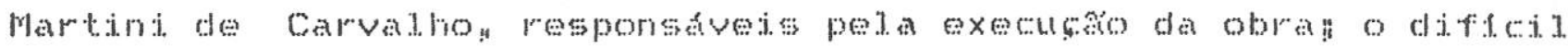

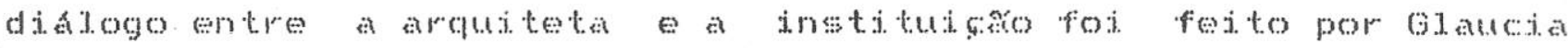
Mercess Amarad de Souzan assessora cutturat do SESC.

A restauracho dos galposes teve seus prinetpios e criterios bassicos fundamentas na carta de Venean documento guia que argutetos e restaudores apresentaran nesta cidade itatiana

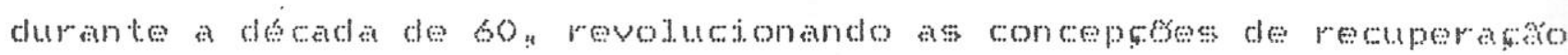
historicomatutetonicas vigentes anteriormenten Esta carta determinou que a reconstrucho dos monumentos edificaces ferta de modo a se reconstituir a maximo o modelo originat fosse rejetidat en favor de uma concepero dintmica que prevendo a evidencia da

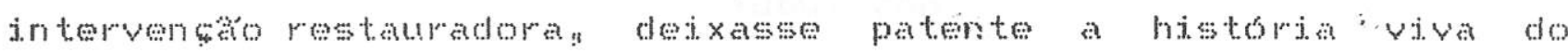
edificio e visfvess as diversas tentess mpregadas a tongo do tempon Assim a restaurato nato passaria mats a ser vista como uma reproducto fiel e imoved de uma obra secular mas siondicira a recuperata de un ambiente vital e vivon intavel ofentro de un espaco histomicon

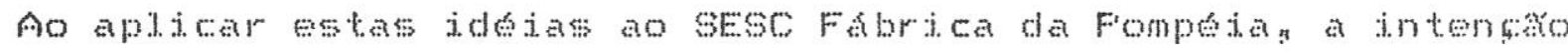
cle Lina Bo Bardi. foi a de evidenciar todas as diferentes intervonges e toonicas empregadas entre a construto originat a pooa da restaurato foderse notar onde as paredes de tijolos foram completadas ou remontadas onde se usaran trenden de colocamo diversas das originass de tal forma gue as cicatrizes contan nao apenas a propria nistoria da fabrican mas tamberm a

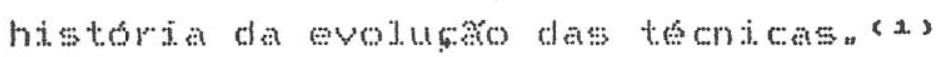

A arquiteta dizida que "naso se trata de devolver o predion como numa matuina do tempo. ao passado. Isto e preciso esciarecers porque a retromania esta tomando conta de tudo na no isso que estou fazendo" "Lina bo Bardi era rigorosa com a fatat de seriedade da sociedade de hoje que segundo ela poderia criar um surto de retromania capaz de gerar fenomenos como casas no estito

(1) obs.: O trabalho de restauraço realizado nos espaç0s do CLSFP estáa descrito no Anexo 3. 
"ruinas romanas" a assim como ja existidn no Morumbit fachadas " " " E o Vento Levou" " "O perigo e se inventar o passado. Nem tudo gue velho tem valor " " Ninguen vaj querer voltar as privadas turcas ou abrir máco da tornejian"

A reciclagem de todos os espaços da antiga fabrita foi uma experiencia brasideira de um ramo argutetonico que prodiferava nas grandes capitais de todo o mundon a arqueologia industrial. E: acrescida do "sentimento da naçon" que segundo os argutetos assistentes de Lina Bo Bardin reflete a preocupaço que ela tem com o pass e que esta presente em tudo que ela faz A restauracio do SESC Fabrica da Fompeia trouxe soluches ja presentes en outros projetos da argutetan como a tubulaço aparente utilizacia no masF e as janelas em treliça de madeira presentes no solar do unhan

A restauraço dos gapoes foi terminada apos cinco anos de trabatho pertodo bem mator do que o inicialmente previston sendo que nos dois primeiros anos lina ko bardi morou num barracko no Jocal. Ao finat os operarios sentian-we valorizadose satisfejtos com o resultado da obra considerada uma grande experiencia na gual. todos puderan nao apenas opinar mas tambem ver suas jdetas colocadas en pratica. Foram recuperados ao finat do trabajo 1.2n 200 ma de área construtda que ocupam parte do terreno de 16.500

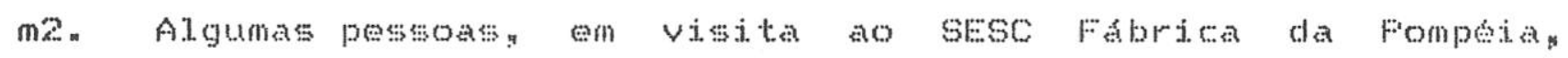
comentavan aos arquitetos" "Farece que vocts ná fizerar nata" : que eless refletindo sobre o assunto acabaran tonando como um elogio.

Eim entrevista concedida a revista Vejay Lina Bo kardi afirmava que a arqueologia urbana e a recictagen cultural sáo atividades distintas. "E cliftej. reciciar un espaso, conservar suas caractertsticas e, ao mesmo tempon trabalhar nele com concejtos modernos "E preciso ter medidas para todas essas tendenciass" E, voltando a insistir na necessidade de se perceber as diferenças ".. "se fornos tomar por principio absoluto o uso que fizemos do espaço da Fabrica da fompeda havera gente querendo recuperar e proteger una salada de edificios que săo velhos e nato historicos. 
Assim a cidade podera transformarme por excesso de zelon numa - cidade dos cacarecos' " o que náo e desejavel " E preciso deixar tamben florescer a nova arquitetura."

o espaco para o uso cutural estava pronto e estimavawse majs dois anos para a conclusáso do bloco esportivo que ao contrario dos gajpess nascia do papel. e apresentava uma arquitetura vertical para intencionalmente contrastar com a fabrican "Desta vez naxo usared janelas mas grandes buracos circulares nas paredesa como na arqutetura tradicionat do antigo taparo. Foren ná tenho nostaloja de qualquer spocan Minha arquitetura pode ser opjos nunca romantica" "disse Lina Bo Bardi.

Na verdade, a arguteta queria que o SESC comprasse o terreno ao lado, que na epoca tinha dois esqueletos de predios com a construçato interompida mas isto náso aconteceu porque di quantia pedida era absurda hojes oito anos depois o os predios foram terminados a alem dos apartamentos residenciais (que sempre reclaman do barulho dos shows da choperiag chegando mesmo a jogar garrafas no telhado da fabricas possuem un complexo de lojas que recebeu o nome de "Shopping Fonpeia Nobre" "

\subsubsection{Inauguraç8ిes}

Ds espagos cutturas dos gatpos foram sendo inaugurados sucessivamente no primeiro semestre de 1982.

A area de convivencia foi aberta ao público a partir do dia 15 de janeiron apresentando-se naquela noiten na regián posterior ao riacho sinuoson o grupo belga Flan $K_{n}$ o espetaculo "Menory stop" năo possuia mensagem, historia ou persongens, sendo constitufdo por imagens resutantes da impressáno que o nosso pats cassou aos belgas quando aqui. permaneceran no ano anterior. 


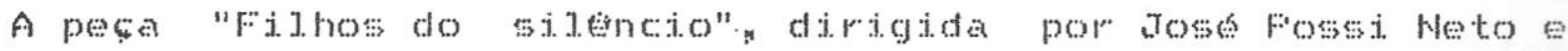
interpretada por Trene Favache, inaugurou o teatro a as de janeiro. como foi una pesa concebida para pateo itadiano e apresentava toda a linguager do universo dos surdosmudos deveria ser vista o tempo todo de frente, resulando na utilizacaro de so una pitatia ou seja, metade do teatron para desgosto de l. ina bo bardia que teve que se submeter at cleterminaço de 70 se fapa runior prestonte do SE:SC:

Fara realizar a primeira de suas grandes exposichos temations a arquteta levantou um tapune divisorio na area de conviveneian tomando independente una das quatro portas que davam acesso ao espacon esta decisang gue possibilitava mator atenço e segurang para as peqas expostas" bloqueou o uso dos banheiros que deveriam servir a area do convivencia e o centro de coriatividacle infantia passou a funcionar como deposito. No dia la de abrit a exposica "O design no krasil - historia e realidade" foi abertan reunindo pesss antigas que pertenciam ao acervo de colecionadores a mo ma e ao proprio SESC os obietos modemos e os projetos de desenho grafico foram emprestados por empresess industrias e designersy parte esta coordenada pelo wejeo de Desenho Industrial da FlEsf -.. Federacto das Industrias do Fistado de sao Fulo.

A mostra havia sido elaborada nos moldes das feiras dom sertoes nordestinos e dos supermercados patistas segundo l...ma bo

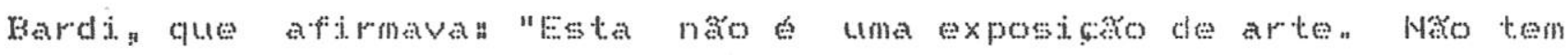
pecas valiosas en destaque nem a ' rarefaço' desses tipos de exposiçes. E uma enxurrada uma falsa confusaco rigorosamente planejadan For contingencias historicass o Brasil industriatizouse de repente, compelido, sem continuidade, dado imprescindivel num desenvolvimento organico."

As ofietinas do SESC Fabrica da fompeia indeiaram suas atividades en carter experimental a 17 de abrila oferecendo quatro semanas de aulas abertas para este projeto o slisc contava com os 28 intertores responsaveis pelas da oficinas de lazer e cultura 
que comecavan a funcionar sendo que o projeto de equipamentos e atuasao de cada oficina havia sido desenvolvido por especialistas de cada area. As propostas variavan de danga a tecelager e logo se notou a maior participasto dos velhose das criansass pois. segundo os instrutoresis "os adutos a inda tem un pouco de meto de semeter com arte" "

A inauguracto oficial deveria ter acontecido en marco, porén. por problemas referentes a agenda do presidente roso batista Figueiredon havia sado adiada para o princtpio de maion mas acabou ocorrendo somente no dia 18 de agoston

Un forte esquema de segurana fot montado para receber o presidente que thegou ao $5 \mathrm{SO}$ Farica da Fompera acompanado de varios ministros ede Tose Frap Tuniora arastado do stesc para se candidatar ao sendo pela legenda do fos eque viaiou com ele de

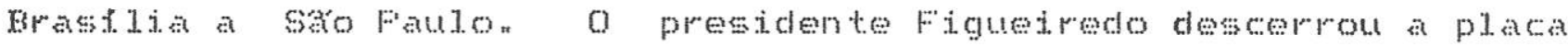
inaugurat ao som do coral sfes: regido pelo mastro water Lourenço: na placa havia referencias a restauraso da fabrica do SESC, "transformada en centro cultural e esportivo para o trabalhador" e se constituindo em "homenagem a menoria urbana da metropole paujista" "

Em seguida falou o enpressio Abrahan szanang presidente em

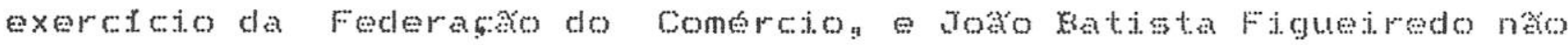
fez o discurso que todos esperavan, passando a cumprir imediatamente a programago da visita Ma ná teve chances de ver o que the foi preparado -- una exposicto fotografica sobre sao fauto e os trabathos artesanais realizados pelas oficinas do sFso tantos foram os cumprimentos! abraşos a atografos desentendimentos entre sua seguranç e a imprensan

Em janeiro de 1.984, pouco mats de um ano depois da derrota nas urnas a Jose Fapa Junior saju definitivamente da presidencia do SESC, lugar que ocupava desde 1969, deixando fbran Szajman no cargo. Sem o amparo de Fienato Fiequixa Lina Bo Bardi permaneceu no SESC ate o finat de 1985 cutando da construcko do predio 


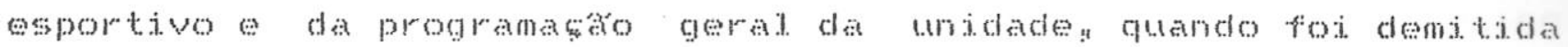
devido a desentendimentos com o novo presterente

0 conjunto esportivo foj inaugurado a 30 de outubro do 1936

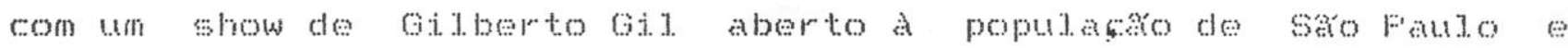

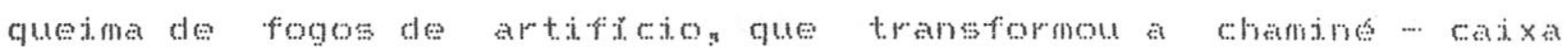

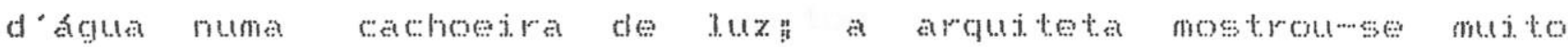
aborrecida com o si:sc" que havia inaugurado os prodios sm

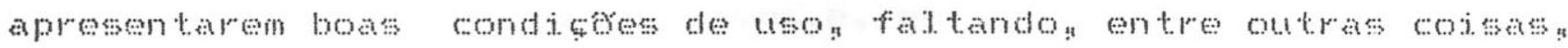

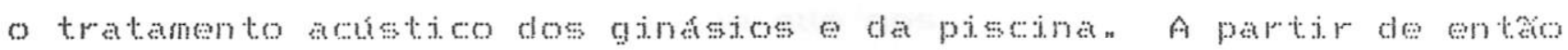

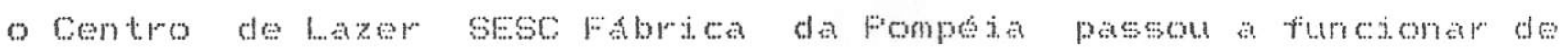

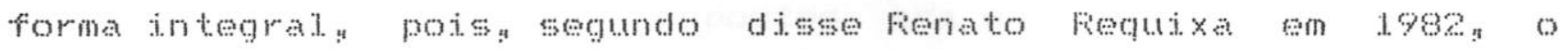
centro so estaria pronto com a abertura do nucleo mportivon "rian

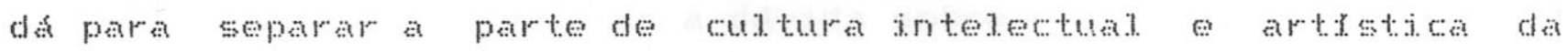

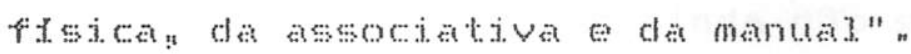

\subsection{Expectativas e RealizaçBes do Centro de Lazer SESC Fabrica da Pompeia}

\subsubsection{Rue se Esperava da Pompeia}

Wa tooca da abertura do sEsc Fabica da Fompona havia no Central. un departamento chamado celazer -. Centro de fistudos de

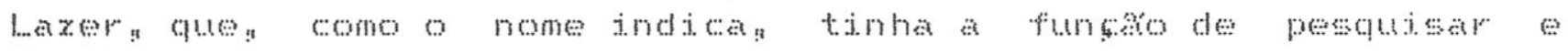

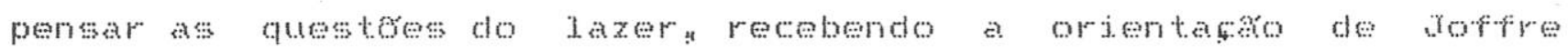

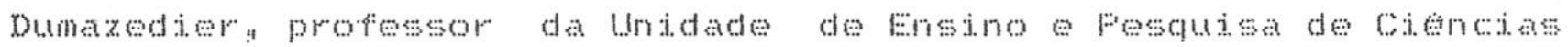

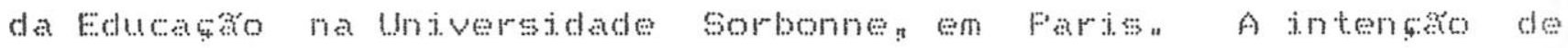
Fenato Fequixa foi a de que Dumatedier pudesse informara formar e

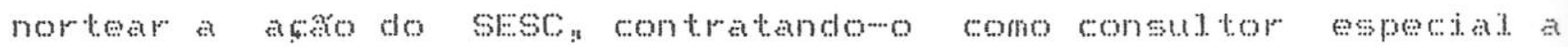
partir de $19 \% 8$

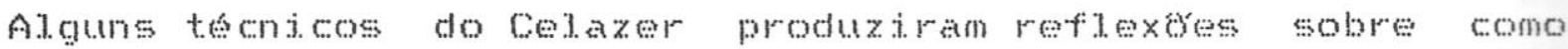

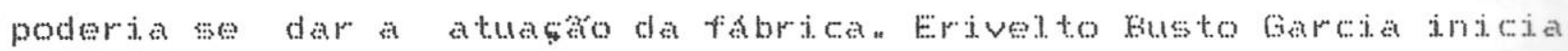
sou texto "quo vadis pompeja?" afiomando ser a Fabrica da Fompeian

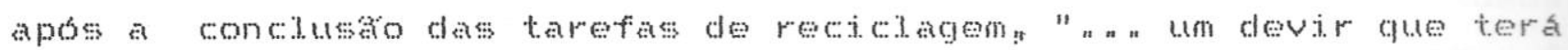

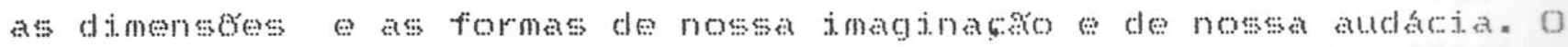
que a transforma num grande desafio o numa maior ainda 
responsabilidaden " o que jmporta f que estejamos seguros de que efetivamente nossa aço seja inovadora a cada momento for fore "no

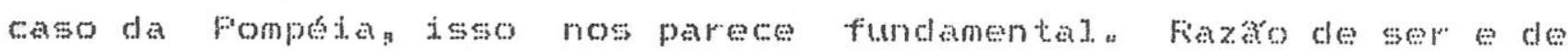

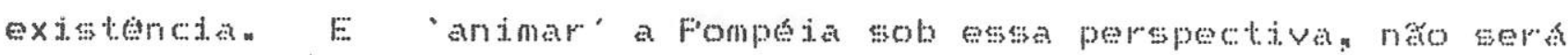
tarefa facil. Mas "onvenhamos năo se realiza un projeto desses impunemente " Adiante propoe o estabelecimento de algurs pressupostos que "possan orientar a aço cultural en todos os momentosy em todos os nivejsy em todas as areas a que traduzidos operacionalmente, possan se constituir em mecanismos que posicionem

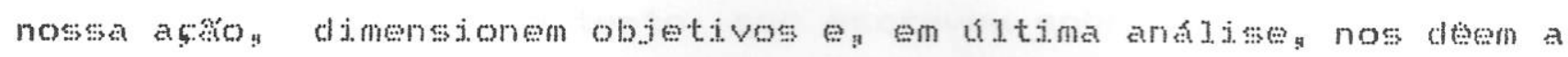
certexa de que avanganos rumo ao que nos propusemos"

o primeiro desses pressupostos era o de que a Fábrica da Fompeja 6 un equipamento de ponta que tem a inovaço como valor" "Assing quando nos assattar a duvida sobre o que fazer" a resposta

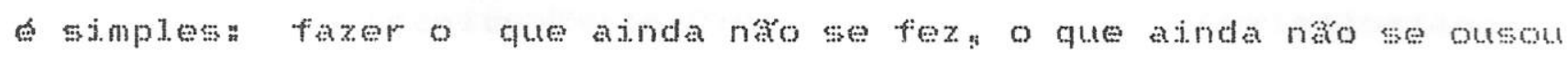
fazer" o segundo pressuposto era o de que a Farica da fonpeja um patrimonio culturat da coletividaden "Considerar a Fompeia mats una unidade do SESC h restringir significativanente ma potencialidaden Nao havera contracicaso dizer que a fompeia se destina a comerciarios en a mesmo tempon definir que seu publico imediato ná e necessariamente essen Atraves la Fompeian clarono SESC atendera su cijentela espectfjea mas num outro nively gerando modificando valores culturais" formando e preparando lideranças institujeses culturais que se reproduzira a nIvel da poputacko em gera] en naturalmente: a nivel da populacko comereiaria. Fun equipanento cultural que para ser rico precisa ser aberto espaco livre para abrigar todas as tendencias e movimentos culturais de forma inovadora."

o terceiro pressuposto referia-se ao publico da fompeia como sendo basicamente constituldo de criadores, de animadores e de

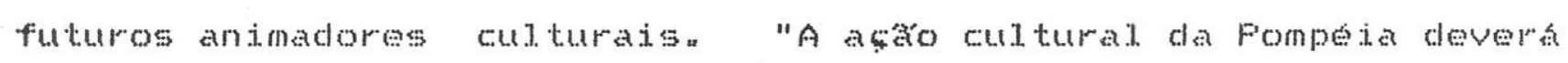
estar centrada no estimulo ao trabalino dos criadoress e na formaço - reciciagen de aninadores cuturajs publico de acentuada capacidade de productio culturat. de difusa de novos valoresn A ideia da producho cultural deverá sempre preceder, em importancia, 
a de consumo" 0 quarto pressuposto era o de que o campo rut turat na Fompeia teria una concepero abrangente e flexivel. "O entendimento do campo cultural. devera transemder as denominadas

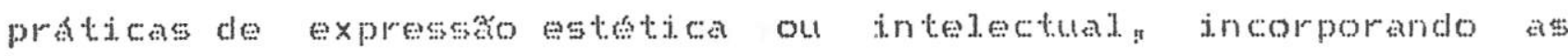

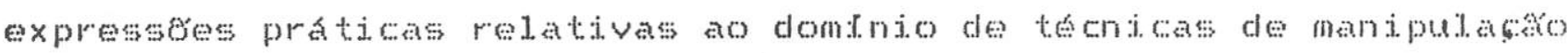

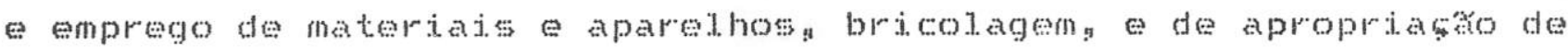
todo o sistema de objetose instrunentos que comperem o nosso totidiano"

Ao encerrar outro texto que escreveu sobre o SESC Fabrica da Fompeis g Erivelto kusto Garkia afirma que " " "os resultados e a

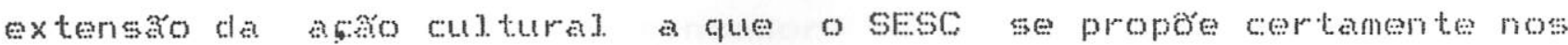

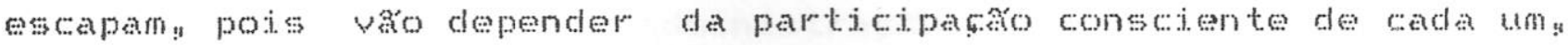
de toda a coletividaden mom todos os momentos e en todos os niveis "

segundo o tecnico Mario Damineli. "O Fompeia obriotoriamente tera que oferecer o novon mas necessitara tamber favorecer e incorporar os processos que levan at propria producko do novon No

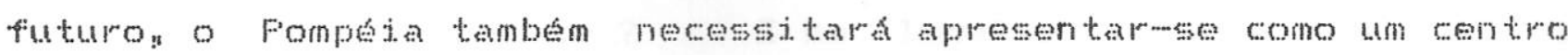

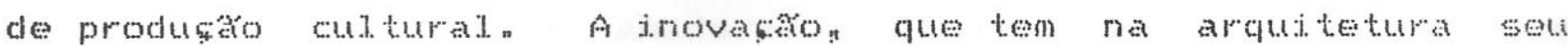
obmento original primarion sera garantida constantemente atraver de una dupla funço culdurata a difusáso a producko de novas formas eteticas "

Dentresuas sugestoes para o SESC Fompeian desus Vasquez Ferejra menciona o projeto para os ateliersa "Fartems do

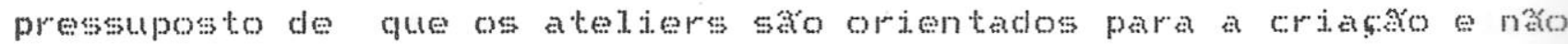
apenas para a criatividaden A primeira significa acescentar algo a cultura existente obietivamente" producto culturat. A segunda acrescenta algo a pessoa que cria mas náo necessariamente a cultura "De acordo som a criaçăo objetivadan todo processo de criacto deve ser um processo criativo e criador e se objetivar em un produto. o processo pelo processo e mais proprio das agncias educativas como a escola " Concebemos o trabalino nos ateliers sempre como criaçio objetivada e com cronograman portanto admintis stono" 
Em palestra proferida sobre o SESC Fabica da Fompeia (da qual.

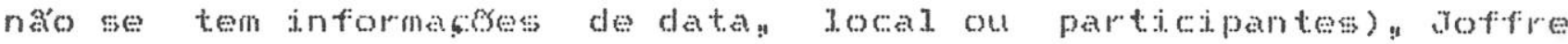
Dumateder referjume a uma vejha fabrica da cidade de mnecy na França gue tambem havia sido restaurada para se transformer em Casa de Culturan "Os centros de lazer giram en torno de un dos

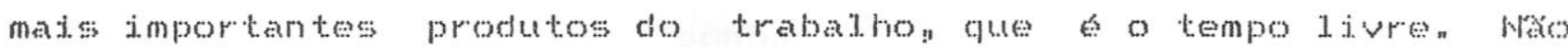
saco lugares destindos a productio de coisas de objetos de bens de consumo. Sao djerentes. Sao lugaress voltados a producho de pessoas. Weles as pessoas se produzen a si mesmas por so mesmas e para si mesinas" "

Nesta palestra o pensador francts levantou questoes concernentes a atugno administracko do novo centro do st:sc! perguntando-se procurando respostas sobre questoms capitais romo para que serve a Fompeian quais seus beneficiariosn qual deve wer e como reatizar o meu projeton alén de quem ira administrawon Alguns trechos de sua fala estro aqui reproduzidos:

"O que f a Fompeia? E un local onde se produz arten" Sobretudo una arte para amadores. E un Iocat onde se procura formar un publiteo amador da arte.

Mas para que serve a arte? Numa sociedade produtivista regida pelos valores da producto do consumo a arte náso serve para nada e incitil. For que, entron a Fompeia? Devemos ter. daf coragem de responder a Fompeda é importante porque e intit. numa sociedade utilitaristag essencial a valorizaço do inuti.

Dra, ha de fato um Brasil. onde a pobrexa fur fato. Náse pode nega-1o. Mas há também no mesmo Brasil outro problema que a soluço pura esimples do problema da mistera en nack ajudara a resolver E preciso estabelecer que has no lado do direito at alimentaşa a moradias ao trabalhon ha o direjto ao sonho, a imaginaçă a encantamento. 


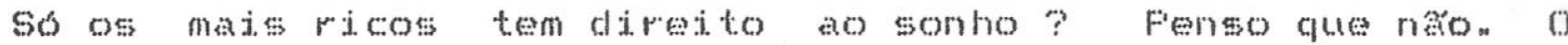
pobre tambern tem direito ao sonho. Ele tem newessidacle de paron mas tamben tem necessidade de sonho. As duas necessidades se manifestam ao mesmo tempo ecom a mesma forcan Ese o sonho ná substitui o păon tamben o păo náo substitui o sonho w Ha a necessidade o direjto de sonhar " preciso náso se intimidar diante das criticas ideologicas os revolucionarios polt ticos tem tendencias a dizer: voces ná tem o direito no sonho antes dese

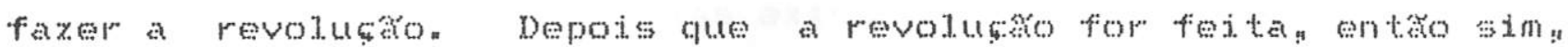
vamos sonhar" "Esse argumento dogmatico e fadso e deve ser combatido com vigor.

Eu repito minha questao. Fara que serve a Fompeia? A Fompeia serve para fazer sonhon para fazer sonhar com intensidaden

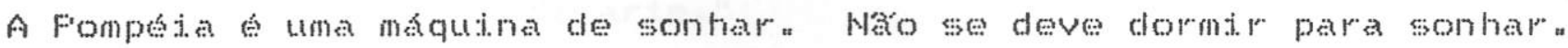
E. preciso ensinar as pessoas a acordarem para sonhar.

" " E urgente começar a diminuir o ritmo da corrida en directo ao consuno desenfreadon E preciso sonhar em ser mais gern lugar de

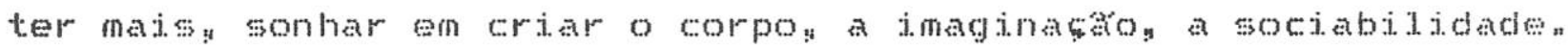

A Fompeia promete modelos novos de cultura ao menos para a classe media mas isso nac importan porque a ciasse median alem de formadora de modelos culturats e difusora desses mesmos modelos entre as outras categoriasn

- Eu diriag enfim. que a Pompera significa uma força de resistencian Fessistoncia a ocupacto do pals pela sociedade de consumo."

Adiante Dumadier fal a sobre as operacose que o SESC Fompeia deveria realizar quanto a culturan afirmando que o projeto de democratizaça cultural. náo deve de forma nenhuma ser abandonado, mas que era preciso ter en mente a dificuldade de se realiza-lon 
"A Fompéia deve contestar a culura de classes dominantesse sua hegemonia culturat. Deve anda revelar que ha dimensegs ocultas na arte cotidiana Ha uma arte de produço de obrasa mas tambem há uma arte de produçóno do bem-viver"

E. preciso sobretudo lutar para reduzir a distancia entrea

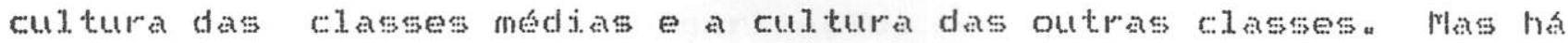
obstaculos diffeds para fazer iston espectalmente atraves do l. azer. Mesmo entre os artistas existem obstaculos m Mutos reduzem - Iazer a atividades medocres. dominadas pelo consumo. A arte para estes seria outra coisa diferenten Eis al um preconceito elitistan E preciso colocar com clareza que qualquer atividade artistica $e$ una atividade de lazer. para a grande maioria da populaçon a exceço de alguns privilegiados que podem viver do trabalho profissional da arten"

As palavas de Dumazedier tinhan grande importancia pois a sua atuaça como conselheiro na formaço dos ténicos do sfece ja vinha de alguns anos e aproximavase o momento da entidade oferecer seu principat centro de cultura a populason sabendowse que todo o aprendizado desenvolvido poderia e deveria ser praticado naquele $10 \mathrm{cos}$.,

"Ha evidentemente o risco de se cair na tentaço de transformar a Fompesia numa escola de arten corn alunos que pagam que a financiam. E como se fosse uma outra escola qualquer de belas artesn Seria un modelo apenas melhorado de formasaco escolar. Ha ainda um segundo mode10. Este náo do tipo escolar mas do tipo comercial-industriala a formaço é vendida como qualquer outro produto de mercado.

Anbos os modelos sáo inadequados porque náo suscitam um movimento social. E a invençăo da arte deve dar infeio a um movimento social. "Movimento social. que deve ser una resistencia. Fessistencia tanto contra o modelo esolar como contra o modelo de mercadon Movimento social destinado a formaģo de uma geraçáco de animadores voluntarios "E preciso fazer crescer o movimento de 
participaço voluntária, envolvendo pessoas de diferentes idades e classes e que tenham o proposito de contribur para enbelezar a vidan Esse movimento deve desejar fazer das pessons naso consumidores de espetaculos poren transforna-1os en artesasos de sua propria cultura artistican corporaly etc. o grande obietivo desse movimento social e o de contribur para transformar a sociedade en sociedade de vulgarizaçán.

A caracterstica principal desse terceiro modelo f que ele e o unico capaz de ser un movimento social de difusiaco das artes mesmo que ele comece pela classe modia. Afinal a classe media term um paped. importante na difusáo e democratizaço de modelos culturats "

E o pensador frances termina sua exposicho falando sobre a administraço do projeto: "Evidentemente" no primeiro momento podera haver uma direço tecnocratican Tsso tende a ser criticaclon Mas e preciso lembrar sempre que a tecnocracia apresenta duas faces. Se de um lado ela fe fascinada pelo poder e seu objetivo e poder. $\Leftrightarrow$ verdade tamber que sua segunda caracterfstica 6 a competencia. E normat. portanto, que de infejo a fompeia seja dirigida apenas por algumas pessoas competentes.

Wo entanto se quisermos que a Fompeia produza verdadeimante un movimento socials e bom que se inclua un dia -- isso ná precisa ser agora - un Conselho de Frogramaço a Fomperia. Esse conselho pode ser formado por artistas y criticosy animadores cuturais: pessoas ligadas a movimentos religiosos, a escolan etcn " E conveniente que ele integre militantes culturats itidos as institutcoss de base na sociedacten fi um convite necessario para o exito do movimento social que a Fompeia deve suscitar Ele pode ter carater consultivo ou deliberativon

" " Os pioneiros da fompeia maj do que qualquer outro corpo de animadoress de qualquer outra casa de culturay tem necessidade de inspiraço arojo." 
Conformese falava o Centro de laner SESC Fabrica da fompera tinha anda o carter simbolico de incorporar duas dimensess humanas fundamentas, a do trabatho a do lazer " E. segundo

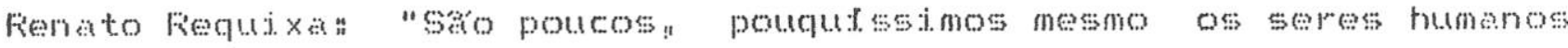

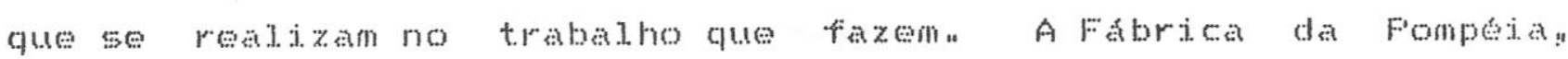
reciciada agora para local de lazery pernitira tenho erteza absoluta que mutas dessas pessoas se realizem como seres humanos. o dazer pode ser entendido nojen como un novo Humandsmo" Aguela undade do SESC difere de todas as outras en todo o brasiln frara nos, trata-se de um laboratorio de vanguarda onde as coisas naco mera feitas de cima para baixon"

Lina Bo Bardi nato escondia seu encanto pela fabrica achando que nela estava embutido o embriâno daquilo que mats perseguta em nome do nosso povon un espaço cuttural democratico. Um lugar onde ela pudesse realizar sua vontade mais rotima que era coroar o povo brasileiron integrandom en una estrutura que tamborm lhe pertencessen

Wa epoca da abertura foi distributo um livreto para os funcionarios que os colocava a par das linhas gerais da uridace do processo de restauratog do equipanento dispontvel en cada area e das intencos pretendidas na sua atugason bentre estas n destacavanse as seguintes" revelar e divulgar novos valores" formar especiajutas en lazer com cursos para animadores

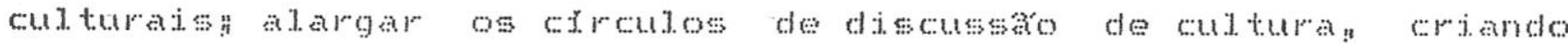

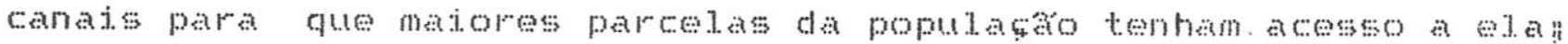

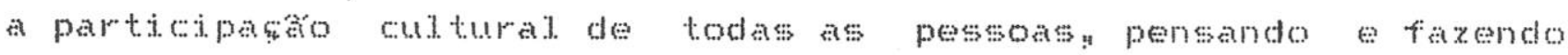
cultura fazer cultura atraves do dialogo permanente entre os tecnicos do st:sc e pubjicon levando em conta suas aspiraçes necossidades e nobilitar appectos menosprezados da rultura considerando legttimas todas as manifestackess quer sejam

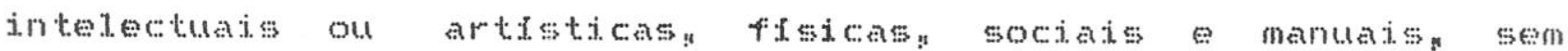
estabelecer hierarguia entre elas 


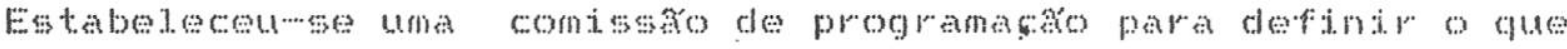
swria oferecido no langamento do sese fabica da Fompera e optou

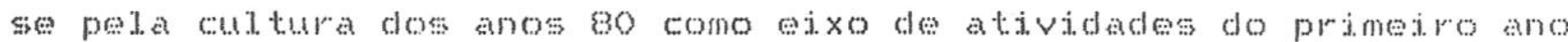
de funcionamento do entrog foram planejados eventos s seminarios. exposicoses atividades que pudessem forma uma panoramian das

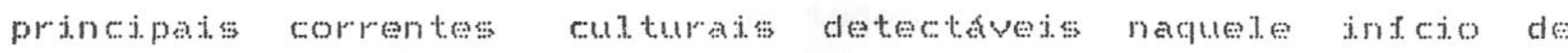
decada, convidandowe as pessoas que supostamenten estavam produzindo algo de valor para a contempormeidade "roda a programaço havia sido pensada na perspectiva de uma obra dentro de outra obran ou sejag os eventos na fabrica restaurada buscando sempre atingir un publico numerosoe das majs variadas gamas.

Os debates deverian estar sempre presentes pois pretendia se que a fabrica trabalhasse com novas ideias e tendtandis nortwaros da cultura dos anos 80. A intença era a de se provocar a disseminacko de temas ou obras ditas elitistas mas que na verdade -.- afimavan -- munca haviam sido apresentadas de modo adequado "e estar sempre ern busca do novo para as novas geracoss proporcionandowhes convivencias esteticas nunca antes experimentadas"

Dutro documento que se referia as intencess operacionats dizia que o clspo emprenceria una tentativa pioneira de difusa cut turat nas artes e expressos modernas que diferenciada da hierarquia obrapublico do museun iria se voltar para os processos de criaca coletiva para o "happening" a festa tribal p para a pesquisa conjunta nos cursos e atividadess para a descoberta para a aventura Esta era a fejoço que deveria assumir o trabaho de

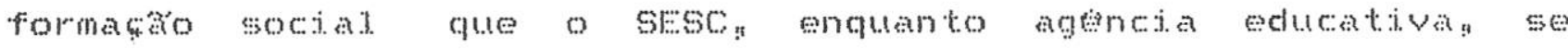

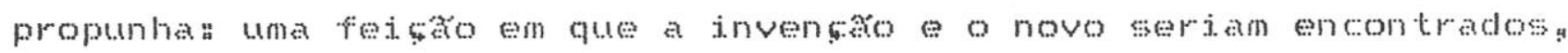
simultaneamente, por instrutores, alunos, colaboradores, equpes tecnicass artistas plateda pateon no mesmo passon no mesmo fascinante caminho, segundo o documento 


\subsubsection{O Que Foi Feito na Pompéia}

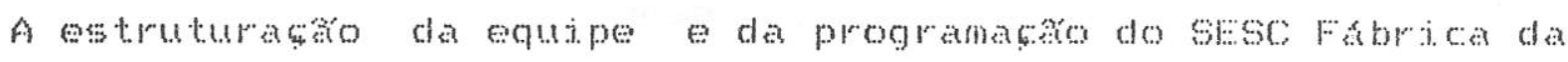
Fompria deumen segundo se contan atraves de um processo extremanom participativon onde todos puderan ppinar diande de um

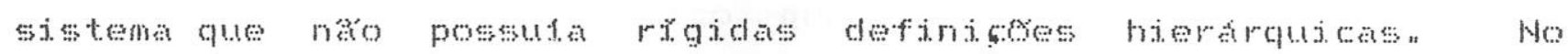
primeiro semestre de 1982 estava dirigindo a undade t..uz carlos zanoll. dizia que "ou todo mundo vai perder o emprego ou vai ser un caso de administratro de empress" "e insistiu com Lina ko barti sobre a necessidade de se ter um bar defendendo a ideia de fazer funcionar o espaco do restaurante como choperian A arquiteta respondia que toda a estrutura havia sido preparada para atender a un restaurante industrial mas diante da persistencia instalou um balcko de concreto que iria possibilitar as pessons beberem apoindo os

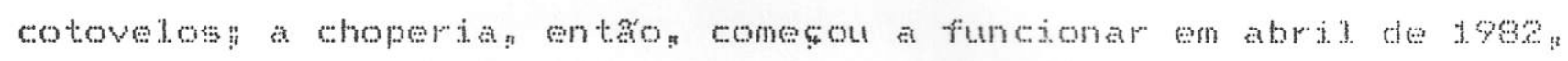
bern antes do restaurante " abra no comeco das tardes s so servindo Janches. zanoliti. pretendia criar no espaso um contro do convivencia con atividades funcionando cono chamariz para as pessoas a aceditava que a choperia poderia tornar a fabrica da Fompotia conhewidan

Durante o periodo en que zanold fot o diretor o que ocorreu

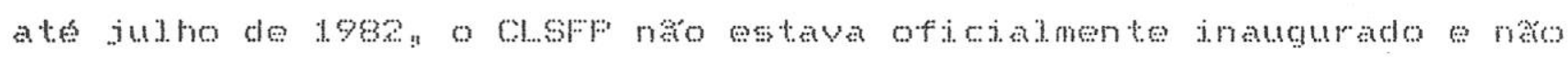

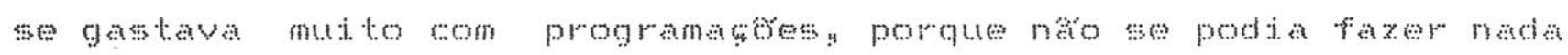

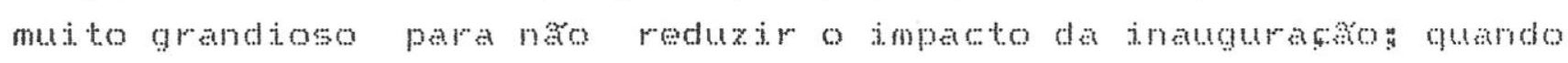

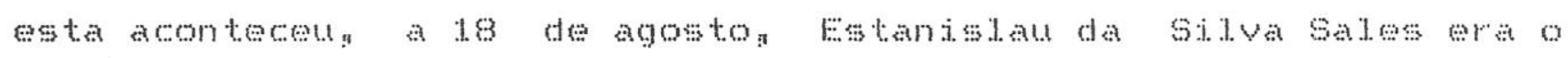
novo diretor da unidaden

A partir de entao a programatro da fabrica destanchous apresentando midtiplas atividades em todos os seus setoresu ha area de convivencia havia exposiches demonstractess de gimaticia ou

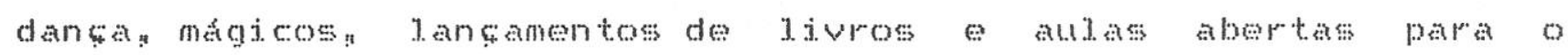
publico! a tarde as pessoas podian descansar nos sofas a almoracias ao som de apresentasoes musicais alen de dispor dos livros de arten das revistas da biblioteca da programasto de video as as oficinas oferecian uma profusaso de cursos "e sempre contavan com 


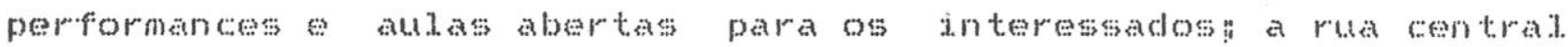

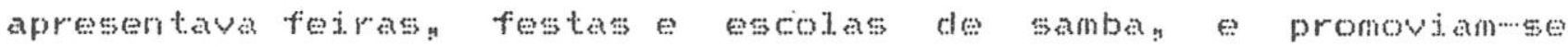
sempre aconteximentos na pracinhe do forno de barrog gue pra cercada de bancos para descanso e encontros informass o teatro

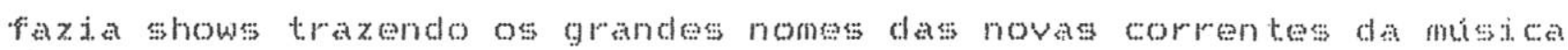
brasileira e espetaculos com propostas ctonises inovedoras a choperian ocupada pelo publico que saia do teatron quase sempres 1.otado, funcionava ate as 3 horas da madrugata oferecendo na spoca shows de rock country chorinho e iazz n En todos os fins de

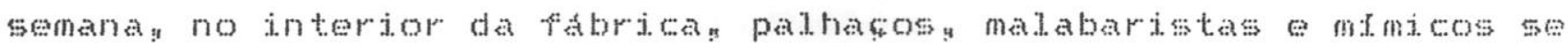
migturavam a público presenten realizando performanese gue provocavan curiosidade critica e participaço os prẹos do sfó Fabrica da Fompeja eran muto majis baratos que os da majoria dos

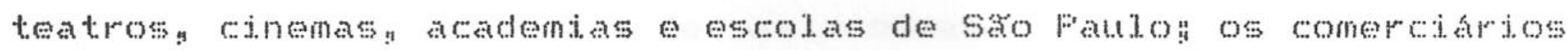
e seus dependentes pagavam menos a inda es axposiços bem como mutas outras atividades a eran sempre gratulas.

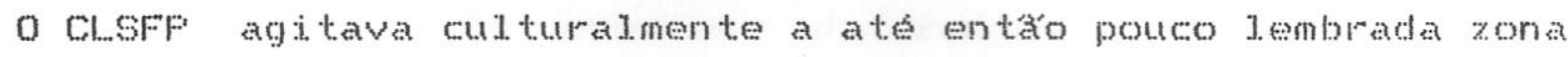
oeste da cidacle As pessoas que trabaharam naquela que a fábrica era um brincon un primory e havia muto carinho a cuidado com o patrimenio da unidade que todos tinham a preocupaço de preservara qualquer un dos funcionarios sabia das historias da fabrica e ja havia escutado bina ko Bardi falando da estation das paredes nus:

Comentava-se que ag novjades se reunian no SESC Fabrica da Fomperian ponto de gente diferente e bonita de badalation de encontro de intelectuais. Tudo que era feito na fabrica brilhavas como seu logotipo "SESO" wn neon vermelho, colocado acima do portán principal. Diziam que la havia o melhor chopp da cidaden o nais gelado, servido ainda com gejinho na beirada do copon alon do requinte dos lanches especiais e da famosa sopa de cobola gratinada. As recepeionistas da fabrica usavam como uniforme uma blusa de seda branca e un "tailler" azulo para as grandes pestass que aconteciam sempre. Nos seus primeipos anos. o cl..sF foi um Iugar muto requisitado para receber visitantes internacionais, e 
qualquer pessoa importante vinda de fora ia la "havendo visitas quase todos os dias.

A imprensa abriu-se en elogios para a fabricas comentando o dinamismo de suas atividades e assessenta areas(z) de atuatasos que oferecian ao grande público o que antes ere privilegio da elitei e dizia we que o lugar estava virando moda pela choperiag montada no estido das tradicionais choperias alemás pelos projetos especiajsy que integravan grande variedade de atividades es principalmentey "por este ser un lugar que sao fato nâ tinha" ou porque "nunca houve en Sac faujo un lugar onde va tanta gente fazer tanta cosea diferente en tamanha proximidade" "Mesmo a sofisticada revista Interview publicava o seguinte" "O SESC Fompeia continu sendo o espaco cultural. paulista onde as cojses sempre acontecem! com programas muto variados! o restaurante o que se pode chamar de novo er termos de anbienten os frequentadoress so os mas diversos e tem sempre uma pessoa fanosa na mesa ao lado lanchando descontraidamente. Os eventos diferentes aparecem por lás constantemente. Fodewse passar un dia na fibrican que una hora nunca será igual a outra"

Fortm nem tudo era gloria pois o articulista Telmo Martinon do Jornal da Tarde havia eleito o SESC Fabrica da Fompeia como um dos alvos prediletos de suas ferinas cronjeas "Lina bo bardi. a ultima fa de Vertnica l...ake, completara su verba mensal trabalhando como massagista seu saläo sera na vizinhạa do st:so fompeia para atender os problemas de coluna dos que passaram duas horas sentados nas cacieiras desse carcere do lazer" Durante todo o ano de 1983. relmo Martino dedicoume a cutucar a arquiteta associando-m a figura da artista de cinema veronica lake devido a franja que lhe cafa no rosto. "Hélio Beltras apenas mais un presidenciavel. g deu festa para jornalistas. Como ele gosta das pessoas certas nos lugares certosa escolheu como local a choperia do sfesc fompeias o

(2)naro se especificaya quais eran estas áreas, as aparenteaente tratava-se de un núnero bastante exagerado. 
carcere do 1 azer onde o maior conforto esta sempre nas cadeiras de Lina bo Bardi, a designer da Marcenaria Garotes a diauhas da Inquisigno Helio Eeltro estava certon os jornalistas se sentiram en casa. Nern estranharam quando Eduardo Matarazo Suplíy resolveu discursar. com aquele mobilidajo qualquer tortura fica menor."

Ate mesmo o presidente do SESC, Jose Fapa duniory gueria colocar estofamento nas cadeiras do teatro, mas lina bo bardi era irredutfved e respondia as criticas feitas a falta de conforto funcionaldade de seus assentos" "A ideia fundamentat dos meus moveis de "anti-confort" Năo es para ficar a vontade no estofamento mas para se sentar. As pessoas precisan aprender esta diferença ou entro procurar uma rede. pleus movejs sáo do lona 'Locomotiva verde e anarela 9 ná de veludo vermetho estofadou" Os sotas da srea de convivencia sáo revestidos com essas lonas enquanto nos bancos do teatro da choperia as pessoas se sentam diretamente na madeira.

Fventualmente una performance diferente causava estranhamento m certas pessoas mas os animadores e instrutores alegavam que nao se procurava o insolito, o chocante, e sim um dialogo permanente do artista, ou tecnico ı com o publico. Comenta-se que naquela epoca a cobranca do sEsc centrat era enorme, exigindo mit atividaciess com o maximo de diversifitacaro em termos de vanguarda precisava-se fazer coisasy razer coisas, o que ocasionava exposigess montadas en todos os cantos da fabrican Foréng mesmo com todas as atividades e equipamentos disponiveis ao publico alguns achavam que a grande atraça do ClofF continuava sendo o proprio predio restaurado $\approx$,

\subsubsection{Mudanças Administrativas}

I:enquanto Fenato Fequixa foi diretor regional do SESC " Lina Bo Bardi jmperou no Cl..FF" apesar das diarias rectamacess que Fequixa

(3)obs.: informaģes sobre algunas atividades realizadas pelo CLSFP estao no Anexo 3. 
recebia sobre o comportamento tempestuoso da arquateta que determinava desce os tipos de impressos a serem rodados para os eventos da programaston utidizandowes dos antiqualos recursos da oficina tipografican ate o cardapjo da cominha gue podia variar

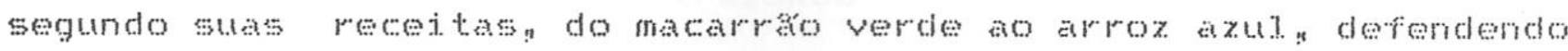

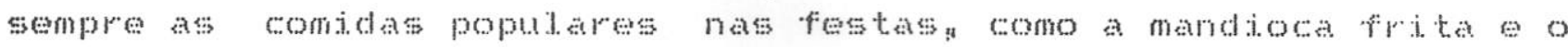
bolo de fuba com carten

A decisan do prestente do SESC dedicar a vida pold tica a partir de janedro de 1904 ocasionou a Salda de Fenato Fequixä Abram Szajman tornou-se o novo presidente

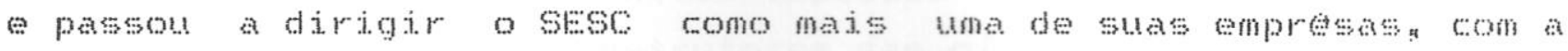

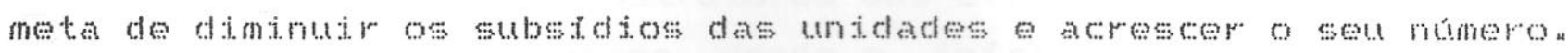
For isso adotou de inteio rtgidas medidas no pagamento dos walarios

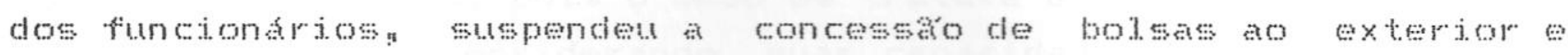
outros beneftcios concedidos aos tecnicos na administracho anterior

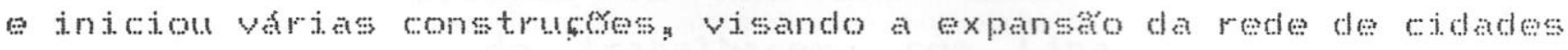
atendidas pelo seso no estado de sao Faulo e o aumento da

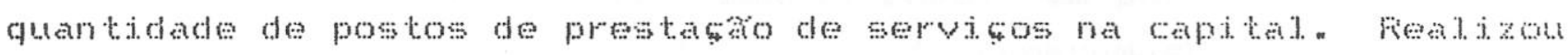
tambem aloum arranjos adminimtrativos no seso central terminando

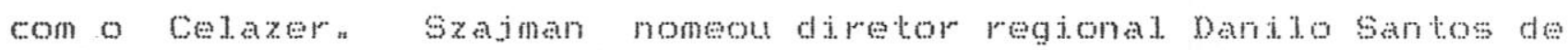
Miranda que hava trabalhado no sENAO como coordenador de recursos humanos Fienato Fiequixan

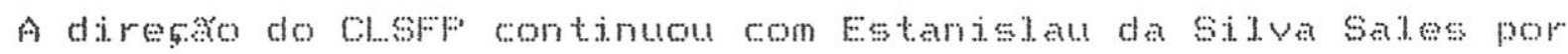
mais seis messes depois da posse do novo presidentep prosseguindo Lina ko bardi como nuradora da programagho e zeladora gorat do

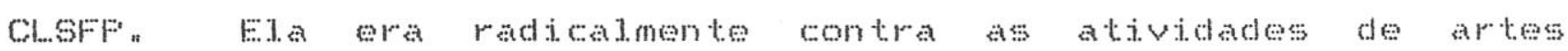

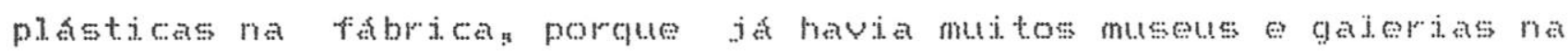

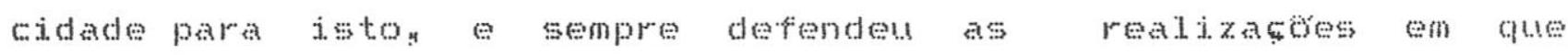
estivessen presentes elementos populares e tanbsm os pertencentes ao alto nivel. universitariog com a meta de colocar os grandes nomes

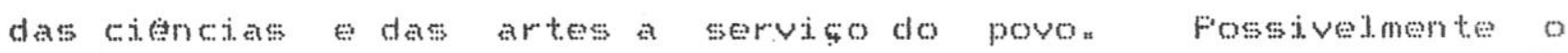
momento en que esteve majs perto do seu ideat aconteceu com a

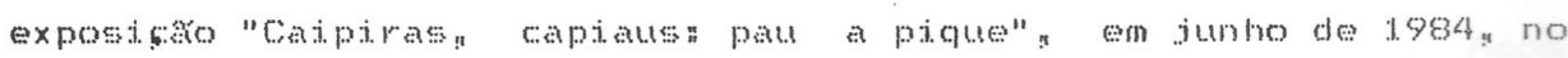
gual o assunto e o apelo eran popularesa mas embasados por teóricos 
renomados. o projeto da exposiço foi destenolvido pela arquiteta

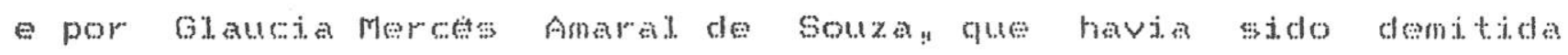
porque naso tinha colaborado com rose frapa rundor em suas pretensoss ejejtoraiss e recontratada por Abram sadmang apesar de discordar de suas jdéas metodos trazendo em sua volta o tema dos caipiras

Dias apos a abertura desta exposiço "Carlos alberto Fampone

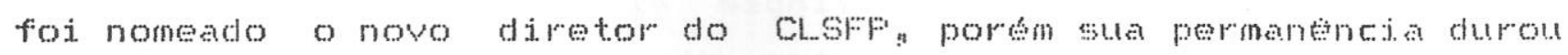
pouco mais de tres meses. Entrou na fabrica com a funcro cie "moralizador" "imprimindo uma linha dura que comesava com os cartoss de ponto 7090 de inteio implitou com a quantidade do horas extras reatizadas pelos instrutores das oficinas ws tes artistas en sua matorian queixavamse desce o inteio da baxa remuneramo que vinham recebendo pois o sesc os tratava dentro de suas tabelas de pagmento nato considerando suas capacidades espectificas 0 que mantinha as pessoas la náo era tanto o sajarion mas a oportundade rara de trabaharem con Lina bo kardi e de materiatizaren parte de suas imaginatges En pouco tempon carlos Alberto Fampone era odiado pela equipe de programasaro produca do chelF" Foi delatado quando promoveu - a portas fechadas no toatro da fabrica - uma festa particular considerada libertinan apos o incidenten o diretor foi arastado e 14 tecnicos demitidos.

Como novo diretor foi indicado resus Vasquez Fereira, que herdou una unidade esvaziada e desnotivadan permanecendo no ci..sm de novembro de 1984 a outubro de 1985 . Fetornando a seu wargo de dirigente tenjeo no stesc centraln resus vasquez fereira foi. substitufdo por luiz carlos zanolita que voltava com a funcro de revigorar a antiga fabrican tentando reunir la os melhores tecnicoss que trabalhavan pelas unidades do sesco l...go apos a vinda de

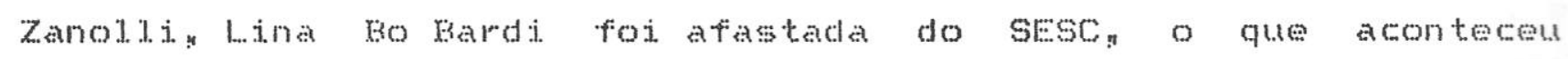
aproximadamente un ano antes da inauguraţo do predio esportivo. Nos ulitimos tempos a arquiteta ia pouco a fabrica permanecia no barracaso que lhe coube junto a construço do predio esportivo, sendo que seu contrato estava por expirary sua ultima grande realizaço no olsfF foi a exposiço "Entreato para Crianças" " Apos 
10 meses de tentativas na organizaso de uma equipe que pudesse

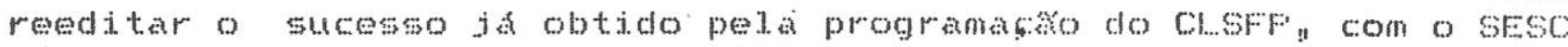
remanejando para a fabrica alguns tecnicos que náa tinhan o perfit adequado para o intuito que pretendia, zanolli demitiuse diante de convite realizado por outra empresa. Foi sucedido por Domingos Barbosa da Focha, que assuniu a funço de gerente en agosto de 1986 - ja completou quatro anos nesta funcho acompanhado por una equipe teconica que sofreu algumas alteraçess como a entrada e safda de Varios funcionarios e dois significativos acrescimosa as pessoas contratadase transeridas de outras undades para trabalhar no conjunto esportivo e la instrutores contratados para desenvolver o Frojeto Curumin.

Segundo Domingos Barbosa da Focha sá duas as principais funçes do ClsFF hojen prestar serviços a coletividade comerciarian tendo como Indte de avaliagro a oferta de servisos o uso que as pessoas fazem deles" "e sobretudo propiciar o convivion desenvolvendo uma programaşo que traga um tipo de cultura diferente da televisiva, que possibitite nator participasáno que esteja m busca da identidade que se perdeun Esta programawa caracteriza-se por sua versatilidaden propondo atividades como teatro experimental Maravilhas" "Feira do Disco" (barracas que funcionarn como locais de compra e troca de discos raros) e festas juninas sem se inclinar a modismos ou a concorrencias comerciais n a atual gerente ressata que o CLSF näo vai perder nunca o pioneirismo de revitalizaça do seu patrimtonio historico industriat e diz ser a fabrica un recorte da cidaden que ele gostaria mesmo de caracterizar como uma antiga ruag com engraxates espalhados pelos cantos nfotografos lambe-1ambe e pipogueiros " Acredita que as pessoas ainda nas se deran conta da importantia dos centros culturats no elevado grau de urbanizata en que estamos vivendo "e que ha poucos formados em animaşo cultural que possan dar uma unjade a tudo o que acontece dentro de um centro, cujo valor ná se encerra ali. relacionando-se como convivio na cidade. "Um cidadaco sern dinheiro pode passar um dia aqui sem precisar gastar diz Domingos Barbosa da Focha - e una famlita pode nadar a amotar, 
apreciar exposiçes e passar por una festa popular" tudo num elima proprio de una cidacle do interior de poucos anos atrsan le uma microwidade do lazer sendo tamberm a linica unidade que propicia 1.to dentro do st:sc."

Ruando foi montada uma exposiçon en abri. de 1989 sobre a obra de l..na bo Bardi na Faculdade de Arquitetura urbanismo ... FAU/USF: a imprensa voltou-we novamente para a atuaço do sesc Fabrica da Fompeia Entrevistada pelo jorna "O Estado de sato Fauto" a arguteta afimou "Eu esperava que acontecesse algum

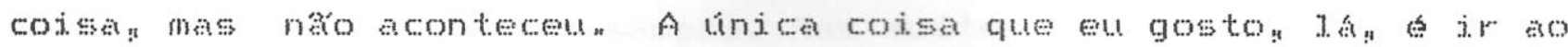
restaurante e ver una cirianga com um pratáo un montáo de comidan Un velhinho com o prato cheio. E a tunica coisa que me da alegrian porque ali eles se servem bems e ninguem diz nada. o reston ná foi. nada daquilo que a gente pensou" Eu fui jogada foran" li. Tao Comes finto en artigo publicado pela revista "Isto E/senhor" escreveu "Hoje o SESC Fompeia e pouco mais do que un 3 ugar de

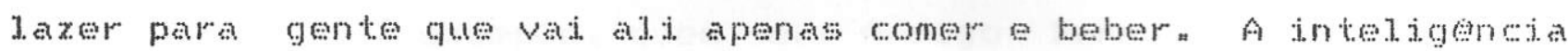

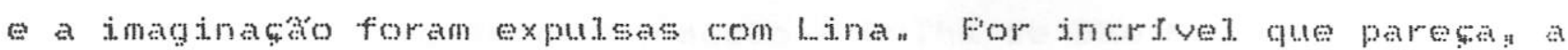
expulsano da jnteliguncia coincide com a mudasa de comando na

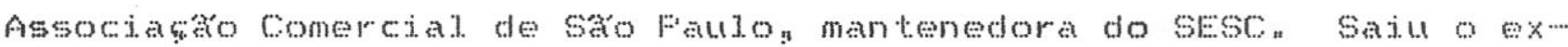
presidente zizinho Fapa jovem empressrio de atitude e posturas potaticas no minimo discutiveis cera consideraco direjtista malufista), entrando en seu lugar un homem serio, equilibradon atual. presiciente mbram szajomn"

o responsavei pela programagro no ClofF do infojo das atividades ate outubro de 1984, foi. Fabio Malavoglia que comesou no stesc como orientador social , realizando trabalhos praticos ma area do celazer. onde so havia teoricosn e teve uma rapidan mara ascensaco dentro do SESC -.. fato que deve ser atribuido ao seu perfil a considerado apropriado para os tempos de initio da fabrica." Malavoglia conta que nos quatro primeiros meses havia atividades barbaras com quase ninguem vendo, como num fim-itemsemana de percussáto com John boudier tocando de graca. o centro tinha una dination que possibilitava atividades para mas de 100 pessoas

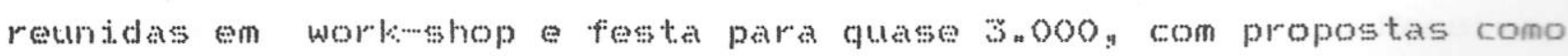


o projeto 'Odisseja na Fompeia' quando zoo pessoas participaram de um 'happening' "Lembrame de que certa vez respondeu a uma pergunta de un reporter dizendo que na fabrica náto havia uma politica mas uma poetica de programaço com os delfrios das pessoas e os "insights" criativos sendo transformactos em

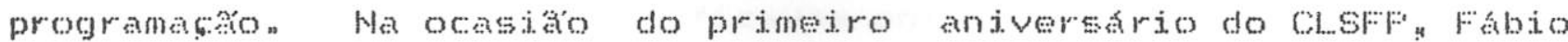
Malavogia deciarou ao Tornal da Tarden "Fara nos a arte e a

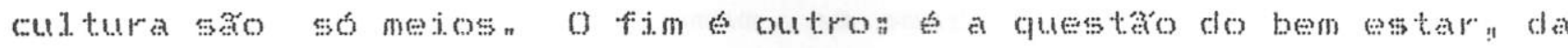
fexicidade, do convivion do encontro, de una vida melhor "enfim. "

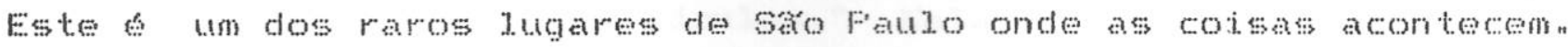
C1 aron a gente ná acerta sempre mas mutos eventos deste primeiro ano ficaran na memoria da cidade "

Comenta que havia una ideologia socializante nas pessoas do SESC Centrat. com una tradicato de cultura popular vinda do ofC Centro Fopular de Cultura, gue os dirigentes tinhan preconostos com os tecnicos da fabrica considerandomos elitistas perguntandog por exemplon quem era frrigo Barnabe " Mavoglia certa vez fez a segunte afirmaca a Folha de sao faulon "Este 6 um lugar de convivion de lazer" nato un centro cultural " lessa parcela de comerejarios que frequenta o sesc fompetia representa nen relaço ao seu ambiente, un elemento de progresso culturaty a passagen do uma informaço mase moderna para una categoria que engole o silvio Santos todos os domingos n"

Hoje, Fabio Malavoglia fala sobre a irrealidade do programa

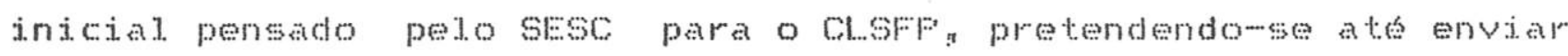
instrutores para a Europa " rsto náo aconteceu mas mesmo assim gastavame muto sendo feitas contrataçes acima da autonomia da unidade e depois a administraça tinha que se virara sobre comentarios da epoca que se referiam a exagerada liberdade entre os tecnicose de haver uma posstvel caixa dojs afirma quen "se tinhan ninguen lucrou com elas sendo o dinheiro revertido para a propria programasă Havian isto sim vidan com todas as variaçes, incluindo-se algumas distorcoes preso a ser pago para se obter alta criatividade "A programaça era táo dinatmica que puxava a reboque a administraşo, contando como apoio de kenato fiequixa, 
que tinha com o que argumentar diante do sucesso de imprensa pois - SESC Fomperia jumdou os jornats eserava nostrando que era possived. ter um modelo de administraço diferente do tradicionat. que fosse anigo dos artistas o que tamber dava dinhero e prestigion so na respondia de questoes poltticas. " " os funcionarjos se envolviam e ficavam encantados destumbados com o trabalhom os eletricistas os garcons se adequavam a esplrito entougueciam junto, sendo comum as pessoas fickrem alem de suas horas de trabalho de bon grado, mas enquanto ganhavamos simpatia nas bases perdiamos nas cupulas" Malavoglia diz que sua funço era a de estabelecer o dialogo da institution com a loucura" faxendo a negociacto entre as vertentes, e percebe que foi ingenus como que acreditando que as coisas aconteciam por benças dos cous mas afirma que o presidente Abram Szajan gostava dele! porgue as; atividades davan divulgagron rendiam publicidade.

Sobre as mudangs ocorridas depois da vinda do diretor oarlos Alberto kampone: que foi considerado pela equipe un

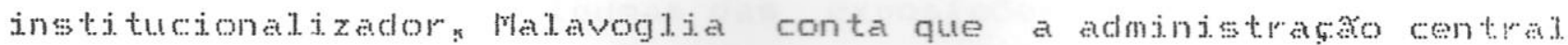
tentou durante dois anos desestabilizar o trabalho do sfec Fompeia "pois este patenteava a ineficiencia das outras undades do sl:sc: odiavarse a liberdade, a alegria, o bom humor a irresponsabilidade juvenil. da epoca do sEsc Fompéia, e isto e tudo que a burociana no SEsc e fora do sEso odeia os buroeratas sao pesson que disputam lugaress resmas de papel. lutam por cadeiras sa so escravos da rotina diaria e invejan o poder estar fora de ordem depois do escandalo, a burocracia negocioun sai o diretor porem sam tambem 14 tesenicosn A luta entre os poderess institucionais e os poderess de criaço esta en toda a historian náso so no si:sc e hoje os chefes dos setores da unidade estaso submissos ao administrativo! mas a experidncia castrada nao deve deixar as pessoas desandmadas pois provou sua viabilidade "

Acredita Fabjo Malavoglia que de $198 \%$ a 1984 o SFSC Fabrica da Fompeia formou um modelo de lugar e de programaço culoturala alem de conseguir nos iornats uma divulgaşo que depois se transformou em espaco permanente para a cutura. Evaj adiante dizendo que 
tudo que se firmou no panorama cutural do pais nos anos 80 passou antes por la, e que o restaurante old spaghetti factory, o bar Fum Fius as boates Fádio Clube "Fadar Tan Tan Espaco off e feromta foram moclelados na fabrica do SESC copjando a arcultetura a cor:

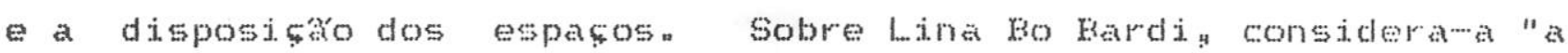
grande criadora daquele espaco e o mais expressivo representante da tendencia criativa masera vaidosa e sentia que as vezes certas atividades ofuscavam sua presença tendo cilumes; da fábrica que era o fitho dela E una pessoa capaz de fazer un trabalho monumentala alguen como Charles Dickens alguen gue constrojuma barragem doma a naturezane coloca as coisas num patamar metafisico dos grandes ideatis"

Referindo-se aos frequentadores" Malavogita afirma que "houve muta alegria na fabrica daguela epocan e isto e mas importante do

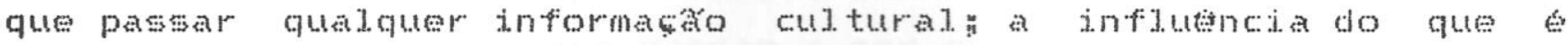
criativo, verdadeiro, esta vai ser lembrada na o SESC de hoje "

Fiesponsavel por algumas das exposigos tematicas e en certo pertodo tamberm pelas oficinas, Miguel Faidino conta que nos primeiros tempos os gastos para os caches e as programacoes eram sem limites, e em termos de material e equipamento compravaws qualquer coisan segundo ele, o pessoal que trabalhava na fabrica naqueda epoca achava que estava no centro do mundo" onde tudo acontecia as pessoas ian sem saber da programaço porque sempre havia alguma coisa de interessen e a grande riqueza era a diversidade de publicoe assuntos pois "essa salada é que era 1.

o técnico lembra-sen tambern, do entäo secretario da cultura do estado, Torge Cunha l.jima em cuia gesta foi criada a oficina Cultural. Tres Fios que afirmou, quando assumiu o cargon gue seu unico plano era imitar o SESC Fompéia "

o diretor do inficio do funcionamento da fabrica Luiz Carlos zanolid, via o Cl.sFF como um lugar que deveria promover coisas fora do convencionat. náo cursos de marcenaria un lugar onde sempre 
acontecessem coisas deshumbantesa portm a orientaço do seso mudou, toda a vanguarda pretendida acabou se concentrando em un ou dois grandes projetos por anon Acredita que deveria ter se ousado mats. mesmo no in ticio.

As pessoas que frequentaram o CLSFF de 1982 a 1984 tem saudades daguela epoca, e algumas dizem que depois disto a fabrica tornouse decadente, mas continua sendo un importante ponto de encontro pela sua bela arquiteturan

\subsection{Divisôes do CLSFP - Coordenaçăo da Programaçăo}

o Departamento Fiegional do SESC en Sá Faulo possui uma reder de unidades espalhadas por varios bairros da capital s sendo que normalmente essas unidades passam a ser conhecidas acrescentando-se a SESC o nome da regiáo ou da rua (SESC SaO Caetanon SESC Carmo) ou, quando se caracteriza por una atividade especticia o nome desta (Tenis SESC, Cine SESC). Algums unidades que possuem sou nome institucional. ligado a algun patrono sa as vezess chamadas por abreviaçes deste nome como e o caso do centro culturat e Desportivo "Carlos de Souza Nazareth" "que passou a ser tratado por Carláa ou SESC Vila Nova.

No caso do centro de Lazer SESC Fabrica da Fompena que nao tem patrono: a unidade de conhecida por SESC Fabrica da Fomperia, SESC Fabrica (nome adotado pela imprensa) ou SESC Fompdia (a arquiteta Lina Bo Bardi. ná gosta que se refiram a undacte sem o "Fabrica").

o Cl.sF", nas areas de pessoal e administrativa obedece ao regimento do SESC regional, ao qual esta subordinadas todas as unidades internamente para se solicitar servitcos "sáo utilizados impressos espectificos e desenvolveu-we uma forma de controle propria. 


\section{CENTRO DE LAZER SESC FABRICA DA POMPEIA}

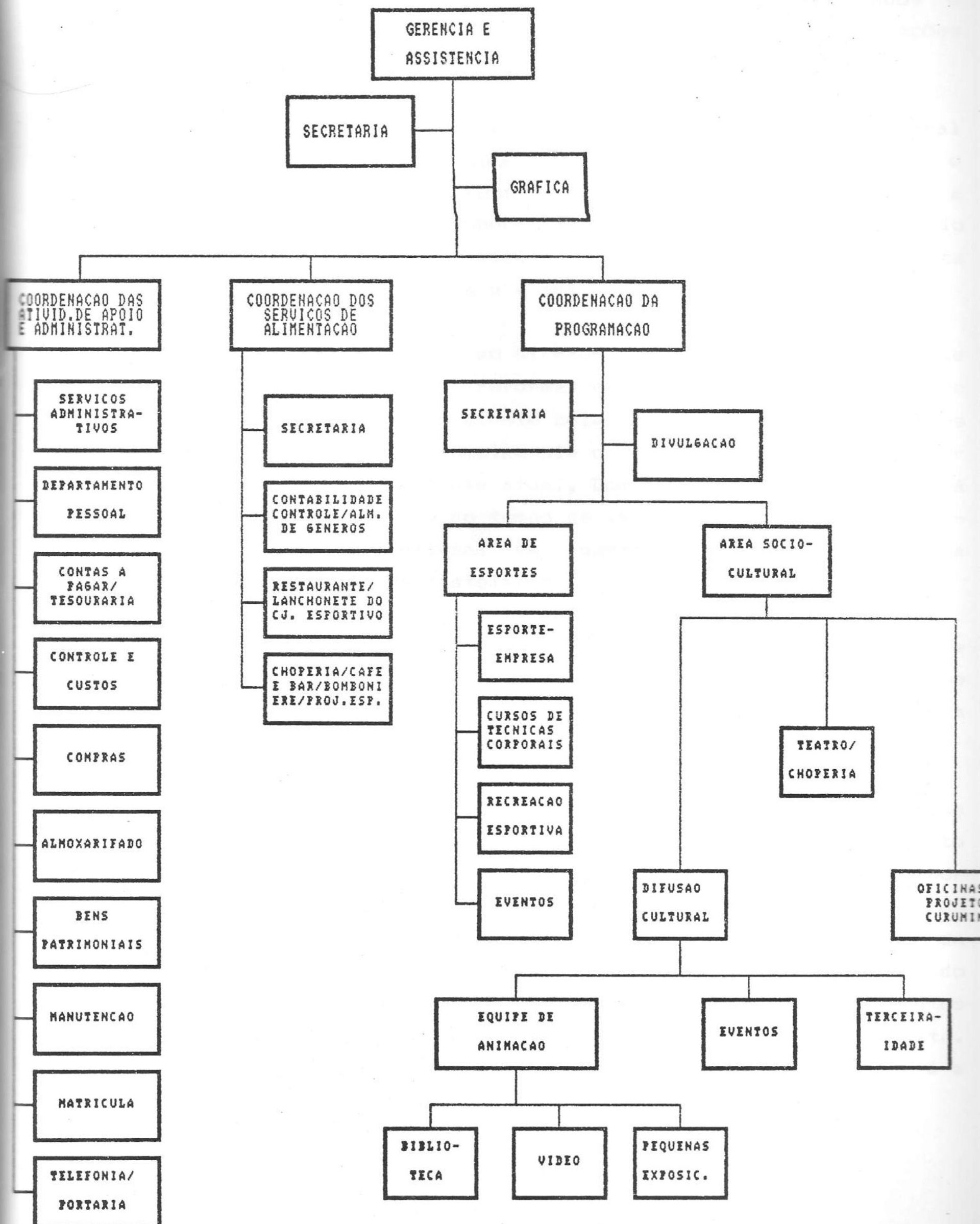


Seguindo-me o organograma estao diretamente ijgados a gerencia a assistencias a secretarian a grafica as coorctenacoses de administrasă de aljmentaço de programatomon

Cabe a Gerencia e Assistencia incrementar a politica cultural que a entidade deterninou para todas as áreass administrar o orsamento financeiro definindo as prioridacles estabelecer a relaço entre receita e despesa procurando reduzir o subsidio

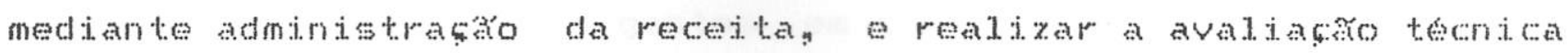
dos proietos das atividades e a administraça de pessoal.

Gerente $\Leftrightarrow$ o nome dado ao diretor da unidade q que passou a se chanar assim depois da reforma de cargos feita pela nova presidtucia do SESC: o assistente colabora diretamente nas funcoss do gerentey sendo que un complementa o trabalho do outro sern haver uma divisăo rigida o gerente atual "Domingos Barbosa da Focha ja completou no cargo metade do tempo de vida do Cl.sFF" considerandow... se sua inauguraga oficial en agosto de 1982. e recebe a assistencia de sergio Battisteli. "4)

o CLSFF funciona como um laboratorio do SESC, sendo a undade que apresenta mator diversidade de programaço. lis a que recebe majs recursos es consequentemente, da qual se espera majs na área cul. tural. .

o coordenador da Coordenacao da Programacao " Antonio Carlos Moraes Frado ingressou na unidade para dirigir o conjunto esportivo sendo formato em educato fiston mas terminou por assumir toda a progranaço da uniclade. Seu pensanento fo que a acko cuturat. deve se dar atraves da educakso náo forma da aprendizagern prazerosa, pelose para os conteudos culturais do 1.azer, havendo no processo a valorizacáo estetica dos elementos legtimos da cultura popular e a vulgarizaço da cultura eruditan Sobre os criterios da programaço, afirma que a linha a segur e a

(a)obs.: a complementaça do que cabe a cada coordenaçato e seus setores está no Anexo 3. 
de otimizaço de espaqos e recursos, desenvolvendowse o maior numero de atividades nos espaços dispontveis e visando atender o mator numero de pessoas durante o maior tempo posstveln os projetos saco pensados e selectonados segundo o coordenador" 1.evandowse conta seu ineditisno, o impacto institucional comuntario que podem gerar, a adequaso do projeto aos peris do pubitico frequentador: as necessidades para o seu desenvolvimento e as limitaçes tecnologicas da unidadey e anda o custo benefficion ou seja, o montante dos gastos en comparata com o numero de pessoas que vaco usufruir para as propostas externas usam ons mesmos corterios, avaliandowe a adequacao a programacko gerat. os temas escolnidos săo topicos de interesse geral. relacionacos a questoes da atualidade datas comemorativas ou historicasi ass vezes os assuntos sáso propostos por instituigoss culturais.

Fara uma exposiço justificar-se, Antonio Carlos Frado acha que ela deve atingir tres niveis: impressionar pelos sentidos. possibilitando una aprendizagem sensorial, prestar una informacaso adequada! que supra o cognitivo, e apresentar vivencias de conceitose tecnicas basicas de un tema cultural, procurando sempre possibilitar uma alfabetizaçáo que visa a autononia culturat. Sobre o conjunto esportivo acredita que tem como principal fun so $^{\circ}$ possibilitar o acesso a varias abordagens da cutura do corpo w No final do ano nomalinente se promove un encontro com tecnicos de cada setor para se estabelecer a programaço do ano seguintes sendo as propostas resultantes reunidas num documento.

A Coordenaço de Frogramatako recebe o apoio dos setores de Secretaria e Divulgaço para as atividades permanentes e eventuais realizadas pelas suas duas divisoes, a Area de Esportes a a Area Socio culturat " Segundo Antonio loraes frado, os funcionarios devem atur de forma polivalentey portanto a separaçao em setores noto absolutan

A Area socio-cultural está organizada em tres setores que sás chefiados por Wi.to Sergio Melo Diniz, sendo sua funsáo coordenar o processo de criaşa, acompanhar o desenvolvimento operacionat e 
fazer a avaliagato das atividades permanentes e dos eventos desta arean alom de propor e realizar projetos integrados com a firea do Esportess.

\subsubsection{Difusáo Cultural}

\section{(Area Sócio-Cultural/Coordenaçăo da Programaçăo)}

A Difusa outural e formada por ténicos que fazem o trabalno de andmato cut tural interdisciplinar conforme diz antonio carlos

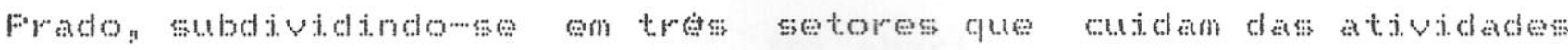
permanentes n dos eventose da terceira idade.

\section{Equipe de Animaçao}

A Equipe de mnimaţo e a responsaves pelas atividades permententes e comprende os servicos de emprestimon informenes andmato da biblioteca e Judotecan a programaţo de vfdeon as pequenas exposiçes temporarias a Todas estas atividades ocorm principatmente na area de convivencian que é cheriada por Araty

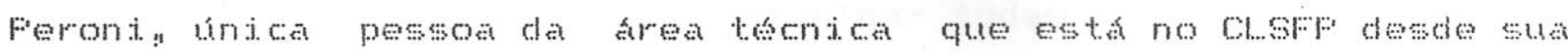
in $\operatorname{auguraçon~}$

Ao se caminhar pela rua interna chega se ao primejo gapao a diresta onde esta localizada a area deconvivencian que possut quatro portas. A primeira delas e o acesso para o local reservado as grandes exposicosę as outras tros locatizam ene frente aos espacos da biblioteca do video dos moveis de ostar os sofas, bancos e mesas de laninado de pinho sao usados para let turas jogos de tabuleiro e de cartas, ou para simples descanson sondo muto procuratos pelos frequentadores da Tercera tade " o espelho d'agua esta d esquerda a area posterior a ele e livren sendo que nos primeiros anos reatizavanse nesse locat aulas abertas de Yoga

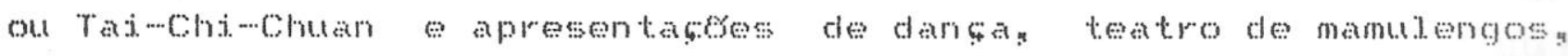
corats o "Froteto l..uz do rejo dia" "com amadores mostrando aos domingos suas habilidadess 
Logo apos a inauguragáo da area de convivencia instalou se una lareira fen frente aos moveiss com tapetes de palha e almofadas espalhadas a voltan foi un dos poucos pontos de discordia entre

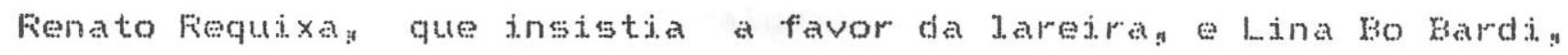
que naxo a tinha previsto. Ate o ano de 1986 funcionou a 10 a que atendia num balca oval em frente ao setor de videon local onde hoje esta a matricula e que vendia objetosn como sacolas camisetas com o stmbolo do SESC Fabrica da Fompeian cartoes postaisn posters e catalogos das exposicoss pesas artesanas a produço dos ateliers --. a loja foin alias, projetada como um apoio as oficinas.

A Bibliotecasss do cl..sF foi aberta a publico a 12 de abrill. de 198\% e com o levantamento do tapume divisorio para a realizacko da exposiço "o design no krasil - historia e realidade" "as estantes foram dispostas entre o tapume e as lajes de leituran 0 seu acervo baseavase en tres coleçes: especial (1.ivros importados de arte e de apoio as atividades culturais da fabrical la la (fiçăo, jornajs e revistas) e miscelanea (curiosidades romances! bricolagem, geografia ilustrada ufologiag almanacues, turismo) " $A$ Gibitecan primejra biblioteca especializada em quadrinhos do Brasily pretendia arquivar e divulgar todas as publicacoes desta 1.inguger feitas no Brasit. e no exterior e fot langada apos cinoo meses de funcionamento da biblioteca, com mesa redondag exibicáo de filmes exposiços .

A biblioteca era livre para quen a quisesse frequentar efoi muito procurada pelas crianças que năo dispunham de um espaco apropriado cpois o Centro de criatividade Infantil passou a ser usacloy depois de uma curta experiencia com crianças apenas para

(8) nota - devido ao grande número de subdivisbes do orģanograaa do CLSFP, torna-se dificil precisar o caninho hierárquico que $5 e$ percorre até chegar ao setor. Por exeeplo, a biblioteca é subdivisto da Equipe de Animasto, que por sua vez è subdivisdo da Difusto Cultural, que pertence area Sbcio-Cultural, que responde à Coordenaçăo da Prograaçato. Na prática evidencia-se o exagero de pessods ocupando cargos de chefia e a faita de funcionários para seren chefiados e executarea a produça. 
auxilitar as grandes exposiçses;, oque resultou a montagken da biblioteca infantil. e un redimensionamento da ludoteca. As estantes eram baixas afastadas dos livros de arten ede facid.

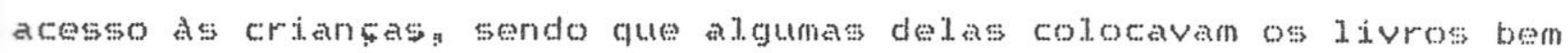
atras para continuar a leitura no dia seguntep enguaro outras os escondian enbaixo da esteira de taboa. No finat de 1933 havia 1800

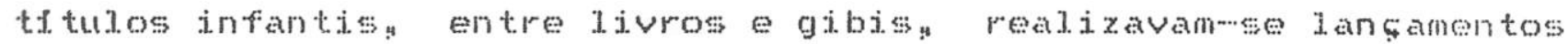
de livros, mostras didaticas sobre o processo de ilustracaso e encontros com i.lustradoress en que as coriansas tamberm desenhavam juntas, e montoume uma banca de jornal para as criangas mexeresn.

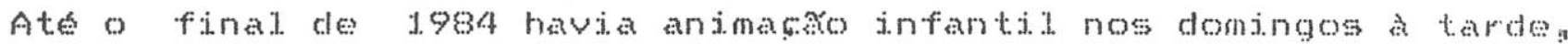

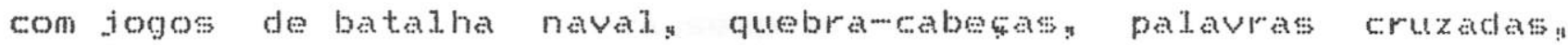

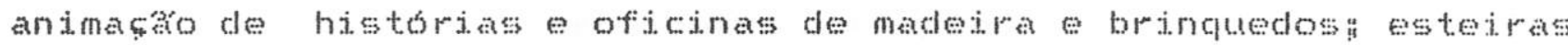
de taboa eran costumeiramente estendidas na frente do espaso da biblioteca para as eriansas construirem com cubos e modulom

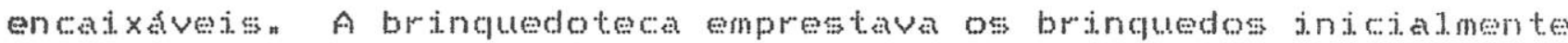
sem cobrar nadan mas como alguns voltaran quebradoug optoume por um aluguel. para 15 dias de uso Fara os jovens e coringas fixarem

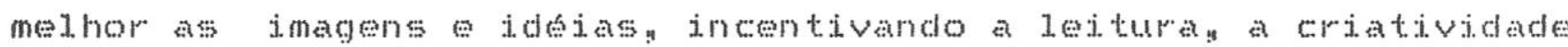
e a fantasin eran propostas atividades com artes platicas o "Tipodrama"; no qual eles criavam a histórian dramatizavama en iam A tipografia executar una edicto propria

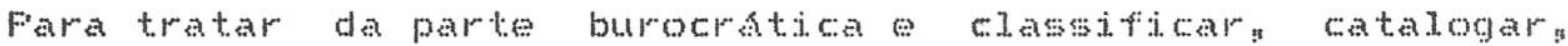
arrunar as estantes atender ao ledtor e cuidar das atividadesy o setor dispunha de duas bibliotectrias una animadorag guatro escriturarios equatro atendentes. fom a dispensa dos 14 tecnicosy salda de funcionarios remenejanento de outros pos pertodos de contença de gasos o setor foi definhandoy a biblioteca dejxou de

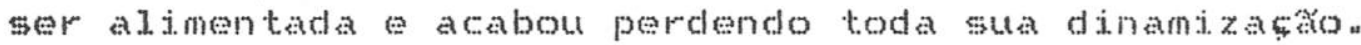

Alguns projetos do setor nă deram certon como a colocaço de almofadas de retalihos nas lajes de jogos; pois elas desbotaram e descosturaran e as familis náso jam a local pois os namorados exageravan no meio das almofadas (o que acontece ate hoje en lugares publicos do enentro -... os vigilantes tén que pedir mais compostura aos casais)! en certa epoca pretendeume desenvolver um 
projeto para constitur un arquivo de catalogos de artistas

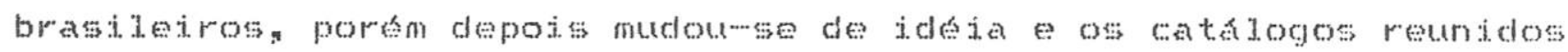
ficam empithados num canto: o videotexto foi desativado porgue as crianças monopolizavam o aparelho sem parar de brincar com os jogos extenicos: a diapoteca ná vingou e os "headphones" sem fio foram comprados mas nunca usados, ou sejas a audioteca náso chegou a funcionar" Mas nem por isso o local da biblioteca ficou sem compementos acusticos, pois acaba recebendo a interferencia sonora do videon da trilha das grandes exposiches tematicas e da programasoso da rua centrat.

Na verdade a biblioteca sempre foi un ponto crit.icon tendo que conviver com diffesis problemas operacionats, cono os preiutzos causados aos livros pela grande variaço de temperatura e a undade do gaparo e poeja constante que cai das telhas que náo possuem forrặon.

Mass o principal problema enfrentado pela biblioteca foj e 0 roubon pots seu espaço muto vulneravel e de dificj. controle. A ideja era a de educar o povo: que deveria perceber que aquele patrinonio the pertence procurar preserva-lon o SEsc acreditava que os roubos e atentados contra o acervo eran o preso que se pagava por se manter una biblioteca mas popular que despertava no

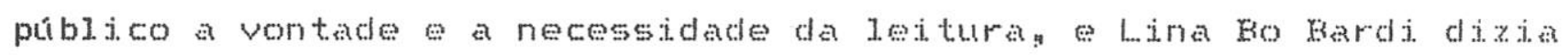
sempre que "quem estraga os livros a a classe median nato a ciasse baixa" "Foubos acontecem em todas as bibliotecas porén no cisfor foram levados livros de grande tamanho inclusive colesoses completas encadernadasy cono no caso da gibitecan que perdeu mutoss volunes" No infeio as pessoas entravan com sacolas e bolsas: posteriormente pediu-se que estas fossem deixadas no bataro de atendimenton Discutiuse algumas vezes o uso do controle eletronicon que ná tiraria a liberdade nem a descontraço do frequentador, mas o sistema nă foi utilizadon

A guarda dos livros deveria caber aos vigilantes que muitas vezes eram deslocatos para outras funceses e os funcionarios do setor acabavain atuando como vigias sendo que em certa época houve 
a formasto de un grupo de anigos da bibliotecan constitudo por jovens voluntarios que patrulhavam a area mas segundo se conta exageravam na repressano comentawse que nunca se teve no $\mathrm{SEs}$ grande preocupacto com os roubos de livros havendo tamben certo desinteresse pela reposişo alom da dificuldade em se achar os importados. A quantidade de livros roubados ultapassou bono unidades em ojto anos - o que representa uma modia superior a dojs 1.ivros por dia -.. e em marso de 1990 o acervo contava com 7 , 870 volunes.

Atualmente esta sendo feito novo tombamento do acervo que nato se encontra dispontuel ao publicon mas náto hat bibliotectrios trabalhando efetivamente no setory encontrame en estudo ot: projetos de se revitalizar a ludoteca contando com o auxido de Mario seabra um inventor de jogos a de retomar as propostas ao

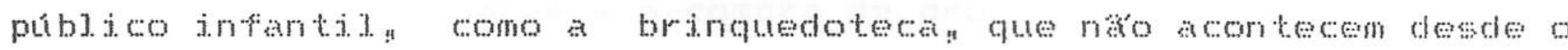
infeio de 1985 a biblioteca esta aberta nove noras por dia trabahando con todos os jomais de sá faulog com diarios de varios estados brasileiros a e com revistas nacionis informatas Het por volta de trezentas pessoes que frequentam a biblioteca com certa regularidade sendo a maidia idosa e os atendentes ja conhecem bem a preferencia destes leitores a Diariamente o setor recebe uma modia de b80 pessoas chegando a 1100 nos finswew semana o bataro de atendimento fornece jornats e revistas trocandowos por qualquer documento da pessoa a ate recentemente os matriculados do $96 \mathrm{sc}$ podian retirar jogos e livros eirculantes (que

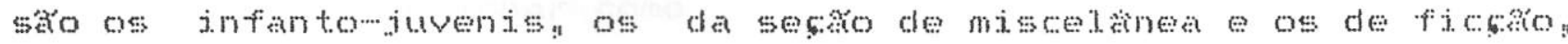
durante o perfodo de 15 dias).

A area de video possui sejs monitores com son direcionato. espalhados por entre as colunas que sustentan as lajes de jogos "e ao final. da cobertura de conceto ha un teláso sony atras dele está a cabine de controle. uma caixa de vidro climatizada para a conservaço dos aparelhose fitas que dispoe de dois videoscassetes Wh" como todo o equipanento domesticon os aparedhos quebram semprey pois ficam 1.jados diariamente durante oito horas seguidas. Apesar da area de video estar localizada na parte mais 
escura do espaco da convivencian a luz interfere muiton

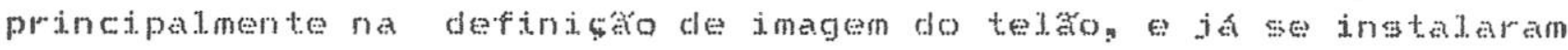
cortinas soltas e tendas para tentar escurecer o iocal.

A responsavel. pelo setor de vfdeo, Denise Marthan normalmente prograna para ds 15 horas filmes de aventuras "para a mog̣ala" as a 1.7 horas documentarioss sempre ben atedtos porque as pessoss gostam

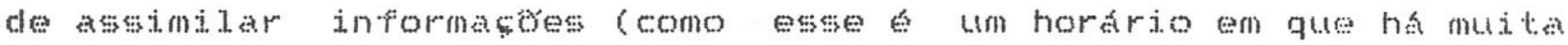

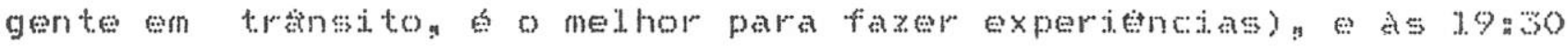
horas filmes para o publjco adulto fo definir un cicion Denise Martha costuma agrupar filmes menos conhecidos com outros des sucesso: procurando começar com estes para pegar o publico preguicoson "que so vern para o que é certo" " obter os filmes na videowocadora 6 o maig facilg mas devewse ter o monimo de contexto para exibl-wos gegundo a programadora que acredita na necessidade de oferecer alternativasy como produtores de televisas mostrando fajando sobre suas obras a compra de programas da rv Cultura mas isto se consegue raramente. Ha algumas apresentabos de desenhos e de filmes eduetivos e infantis, e foi realizada no ind cio de lygy uma oficina de efeito "zapp" " com a possibilidade de transfornar a

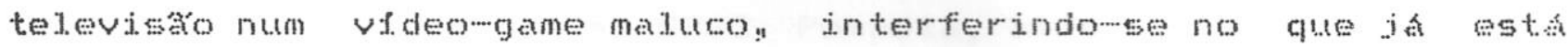
prontoy porsm o retorno foj fracon pois as eriangas gostam da televisaso como ela e e o "zap" acabava incomodando os filmes que querixin ver.

A programadora acredita que se o monitor estiver ligadoy deve estar passando alguma programaço esperial gue tenha certo objetivo sem funcionar como televisaso de rodoviarian pojs "quem

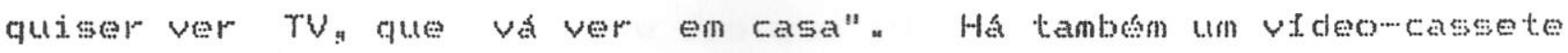
instalado na lanchonete do conjunto esportivos a quando há eventos da área de esportes geralmente en torno de temas como o veráto e a

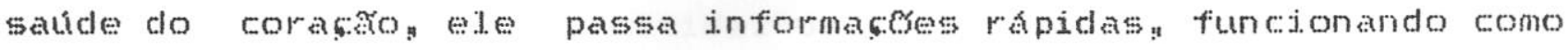
uma especie de almanaque quando ha corridas ou jogos importantes

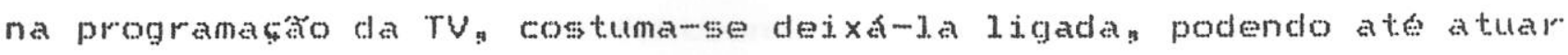
"como pretexto para as pessoas estarem juntas, e mesmo aquelas qus năo me conhecem trockm impressoes". 
o pubico náso se prencle as imagens Entra e sai da lanchonete ou da area de videon a ná ser que veja algo espetacular como um prograna sobre acidentes automobilisticos ou algum inagem veloz, com muta açón. Fara Denise Martha o lugar dos filmes é no cinernas com projesăo 35 mm e confessa nán conseguir assisti-jos no SESC Fomperia segundo ela a programago de video da fábrica deveria ser

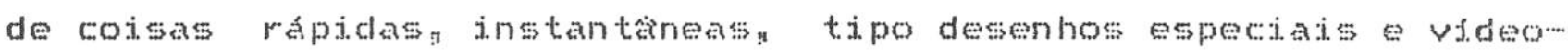
clips, porén e clificil obte-1os. Wa area de videos totalmente abertay o publjco éflutuanten sendo que ha pessoas que procuram os filmes da noite mesno sem saber da programaçog os filmes intimistas term um numero pequeno de interessados que vem especialmente para assisti-los" o publico habitual e composto por homens de mais de 40 anos, e observarse que inutitas pessons se comportan durante os filmes como se esperasem o intervalo comercian. n

0 documento de intençess operacionats do clofF propunta cursos de video abordando desde o dominio das ténicas smanuseio do equipamento) ao da expressao (videowarte) registros en vfdeo das principais atividades e resumos audiovisivos de cursos e confertncias realizados no $5 \mathrm{sc}$ Fompeian alem de prever trabalhos experimentais en videowarte e uso do vr como suporte de outras areas. Fretendiase inicialmente adaptar a central de video no espaco dos escritoriosp depois cogitouse fechar a laterat da galeria da area de video. colocandowse vidro entre as colunas iddeia prontamente rechạada por Lina Bo Bardi.

A area de video sofre e provoca interfertncias pois perturba o silencio dos que jogame dos que ltem na bibliotecan es vezess inundada pelo barutho vindo da programasao da choperia ou da rua central a ijuninaçăo das lajes, embora insuficiente para leitura penetra ali e prejudica a nitidez do telá sous bancos feitos cle pinho, saco triangulares e com rodinhas "juntando-se a outros modulos triangulares que funcionam como mesinhas saco estoticos e provavelmente foran concebidos para a ludotecan porém o pubilico os acha desconfortaveis e prefere as cacleiras tipo securit. o espaco do auditorio (uma grande sala localizada entre os escritorios onde 
se colocan cadedras e normalmente usada para palestrass "năo peca para a programaça de vfdeo porque é nuto forma" "cono diz Dendse Marthas ela tem esperanças de que apesar da inquietuden dos barulhos. da luz e de toda a dispersaco da area de convivencia, "pelo menos una imagen as pessoas váo sentir" văo curtir. váo conseguir guardar" "

"O video năo apenas uma opţo de programaţon como acontece no SESC Fompeta - afirma Denise Marth - mas una 1 inguagemn escreverse com eles f un recursoy podendo estar en todas as outras areas" " Nas programages importantes e nos langanentos usa se a vinheta propria do video do sesc fompeian que traz as flores saindo da chaniné.

As Pequenas Exposicöes Teporarias da area de convivtncia sâ realizadas em tres espacos proximo at biblioteca permanecaram instalados no tapume divisorio durante varios anos quatro grandes painejs com vidros protetores que foram usados para exposiçes variadas sobre temas relacionados a leitura en geral com mostras de ilustraçes de livros infanto juvenis personagens de historias em quadrinhos "ete " " Estes painess foram desativados devido th montagen da exposiça "Al. ce no Brasil. das Marathas" "e agora pensa-we rem recupera-josi na lateraj esquerda da area de video estáo dispostos seis paneis formados cada um por duas bases de conereto e um vidro blindex (paineis jouats aos usados no acervo do MASF), que possuen uma superficie de madeira acoplada ao vidro para receber fotografias cartazes e demais imagens que possam acompanhar os temas escolhidos nos projetos da fabrica e na regiaxo posterior ao espelho d'agua săo montadas as exposicoses matores com a constructio de suportes e ambientaces especialmente desenvolvidas para cortos projetos, ou sao trazidas mostras de consulados, museus $e$ de outras instituiçes " Mutas das exposicoes apresentadas na area de convivencia saco propostas oferecidas ao SESC por artistas ou orgáos culturais e sáo visitadas por um publico bastante diferenciado, que vai do adolescente ao idoso, do balconista a universitario. O CLSFF poderia gerar exposiçes para outras unidades do Slesc, principalmente as do interior, 
aprovatando-se a pesquisa ja feita eo dinhejpo ia gaston mas isto năo acontece.

Os materiais de suporte como os paineis suspensos a as estantes e vitrines: saro guardados no centro de criatividade infantide na manutensato sendo quebraclos varios vidros devido a falta de um espaco apropriado para deposita-jos: os cubos.

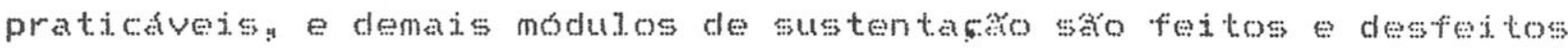
de acordo com a necessidade que se apresenta A arte murate o grafite tem um painel de $4,40 \mathrm{~m}$ de altura por $11 \mathrm{~m}$ de comprimento localizado no deck-molarium na confluencia com o final da ma central, sendo portanto visto deste a rua clélja. E usado para i. 1 ustrar os temas dos grandes eventos.

\section{Eventos}

o segundo setor da Difusa culturat 6 o de Eventos q que sato as grandes exposiçes tematicas as feiras a festa junina anual a as apresentacoses demonstracoss e animatos en torno de un assunto escolhido, cabendo a este setor fazer a ligaço entre as diversas areas e departamentos do CLSFF.

Com o levantamento do tapume divisorio para a expositaso "0 design no brasil-historia e realidade" (abril a julho de 1982). defindu-we un espaco de $51 \mathrm{~m}$ de comprimento (extensaco gato gá) por 13 in de 1arguran que viria a ser ocupado pelas grandes; exposiçes tematicas 0 cor - Centro de Criatividade Infantila foi usado para as oriansas apenas nos primeiros sejs meses da fabrica para se chegar ate lá era necessario passar ao lado da exposiga montada o assessor infantil. contratado pelo SlEsc, Ilo Krugli, havia planejado o material ludico das crianças como rampas e meias-luas, que estava neste espaço. Forem o col foi transformado numa escolinha para sanar a carencia de escolas criativas na regiso, o que se constituiu num ero, segundo miguel faladino, pois nå havia um orientador pedagogico, o local náo era adequado, nao tinha iluminaşo natural e os instrutores rectamavan do pagamento do SESC na reunia dos pais " o espaço tornouse logo depois um 
deposito que guardava suportes de montagem e ia recebendo o material que sobrava das grandes exposicyesp alem diston hoie abriga duas riquezas do SESC o acervo de brinquedos regionats

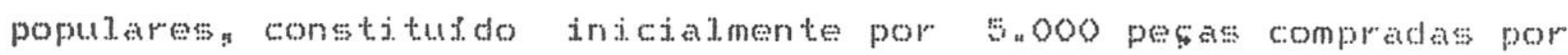
todo o Brasil. (hoje deve estar com menos da metade pois elas foram se perdendon sendo roubadas e estragando) y o artesão Mestre Molina que tem la instalada sua oficina e bastante conhecido pedas suas geringonsas cens com pequenos homenzinhos ern aço, animados por correias e polias movidas por un motor "ranto o acervo como o artesán porem, so sáco considerados pejo SESC quando os visitantes do estrangeiro mostram por eles grande interessen

De 1982 a 1985 as exposichess tematicas estiveram sob a orientaço de Lina ko Bardi. a a principal tonica deste perfodo foi. a de se considerar os valores proprios a cultura verdadeiramente popular. procurando-se sempre una harmonia entre o espaso arquitetonicoe a distribuiço das exposiçss, que eran montadas com a ajuda de seus dois arquitetos e dos instrutores das oficinas. Apos a mostra de design! foran realizadas as exposiços "ilit bringuedos para a criança brasideira" (dezembro de 1982 a julho de 1983 -... mostra do acervo do stese de bringuedos industriats de colectonadores" que reuniu en sua abertura o major publico da

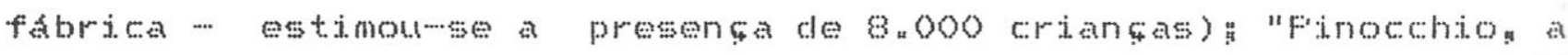
historia de um boneco italiano" (agosto a outubro de 1983 -.. em comemoraço aos 100 anos da famosa criaço de collodi mostra das joumeras interpretacos graficas que o boneco de pau havia ate

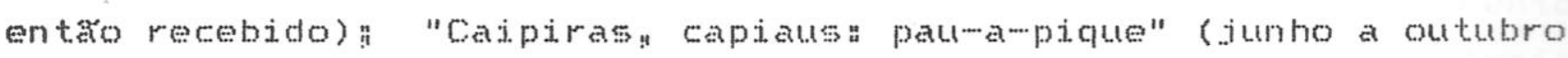
de 1984 - montagens de casas de pau-a-pique e estudo da cultura cajpira): "Entreato para crianças" (março a agosto de 1985 reunia do de varias peșas representando animais).

Ate maio de 1990 ocuparam o espaço oito exposiçes tematicas, quatro apresentactos teatrais e quatro exposicoses de artes plasticas: as trtes exposiçes tematicas feitas depois da saida da arquiteta foram "O de casan com 1icenca-Tequitinhonha" (maio a julho de 1986 - mostra da (ultura do vale do Tequitinhonha); "Madeiran árvoress ferramentas, objetos" (fevereiro a agosto de 
1987 -- mostra de ferramentas; movejs e pesae artesanais) g e "Alice no Erasil das Mravilhas" (agosto de 1989 a fevereiro 1990 ... a historia de Lewis Carroll transposta para o Erasil pelo carnavalesco Joaxinho Trinta).

As exposicoss tematicas trazen pecas caracteristicas e significativas dentro do tema escolnido (destign" brinquedo" madeira) e crian anbientages cenográficas (caipiras a fice), com os objetos tridimensionats dispostos deforna a ocupar a grande area, recebendo recursos de som (todas as exposictses tiveram tri.has sonoras proprias) e luz n Costumanse realizar programackes de apoio para dinamizar os temas escolnidos, como mostrass

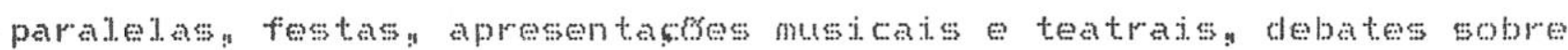
questoes pertinentes; exibitoes de filmes, videos e audiovisuais enfim, todas as atividades que permitam o envolvimento do pubjico com os elementos propostos na exposiçon buscandowse integrar vários setores da unidaden sao feitos folhetos e catalogos com textos didaticose informativos a regtstros da montagem da exposicho - imagens relativas ao tera trabalhado.

Ruando saco expostas obras de artes elas esta sujedtas a larga variaço de temperatura a po segregado constantemente pelas telhas francesas a a chuva que espirra pelos varos do telhato: os bueirosy devido as suss estreitas galerias, expelen de tempos em tempos agua fetida na ha espaço apropriado para se guardar o material ate ser exposto e a equipe de trabalho naso tem treinamento especializado para lidar com as obras n As quatro pesas teatrais montadas durante o pertodo entre exposiches distinguem-se pelo carater experimental. foram propostas ao SESC pelos grupos, enquanto as exposicoes tematicas săo produçess do SESC, recebendo as vezes patrocinio ou apoio de empressas a contan com a contrataça de terceiros para a realizaço de trabalhos especticos. Todas as exposiçes realizadas no CLSFF sempre foran gratuitas as exposiços tematicas merecem algumas criticas, sendo tambern dificil fazer a sua manutenţo por seis meses, porén sao 
determinantes na historia da fabrica e o SESC e praticamente a

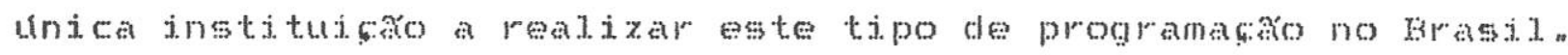

\section{Terceira Idade}

0 setor da Teredra Tdade cuida dos grupos de 1 dosos que frequentam o CI..FF" 0 SESC vem meatizando programas para idosos descle 1963 sendo a primejra entidacie a apresentar uma proposta de trabalno social. com estas pessoas na tres projetos desenvolvidos pelas unidadesa os Centros de Convivencian que reunem pessons com idade superior a 50 anos, epropoem praticas frsicas atividades de expressaso visando una integraço social o convivio grupal a Escola fberta da Terceira Tdades que oferece cursos com informacrs sobre o processo de envelhecimento " com o objetivo de levar o idoso a rectescobrir interesses que o requilibrem socialmentea a Freparacko para Aposentadorian que sugere como aproveitar o tempo com ocupacoss que possan valorizar a vida aposs a desvinculato profissistional.

Nas jobia de Lina ko bardin o trabatho com os dosos deveria ser tal. que os integrasse ao espaco a dos demajs frequentadores 1. evandowos a participar da movimentaşo da fabrica portom comenta se que a tendencia inicial no sESC Fomper foi a de separaros protege-10s: atumimente os grupos de idosos concentramse nos bancos da area de convivancia passam as tardes jogando baralho gostam " principalmenten de dancar e viajar " Desde 1984 Trene Marques D'Avida a responsavej pelos idosos que tambem a auxiliam

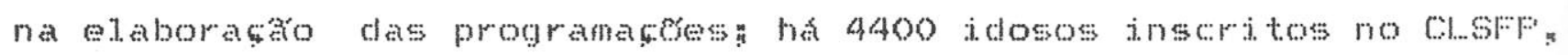
com o comparecimento diamo de 400 , numero que aumenta bastante nos dias de baile. Duas vezes por semana realizanse atividades de ginatica aquatica recreaço esportiva coral dangas to teatro e oficina literarjag una vez por mbs ha un sarau quando cada um apresenta o que pode (contam piadas ou cantam) e contrata-se un grupo para a Noite da seresta tamberm mensamente ha uma visita aos museus e e promovido un passeio as cidades proximas. o programa da Terceira Idade mantém uma cooperativa de serviços onde cada idoso inscreve suas aptidøes para ser chanado por quen necessitar daquele 
tipo de auxidion o ClsfF reatizou dois Encontros vacionais de Idosos (setembro de 1.932 e Outubro de 1984) com apresentaşes de teatro, musica edanca realizadas por grupos de idosos de varias cidades, debates sobre os problemas dire dos do idoson

Sabe-se que o velhon com a perda da beleza do vigor fisicon f rejeitado edepreciado por mutos sendo vt tima de preconceitose jmpedido de vivenciar sua sexualdade pois para a nossa cultura, "ele ja passou da idade" now ha trabaho preventivo para se acejtar o envelhecimento a pelo desprezo que as pessons apresentam, parece ser a velhice una dimensáo a qual nunca văo chegar. Mesmo no SESC Fompeia a Tercejra Idade é un programa ao

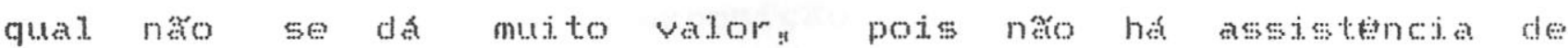
profissionats especializasos naso se gasta dinheiro com

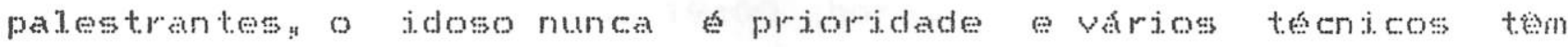
aversaro por eles, sendo que em outras unidades do stiso ha o mesmo descaso. Os idosos que frequentan o Clspo sao ansiosos para comer negan-se a falar sobre a morten brigan entre si por ciumes nas trocas de namorados " e na sua matoria sao indivfduos que foram

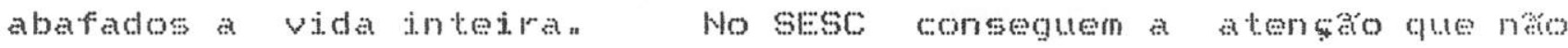
receber de suas fantidas dada pelos professores e pelos cologas de grupo, possuen un espaco para encontrar pessoas que viven as mesmas angustias acabam sentindowse mais seguros.

\subsubsection{Teatro/Choperia}

\section{(Area Socio-Cultural/Coordenaçăo da Programaçăo)}

As programaces realizadas pelo teatro pela choperia do CLSFF sáo phanejadas pelos mesmos tecnicos n o Teatro cu cua concepsáo arquitettnica difere dos modelos habituais a assemel ha se a um teatro de arena retangutar, com cadeiras inteiriças formando as duas plateias (700 lugaress) defronte ao palco de praticaveis, e bancos dispostos nas gaterias lateras (100 lugares) "Todo o mobilifario de deminado de pinhon o piso e de concretoy as paredes de tijolos originaiss ("que fazem qualuer refletor virar luz ambiente" "segundo Tose Fossi. Neto) " hăo ha coxias es dos tres 
camarins, o mais amplo náso tem 1 igatro con o patoo, sendo usado

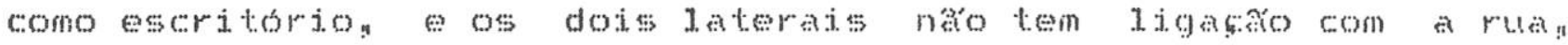
obricgando o artista atrasado a passar por entre seu públicon

o hall do teatro coberto com telhas de vidro delimitado por altas portas de trelisa nesta arean alem das portas de entraca do teatro "estáo instalados banheiros bancos" a bombonjere a bilheteria movel. (um grande caixote de maderira) y a as escadas de concreto para acesso apos o inteio do espetaculo. Sáo reatizacas no 10 cal exposiços de apoio a programacao do teatro (poucas durante 0 ano) e eventualmente se usa o espaco como alternativan quando os locais habituais esta ocupados por outras mostras correndowe o risco de a exposiço presente náso combinar com os espetaculos apresentados o hall do teatro esta liberado para o publico da unidade ate as 19 mo horas e a noter o acesso faculado apenas ao publico do esetaculos trinta minutos antes do seu inf.tion

O teatro nunca dispos de bons equipamentos operacionats. Os primeiros projetores $35 \mathrm{~mm}$ tinhan problemas cronicos de som com a vinda do novo equipanento do cine Sesc: a fabrica herdou proietores que nao foram ainda instalados navendo problemas devido a necessidade de se adaptar a cabine para recebe-1os e a distancia que pequena ate a tela. Năo ha urdimento para quen se apresenta o tentro oferece quarenta refletoress una mesa de controle e ofuminador Abel Kopanskin un dos melhores de sato Fauto, cabendo o som a produço do espetaculo.

o criterio de locaço determina ao\% da bitheteria bruta ao SESC, 0 tempo de uso restrito no limite de duas semanasg a liberaço junto aos escritorios de arrecadacho de impostoss a

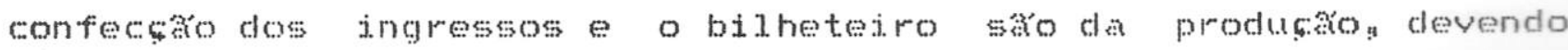
sempre haver desconto aos comerciarios. Adenor Serrano, responsavel pelo teatron acredita que se o SESC fornecesse o servico de some un sistema de iluminaço de melhor qualidade seria aumentada a procura do espacon que em certas epocas naco apresenta nadan 


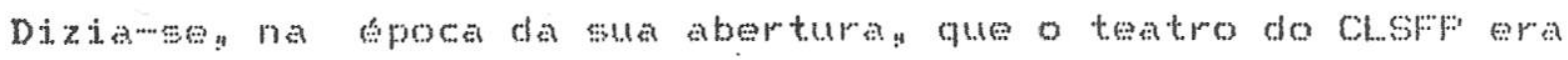
um local apropriado para pubjicos novos a procura de ares menos abafados que os dos camates de palcos intelectualizadosy porem comesou a ser usado de forma bastante convencionat com a pecta "0s fithos dos sitencio" para todos os seus assentos serem ocupados. há que se programar apresentaçes experimentais e mutimfdias com linguagens diferenciadas, o que nato fe ficil de se consegur." portanto o teatro tem una rotunda que separa as plated as y de $\mathrm{x}$ ardo

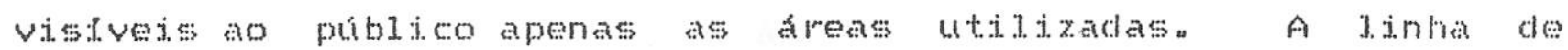

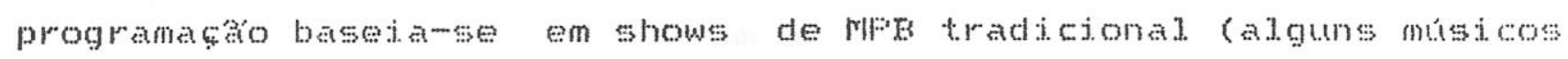
acejtam se apresentar para un lado e depois para o outron porkm muitos se recusane usan so uma plateia) projetos panoritnjecs de musica pop e urbana e apresentaçes de danç e mimican os grupos Fumo Fremeditando o kreque e os musicos Arrigo Earnabe tete Espindolan Eliete Negreiros e Itamar Assungron tidos como a vanguarda da musica paulistana tem seus nomes vinculados a jmalom cla fabrickn

A porcentagen de comerciarios e minima náo utrapassancio $15 \%$ wom qualquer espetaculon os publicos diferem bastante conforme o que se oferece sendo que a pior audiencia $\mathrm{e}$ a de shows de rock as pessoas timan a camisan uriman nas galerias a chegan ato a putar da galeria para opacon A segurança nomamente precisa pedir para os namorados se controlarem nos bancos do hata o camarim deve ficar fechado para que as lampadas náse iam roubadas o os banhejros sempre sofrem atentados portas sendo quebadas e arrancadas e os rolos de papel higituco espalnados pero than

A choperia en seu infeio apresentou bons shows que se constituiam erm atornativa para o teatron e depois passou a trabalhar con grupos fixos, gue se 1.gavan ao espaco durante mesess Hoje, ao contráron buscase diversificar ao maximon com a

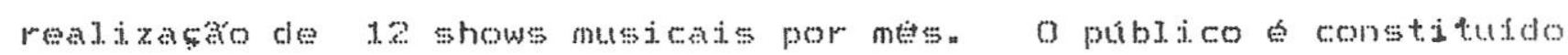
de jovens na sua grande matoria a programaço obedece ao seguinte

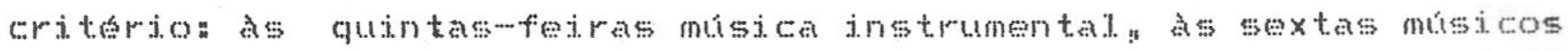
de Mron aos sabados samba aos domingos rock a tentativa de 
trazer espetaculos majs atemativos falhoun o publico os vajava jogava cerveja no patco. o programador welington Wagner Andrade conta que o langamento de discos nunca deu ento na choperian.

Houve aos domingos, durante um ano meio. progranacaso de

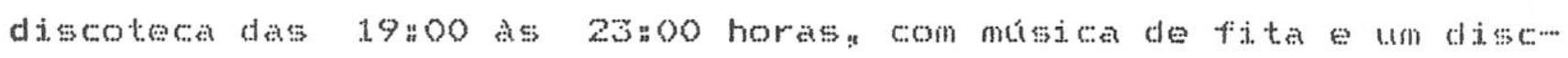

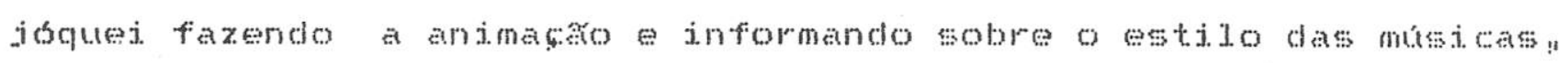
repetindowse modelo das danceterias a presos baratosn forem a discoteca fot suspensa devido as brigas des gangs da regia so seu vandalismon certa vez colocaran uma bomba dentro do vaso sanitario que abriu um buraco no chao do banheiro da choperian

Os batios da fabrica reuniram mutas pessoas nos primeiros anos da choperia chegando a manter boa frequencia ato 1988. depois decaram muton Ha baties trationotis que anda sa

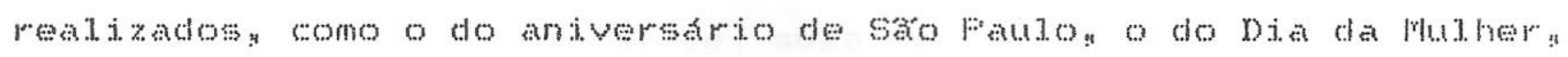
o da Imprensa (tradicionalmente com Faulo Poura), o dos Wamorados" o do aniversario do sfisc Fompeta e o do Dia dos comerciardosn

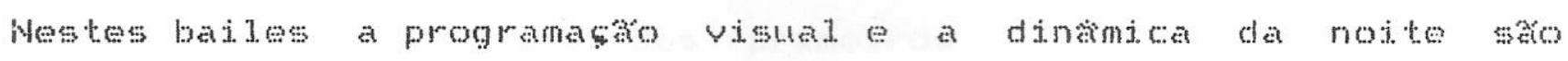
produzidas pelo sesc.

Alguns problemas impeden que a choperia funcione como casa de

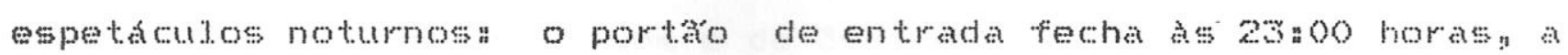

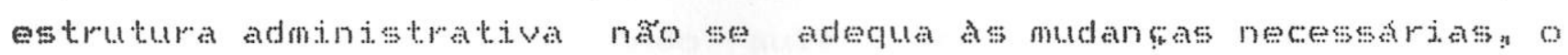
preconceito do publico elitizado que náo quer se misturar con as pessoas mais simples que frequentan o Cl.spF a periculosidade da área que circunda a fábrican

\subsubsection{Qficinas/Projeto Curumim}

(Area Sócio-Cultural/Coordenaçăo da Programaçăo)

Ass oficinas foram concebidas como centro Experimental de Criaço Artistica planejadas com o equipamento necessario para se desenvolver diversas tecnicas plasticas pensandowse na conceptro da atividade artistica como expressaco mas acabada do lazer. Durante os estudos feitos para estabelecer a programaço no SESC 


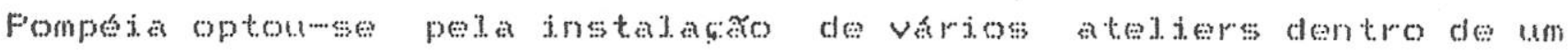

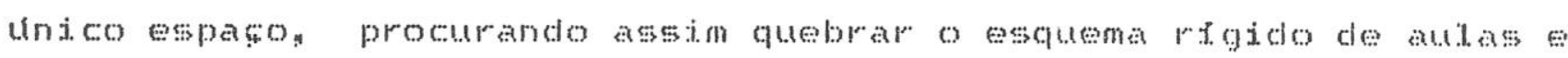

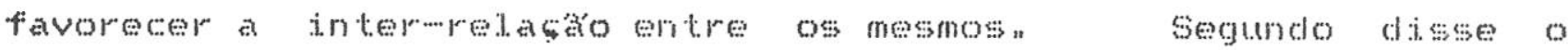
diretor Estanistau da silva sates " " " aquit as pessons nato

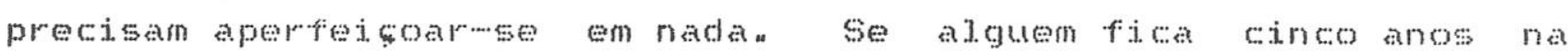

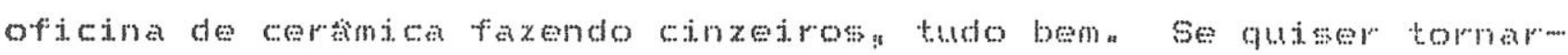
se um ceramista profissionat n tera condicoss mas nada joposton o exeretcio do taxer os jogos ludicos sao que nos interessan"

As criticas feitas aos primeiros tempos das oficinas foram a de que os instrutores eran eriativos mas naso tinham didatima naw havia controle nenhum dos materiats e tudo acabava se percendo em euforia Acontecen porem que apos un curto pertodo as oficinas da fabrica ficaran bastante desareditadas pois o sesc naxo consegua estabelecer un plano para a atuata dos ateliersy varios instrutores 1090 deststiran de suas aulas e mutos alunos so frustraran com os cursos.

Todos os instrutores dos primejros anos sallan an dos cursos oferecidos, apenas os de marcenaria e certimica possuen instrutoress

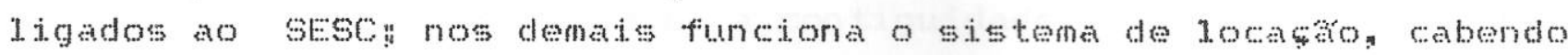
$20 \%$ ao $5 \mathrm{sc}$ do total arrecadado (com excesa do laboratorio de fotografian cuja porentagem e de $30 \%$ e tambom o curso matis caron e ha cinco professores dando autas) com o compromisso de se oferecer presos mats batxos aos comerciarios como o seso cobra pouco nos cursos dados pelos seus instrutores, os professores acabam sendo obrigados a adequar seus precoss o que faz com que alguns cursos sejan ate desacoditados por estarem muto baratos.

Ass oficinas recobem fazen propostas de cursos! tendo sido mecentemente convidados professores de Thebanan encacternation historia da arten pintura de tecidos e restauraço de moveis o os cursos normalmente tem aulas uma vez por semana (com excecto de fotografia e teatroy com duas autas semanais), sendo os mais

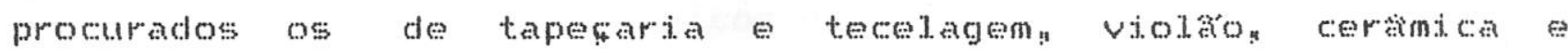
marcenariag que contam com fila de espera atuamente hat 19 modalidades de cursos (sendo 16 regulares) que possum soo alunos 
inscritosn Notase muta variacso da frequencian com pessoas entrando e saindo - apos tres meses a pessoa aprende o que acha que deveria aprender e vai embora os meses de maio e outubro saro os de maior púbilico.

Ferjodicanente saro fejtas exposiches para se mostrar imagense pecas relativas aos trabalnos desenvolvidos nas oficinas (a mostra "Artificium" jat e tradicional sendo realizada em dezembro com o que se fez durante o ano) e ha tamber exposicess com os desenhos pecas resutantes do Frojeto Curumin. os paneis sáso pendurados nas paredes divisorias dos atelders as vitrines sato colocacs nos corredoress porem nao ha juminaço adequada e as pẹas se sujam com mut ta facilidade devendo tudo ser protegido com vidros.

A seguranģ o um serio problema nas oficinas pois nás ha espaco para se guardar nada os teares as matrizes de gravura

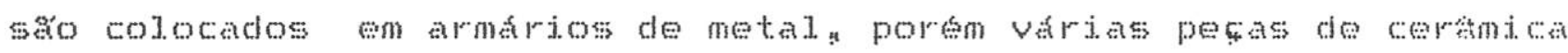
e marenaria foram roubatas durante sua execuçon o que ocasionou a improvisaço de prateleiras com grades e porterms para techar a entrada dos ateliers. As criancas do Curunim atrapalnan as aulas da tarde com sua gritaria e a contiguidade das oficinas causa certos transtornos! tais como a poejra que sobe o o barulho da serra da marcenarian

o Projeto Curumi esta vincutado as oficinas por utitizar principalmente desse espaco.

Fara participar dos grupos regulares as inscribos sao gratutase estao sempre abertas a quantidade de criancas que realmente frequenta varia chegando-se ao maximo de 150 criancas. o que corresponde a 50 ou $60 \%$ do total de inscritos. A maioria das crianças no saco dependentes de comerciarios; apesar do objetivo inicial (apenas $30 \%$ das criancas que frequentam sao filhos de comerciarios)" mas normalmente pertencem a fartidiss de baixa renda, que vivencian problemas cronicos de fat ta de espaço e de condicoes razokveis de moradia apresentando deficiencias na saude e na educałăo -.. nem mesmo sabem como podem utilizar o tempo livre. 


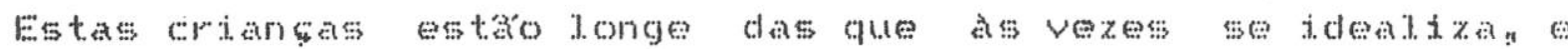

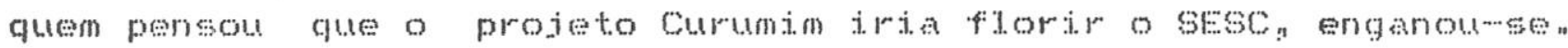
Houve no infeio un choque entre o curumine os outros setores do SESC Fompeia pois a presença dos grupos de criangas -- mutas vexes una molecada brava -- perturbava, com barulho agitacaso, espacos e pessoas ná acostumadas at presença de erianças como os idosos reunidos habitulmente nos seus jogos de cartas na area de convivencia. A forma agressiva das criangs ocuparen o espaco contratava com os desejos da administraço do seso fomperia pois nao queriam que as crianças deixassem rastros ou marcas da sua presença Nos espaços mats vistvejs como as paredess dos ateliers. só podian ficar as coisas aprovadas esteticamente "e os trabahos en andamento independente de fazerem bem As criansas s se nás fossem bonitos de ver" nato podiam aparecer" A segurang ou permitia ou proibia tudo "com atitudes curas contra o comportamento natural. dessa idade parecendo náo compreender o que é ser coringan A fabrica representava para elas un parafso com livros a lanches: piscina bolas, espaco e provocava una excitaço e una piraço differs de segurar sendo tarefa dos instrutores estabelecer certos limites e enderesar este frenesi para algo criativo mostrando algunses vias de expressan.

O SESC Fompera 6 composto de espaços abertos sem definicoses para usos especticos ne as criancas por eless se esparraman 0

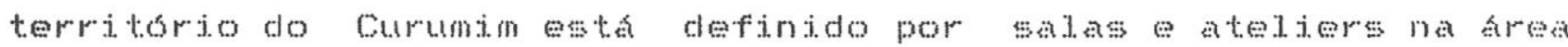
das oficinas e una quadra e salas de ginastica no centro esportivo. Estes espacos sáo compartihados con cursos e progranacos regulares da unidaden o contato ecologico localizase no ato do grande prêtio esportivo no heliporto sa que náa foi permitido cultivar un canteiro em local vistvel. Fara se identificar quem pertence ao curumim, faz we uma carteirinha com foto nome e idade da criança essa carteirinha e perfurada e pendurada ao pescoso por um barbante. o que facilita o transito para o predio esportivo e piscina. Ha muta dispersán nos elevadoress escacias e o espaco nao facilita a organizaço de un grupo coeso de criansas que se perderm nas idas a banheiro. Segundo os instrutoress o problema do curumim náo e tanto de espacos mas de estruturan com fata de 
equipamento basicos como bebelouros no conjunto esportivo e estantes armátos e bancos nas oficinas. Tudo se improvisa ese arma de forma precaria e provisoria.

A presenca da criança no SEsC Fompoja ressalta a atuaço

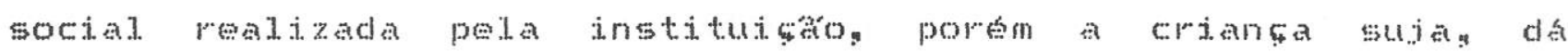
trabalho e requer cudados" 0s instrutores dedicam muto do tempe do Coumim a harmonizaço dos participantesa pois há diversidades

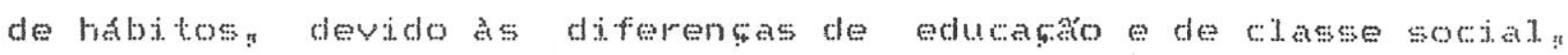

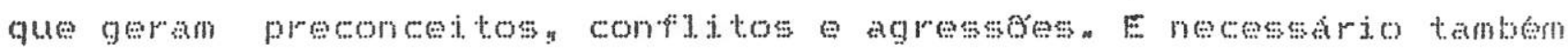
orjenta-las para que tenhan maior cuidado na utiazaça do materiats, objetos espasos de uso coletivon

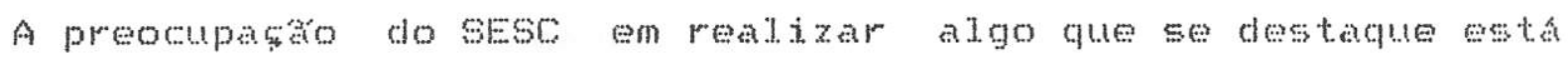
presente na insistencia com a producho de pequenow eventos infantis

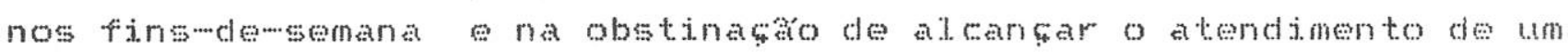
numero massivo de criangas. segundo a adminjstrackon propeto serat bem sucedido quando se tiver 500 crimncas por dia no curumim

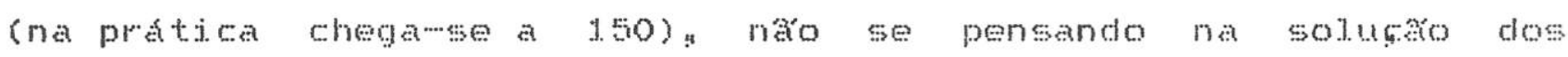
problemas de espaso e equipamento que isto iria ocasionar.

0 Curuming porkm apresenta tambem aspectos bem positivos! pois tira a crianca da frente da televisto possibilitandowhe atividades ludites e convivencia socialn alén de cutidar de um segmento de publjoo que permaneceria discriminado caso năo houvesse

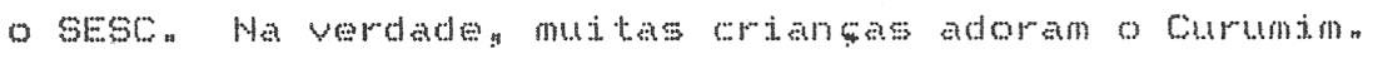

\subsection{Frequencia e Funcionários do CLSFP}

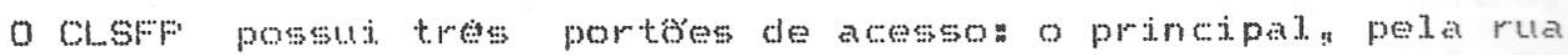

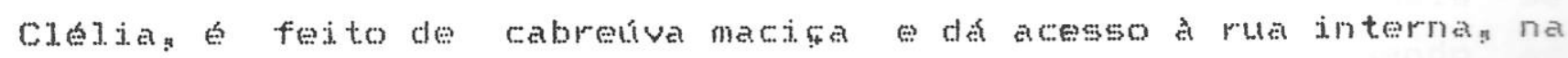
qual naso se permite a entrada de velculos a estando aberto aos

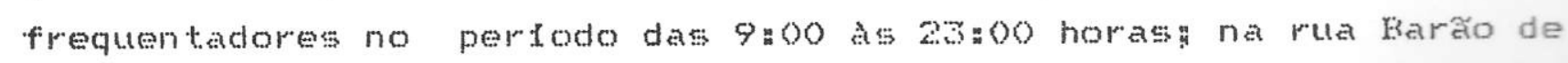
Bananal. a alta porta de trelica fo usda quase que exclusivamente para a passagem do material de produsáno dos espenteulos do teatros * portá de tela de arame do conjunto esportivon na avenida

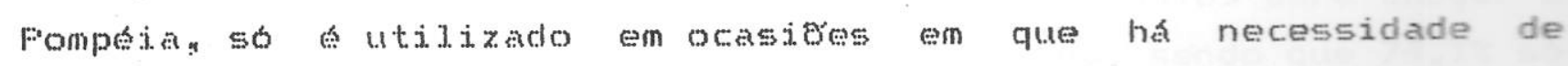


separar o publico esportiata como guando ocorre alguma comerorago especiat nos galposs culturaism

A frequencia ede 2.200 pessons erm media por dia da memana aumenta aos sabados e chega a dobrar aos doningos porem esta longe do que se previa após o funeionamento do conjunto esportivo: ou seja, 8.000 pessoas por dian

Conforme estudo realizado pelo sESc en 1986 o frequentador do

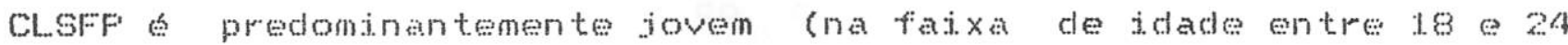
anos), do sexo masculino solteiro mora com a fambian que se compoe de quatro a seis pessoasn seu nivel de escolaridede de segundo grau ou superior vinculos empregatfcios) e ganha ate 3 saldrios minjos por mes (40\% deles exercem trabahos administrativos $30 \%$ estro jodos a empresas de atividades comerciais e $14 \%$ sán trabathadores do comercio) " Este frequentador ia teve empregos anteriores e estát no atual ha mas de tres anos: trabalha de segunda a sextarefira de oito a dez horas por dia o cine SESC o OESC Fabrica da Fompeia sao as duas linicas unidades cuja major frequencia e de náo matriculados no $5 \mathrm{se}$.

Quanto ao tempo livren a media dos frequentadores tirou ferias até há un ano atrase o que mais fez foi viajar para fora da cidade, assistir televisaso ouvir ration Dispoe nornalmente de duas a quatro horas iveres por dia durante a semana mas de dez horas livres aos sabados e domingos: quando procura encontrar amigos, namorar ou conhecer pessoas, ir a clubeg ver televisason ler jornais e revistas, ouvir musica em casa ir ao cinema teatro, shows, festas e bailes: os assuntos sobre os quats mais se interessa săo principalinente artes ern geral (57.8\% s\%ondo as respostas multiplas) e polftica e economa $(49,6 \%)$ n

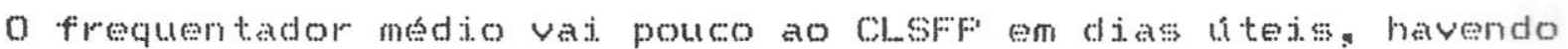
grande preferencia pelos domingos" quase sempre esta acompanhado por andgos colegas. Gasta no maximo zo minutos para chegar a fábrickn fac o percurso a pé ou de tonibusq sendo gue $74,1 \%$ só 
frequentam esta unidade. Frocura o SESC Fabrica da Fompeia principalmente para descansar ou "ficar solto", encontrar amigos: almofar e assistir apresentagess de musica ou danga praticando pouco esporte.

Na epoca de Jose Fapa Juniorg quando se faziam oss projetos grandiosos, o público da fabrica era a classe media alta y com uma frequencia minima de comerciarios nos cursos e nas atividadesa depois a con as alteraçes no corpo de funcionarioss as mudanças na programaşo e a abertura do conjunto esportivos comesaram a aparecer jovens carentes de atividades culuras e esportivas segundo Francisco Carlos fivess "un pessond da ciasse baixa e da periferia descobriu o SESC Fompeia e esta faxendo aqui seu chube particular" De acordo com Domingos Barbosa da Focha atualinonte os frequentadores saro de baxa renda com exceso dos que vern para eventos determinados: destacando-se principalinente dois tipos do pubjico: os que recebem a informaço via jmprensa e vaco procurar um produto especificon e os frequentadores habituaisa principalmente comerciarios que guerem passear - alguns chegan a comparecer tre\% vezes por semana Destas pessoas ja se conhece os costumes e ja se sabe de seus tracados pela undades onde passam o dia "sa como que comproprietarios da fabrica, considerada extensaio de suas casas a forman un contingente de pessoas querendo administrar cobrando ate mesmo a limpeza nos banheiros as tecnicos comentam que o publico atual do SESC Fompeia vem sendo composto por pessons de culdura restrita e massificada que saco pouco exigentes e aceitan qualquer coisag o que na obriga o sl:sc a melhorar a qualidade de sua programaço.

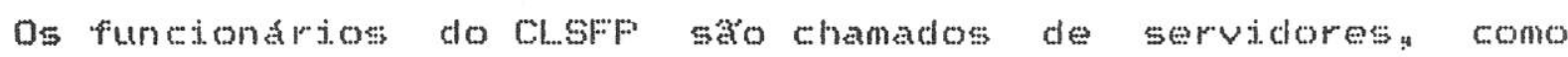
todos os empregados do SESC, tem suas jornadas de trabalho. ferias licenças: direitos e obrigatess regidos pela cl. Consolidaçăo das l..eis do rrabalino que e normalimente usada pelas empresas; sendo que a ela se acresce o regulanento interno da instituigro na parte de pessoal. A antiga lei de estabilidade por tempo de serviso apos 10 mos de trabalno vale apenas para os contratados antes de 1967, e o SESC possui ainda hoje pessoas 


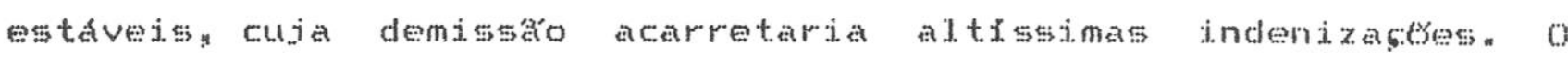
diretor regional. Danilo Santos de Miranda ao contrario de seu antecessor Fen to Fequixa e optante do fundo de garantia, ou seja, se for despedido a instituiço năo lhe pagara nadan e isto acaba por deterninar certos limites na sua atuasto.

Fara os tecnicos do SESC o quadro de carreira atual se inicia com o cargo de animador culturat. passandome a animador socjoculturat coada uma destas categorias tem 5 cotasn a diferenca salarial entre as cotas e de 10\% sendo que o que recebe un animador cultural. cota 5 equivale ao ganho de um animador socio cultural cota 3$)_{n}$ assistente tecnico un e dois assessor as assor consultor e consultor tecnico un dojs e tresp o lid timo cargo deste quadro tern un salario nove vezes maior que o primeiron os animadores programam e realizam as atividades nas unidades, os assistentes tecnicos normationte ocupam cargos de chefia e os gerentes sacos assessores e consultores que estao dirigindo as unidades. Com o novo presidente as nomenclaturas anteriores de monitor cultural e orientador social (que jat ha algum tempo năo definian as functos dos tenicos) foram mudadas para animadoress o diretor das unidades passou a ser chanado de gerente (com a incumbencia de gerenciar as determinaçess centrais) e adotoumse uma politica apertada de pessoal e salariosa com o corte da gratificaço de funço (10\% a mais no salario por se ocupar cargo de chefia). corte do quinquenjo para os novos funcionarios (a cada cinco anos de casa, $60 \%$ do salario mensal dado anualmente) e dificuldade de ascensa nas cotas (no pertodo anterior ara concedida una cota a cada dois anos, mesmo sem muitos moritos. apenas por se ter permanecido na instituiço) "

A grande meta de Abram Sziaman é construir unidades" sem aplicaşos no corpo técnicon comenta-se que a intencko do presidente 6 de se firmar como lider empresarial, ocupando-se mais com a relaşa da Federaço do comercio diante dos ministérios governamentais do que con a imagern e atuaşo cultural do SESC. 
No seu intejo o ClsfF possus a em torno de 150 fúmionarios a hoje, com o funcionamento do prodio esportivo" conta com zoz" Apenas uma pessoa da area tecnica esta na fabrica descle a sua aberturas os outros funcionarios ou foram dentidos no episodio de outubro de 1934 ou se desiludiran com o sesc e sall ram por conta proprian As pessoas que entram hoje para trabahar no cl.sFl nao saber que naquele espago havia uma indistria de tambores e geladeirasy sendo que no indeio a historia da fabrica era rutuata por todos: o funcionario comeşa ja direto no seu canto e la permanecen como foj. o caso de uma telefonista que ficou meses ro SESC Fompeia e nunca foi ao prétio esportivo. os funcionarios comentan que quem entra hoje no st:sc năo sabe o que a instituja ja fez nem o que pretende fazern como se as definjeces da entidade estivessem di.tudas wom novo contexto que nato se utidixa mais de antigos aprendizados "como os da spoca da unimos"

Quando rose Fapa Tunior era o presidente: $60 \%$ dos gastos do SESC jam para o pessont e naquela poca se ganhava realmente bemy mas hoje apenas $25 \%$ se destinam a folla de paganento E costumes funcionarios reclamarem que estáo recebendo poucon porem que se observa que o sesc vem acompanhando a media do que se paga nas

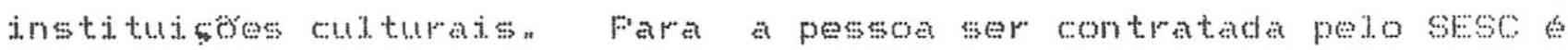
necessario assinar certos termos de acordoy todavia $10 \mathrm{~g}$ os funcionarios comegam a reciamar por terem que trabalhar aos domingos e feriados sem ganhar o extra correspondenten aum entra com processo trabalnista contra o sesec quase sempre ganhan

Apesar de possuir un quadro de carrejra ben defindo para os técnicos culturass năo se sabe o que deternina o aunento de cotas a ser concedido a un funcionarion ja que nato ha corterios visivejs para a avaliaço profissiona. o setor de recursos humanos do SESC nó conta com a participaço de pessont tecnico, sendo dirigido apenas pela area administrativa e nota-se que para os funcionarios 1.jgados aos departamentos burocraticos hat ainda certas possibilidades de ascensân As pessoas permanecem no SESC pela segurança que possuem lá - afinal năo ha mutas opceses nesta área e porque gostam do que fazeng o contato com a materia cultural é 


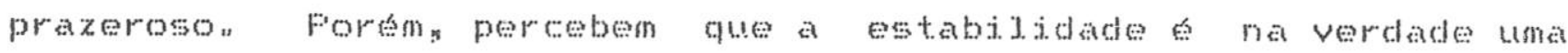

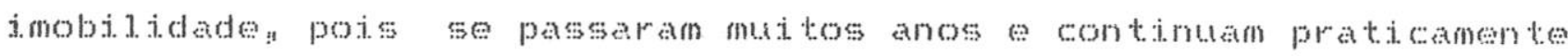
na mesma condjesto profissionat.

No intejo os professores. coordenadores e andmadores estavam sempre presentes nos eventos; ficando muto tempo ha fabrican mesmo sem ganhar horas extras garantindo assin o sucssiso das sus atividades " Hoje os servidores esperam ansiosanente a hora de bater a sata no carta de ponto e vivem rectamendo da comida dos

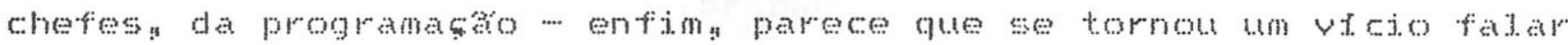
mat do st:sc contudo gostam bastante da fabrica wapanto lugar.

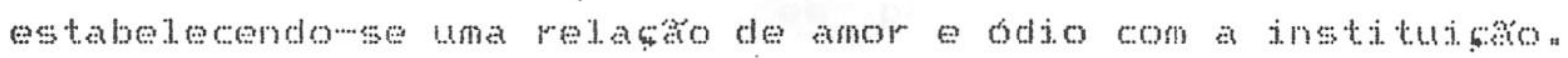

Os funcionarios da area tecojoa reclamam de serem tratados

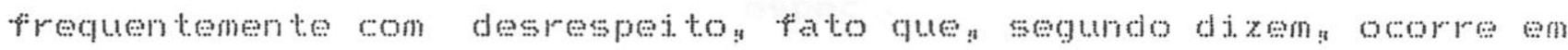

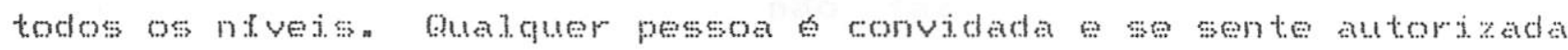
a dar palpites na area alneia nao se considerando o maior conhemimento que determinado tecrico supostamente possuis do seu

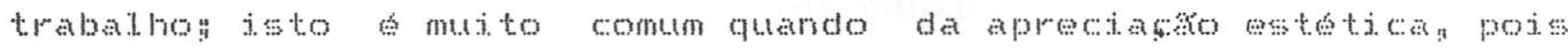
como se trata de um criterio subjetivon todos se acham possudores da sensibitidade que determinaria o bon goston Desagrata ans

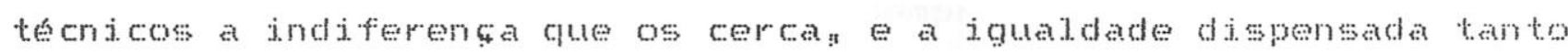
aos que se empenhan quanto aos que se encostam ou seja

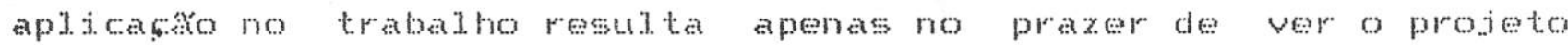

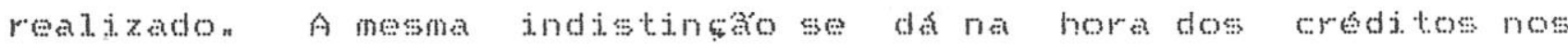
impressos, quando os tecnicos que realizaram as atividades se vom acompanhados por uma boa quantidade de companheriros que nada

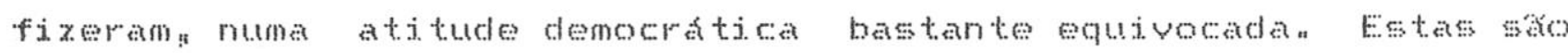

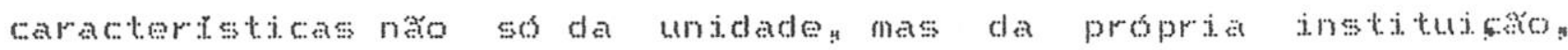

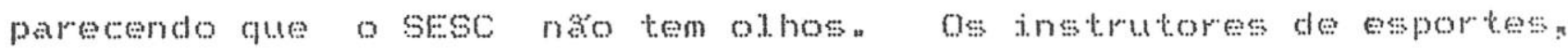
das oficinas e do Curunim sachoristas e receben conforme a tabelat nå ge fazendo distingso entre as diferentes habididade de cald un

E. importante notar que náo ha profissionats esperiatizados trabalhando no slesc com a ressalva feita ao iluminador do teatro, sendo contratados servigos de tercejos quandose necessitas isto provavelmente se deve a atumboro polivalente dos tecnicoss que 
depots de un erero tempo peremere que o tipo de experiencia

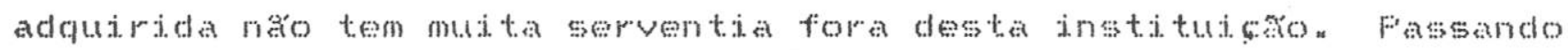
aos funcionarios a ideia de que enecessario "vestir a camisa" vigora no 8 Se a tendencia de que todos deven faxer un pouco de tudo (o que perceberse depois. representa um pedido abusivo)" acontecendo casos como o de un jardinejro que e transformado em proiectonista e tecnico de som numa estrategia provavelmente economica que compromete a qualidacle dizse que o pagamento previsto para tal. cargo ná daria para contratar um bom profissionatn e jmprovisarse a inves de se tentara o que parece muto difficil ajustar o valor pago conforme o que se exige na

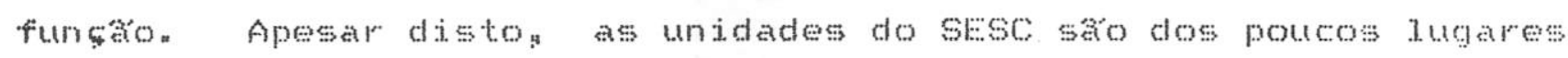
que oferecen razodveis condiceses para quem quer trabalhar com cultura en sa Faton

Como os profissionais especiatizados os equipanentos contemporaneos tamberm parecen ná fazer parte do sistem de trabatho do SESC que os aluga quando saso necessarios apesar da insisteneia dos tecnicos en mostrar que com a soma dos alugueis ja poderian ter sido comprados varjos equpamentosn o cine sesc possui. otimos projetores em sua salan mas o mesmo nấo acontere com as outras unidades do SESC, que se serem de aparelhos obsoletose desgastacoss Dizase que o SESC visa sempre o mais barato em temos de equipanentos: a insistencia no descompasso tecnologico cria algumas dificuldades como a do conjunto esportivo que tem que renovar a a 500 inserignes por mes at más quando qualquer academia tem un sistema de computaston. 


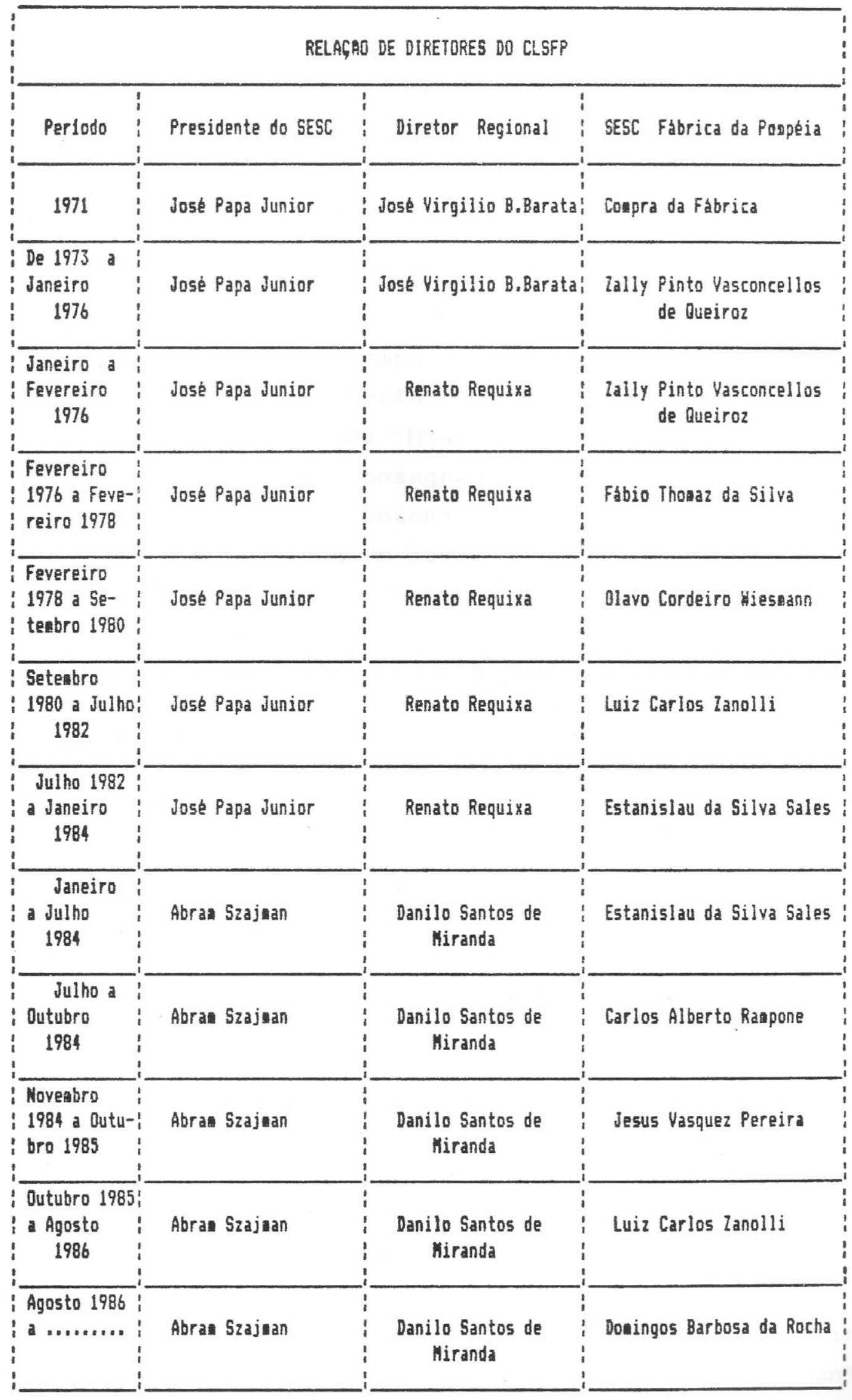




\section{IDENTIDADES E DIFERENĢAS ENTRE OS TRES CENTROS}

\subsection{Conceitos}

\subsubsection{O Que Fazer em um Centro Cultural?}

Observarse ja hat al gum tempo certas tendencias gue vem tomado corpo mas organizacos culturats da Europa e dos Fistados undos. Os museus antigos bancos da Historia e da firten de espacos sobrjos que exibiam pecas consagradas passam tamben a atuar como centros de lazer e locat de encontro entre as pessoss o que gerou Várias discussoses o museu deve abrirme para a cultura de massa ou continuar elitista?

Os grandes museus cada vez mais viven da grandiosa exposicto de carater historicon chamada "block-buster" coria americama que se refere as bombas de arrebentar quarteiro usadas na segunda guerra mundial) " Este megashow das artes platsicas rende bons lueros, reunindo en filas grandes mutidfes que nem sabem bem o que vao ver no tempo initado de visitan e depois compram posters broches: cartoes postais, cambetas agendas outras bugiangas que valem como fetiche, pois trazem o valor encantabrio das obras

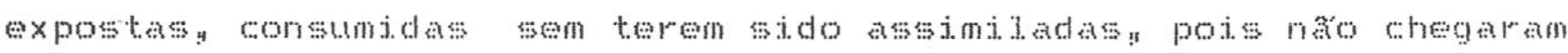
a ser compreendidas.

Ass exposigoss interativas saro a nova coqueluche dos musens a elas tem seu chmax no centro paristense "La Villette" "Tratase na matia das vezes de grandes jogos planejados para explicarem fentmenos das witncias ou da matematican consturdos com o apoio da mas al ta tecnologia Nomalmentey a atividade da pessoa é restrita ao aperto de botbes que chamam os acontecimentos mas as criancas adoram provocar aqueda tempestade de ereitos luminosos e sonoros e fican terrivelinente excitadas pelo encantamento eletronico dessess videowames gigantescoss querendo fazer tudo funcionar ao mesmo tempo. Acontecen portm que as pessoas recebem 
apenas o espetaculong a informaço que a exposicaso pretendia passar acaba sendo descartada desviandowsen assim da sua intencaso inicial. Nos Estados unidos os museus parecem competir com a Disneylandia, com atrativos sonoros e visuais estimulando os visitantes que passan a va-bos como una altemativa de diversa que provoca sensaçoss

No Eurasid parece permanecer a jobia de que muse bu lugar de intelectual! e ha ainda o concejto do museu como coisa rancosa, velha empoeirada! sendo comum o pensanento de que para ser sto io e preciso que seja assim mesmo. 0 museu "entäon nâko a aceito como alternativa de 1azer, quando ate a igreia ja acolneu gutaras eletricas en shows musickis

Fecentemente inauguroumse na Fislgica um grande centro de cultura que conta com piscinase ate cabeleireiros a once esta presentes os produtos cuturas tipicoss como videosn filmes e J.juros, mas organizados em lojase participando de um sistema de vendas. Este shopping cultural qualificou e selecionou seus produtose oferece videos de forma citieriosa vende livros depois de realizar oficinas literarias e tem a proposta de promover um processo educacional. que visa a possibilidade de comprar bem. desenvolvendo un discernimento consumista Faraledarnente. o pensamento na universidade de Ruebec. no canata do animador cultural esta na educaço do consunidor "o animador deve ensinar a se valorizar un bom produto cultural, aquele que vale a pena ser consumido. Fara isto procura aumentar a informaço do individuo, sem pensar muto en atividades, que caberiam mais a escolina

A polf tica cultural das instituicoses esta cacta vez mas ligada a planejanentos mertadologicos que mutas vezes aciban sendo determinantes "causando questionamentos sobre o peso a ser dado aos lucrose aos valores culturasis esteticos e humanosn A pósmodernidade tende a mutiplicar as caracterfsticas e finalidades de qualquer espason e mator perigo do museu como entretenimento talvez seja o de pernitir a perda da funço que o jdentifica. 
Nota-se nos Estados unidos uma disposisao de certos museus a que ja possuem lojas internas, instalarem obras de seus acervos nos sagures de shoppings-centers e supermercados de suas cidades. No Japa sabe-se gue as grandes lojas promovem exposiches em suas dependencias e no Brasil comect-se a utilizar os shopping-centers para exposisoes en iniciativas que exiben arte e cultura fora do lugar que sempre as abrigou. os shoppings sa espacos artificiats con ruas e praçs internas no ambiente comun as lojass apresentando normalmente locais quentes a luminosos decorados con materiais brilhantes cascatas e espelhos; que representan a idolatia da vida en anbientes fechados. oferecen un espaco atrante sempre 1impo, banheiros ben cuidados: varias operes de ianches

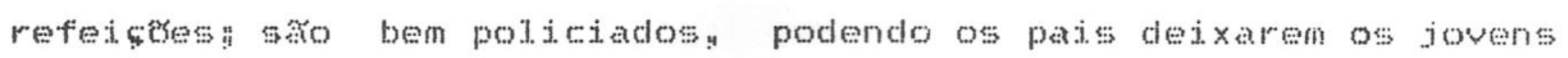
para ir busca-1os no fim do dian e possuem tambem estacionamento gratuton As vitrinas das 10 iss esteticas bem planejadas g sa cada vez mais chamativas e disputam a atençio, estimutando o sonho de consumir. os visitantes apreciam o passeio pelas dependencias dos shoppings que os deixa circutar livremente, e jomtificam-se no se sentirem parte do grupo frequentador"

Weste monento so caso de se perguntar o que cabe aos centros culturais en uma epoca na qual gem princtpio, tudo pode acontecer en todos os lugares. Hoje qualquer hall de banco é considerado

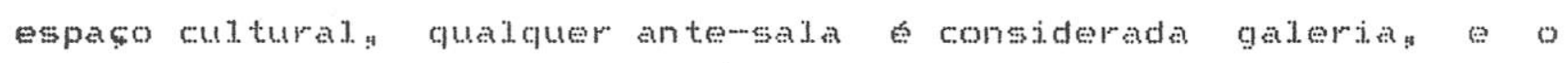
lazer esta espalhado pela cidade em multiplas alternativas: ocasionando indefini çes gerais de jontidade functon.

A indistingso soma das maiores dificuldades de nossos tempos. Hoje parece comum se confundir cultura com turismo -.. como diz Luis Milanesj. - ou cultura com educaço -- como afirma rejueira coelho -.. e mutos pensam no cinema, no teatro, ou no centro culturat como substitutos do sistema educacional 6 , tamben, frequente náo se discernir o que e aço cultural e o que cabe ao serviço social." Além diston quando estáco presentes elementos tidos como culturais. tudo que se faz ou que se pretende fazer vern sendo chanado de aço

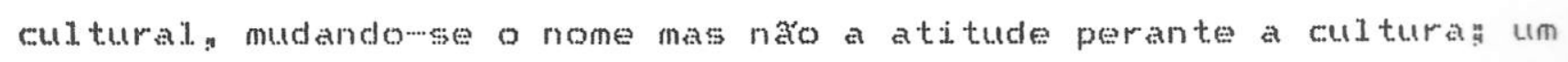


bom exemplo vem do metro paulstano, que tem colocado esculturas e promovido apresentafoes musicais em suas estaceses e manda telegramas urgentes. para a casa das pessoas comunicando a aça cultural da Companhia Metropolitana. Wa d dificil perceber que quase todas as atividades culturais da cidadesa propostas para assistir a projectes e exibicbes de espetaculos participar de cursos com programas estipulados que visam a un desenvolvimento dentro de determinatia forma de expressaco artistican p planeianento culturat para sstas realizaçes apenas se preocupa en que haja una boa frequencia para o que se oferece, naco verificando depois qual o destino dos conteúdos culturats propostos se foran consumidos ou se foran usufruldos e integrados às pessoas.

Fara Luis Milanesi. autor do linico livro brasileiro dedicado a centros culturais "un centro de cultura tera sentido se for construfdo para abrigar açes que se oponham as ideologias

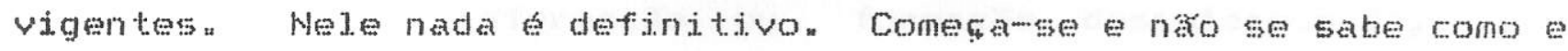
quando acabar. Ele. escapando do sufoco masivo da sociedade contemporzinea e buscando na convivencia humana um retorno a tribalizacaro perdida $e^{\prime}$ un espaço de liberdaden uma casa de contradiços emocionantes de desassossego onde o prazer essencial. \& a resolucho provisorja dos confitosn"( 1 )

\subsubsection{Lazer}

o tempo Ijure das pessoas e bestante usado no convivio. Fara os que viven numa cidade sem praiks as opctes de encontrar pessoas interessantes apontan quase sempre para os bares e restaurantes: a principal atividade de "lazer sociall no brasil fe frequentar o bar da esquinan stmbolo da convivencia brasileira, que recine aposentados, trabalhadores brasais mesmo executivosy para conversar sobre futeboly politica e coisas da vida. As pracks e parques recebern as criangas que váo encontrar os amigos e brincar nos balanços e tanquess de areian enquanto as mases conversam nos

(1)Milanesi, Luis - Centro de Cultura: Forna e Funç\$o, Sto Paulo, Hucitec, 1989 (pg.91) 
bancos. E os shoppings foram eleitos os quartoisgenerais da juventude. que se agrupa en seus espạos ou é encontracla nas casas de videowganes. Havendo essas possibilidades para os moradores das ciclades! 6 mut to pouro para un centro cultural propiciar apenas oportunidades de convivio entre seus visitantes.

o ocion que anteriormente se constituia num privilegio das classes sociais favorecidas comecou a ser possibilitado as outras chasses com a crescente tendencia da reducto da jornada de trabalho, surgindo assim a questao do que se fazer com o tempo livrey iniciase, entán o estudo do que significa esse tempo e como poderia ser usado. Toffre Dumazedier, que criou a Sociologia do Lazer. é o teorjeo majs conhecido nessa arean frara o pensador

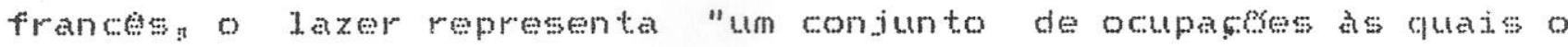
individuo pode entregar-se de livre vontaden seja para repousar: seja para divertir.men recrear-se entreter-sen ou anda para desenvolver sua informaţo ou formatho desinteressada sua participasá social voluntaria ou sua jivre capacidade cridora

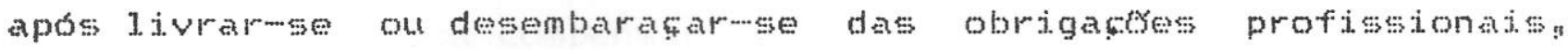
fanili.arese sociatis" (z)

A instituiga que mats se ocupou das questbes do lazer no pais foi o SESC segundo texto entregue aos novos funcionarios da instituisaso o lazer e visto como "superador do tedjo causado pela monotonia do trabalho que caracteriza a sociedade urbanoindustrial. E no lazer gue o individuo vai recuperar ou revitalizar suas energias perdidas ou contidas " " 0 lazer funciona como un equilibrator que ajuda a suportar a disciplina e as imposiçoes obrigatorias da vida social " Finalmentes o lazer propicia o desenvolvimento da personalidade do individuog na medida an que o libera dos condicionamentos que 1 he automatizan o pensamento a aço 0 aspecto educativo, en seu sentido mais amploy de educastio da existencia humana esta jmplfito nessa l. iberasan permitindo ao indivfdulo opeses reveladoras de 


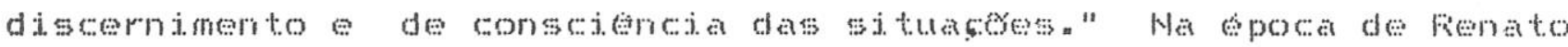

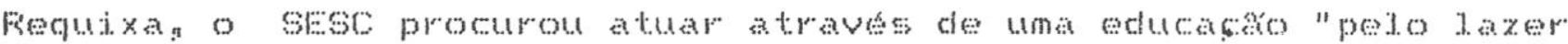
e para o lazer" o responsaved pelo celazer - Centro de Estudos de Lazer, foi Luis octavio camargon que afirmoun "O 1 azer abre um campo educativo ná para se aprender coisas mas para se exercitar

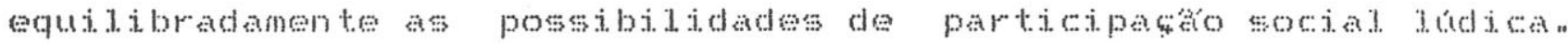

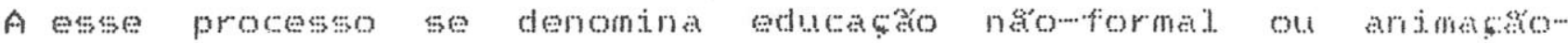
culturat, ou ainda animato sociomentural. seu obietivo mostrar gue o exereicio de atividades voluntarias desinteressadas prazerosase diberatorias pode ser o momento para uma abertura a una vida cultural intensan diversificada e equilibrada com as

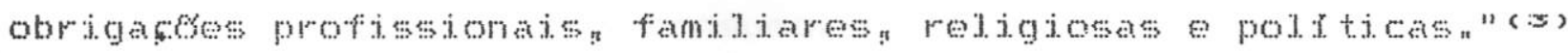

A logica da produtividade industria possibilita pouda ligano

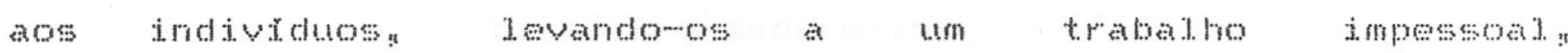
desinteressante fragmentado e artificiat segundo o exteorico do SESC En contrapartida o lazer e sempre liberatorio de obrigatoes $e^{e}$ busca compenser ou substituir os esforços que a vida social impoe en toda a escolha do lazern que permite gra de 1. iberdade mator do que en outros campos existe o prineipio da busca do prazer, e notarse que as associacoes politicas profissionats e redigiosas tem programado o lazer com fregutana crescente en resposta as solidithes de seus participantes " Sobre is to alerta Dumazedier que os riscos de evasaso en redato a todos os engajamentos inclusive os polfticoss multiplicamse pela crensa nas possibilidades de divertimento. considera anda l..uz octavio Camargo que "o papel educativo do animador culturat. menos o de 1.derar praticas de lazer e mais o de mostrar as infinitas possibilidades de participacaro social e de autorealizacio atraves do lazer" n" (4)

(s)Camargo, Luiz Octávio de Lima - O que e lazer, Såo Paulo, Brasiliense, 1986 (pg. 75) 
o lazer foi e bastante criticado pelos que acreditam que a forma de tratar esse tempo de descontraca o determina como apenas sendo um complemento da estrutura social produtivan dizen gue estes momentos nás representam mais do que intervalos de descanso no meio das tarefas e no ocupan espaco junto a outras realizaçes; que se encontian num primeiro nivej de importancia na vida das pessoas. Considerase que os atrativos do lazer naso supram o nfvel do passatempo que os artigos de sua industria tem curto alcance e pouco poder de sedimentaçăon

Na palestra piroferida por Dumazediercs, mobre o sfes Fompeian o teorico franctes arirnou que "mutos reduzem o lazer a atividades medocress domjadas pelo consumo. A arte para estesseria outra coisa diferenten Eis al un preconceito elitista n prewso colocar com charexa que qualuer atividade artistica o una atividade de lazerg para a grande matioria da populaçon a execta de alguns privilegiados que poden viver do trabalho profissional da arten $n$

linfim, o que se entende por lazer? se for tudo que se faz por escolha proprian no tempo que nâso sesta trabalhando o lazer em si. năo representa nada que meresa quaisquer criticas a questán esta no que se induz as pessoas a fazera na maneira como saso convidadas, pela industria do lazer - que objetiva o lucro em nome do bcio -- a preencherem seu tempo livre. A questán portantos julgar como o lazer a processado por nossa sociedade . Ate agoray ve-se que e costume da pessoa que se considera "en lazer" largar-se comodamente năo querer se aplicar em nadan a espera de ser alimentada por prazeres" sendo incomoda qualquer atidude de busca ou compromisso diante deste estado de passivo torpor.

Fara o SESC, cutura e lazer. Iazer e o dominio da diversáo. seu programa institucional procuras portanto, basear se en propostas de atividades para relaxare distrair as pessoas sem

(0) sobre esta palestra o SESC nao possue referencias de data, local ou participantes. 
pedir empenho ou levar a uma profundidaden sená perdewse o carker de entretenimento Ha momentos en que e necessario benofico chegar-se a um estado de aushocia das obrigachess e das preocupacyes; cotidianas, porem este descomprometimento mutas vezes tambern tende a afastar a pesson do que lhe proprion da sua realidade das suas condisoses E assimn inebriada e inerten a pessoa passa grande parte do seu tempo en mejo a sedutoras propostas pseudowculturais que nada tem a ver com a sha vidag aternando um trabalho ardio burocratico - ao qual. f obrigada para obter seu sustento -.. com esse estado de prazer catatonicon

0 melhor aprovejtamento ou o simples consumo do tempo livre depende da atitude que a pesson tem diante do que esta fazendon de quat maneira esta presente. A questa de naco ser un tempo profissional nấo impede o empenho, que pode năo so ser determinado pela necessidaden mas tamben pelo interesse da pessoa em querer aprimorar suas condiçes pelo prazer de se desenvolver enguanto ser humano. A arte resulta do fazer de uma pessoa que tem a capacidade de processar as suas percepgese atraves de uma lingugem expressiva acompanhada de poder estetico e comunicativon o lazer costumeiro está longe disso, pois além de náo proporcioner mutas chances para a pessoa se manifestar atrativos superficiajs de satistaço fáciln o fato de o individuo se assumir como un ser vivo, cheio de problemas fisjocose mentajs; que um dia vaj morrer" "que portanto presisa aproveitar o tempo" talvez seja uma visăo meto desagraduel e pesada re mas simples preencher esse tempo com atividades joscuasn que afastam os pensamentos angustiantes.

Considerandowse o conceito s proposto por Teixeira coelho, que afirma ser a cut tura o saber escolher, a capacidade de diferenciar, pode-se dizer que o lazer tal qual vern sendo desenvolvidon é um processo anti-couturat. pois jnibe a percepsăon A constataça de que o homen da sociedade de massa no guer cultura, quer é lazer, e trata os produtos culturais como qualquer outra mercadoria, reafirma grande tendencia ao comodismo hedonista e expre o 
fundanento da cultura industrializadan que deternina que para poder ser e preciso ter.

\subsubsection{Açăo Cultural}

A materia prima do centro cuturat bs evidentemente a cultura, e a determinado modo de se trabalhar com ela chanaws acko cultuma asta aço ó un processo que envolve elementos polfticos a questom psicologicas e aspectos sociats que se presentificam no campo das relatoes humass mantendo a cutura como seu alicerce. Fodewe dizer que aço culturat fo trabalho reatizado pelo agente culturat junto a un grupo levando seus integrantes a uma producho (ou a uma apreciaço crtica, quando devidamente reatizada) que lide com os elementos wuturats de forma a que cada indivteno possa

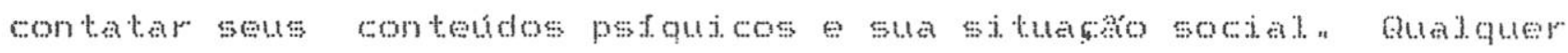

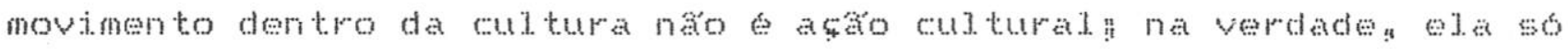
se caracteriza quando algo se move no interior da pessoa

Dedicandowe a examinar os fundanentos da aço culturat. reixeira coelho a ve cono fitha contemporsnea de un pensamento utopista tao velho quanto a propria humanidade que conten o desejo de fazer da arte da cutura instrumentos deliberados de mudana do homen edo mundo. Fara reixeira coelho, que coordena un curso

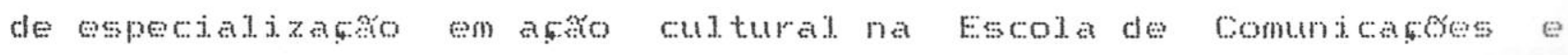
Artes da UsF: a cultura assim como a educagnon estat voltada a constitujeso de individuos pojs ha que se começa da basen e a base o o indivfdu, que ire depois constituir o coletivo a aço cultural o assim un processo que forma sujeitos n considera que náo se deve impor un prograna, se sim descobrir com os interessados o que querein fazer ye diz que no krasil o problema a se enfrentar é

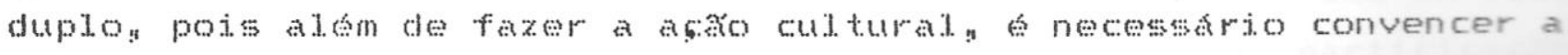
sociedade da sua importancia. A preocupaço basica da acaio culturat, conforme sua visaso, deve ser democratizar o acesso a criaço facilitar o acesso a producho da cultura, ná se importando com o incentivo ao produto. Buscando especificar a acto culturaly diferencia da da animaçon expressăo que relembra una 
spoca em que o objetivo era levar as pessoas a esquecer dos sems problemasy sendo o animalor aquele que organizava brincadeiras e tratava de incentivar as pessoas a se agruparem para mejhor passar o tempon baseado na "mentalidade positiva"y e a fabricacto cuturat possui. un comeso e um fim previstos gerando produtos a a contratio

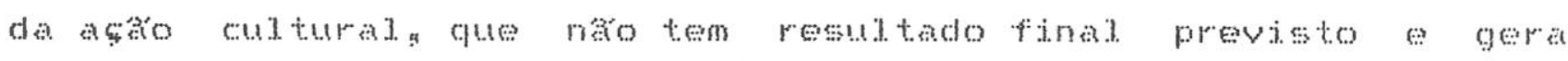
processos.

Examinando-se estes conceitos iunto ans centros estudatos tem-se que o sesc tradicionamente atua prineipalmente wr suas und dades do interior e nas colonias de ferias na drea de andmowo cultural, feita para divertir un grupo de pessoas, com a proposta de jogos e atrativos que term a intencto de ligar os integrantess deste grupo atraves da dinsmica oferesidan rratawe de trazer passatempos para alegrar o ambiente pratica que pode tanto ser vista nas ricas festas dos navios como nas simples quermesses de

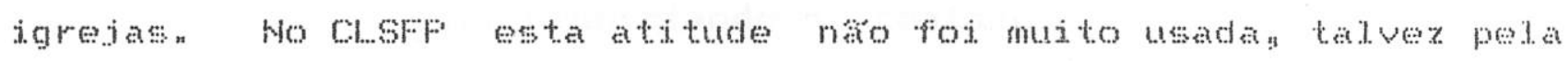
unidade ter sido considerada logo de initio como centro de vanguarda, que acabou se caracterizando pela realizaço cie grandes eventos: o setor das oficinas apesar de sua indefinisa inicial propose cursos na inha da fabricasto cutural com auba para se conseguir fazer determinato objeton ou para se desenvolver preterdidas aptidoes espectificas

0 CCSF apresentou aloums propostas significativas de oficinas infantis nos seus primeiros anos " quado predominou a inventividade e hoje esta area achase bastante enfracuecida. estando mas voltada a formatomo de professores da rede municipal. o centro oferece principalmente exposiçes espetaculos teatrais para serem apreciados mas pouco considera o tipo de contato que podese dar entre os visitantes e o que esta sendo mostracio em suas dependencias: en alguns perfodos estimulouse a participacao popular" mas foram si tuaçes esporadicas na vida do centro.

Dentre os tres centros a o linico que esta prósimo de praticas de aça cultural o o MLs pois o seu Departamento de Atividades criativas tern a intenço de que as pessoas se desenvolvan nas 
Iinguagens propostas mas naso jimpere programa fixos n estimulando experimentar as descobertas as trocas de vivencias entre on

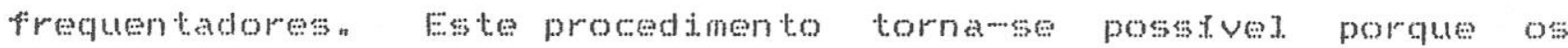
responsaveis por cada setor tem bastante conhecinento nas suas areas e pela joologia do museu, que nato pensa em exibir os produtos resultantess preocupandowe mats com o processo que ocorre nas pessons.

A aço cultural traz en si a ideda de uma intervengon de algo ou alguem de fora que vai actonar um processo, o qual. prosseguirs de forma espontanea no cutro ou no grupo processo que provavelmente nao aconteceria sem aquele impulso inteial " Fara que a aço cutural se des o fator determinante e a pessoa gue im realizallan ou sejan o aconte cuturaly que e um indutory que incita e instiga, criando condiçes para que ocorran as e 1 aboracos as praticas cuturais, efaz a mediacho entre os elementos presentes nos produtos culturais mostrados no espaco do centro os seus frequentadores propiciando o contaton se ná houver a presenca deste agentey se apenas se colocar a disposicho objetos valorizados esteticamente -.. que e o que normamente se raz centro cultural năo estará reajizando sua principal funço e apenas aumentara a oferta para as pessoas que tem o vicio de consumir nao representando muito mats do que un supermercado da cultura.

\subsubsection{Agente Cultural}

Fara Dumazedier: a animaşo social e um complemento e uma crttica aos serviços de assistencia social funciona como meio de desenvolver um novo tipo de relagoes na eidade 6 uma forma de se opor a burocratizaço da vida socialn traz major participaca social dos cidadásos na organizaço da cidade, e recusa se a ver o poder social manipulado pelos dirigentes e tecnocratas ativos sobre uma populaço passiva Enfim, a animaço é feita para melhorar a quadidade de vidag podendo ser diretiva - forma que permite a conscientixaço mas cria uma relagro paternalista de dependencia que nao leva os indivfduos a um melhor entrosamento com o mundo - 
ou nao diretivan maneira em que se sumpeita menos do anjmador, com possibilidades psicologjcas mats profundas reatizando-wse grupos de longa duraço que so trabalhados pela acho educativa e

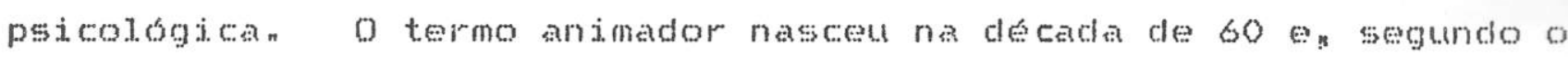
testico frances; "o animador te un personagen que foi pouco a pouco aparecendo ao lado do pregador, que năo mass bastava para animar as obras religiosaş surgiu ao lado do educador que bruscamente encontrou-se cercado por animadores pre-escolares ou pos-escolares que contestavan a escolay repensavanna prolongavan an apareceu ao lacio do inilitante politico, náo mais suficitente para animar a sociedade " Ele deve ser um apaixonado pela cultura gue da vida ao projeto ou ao equipamento eque se propoe a un fazer politico na comundade na so sendo porem un militante polftico partidarion Senăo estaria trapaceandon Dumatedier considera um animador cultural de espirito denocratico como sendo un animador sociow cul tural "(o)

Divergindo desta opinian pelo menos en termos de nomenclatura, reixeira coelho acha que o agente cultural visto como um animador com a conotaço que a palavra carrega significa que dele que parte a açay é ele o sujeito e os tempos de animaco cultural se acabarang afirma que na aço cultural o objetivo do agente culturat nace criar diretamente mas apenas criar as

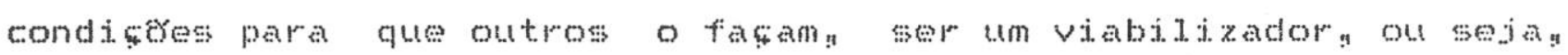
fornecer ds pessoas o maximo de meios para a inventra coniunta de seus proprios fins. Se isto ná acontecer" sempre se estarko montando situacoses artificiats" "O agente cultural estat num cruzamento que liga diversas figuras normalmente afastadas unas dass outras: a arten o artistan a coletividaden o individuo e os recursos economicos cou fontes financiadoras como o Estado ou a iniciativa privaday que năo produzem a cultura diretamenten mas deten o poder de torna-la realidade)" a diz reixeira coelho para quen o agente cultural deve saber o que está en jogo quando se mexe

(6)estas colocapbes de Dusazedier estato en un texto, usado pelo SESC el seu curso de formağa de anieadores culturais, que nato possui qualquer referencia. 
com cultura como se da a abordagem do muno atraves de um codigo artisticon o que fazer para as pessoas aturem corativamente em grupon (\)

A escolat tradicionat. nâo ve com bons ollos os agentes

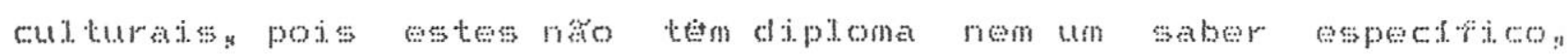
somando alous conhecimentos de antropologian psicologia e comund caçes e exercendo um pouco o papel de assistente sociat o de educaror os professores ter uma funcho reconhecida pela

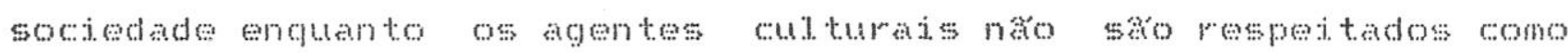
profissionats sendo nomamente sub-utilizados porsm como no caso do ensinon para a cultura na importa tanto o programa esim quem vat reatizaton o principat indmigo do agente cuturate a

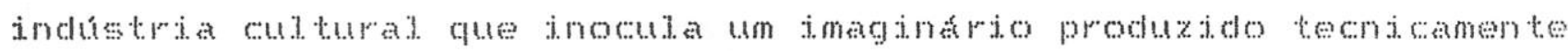
en estudios, o que dificuta o trabalno de possibilitar as pessoas retomarem contato com o que thes o proprion utitizando stmbolos

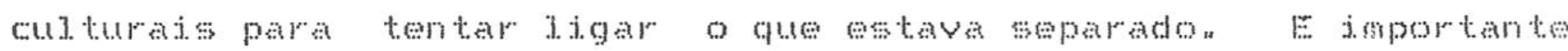

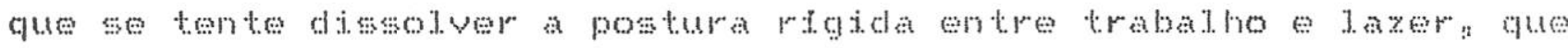

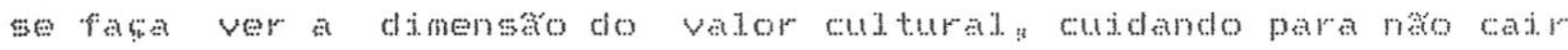
numa auta que arugenta as pessoas, te tamber que se saba distimguir entre fomento paternatisno naso sufocando o que deveria ser estimulaton

Levando em conta sua experitena em bibliotecas publicas "wus Mijanesi afirna que a aço cultural fo feita por pessoas preparadas para isso, que devem compremder o que o publico desejan nao por funcionarios publicos nem apadrinhadosy colocados em locats que se acredita de pouco trabalho responsabilidade "s

Estas paravras se adequam especiamente a cos que como dizem sempre possuju uma quantidade exagerada de funcionarios e quase muna apresentou una oferta de serviçose atividades que

(7)Coelho Netto, Jose Teixeira - O que é aço cultural, Sto Paulo, Brasiliense, 1989 (pg. 67 )

(o) Hilanesi, Luis - Centro de Cultura: Forata e Funçgo, Sto Paulo, Hucitec, 1989 
fosse proporcional a iston A possibilidade de preparar oss funcionarios e agentes culturas para que possam desempenhar melhor suas funços esta bem longe da realidade desse centron

o $6 \mathrm{sc}$ en sua administraço anterior aplicou na formaşo de tecnicos mas hoje os valores institucionats sato bastante diversos e nem ha interesses en se discutir a programatso ou a eficitencia dos seus temicos cuturats estess realizan atividactes esparsas que raramente tom continudade " A maneira como essas duas instituiges tratam seus tomicos alificuta posstrejs praticas espontaness de aça cul tural.

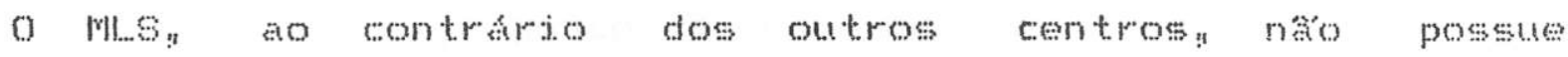
funcionarios que ocupan cargos por arranjos polt ticos ou por outros favorecimentos " A maioria do seu corpo ténjeo esta no musen há Varios anos e dentro de cada trabalho espectido vem procurando desenvolver conhedimentos estreitar a relaça com os frequentadoress

0 periti do agente cuturat o normalmente o de un militante viciado en cultura, que ter prazer en descobrir tesouros soterados pela jondustria cultural q que acredita nas relaçes humanas sempre motivado por seu idealismon seu trabatho solitarion pois ná recebe o apoio comum a uma luta sindicat ou de partidos polfticoss alem de precisar convencer as instituteses do valor e da viabididade do que pretende realizar com erera frequencian os agentes cut turas atuan durante varios anos a diante da intransigeneia burocratica de um sistema que jhes dificuta o trabalno acaban por se desiludir e tentam outras atividades profissionats -..- dar aulas arranjar seus proprios negocios em outras areas e ate o que pareceser o sonho de todos montar seu escritorio de produço assemsoria culturala algo diffeit de se conseguir diante da instabilidade do pafs.

o grupo a meta principal da atuaço do agente cultural, que deve viabilizar a predisposisâa das pessoss a se reunirem, ben como fazer o processo marchar muno a autowandis.sen al auto-gestao. 


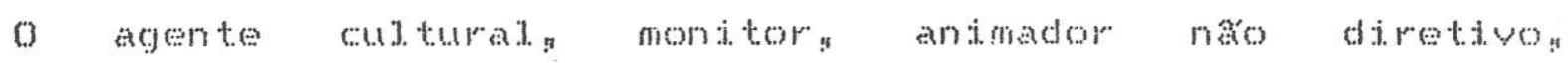

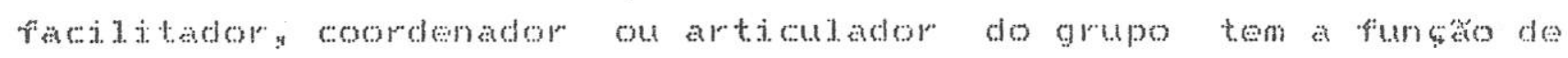

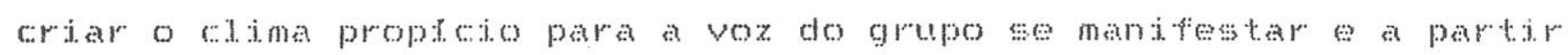
dat funciomar no so como espelinon mas tabom procurando compremder e ajudar o grupon deve apontar as contracticeses dos

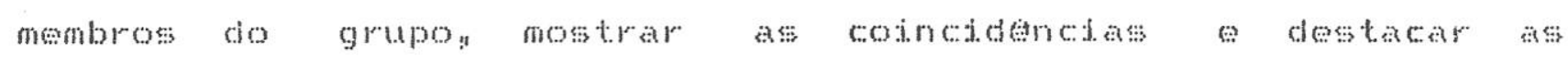

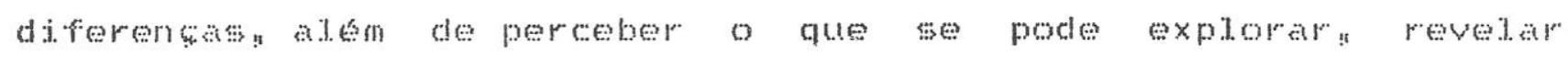

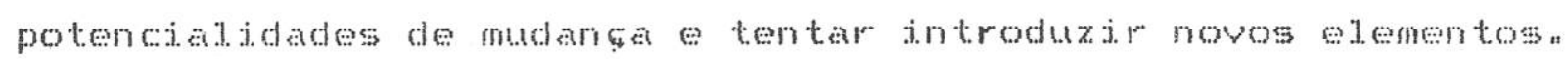

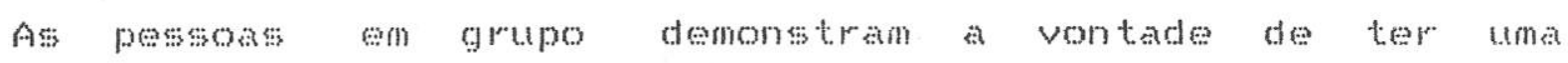

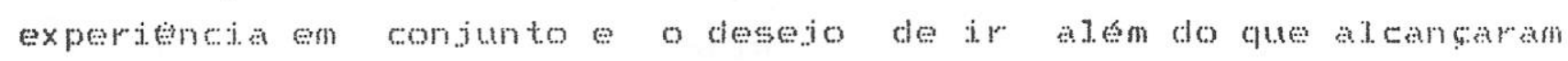

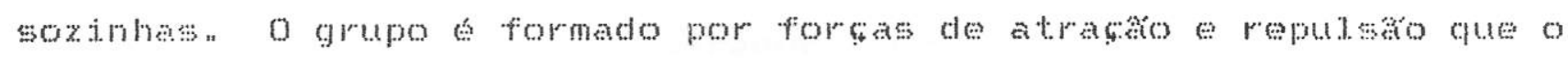

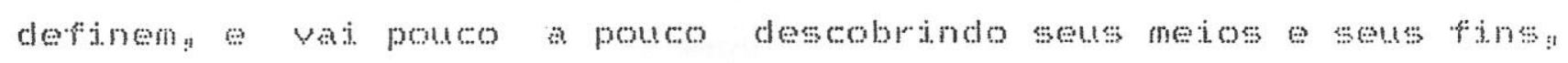

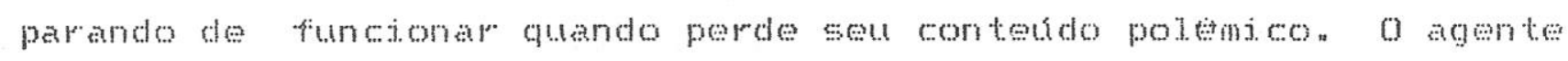

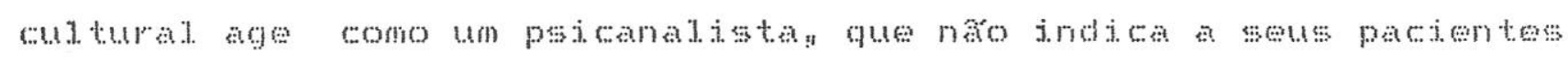
qual o runo de vida que devem segur no futurog aguralando que o

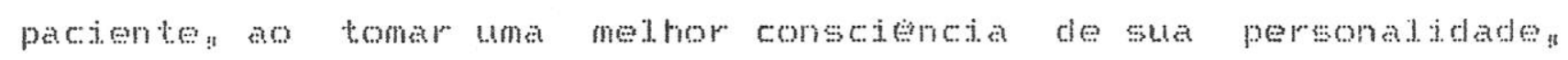

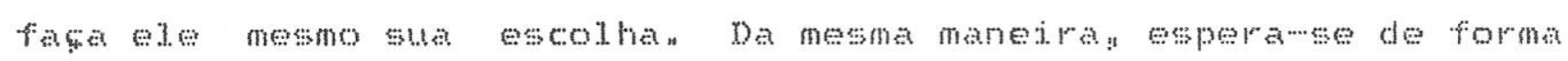

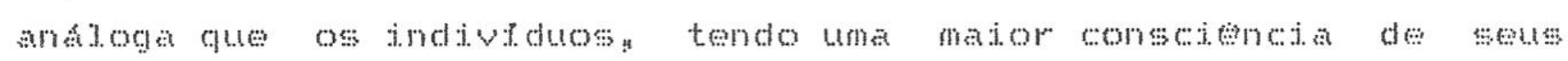

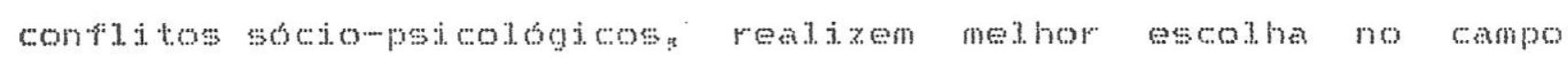

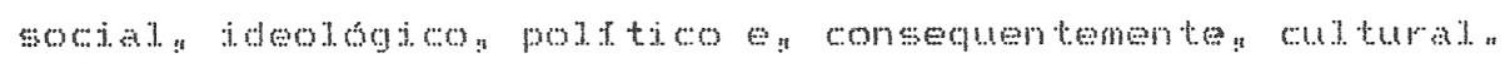

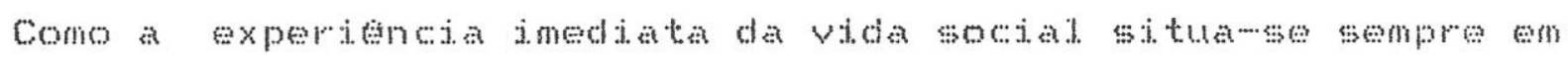

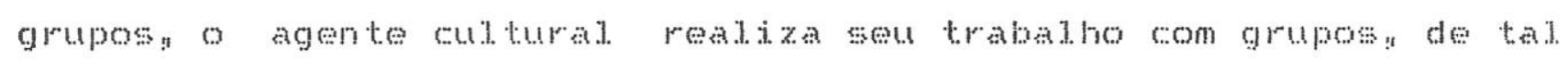

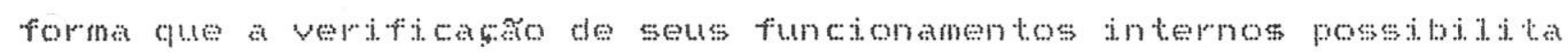

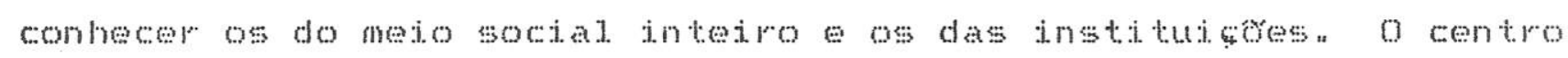
cultural estarat cumprindo o que lowe cabe quando promover trabathos

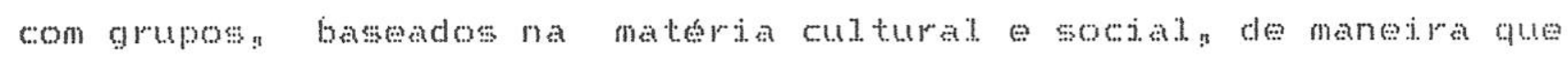

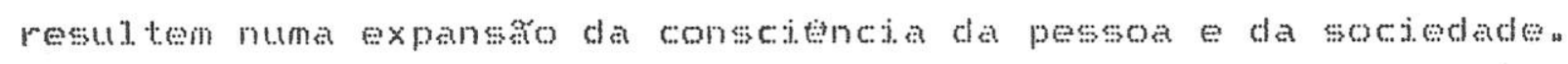

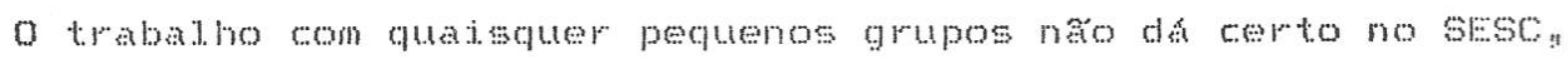
pois ou náso oferese o mfnimo incentivo necessario para a continutato dos grupos ou se tenta colocar mas pessoss para

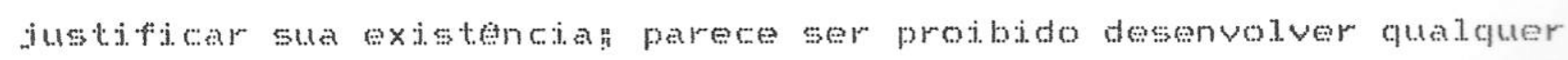

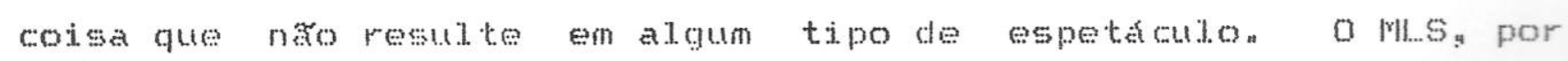
outro ladon sempre manteve cursos e atividades para grupos reduxidos nas propostas participativas de mus divisbes a esses 


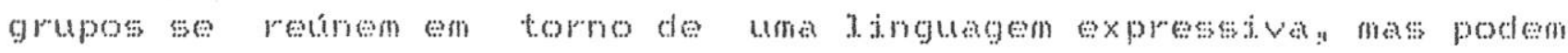
apresentar outros tipos de desenvolvimenton wo cos os grupos

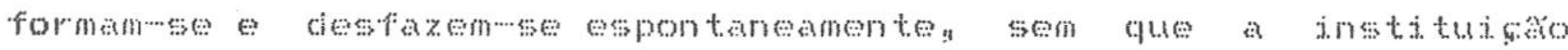
perceba a existoncia deles es portanto sem serem acompanhados por agentess cur turajs.

\subsubsection{Burocracia e Experiencia}

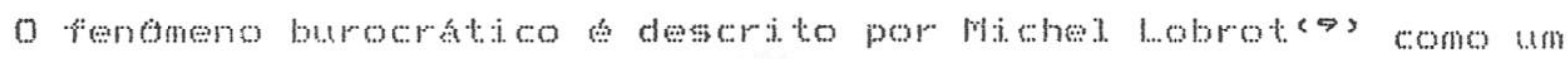
modelo para as relacoses humanas pue fintroduz um novo sistema de vajoresa mostrawse como essencialy visando ao bem de todos a oferece segurang ao administrador que se dedicar ao crescimento material das riquexas paxendo srer a coletividade que esta protegida pela instituiço levando as pessoss a se sentirem excessivamente pracas para tomar decisoses neutratizanowas psicologicanente os burocrats despersonatizan apan o indivfuo atraves de estatutos e papeds retirandowhe o poder de decison a iniciativa a responsabilidade de seus atos a comunicasko -.. entim privam os seres humanos de suas atividades proprianente humanas o controtat os instumentos de protusan apropriandowe da coletividade " Fepresentam a vontade do poder: organizando a separato entre dirigentes e executoress a a tendencia autocratica na gesta das instituseses. A burocratizaxo esta presente quandon em lugar de procurar os objetivos que

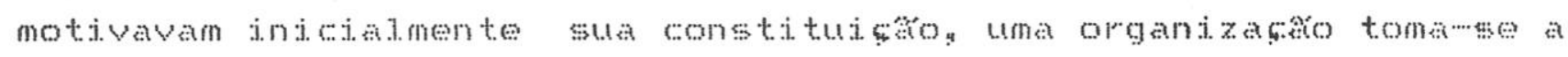
sj. mesma cono objetivo, deixando de ser um meio para se transformar em um fim.

os grupos reundos nos centros cuturais poderian vivenciar experimentos de autogestan constituinclowse nucleos de revoluso permanente en resposta a regime de burocratizacton forkm os contros estudados nâso apresentam disponibilidades ou intencoss de que este processo venha a ocorper em suas dependencias.

\footnotetext{
'"Lapassade, Georges - Grupos, organizaçסes e instituiģ̋es, Rio de Janeiro, Francisco Alves, 1983
} 
o dominio burocratico sucede ao donfnio pedagogion que adapta e ajusta a coranga para a vida adula impedindo que se estabejeca com ela una experiencia humane atentica os dois dominios náso

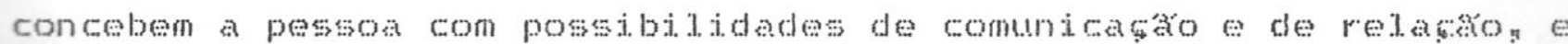
impeden una situaça total de reciprocidadeg o ponto de partida esta na angustia com relagho ao outrone na vontade cie defesa contra ele, neutratizandowo possutindo-o no mesmo tempon pessoas

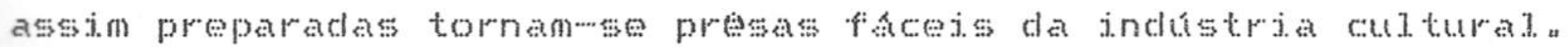

A escola privilegia a inteligencia em detrimento da imaginatao e da sensibilidade naso leva o indivfduo a descobrir. a se expressary a sentirn neste processon separa a raza da enowan de tal forma que a vida as experiencias pessoass dos alunos nato sao consideradan Mutas vezes a rejeisto que os individuos experimentan diante da cultura lidarse a reminisconcias escolares. mareadas pela impressaco de contrariedade aborecimento por serem obrigados a estudos puranente intelectuais e abstratos que causan repulsa pelo tato de se jos arem as coisas da sua contextura humanan A verdadeira conquista de un publico interessado nas questees culturas so aconteceratuandowe no sistera educaronat de una maneira mass seria e contundente "Ensinando respostas que náo correspondern as jnquietagos de cada un a escola fornece como conhecimento basico o dominio dos simbolos graficos buscando habilitar o individuo a atuar de forma produtiva A concopo do mundo, os referenciais e os valores que se ten foran determinados pela educaço que deveria tamben munir o individuo da capacidade de poder pensar sobre sua propria vidan possibilitandowhe a conscitnoia de sua situagho no mundo e do significado do que the acontece. Mas as escolas de hoje cada vez mas estäo empenhadas em preparar seus alunos para passarem nas provas seletivas e náa ensinam nada da relaça com a vida instituindo o divorcio entre pensamento açă

Fara o filosofo norte americano Tohn Dewey educacko

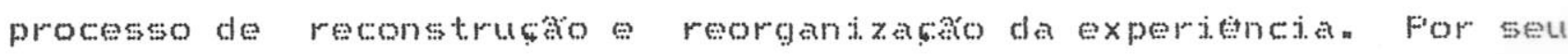
intermedio percebemos mats agudamente o sentido das experiencias vividas e nos habilitamos a melhor dirigir o curso das futurasu $A$ 
meta da educapa deye ser a vida progressivan erm contante ampliastos em constante ascenstan e isto acontere a medida que se aumenta o conteudo o controle da experiencia al arganchowhe

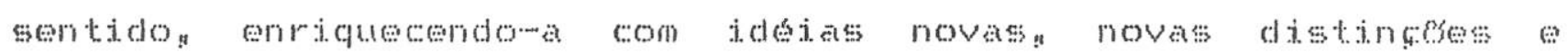
percepsess o processo educativo" segundo seu pensamenton deve ser un processo de continua transformataso da viday de tal forma que mats educaço sionificu mator capacidade de pensar, comparar decidir com acerto e Intima convicton sendo a pessoa liver na medida em que age sabendo o que pretende obter adcluirir um novo modo de agir e a aprendizagen deve ser intrfneca a vida pois o que e aprendido fora do lugar reat perde seu sentado e valor $(20)$

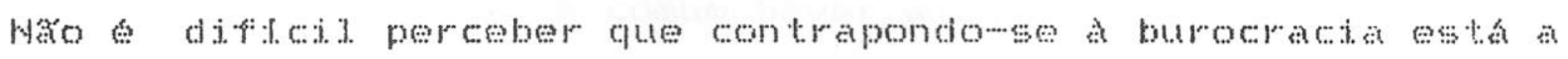
atitude de se experimentar que ativa os smbolose sentimentos em busca de significados" E o centro culturat o o lugar onde a experitncia deve se dar. con o agente culturat possibititando trabaliho con os elementos artisticos e culturais de forma a favorecer o encontro do frequentador com suas proprias enofeses.

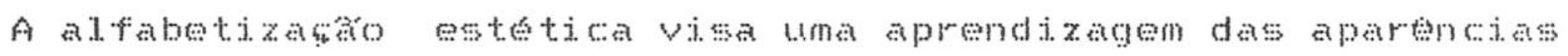
atraves da educaso sensoriala vivificandowe as sensacoses de volumes "cores e rutclos para se habitar o mundo de forma mais intensa se significativa percebendo-se a estrutura a forma dos

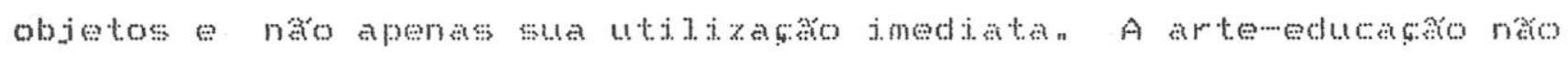
busca formar artistas mas ve na arte a possibilidade de mellorar a relaço com a vida e ampliar o contato senstvel com o munclon pernitindo decodificaton en assim! un importante instrumento para o indivituo siturasen.

(20) Dewey, John "Vida e Educaf̧ăo" in Dewey - coleço 0s Pensadores, sto Paulo, Abril Cultural, 1980 


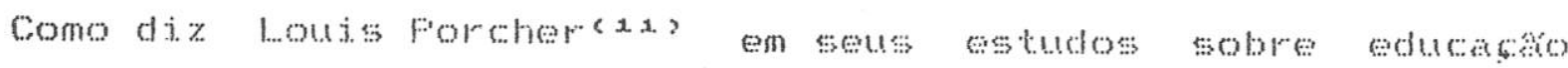
artistican dentro de cada criançaxistem imensas virtudidades

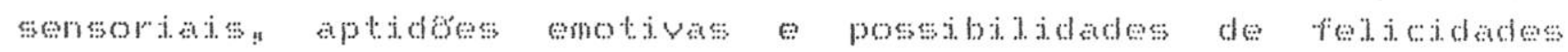
senstveis" o momento oportumo para exatur essas viruatidades

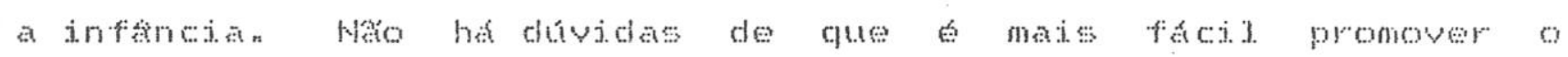
desenvolvimento de uma erianca do que ajuda o amadureminento tardio de un adulton que ja esta constitudo com formas de olnar

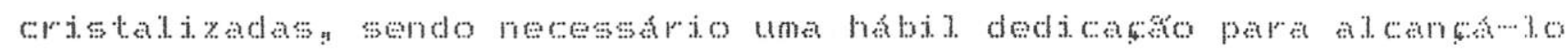
e favorecer o sen wncontro com a propria afetividade sen lhe causar uma imensa inseguranga mas ha que se tentar " "

Nas grandes cidades e comum haver adguns espacos que orereman atividades artsticas en oficinas intantis porem para o adulto existem apenas cursos com programacos especticas que nas dxo chances para experimentarn o lowa onde isto pode deve se dar ó o centro culturat que deveria possibilitara atraves do contato da produço de elementos culturats um fuj de sentimentos sem a

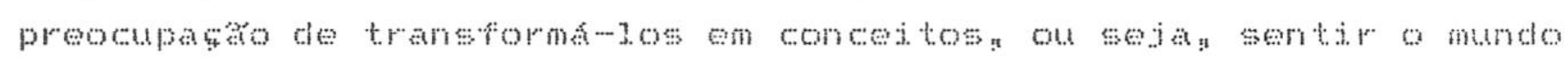
* nato ficar pensando sobre ele o centro cutural pode ser um espaso onde se exercita a tantasian a afetividade a a sensibitidade, atributos com poucas oportunidades de seren desenvolvidos mas que estro sempre presentes a atuando ne nessitam

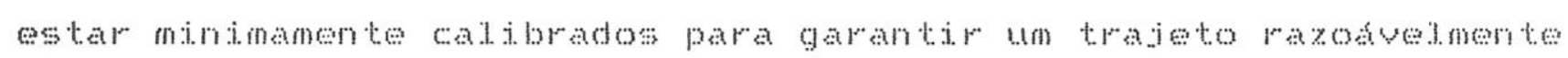
feliz do individuo pela vidan

o fracionanento vivido no finat do seculo $x_{n}$ provocado principalinente pela grande especializacto dos conberimentos la leva a necessidaci para a grande matoria das pessoas de encontrar un manejra de ver o mundo gue as integre numa totalidade significativa si tuaso que pocteria ser amenizada possibilitandowse un mator contato com o tazer artistico e com os produtos culturais, de tal maneira que as sensaços e os sentimentos provenientes deste

(22) Porcher, Louis - Educaçăo artistica: luxo ou necessidade?, Săo Paulo, Sưnus, 1982. 


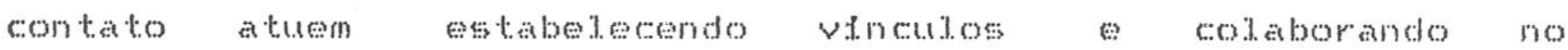

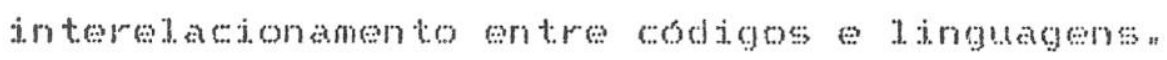

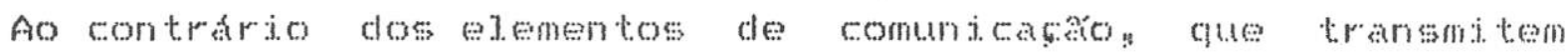

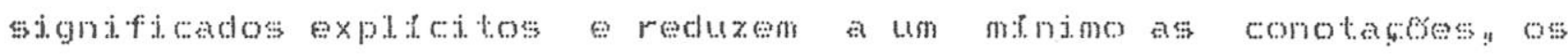

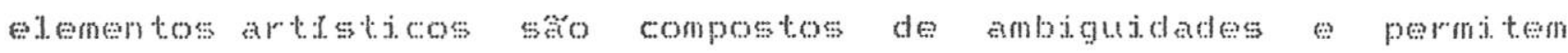

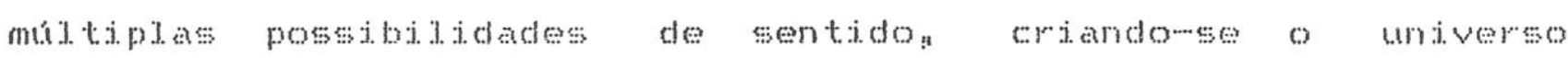

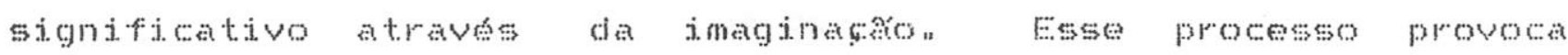

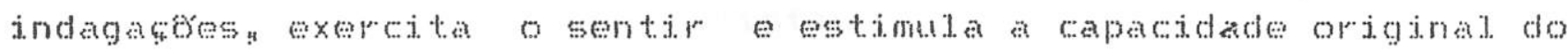
cerebro humano de construtr imagens mentaiss com o praxer de

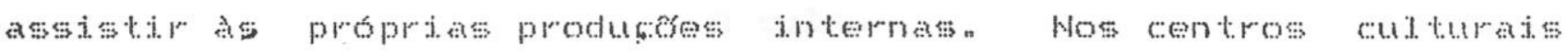

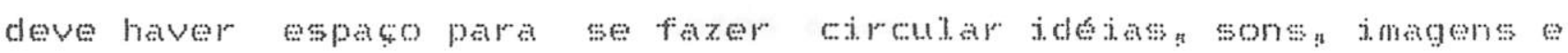

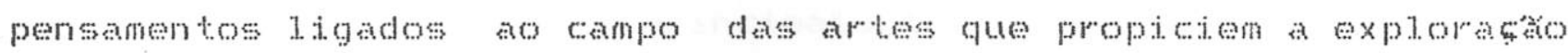
do subietivo en aventuras do frequentador atraves de

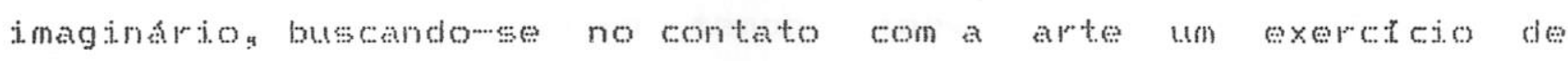

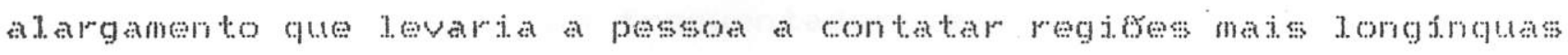
do proprio ser" ampliando o rejacionamento consigo propria e

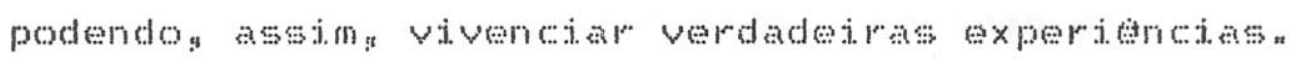

os centros cuturais deven possibilitar o direto de todom participarem ativamente como criadoress estimulando seus frequentadores a mapessarem o que perceber esentem a partir a trabalno nas oficinas o da confecto de objetos esteticos os

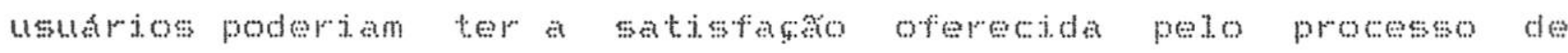
produço no no importando se o resultado final e uma obra de arte ou

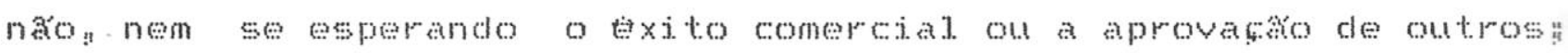
deve-

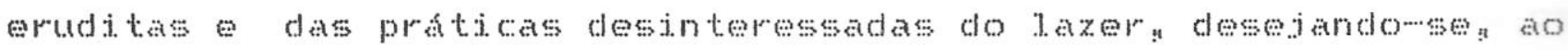

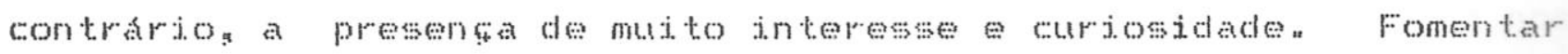
is

A produço artistica permite um molnor entendimento e

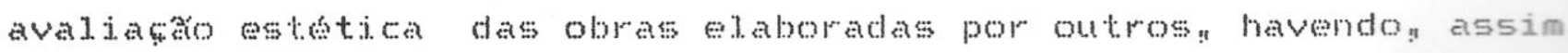
como pelo artiatan um trabalo realizado tambern pelo que percebe As verdadejos obras de arten como os grandes romances e pinturas, trazem a experithcid viva de seus autores e possibilitam una 
investidaço do mundo da existoncia que aumber o repertorio as at ternativas de comunicata do individuo este repertorio pode ser usado para averiguar os contatos humanos para se saber do redacioname com as imagens ato mesmo para a jeitura dos

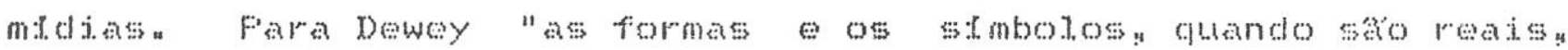
representam e reunem experiencias pelas quais o individuo realenter passoun serven de motodo para a descoberta a a aguisisto da verdaden saco instrumentos con os quats as pessoas avangan tom seguranga na progressiva conquista de fatos novos n sao os meios pelos quats elas poden se utidizar da readidade adquida m

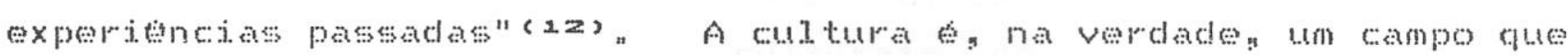
permite a descoberta de elementos a serem usados na vida da pessoa: possibititar isso e un dos principais trabalhos que cabem ao centro cultural. A arte o territorio da cutura no qual os julganentos de vator sáo a mesmo tempo jnevituvis e praticamente inconscientes quando un frequentador estatento diante de certa obran podese procurar saber qual a directo predominante de seu interessen de seus sentimentos de suas dispostoges - tentar ver. por exemplog porque certo filme atrai, o que o i.ja aquelas cenasa quats elementos seus esto projetados junto aquias imagens ou sejan usar o campo estetico como forma de se saber sobre a pesson.

A urn centro culturat compete trabahar o relacionanento entre o seu púbico e os elementos esteticos a compreensáso das linguagens artisticas e isto foris importante do que realizar boas exposiçoes de artes, que podem ser vistas nos museus gaderias da cidade considerandowe os centros exantinados apenas

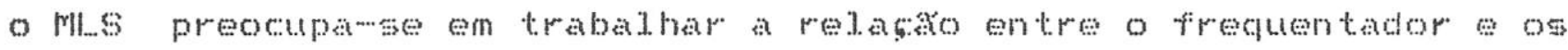
elementos culturats o que acontece nas atividades de producto nos atelierse nas propostas de leitura das exposictes feitas pelo serviço eclucativon

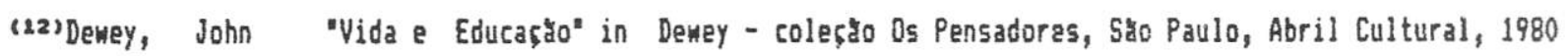
(pg. 148) 


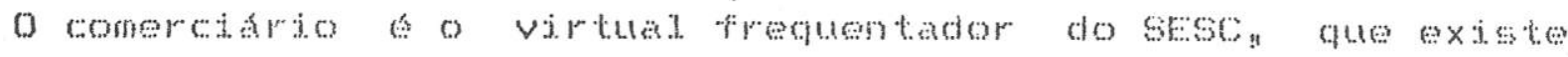

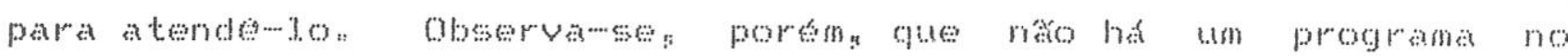
Co.sF",

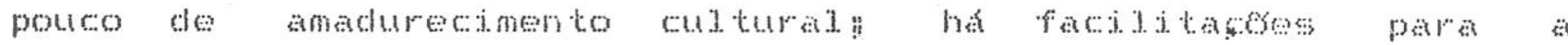

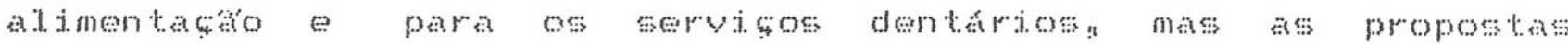

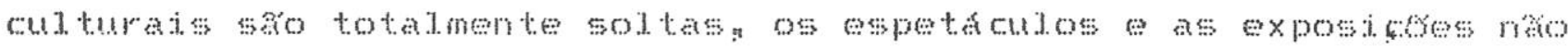
tem continudade dentro de um program de conswentizacko

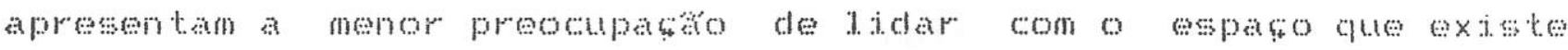
entre a obra 0 espetador: que no caso dos comeriarios

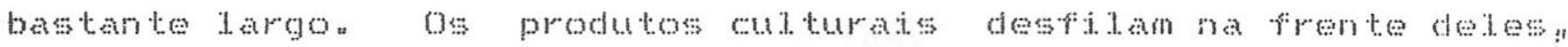

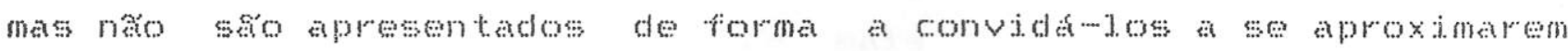
para un contato fontimo do que decorre a pouta guandade de

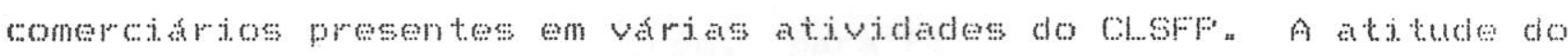

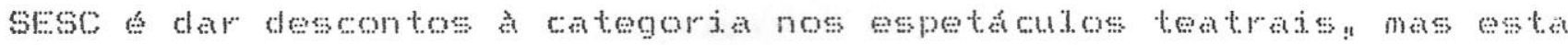
providencia nato nuda o desjoteresen apontado pela baixa prequtroia de comerem

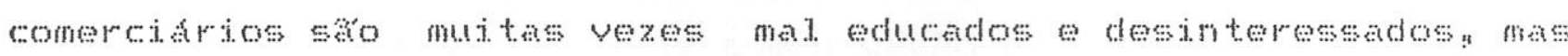

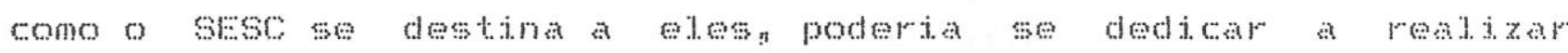
programages que nato trouxesem so o entretentmento mas tambon uma evoluçon As propostas poderim ser constitutdas por elementos do universo dessas pessons e dat evolujem preservarto o apto

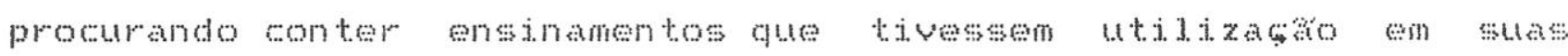
V.j. $\mathrm{d}$ ats

Da mesma forma o COF poderia abquar sua programano a

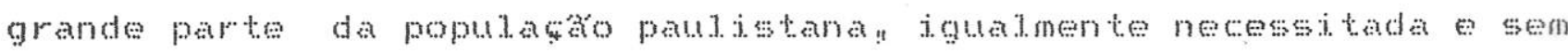

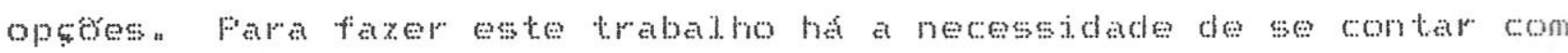
profissionats devidamente preparadosn mas o destinteresse das

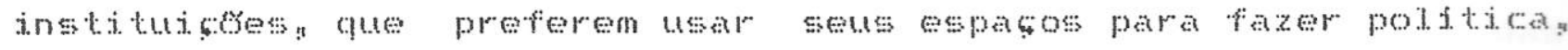

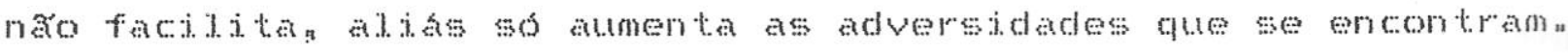




\subsection{Possibilidades de Atuaçăo}

\subsubsection{Dficinas de Discernimento}

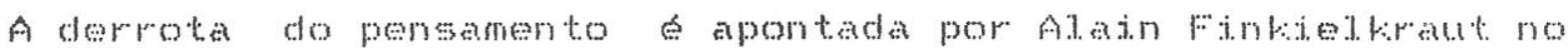
seu livro que recebe essese nomen onde arirma que a tendencia 6 a de uma sociedade polimorfa onde todas as formas de vida están a

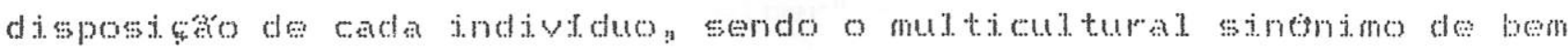

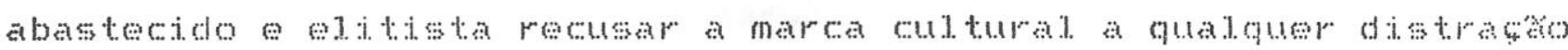

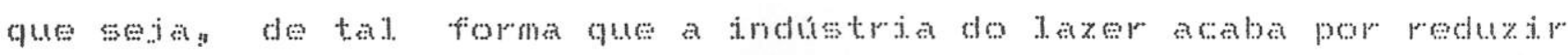
as obras do esplrito a quinquilharias a as fronteiras entre a cultura o divertimento nas sao mats chras com os livros de

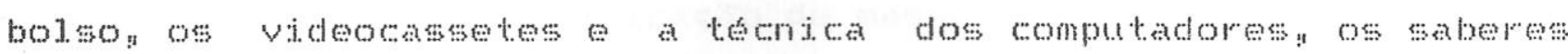

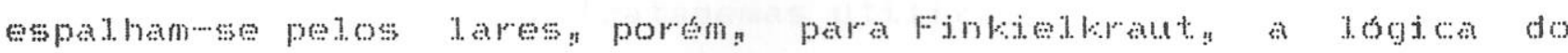
consumismo destroi a culturan(1心)

A industra culturat dissemina imagense sons esteridizados atraves dos sedutores meios de comunicaso de massa que valem como

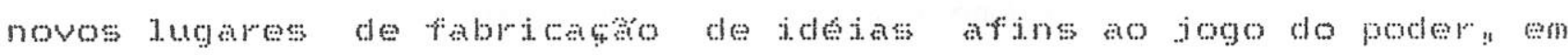

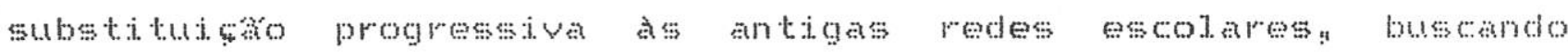
apaziguar manter cativa a mente de quen deles usuruin ou seja a quase totalidade da populatso que pode cobrindowe com o discurso dos midis: protegerse dos medos e aneases que aprocem nas

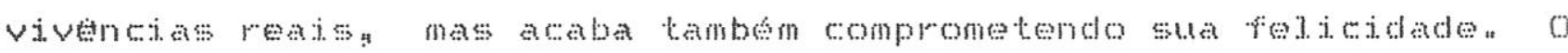
sociologo alemáo dieter Frokop aftrma que "quem pode organizar seu cotidiano de maneira a ter, por si proprion fortes emoges -.. no somente na hora da ruptura, "do lazer... "quem pode

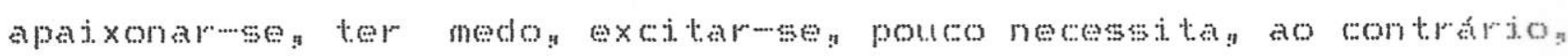
dos meios de comunicaço de massa e certamente nâso estara em condiçes de acompanhar fascinado as novelas popularess da Ty das revistas ifustradas edo radion"(14) $A$ industria culturat informa

(23)Finkielkraut, Alain - A derrota do pensamento, Rio de Janeiro, Paz e Terra, 1988

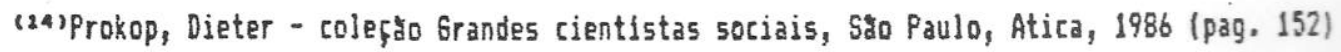




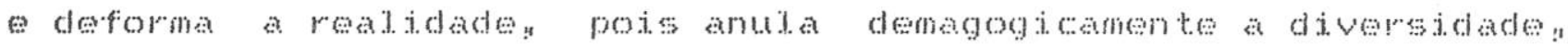

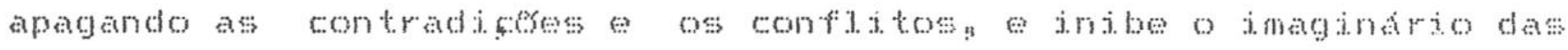

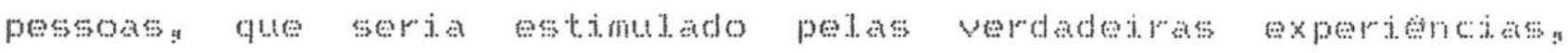
quando coloca pronto o que poderia ser a taborado pela mente de cada

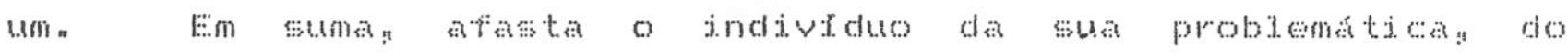

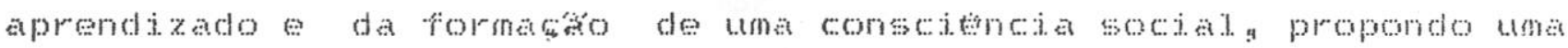

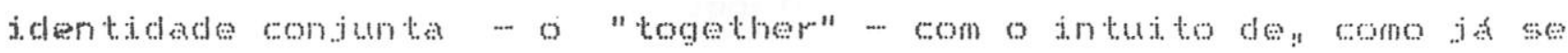
sabe "homogonotzar para controlarn

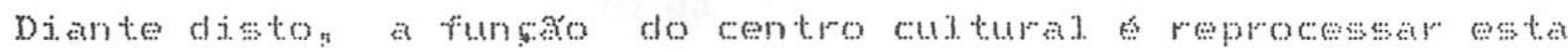

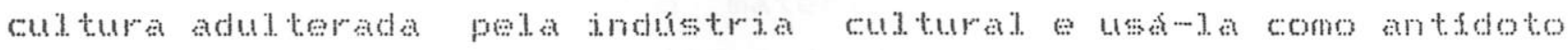

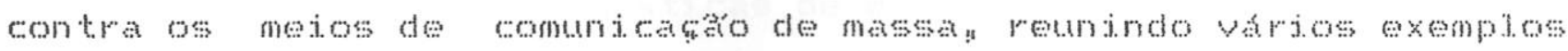

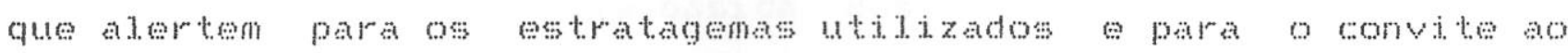

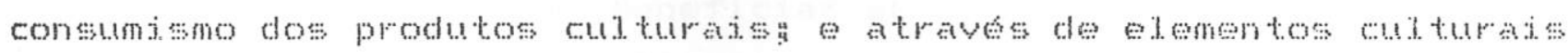

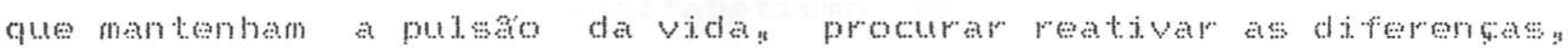
diversificar o pensamento e mostrar que ha outras formas de se

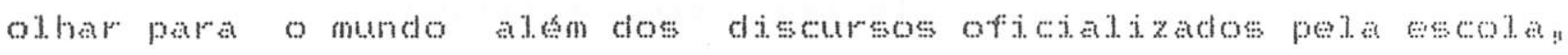

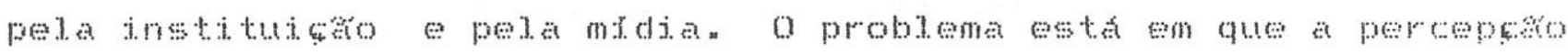
de que a vida nas precisa ser assime o que acontece quando na o

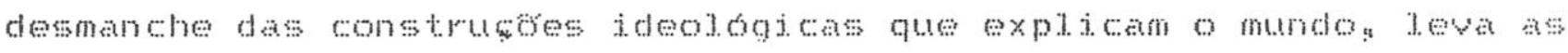

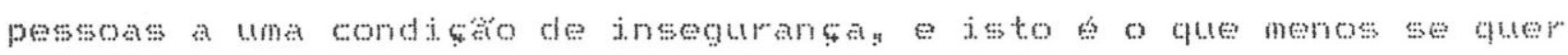
(e talve esta ojeriza seja un dos maiores contribuintes para o

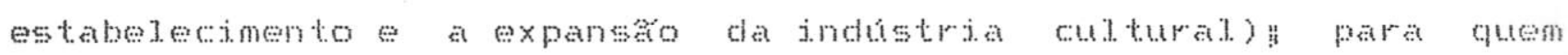
suportar turbuldnoias ose dispuser a atravesar as suas duvidas o premios swa o de poder pereber o mundo com os olnow 1 iveres da

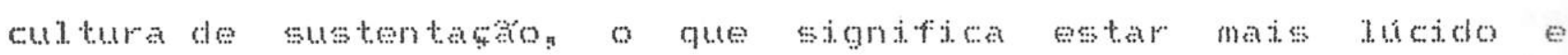
dispontuel para viver sua propria vidan

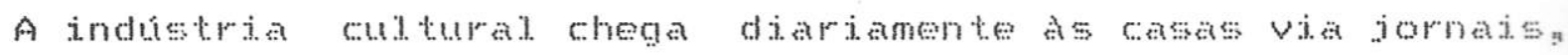

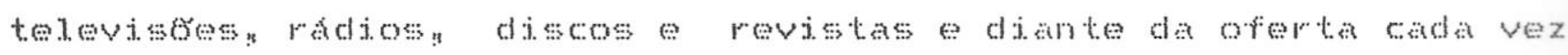

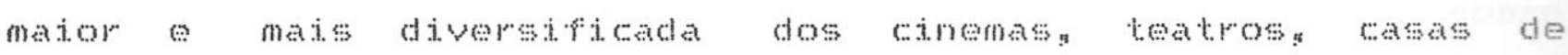

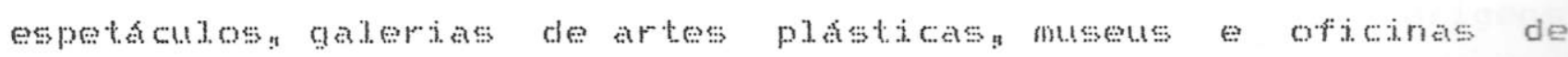

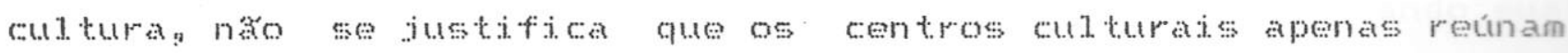

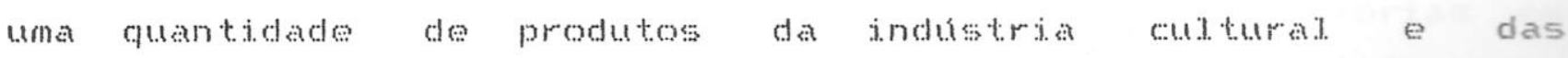

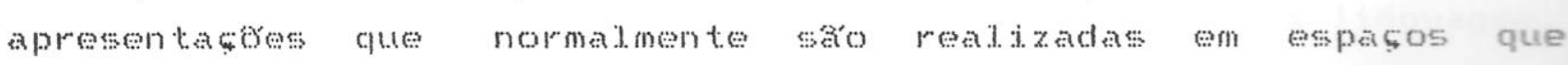

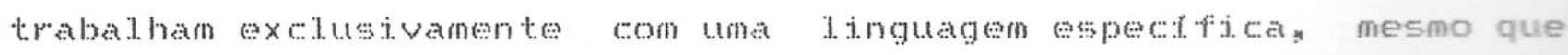




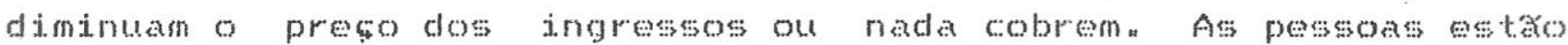

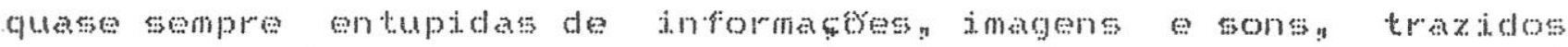

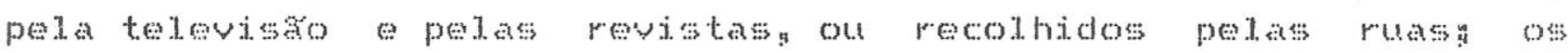

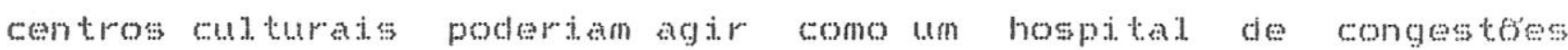

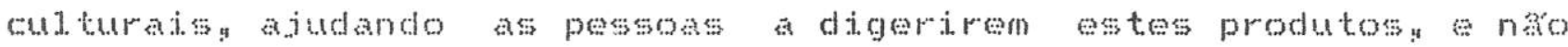
simplesmente empurrando mats coisas para as sus cabecas. E preciso que estes espasos proporcionen o que as pessoas nowo possam ter en outros lugaresa dando oportundades a quer quer se emancipar esmonte necessidade de algo mats do gue se distrair.

Aiudar o desenvolvimento da sensibilidade estetica on tornar prazeroso o contato com o materiat artisticon facilitando e

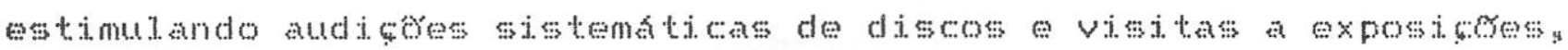

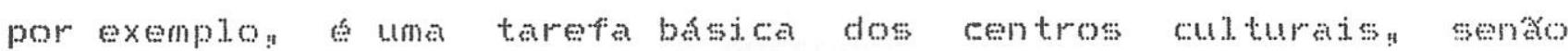
aqueles que naso puceram beneficiarme de un anbiente favorsvel.

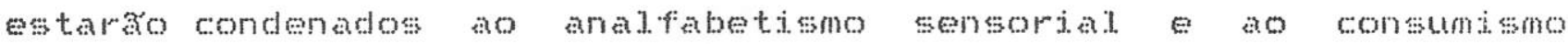
embotadon Diante das inumeras atemativas que a cidade ofereces

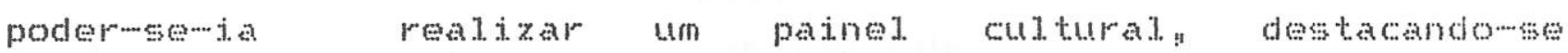
caracteristicas e propriedades de cada proposta para a pessoa escolner o que mase lhe interessen assimp a inves de

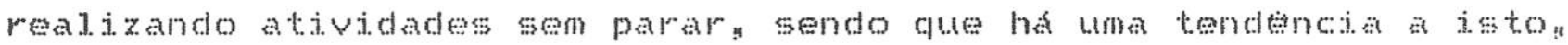
o centro cultural poderia dedicarme a desenvolver o discemimento para a escolha do que e fejto fora do seu espaco e mostrar apenas o que a indistria cultural jomede de aparecora desce gue representer

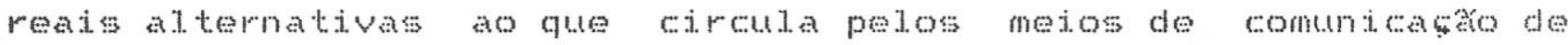
massas garantindo o contato com expressbes que tragan a diversidade cul.tural. E com isto haveria a possibididade de se conherer outras

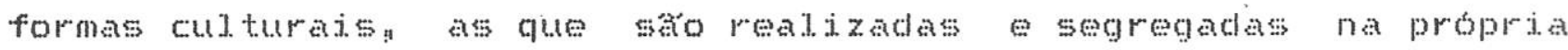
cidade as de patses estrangeirosn mostrandomen por exemplon a música mundial que eculta pela midian

se o centro cultural. resolver realizar uma exposiço so sobre certo teman que o trate de forma completa explaicando suas origens e desenvolvimento situandowo num contexto geral. mostrando sua importancia hojen Ao se fazer uma exposicho de Historjas em Quadrinhos: por exemplo, procurar mostrar o poder desta 1 inguagem, 


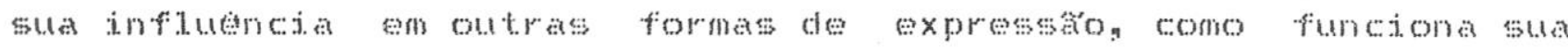
industria edjorjat. como foram criados certos personagens a mesmice de alguns herojs o porqute do sucesso do gtheron De nada vale reunir certas imagns se nao se da a elas sua significknoin No caso de exposiçes de artes plasticas atividacies faceis de

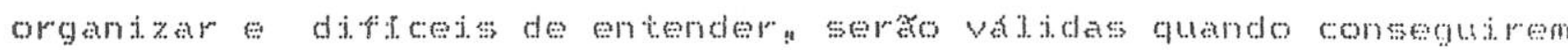
ao menos que as pessoas leven consigo imagens que venham a fazer parte de seu jaginarion E desejuvel que se facitite a compremsa e conhecimento por fothetos pe pa presenç de monitores n descie que bem preparados e com certa sensibilidade disposiçon a fun tao

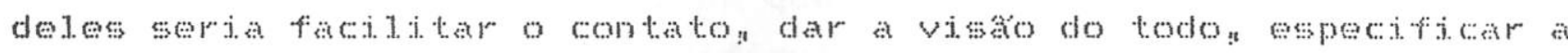
propostan imprimir una cadencia de visitacho e criar para os viatantes oportunidades de conversar sobresuas duvidas farer observactes podendowe assim perceber como o que esta exposto chega as pessons n

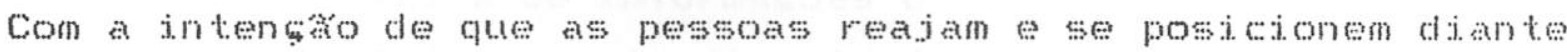

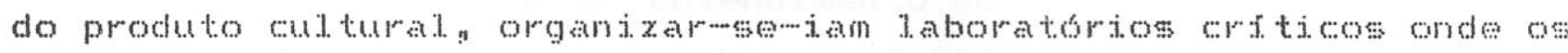
frequentadores pudessem escrever suas proprias criticas sobre os filmes pe pess teatrais em cartaz na cidade! shows musicais: programas de ratio e televisto exposigose de arten para depois confronta-1as com o que foj vej culado na jmprensa analisando se as

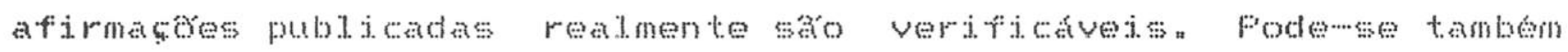
propor a relejtura do que foi apreciado realizandowse desenhos ou dissertagess que traduzem o que a obra motivou.

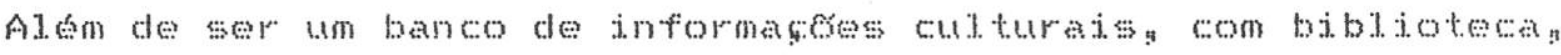
hemerotecan discoteca e videotecan o centro cutural poderia dispor de um servigo de auxtho a duvidas que trabahasse como uma cifnica cultural dindmica com telefones para informacess que estivessem abertos a consuta populares -- este servico as bibliotecarias do CCSF realizam ao atender as charnadas dos estudantesn

Normalmente, pela relackio que se propoe, chega ses a respeitar a "cultura culta" sem que esta venha a se tornar parte integrante das pessoas a doves dos cursos que permitam aos frequentadores a 
i.usaro de quen por un breve contato que tiveran com certos fundamentos do tema, pertencem ao grupo dos literatos a dos cineatsas ou dos artistas plasticos seria mas provetoso tratarme de algo gue esteja ligaclo eque tenha aplicasto a vida

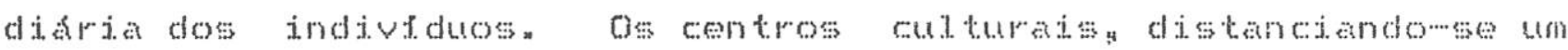
pouco da visaro habituat do que lhes competiria podem ser espasos em que as pessoas conversem sobre seus problemas, o recobar informacess sobre certos saberes basicos que as a judarian a fazer melhores escolhas en varias areass aldm da opto entre os produtos da industria culturatu como a definicho profissionala a

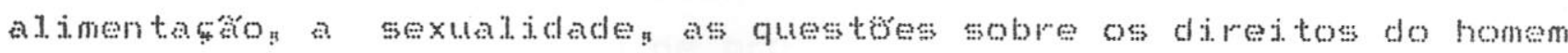
e do cidadăn e tamben dificuldades mats fntimas se assim desejarem! com o cuidado de naso se transformar o centro num prontow. socorro de angustias -.. a dosagen certa para que isso nao acontecax cabera a habilidade do agente cultural.

Sabendowse da falta de informaços e conceitos na formagro das pessoas, que dificulta o entendimento do que as rodein seria benefico possibilitar o que lhes falta para compremderem as articulaços polfticas nacionaise internacionais e o significato de certas atitudes tomadas hoje no mundo de tal forna que se sintam ocupando a mesma dimensao dos protagonistas envolvidos nas noticias dos jornats. Fropiciando situaces em que as pessoss se sintan a vontade para mostrarem seus desconhecimentos pois normalmente tem vergonha de perguntar aos antoos por medo de serem julgadas incultas, os agentes culturajs poderian suprir as lacunas deixadas pela educagon Aseim as pessons se sentirian gratificadas por poderen superar o sofrimento vindo da ignorancia.

o estimulo a grupos formados por quen tem o desejo de explorar certos temas deveria ser naturat nos centros culturass ben como as oportunidades para as pessoas exibirem suas habilidades (náso so crianças ou jolosos! mas todos)" favorecendo a convivencia e respeitando-se as possibilidades e limites de cada un. Esse trabatho poderia ser realizado principalmente a atraves da música, que a grande aspiraço popular existe de forma viva em qualquer 
parte da sociedade presente na dangan no teatro e em varias outras formas de expressato artistican A musican da mais corebrat a metis primitiva mobitiza os matis diversos envolvimentos afetivos por

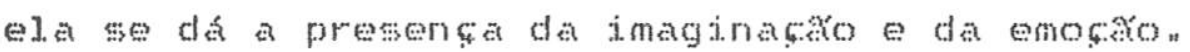

o sentro cultural. pode promover encontros. debates conversas; que possibilitem a aproximatro dos frequentadores a

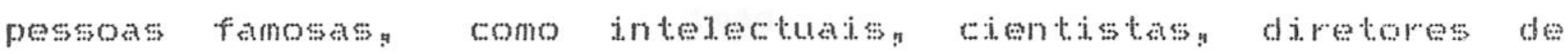
cineman ou atores de novelan trazendo assim os rolos cultudos nos

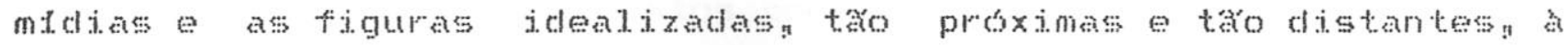
condiço humana Este tipo de programagro foi reatizata no cosf em un de seus projetos mas significativos" gue se chamou "De conversa en conversan"

Todks essas atividades deven ser demenvolvidas por pessoas devidamente habilitadas, que precisam receber as condisoes y merecido respedto para o trabalno que vao exereren Apenas

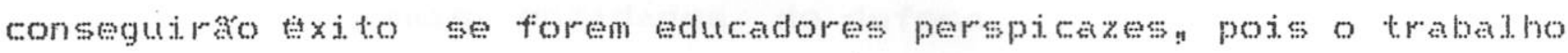

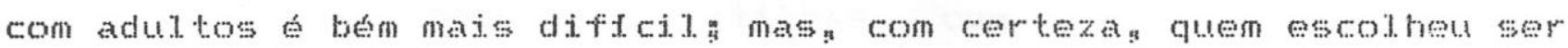
agente cultura. nầ esta apenas buscando uma maneja de ganhar

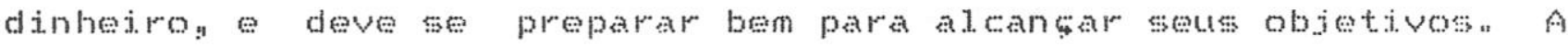

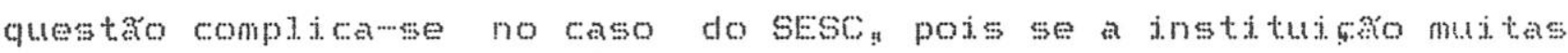
vezes náso consegue discernir para si propria a como pole se propor a 1. evar os seus frequentadores a perceber?

\subsubsection{Temas para Centros Culturais}

Dentre as propostas que podern ger exploradas nos centrom

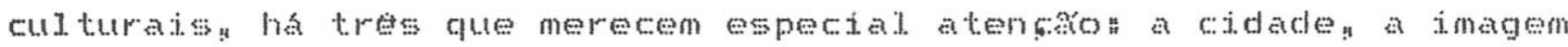
- a posmodemidade que sxo o local a forma de comund cacko por excelencia e o tempo en que se vive.

Foucos perceben o lugar en que estân faltando conscitoncia

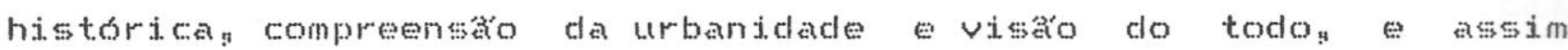

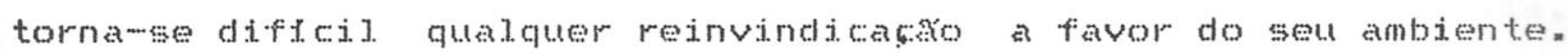
o centro cultural pode levar seus frequentadores a uma maior 
intionidade com a cidade atraves de propostas baseadas na atenço ao cenario urbano a a conduta de seus habitantes, dividindo os participantes en grupos que estariar alertas a deterninados aspectos a serem examinados Andar a pe pelas ruas e una oportunidade de observar o universo fragmentado que comper a urbandade, acompanhando os elementos incrustrados nas calcadas cbancosin placas de ruan postes de iluminackon caixas de correion cabines telefonicas), as imagens constituintes da paisagem (diversas formas publicitarias cores dos produtos a a forma de dispo-los nos estabelecimentos comerciats) y os barulhos (a soma de rufdos que form o cinturáso sonoro que envolve a cidades a povos da rua (artistas populares, mendigos, vendedores ambulantes), os comportamentos (motoristas: roupas dos transeuntes p pequenos rituais urbanos do cotidiano), sempre com o intuto de fazer as pessoas enxergaren seu entornon o centro cultural aproveitando o fervor ecologico do momento orientaria sobre as cartencias da cidade neste setor e o que ela oferece de parques; areas verdesa contato com animais mesmo editando pequenas cartithas com a base da ecologia, procurando fazer emergir a consciencia da solidaridade com os outros seres que convivem no mesmo ecossistema.

Desde o infeio de seu funcionamenton o cos: tem a intenço de trabahar e trazer para suas dependencias aspectos da cidade de sao Fruto, portanto essa sugestano seria mais propleia no seu espaço ou seja, dirigida aos seus frequentadores.

A era da tipografia que atraves da eserita apresentava o mundo enquanto ideian foi. substitufda peja da imagern que o mostra como un objeton A imagen e a mainha da posmodernidade e a imbricaşa entre realidade e imagen e a marca da cultura contemportinea. 0 espaço é cada vez mais povoado por sedutoras imagens que merecen ser examinadas. assim como a ressonancia que causam nas pessoas. As formas para sua producra se multiplican atraves das conquistas tecnologicas como a TV a cabon a holografia, a inagem a laser, as imagons computadorizadas as imagens-sintese, 
que : atumentendo esperificidedes de nouoss sestimulos. continuamente o poter de definjestog possum

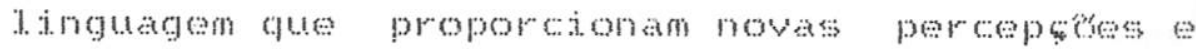

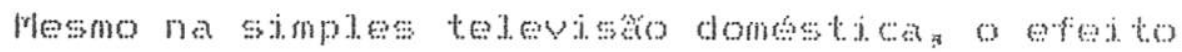

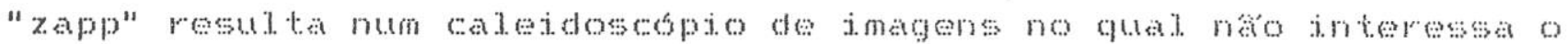
desenvolver das historiasp o universo do telecomano

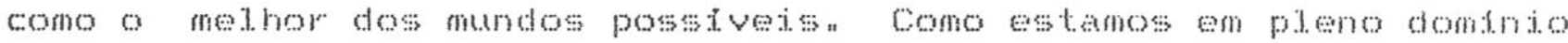

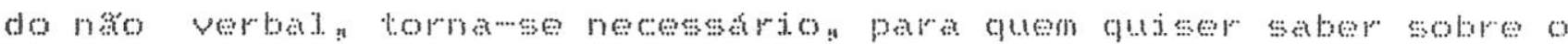

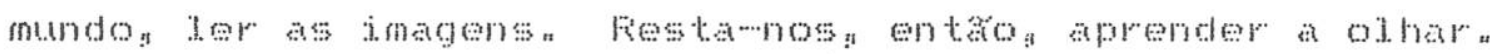

0 centro cultural pode sor o lugar para se apronder sobre as

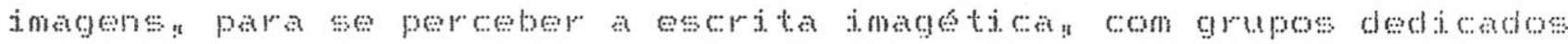

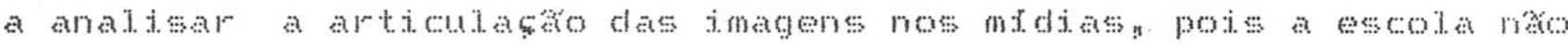

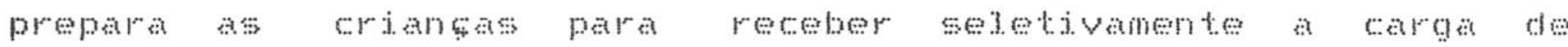

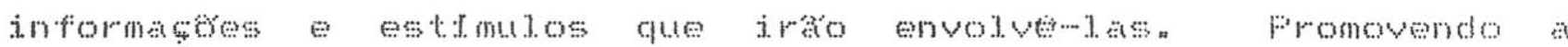

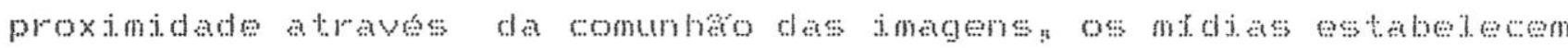

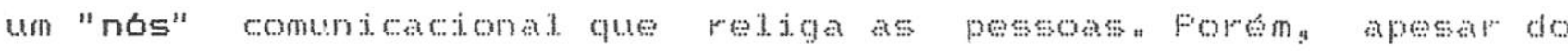

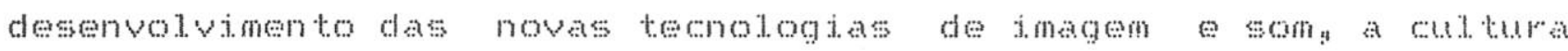
esta paradoxamente vinculata a planos restritos estabelocidos por

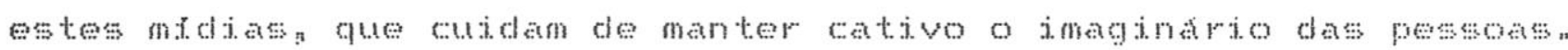

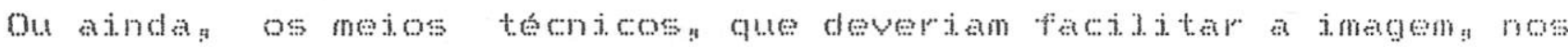
intoxicam com ela indbindo as possibilidades de

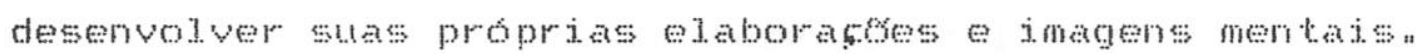

คo

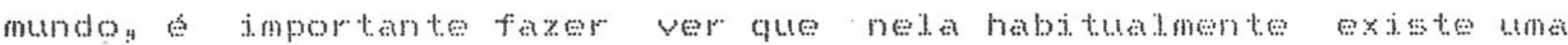

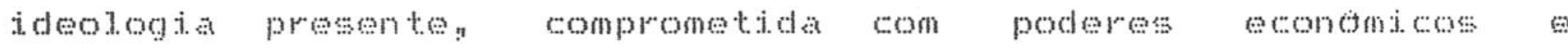

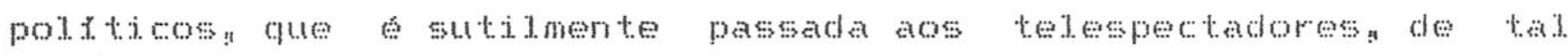

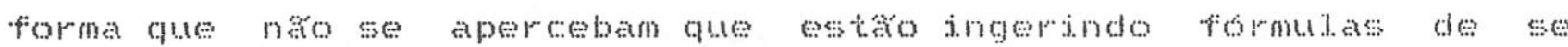

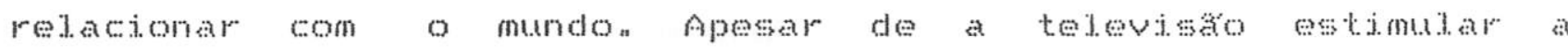

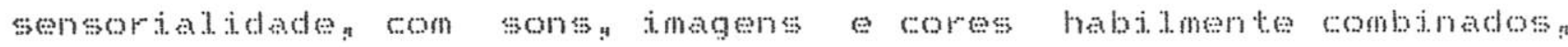
seus produtos raramente levan at reflexă pois a forma como sao

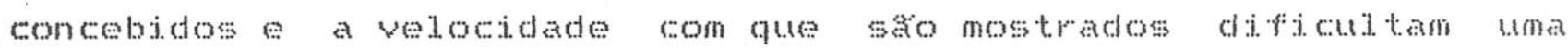
retenço constienten Acabam, isto simp oriando um voracidade

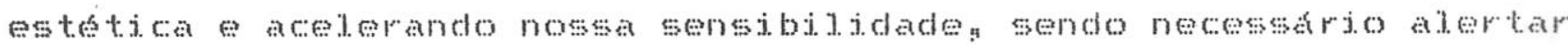
as pessons sobre os codigos a que estro acostuadas os codiog que thes pertencen. 
0 cosf vem reatizando con certa prequencia eventos sobre a

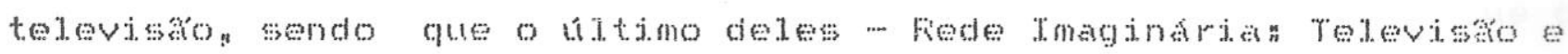
Cutura (setembro de 1990) -- reuniu varios palestrantes que expuseram e debateran questoes gerajs relativas a televisano.

o olhar critico para a tejevisaro pode ser traballhado wo oficinas compostas por gruposs que permitem mator proximidade entre os participantes com a intenço de discutir elementos especticicos presentes na programaço de televisaso apresentando propostas como: andise dos telewjornatis procurandowe saber o que considerado notfeian a forma de passa-1an o peso que recebe cadotivaton

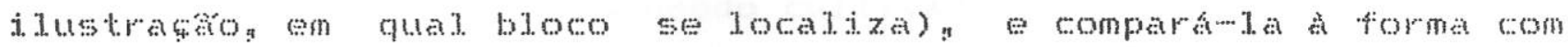
que foi tratada nos jornats impressos" examinar o conteudo das novelas que reorganizam grandess mitos humos o problemas existenciass o impacto que causan e como dosada a expectativa a sua utidizaço engunto fiperama de emogres e escola para aprender a viver analisar os comereiajs que se utidizan do sfobolos de felicidade inalongaveis para a gande maioria das pessoas; observar as vinhetas da tejevisan a linguagen dos videow

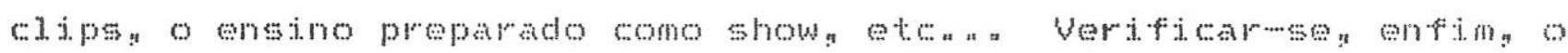
processo das imagns esons que chegam como a zuz a dquan ou o gass nas casss e oferecem companta e consolo as pessoas que tentam cobrir o vazio com musica "non stop" y ou com o "rio" de jumgens vertidas pela rvi podeme perguntar quass as imagens que realmente penetram e permanecem nas pessoas o que sobra do que V.i.ramn

Como nomalmente a universidade e os museus se voltam aos estudose a guarda do passadon os centros cuturais poderiam cledicarme a observar o que acontece no presenten reatizando o trabatho de desvendar a contemporaneidade para os seus protagonistas que colaboran em uma historia que esta sendo montada sobre una cultura que esta sendo vividan a imaginacason a rebeliaco do corpo da jogem, a comunicaşo năo verbat e partithar com os outros estao agora presentes n num fooca onde prevalesce o lúdicon o espaço, o ecologico e a multiplicidade o principio vital. $A$ 


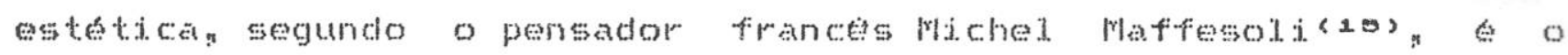
canpo onde se vive ese exprime a sensaço coletiva sendo gue o rementamento do mundo pode se dar atravos da omoşo da sensibilidade vividas en comum de forma gue a comunha dos sentimento realiza a funço de cimento sociotala o estar junto mais importante do que o objetivon os centros culturats poderian funcionar como laboratorios, para se experimentar e procurar entender os elementos determinantes da posmoderndade e tamben os grupos componentes do neotribalismo das megatopoles observandowe o que cutuam quats seus processos de identificacton os rituats de pertença a grupo e o que leva as pessoss a se juntareme gual 6 a paixaro partilhada ou o segredo cutivadon o centro culturat deve ser uma drea neutra que receba quen o procurar e pode mesmo realizar trabalhos com rertos grupos espectejocs mas sem permitir

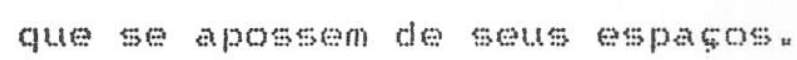

Com o descretito da posmodernidade nas promessas dx

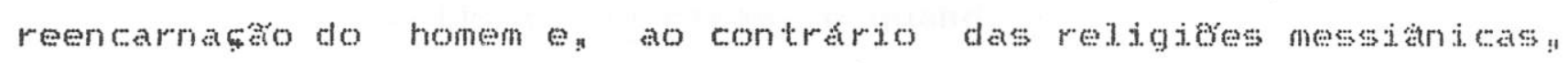
incitando a viver o presenten a tendeneia maximo de un momento. A vejocidade com que as jmagon sack substitudas parece guerer suprir o desejo de ondpotencia dos

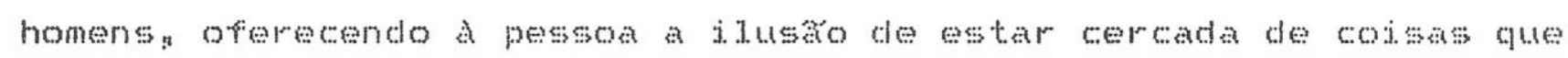

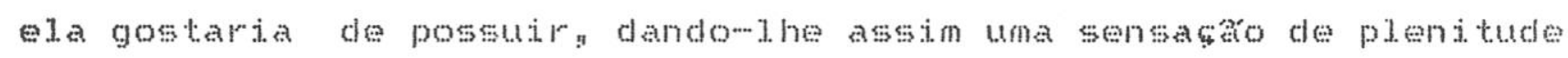

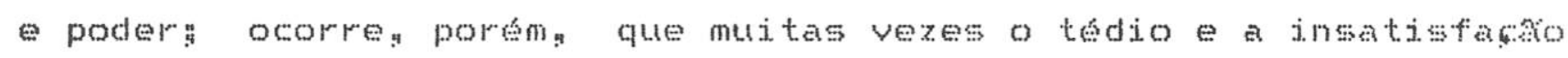

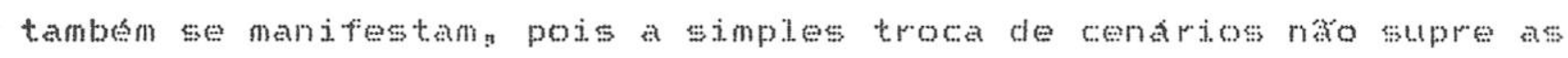
necessidades vitats do ser human saber de si e se transformar am busca da feijeidade. Nac participando do onipresente ritemo frenetico ditado pela televiskog os centros culturais serian como

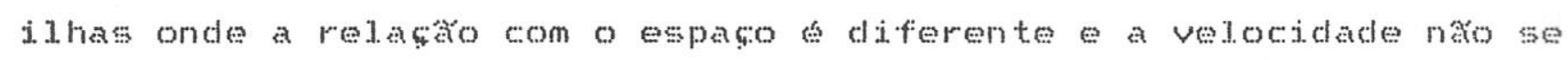
torna un fator obsessivo! mantendo a lestura cirtica da fopoca dos seus produtos. esses locais poderian desenvolver una estrategia de concidiaço com o contemporsineo buscandowse descobrir o sublime e o desejo na ambisncia da posmodernidades r fimportante alertar

(10) Maffesoli, Michel - O tenpo das tribos, Rio de Janeiro, Forense Universitária, 1987 


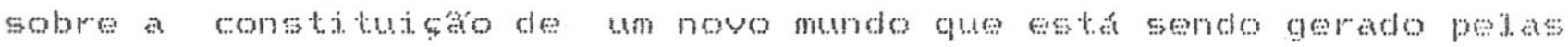

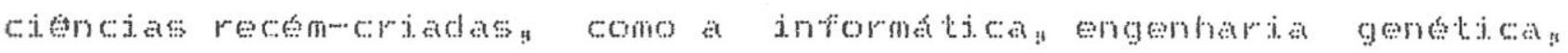
fisica nuclear: e astronomia quantica.

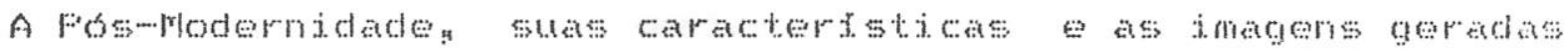

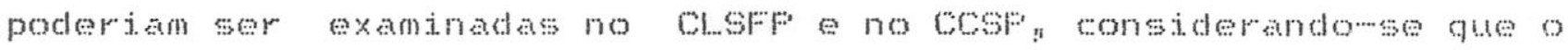
Mit.s tem bastante definda sua optro de trabathar linguagens tecnjcas mas antigas que foram utiazadas por l..sar segalin como o caso da gravara gue inclusive ná possui centros que a estudem en sio Fraton

\subsubsection{Atividades Corporais nos Centros}

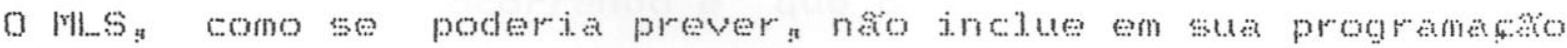
qualquer atividade corporal para seus frequentadores no waso do

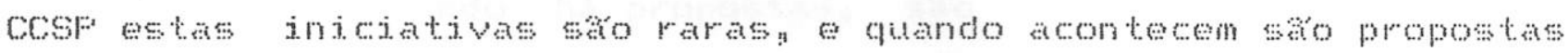
de oficinas de danga 0 Clsfw ao contraton dispoe de area espectica para o trabaltho de corpon

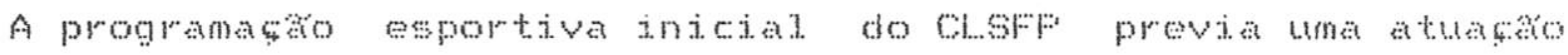
pionetra na arean tratando o esporte de foma naomonvencional abrindows para novas altemativas corporais o que raras vezes

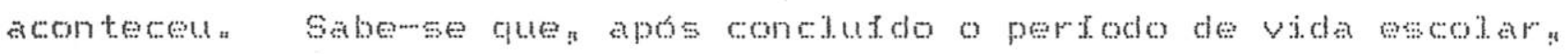
ha uma queda vertical na pratica de atividades esportivas serdo que apenas $24 \%$ da populacto acima de 18 anos fax algum tipo de ginastica $e$ menos de 8\% da populaso aduta pratican mesmo informatmente algum tipo de esporte. Este numero bastante baxo e possivelmente se deve a falta de locats para se exercitar o corpo e ao mator interesse por outras atividadess pots o estrmu ao esporte nao foi devidamente desenvoludo nas obrigatorias aulas de educaço fiston na escolan E notoria a necessidade de se tornar o esporte mais atrante e perceber na sua pratica algo mass do que uma simpless possibilidade de extroversan 
Ao se trejur votej por exemplon as or gens do jogo poderiam ser ensinadas aos esportistas, ben como a formasto das regras os musculos empregados e o comportamento do romo nesta prática esportivan atem de mostrar vtdeos de grandes jogos e trayer para debates atietas consagrados Assim certanenten a pratica desse esporte teria outro sabor" Serian bastante uteis atividaces gue possibititassem a pessoa a conscitncia da sua postura fisica do que se passa no seu corpon e ensinassen sobre os nutrientess necessários ao bom funcionamento do organismo quajs os alimentos que os fornecen. Ruanto ao espetalo esportivon ha a possibididade de se avaliar as performances dos participantes a

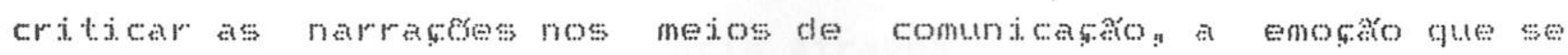
consegue transmitir a linguagem usada.

Mass o que acaba ocorrendo e que o SESC simplesmente abre as quadras de suas unidades e da bolas em troca das carterinhas dos frequentadores quando há propostas "sao nomalmente de macro

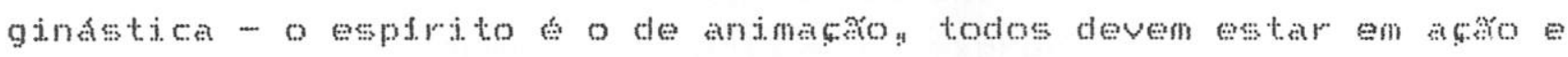
agitando alegremente seus corposn Alguns tecnicos da area esportiva tem consciencia do que ocorren mas dizem que a institutaso ná oferece condiçes para que seja diferenten

A maioria das atividades dirigidas ao publico do sescatanto na area esportiva quanto cutural guando nâ sáo de simpless contemplaşo tendem a colocar as pessons em movimenton nao jmportando muto o que se faça Varjos frequentadores habituats iat tem uma excitacto propria e mexem em todas as coisas ao seu alcancen porem esta curiosidaden que poderia ser um ponto de partida nao é trabahada para se chegar a emosion pois as propostas do SESC náo vao adiante do que perceptivel aos olhos: desconsiderando o mundo subjetivo e a importancia da pessoa contatar seus sentimentosn

A pulsaro do tocar os jogos de rosar: a multipliteaço das academiass a presenç do corpo na publicidade " na televisáo e nos muros da cidade tudo leva a se valorizar a epifanizar o corpo. 
Diante diston os centros culturas estarian colaborando se reatizassem oficinas sobre o corpo mostrando tenticas como Folfing Bioenergeticas Eutonia e esciarecendo sobre o metodo Fieldentratse as dinamicas de movimento estudadas por taban por exemplo: afen de palestras sobre a relagko entre a pessoa e o corpo, tentando trazer conhecinentos teoricos e vivencias sobre o assunto, montando un painel para gue a pessoa possa escolher o gue mais a satisfaz e entáo procurar se desenvolver em una academian

\subsubsection{FunçBes e Limites de um Centro Cultural}

0 homen busca a coerencia atraves dos stmbolos a a cultura que articula todas as dimensos de sua vida 6 o universo das mediaços simbolidess as quais trabalnam em busen de un sentido para a existencia. A principal funço de un centro cuturat ajudar as pessoas a processaren os stobolos presentes em s. ex sua epoca por meio da materia artistica e deseus codjoos que pernitem criar fornas perceptiveis expressivas dos vistubres interiorese dos sentimentos hunanos Este trabalho tera texito se possibilitar novas perceperes as pessoas que se configurem em

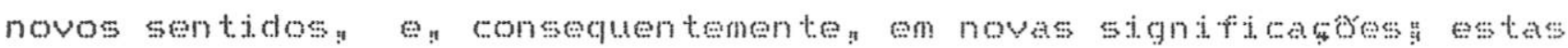
levan a atitudes que esperasen venhan a transformar a vida das pessoas " Esse processo pretende levar a pessoa a sentir...se um indivfduo, e como tal assumir toda a responsabilidade que ine cabe ou sejar assunir seu proprio corpon sua propria conscitencian sua própija mente.

Ein um sistema capitalista caracterizalo pelo egotsmo acumulativo que aguça as disputas encontramse poutas iniciativas sinceras para a coletividaden realizando-se certos investimentos culdurass porque poden reverter en beneffcios politicos para quem os implantou nă se ve motivos para efetiva-los se ná forem posstveis futuras vantagens. 0 universo subjetivo é desconsiderado - principalmente tratandome de un pais subdesenvolvido -..- as pessoas acaban vitimas de constantes desrespeitos e crimes a nivel psicologicon que sempre permanecen 
impunes: so se considerando o que atinge a vistan como uma facada ou un tiro. Dentro destas ideias e dificil conceber a existoncia de um centro culturat. que despreze as aparencias te trabalo para o

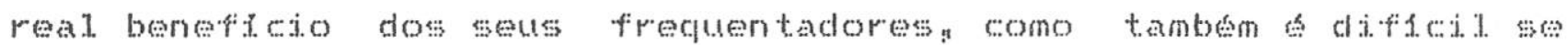

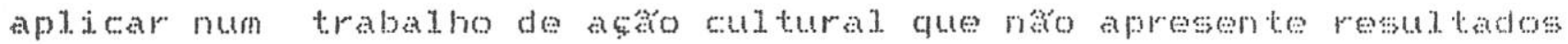
para serem extbidosy pois o que se obtiver pertencera as pessoas e sera levado com elas. Farece improvavel que se possa ter algum prazer em posmibilitar o desenvolvimento do outroy a maturidade emocional dos individuos"

Da mesma forma que o governo brasilejo destina recursos a

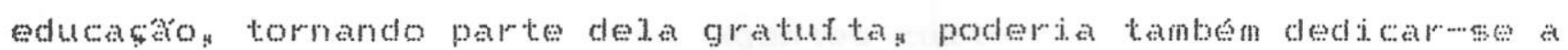
possibilitar a expressáno culturat da sociedaden cono jsso natesta mut to proxino de acontecer. pois o proprio apoto a educaso format. e deficitarion a safda é a captaço de recursos privados que 60 que ocorre en diversos pafsesa como diz reixejra coentho "sera ingenuidade acreditar que a sociedade ira financiar pration que a

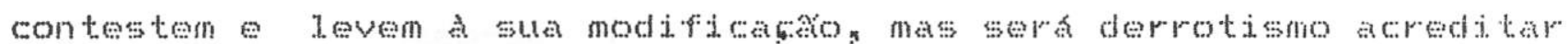
ser jmpossivel criar as condipos para que esta sociedade se confronte dialeticanente, e com sua propria ajuda com aquilo que a contestan"(20) Fazer shows, espetaculos projegess nák jncomoda a ninguém, mas quando se aproxima da esstencian quando se mexe na estruturaça social quando se procura dar lucidez as pessoas significa perigo. Buem tem o poder trata de mantewo com as estrategias que puder como por exemplos fazendo com que todos vejam o mundo da maneira que lhe converny e para isto os meios de comunicasco de massa saco possantes instrumentos. A arte tornawe importante quando ameaça sistema institufdo e atua ao nivel das crenças basicas sendo esta a area que a acoso culturat deve atingi.r.

(16) Coelho Netto, José Teixeira - 0 que हe açăo cultural, Săo Paulo, Brasiliense, 1989 (pag. 50) 
A atuaga de un contro culturat dependera das decisoss politicas daqueles que o administram. Como nas ha dispositivos para se medir a intensidade a valdade de un trabalno culdural. quem ira julgar e determinar a continuidade das propostas sora os administradoress que podern ser influenciados por una comundace ativa os agentes cutturats nomalmente estás sujejtos a administradores que naso se interessan pouco se sensibitizan com certas propostas sendo frequentes as disputas entre as areas administrativa e culdurat, e saber lidar com isso o umas darefas que thes caben. 0 sucesso da atuaço de un centro culturat dependera en grande parte da relatso que se estabelece en seu interior entre os dirigentes agentes culturas e frequentadores.

Frovavelmente a persistencia e a sobrevivencia do mbs diante das varias dificuldades por que tem passado deverse a uniso conseguida entre seus funcionarios " Os outros dois centros a contrario, provocan mutas vezes sensaches aversivas aos seus tecnicos que sentem-se incomodados com a ineficitencia a palta de respostas dos processos burocraticos vigentes n com o desejo de receber o maior numero posstvet de pessoas o clefF e o cosf náse se preocupan em compreender o seu púbicon en pesquisar o que as pessoas pretendem e porque estäo da nesta atitude contribuem para que tudo permaneç como esta implantando a mesma imobilidade que possuen seus organismos institucionais. Quanto mais se freguenta estes centros, menos 6 sentida a necessidade de mudar a disto oposto do que se pretende na aşo culturaj.

As propostas de trabaliho de un centro culturat podern variar conforme suas caractertsticas localizacko disposicho fisicas equipamentos, recursos" publito frequentador aquipe de trabalho, experiencia adquirida ideologia presente e pretensoes.

prineipat $\&$ que se tenha bons agentes culturais e lhes seja dada certa liberdade de atuaço pois criativamenten podern lidar com posstveis condiches adversas e realizar un verdadeiro trabalho de asaro cultural" pouco adianta, a contrario, entregar un local con amplas condiçes para quem năo tem capacidade de usa-las. Uma das 
prineiras questoes presentes a a de comose trabalhar em larga

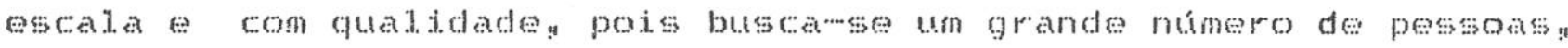

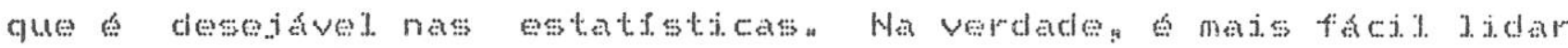
com uma mutidaro de espectadoress para a quat se exibe qualduer coisa enquanto as pessoas ficam olhandon do que optar por um trabatho mats profundo com un grupo reduzido, porem o que mais pode se desejar a um centro o que tenha a devida coragem para experimentar novas praticas culturais.

E como fazer para que a populaciato use de forma efetiva o centro cultural? Du se prograna o que as pessoas sabidanente gostam da industria cultural, ou se faz com que elas sintamse devidanente consideradas e perceban que ha uma preocupaso verdadeira em contribur para que melhorem suas vidas dentro de un processo de busca de conscitncia atrass dos elementos culturajs. En qualquer lugar havera pessoas carentes de contatos culturajs e humanos: a credibilidade da proposta irs depender do respentio gue se tem pelo que se pretende fazer. charo ha o problema de cono se despertar as pessoas aconodadas que nao tum o menor interesse en ver o que traz un fithe ingles sem legendas a a ostumalas que estao a televisaro onde tudo ven matigado e na quat se satisfarem com poucos efeitos aloumas cores e muta achon certas pessoas empenham suas energias apenas en consunir, nao saem em busca de qualquer aprendizado -.. para o qual năo tem nenhuma curiosidade -.. e nem possuen disposiço para descobrir as outras possibilidades da vida E cliffcil indispor a pessoa contra sua apatian despertar-ine o esplitito de irritabilidade "mas ha que se tentar"

o centro cultural a o lugar apropriado para que se reúna uma grande expectativa sobre sua atuaço e o que resultara dela. Alguns acham que e un local favoravel para se cultivar o infcio de uma proposiço alternativa outros o veren quase como un posto de una nova doutrina humanitarias e ha ainda os que pensam que, de forma analoga do planetario que descortina o universoy o centro culturat seria o espaco com a missăo de despertar o homen para as outras posstiveis dimensoes do seu proprio ser. As experiencias 


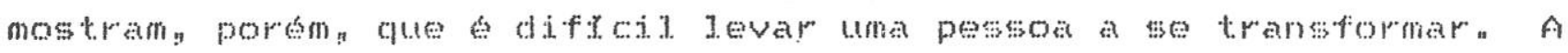
psicandi.je pode atestar o tempo que demora para se consegur uma verdadeju mudanga por mfnima que seja quando se consegue "

Euma das questoes mas importantes talvez seja a de se perguntar o que as pessoas vao buscar num centro cultural. Frovavelmente ele represente um espaso alternativo as tensoses insatisfacoses do mundo contemportineon atgo como uma casa gue abriga as imagens, os sons os tonhos. Ao lidar con a sensaço a

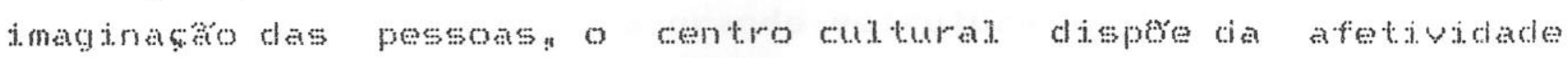
como materiaprima en certamentes o uma estaço majes proxjma das utopias ald inentadas pelos homens, reacendendo a esperangan.

\subsection{Caracteristicas dos Centros Pesquisados}

Abertos at populaço em geralu cada un dos tros centros pesquisados mantem ao mesmo tempo variadas atividades na area cultura e/ou do lazer. gue sao em geral gratutas ou tem presos simbolicosn Em suas falas ha pelo menos un grande objetivo wm comum que do de tornar a cutura acesstivels despindowa da sacralidade que costuma reserva-ia aponas para as elites.

\subsubsection{Arquitetura}

- projeto da cut tura sem barrejas e a grande marca do cosfa nesse plano se excluiu a compartimentagko definida por paredes, divisoriass portarias e qualuer outro bloqueio. Nato existem,

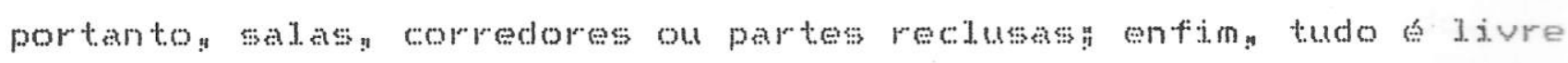
- foi. arquitetado para que o centro possibilitasses no mesmo cenario panorimico constituido por tres niveis.s multiplas atividades simultaness n

0 cCsF estál localizado em una regiă ariday possui apenas aloumas arvores em seu interior 0 de muto ventog mesmo assin pessons escalam suachada irregular os meninos de rua se divertem nas areas externas enquanto vigilantes os expulsam de 
cima dos canteiros ocupados por una grama rala que divide seu

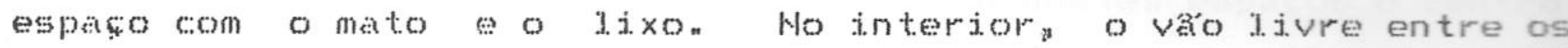
pisos o perigoso para as criangas para os cegos gue frequentam a biblioteca braille na no ha un local para se fazer lanches desde a

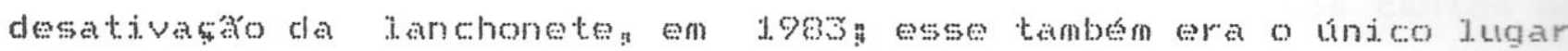
onde se podia ssutar descompromissademente no centron a falta de bancos tem influenciado de forma decisiva para a pouca visitacáo de i. dosos:

o Cosfo roi a primeira grande estrutura fabrit a ser reciciada

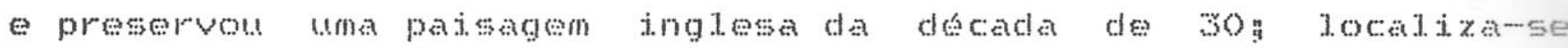

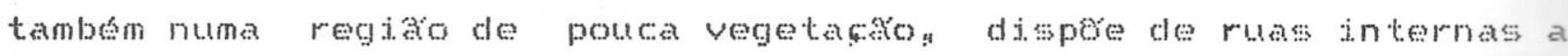
ceu aberto por entre os galposes culturais tem a area

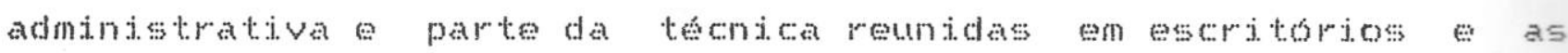
atividades esporivas concentradss no conjunto constructo com festa finalidade o o restaurante/choperia estat fechado durante a barde e

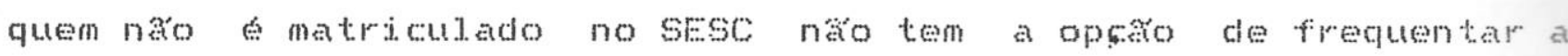
1. anchonete do conjunto esportivo. Af area de convivencia funciona como uma grande sala de estar que pernite interacosesocias a en boa parte das tardes suas poltronas sao ocupadas por idosos.

o m.s.s constitudo para abrigar e divulgar a obra do pintor

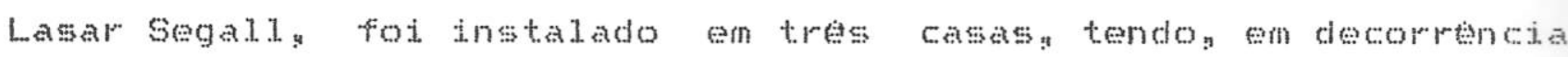
disto, seus sespasos bem demarados apesar de ter sofrido varias reformas que visavam adaptar melor o looa as funcionamento manteve as salus mejo escurss com mobilidrio antigo" que convidam

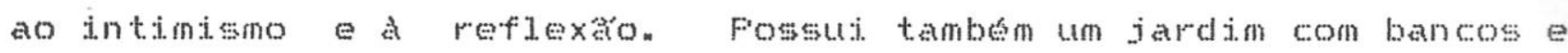
uma cafeterja aparentando estar sempre cudado e bem arrumadon

\footnotetext{
Neste sentido deve se ressaltar o SESC ques tanto no CLSFF

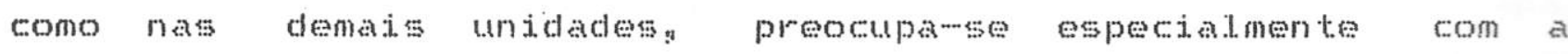
apartacian procurando sempre passar a imagen de un lugar impecável, meluzente a alegren da no CCsF destacase a improvisaçon com os teconicos semi-matapados e expostos na grande area livre do centro e uma barricada de biombos montada para salvaguardar a diretoriaj um dos maiores problemas enfrentados pelo centro municipal é o da protecton sendo os niveis da pinacoteca e da rua interna rodeados
} 


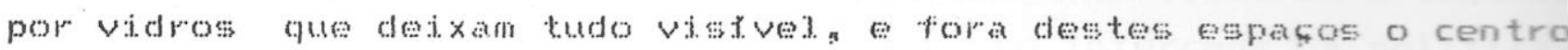

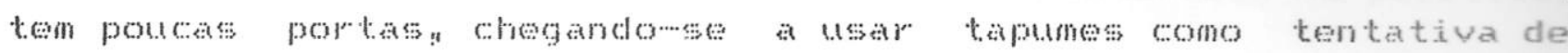

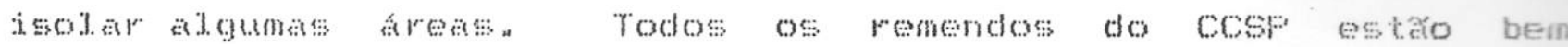

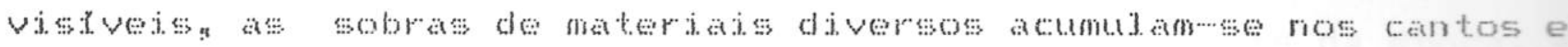
a

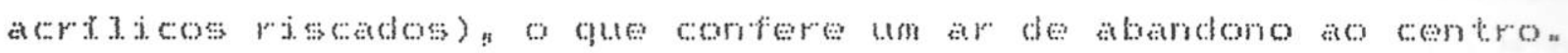

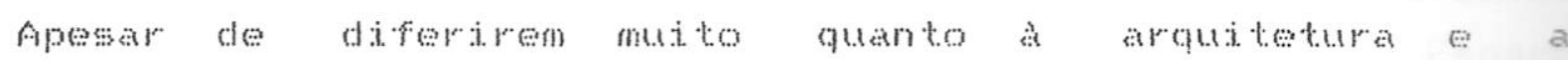

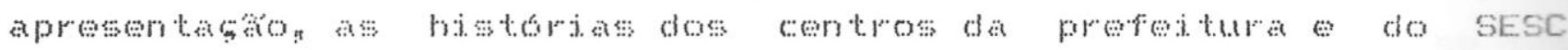

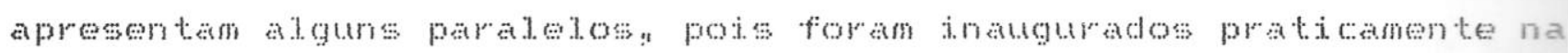

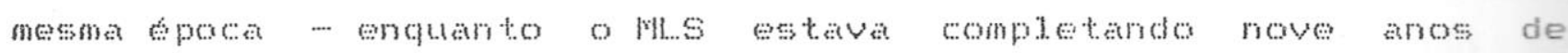

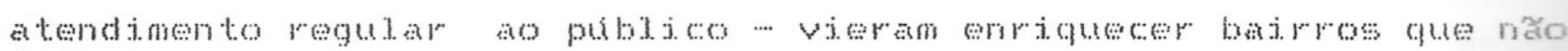
of

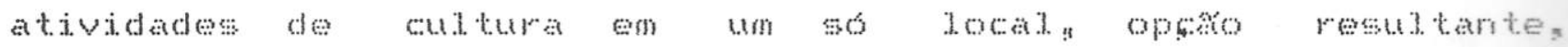

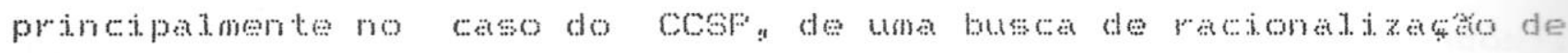

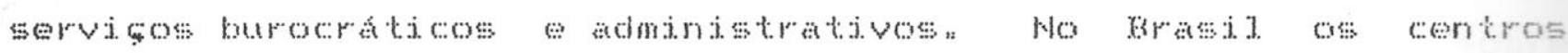

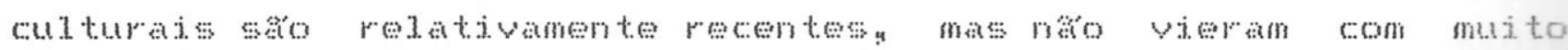

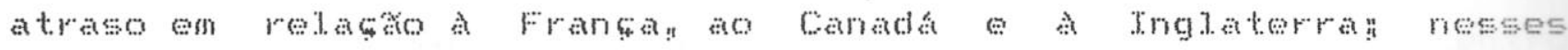

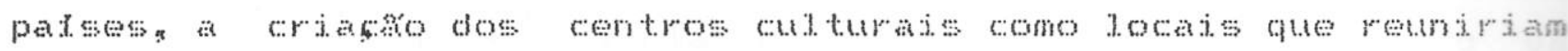

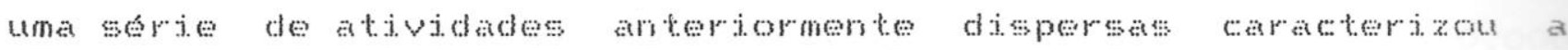

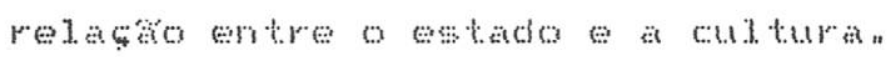

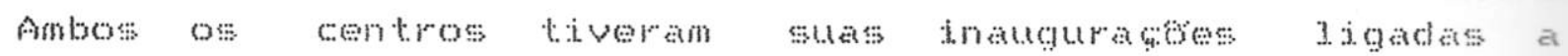

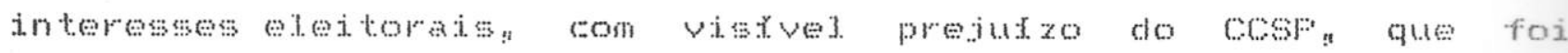

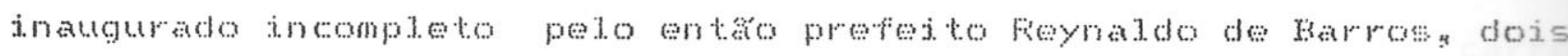

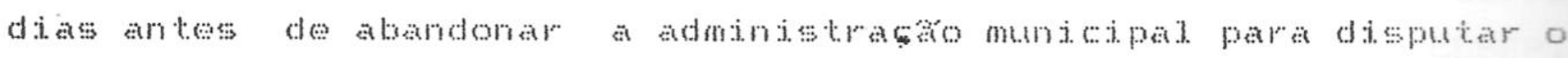

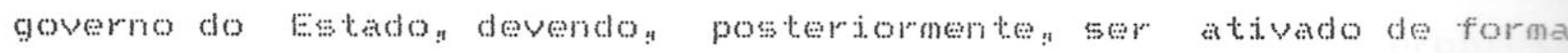

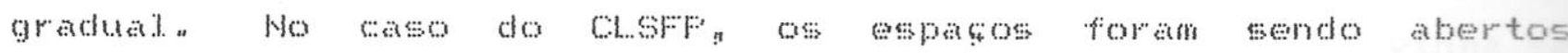

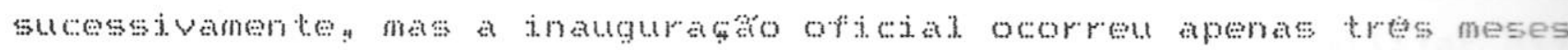

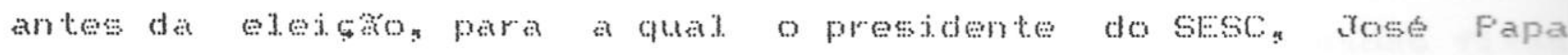

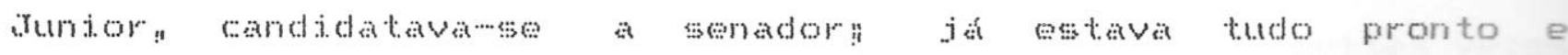

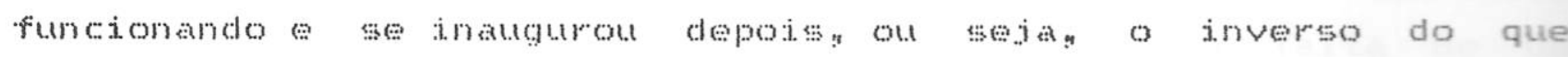

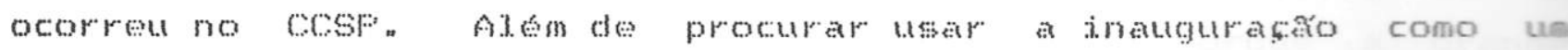

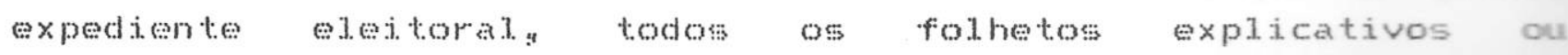
promocionatis da fabricia trazin sumpres uma maxima de José papa Tunior sobre an atividades descitisn compraram-se pequenas

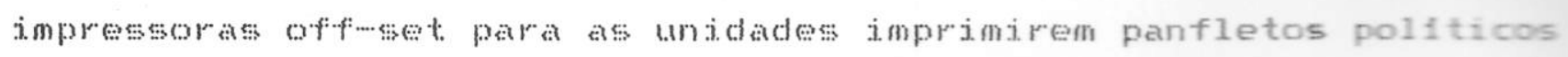




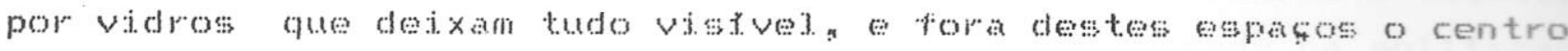

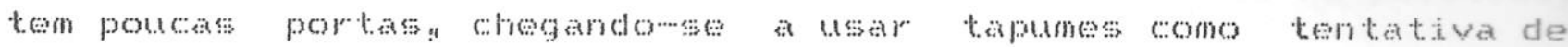

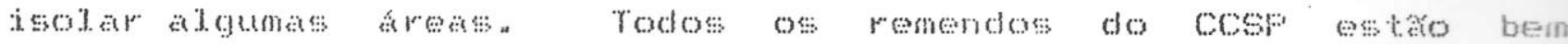
vis.r. a

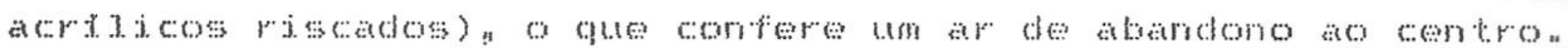

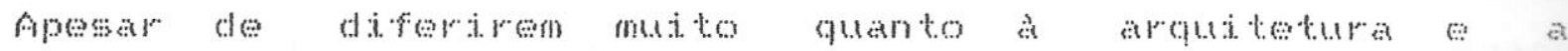

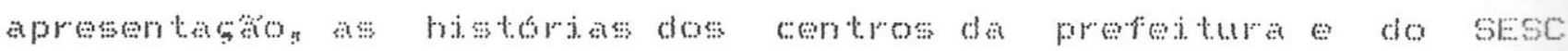

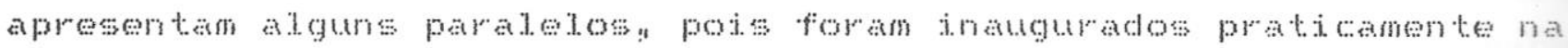

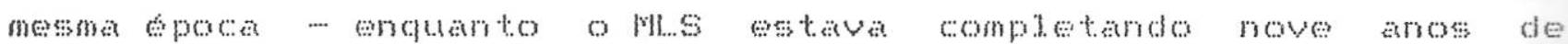

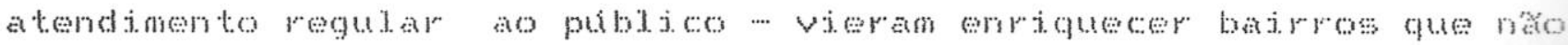

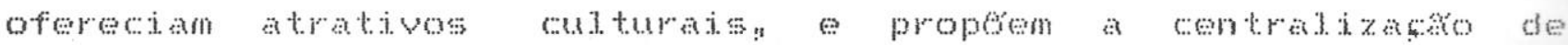

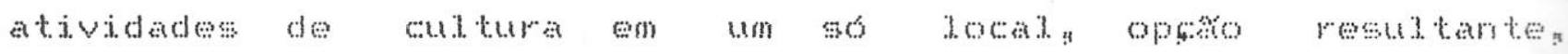

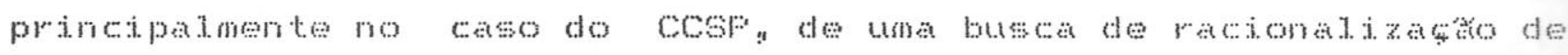

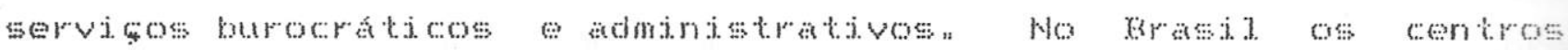

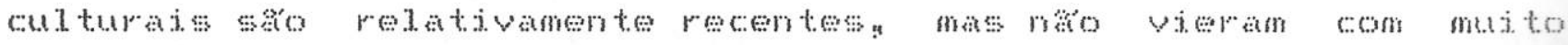
atraso

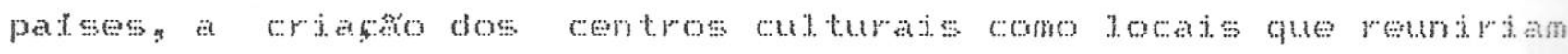

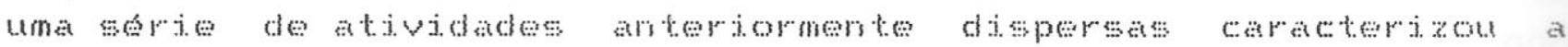

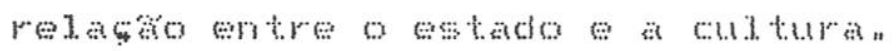

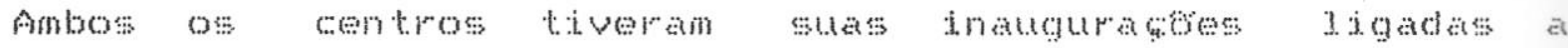

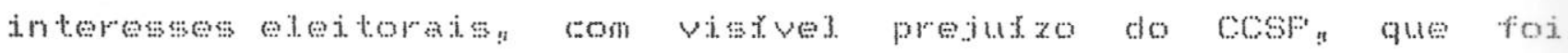

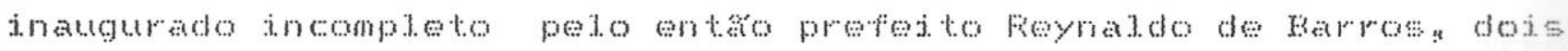

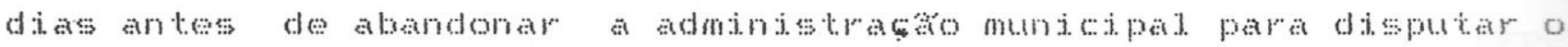
governo do fistadon devendon posteriomente ser ativado de forma

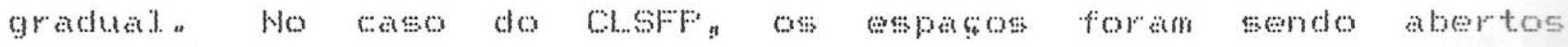

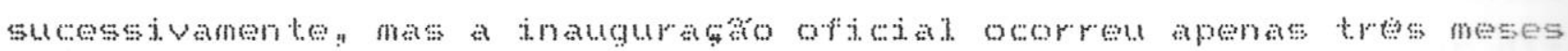

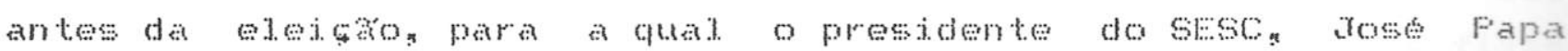

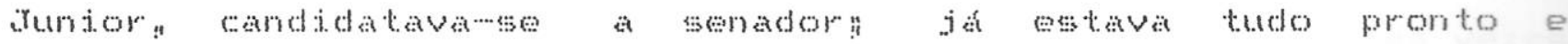

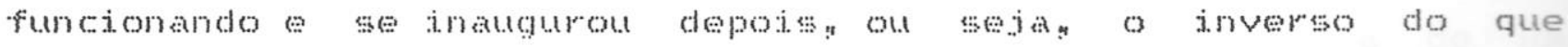

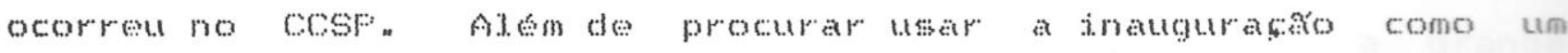

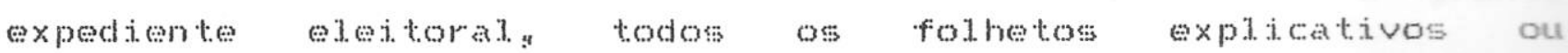

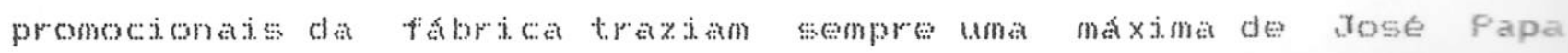

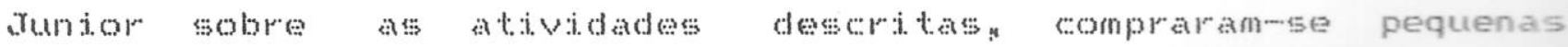

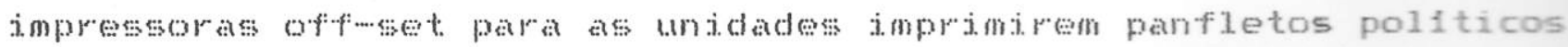




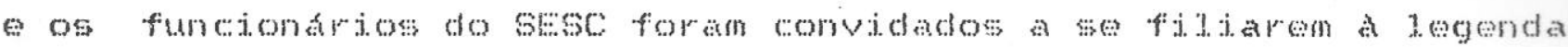
do Fds mparentementes porem, cutura pouco interede na polt tica, pois os dojs candidatos tiveram baixa votaçon

Conforme os or samentos apresentados pelos jornats da pocas a construço do Cosfo custou dez vezes mass do que a restauraso do CLSFF" Diziame que o centro municipal era o linico do tipo porte mantido por un organdsmo público e que havia se construfdo o major centro cultural do brasil (mas depois foi jomourado o Espaco

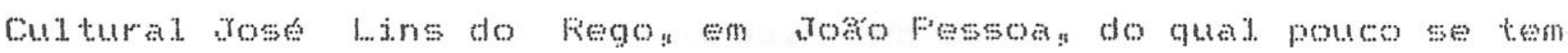
notician mas parese ser o mator en arean comentase que nás se sabe direjto o que fazer com seu imenso espasol. o ci..s: nas so constitufa numa realizaço publica fiato incomum em projetos desse porten foi apresentado como sendo o mais avangado e mats bem equipado centro cuturat do pats corth seus equpanontos sw tornaram obsoletos en pouco tempo ate hoje nas foram renovados). Wapoca das inaugureses perguntaram a Fenato Fequia sobre

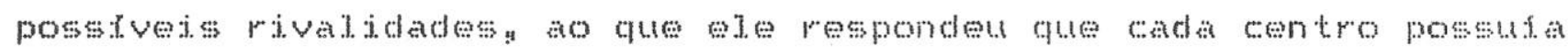
suas carateristicas proprias e iriam dinamiar a cidacien o centro da prefeitura tinha a vantagem de estar plantado ao lado da estago verguejo do metro por onde passavam na epoca 600,000 pessons diarianente enquanto o sesc Farica logo deservolven a reputaços segundo os comentarios dos jornatsa de ser o centro cultural. mais ativo e frequentado da cidade.

Nenbum dos trtes centros tem estacionamento o parar o carro

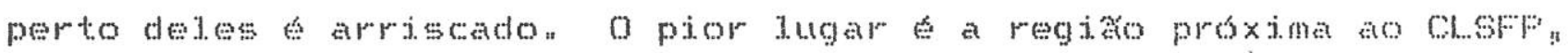
onde os roubos sao muto comus a qualquer hora do dia b o problema ja preocupou a admindstraço do centro pois a frequencia vinha se reduzindo mas parece ser insoluvels ja que a policia militar diz năo dispor de funcionarios suficientes para destacar pessoas fixas para o local. Was cercanias do mos os carros saso mutas vexes abertos, para os frequentadores do cosp a fatta de un estacionamento náso sise constitui. en problema porque a grande matorja deles se serve do metro. 


\subsubsection{Organizaçă Administrativa e Progranaçă}

Fodewse perceber a atitude administrativa as preocupases culturais de cada centro por meio da organiaşa do funcionamento de suas bibliotecas" A do cCsF tem de tudo e pretence atender a todos: como é a parte majs importante do centro precisa funcionar bem e pareceser a divisás que mats exige dos funcionarios os quajs nem sempre tem boa vontade no atendimento ao publicon $A$ biblioters do mo possui... un acervo espectifico a atende

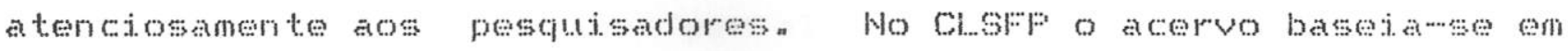
gibis jornais; bestsellers e colestes incompletas naso ha bibliotecarion a a arentemente a institutio nas se importa com os constantes roubos " como tambem nás se importa com o setor" provavelmente porque ná pode ser transformado em notfi.ia.

As exposisoss a a programaţo desenvolvida pelo Mlls sas condizentes con suas estruturase diretrizes estabelecidas apesar de alguns as considerarem elitistasn conservadoras monotonas Ha que se levar em conta que a arte acaba sendo uma srea elitista mesmo, porque poucos podem dedicar-se a relacko com os elementos artisticose perceber nisto uma possibilidade de desenvolvimento pessoal. As propostas do museu sá as de se trabahar as formas de expressa mas traticionats nato se ocupando fom os sistemas de imagens da pósmodernidade c... como fax eletrografia e imagens computadorizadas -- mas estando atento equestionando a relaço dos frequentadores con as manifestacos artfsticas como conver a um museu comuntarion preocupa se en náo receber apenas un so publicon procurando atender do profissiond ao amador em todas as propostas" 0 museu caracterizase por una continuidade no desempenho fato devido a permantencia de Maurtcio Segaj. en sua direço.

o Cl.sFF, conforme diz a propria institutaso, reline num mesno espaç atividades de lazer fisico-esportivo intelectual artatico e socialn rambém desenvolve um programa de alimentaçáo do trabahador e talvex en breve preste assistencia odontologica; recebe ocasionalmente algumas convençes, como as do bions club, da Hoecht da Follcia Militar, Na area cultural procura 
caracterizar-se como promotor de shows o eventos 0 CCSF nao se abre para tantos lados permanecendo apenas na area cultural, e rexne em suas dependencias varios serviłos que anteriormente eram prestados sem organismos distintos da secretaria munipal de Culturan Descle a inauguracho os dois centros prometim estar abertos a todas as pessoas de todas as idadesn com todos os interesses" Frometiam, anda trabajor com todas as artes com a cultura em geraly sempre propondo atividades mutidisciplinares. nunca ser sejetivos ou elitistas" pelo que afimavan parecia que tinhan a intenço de vir a ser algo como un "shangrida" "um posto avancado do paratso na Terran

Há poreng un engano quando se pensa que se pode fazer qualquer coisa en qualquer hugar desprezando-se as especificidades presentess A proposta seratanto mais adequada quanto mais se aproximar das caracteristas do espaco onde jra acontecer devendow se, portanto respetar os favorecimentos e limites deterninados pela arguteturan pela estrutura basica do centro e pela mu frequencia habjual. a qual guerendowe ou naon acaba por se definir: devendo se elaborar a proposta de forma a poder ser recebida aprovedtada por este publicon Nos casos do cosfe do

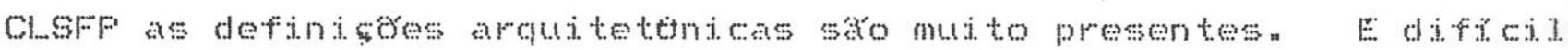
fazer algo mats dirigido en espaço táo aberto elispersivo como os pisos do CCoF onde se tern tentado definir algunas regioes para funcionar com progranacoses constantes ou a area de convivincia do Cl..sFy: que naso possibilita a intimidade ou privacidade necessarias a certas atividaces propostas na e facil estabelecer epelicar una programaço concentrada e apropriada a todos os espacos de um grande centron porsin deverse ter ao menos uma certa percepta do que cabe en cada lugar: e isto parece que inexistiu en mutos momentos.

Como o Ill.s naco se aventura a fazer uma exposicho sobre Carmen Miranda, O CLFF 0 oCSF poderian verificar se thes cabe mostrar gravuras inglesas do século passadon en caso resolvam exibi-las, deverian preocupar-se en melhor adequar o espaç para recebe-1as e en como aproxinar seus publicos destas obras Houve épocas en que 
os dois centros fizeran tantas coisas dispares ao mesmo tempo que custava supor que havia alguna linha de trabalho estabelecidag nao se observava tamberm empenho em produzir crtticks ou reflexoes nos frequentadores. Foderian decicar-se a montar exposiçes mais coerentes a anda que ern menor numero. For exemplon seria adequado o Cl.sFF elaborar exposicoses produzidas com materias brutos e crus e propor oficinas a partir de elementos primarios praticas que estarian de acordo com seu espaco de fabrica e condizentes com a arquitetura despojada de Lina Bo Bardin ou ate mesmo exibir a alta tecnologiag realizando um contraponto com as linhes da fabrican mas sempre buscando un diatogo entre os objetos a serem mostradose a ambiencia disponfvel.

A programasa do CCSF passou por algumas etapas de maior

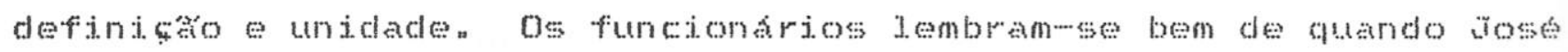
Geraldo Martins de oliveira promoveun en 1985 a pesquisa e a discussa das questoes urbanas criando atividades voltadas a abordagen dos problemas projetos da cidaden fiecordanse tambom de que no ano anteriora o centro se tornou un espaco para a discussa cultural e polftica travada na eoca a A secretaria Municipal. de Cuturas atraves de seu Departanento de Bibliotewas realizou algumas boas iniciativas no centroy como a pronotáto de encontros com escritoresa a idfia era a de que o contato do autor con o público permitiria maior compreensăo da sua obra literrarian do seu processo eriativo e de suas intencoes e fungess n Foram tamben programados encontros com artistas plasticoss procurando mostrar que eles nâa sáo seres tao diferentes como tantas vezes se imagina

No jnfcio de seu funcionamento o ClsFF passava a sensagra de ser un lugar onde tudo poderia acontecer"algo como a criacaso da dimensaso do lazer e do prazer tentando envolver o visitante num sistema de animaço que impressionasse os cinco sentidos ou seja, queria provecar tudon Eo sucesso veio con a conjunça de condiçes favoraveis, como a aplicaço de mulo dinheiro para a unidade "pegar": a reunia dos melhores tenicos do SESC e a contrataşo de instrutores que eram artistas e participavam das 
produçes a sendo que a orden lindea era a de se fazer sempre mats atividades sem parar. No cosf o empenho ná foi menor. segurdo uma publicasao do centro" realizavamse 130 eventos por mis. atingindo a frequencia de 1.300 .000 pessoas nos primeiros de\% meses: as apresentaçes contavam com os melhores nomes que se podia imaginar e tentava-se cobrir todas as mantestaçes culturais do teatrinho de bonecos a música indianan

E muito mats facjl trabahar nos primejros meses a mesmo anos de langamento dos centros cuturais, porque dinheiro naro fata a imprensa acostumase a cobrir tudo que acontece por la os mass competentes funcionarios da instituscoso esto prosentes ex prece que todo dia ha um clima de novidade e festa quem participou dos aureos tempos do CCs: e do ClSF jamajs vai se esquecer da satisuacto de conceber e realizar projetos e eventos u un fator muito importante para quem optou por trabalhar com culturan Impossivel es manter a intensidade dos primeiros messs navendo sempre una decadencia natural. quando as programaços comegram a repetir.se por falta de alternativas e o sucesso bombatico vai passando. Depois vem outra administraça e como a oba nấ sua, o dinheiro comesa a minguar, ou o centro năo recebe as necessarjas condiçess para seu bom funcionamento 2 as publicacos que trazen o nome dos antigos governantes e dirigentes náso podern mais circular: guer seja un folheto ou um fantastico livro sobre brinquedos populares. Chega-se até mesmo a vetar nomes de atividades que ficaran vinculadas a antigos periodos da insti. tui ça.

Com o tempo a burocracia se espalha e enrijece ate se tomam impeditiva para a açăo clos que pretenclem realizar uma initiativa culturat. significante necessitando-se uma forsa hercuilea para conseguir vencer as dificuldades invistveis . A partir de entaco quem manda saco aqueles que tim o poder de paralisar a situka so inverter com a administraço, que deveria possibilitar a atuaço do agente cultural. passando a se constituir no seu mator obstaculo. A execuço de certas tarefas e vista como se a burocracia estivesse fazendo a gentileza de conceder auxidos aos setores de cutura 
os artiatas e os agentes cuturas fican totalmente submetidos a

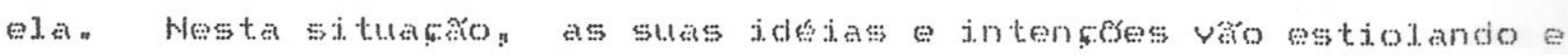
morrem.

Wo ccsF consolidou-se a estrutura rigida e hierarquica do funcionalismo púbico en segundo alouns funcionarios a possibilidade de realizar um projeto ira depender da habididade de quem esta ros postos decisivos de comando de consegur imprimir dinamisno ao organograma dizen que ou se tem certa iberdace con com as pessoaschave circulando como a ambutancia ou o carro de bombeiros que naso precisem obedecer as lejs de transito on raso se consegue nada, os funcionarios acabam se acomodando wh seus lugaresn outros afirmam que se trabalha para alimentar a burocracian que de árearmedo teria passado a sreatimn que o proprio diretor tem dificuldades de estabelecer mudançs a A unica satda seria modificar a led pois o difucil sistematizar uma linha de atuman ou mesmo certas praticas, e quase impossivel mante- las depois da substituicho das pessons que administram se por un lado o CCsF esta amarado por sua legishagon que deveria derinir funçoes mas pelo que se diza saralisanten por outro esta sujeito

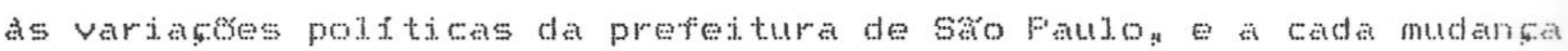
de governo ha uma alteracto nos postos mats significativos do cention impossibilitando a continuidade de una politica estabelecidan

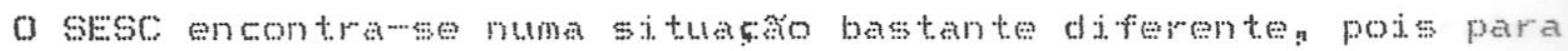
mudar sua forma de funcionamento nao depende de nada que necessite de una aprowaşa externa a jnstituţo e nâo sofre as interferencias e comprometimentos polfticompartidrios. Wo $5 \mathrm{se}$ as coisas

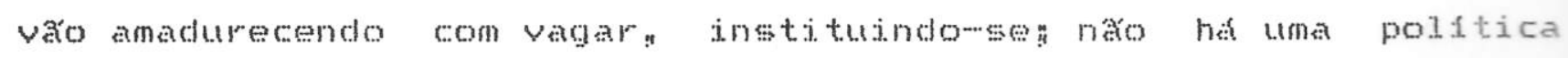

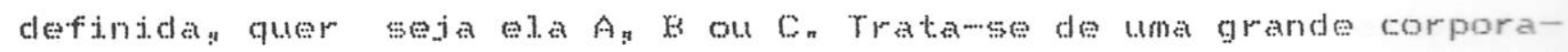
cho formala por varias corporaçoss que as vezes nás se entendem, chegandome a perder muta energia nas desavencas internas e obtenclome poucos resultados en ternos de realizaços da entidade. O SESC \& na verdade u uma instituiço privada com estrutura publica Normalmente "as instituteses privadas tem certas metas a alcancar, como o lucro e o seu desenvolvimento com definiçes a 
serem cumpridas estritamente os orgäos publicos que náo objetivam o lucro, acaban, em nosso pats nato tendo compromissos majs serios. e as suas deteminaçes resutem frouxasi que es um pouco o que acontece no $\mathrm{Sis} \mathrm{s}$.

o ClsFF e uma undade que atua em varias areasi como un grande clube 9 a predomintreia do setor administrativo acaba sendo inevitave] g com funcose como a de cuidar do fluxo financeiro dos problemes que ocorrem no restaurante na piscina fazer reparos, arrumaceses para bajes. e atender a programaso quando tiver tempon

o lles tem a parte administrativa, a manutenço os servicos gerais servindo de apoio aos interesses cuturats deterinados principalmente por seu diretor matrte segall quen atraves de um processo democratico-autoritariog ven consegundo a unidaten a continutide e o desenvolvimente do museu nos monentos de

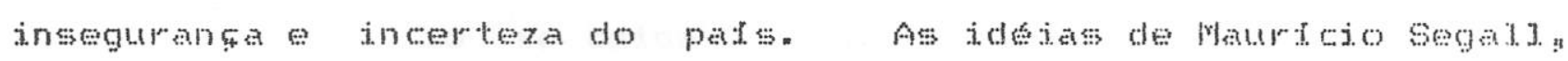
que junto a forma espontinea de ser delineian ciaranente sua personalidade, estáco sempre presentes na vida do museun fpesar das decisoes se darem en varies justancias coletivas -.. consenho

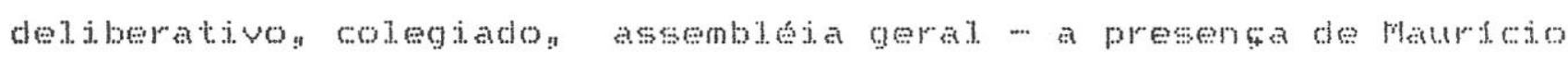
Segal1. sempre deterninante chegandowse a dizer que ele o o beme o mal de todo o museu Diante dos meios de comunicaca de massa sua posiço e purjsta pois considera que os midias contribuem

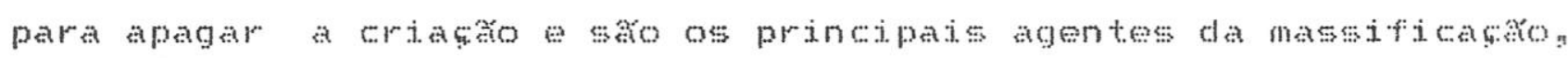
o que resulta numa existencia discreta para o mis. como o diretor tem certa repulsa ao mercado de artes decidiuse vetar a colocaço vistvel dos prefos das obras para qualquer exposiçon e os cartazes a serem pendurados dentro do musu so saco aceitos se ná trouxerem apelos comerciajs. 0 Mis.s tem a sua memoria bem guardaca em documentos, textos e impressos a ha bastante respeito dos funcionarios pelos bens da institulonon

Nestes pontos ha grandes diferencas entre os tres centros em questan 0 Cl.sF": e de uma forma mass geral o proprio st:sc, quer sempre estar na pauta dos meios de comunicaço de massa, năo tem muta preocupaça con o que pode resultar para as pessoas das 
atividades propostas. a n receptividade que mass interessa a da imprensa e a do SESC Central quanto a membria o SESC nutre descaso pelos arquivos que fora os recortes das materias jornalisticass se resumen a aloumas poucas fotos sem nenhum registro escrito do que resutou cada projeto. 0 sesc substitut ao inves de somar, o tempo evisto de maneira verticala com una atividade sendo colocada náo ao lado mas em tima da outra de tal maneira que o que se fez nao é processado e nao pode ser revertido como vivencian Waso se consegue guadar nada na institusto os acervos vao se destazendo aos poucosi nao se manteve reunido o acervo de artesanato comprado por ténicos en viagens por todo o patse a propria biblioteca do clsfo sofre constantes roubos significativos. Em suma nato se tem a consideracto devida pelo patrimonio de bens materiass e ná se zela pelo equipanento dispontvels constituindome este comportamento un corto vfeio

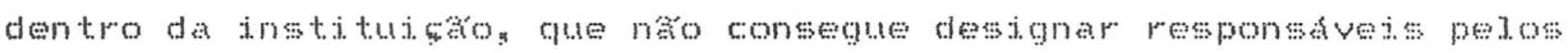

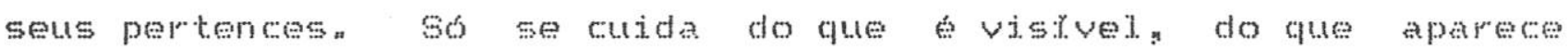
diante dos olhos dos que visitan sus dependeneias.

Os proprios funcionarios do cosp irritam-se com o que dizem ser uma vergonhosa fajta de preservaca da memoria do que foi feito no centrog na foram guadados nem os livros de assinaturas o que ! segundo ejesn reflete o clescaso a falta de profissionalismon Nos dois centros o que se encontra sao apenas textos institucionats de

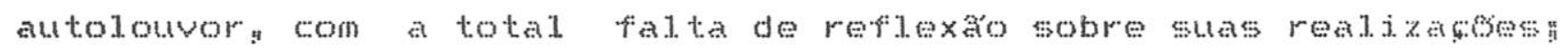
nota-se o hábito brasileiron principalmente na administraço publjcan de apagar o que vejo antess uma tendencia de esquecer o que houve jogando-se cal no que os antecessores fizerann liste s. sern divjda, um ato prepotenten que determina o comeco da historia a partir da chegada dos atuais administradores. na so tendo a capacidade de incorporar a experiencia ja desenvolvida por outros e dar uma continuidade ao que foi bem feito. 


\subsubsection{Oficinas}

Depois de varios anos de experitundas desenvolvidas nom seus

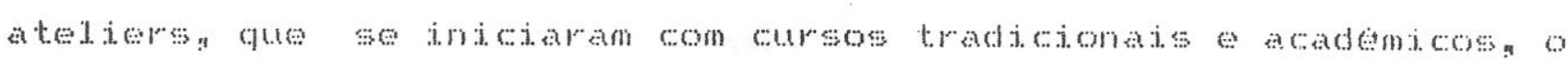
Mlls continua a tentar mostrar que é ertonea a joba de que arte so se faz com muta formaţo especializada o com o emprogo de tecnicas moficticadase utensidos complexos o carosa alom de procurar esciarecer que nas se trate de uma prerrogativa de pessoas

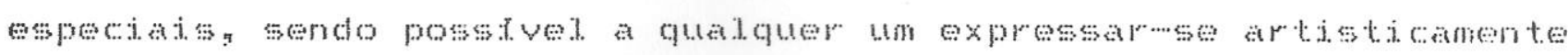

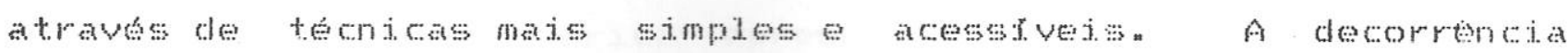
natural da maturasca do processo de expressa fo mostrar o que se produziu portm maurteio segall pede para ná se exibir os resultados visuass das oficinas possivelmente para náso misturar o protissional das salas de exposicoes com os trabahos amedoss dos atejiers 0 trabalho desenvolvido nas treas de fotografian

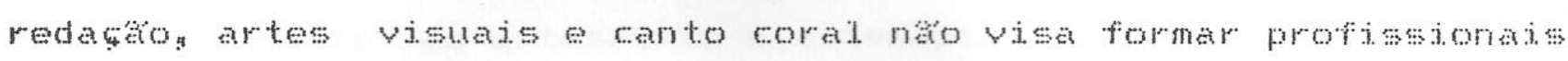
nem artistas o naso da certificado pois naso so trata de cursos com um programa determinado. os caminhos surgen espontaneanenten de acordo com as notivatoes dos grupos a o que se pretende dar uma chance de a pesson se manifestar por meio da experimentamo

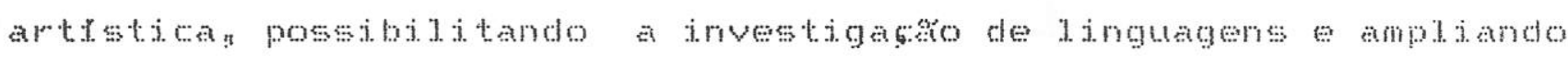
a perceptro a postura cituca os prequentadores comentam que nao ha outro lugar que ofereca gratuitamente a qualdade do orientactio do muset.

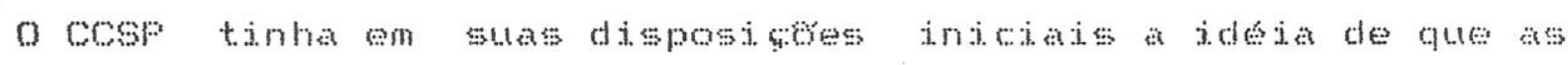
pessoas tamben deverian ter oportunidades para desenvolver producoss proprias o que ná se verjoficou excetundows os pertocos iniciais m Mrio chamie insistia que o contro nas seria apenas un espaco para a convivencta com as artes, um lugar para a absorcto passiva da informaço culturat mas tinha a intencko de vir a se constituir num polo dinatico de criacho culturd e artistica, oferecendo recursos para que a propria comundade pudesse criar. Frara tanto havia apenas o espaco do atelier jufantilin que se estendeu ao atendimento juvenil se tamberm adulto, mas observa se hoje uma frequencia bastante bata no local. 
Enquanto no museu e no CCSF as oficinas saso gratutesn o chop cobra pequenas taxas que aso monores para os comerciarios o sistema de locaço que retem para o sfec so\% da verba paga pelos alunos: acrescido de un limite maximo estipulado para as taxas afugentou mutos dos bons professores que la comesaran a dar audass Esta forma de funcionamento vem recebendo criticas dos tecnicos

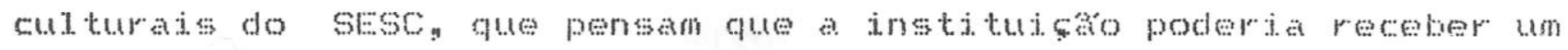
pouco menos, os frequentadores pagarem un pouco mais, e assim tentar manter os professores competentes.

As oficinas da fabrica apresentam varias alternativas de cursos que nomalmente se mantem ao nivel da juictatson com os professores trazendo propostas ensinando etapas de montagm propondo copjas de modelos, sendo essa a expectativa da grande majoria dos frequentacores. Ha excegoss como os cursos da srea de fotografian que tom dinanicas diferentes n Ensinam tendendowse mais ao artesanato e terapia ocupacional com poucas incursos no universo da expressacou nas buscas de linguagens. Essa 6 uma opta como outra qualquer porkm o problema asta na dificuldade que o SESc tem de tiferenciar o que arten artesanato

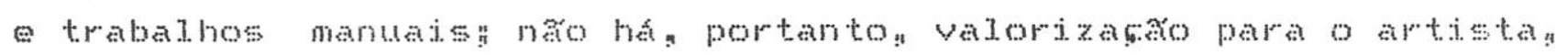
que nem e jontificadon

o que pode ser desenvolvido nas relatoes com os frequentadores e o que trazen os processos de elaboracto quer seja nos wusos no projeto curimim ou na rerceira rdade na constituem ejementos

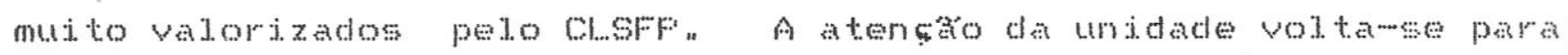
os eventos nos quas as pessoas sao chamans para se divertirem con o que esta acabado pronto para ser mostrado consumidon o SEsc prepara de forma competente alguns grandes eventos mas náso se preocupa en como pode se dar o seu contato com o publico omitindose na compreensaco na exploraço do que poderia vir a acontecer nesse encontro. Năo há tempo nem espaço para pesqujsas e reflexbes no SEsc acreditandowse que isto cabe aos teoricoss que em

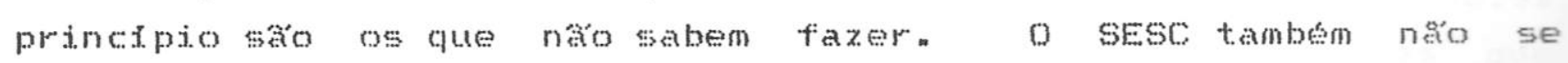
pergunta sobre a fungáo cultural daquilo gue realiza e naco avalia 
os resulados do gue faz e nem a conduta dos seus toconicos culturats

\subsubsection{Funcionários}

A supervisto do corpo fasico da fabrica e a parte que lida com 0 seu concreto como servigos de alimentacho processamento financeirog reparos e montagens) efeita por funcionarjos que tem claras as tarefas que devem cumpriry as nas hat iguat ordem definiça para os técnicos da programaçon que normalmente trabalham de forma polivalente com funçes e responsabilidadis pouco determinadas, num convite no amadorismo, com a atuaço de um imbricando na do outro. os animadores cuturais sao ternicos em generadidades, sem mutas chances de desenvolver conbeimentos espectficos en alguma coisan o expediente do seso fora nolocar parametros para sua area culturala năo situano a pesson dentro dos limites institucionats o no favorecencio a percepco da sua propma capacidade de realizaço, do que resulta a impressaso de uma onipotencia -.. o ceu e o limiten ate que se tenta fazer alguma coisa.

Was concretanente os animadores cuturais nem podem evoluir

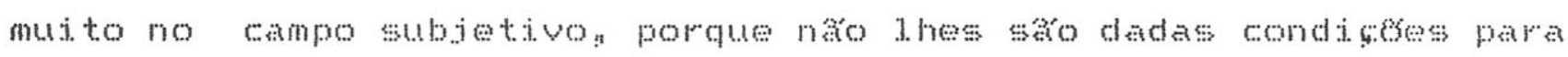
se dedicarem a andisar os elementos culturats que se preswntificam nas atividades propostas" se o sesc pretende atuar de fato na area culturat, poderia confiar mais no discernimento dos seus tecnicos -. que varias vezes se perguntam sobre suas reais capacidades sentindowse inteds - possibilitando major aço para os que sao competentess कo inves asso contrata nomes consagrados para sensibilizar a midia e costuma dijuir a autoria interna chegando.. se a situaşo de os seus ténicos serem mais respeitados for da

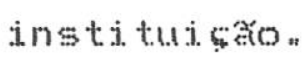

Os tenticos do SESC possuem diversas formacoes profissionats ha muitos sociologos psicologos e ate varios seminaristas que destistiran da batina sendo que, com poucas exceçes, quanto mats 
alto o postog majs distante a pessoa estat da vivencia e do conhecimento at turni.

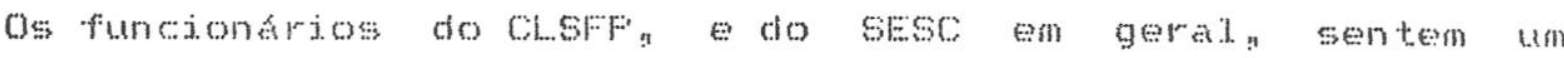

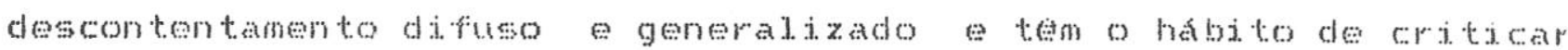

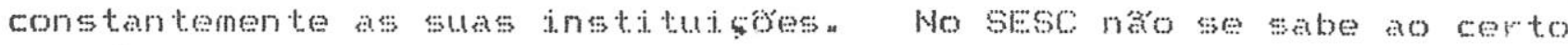

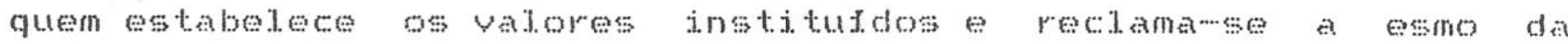

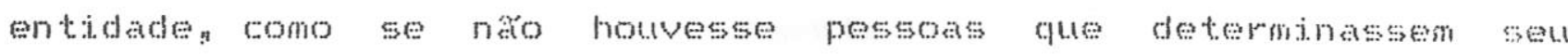

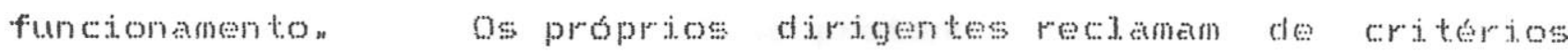

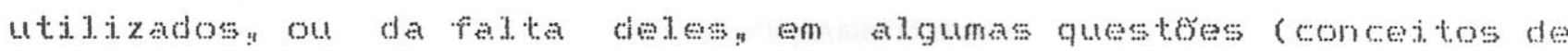

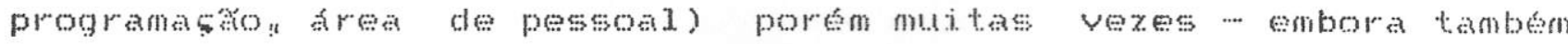
responskvejs por aquito que criticam - agen como se nacia pudesem fazer diante da fatalidade institucional.

0 CCSF $_{n}$ que tem o triplo de funcionarios que o cl..sFF e dez

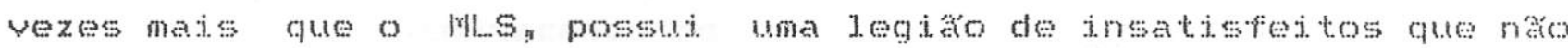
tem majs esperangs de que em algum dia possan oorrer no centro mudanças realmente significativas.

No SEsC o controle de funcionarios te feito pelo carta do

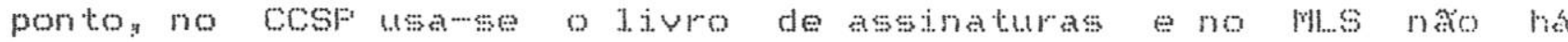
registros de presenca confiando-se em gue cada um cumpra o hor ámo que 1 he cabe

Tanto o $5 \mathrm{SC}$ como a presejtura chamam seus funcionarios de servidores, una denominasä que lembra os tempos medievais em que

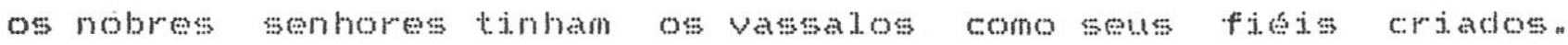
Comentang que quanto mats alto s o posto de uma pesson dentro

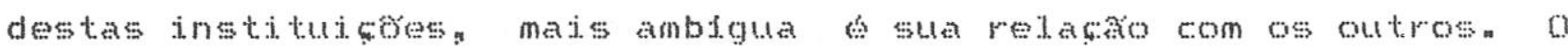
SESC a prefeitura aparentemente nâs acompanham o desempenho de seus funcionádos m mantendo deles apenas os dados burocraticos na

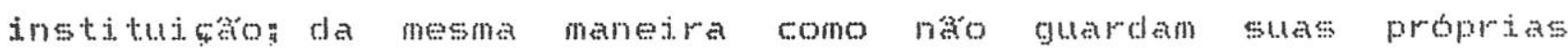
vivencias, estes organismos nâ preservam o trajeto e a valorizaço subjetiva do que ja fizeram seus servidoress tratando todos da mesma maneiray o que causa uma estagnaço no corpo do funcionámos. com a incapacidede de se promover os que merecen despedir os incompetentes, sendo que para esses tratame de um bom negocios 


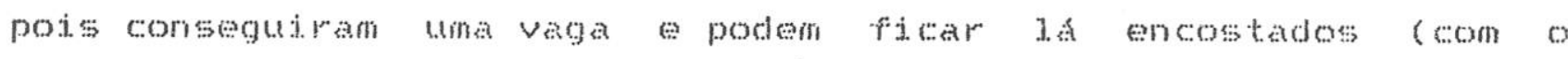
agravamento da apadrinhagem e da estabifidade no caso dom

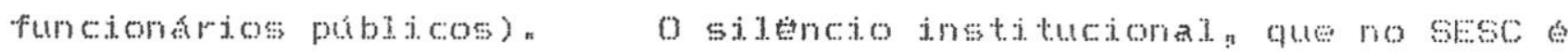
sentido ate mesmo pelo renomado diretor teatral fotunes Filhon causa una evidente revolta nos funcjonatros mats dedicados que apenass recobom cono resposta de seu empenho a satistapo de verem o seu trabalno ser usufrudo pelos frequentadoresa a incapacidac de diferenciaço acontece simetricamente quando a instituitio vai. 1.jar com seu publicon o qual se pretende sempre que seja o mator posstuel, et tratado como un agrupamento de pessoas indistintas.

Mutos dos funcionarios do CCSF sáo subaproveitados ou desviados de suas funçes e outros pouco aparecem no controu decidindo trabalhar conforme seus salarios Dependendo da diresto ha pequenas muancess was năo se tem grandes expectativas de melhora sempre acontecendo os favorectimentos do partido que weta na situaşo: alias, comentase que no centro năo ha funcionarios publicos " mas servidores polfticos " Levantou-se a suposicho de tue algumas pessoas estavan adoecendo no cosf por causa da grande quantidade de metal empregada na construgason mas parece mats provavel que se sintam mal por estarem em un lugar pouco cuidado por se perceberem vitimas do descaso. As unidades do SESC e do mas tem espaços arrumados o limpos passando a sensaţo de que ajouem gosta deless o que ja provoca respeito dos funcionarios e do publitico.

$0 s$ departamentos" divisoes e seçess do mos contam com

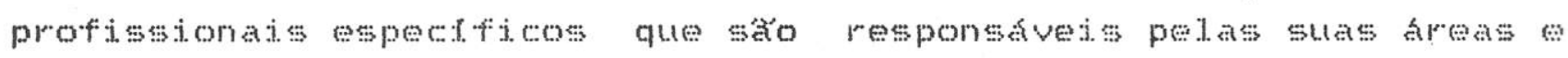
recebern a confiança de Marfcio Segal. Ha solidariedade entre os funcionarios q que vivenciam as dificuldades por que passa o museu e sao sempre defendidos por seu diretor" o que garante uma forte alianca entre todos " certas pessoas se cansaram da relagho com Mauricio Segali, que consideravam desgastante, e se demitiram, enquanto outras saso capazes de apontar contradicoss no funcionamento do m...s, mas dificilinente comentam sobre falhas, realizando seus trabalnos como militantes do museun Ma fase da Associacto Museu Lasar segall houven segundo se comentas um 
comportanento mejo populista todos fazida tudo como numa grande

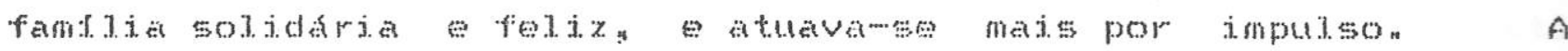
entrada na Fundaço Naciona Fromberoria trouxe a profissionalizacto ao museu exigindo planejamentos meticulosos defindindo as funçoses responsabilidades de cada unn a burocracia esta presente quando ha questoes 1 igadas a FwFr sendo dispensada nas relacoses de trabalho dentro do museun

A dinamica estabelecida entre Maurtcio Segalln o colegado a as assembleias de funcionarios colabora para a manutençá do elo entre os funcionstios e possibilita as redacesesentre os setoresn As pessoas tum a opotunidade de expor suas ideias he constantes consideracoses e questionamentos sobre as dificuldades as necessidades a forma de funcionamento do musu num exercicio que pretende tornar os individuos mais conscientes " Todos poden opinar e procura se respeitar o consenso da reuniaso que mutas veres tende para o lado de laurteio segalin pois mesmo sem premeditar ele

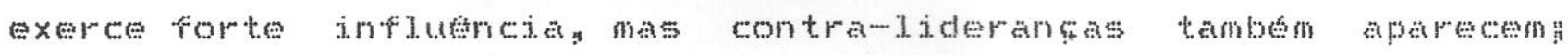
durante as assembleias en certos momentos pedewse socorro ao diretor para tentar solucionar alouns impassess

En suma no museu os funcionarios tem fungeses bem defintelas es chegam a fazer seu trabalho com prazer porque percebem que ha um espaco que permite reatizgos dentro de suas areas protissionats. No sesc en geral e no COF os funcionarjos trabalhan por obrigacho - provavelmente por se sentirem impotentes diante da impermeabilidade dos sistemas institucionats que os leva ao destuino e a inértia - e sonegan trabalno nato se dedicando a quem nao lhes respeita. Isto. evidentementes se reflete no atendimento e nas propostas oferecidas aos frequentadores. Acaban sendo institufdas preticas internas de relacionamento so se consegu a aşo de una grande quantidade dos funcionarios por meio delas. sendo necessario "negociar" o que se necessita da outra pessoa que precisa ser convencida a executar o que deveria ser sua obrigaço. se o agente cultural quiser realizar un bom trabalho precisará fazer o que the cabe e ficar sempre acompanhando -- aldin de ter que cobrar, mutas vezes tanbem precisa completar -.. os serviços que 
competem a cada area espectica nisto se inclue tudon desce o transporten o materiat grafico e mesmo a seguranca do que esta exposto.

\subsubsection{Frequência}

Como o rlas nâ possut instatapes adequadas para receber

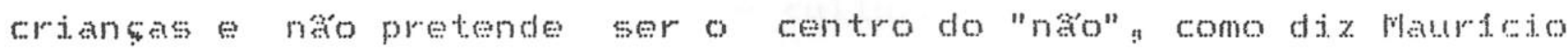
Segall, a idade dos frequentadores para as atividades do museu fo I.mitada para matores de 16 anos, havendo grupos de eriancas apenas no trabatho do Serviço Educativon A media de publico e de 100 pessoas por dian e vinte anos de funcionamento as obras nada sofreram e nunca houve depredactess no jardini segundo marteio Segali, o mis nas se pata por oriterios tipo raore e sempre procurou dar coertncia aेs suas preocupaçes cuturais mantendo programecos de filmes menos conhecidos ou atraentes n com sessess pouco frequentadas que causan reflexos negativos nos rejatorios anuais.s.

o Mlls recebe intelectuats principalmente para consultas na bjbijoteca eles pouco frequentam o cl.sF e quase nada o cosp. Enquanto as pessoas que varo ao museu tem interesses ben derinidos e pouco participan de outras atividades que nás as que foram procurar, fantidas inteiras visitam os outros dois centros sem saber ao certo o que irao encontrara buscando principalmente lugares onde possam soltar os fixhos e rectaman quando hat exposiços que ocupan grandes treas e exigen cujados especiats. E. comun os centros abrigarem en seus espacos pessoas que vagan pela

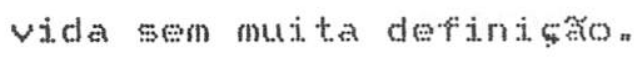

Ao SESC interessam os numerose sua proposta considera a coletividade mas náo atenta para o individuog promovendo vámios eventos dos quais decorre o ajuntanento mas naco oncontro entre as

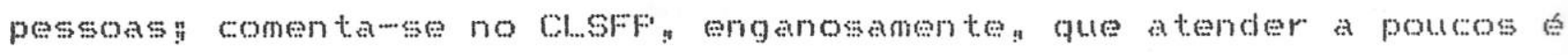
elitismon e as suas atividades mutas vezes seguern pella linha da macroginastica "quando apenas se copian modelos " Há vários 
publicos frequentando os espacos da fabrica - jovens nas apresentacoses mustas.s grupos de idosos jogando cartas criangas participando do projeto curuming artistas vendo exposicoss: esportistas visitantes estrangeiros e comerciarios, mas cada

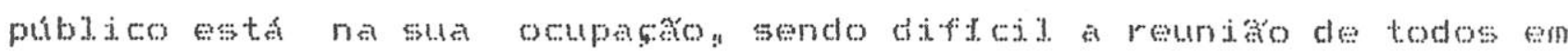
atividades conjuntas. os comerciarios em sua matoria să balconistas que ganham baixos saldros e apresentam desconhecimento -- mutas vezes desinteresse - cut tural sendo grandes seguidores

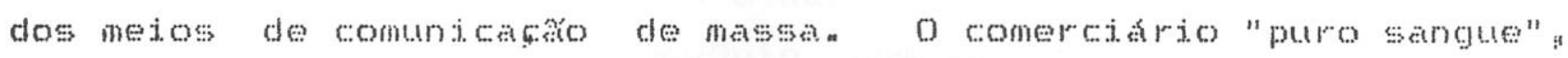
como dizem os funcionarios do stscy e aquele que trabalha fon redos de lojas de vesturito ealcados para consuno popular e anda com um "radian" ligado a toda clebaixo do braţo tatuado. A programatáno inicial do ol.sF năo poderian evidentemente s se dedicar ao universo do comerciario" que talvez em consequencia disto nato frequenta a fabrica com constancian preferindo as outra unidades do sEs. nessas unidades ja se questionou por varjas vezes se vale realmente a pena insistir con atividades mais sofisticadas pois os comerciarios parecem querer somente um lugar de relaxamento depois de trabalharem a semana inteira.

A frequencia do CCSF constitufda en sua majoria por jovens estudantes que vorom busca dos livros da biblioteca de espaco para estudar nas pesquisas de publico as solicitiacoses para melhores condicoses de estudo no local estáno muto a frente de qualquer outra reivindicaça.

Nåo há estatisticas precisas mas estima-se a mesma quantidade de publico (aproximamente anoo pessoas em media por dia) para o Cosf (que recebe grande afluencia aos sabados) e o cl.sFl (que tem seu maior público aos domingos). O centro do SESC foi criado com o dinheiro arrecadado junto aos donos de estabelecimentos comerciats, para atender principalmente a seus empregaclos comerciarios n o centro da prefeitura es una obra feita com o dinheiro dos impostoss recolhidos junto a populaço da cidade de saro fauson devendo a ela ser destinado; aparentemente porem, poucos tem conscitencia de que o seu dinheiro esta la aplitacio e náo se exiges náo so por 


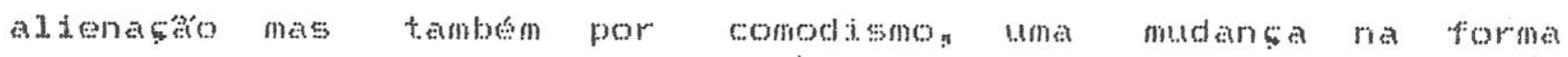

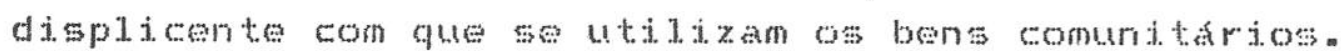

\subsubsection{Consequencias do Plano Brasil Novo}

Apos a implantaço do plano economico do governo collor pouve un confronto entre a politica ferderal. que extinguiu orgásos de

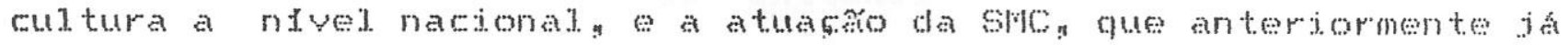

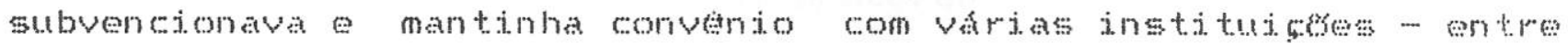

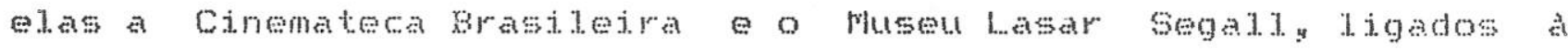

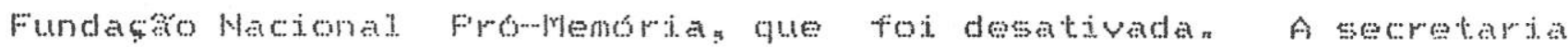

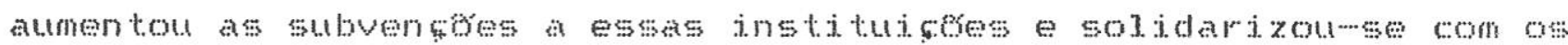
funcionarom da area federaln realizando com sles diversas atividaces no cosf" tidas como "womtos do resistencia culturan" Fassou tamberm a apoiar os produtores independentes que roram prejudicados com a extincaro dos orgás es da lej. Sarney"

Quanto a programaço geral do Cosp no ano de 1990 destaciram se a exposicose coletivas de arte contemporanea realizada pela Diviså de Artes fissticas" criticos convidados selectonarm os artistas participantes, que em muitos momentos chegarm a apresentar boas obras o conseguiuse bastante divulgacho now

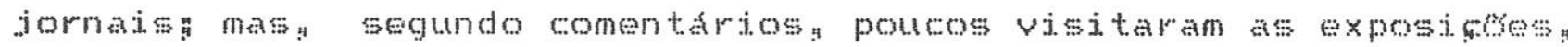
o que leva a se questionar sobre a validade destas propostas sarem

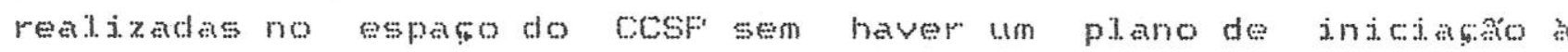
estetican

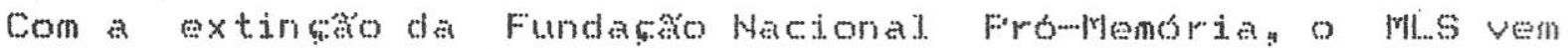
sofrendo diversas modificacosen o corte de functonkios afetou primeiramente os prestadores de serviço e a chefe do Dac - que tinha funço definida mas estava sem cargo base - mas gracas a um patrocinio particular. ela pode continuar no museun A falta de funcionarios foj criando uma urgencia de resstruturasás internas a

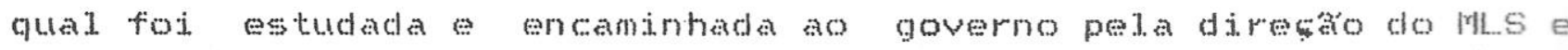
ate hoje continua a ser discutida na assembléta geral. o corte de verbas afetou fundamentalmente a muselogia m a biblioteca, 
determinando a necemsidade de

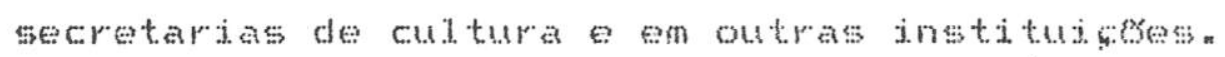

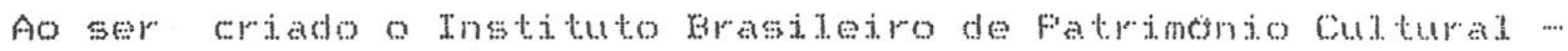

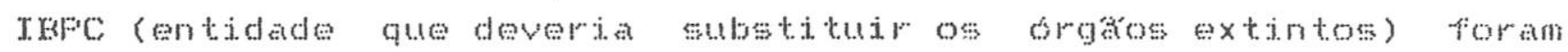
cortadas todas as gratificasose de funço dos funcionstom do

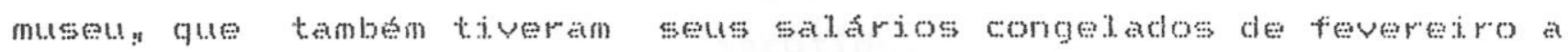
novembro do 1990. Aposar da instabilidade da situsason o mas continua a prestar seus serviços procurando naso alterer a forma de atendimento a públicon

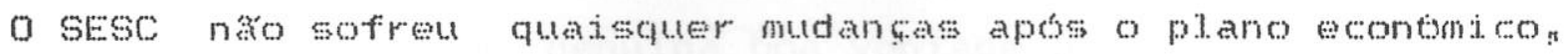
logo reavendo o seu dinheiro retido nas apli anceses 


\section{CONCLUSAO}

\subsection{Centro Cultural Såo Paulo}

0 Cosf tomoume famoso muito mats pelas suas complicactos de

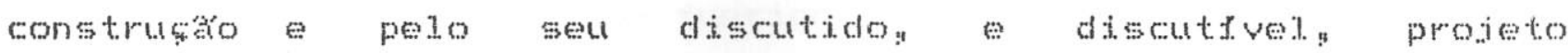
arquitetonicon do que por sua atuaga como contro cultural. com suas chagas expostas, nostra o descaso proprio daquilo que púbico em pafsess subdesenvoluidos. o territorio publico se torna territorio de ninguen, e acaba sendo diffeil acrecitar que em algum momento possa haver uma genutina boa vontade por parte do governon E como o centro esta sujeito as variages poltticas da administraça municipaln corre sempre o risco de ficar sob o dominio de pessoas que nao tem nenhuma afinidacie com cultura 0 transformem num simples joguete a servico de outros interesses. Conforme varios depoinentos colhidos o quarto secretario municipal. de cultura nomeado pelo prefeito Janio audros era tido como fascista e deixou a marea de un perfodo negro para o cosf "Renato Ferraria que foi secretario de março de $198 \%$ a janeiro de 1989. chegou ate a montar una comissato de funcionarios do centro para realizar a censura das pesas teatrais e das letras dos sows de rockg enquanto era presidente da Fundaca Fadre Anchieta tirou do ar, en jutho de 1984, o programa Fabrica do som ut trapassando a sua functo de administrador e se intrometendo na divisa de programasay segundo noticiaram os jornajs da epoca.

o arquiteto Lutiz. Telies lembra-se de que houve ate rumores de se trazer a prefeitura para o espaco do cosfo transformandowo numa grande area burocratica Lamenta o estado em que hojese sencontra o centro atribuindo isso a falta de criterios do poder público: que arruma dinhejro para construir mas na consegue acabar a obran. nao destina verbas para manter o centro e deixa em uma situaço de indefiniça e deterioraço generalizada. 
Um dos vigitantes dentara que o cose tinha tudo para ser um carto postal da cidade mas acabou igual joreja que muna termina de construir " A utopia do projeto contratou violentamente com a arjog da mánuina administrativa publican incapar de solucionar os problemas con a empreiteira construtora estagnando a situacto do centro por anos a a iandowse isso ao fato de que certas circunsw. tancias do projeto teten sua funcionalidade comprometida na pratica e falta de perceptro de alguns dirigentes que nấo respentaran ass especticidades determinack pelo espaçon o resultacio foj uma verdadeira barafunda no uso do centro. Ha inimigos deciarados do projeto arquitetonico "como o segundo diretor do cosf Ferrando Lemos; que dizia ser o centro un exemplo de "obra faracnica" destitutda de qualquer racionajidade ou sentido comutitiou para ele o edificio apresentava uma arquitetura que divergia de seus objetivos"e afirmou que " " o modelo arquitetonico plantou uma contradiço fortissima Acho que o edificio e mais adequado para ser um mercado ou una continuaşo das estaçes de metro" "Mesmo inacabado, o cosF s apontado por outros como una solucho origimat. para o complexo problema arquitetonico de erguer un espaco cultural. numa nesga de terreno espremida entre duas avenidasn

0 idealizador do cosf " Máro Chamie afirmou como tato a dejxar a smo, o desempenho que na verdaden esperava que o centro viesse a cumprira "o cosf s hoje o ponto da convergencia de todos os projetos desenvoludidos pela secretarian uma ponte sobre o varo que existe entre as manjfestapess artstijess do centro da cidacle da periferia - un complexo interdisciplinar capaz de estabelecer elos entre as jhas culturais da cidade s seu estilo arquitetontcon de linhas horizontais e sern barreiras separando os espacos ná opressivo e elimina a solenidade que trationalmente tinibe as pessoas" " Enquanto o desejo de ligaço de Mrio Chamie estendianse para toda a cidade, o diretor Jose Geraldo Martins de oliveira preocupouse com que o proprio centro funcionasse de maneira unificada e năo como simples justaposiço de espaços buscando a integraçaso atraves de una polftica que aprofundasse as formas de inter-welacionamenton A resoluça de se criar un grande complexo 
cultural g reunindo orgás muncipais de cultura ja existentes e procurando centralizar a burocracia en un so lugara com a expectativa de se atender a ate 20.000 pessoas conforme dizia Chande (baseandowse na media de 25.000 pessoas que passan pelo centro Georges Fompidou diariamenten sendo o lugar mas visitado da Frangal, tinha ja de indcio o problema de acomodar un publico maior nos seus modestos auditorios pois qualquer programacko razoaved causava disputa de lugares fato comun principalmente na sala de cinema, que ná possui. cadeiras para atender nem a un centesino da populaço que se pretendia que frequentasse o centro di arianente.

A publicacto "CCSF - Ano I" assim se referiu ao local: "O Centro Culturat Să Fulo ó orimeiro espaço comuntario de que o pafs dispoe. Com isso, sem sombra de duvida inauguroumse a $13 / 5 / 1982$ um nova tradisaco convivencia entre o povo os bens e servicos de lazer informagson consulta utilidade publica! pesquisa, memoriag documentacko e criatividade artfstican" Esta afirmaço destoa bastante do que Faulo Sergio Finheiro declarou em Fevereiro de 1989 , quando foi nomeado diretor do CCSF a sh sua opiniason o centro ná tinha condicoes de cumprir o destino para ele imaginado de ser una repilica paulsta do centro Georges fompidou, podendo no máximo se aproximar de "un Beauborg populista, que se encaxa dentro do padra da polf tica brasilejra da dispictencia da onissan"

o poeta Mário Chamie é visto por alguns funcionarios do cosf como o criador de um projeto purista muito interessado nos eventos e no visual de vitrine outros portomy o consideram un realizador: respeitando-o bastante. Com o FT recentemente eleito para a prefeitura da cidade, a questacontro cultural sac fauto voltou a ocupar os jornats. prosseguindo as criticas desferidas contra o centrö en resposta a ejas Mario Chamie escreveu um artigo em março de 1989, para o jornal O Estado de Saro Falo, no qual aponta a eficiencia da biblioteca do CCsF e o que o centro ja havia realizado de bom. Frocurando justificar a sua apressada 
Inauguraço, comenta que "na jinha desse multuso precursor gue surgiu por exemplo: 0 SESC Fompeis: quen assim como o centro Cultural sao Fato inaugurou suas atividades iniciats a partir de areas dispontveis " yindo anos depois: a 'completar' o conjurto de suas instalacoses com as quadras esportivas da arquiteta Lina $B o$ Eardi." Saberse, porén, que os casos sao bastante distintos pois os gaposes culturats da fabrica tinham todas suas dependencias funcionando a area esportiva representava un setor totalmente diverso, tanto en termos de arquitetura quanto de programaço ou uson Alias; o que algumas pessoas do sEso comentaram qu mario Chamie ficou inspirado para fazer o CCof depois de visitar as obras de restauraço dos galooes da fabrican E ha uma grande

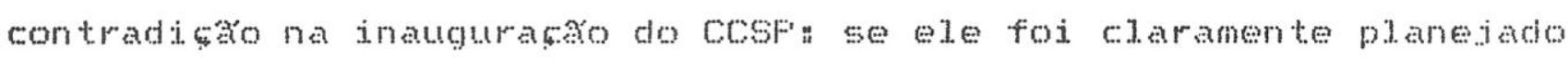
para funcionar como um todo intenço que foi propagada a todo momento, como pode ter sido inauguraclo em partes?

o artigo de Chanie ternina da seguinte maneira "Infelizmente: hoje por obra de administractess posteriores a marco de 1983 . 0 centro Culturat saco fato conforme o que foi escrito neste jornat. esta en franco estado de deterioragro Causas evidentes disson abandono deliberado, a desativaça de servicos e projetos bensucedidos a närolicaşo de verbas existentes para complementacoes secundarias do ediftcion a transformacko dos pisos inferiores en deposito infecto de materiats de outras unidades da secretaria e sobretudo, a conversa progressiva do centro em repartiço publica inchada ou reduto de desenfreado empreguismo. Este 0 quadro presenten um quadro que podera ainda ser revertido, se a atua administraço năo prolongar mais a miopia provinciana con que, ha sete anos; o Centro cuturat sao fralo vem sendo olhado."

Como e de praxe nos setores da adininistraço ptiblicas as criticas abundam numa tentativa de justificar o estado em que as instituicoses se encontram hoje com uma administracko empurrando a responsabilidade para outra. E. segundo varias declarages de Mario Chamien ele considerava seus antecessores pessoas com pouca 
visán seus sucessores como os responsaveis por estragarem o projeto do obF" sob o fogo curado das mútiplas acusages, o cCsp continua o mesmon com os problemas se somando pouco se conseguindo resolver"

Hoje porsm "toma"se necessario discutir o que o CCSF significa enquanto instituçán. Fensavase iniciamente que o centro deveria funcionar como una central irradiadora de cultura pela cidade sendo que essa cutura deveria entrar pela cabega das pessoas: hoje o CCSF vem principalmente realizando o atendimento público da secretaria lunicipal de Culturan Em principion a secretaria possui. seus planos desenvolvidos a partir de uma concepcro de cultura que e determinada pela sua administrato conta com una realidade de infra-estrutura en suas unidades para colocar estes planos em aço. A questao somples poren segundo alguns funcionarios na prática as conexóses entre o pensanento as possibilidades existentes naro tem sido mujo frequentes em algumas administraços

Ao contrário de seu projeto arquitetonicon que propos a p.uridisciplinaridade nos espaços náo demarcados " hoje o cosf precisa de uma definiço, uma resoluçon devendowse aplicar tum thoque, numa atitude de corageng que permita reativar o funcionamento do centro e redefina agora dentro da realidacle a sua existencia e importancia para a ciclade. A questáso que se coloca 4 a de como definir una polftica culturat num espaco todo cristalizado pela lei. que hoje ainda permanece como foi. determinada no inteiog para mudala poder se ter outro organograna de funcionamento, un novo projeto deve ser aprovado pela Carmara Municipal.

o que chama as pessoas ao centro o a sua bibliotecan a majs consultada e frequentada de todo o pafs n certamente o cosf nám estaria numa situaça tá problematica se Ihe tivessem preservado o destino de ser una grande Biblioteca frólistudon ou seja apenas a biblioteca inieialmente pretendidan com mutiplos espasos para os 
estudantes se acomodaren con seus cadernos o reajizarem suas pesquises no acervo de livrosn Essa biblioteca poderiat assumir an

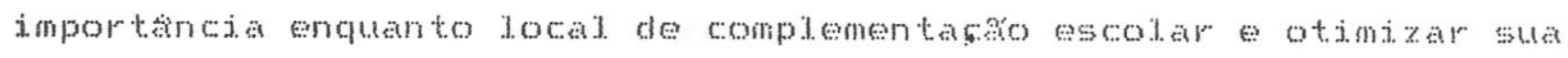

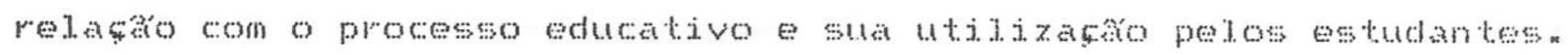
Assin atenderia a maior desejo sobre melhorias mejonciado nas

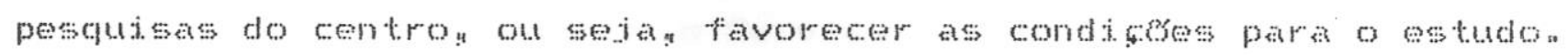
Apesar de todos os problemas aparentes as pessoss sesentem ben no

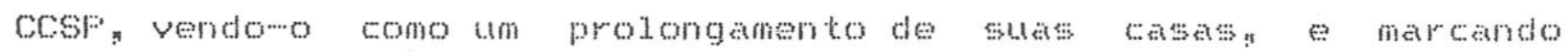
mutos encontros a mesmo reundoes nas suas dependencias “

\subsection{Museu Lasar Segall}

A bibliotera do rise possuj a melhor colecono bibliografica que

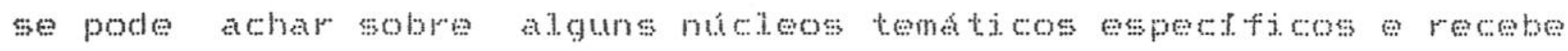
principalmente pessoas interessadas m pesquisas sobre teatro m cinemax.

Suanto ao acervo de obras do artista lasera segall que representa o inteio e o motivo de sua existoncia o mis posiciona se conforme a tradiço museologica europeian na qual a colerso

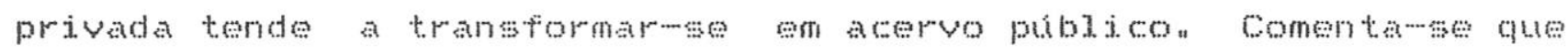

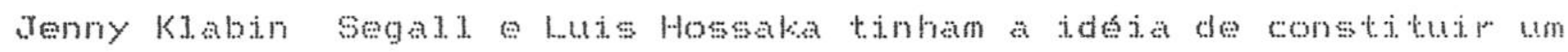
museu internacional. com as obras do artistagentretantog apos a

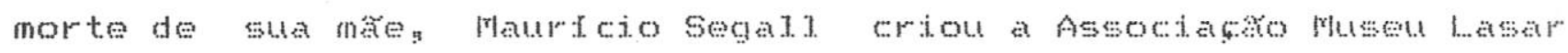
Segall. e logo se preocupou en dinamizalan propondo vivencise e experiencias esteticas aos frequentadoress sendo que com a jobia do "museu vivo" tambom se pretendia levar mas pesmons a terem contato com a obra de segall.

A atuaço do miss ver se basendo no tripe formado pela Museobogia Biblioteca o Departamento de Atividades Criativas o que lo confere certas caractertsticas de centro cultural. segundo

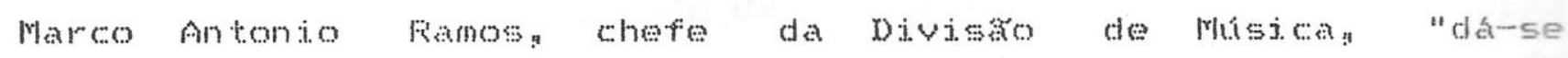
interessante intercambio entre o lastro que os acervos plastico e bibliografico significam e a construgro cotidiama que as atividades

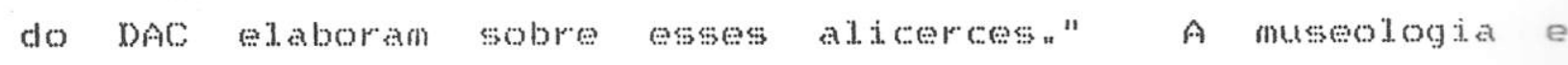




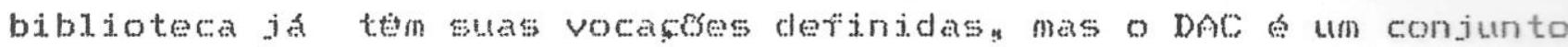
de propostas no qual cada atividade a lidada ao seu orientador que possui. uma maneira individual e propria de orientar " Hoje um dos maiores objetivos do museu a conseguir o funcionamento jntegradon a na owepartamentalizacron mas sentewse a diflculdacle de se chegar a uma organicidade outro setor que esta bastante presente na concepsaso atual. do museu é o Serviço Educativon que atenta para desenrolar da relaço entre visitante e obra.

Ha spoca da associacho Maurio segall havia se aperebido da necessidade de ná se ater as atividades didaticas formats, tais cono exposiçes; visitas guiadas, confertencias projecoss e cursos, mas complementar este quadro tradicional com atividades criativas dos frequentadoress procurandon dentro dessa proposta identificar o museu e favorecer as pessoas o contato com algo que acreditan ter de senstyel. de valioso dentro de si. propiciando assim a busca do "outro" ques em princtpiog existiria en todos a segundo disse seu diretor" "o Ml.s năo quer ser una instituişo museotogica tradicionals nem quer ser visto como algo de acabado cristalizado. Fretende ser um centro cultural eciletico repleto de interrogacoes sobre a arteg a cultura e a sociedaden propondo coisas que ninguen faz na cidade." o museu sempre procurou desenvolver projetos inovadoresin baseados em propostas experimentais, cuias atividades podian ser posteriormente incorporadas a programaço. Aconteceun porem que a sua atuagan pioneira e linica durante varjos anos a partir do infeio da decada de 80 năora mas exclusiva na cidadeg pois progressivamente centros culturais ian sendo abertos, os museus buscavan novas propostas para seus públicos. os cineclubes apareceram com programacoss alternativas n foram criadas incimeras instituiges culturais, e produtos da cultura internacionaly desde cantores de rock a filmes de arte. começaram a ser trazidos com frequencia crescente, destacando-se a presença do Instituto boethe em seu trabalho constante de difusa da cultura alemá A nova situatro criou un impasse para o m...s, que deveria buscar outras formas de atuato se quisesse permanecer realizando un trabalho que o 
caracterizasse enquanto instituçáco culturat com propostä diversas das habitualmente oferecidas ha que se considerar que nos novos tempos a vanguarda es mutas vezes tida como sinonimo de avanco e1etronico e tecnologicon o que náco se compatibiliza com os anseios e desejos de Maur cio Segali.

0 ex-instrutor do atelier de artes plasticas Antonio Helio Cabral escreveu em un folheto que "a nossa ideja sempre foi criar um espaco proprio para a expressa fora da linha de rebogue da tecnologia capitalista. Esta nos impinge a idéa do novo ao preno da alienaço Sonhamos o espaço vivo" Essa afirmagko segundo se comenta reflete bem o pensamento que vigora no museu sendo a sua imagem institucional ligada a esquerdag opgos polstica de Maur cio segall. cuando fala ou escreve, o diretor procura sempre ressaltar una visao humanista da cultura e da arte contraria a massifitasto, que evista como uma unifornizaço que anula as especificidades e cria uma massa compacta gue to toda exa a mesma cojsa arguido sobre a necessidade de se ter un publico pequeno (condiço presente no ms $e$ ausente no CCSF e cl.sFF) para desenvolver um trabatho que considere o individuo Mart cio segal diz que a quantidade de pessoas envolvidas nă determinante e que importa 6 a forma da relacko proposta pois se desperta o esplrito critico năo $a$ mais massificante . Fortanto segundo Maurcio segalin a proposta cultural do mese de critica e autocritican para isto adota-se una dinamica cultural particular. sendo sua "atipicidace" (como as reunibes dos funcionkios) correspondente a un processo organico da sociedade em busca da recuperaço de sua autonomia de sua idberdade o proprio sistema do museu, conforme se diz, replete en si as contradiços presentes ern una sociedade democratica.

Constantemente lutando pela sua sobrevivencian uma das principats caractertsticas do ms e manter a posiço de oferecer qualquer servişo ou atividade gratujtamente" como consequtincia, nå pode contar com nenhuma receita para diminuir despesas mais al tas, como as das projecsess cinematograficas. 
questionam ate onde as discussoses conceituas que fomentam as

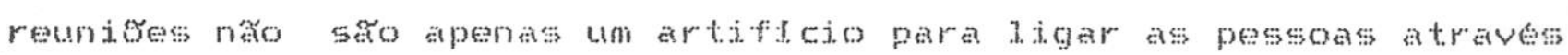
da enoçion devido a dificuldade de serem colocalas en pratica certas ideias, considerandowse os limites do museun Efetivanuten:

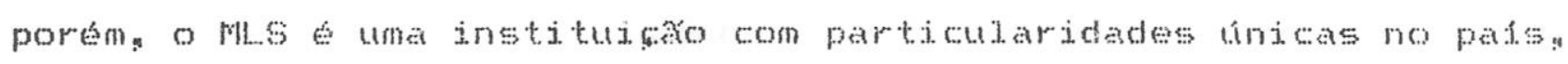
reajizando propostas que ainda hoje o diferencian de qualuer outro museun Fernando l...emos" entre outros" considera o ll.s como un dos mais bem implantados musus de sao Falo funcionando no seu I.mitado espaco fisico de maneira intensa eficaz a boa imagem do ml..s certamente se deve ao fato de as pessoas sentiren que hat coerencia nas suas açess"

A absorça do rll.s pela FrFm eriou uma nova situagro nas relacoes dos aparelhos estatais com as dinamicas dos espaçs culturats pois o orgaro federal incorporou manteve uma cultura de trabalio ja existente. E, conforme diz Fegina sawaya chefe do Departamento de Atividades Criativas "o Mllo o um Iugar gue funciona, apesar de ser publicon"

\subsection{Centro de Lazer SESC Fábrica da Pompéia}

Mesmo sendo conhecido por todos f comum as pessoas naco saberen da estrutura organizacional do $5 \mathrm{sc}$ gue fe frequentemente considerado como uma instituicto pubjica wo documento "Diretrizes Gerais de A̧̧ấ do SESC" que foi escrito en 1973 mas ainda hoje 6 distribufo aos funcionarios que comẹan a trabahar nas unidades" a educaço e colocada como diretriz magna da entidade. a ser elaboratan conjunto com as atividaces de lazern As tecnjeas utilizadas saco as da educaço social permanenten que promove 0 desenvolvimento os necessarios reajustes da personalidace om qualquer epoca da vida do homeng segundo o documenton saco possibilitadas ocupaços que atualizam e ajustam o jndividuo a multiplicidade do medo socialy sendo este convivio considerado indispensavel ao pleno equiltbrio emocional e a seguranga pstoutcan 
o lazer deve funcionar, segundo o texto, como recuperador de energias e vigor fisicon como incentivon como recreachon como desenvolvimento da personalidaden o documento afirma que "a aço do SESC no campo do lazer implicara sempre no aprovejtanento das horas livres da cilentela em ocupaçes que permitam atingir os objetivos educacionais, em consontancia com o sentido do progresso nacional" o SESC aproveitara o tempo livre a a disposicá psicologica do individuon fora de suas ocupacyes obrigatorias para notiva-io a sua autompromocto sociala atraves dentre outros procedimentos "do incentivo ao aprimoramento de sua formaço e do estimulo a sua atualizacto em face das muangas "

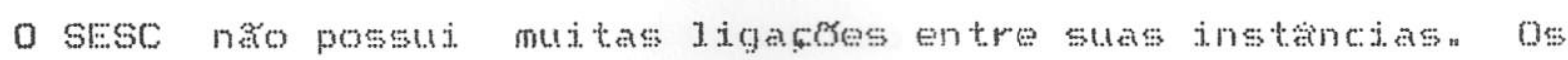
departanentos regionats desenvolven seus programas de forma totalmente independenten sendo que un estado nao tem conhecimento do que o outro faz havendo raros programas comuns promovidos pelo Departamento Wacional. As unidades de Săo Fauto reitacioname pouco entre sia havendo as vezes emprestimos de equipamentos 6 comum duas ou mais unidades dedicarem-se a nontar exposiches sobre o mesmo acontecimento ou data comemorativa sem uma saber do projeto da outra ocasionando concorrencia na busca dos materiats n mesmo dentro de una unidade nota-se a dificuldade dos setores se interligarem. A integraço e una coisa que sempre se tentou no SESC, mas normalmente o afastamento acaba predominando rodas as unjoldes, porem, possuem as caracterfsticas institucionats do st:son presentes na manedra de tratar os funcionarios e na forma de lidar com a cultura. Mesmo a fabrica, que comecou en total descompasso com os outros centros depois desorrer o processo de intervensaco foi incorporacla ao $\mathrm{SES}$. algo como a volta do fitho rebelde: mantendo a independthcia inicial em algumas dreasy cono uma assessoria de imprensa e un setor grafico proprios. Apesar dessa aproximaço să frequentes os desacertos que ocorren entre o clsFF e os departamentos do SESC Central quando se pretende algo em conjunto. Hoje esta quase definida a instalaşo de un gabinete odontologico no segundo andar do galpáo das oficinas o que segundo we comenta iria sedr definitivamente a marca do sEsc na fabrica. 


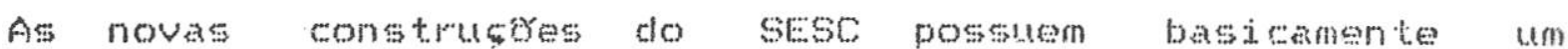
restaurante, piscinas, guadras de emporte e un teatroy demonstrando poucas preocupacoses cuturajon Notamse que ha cada vez menos

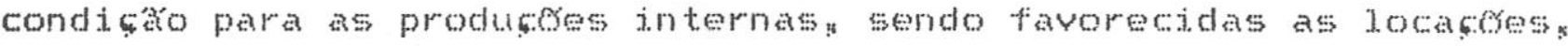
com o produto culturat vindo pronto do fora e os tecnicos funcionando apenas como agenciadores. Alguns furstonarom antigos comentam que o SEsc deveria se definir de vez pelo "esportán o pelo seu earter assistencial p procurando tornar acessiveis as

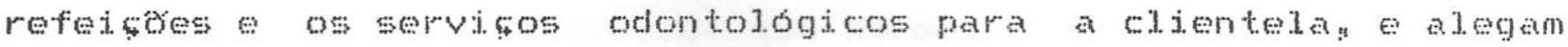
que o stwac. que ten claros seus objetivos protissionalizantes. funciona bemp dizem tambem que caso se insista em continuar com a parte culturaly deverian ser contratadas pessoas habilitadas a

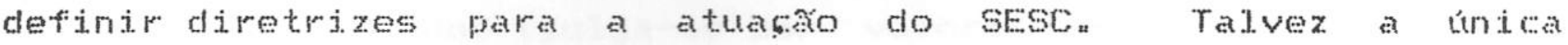
tendencia cultural vistuel no siso de hoje seja a de determinar a vocacto de cada unidadey de maneira que cada linguagem cultural praticamente sh vigore em um expacos por exemploy pegas teatrajs no SESC Uila Nova programases ecologicas no Centro Campestren timema no Cine SESC e atividades cuturats mais significativas no SESC Fompeian sendo que atraves das unidades do interior alguns projetos

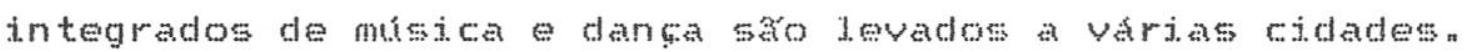

Diz-me que o SEsC o uma instituiforo nareisican vive buscando

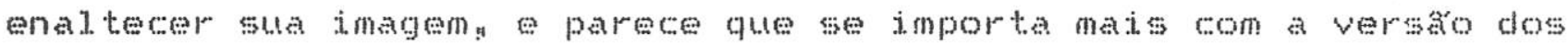
fatos, com o que certas pessoas falan e com o que sai nos jornais do que com os proprios acontecimentos. Tsto ocorres segundo se dizy porque o sEsc julga por criterios externosa como se a

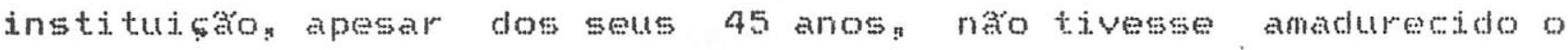
suficiente para ter o seu proprio dismernimento e capacidade de avaliaşo. Se os jornais noticiarem com destaque a missa satara cumprida, podendowse encerrar o projeto no dia seguinten Fara ilustrar a questán ha un caso que virou fololore no sEscy um técnico da época da Unimosy responsavel por uma unidade movel. no interiory nåo era muto dado ao trabalho e acertava com a grafica do iornal local a impressaco de falsas manchetes sobre atividades supostamente desenvolvidas por sua unidade naquela cidade n enviando o exemplar "preparaco" para a capital. Fodense tambern citar o 
acontecimento de majo de 1987 na progranaço de fickso cientifica

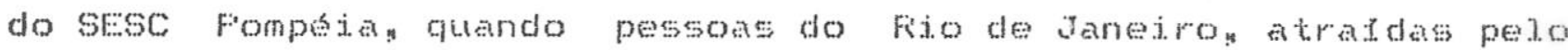
que a imprensa publicou, vieram conhecer un disco voador que nato chegara a ser construlo.

Aparentemente os processos internos: que poden ocorrer nas pessons estimulados por atividades culturais nato sa considerados pe10 SFsC pots nao podem ser medidos ou fotografados para ocuparem as manchetes dos jornajs. 0 que normalmente acontece ${ }^{2}$ que se prepara um produto cultural e as pessoas se relacionan con este da forma que quiserem ou puderem nạo ha un trabaho empenhado em favorecer esta relacto. Guando o produto cuturat estiver devidamente adequado (julgase por valores esteticos) para ser consunido pelos seus apreciadores, a funça dos técnicos terminou.

Fossivelmente, a concentraca das forcas do 5 Ec atumdo no nivel do vistvel -.. comprendendo desde a construcko de unidades ato a programaço. que se pretende que seja amplamente divulgata -. busca tambem garantir sua existencia diante dos movimentos de incorporacáo esbọados periodicamente pelo governo. E costum do SESC caminhar de acordo com o governo cono se pode facilinente prever: quase náo realizando atividades próximas a area polftica.

o que define o SESC no campo cultural a a sua inderinigon Fretendendo oferecer atividades as mais variadas e divertimentos para todas as faixas e todos os gostosn nato sendo capaz de escolher onde vai atuar, o sEsc fica no meio do caninho en tudo a que se propoe e ná consegue resolver efetivamente questoes cruciats como a da renovacaro da biblioteca do Cl.sFF"

A indefinişa de seus limites e a impressáo de liberdade descomprometimento que passa aos seus técnicos e enganosa perigosa, parece que "tudo a para se fazer e ná so para se fazer" conforme dizem seus funcionarios, ou seia, pretende-se realizar mas nă se oferecem as condiçes, o que cria grande ansiedade nos técnicos "Alias, a pretensaro do SESC en alguns momentos of grande: 


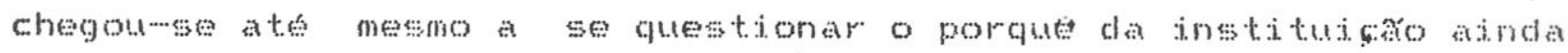

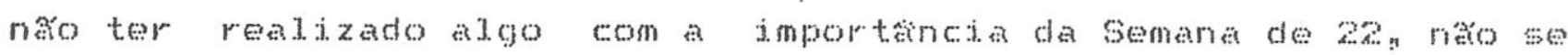

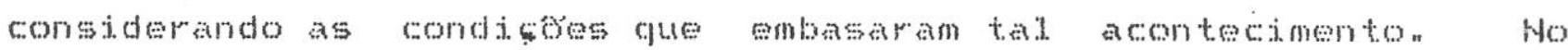

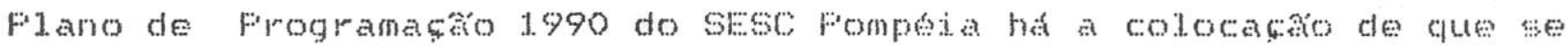
amejan "experiencias educacionas inotibas" para o frojeto

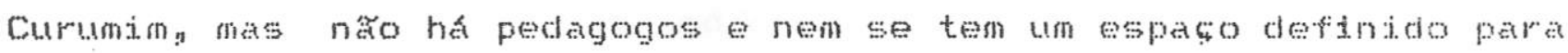

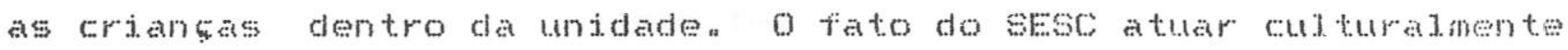

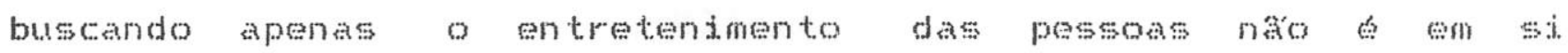

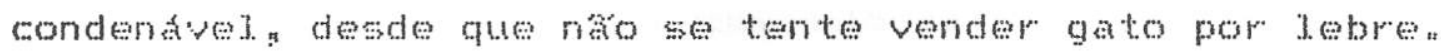

Algumas pessoas critican duramente o SEsta dizendo que suas

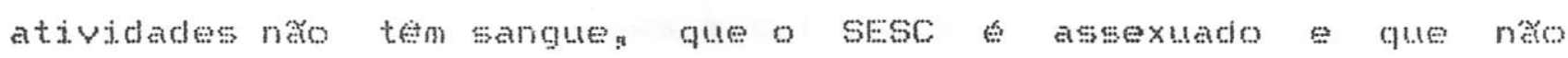
representa mats do gue o "Grupo sergio" (rede populu de restaurantes espalhados por Sä Faulo da culturan Afirman ofu o

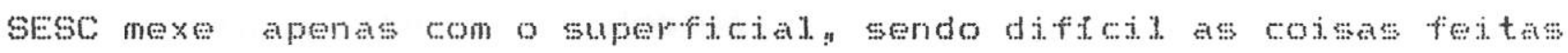
1át resultaren de un processo de anaduresimento e apresentaren

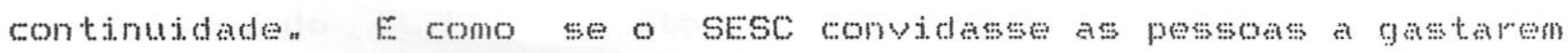
seu tempo, mantendowas en un refrescante estaio de iluso no no lhes ensinando a construir nada de sólido no decorrer.

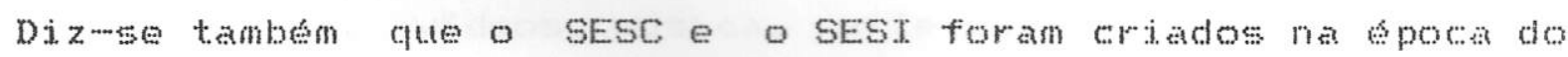
listado Wovo esato entidades patronaisn cultivando a imalom do patró bom que da coisas aos seus empregados b bastandon para se conferir essa impressay olhar quem dirige e como dirige o st:scon Forem, se o sEsC näo existissen os comerciantes apenas seriam mas

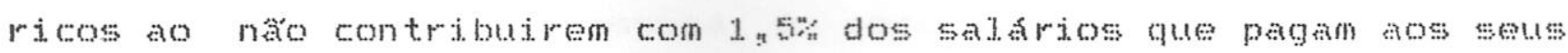

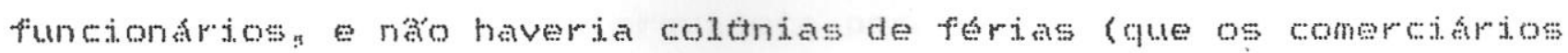
adoram), nen centros esportivos, enem aloumas bos atividades culd turas cuja fata seria ainda mass sentida nas cidades do interiors que contan com poucas alternativas en cuturan

Apesar do forte preconcejto que hat no interior do estado de

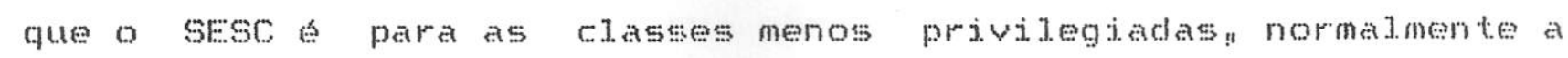

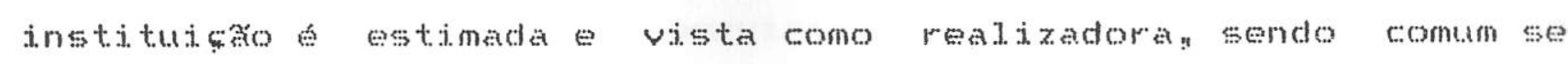
ouvir que "o stesc simg funciona!" " Com a elaboraço da nova constitutáco o perigo do sesc ser encampado pejo governon 
mi.hares de pessoas assinaram a lista visando sua preservacáo. Antunes fillo disse certa vez que o stesc faz o papel do Ministerio da Cultura e pode-se perceber vazios culturats a seren trabalhados na cidade de sao Fauto aos quas a atuaca do SESC poderia se adequar e apenas as vexes sáo ocupados pela instituighon na verdade há coisas que praticamente só o sesc pode fazer cono as grandes exposicos tematicas algumas festas e certos eventos produzidos, sendo que algums destas reajzacos se tornaran memoraveis principalmente aquelas en que nás fatou coragem de experimentar.

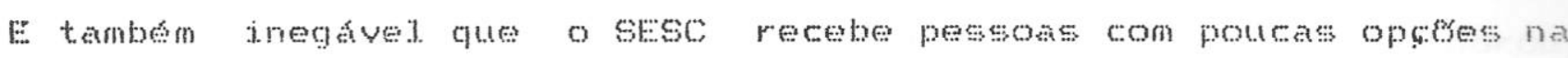
vidan como os comerejatose os idosos, e thes oferecen no minimo. algumas atividades esportivas e culturats a am da possibilidade de conviyion

Quanto a fábrica todos a acham un lugar muto boniton de "alto astral" " os estrangeiros fican maravilhados com a arquitetura do clofFe mutos admiran as criancas entretidas ras montagens e construcoes feitas com pequenos blocos de madeira sobre as esteiras espalhadas a frente da biblioteca os ingleses afirmam que seu pass naio tem un lugar assim que reuna tudo mostras de

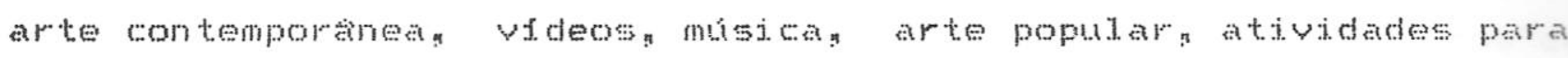
criancasn grupos de josos" e dizem que na togiaterra ha espacos distintos para cada una destas iniciativasn

0 CLSFF tem a sua identidade intimamente ligada a pessoa de Lina ko Bardi. Sua presença 6 percebida en varias solucbes esteticas en enquanto a arquiteta permaneceu no sesca tamben na programaso cultural sempre em busca da verdadeira referencia populare das genunas tradiches brasileiras. Com personalidade impetuosa e irascivej, náo admitindo seus errosa esbravejando para todos os lados (poucos escaparan de un xingamento da arquitetan do tipo "imbecili." "fatchista" ou "isto é uma porqueria"), enciunada com sua obra (tudo tinha que ter seu aval e o que os outros faziam năo servirian se náo houvesse antes passado por ela), a arquiteta espalhava respingos de genialidade num folheto n num arranjo de objetos; numa pequena concepço. Lina Bo 
Bardi foi considerada una herotna pelos tecnicos e instutores da fámica era detestada pelos funcionarios da área burocratica administrativa, que a consideravam una bruxa. mesmo atualmente aloumas pessoas do SESC reconhecem que a arquiteta deu unidade colocou o ClofF num tritho, e que sem a sua presença rabrica teria sido apenas un amontoado de coisas.

o feroz patruhamento estetico exercido pela argutetan que nao suportava as descaracterizacoes (como a colocacho de mesinhas de metal no restaurante para acomodar mats pessoas) vigorou: segundo funcionarios por alouns meses apts sua satda depois as coisas relaxaram un poucon chegando-se a pendurar quadros nas paredes de tijolose a se mudar de lugar os moveis/imoveis da arquiteta que ia os havia feito bem pesaclos extamente para impedir a mobilidade. Mas as marcas da arquiteta continuan em detalhes como a pequena vitrine ao lado da porta do restaurante (que exibe entahes de madeira pintados representando alimentos, feitos por un funcionário da manutenço) n nos vincos apticacos nos concretos da convivencian no efeito dinamico do sol nas treliass criando desenhos Iuminosos no chá e nas paredes esombras que se alongan com o passar das horas sendo os tracos caractertsticos de sua arquitetura a nudez dos materiais a a simplicidade.

A critica feita a Lina Bo Bardin comu a eategoria dos arquitetos; 6 que foi privilegiada a estetica em detrimento da funcionalidade, observandowse, por exemplo, que a igualdade de condiçes para todos os ateliers -. mesmo náo sendo eles profissionalizantes -... dificultan o uson que nám há lugar para se guardar nada e que as galerias do esgoto nă foram devidamente dimensionadas para a vazáno necessaria os grandes problemas da unidade, porem, estato no conjunto esportivo, sendo que muitas das falhas atribuldas a arquiteta sao na verdade "de responsabilidade da engenharia do SESC que na fopera da construcko abriu grandes buracos en volta do casebre de madeira que funcionava cono escritorio da arquiteta na obran para dificutar o seu transito pelo local. 
Quanto ao funcionamento do CLFF como centro culturat, o SESC wo fez os estudos do que se pretendian náo havendo nada escrito sobre a experiencia do que foi realizadoe o que isto representou. o texto sobre as intençes de atuậa cultural da fabrica presente no livreto que traz as linhas gerais da unidade que foj no intcio entregue aos funcionarios, levanta certos topicos sobre os quass se podem realizar algumas observaçesa a intenço de "revejar e divulgar novos valores" foi efetivada principalmente na area de musican A jóia inicial de "preparar especialistas em laxer" pensandowe ate num centro formador de animadores culturaisa nao foi adiante nem com os proprios ténicos do SESC! tendo sido realizados apenas cinco pequenos cursos. o objetivo de "alargar os ctrculos de discussaco de cultura" naco deu certo na fabrica pois o publico que costuma frequentar o ClSFF no se interessa por palestras ou por conversas sobre cultura sendo necessario o uso de varios artiffcios de seducho para se conseguir algum resultadou alem disso o SESC náo tem credibilidade como realizador de debates. nå consegue reunir as pessoas habitualmente interessadas e recebe a recusa de intelectuais consagrados en participar de atividades culturais propostas pela instituison sobre as "pessons se transformarem em produtores culturais" no for fom oferecidas maiores condicoes para isso a jem dos cursos dados nas oficinas. o pretendido "dialogo permanente entre os tecnicos do $5 \mathrm{~s}$ e 0 publico" náo se efetuou porque existe una grande vala entre o

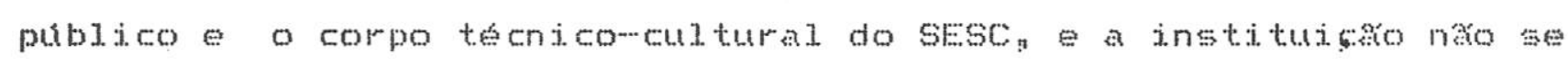
empenha en construire manter uma ponte entre eless. Quanto s "globalidade cultural. que considera legltima todas as manifestaçes da cultura, quer sejam intelectuais a artisticas: fisicas, sociais, ou manuais, sem estabelecer hierarquia entre elas": a questao e levada ao pe da letra náo se estabelecendo distinçes de nenhuma ordem a intencro, estimasen era a de na se nutrir preconceitos o que a distinto de náo se manter a especificidade cultural de cada manifestacă 
Ao se exaninar o planejanento cuturat pensado para o SEsc Fompeica a fácil. verificar que vingou apenas aquilo que aparecian Apesar do corte dos 14 tecnicos ter afetado significativamente a vitalidade de fabrican apos este incidenten ate mesmo depois da salda de Lina ko Bardi, ven se realizando algumats atividades culturais significativas no clofFr embora com una freguencia sensivelmente menor. Certas pessoas que participaram diretamente das atividaces dos primeiros anos passeram a desprezar as iniciativas da fabrica apos o periodo es que la estiveram, comportandowe como se so fosse possivel. realizar algo relevante quando o $\mathrm{SESC}$ contava com as suas presencas. flouns eram realmente competentese colaboraram para a fase aurea do clofip mas ná se pode desconsiderar que no infcio tudo contributa para qualquer coisa que se pensasse en fazer, e quem se dedicar a perceber as alteraches que ocorreram na vida da instituicho provavelmente valorizara o pouco que os técnicos conseguem realizar hoien

Considerando-se a posiço da instituişo e comportamento do

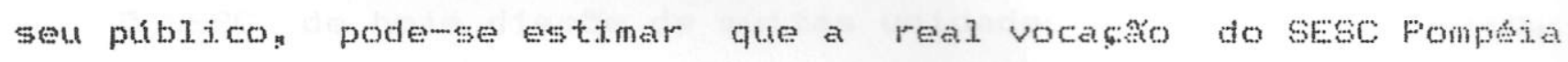
esta na producro de grandes festas. que se resolvem naquele momento e nao pedern qualquer continuidade. o centro, desde o infeion ven promovendo varias realizacoes gue cultivam este esplitos como as feiras de ruag as festas de passes (principalmente a portuguesa). os festivais Funke New lave, os arraiais as gafieiras a ate mesmo. a exposicá "Alice no krasil das Maravilhas" que apesar de sua longa permanencia, pode ser considerada una grande festa.

A idéa de se fazer atividades repletas de cor e baruho: espetaculares e espetaculosas" de forte impacton com caracterfsticas de "happenings" e fustas tribais esta presente no proprio texto "Intençes operacionais do CCD Fompeia" que propee o seguinte para o centro: "Como nos Halles de Farisa em Fortobello Foad, no Mercado de Salvador, ou no Kashba de Marrocos, abrir" para sao Faulo, una nova possibilidade onde artes, tecnicas cenas e sons, em un perene festival que tudo inclua - nada excluas envolvam 


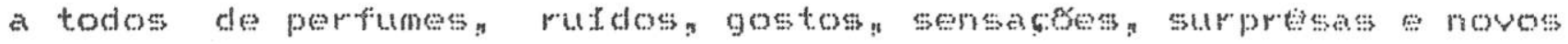
penstantos „"

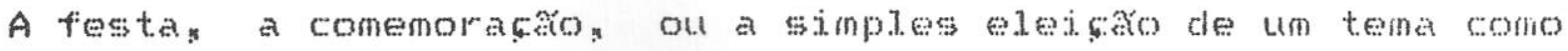
pretexto para as pessoas se encontraren descontratamente resultam sempre em eventos de grande porte, massivos co fator determinante do sucesso s o numero de participantes que conseguem remir) gue

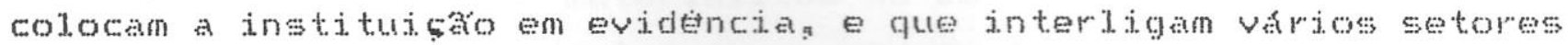
da unidade bem como quer o SESC situąos que abrem outras dimensoes alfm da realidade cotidiana e nelas me permitem oertas liberdades, como vestimentas aberrantesn rapidez nas aproximatoes afetivas e comportamentos que serian considerados inapropriados fora da festas o que agrada aos frequentadores. As artimanhas e os efeitos pirotecnicos logo cossan etudo se desvanece no dia seguinte sobrando as lambrancas de mats una reatizaç冖o que impressionou os sentidos das pessoss a espera da proxima festan

- SESC de hoje dispoe de mutas unidades bastante dinheiro. mas --. levando-we en conta as suas possibilidades -.- mantem bem poucos programas representativos e duradouros na area culturalu contentando se quase sempre en mostrar folos ou produtos culturats ja consagrados e no ato de oferecer seus espacos as pessoas. 


\section{ANEXo 1 - CENTRO CULtural sad paulo}

\subsection{Arquitetura}

0 projeto do cosp materializou-se em quatro compridos andares entre os dois nivejs do terrenos com a forma aproximada do un

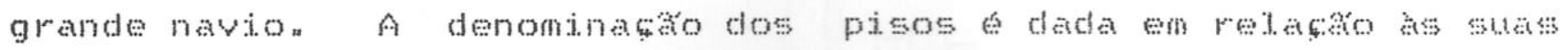
altitudes" portanto o piso eto esta a 810 metros acima do nfvel do

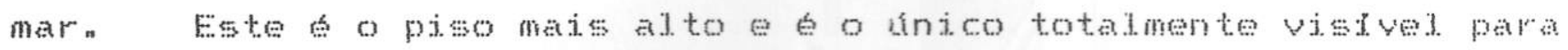
a rua Verguejrọ

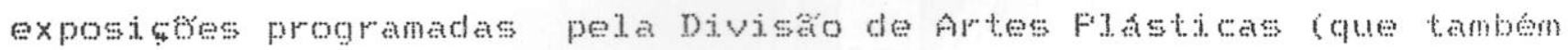

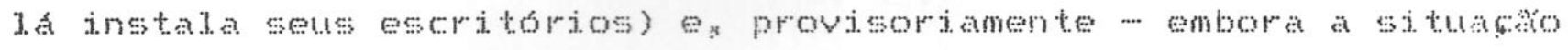
perdure ha quase nove anos - o ocupado pela administraba or diretoria do contron

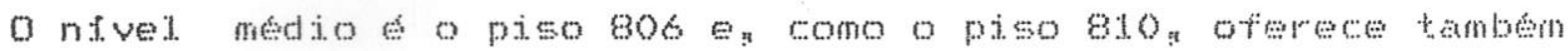

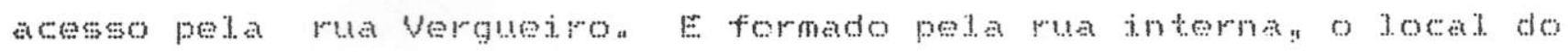
foyer (hall com escadas para as salas de espetallos) superior do teatro de arena e o jardim internog as ranpas do acesso

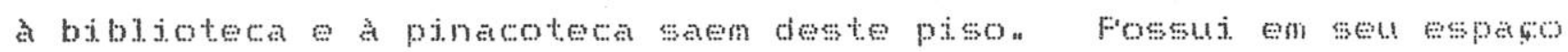

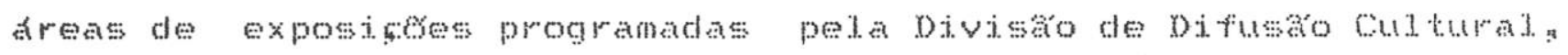

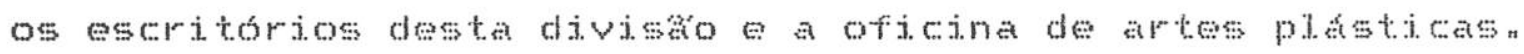

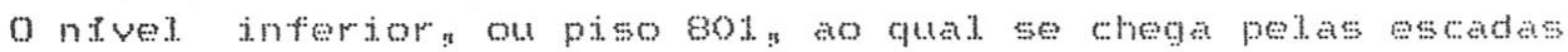

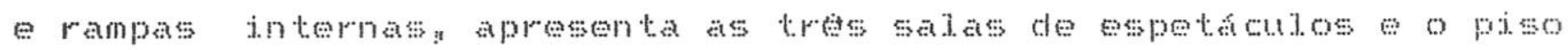
do teatro de arena os escritorios da Divisto de Artes Cendens a discoteca oneya fivarenga todos os setores da biblioteca os

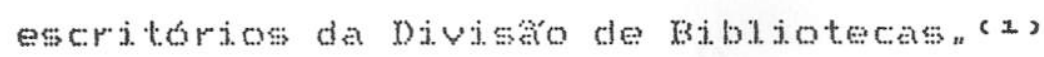

(2)As três plantas dos pisos aqui reproduzidas foran apresentadas no boletin $84 / 85$ do CCSP e sato as aenos confusas a as a ais proxisas da realidade que hoje se encontra no centro; no desenho realizado para o convite de abertura consta alguvas alternativas que não se caracterizarao e na publica̧̧ăo CCSP-ano I ainda se insistiu con eleaentos que na chegara a existir. Portanto, dada a grande escassez de aterial sobre o centro, optou-se por estas plantas. 


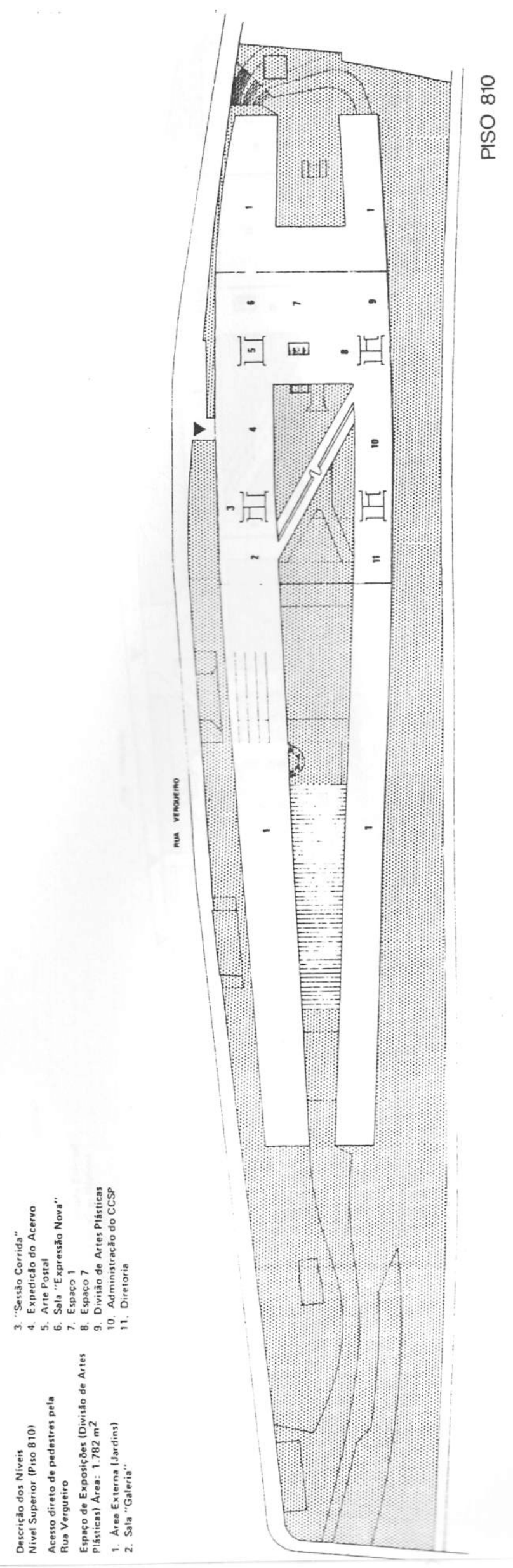




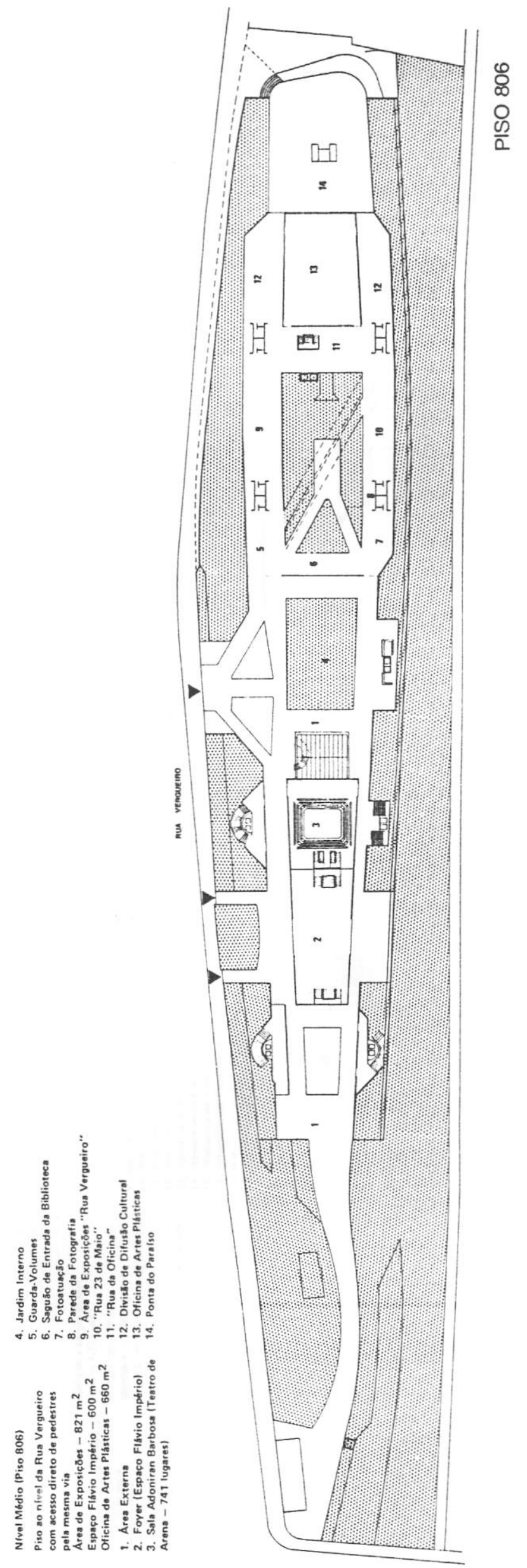




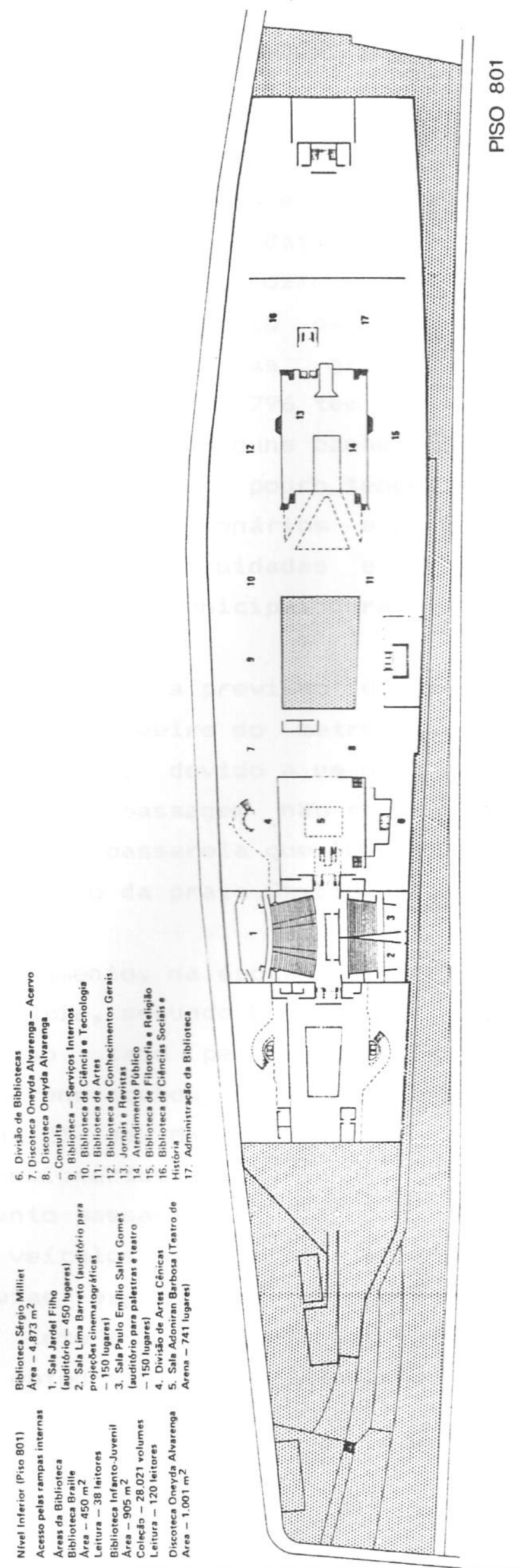


o piso 799 s o chamado piso tenico para serviços de infraw estrutura onde funcionan apenas tubulactes e condutoress eletricos: de telefone de agua e de ar condicionado sendo que todas as centrais estaro nesse pison

Ao nfvel. da avenida 23 de Maio esta o piso 796 e para ele foram previstos todos os escritorios das divisoes os camarins dos teatros, o cofre da pinacotecan a cozinha areas fechadas para estoque de materiais salas de ensaio para grupos teatrais de dançan ambutatorion e as oficinas graficas de recursos audiovisuas e de restauraça. 0796 tem o piso inacabadon están sem paredes esem divisorias, com alguns banheiros prontos outros nå terminados " Acabou virando (por pouco tempo! devido a falta da segurança) estacionamento de funcionários e ainda hoje deposto da prefeitura con coisas mal cuidadas e risco de incendio. Fecebeu todo o acervo do Teatro Municipal durante a sua reforma

Havia no projeto inicial a previsáco de un acesso direto ao CCSF atraves da estacko Vergueiro do metrt, importante ponto de pulsaça da cidade. Forén, devido a um desentendimento entre o metro a prefeitura essa passagem naro chegou a ser executada como tamber ná foi feita a passarela que levaria ao cosf por sobre a avenida 23 de maio "saindo da praça oswaldo cruz.

Quanto ao estacionamento, na epoca do projeto era un elemento de importancia quaternaria, segundo Luiz Telles. Deveria ter sido anexado un terreno ao lado pertencente ao INFG para sua viabilizaço, mas o terreno acabou náo sendo cedido. o piso 796. que dá para a avenida 23 de Maio e chegou a funcionar como estacionamento de funcionarioss deveria receber circulacko de transito apenas enquanto passagem para a obra. Na consta no projeto entrada para veiculos por lá alem disso. sáo proibidas as saldas diretas para vias expressas. Como o local possui ainda pouca ventilaço e o teto e baixo. náo permitindo a entrada do carro de bombeiros, optou-se pelo fechamento dessa area para velculos. 
o cosf foi. un dos raros exemplos de edificios programados e equipados exatamente para a finalidade almejacta por isso. dizian na focas sua grandiosidade e de outro tipon Eurico fraclo Lopes negou a monumentalidade da fachada, alegando que em geral o: ediffeios publicos săo grandes volumes que se imporm a paisagem urbana para tornar inesquecivel a memória dos governantes, optando por uma construço que se dissolve na topografia do terreno. Fela avenida 23 de Maio pouco se notam as plataformas de concreto no decilive lateral. do predion semi-encobertas por maciças jardineiras: colocadas em terraços no seu flancon e que servem como proteçáo ao barutho do transito - e portanto una construço quase ausente na paisagem urbanan

\subsection{Divisges e Seç8̈es do CCSP \&z,}

\subsubsection{Divisăo de Administraçăo}

A esta divisáco competen de acordo com a lej o controle geral dos servicos de expedienten pessonta zeladoria e manutenço montagern.

E uma divisá de apoion presta servi cos a todas as divisoes abrange seis seçes. A Seço de Almoxarifado controla armazne fornece todo o material de uso administrativo cutural gue to usado no cosf" A Secào de Treinamento é responsuvel pelas entrevistas com funcionarios a serem admitidos e pelo treinamento profissional, sobretudo a niveis operacionais (vigilanciat

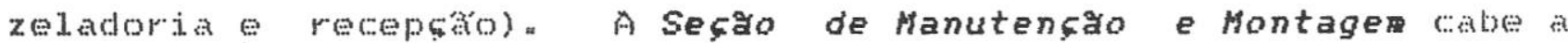
parte de cuidados com o predion instalacoses eletricas marcenarian ajuda na montagen de exposiçoss etc. .

A Segro de Pessoal reúne as informactos de cada seço Administrativa encaminha o historico dos funcionarios para o

(2) o organograna do CCSP está na página 41. 
Diario Oficial a estabelecendo os contatos com a segáo de Fessoal da Secretaria Municipal. de Cultura. A Secăo de Expediente responde pela circulacto de todos os papess (tanto internos como externos)! correios e xerox, bem como pelo controle dos vel culos que servem ao centro. A Secao de Zeladoria cuida da limpeza (realizacla por firma contratada), da seguranca observa e encaminha os problemas qua cabem a manutenço.

05 escritorios desta divisăo estao instalados provisoriamente no piso 810 desde a inaugurata do centro.

\subsubsection{Divisão de Difusăo Cultural}

A Equipe Técnica de Exposiçes e Publicacres coordena os setores de Exposiçoses Confectomo de Cartazes Manuais e Editoria.

o Setor de Exposiçes orienta projeta e monta grande parte das exposiços do CCof (exceto as mostras de artes platsticas) n e se responsabiliza pelos paineis de aviso e de programation. Em principio está aberto ass solicitaçes da comundadẹ e realiza tanto exposicoes de presidiarios como mostras dos sindicatos dos jornatistas

Ao Setor de Confeçao de Cartazes Manuais (Divulgacho Interna) cabe padronizar a divulgata atraves da elaboracko e distributa de cartazes a de outros materiats destinados a promover as atividades nos espaços internos do cosm.

o Setor de Editoria inclui. trabalnos de texton de proieto de producto grafica para criar executar todas as pecas impressase publicacoses do cosf cnormamente apresentadas en vermelhon preto branco, as cores oficiais do COSF, cono livros da Divisao de Fesquisas catalogos" cartazes jornaiswabloides, convites e programaçes; entre outras. 
Houve poucas tentativas de se fazer uma publicasco quo servisse de apresentaço do Cosfo com informases gerats phantas dos pisos, suas diviseses e que pretenden " Tentou-we un folheto bilingue, mas saiu com mutos erros de ingles e parece que nem foj. distributdo" o pequeno livro "CCSF - ano I" (Memoria ativa za -.. coleço do CCsF) e um album de fotografias do primeiro ano de vida repleto de textos laudatoros n com largas listas das atividades ate entác desenvolvidas e trazendo desenhos confusos e mal feitos para se compreender os pisos: e o "Boletim 84/85" trouxe pela primeira vez um breve relato sobre a funço de cada uma das divisbes do CCSF "sendo realizado durante a administraça de rosé Geraldo Martins de oliveira. Estas são as únicas publicaços do generon e bastante raras de se encontrar.

Anteriormente publicavame un boletim informativo do cosf

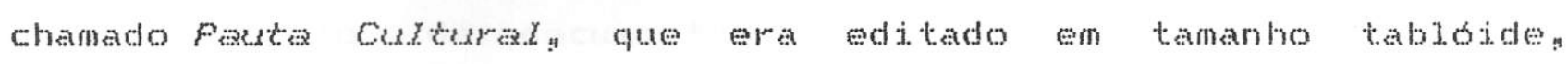
trazendo os eventos do centro. Chegou a ser suspenso algumas vezes por falta de dinheiro para o fotoliton por falta de materialu pois as divisoes nâso entregavan as informactess que lhes cabiam

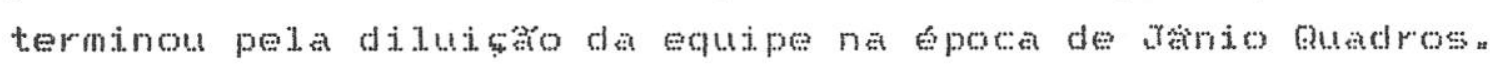

Com a administraço do FT esta vigorando a ideia da grafica do cCsF nato funcionar apenas para o centro e realizar os impressos com informages gerais da secretaria municipal de cultura como acontece com a Agemo cuturay que agrupa todas as atividades dessa secretaria e dividida por assuntos e por ordem cronologica informando os espetaculos, locats e horarios.

Fortanto. hoje a grafica atende diversos citentes" o cabinete da Secretarta runicipal de cuturali grupos de bairos que fazem solicitacoses atraves das suas administractos regionas o reatro Municipal la impressora do teatro foi removida para a grafica do CCSF), que imprime folhetos e os programas de apresentaçess dos seus corpos estaveiss Alem disson a grafica imprime o Informatiro she dirigido aos funcionarios da prefeitura com notucias gerais ... desde as variaçess do IFru ate mudancas no Departamento do Fatrimonio Historico devido a inctendio na casa das 
Fetortas ge todo o material que o cosf necessita, como fichas de retirada de livrosn crachas e jmpressos administrativos a dem das

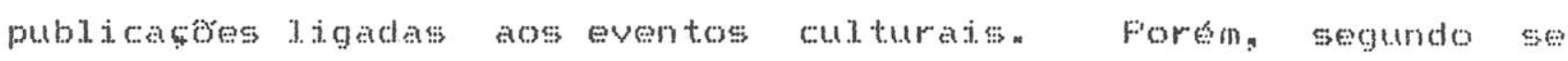
comenta" fazendowse este "picadinho" distanciase do objetivo de gravar a memoria do Centro Cultural Săo Faulon

A Equipe Técnica de Recursos Audiovisuais coordena os setores de Fotografian Audiovisual e Fadioatividades sendo chefiada por

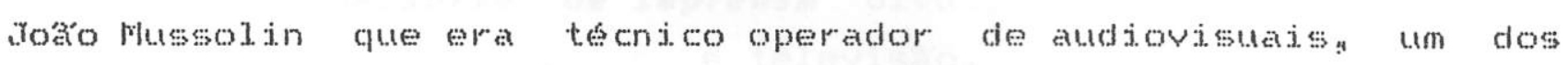
poucos casos de ascensa profissionat no cosf"

o Setor de Fotografia tem as seguintes funçes: documentacso de eventos ocorridos no cosfi prestaço deserviços fotograficose assessoria tecnica as outras areas (reproduço de obras de arte" copias fotograficas para rejeases "imagem para audiovisuais. eten)" e apresentaço de documentos fotograficos para pesquisas. exposiços e projetos programados para o Cosfa tais como retrospectivas, Ievantamentos historicos n etc. Atuamente o setor conta com tres documentadores fotograficos quando em 1984 havia doxeg existem seis vagas para eles mas ocorreran desvios de funcoss. Havia na administraço atual a pretensaso de cobrir as manifestacoses culturats mais importantes da cidaden portm por falta de pessoas; a ideja restringiume aos eventos da smo bem como a documentaço das atividades polfticas de seu gabinete " setor chega a enfrentar deficiencias basicas como a falta de fi. 1 mes.

o Setor de Audiovisual presta serviços aos departamentos da sill nas linguagens de audiovisual (por exemplo, o frojeto Direitos Humanos virou un audiovisual. s evideo, área ainda incipiente no centro, apesar da doagáo recebida de 12 aparelhos de videon que esta trancados em varios pontos do CCSF como banheiros camarins, para se evitar roubos $<\approx$

(3)ob5: O Setor de Radioatividade encontra-se no iten 2.4.. 


\section{A Equipe Técnica de Integraço con a Comunidade comprencene} cinco setores que visam integrar a comunidade com o eventon sa so os seguintes:

A Divulgasao Externa cuida da distribuiba de material suporte em diversos locais, responsabilizando-se pela colocaça de cartazese circulaço de fitipetas evolantes.

O Setor de Assessoria de Imprensa divulga os eventos na imprensa escrita enissoras de ratio e televisá, recebendo os reporteres que varo cobrir os eventosn E composto por cinco jornalistas que antes so se dedicavam ao CCSP e agora cobrem toda a agenda de atividades da secretaria Municipal de Cultura.

o Setor de Cadastro cuida do agendamento de novas entidades e de pessoas para receberen os impressos do CCSF. conta com aproximadamente 5,000 nomes.

o Setor de Expediço e responsável pela remessa postal m embalando" selando remetendo convites " programaços mensais e outras publicacoes do CCSF"

o Setor de Honitoria! que já contou com seis monitores na tepoca da inauguraço e hoje possui apenas dois atende visitas de escolas. coordena a vinda de crianças carentes e orienta grupos de fora. alem de fornecer as portarias informactess sobre os espetaculos.

o responsavel pela Equipe Ténica de Integracko com a comundade Ge Gerdo klota aunior" que afirma que o divulgador uma especie de camelt que tenta convencer que o seu produto bom para poder vender (ou, no caso, para render divulgacro nos meios de comunicaços)" porén, quando a mercadoria de fato é boa há um interesse natural da imprensa.

Independente das equipes tecnicas esta o Wuleo de Fotografia.

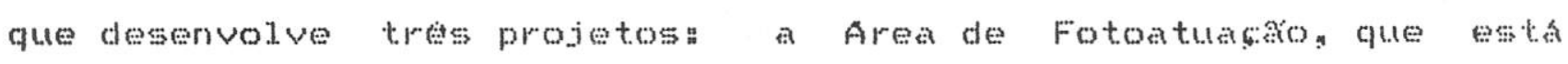
reservada as grandes exposiçes (como a de Marcos Santidi sobre a Amazonian realizada en junho de 1985 e reunindo 5000 fotos ou ass 
exposicoes coletivas" a Farede da Fotografian que aneciona as fotos por concurso e e o espaço utilizado para as mostras; individuas de fotografos amadoress e profissionatsp Fotoinforme que inclui palestras e debates entre os profissionats de fotografia e publico interessado nessa linguagem.

Há tambern o "Mural. de MF" que retine elementos como fotografias letras de musicas e capas de discos de grandes compositoresy alem de textos criticose outros materias que venham a colaborar alouns artistas convidacos fazem esporácicas apresentaçes ao vivo no local da exposiçon

\subsubsection{Divisåo de Artes Cênicas e Música}

A Divisa do Artes Cenicas e Música e composta por sua secho Administrativa e por tres seços que programam e registram as: atividades.

A Seço de Auditorios administra as quatro salas do centron e responsavel. pelos desenvolvimentos na área de artess coni cass.

A Sefaro de Desenvolvimento Musical cuida das programacoses dos shows na Sala Adoniram Barbosa de musica erudita na sata darded. Fillo.

- Laboratorio Musical Eletro-Acustico é responsavel pelo registro de eventos apresentados no centro, gravando os shows os debates promovidos.

o foyer o un saguáo que se destina a exposicesess performances. 1.angantos de livros e eventos congtineres a sendo o seu piso de pastilhas a cobertura feita por modulos de acrilico transparente - arredondadog funciona como sala de espera dos auditórios, dandolhes acesso atraves de duas escades de aço pintadas de vermelho. $A$ divisáso possue ainda una sala grande de ensaios, usada especificamente para dancan 
Săo desenvolvidas aproximadamente dez oficinas por ano, nas areas de dança, cinema, musica, teatro teatro de bonecoss "sendo pago un pequeno cache aos professoress e cobrada uma taxa minima dos frequentadoress. "para dar una certa responsabilidade as pessoas que estác fazendo o curso", conforme dizem os funcionarios dessa divisan

A equipe técnica da divisaso fo formada por um administrador (que faz o trabaho de gerencian cuidando dos ingressos a limpezas de camarim" a vinda do afinador de pianos gtc, " un chefe tecnico (responsavel pelos técnicos e pelos acertos como horario de montagem com as companhias) e um projecionistas cinco juminadores. cinco sonoplastas equatro maquinistas para construir e montar cenarios. Há um programador para cada una das cinco ámeas: música, musica erudita ta teatro adulto teatro infantil e dansat n

As propostas de apresentaços sáso encaminhadas atraves de um oflcio que as especifica sendo anexados dados de identificacto do responsavel e release do grupo. Abrewse un processo para cada contrato de locaça de espaço, que depende das assinaturas da direço da Divisáno de artes cenicas da secto jurdica do dipetor do cosF" "Fosteriomente encaminhawse o processo a secretaria Municipal de cutura cuja chefia de gabinete opina apos a apresentaço, anexase ao dossite bordert das bilheteriasm

\subsubsection{Divisă de Biblioteca}

Conforme o organograma do CCSF a Diviša de Biblioteca composta pela sua seçăo Administrativa pela sệa de Frogramậ́o por tres subdivisoes, sendo que a cada uma dessas subdivisoes responden cinco seçoses.

A Secao de Programacao cuida dos eventos n exposiçoss, palestras, shows, levantamentos bibliograficos baseaclos em datas comemorativas e outras atividades, como o uso do auditório (espaco improvisado por panos pendurados, onde poder caber de 100 a 200 
pessoas - dependendo de como o montado - e localizawe em una das beiradas da biblioteca), que na bitima quinta-feira de cada mes reservado pelo Centro de Convivencia do Tdoson para exibir filmes e audio-visuais" Segundo Lenira libeirol.tima atual diretora da Divisa de Biblioteca "tudo que e feito da Ibope" "

\section{A Subdivisgo de Informaçes e Referencias Gerais abriga as} enciclopedias $e$ as obras que abrangem todas as cissises do

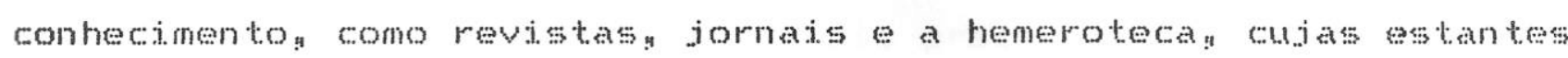
acham-se proximas a rampa de acesso. Esta subdiviskon atraves da atuaço de suas secoess e responsavel pelos serviços de base que promovem o funcionamento geral da bibliotecan

A secao de Atendimento cuida do serviso de reprografia edo atendimento ao publico. A Secro de Informaçes e Referencias Gerais possui. un fichario com o acervo dispontyet no cosf "e o terminat. de computalor que ven funcionando desce a abrtura da bibliotecan Essa sesco tem registrado o acervo totat do Departamento de Eibliotecas Fublicas para os livros do CCSF o consulente obtem as informatose e codjo do que deseja pesquisar e vai a seca apropriada tendo liure acesso no acervo.

Na Biblioteca Mario de Andraden por exemplon a consulta indiretag a pessoa vai a ficharion escolhe o que quer e marca os

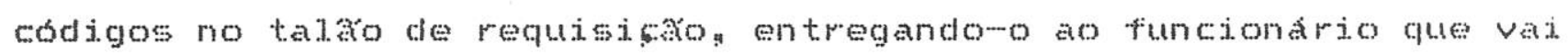
pegar os livrose atende a tres pedidos de cada vez. o jivre acesso estimula a pesquisa da obra pois as pessoas podem se aproximar de livros caros e julstrados; e na consulta ao indice logo perceben se thes interessa ou năo a comunicacto e mais informat, mats direta, mais dintimica porem a manutenço do acervo * mais trabalhosa e as obras se estragam mais.

A Seço de suporte Técnico faz a catalogaçon a classificaço e a etiquetagen preparando o livro para chegar ao leitor. A segao de Microfilmage trabalha com fornais antigos. para nå sobrecarregar as pastas da hemeroteca que guarda os jornats mais novoss Os livros danificados sáo tratados no laboratorio de 
restauro da Secao de Conservacăo e Restauro "que tamberm possui uma oficina de encadernaço e montagem en espacos improvisados.

A Subdivisao de Informaçes e Referencias Especializadas o dividida en cinco seçes que possuem obras de conhecimento espectico. Fara facilitar a reposicho foram colocacas cores diferentes nas lombadas dos livros de cada seça. Assim sendo. o

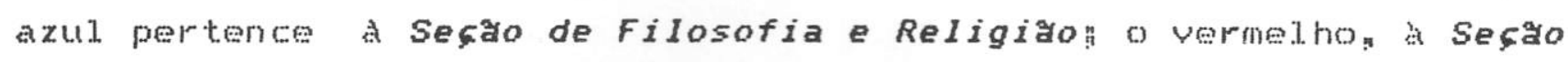
de Ciencias Sociais e Historia (a mais procurada) o anarelo define a Seço de filologia e Literatura! o verde indica a secao de ciencias e Tecnologia (que e a segunda mais pesquisada) e o preto * a cor da Sefao de Artes (os liuros mais caros acharme no segundo acesso. para o qua se necessita de un cracha especial). Fora desta subdivisaso estao os livros com tarias brancas (enciclopedias dicionariose livros de conhecimentos gerais) e marrons que sao sobre musica. Ha pontos de atendimento em cada seba en para evitar que o consulente peregrine muto. dispos se o material do acervo de tal forma que a concentraço do assunto esteja em cada area, com Iivros, audiowisuais e revistas sobre o mesmo tema.

A Subdivisao de Colecaes Especiais reune os discos os livros dos cegos a literatura infanto-juvenily alem dos materiats de pesquisa que ná saro livros. Este setor foi o que mais sofreu diante dos problemas de termino da construgho do cosfa $e$ a ele estáco subordinadas as sequintes seçes:

A Secao de obras Raras que compreende o servicho de manuscritose o serviso de iconografian As obras que deveriam pertencer a essa seço estao na Biblioteca mario de findrade por falta de condiços do CCSF recebe-1as. A Secao de Recursos Audiovisuais "que oferece fitas" diapositivos" slides" filmes e laboratório de linguas sendo este bastante procuraclo pois possibilita as pessoas fazerem cursos inteiros sozinhas, contando 
com gravadores de fitas cassete, fones de ouvido e metodos que acompanharn. (4)

A Secào Infanto-Juvenil anda náo foi instalada porque para funcionar necessita que se tenha uma entrada separada para crianças e banheiros apropriados no setor e durante o periodo de litio do CCof nada dis\$o foi feiton

De acordo com o projeto original, a parte dos cegos seria fora da area da Biblioteca sergiomiliet. Forem como as obras do CCsp foram suspensas, acabou sendo instalada numa das pontas da biblioteca para la foi levado o acervo de obras para adulos que funcionava na Eiblioteca Monteiro Lobato. Atualmenten a Segao Braille conta com 4 no00 titulos dispostos ern 16 noo volumes (pois estes livros ocupan muto espaço) e nela trabalhan 20 pessoas sendo 15 cogos ou deficientes auditivos as rampas do cosp saso perigosas para os cegos, que estao autorizados a usar os elevadoress e sáo guiados por ripas de madeira pregadas no chăo da bibidotecan For meio de uma máquina especial com papel apropriado voluntáros fazen transeriços para o alfabeto braile sendo tamben gravadas fitas de narrạ̧eş há um xerox proprio que molda as folna pelo calor e un microcomputador que trabalha em brailen porem seus sinais sao fracose pereciveis. Esta e a unica biblioteca de brailie em Găo palo planeja-se que a parte infantil seja acoplada a seço Infanto Juvenily para que as crianças cegas possam conviver com as videntes.

Outros materiais sato tamberm oferecidos aos frequentadores da Biblioteca sergio Mili.jet havendo um setor de folhetos turisticos (que as monitoras do COSF pegain em agencias) "folhetos sobre saude esobre servicos de informaces gerais folhetos de ecologit a meto ambienten catalogos de exposiçoses de arte (cuja listagem estáno microcomputador), uma estante apropriada para diarios e publicacos oficiaise un setor de apostilas de cursinhos para os que náo os

(4)obs.: A Seção de Discoteca encontra-se no capitulo 2.4.. 
poden frequentar), alem de livros que orientam nas profissbes u um contato direto com o creE -.. Centro de Tntegraço lempresa

\subsection{Funcionários}

A Seço Administrativa que existe en cada diviano tem fungess de una secto de pessoat propria de cada areas com prontuarios nos quats se anota tudo sobre os funcionarios. Ha urn liver de ponto wm que todos os funcionarios deveriam marcar a entrada 0 almoto a safda sendo feito um controle de presenga depots preenchida uma folha de frequencia individual " enviada diretamente ao D.F. „H. Departamento de recursos Humanos, que reune informabes sobre todos: os funcionarios da prefeitura. Quando o funcionario esta en servico externo e náo assina o ponto, faz un pequeno relatorio wim folha a parte que recebe a assinatura do chefe de secá do do diretor da divisason

O chere da seço Administrativa tem a funço de analisar a folha de paganento providenciar vale-.transporte, solicitar o pagamento de un terço das forias e tamben acompanhar o diario ofjeial gue traz o historico da prefeitura publicando licencas medicas ferjas inqueritos administrativos e exoneracoss nomeaçese substituiches como quando o chefe sai de forias qual funciondrio que o substitue). As noticias de cata divisao sao

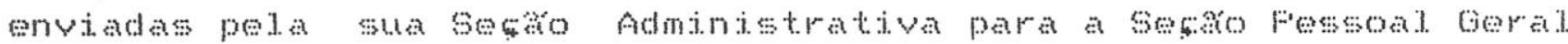
do CosF" que encaninha listas para o Diario ofician.

No cos: trabaham tres categorias de funcionaros: os efetivos que entraran por concurso publico cuja validade de dois anos pertodo no qual os classificados podem ser chamados) possuen estabilidaden so sendo demtidos por faltas graves. realizandome un inquerito administrativo para estudar os casos de puntwos "supensess ou exoneraçess os funcionarios do cosf que sa efetivatos ocupam nomamente cargos na divisás de

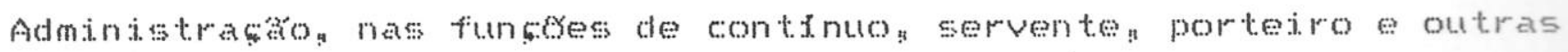


(sendo que ha tambem admitidos na área aclministrativa) ụ os

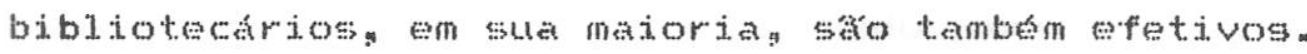

Os comissionados ou nomeados, saso pessoas escolnidas para a funça por seus superiores, e podem ser exonerados a qualduer

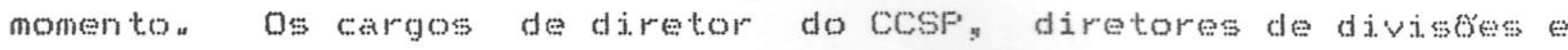
chefes das seços soro tidos como cargos de confianç en como tambem

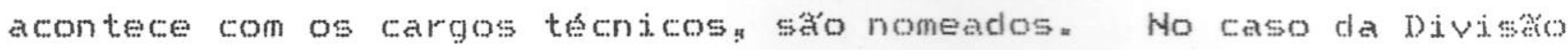
de Artes Flasticas por exemplos apenas o chefe da seça Administrativa é efetivọ todos os outros funcionários desde os professores da oficina até os chefes das seçes, sâo comissionados" o procedimento normal. para se nomear un individuo s o seguinten o chefe da seço pede ao diretor da divisarog que solicita ao diretor

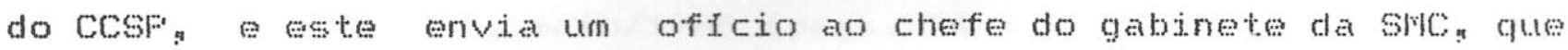

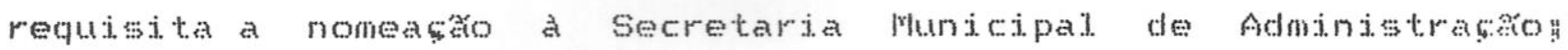
depois de tranter por lat en diversos setores a a nomeatso sai. publicada no Dífrio oficial e a pessoa toma posse do cargo no Departamento de Fecursos Humanos.

A terceira categoria e a dos admitidos qu gu moram erm determinado cargo para reajizar servicos em carkter temporarion devendo prestar concurso táo iogo seja posstrel. Foren ha gente

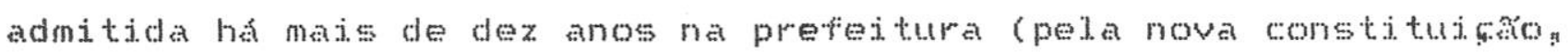
os admitidos hat mats de anco anos tornam-se estavis)"

Há a possibilidade de contrataşo de servişos tocnicos especializados, como no caso de um modelo vivo profissiond ou um professor para determinado curson o servico de 1 impez e fejto por una empresa contratada portanto os jimpadores năo sáto funcionariom do cosfor.

A forma de provimento que sáso as caractertsticas que as pessoas devem apresentar para exercer os cargos está determinda em Iej. Forem o espaco do Cosf oferece város problemas para o usuarion e ja se chegou a fazer um relatorio com quase loo pontos de falhas de seguranga a serem sanadas seria necessajo un corpo 
de funcionarios muito bem treinado para diminuir os problemas no uso do cosw"

\subsection{Entrevistas e Dados Bibliográficos}

\section{Revistas Especializadas}

- A constructo em sko Fauto -.. no 1785, abrit/1982

... A Construsto en sao Fato ... no 215\%, junho/1989 (pag. 12)

-. Moduto -.. editro 72 ano $198 \%$

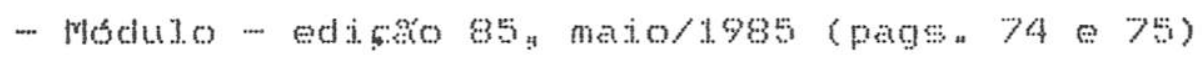

-.. Frojeto -.. no 40, ano 1982 (pags " 31 a 37 )

\section{Revistas}

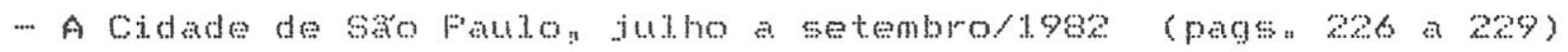

- Tsto lE, no 272n 10/03/82 (pags" 28 a 30 )

-. Isto E/Senhor: $1 / 02 / 89$ (pagn 79)

... Veja, 1.9/05/82 (pags. 66 a 70)

-.. Visan $14 / 03 / 83$ (pag. 39 )

\section{Jornais}

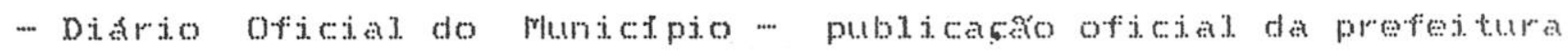
municipal de sá frulo. 7 de maio de 1982 -...e de criagro do CCSF"

- O Estado de Saro Fato - diasa 14/01/79, 10/01/80, $02 / 07 / 80$, $03 / 07 / 80,14 / 05 / 8 \%, 06 / 08 / 87,16 / 03 / 89$ " 


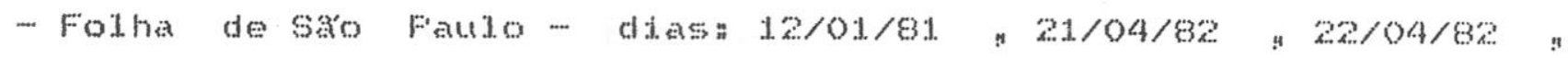
$25 / 04 / 82,13 / 05 / 82,14 / 05 / 82,20 / 05 / 82,28 / 05 / 82,28 / 05 / 82$, $17 / 05 / 84,13 / 04 / 85,01 / 02 / 89 ; 02 / 02 / 89$.

- o olobo - - dian $06 / 07 / 82:$

- Folha da Tarde - diasn 17/12/81 "20/05/82, $21 / 05 / 82,06 / 10 / 87 "$

- Metro News -- dian $13 / 05 / 82$.

\section{Publicaģes da SHC}

$-1989 / 1990$, boletim da 5 re

\section{Publicaçes do ccsp}

- follheto distribudo na inauguratón

- Cosf - Ano I coleşa do Centro cultural sá Faujo- Memoria Ativa 2.

-- Boletim Seminarios Internos" 1984.

- Boletim $84 / 85$ " editado en 1984.

\section{Trabalhos Realizados sobre o CCSP}

- Centro cultural Săo Fauto trabalho de zo grau realizado na Escola recnica Federal de Saro Faton para a disciplina "Introduço a construcko civid" e feito pelas alunas cristiane Yamaguti, Flaine Cristina Helena Kosaton sem datan

- Fesquisa realizada por Vanda Teixeju sobre o uso das mesas de coqueter. por estudantes "sem datan 
-.. Tese de Mestrado "Folftica de Desenvolvimento na Esfera do l...as Cuttural: Estudo de Caso do Centro cultural do Tabaquara" Marflia Gomes dos fieis Ansarah corientacao de Sarah smacal, 1983).

\section{Entrevistas a Funcionarios do CCSP}

(todas realizadas durante o ano de 1989)

-.. Ana cristina Ferejra de Almeida - chefe da oficina de Artes Flasticas de 1983 a 1985, DAF ( $5 /$ abri.1.)

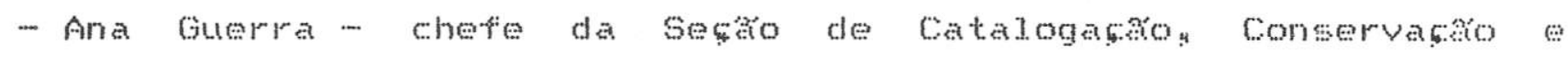
Montagem, DAF (20/outubro)

- Arlenice Tuliane de oljvejua - responsavel pela frea de frodugho Grafica, DDC (21/novembro)

-. Camem Aranha -.- chefe da oficina de Artes Flasticas Dow (17/outubro)

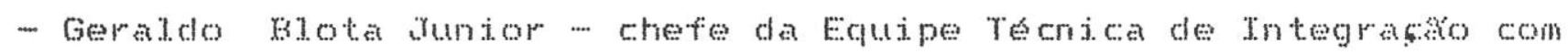
a Comunidade, Doc (21/novembro)

-. Toă Hussolim - chefe da Equipe Tecnica de kecursos Audiovisuais: DDC ( $21 /$ novernbro)

- Tose Amerjo Mota Fessanha -.- diretor do CCSF (2s/setembro)

-.- Tosé Salvador Fodrigues -- programador da Divisao de Artes ctondeas e Misica (20/outubro)

- Lenira fibeiro Lima -.. diretora da Divisa de Biblioteca (10/novenbro)

- Luz Benedito Castro Telles - arquiteto cowator do fropto do $\cos (06 / d \operatorname{combro})$ 
- Magaly do Frado -- responsavel. pela Fidioatividadeg DDC (06/dezembro)

- Marisa Campos Viana - chefe da Secro Administrativa "Daf (17/outubro)

- Faulo Vasconcelos - chefe da seço de Arte Fopulara daf (28/novembro)

- Fita Daher -- programadora da Fadioatividade, DDC (21/novembro)

- Foque S. de Souza - coordenador do Mural de MFin dod (28/novembro)

- Tamico Shimizer - chefe da Seça de Discotecan DR (10/novembro)

- Vanda Teixeira - assistente da Divisao de Difusáo Cultural de 1983 a 1985 e atual assistente da Divisáco de Fesquisas (17/outubro e $23 /$ novembro)

- Vigilante (pediu para náo ser identificado) - funcionário da Divisaso de Administraço (20/outubro)

- Wisson Tadeu Quintao Nogueira da Silva - diretor da Divisăo de Administraça (05/outubro) 


\section{ANEXO 2 - MUSEU LASAR SEgALL}

\subsection{Departamentos e Divisôes do MLs (1)}

o Diretor Presidente promove as mediclass atos concernentess at gerencia financeira e a guarda e conservaço do patrimonio: supervisiona a coordenaşo funcionamento dos orgasos do mis.. apresenta a FWir as propostas do quadro de cargos e salarios do mos dentro das normas daquela fundasas e define normas de acesso de terceiros as instalabess "equipamentos e ao acervo do ri..s.

A Assessoria do diretor presidente é constituta pelo assessor de museus Luts Hossaka, gue trabalhou rom a vitua de segall desce as primeiras exposiços da obra do artistan ha maje de zo aros atrass pela Assessoria de Divulgatron que cuida do planejamento execuço da divulgapio das atividades do museu "faz o axompanhamento iunto aos veiculos de comunicago e organiza e mantem o cadastro de envio do material do museun

O Diretor Adjunto coordena e efetua contatos com os orgasos da

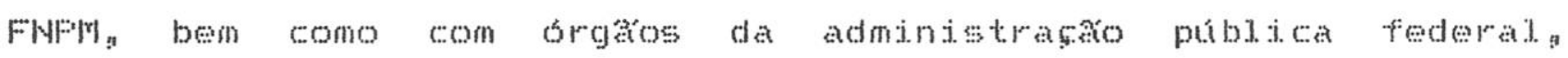
estaduat ou municipaly pianeian diriges supervisiona e coordena as atividades de captaço de recursos.

\subsubsection{Departamento de Atividades Criativas}

A Divisao de Fotografia conta com dois orientadoress Vera Albuquerque e Clovis Loureiro dunior sendo que este já esta no museu há J2 anos gosta do seu trabaltho que the permite novas experitucias e aperfeicoanento. 


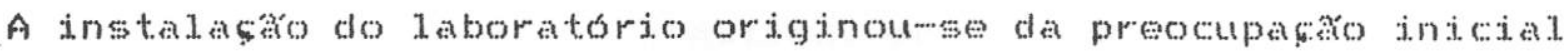
de dotar os cursos de fotografia com o necessario para que estes nao se tomassem meramente teoricoss e hoje conta com um laboratorio equipado com quatro ampliadores para preto e brancon um laboratorio de revelaço de filmes; equipamentos de iluminatso artificial, projetores de sides e una sala de reundess onde os frequentadores informalmente expoem e discutem suas fotografias

Os cursos sa desenvolvidos com turmas de doze pessoss n ciurm cinco semanas e normalmente cada professor da seis cursos por ano. Antes eram convidados grupos de pessoas como operarios estudantes pobres, mas atualmente nem se faz a divulgacto pois as pessoas dos cursos falam a outras, ocorrendo principalimente uma freputincia da classe media que anda de metro enjbus os cursos basicos se iniciam com a construço, pelos proprios alunos de una cutmarasecura de papeláo com um furo em papel metalico de mato de cigarrose com a qual são dadas as primeiras aulas praticas! atraves do furo, a luz sensibiliza un pedaço de fil me fotografico, que depois o revelado, nas repetiçes da experiencia -... variando o tamanho do furo, o tempo de exposiçâa e a proximidade do filme com relaţa a furo -... sato compreendidos os princtpios basicos da fotografian sao tambem desenvolvidas as ténicas basicas para o uso livre do laboratorio e ensinawse cono revelar em qualofur lugar e como ampliar usando projetores baratos de sijeses motivando os usuarios a experimentarem o processo fotografico.

Fara os alunos com dificuldades economitas o museu dispoe de aparelhos fotograticos simples que sás emprestados semandinenten iunto ao fornecimento gratuito de un filme.

o primeiro passo dado pelo museu na concretizacio de sua Divisào de Artes Plasticas fot em 1974, com um curso de formatân em

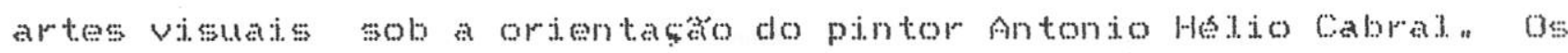
atunos preparavan seus pincess. tintas e suportess sendo tudo fabricado com restchos industriats e utitizavase tambern como pigmentos os diferentes tipos de term do solo da cidace No segundo semestre de 1976 comecoume a desenvolver o atedier 
permanente de livre criaço plastica possibilitando a expressaso plasstica para qualquer pessoa que a desejassen independente de formaço provia ou de quatsquer outros compromissos estotion pois o que se pretendia era dar espaco ao simples prazer de se expressar

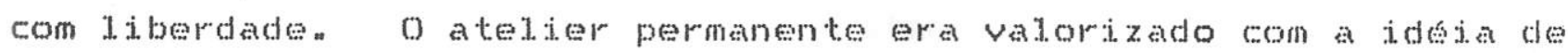
que náo haveria outra maneira dese entrar no mundo das artes que nao fosse a de cada un fazer a sua propria arten sem se prococupr com o produto acabado ou com a aprovaço de quem o rercan 0 museu alimentava o atelier permanente dando o material basico necessario para os frequentadores acima de 13 anos.

Foram desenvolvidos cursos de iniciagro a dinguagem visual, com autas teoricas para estudar os elenentos principaje desta

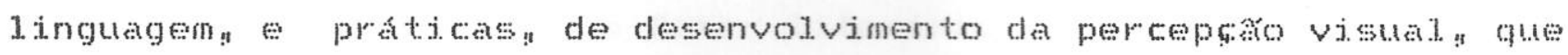
teria sido preterida a partir do momento em que o individuo aprende a 1ere a escrever n Houve tamben o projeto de releitura da obra de Lasar segali, acontecendo encontros con a obra do artista e discussoses entre os participantes" questionou-se a influtencia que cada artista recebe conscientemente ou nás, de outros artastas a busca de repertorios proprios no desenvolver de uma linguagm sua especificidade a proximidade entre linguagens distintas.

As atividades da atual Divisao de Criaço Literaria tiveram jufcio em 1975 atraves de cursos livres de andisse de textos. 1.teratura brasileira e redaço para operarios e colegiais.

Laboratorjo fermantente Fedaço surgiu da surpresa de constatar a inexistencia de outross e propunha a exploracko do lado experimental mantendo permanente un seminario de critica da 1.inguagem o texto que ofundamentava na epoca era o seguinten "o Laboratorio fermanente de Fedacto nato um curson naco oferece formulas receitasn năo tem modelo ou ideian Nao ministran nato admindstra nao faz pedagogia. Fortanto ná ha professor de redaçáo en salia Havera "como dizer" 'animadores' "pessoas encarregadas de agrupar, provocar: incitar ao desenvolvimento da linguagem discutir" ver as atividades de todos os participantes. Os 'professores' sáso besicamente os primeiros inscritos para o "laboratorio" "ahunos" mut to interessados" 
o intuto era o de que as pessoas se utilizassen da reclacaro como un instrumento de aprendizagen! fazendo da palavra un ver culo efetivo de expressiono o laboratorio nă pensava a redaço como uma prética jolada mas sim imediatamente relacionada com a leitura "a critica e fala desenvolvendo simulanemente andijes de textos, le turas e seminarios pretendia se promover a formactio de grupos com interesses comuns que eles se definissem num projeto de trabatho ou na experitencian

Apos alouns anos de trabalho, as pessoas que haviam tido inicialmente niveis variados de qualidade expressiva com a palavra possufarm uma capacidade de redaça superior a métia dos frequentadores mats recentes i os componentes desse grupo encaravam o ato de redigir como um fazer literárion buscando circunstáneiass em que pudessem apresentar seus textos fora dos encontros semanais do museu Esta busca do leitor acontecia de forma espontanea" como consequencia natural da maturaço de seus processos de expresson como as atividades do laboratório eran comuns a todos os frequentadores! propos-me a criaço de um laboratorio avanado. do qual. participariam os que haviam esgotado a proposta da iniciaç:o do curso normal, mantendo o carater de um grupo aberto que j.ria definir o seu trabalho. Estas duas modalidades de laboratorio existem ate hoje

Desde o inficion o corat da Divisao de Musica apresentava certas carateristicas: sendo principalmente constitudo por moradores do bajron com a joja de ser um coral em que mats do que apenas cantar tamben se aprenderia musican o que se pretendia era reatizar un trabaho didaticoweriativo com seus integrantes năo se considerando as apresentaçess como un fim em si mesmo, mas como uma decorrencia do processo.

A decisaco de ensinar musica lanģou as bases para a formaço de

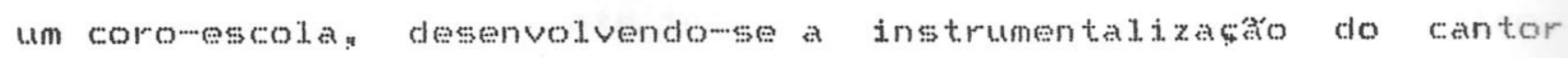
atravos de atividades como aulas de solfejo regulares d desta forma a menoria dejxou deser a línica base do aprendixado e se conseguiu major autonomian pois os cantores nó fican na dependencia de 
alguem que 1hes cante exaustivanente ass peçs ates que sejam

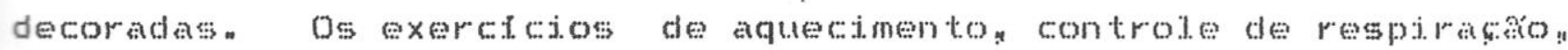
colocaşo da voz e outros foram sistematizados garantindo a cada integrante condicoes de desenvolvimento de suas potencialidades vocaiss sendo que o cuidado individuat resulta num som coletivo majs aprimorado: como pratica de solfejo todos os naipes lem todas as vozes "o que facilita a compreensazo global da obran

Em varios momentos porén, o coral sofre altos batixos " Como quase todos os coros" vive crises ciclicas pelo movimento de entrada e sada de cantores pela "populata filutunte" "formata

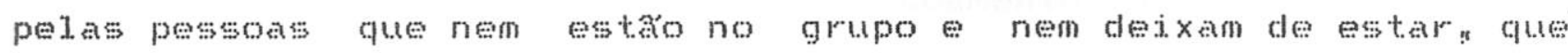
a ternam semanas de ensaios com outras de ausencias e apresentam as razoes de sempren mudang de empregon de endereco a descoberta de que o coro naro era exatamente o que desejavam fazer" entre outrass Nestes momentos decai a produça sonora demorasese mas tempo para preparar o repertorion ressurgem dificuldaces ja superadas instaurase um curtowircuto no processo coletivo de discusso reflexă en contrapartidan os melhores momentos do coro do museu ocorreram quando a organizaço interna estava fortalecida.

o coral conta com a presenşa de un regente titulara de una regentemssistente de una professora de tecnica vocal a saio realizados dois ensados por semana com a duraçaso de duas horas meia, alén de ensatos extraordinarios aos domingos nas epocas de montagen de programas para apresentaço.

Nos ensatos esperawe o desenvolvimento de algunas qualidades: quanto a emissan pretende-se que o som do coro possa chegar com presenga a todos os espacos da sala de concerto espera que que o coro consiga se ouvir en salas con qualquer condicáo acustica objetivawe que cada cantor. cada nape e o conjunto completo consigam emitir as notas afinadamente e que o texto das obras executadas seja plenamente inteligfvela para o aspecto ritudco. pretenderse que o coro seja preciso na resposta ao gesto do regente e que a boa articulacko ritmica permita-1he um methor resultado de afinaça. como resulato gerat. segundo o regente llarco Antonio. 
desejarse que o coro consiga bom conjunto, que possua certa maleabilidade seja capaz de cantar un repertorio tipo miscelatrea

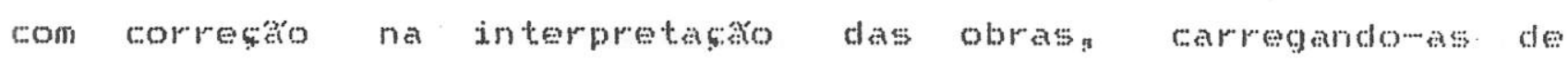
significado. Todas essas saro qualidades que se almejam a a vezes se consegue alcangare as vezes nay pois o coro e sempre um instrumento com certo grau de instabilidade.

\subsubsection{Departamento de Biblioteca Jenny Klabin Segall}

Como se trata de uma biblioteca que trabaha com areas espectficase que pretende o aperfeicoanento de seu acervo nos cinco temes escolnidos acumidame pequenos acervos paralelos qus ficam desatualizados e sem condiches de repositaron hestes casos o museu prefere encaminha-los a quen possa lhes dar melhor uso. Foj. o que aconteceu com a colecaro de Historias en quadrinhos doada a ECA - Escola de Comuntaço e Artes da USF " com os catalogos de exposiços encaminhados ao centro Cutturat sa Fauto e com os titulos de jomalismo, cedidos a Imprensa oficial do Estadon sendo que os livros de arte agora esta no atelier do museun fonsase na possibilidade de se constituir acervos de arteweductack museologia pois naso há bibliotecas que se dediquem a isto em sao Faculo.

Segundo a bibliotectria Amelia Maria loreiran mesponsavel pela kiblioteca Tenny klabin segally um de seus problemas o a umidade relativa de $90 \%$ devido ao jardim mon frenten e durante as ferias semprese forma bolor nas estantes a biblioteca ia teve cupins. mas o material atacado era destinado a permuta com outrass

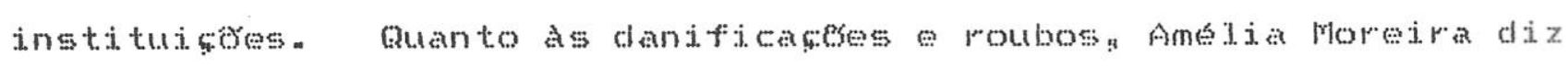
se tratar de un problema geral. que acontece en todo o mundo, inclusive nas bibliotecas universitariasm mpesar das dificuldades que enfrenta, esta biblioteca 6 considerada como a que melhor cuida e processa seu material. tanto que recebe doaços constantemente.

No ind cio de 1989 houve un corte de verbas da FNFily e com a flutuasăo cambial o dolar.jivro atingiu alto valor" dificultando a 
compra de revistas. Tentou-we a captacta de recursos com algums empresas; mas nás deu certo a assinatura das revistas foi conseguida atraves de verba obtida da Associagro de finjogs do maseu I...sar Segalin A biblioteca recebe por volta de 90 entre ass principajs revistas racionatse estrangeiras publicadas nas areas de sua vocaça eno Amelia loreira considera que a assinatura de revistas a vida da bibliotecan uma das prioridades do museu pois as novidades aparecem em periodicos antes de passar a livros. Havia, para 1990, o projeto dese informatizar a bibliotecan

\subsubsection{Departamento de Museologia}

o numero de obras de autoria de Lasar Segall que pertencem ao acervo do Ml..s na FWF 0 de 1.711 , constando 26 pinturas: 386 gravuras, 50 desenhos, 67 esculturas, 350 estudos para desenhos: 750 esbogos e rascunhos para desenhos e 48 cadernos de desenhos. Estas obras ficam guardadas na reserva técnica (cofre) sob controls de luz temperatura (200 c) e unidade relativa do ar (60\%) 5 â expostas en sistemas de rodizio e reunidas en mostras maiores nos perfodos de ferias escoldres. En janeiro o museu abre apenas suas

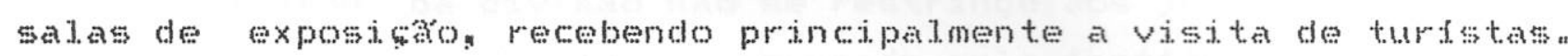
sempre ha alguma mostra das obras de segalit no museu. desenvolvendowe para tanto un projeto critico baseado en pesqujsas de forma que a exposiço pode ser concebida adotandowse criterios como o perfodon tecnica ou tema por por exempto a guerra a natureza e aspetos sociologicos ou esteticosn As boas condiçess de armazenagem e manusedo limitado das obras asseguran que o seu estado permanega estacionarion sendo que os oleos ficam on exposicaro uma media de tres meses a cada dois anos.

o rl..s ja chegou a promover tinco exposiçes itinerantes " que visitaran 45 cidades do pats e foran inclusive enviadas a Europa" sendo que agora esta se planejando una grande exposicho na Alemanha para a comemoraça do centenario do nascimento de segali. Foram reatizadas retrospectivas de l.asar Segall no fito de raneiron en Curitiban em Forto Alegre e em Campinass o Departamento de 
Museologia editou 55 catajogos i.ustraclose com textos corticos gue foram vendidos a baixo custo porem sempresa fortos folnetos de distribuiço gratuta contendo dados e informaçes didaticas que complementarn a exposiçăon

A Divisao de Agaro-Educativo Cultural diante da dificuldade de adequaço da hinguagen das exposiços as faixas etarias mais baixas" elaborou em 1986 uma mostra dirigida especificamente ao

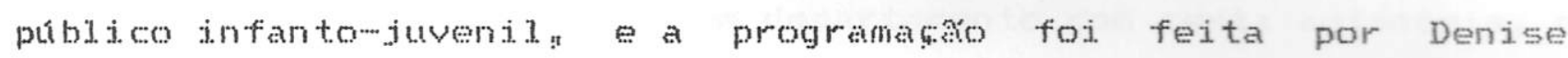
Grinspum coordenadora da divisano. Com o intuito de usar o trabalho de sogall como incentivo a criaço expressan tres salas foram ocupadas por obras selecionades dispostas a uma altura inferior a convencioneln deixandowse grandes espacos livres entre e1as dez escolas participaram do projeto es a partir do contato visual com as obrass os estudantes form estimulados a se expressarem verbal. gestual e plasticamente sendo que todos os desenhos guaches feitos foram expostos ao lado das obras do artistan o resultado deste trabajho foi registrado na primeira publicaço do serviço educativo com o titulo "A crianç ve segall."

o trabatho da divisao ná se restringe aos jovens "Em meados de 1987" quando o museu foi procurado pela instituicáo "sociedade Feligiosa e Beneficiente Tsmalita l..ar dos Velhos" a que pretendia organizar para os seus residentes una serie de visitas recreativas no museug foi realizado un trabatho como grupo de inigrantes pertencentes a este organon Tomou-se a obra "Wavio de Enigrantes" como ponto de partida para reflexoes en tomo das causas da

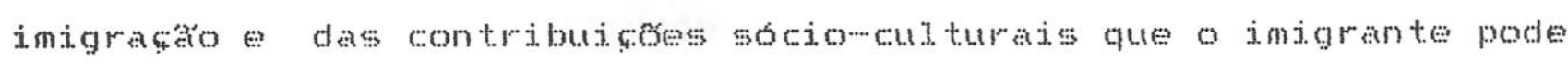
trazer para a terra que se estabelece recolheram dopolmentos das pessoas que contaram suas historias e apresentaram documentos: obietos fotos que resultara na exposiço "ketrato de Emigrantes" "cas

(2)obs.: tanto a obra de Segall cono o folheto da exposicto trazen a palavra "enigrantes", sas ao se referir aos estrangeiros que viven no Brasil, o correto seria O uso de "inigrantes". Os israelitas enigran de Israel e inigran para o Brasil. 


\subsubsection{Departamento de Administraçăo}

Ao Departamento de Administraço compete o desenvolvimento das atividades de administraço dentro das norma regulamentares da Fundaça Nacional Frómmemorian

A chefe deste departamento, Beatriz Gonçaves; lembrase da epoca da Associaço Museu Lasar Segall e do nascimento con junto da bibliotecan que sempre foi um departamento com certa autonomia, do musen a qual estavam ligadas as artes criativas a administrạ̧o a museologia. Naquela época cada pessoa era um

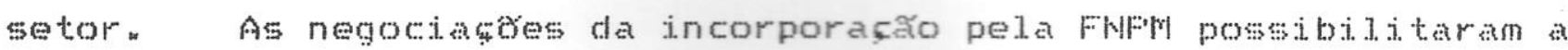
admissá de pessoal tentco principalmente para as areas de museologian documentaço e serviço educativon porkm em todos os departamentos permaneceran varios funcionarios com tradica no história do museun

Aposs a incorporaço, os funcionários do museu estáso sob regime da Cl..Ty que determina certa forma de conduta na legis lacko trabalhista e se diferencia do funcionalismo publico: o indivfduo classificado segundo seu tempo de trabalho sescolaridade experitencia em un plano de cargos e carreiras com nomenciatura espectfica. A FMFM avalia os cargos de atribuicoes de nivel modio - superior" baseando-se nos seguintes fatores: conherimentos teoricose tecnicos tempo de experitencia profissionaly grau de dificuldade para o desempenho das tarefas a ele cometidas. responsabilidade por elementos confidenciaisy responsabilidade por planejamento, responsabilidade pela preservaça e administraço de bens e recursos responsabilidade por contatos o informacos teconicas! e responsabilidade por andise e recomendaçosn

Forsmo acordo estabelecido é de que o museu escolhe as pessoas para as vagas. Sobre a possibilidade de crescimento profissional neatriz Gonçaves diz que una promogsio so pode ocorrer ou quando alguér se desliga do museu e possibilitia remanejamento interno sendo que normalmente se procura ocupantes para os cargos que vagan no proprio museu, ou atravos de abertura 
de vagas, o que ná houve desce o estabelecimento do quadro de funcionarioso alias, algumas pessoas safram e seus cargos náso puderan ser ocupados. os interctabios de emprestimos e transferencias definitivas de funcionarios saco posstyeds mas raros

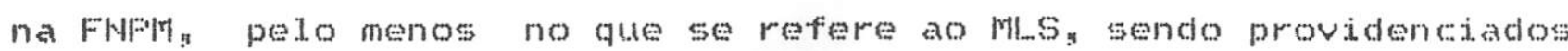
atraves de processamentos burocraticosu segundo a nova constituinten as pessoas com menos de 5 anos seriam obrigadas a fazer concurso público "caso aprovadas "receberian estabilidacle.

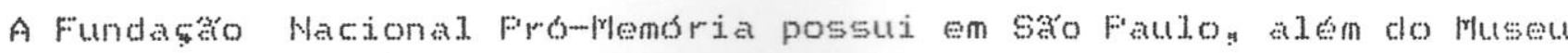
Lasar Segali, a Cinemateca Brasileira e o escritorio de sua ga Delegacia Fegional,

- Departamento de Administraço é composto pela Divisáo de Apoio Administrativon pelo Setor de Grafican pela Secro de Frogramaşáco Visual. e pela Divisăo Contábil.Financeiran

A Divisao de Apoio Adinistrativo planeja coordena supervisiona e avalia as atividades relativas a serviços gerass administraça de material e patrimonio, administraço de recursos humanos e atendimento ao público do museu a e possui cinco subdivisbes; com as seguintes funços"

A Secao de Servicos Gerais compete executar e avaliar as tarefas de limpexa e conservaça do imovel e suas dependtencias e coordenar os serviços de guarda, seguranç, portaria, zeladoria transporte jardinagen. entre outrosn o museu nao term matores problemas quanto a segurança As vezes acontecen pequenos incidentes con algun frequentador: que se irrita quando no lhe deixam entrar numa sessăo de cinema ja comesada mas nunca una obra sofreu danos.

- Setor de Conservacao e Limpeza cuida destas condiches em todas as dependencias internas e externas do museu.

Ao Setor de Recursos Humanos compete coordenar executar e avaliar as atividades relativas a administracao de pessoal. 
A Seço de Atendimento ao Publico e responsuvel. pela orientaço e controle do púbico visitantey cujidando das atividacles de apoio como recepsán telefonian copa e cafeterian sendo esta um ponto de encontro entre frequentadores funciondrios do museu.

o Setor de Material administra os pedidos de aquisis a guarda - conservaçẫo do material e cuida do controle patrimonial que náo se insere na area artistica bibliografican

Frosseguindo no organograma, ao Setor de Grafica cabe realizar os trabalihos de impressao e montagen de todo o materiall de divulgasto de uso interno do museu, como circularess follibtos. boletins e publicaçes da instituigo, e para tanto dispoe de una impressora off set.

A Secao de programaço Visual realiza todos os trabalhos de programasaro visual. do museu, desde os impressos até certos cuidados nas instalacoes do predio.

A Divisao Contabil-Financeira cuicla da execucho orchentspa financeira do museu de acordo com o plano de trabalho aprovado para o exerctio e respeitadas as normas regulamentares da FNFin para tanto acompanha anaisa a movimentacto aplicacto de recursos: elaborando os relatórios da gestácinanceira do museu e prestando contas das subvencoses recebidas e dos convenios firmados entre o museu outras entidades publicas e privadas.

\subsection{Entrevistas e Dados Bibliográficos}

\section{Folhetos e Publicagaes do MLS}

- MLs = ofrequentador ativo, abri1/1983

- Boletim Tnformativo No 115 - numero "um" apos incorporabo pela FWFin -- janeiro/1985 


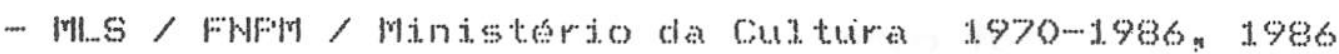

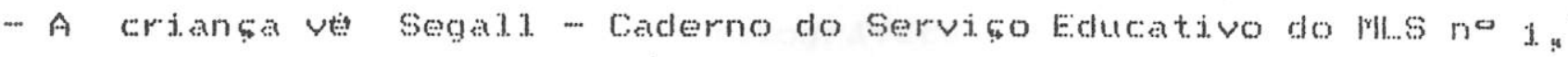
1.986

- Associacro Culturat de Amigos do rll.s. 1989

-. Museu Vitalidade -..- una opcro n 1989

-.- Fetratos de Enigrantes junho/1989

- Atelier de Artes Fusticas julho/1989

- Fotografia 1990, dezenbro/1989

\section{Textos sobre Departamentos e Divisbes do Museu}

Geral

-.. Texto de objetivos do CErca -- Centro de Estudos Interdisciplin... nares en Expressess outurats Artisticas "Tose Barrientos Renard, $S \mathrm{CH}$

\section{Centro de Atividades Criativas}

- Texto sobre objetivos do cac! sun

- Frojeto memoria das atividades do rilsa Historico dos setorese formaço do CAC - texto base para a primeira publicaşo do CAC, $\mathrm{Sn}_{\mathrm{n}} \mathrm{d}$

\section{Divisao de Fotografia}

-.- Fotografia expressaco individual, s.n 
- Normas de utilizacio do laboratorio fotografico s a n

- Froposta para uma atividade fotograficas agosto/1980

\section{Divisào de Cinera e Video}

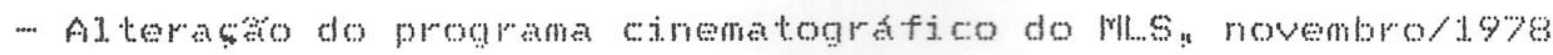

- Sala Faudo Emilio sales Oomes - setor de cineman 1987

\section{Divisa de Artes PIasticas}

- O atelier permanente de livre criasco em artes visuaisa jut $11.19 / 1976$

- Frojeto "Feleitura da Obra de Lasar Segal1" " 1985

\section{Divisăo de Criaçăo Literária}

- For un laboratorio permanente de Fedaço so an

- Consideraçes para un plano de trabalho do setor de redachon oi.1.son Fampazzo: dezembro/1984

\section{Divisa de Música}

- "Lasar segali a onde se aprende mísica" in caderno de musica no b. maio $/ 1981$

\section{Departanento de Museologia}

.... Frojeto CFAM -.. "Uma proposta de integrasto musemescon" 1989 


\section{Textos de Maurficio Segall}

- Froposta para a definiçáo de uma polftica cultural para o mls.s. 1977

- rlus - Una proposta museológica num pass en desenvolvimento (artigo escrito para a revista Museum, da Unescon en marco de 1979, atuatizado en 1985)

- Marketing e Museu (palestra proferida no IX Congresso Nacional de Museus): 5 , dn

- Intervenço de Maurfico segall na mesa sobre inuseus e fundacoss culturais no forum de debates "A Cidade e a Cultura" no centro Culturat sao fraton $22 / 4 / 1983$

- Um depoimento nostálgico-umbilical (escrito quando da apresenta-5ăo de "A Gravura de Segal1", no Faço Imperial do fío de Taneiro), 1987

- Farticipaço de Mauricio Segall no painel "O museu e a questao do negro na atualidade brastleira", no seminario "o negro e a escravidáo nos museus brasiteiros" "11/6/1988

- Texto para ser apresentado no encontro de museologia na Holanda novernbro/1989?

-. "A republica nos museus -- os museus na republica" "participacko de Mauricio Segali. na mesa redonda "Freservaso de patrimtonio cidadania" -- Congresso Internacional do Centenario da fiepublica Brasileira - 130 modulo, Fio de ianeiro, 8/11/1989 


\section{Trabalhos realizados sobre o MLS}

- Felatorio final dos trabahos realizados na primeira etapa da pesquisa "Comportamento, atitudes e motivaçes do púbicico do Museu l.asar Segall." Jose karrientos Fenard (pescluisa readizada com o auxitio da FAFESF e do CNFq), $1980 / 81$

-. Tese de Mestrado "Canto Coral = do repertorio tematico a construço do programa", Marco Antonio da Silla Famos (orienta ça de Tose Tejuxeira Coelho Netto), 1989

\section{Documentos}

- Documento de incorporação do MLS pela FNFM $12 / 11 / 1984$

- Fiegimento interno do MLS, 4/7/1988

\section{Acompanhamento de reuniaes}

- Feuniăo do Colegiado: 30/11/1989

- Feunifes Gerais a 24/11/1989 e 1/12/1989

\section{Entrevistas a funcionários do MLS}

\section{(todas realizadas durante o ano de 1989)}

- Amelia Maria Nogueira - chefe da Biblioteca Temy Kabin Segall. ( $13 /$ dezenbro)

- Beatriz Gonçalves - chefe do Departamento de Administragáo ( $30 /$ novembro)

- Claudio Mubarac -- chefe da Divisáo de Artes Filasticas DAC $(1 / d \in z(n b r o)$ 
- Clovis Loureiro Tunior - chefe da Divisao de Fotografian DAC (16/novembro)

- Dario Mata Siriaco - chefe da Segao de Serviços Geraisa DA ( $13 / d e z e m b r o)$

- Gi.son Fampazo - chefe da Divisáo de Criaga Literarias DAC (22/novembro)

- Marcelo Araújo - chefe do Departamento de Museologia (1/dezembro)

- Marlia Xavier Cury -- técnica da Divisáo de Aço EducativoCultural, Dr (14/novembro)

- Maurfio Segali -- diretor do MLS (1/dezembro)

- Regina Sawaya -.. chefe do Departamento de Atividades Criativas ( $30 /$ novembro)

... Takeshi. Ishihara - chefe da Divisăo de Cinema e VIdeo, DaC (16/novembro) 


\section{ANEXO 3 - CENTRO DE LAZER SESC FABRICA DA POMPEIA}

\subsection{Que e o SESC}

- SESC - Serviço Social do Comércio declarawen en seus textos, uma institujşo privada de ambito naciona que tem por finalidade a pronogáo do bem-estar social e o desenvolvimento culturat dos comerciarios e de suas familiasiatraves da oferta de serviços a custo recluziclo.

Foi fundaclo por jniciativa do empresarjado comercialu que decidiu prestar essa colaboraço a partir de una reuniag que visava garantir a paz social no pais, realizada ern 1945 na Conferencia Nacional. das Classes Frodutoras realizada na cidade de Teresopolisis Fio de Taneiro. A institucionalizacho do SESC deume nos termos do Decreto-Lei Federal nr. 9.853, de 13 de setembro de 1.946, tendo sjoto o seu regulamento aprovado pelo governo federal."

Desde a decada de 30 já surgiam problemas decorrentes da crescente implantacko de industrias nas cidadess pojs os trabalhadores se deslocavam do campo a procura dos empregos oferecidos pelas industrias e em busca de una melhoria do padra de vida. Forem, estes migrantes nao possulan qualquer qualificaso profissional e as cidades nao tinhan estrutura para receber tantas pessoas que ficavan prejudicadas nas suas necessidades de assistencia medica social e no seu desenvolvimento cultural.

A eriaga do sfisc visava prestar este tipo de auxilio ss pessoas que estavam trabalhando em empregos comerciats a o SENAC -. Serviço Nacional de Aprendizagem Comercial -.. foi institudo para oferecer cursos de habilititaço as atividactes do comercion com ofertas nas areas de alimentaços estetica e hotelarian entre outrass Felas mesmas razbess e na mesma epoca foram criados. para o setor industrial. o SEST - Serviso Soctal da Industria e o SENA Servico Wacional. de Aprendizagen Industrial. 
A Confederaça Nacional do Comercio a a enticlade que rebine os

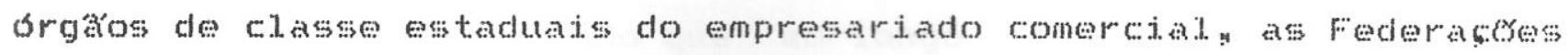
do Comercion Coube a ela a organizagho do stesc que ficou estruturado atraves do Conselho Nacionat orga deliberativo cujos membros sa indicados pelos comerciantes dos varios estados do pafs; do Departamento Nacionals orgáo executivo que tern a

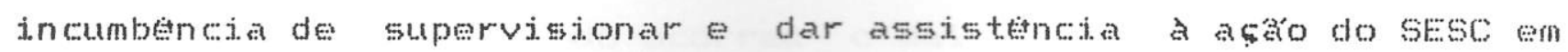
todo o palsy e do Conselho Fiscaly que exerce a riscalizacro financeira estes tres orgás estáo sediados no ki.o de Janeiron

No nivel. estadual. estao as Administracoss Fegionass que tem o mesmo prosidente que as Federaços do Comercio de cada estado: saco constitudas pelos sindicatos patronats do comercio dentro de seu estado. As Administraçסes Regionais saco compostas pelo Conselho Feginal orga deliberativo formado por representantes das categorias economicas do comércio, do Ministerio do Trabalho do IAFAS -- Instituto de Administraça Financeira da Frovidencia e Assistencia Social" e pelo Departamento Fegional orgaro executivo cuja finalidade eperacionalizar os programas estabelecidos! tendo em vista os objetivos do SESC.

As metas do sEsc variaram no decorrer de sua existencian De infcio sua aço wncaninhou-se de forma assistencial. e paternalista diante de un quadro social de alta fincidencia de tuberculose de outras doencas infecto-contagiosas favorecidas pela desnutiono. Nesta epoca surgern no SESC os restaurantes populares e servicos de educaşo sandtaria e nutricional sendo tambem realizados convenios com sanatorios paralejanente foram eriados os centros de Atividades Sociais: com cursos de arte culinaria e formago domestica, areas de recreatro infantil e serviços odontologicos " que tinhan o aspecto de grandes residencias.

o assistente social era o profissional predoninante na entidade, mas com a criagro das coltonjas de ferias surgiu a necessidade de entreter o divertir os comerciarios e seus familiares, os Centros de Atividades Sociais comecaram a promover festas e reunibes dançantes. A preocupaço inicial com a saúde 
Jevara ao desenvolvimento de un programa de lazer, baseado em conteúdos culturais a sendo que a longo dos anos o lazer iria se tornar o objetivo principal do SESC, cabendo a saude uma participacáo complementar e acessoria.

Wo inteio dos anos 60 houve a reforma do poder executivo federat. Wesse pertodo ocorreu o maior numero de tentativas de absorço da institusto pelo governo federal. A cobranca da contribulfo compulsoria das empresas havia sido legitimada pelo Estado que se sentia no direito de propory impor as vezes ate mesmo tentar absorver a aço social supletiva desenvolvida pelo SESC. Forem os dirigentes sindicais patronais se empenharam em assegurar a sobrevivencia da entidade e garantir a maximo sua autonomia institucional. Acabam percebendo, entretanto gue 0 SEsc enquanto complexo medico-ambulatorial e hospitialar naxo poderia i. alfom de un pequeno aptindice dos serviços de saude prestados pela previdencia e assistencia social. phiblica.

A instituiço desenvolvia serviços para uma categoria de trabalhadores que aumentava seu tempo livre numa cidade com dificuldades resultantes da rapida urbanizaçon consequentementen a preocupata com os problemas macromociais de saude e alimentaço foi sendo substitufda por atividactes associativas de prestaça de serviços. Apareceran descompassos entre a concepsaso da aço eso equipamentos disponiveis: constatando we que as instalacoss naco eram mais apropriadas pois nă possutam prasas esportivas proprias e a formatso de grupos era prejudicada pela falta de espacos suficientes para reunir os interessados e com eles desenvolver atividades" ou seja. o crescimento da cilientela excedia ein muito a capacidade de atendimento dos Centros de Atividades Sociaisn

Os investimentos imobiliarios passaram a se dirigir para constructes do tipo escolan com salus de aulan saláco de festas, pequenos auditorios a cifnica odontologica e area de administraço, sendo o conjunto completado con una quadra de esportes. 
0 Jazer ganhava espaco e era visto por alouns nás apenas como um instrumento para se educar cade pessoa a fin de que old videsise a promover seu proprio bem-estar: mas tamben como aloo capaz des possibilitar reformas o mudançs estruturais nesta etapa a entidade caracterizavase como una agencia de educaso social promovia principalmente o trabatio das unidades moveis de Orientasto social -... UNIMOS.

A unidade se resumia numa perua veraneio for o stmbolo do siso que transportava os tecojocs e os equipanentos esportivos es culturaisy dos quats fazian parte desde bolas a projetores de filmes 16 mon No perfodo de 1967 a 1976 as Unimos atuaram nos bairros periffericos da cidade de Sáo Faulo (trtes undades) n na

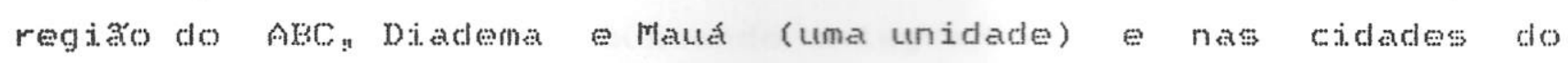
interior paulitsta (dez unidades).

Ao chegarem As regioes ou cidades, 1090 eram feitom contatos com as lideranças formais (prefeitura, vereadores! presjomtes do Hindicatos, diretores de escolas) e se estudava o tipo de aço que poderia ser desenvolvida. O Trabalho Social da Comundade -.. rsci praticado pelo SESC, nucleava e mobilizava voluntarios para produzir eventos dentro da comunidade como campanhas de saudea orientacós profissionais em escolas cursos de relaceses humans no

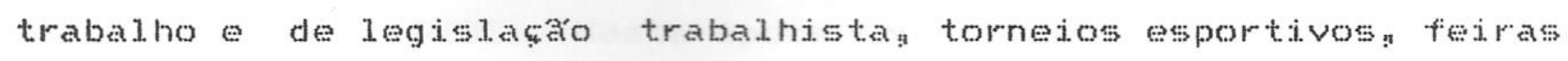

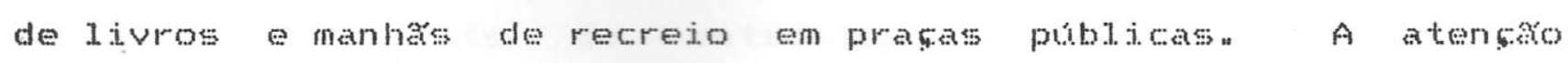
injoial dada ds questoes de higiene e satide promovendowe

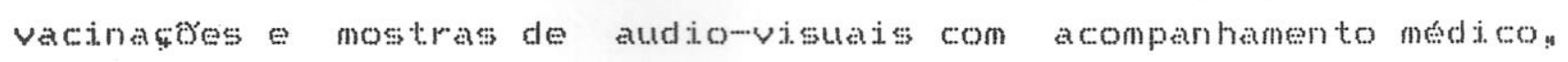
foi transferida para as atividades de lazerp promovidas corn a

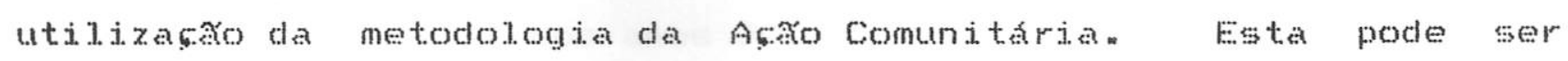
definiday conforme o pensamento do teorico de lazer Fenato Fequixay como um processo educativo de funcionalizasto de forgas latentes e de movimentos casuais de una deterninada comunidadeg a fin de torna-i.os socidimente eficazes;

A reflexso a respejto das caractertsticas que esses processos

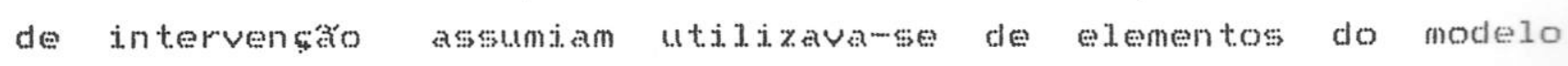
analitico desenvolvido por sofife Dumazedier e conhecido como 
Teoria da Decisaco que se propere a pensar a problematica da aço social. agrupando os elementos que a determinam ern quatro conjuntosa a situacho sobre a qual se age que compreande tanto os recursos com os quais se pode contar quanto as necessidades que se pretende satisfazery os valores; en nome dos quais se desenvolve a aço que implicam en ideass que saro buscados atraves dela os objetivos que se procura atingir no tempoe no espacon e os meios mobilizados para alcanca-1os: os resultados obtidos atraves da acko desenvolvidan

Os objetivos principais eram informar a comunidade quanto aos aspectos sociomeductivos referentes ao lazer e promover encontros de lidmançs formas e informais para estudo e discussaso do:s problemas da comundade "buscando integrar iniciativas esparsas. A unidade movel. permanecia de 40 a 50 dias numa cidade des locando-se depois para outros nucleos na regiao, e evitava entrar nas questoss polf ticas inerentes a cada localidade.

A busca de espaço nas escolas sindicatos e praças entre outros lugares, a preparaço para exibir teatron musica cinema realizar festas exposiçes e atividades esportivas a ensinou a pratica da animaço cultural aos ténicos da instituickon experiencia que seria utidizad para a construcko a atuacso dos novos centros do SEsc. Nesta foca houve o predominio dos chamados orientadores sociais da entidaden que eran pedagogos e profissionais na área de formaçon estavan empenhados en educar para transformar.

Nota-sen, no SESC dos anos 70, a constitutho de una empresa de prestaço de servicos de lazer: prevalecencio a jeleologia da denocratizaço dos bens culturas no tempo livre. Havia grande influencia do pensamento dos tésicos de lazer nas decisoss dos; dirigentes: que contavan com o apoio governamental. Os principajs estados que trabalhavam o lazer eram o fito de Taneiro e Sáo Fato. e nas outras areas viam-se combinaçes das etapas ja vivenciadas pelo SESC. 
o Centro Cut tural e Desportivo veio representar, nesta epoca. um novo conceito de equipamento urbano dispondo er suas instalacos de amplos espaços e inframestrutura para atividades sociais: culturais " esportivas e recreativas substituiu progressivamente os Contros sociais do tipo rasa ou escolan 0 primejro Centro Cuturat. e Desportivo de Säo Fulo foi o SFsC Vila Nova criado no final de 1967. Havia tambem a preocupara de possibilitar un lazer que oferecesse como principais atrativos a vegetacto a paisagen! o que resultou no centro campestre de Interlagos: foran mantidos os restaurantes popularss os oserisos odontologicos da fase inicial do SESC.

En seu texto sobre a história do SESC, Dirreu Nogueirat Magahas define esta etapa como sendo a fase de afirmago da personalidade da instituiça como entidade de lazer das massas onde a cultura desempenha um papel importante e entendida como um bem a ser desfrutado, e apenas secundarimente vista como instrumento de transformaço humana e agente de muansa social.

o governo fecieral. mantinha se afastado das propostas de trabalo institucional. da entidaden forém a discussáco na area parlamentar surge na segunda metade dos anos 80, resultante dass

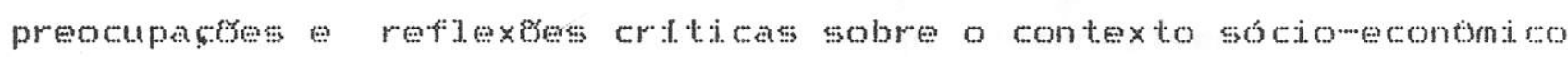
do pats; o Congresso Nacional atraves da Constitutinten tornou-se forte agente na discussaro e sugesta de propostas chegandowse a avaliar publitamente o que são e que fazem entidades como o slesc. o diatogo com a constituinte passa a ser fundamentat para os clirjontes sindicats que preocupados con a sobrevivencia e a autonomia institucional procuran mostrar a validade da programaço de lazer desenvolvida pelo slesce suplementada pelos servisos de alimentaşo saude oral. Certa parcela do quadro tontio do SESC defende a ampliaço aprofundamento de taj atuabso enquanto una outra prefere recuperar a dimensáo de saude por meio das unidades de atendimento primariog ha ainda os que acham que na programaço culdural ná deve haver apenas diversacos mas tambem atraves dela se coriar novas praticas valores no meio trabalhador assatariado. 
A linha de aço dominante entre os dirioentes sinclicats torna se nftida ao se examinar o friano de Investimento Tmobiliario -.. a grande maioria dos equipamentos novos e ampliados destinawse ao lazer" A imagem do SESC semelhante a un clube $\Leftrightarrow$ a que está presente nos poteres constituldos e na opiniáo publican.

Este conceito proprio dos anos 70, encontrou o apoio de mi.hares de pessoas, que assinaram a emenda popular en defesa do SESC, das personalidades que se manifestaram na imprensa Essas iniciativas foran deterninantes para a sobreviveneia da instituja cao en momentos de recessaso e de questionamento das cartencias da populaţo trabalhatora do pass. Fensa-se no stes que a partir do momento en que o pals retomar seu ciclo de prosperidaden o lazer sera a matriz contral das futuras açes institucionais.

Atualmente a Administraça Regional do sEs no Estado de sao Faulo procura dar continuidade a polstica de crescimonto interiorizaço de serviços e atividades, prosseguindo a construcko de dois centros culturais e desportivos no interior do estato intensificando as obras de um centro cultural e desportivo de um novo centro campestre na capital. Mantem en funcionamento vinte unidades na capita e interior contando com centros sociais. centros culturats e desportivos, colonia de ferias" wentro campestre centros especializados que desenvolvern programas de esportes a culturan turismo social a andimento a terceira idade alimentaçáso e satide "unidos sob uma proposiço educativa"

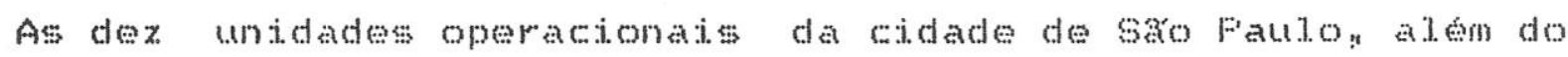
predio da administracho centrat na AV Faudista saro as seguntesn SESC Foosevelt (reservas para as colonias de forias do sesc en todo o pass) : SES Florencio de Abreu (tratamentos odontologicos de

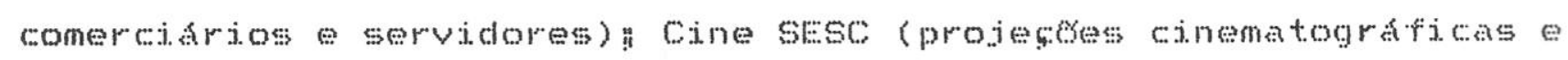
cursos de danga) "Teniss SESC (quadras de tenis) \# SESC Traipú

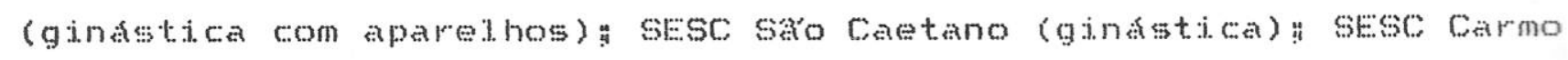
(refeiçes): SEsc Vita Nova (predio esportivo Teatro Anchieta); SESC Fompeda (atividades culturais esportivas) a SESC Interlagos (clube de campo). 
Os recursos do SESC provern da contribuisa compulsoria dos; empregadores, os comerciantes, que 1 he destinam 1 g $5 \%$ do total da folha de pagamento de cada empresan este valor deve ser revertido em favor de seus empregadoss os comerciarios s Sáo contribuintes do SESC as empresas comerciais e de servicos, como os bares restaurantes" todo o comercio atacadista e varejista organizasces de turismo e hospitalidade, clubes esportivos empresas de comunicacho de publicidade e jornalisticas unidades de servicos de satcen imobiliariasy estabelecimentos particulares de ensinon entre outros A A arrecadaço féta pelo IAFAs que faz o mpasse ao SESC trimestralinente.

- Departanento Regional do SESI em Sa Faulon que obtemp de forma simetrica a SESC seus recursos dos industriats para beneficio dos industriários, conta com uma grande rede de serviços em decorrencia do desenvolvimento do parque industrial paulista. As unidades de atendimento do SESI de Saro Faulo estro distibutdas en cerca de 140 cidades, atuando nas area de educaco. saude. alimentaços esporten lazer e cultura fara tanton dispoe das seguintes unidades" aproximadamente 200 centros educacionais (educata infantily ensino de primeiro grau esupletivo) inajs de 60 ambulatorios medicos; com atendimento policlinico e postos odontologicos: 22 centros esportivos que tamber desenvolvem recreaço atividades intelectuas e sociais e dois teatros com

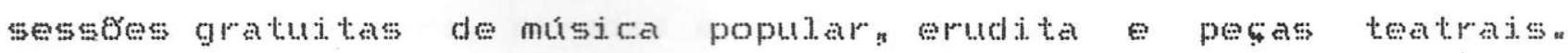
Esses numeros evidencian que o SEST dedica se as areas de exucho e sacie com major enfase que o sEsc que se incijna ao lazer.

\subsection{Arquitetura: Restauraçăo e Construçăo}

o trabaliho de restauraçăo iniciou-se com o levantamento do conjunto, tendo se medido parede por paredey os chás, janelas. jardinse telhados " para que a equipe pudesse conhecer a fundo a construcso de 40 anoss atras. A fase dos desenhos contou com alguns que foram sridos ate no proprio locat a sua execuço se reatizou com o acompanhamento constante dos arquitetos. 
Fara conservar o estito ingles da fabrican decidiume preservar as alvenarias e as estruturass unindo a isso o concreto aparente que da o toque contemportineo a obra fis paredesa antes cobertas por reboque e cal y tiveram a argamassa descascada a mán foram raspadas com talhadeira e receberan aplicacoes de iatos de areiag os tijolos avariados foram trocados por outros somente encontrados em demoliches de casas antigas pois sao mais pesados e apresentam una cor e textura diferentes dos atuais. Todas as paredes internas e externas ficaram com os tijolos aparentes m monos; os escritorioss que tem as paredess revestidas e os dois andares das oficinasy com paredes chapiscadas.

As tesouras e traves que se cruzam no madeiramento de sustentacko do telhado foram mantidas apresentando a armatho classica do perfid industriat de telhados simotricos e sobre elas foram colocadas em varios pontos telhas de vidro para ciarear o ambiente. As telhas francesas foran retiradas lixadas lavadas una a uma com jatos d'água e novamente colocadas quando se fex necessario foram trocadas porem as telhas novas nem sempres se encaixavan com as velhas, resultando en goteiras.

Nas vigas e pilares originais de concreto tamber foi tirado o acabamento exterior: mostrando-se a antiga tecnica empregacla $A$ construço assim despida apareceu entáco com sus partes originats mantidas "estrutura paredes cobertura.

Os acrescimos arquitetonicos buscaran patentear a intervenço servindowe da mais simples tecnica contemportinea e evitando o rebuscamento conceitual. Os concretos saco brutos " imediatanente diferenciaveis das colunas e vigas originats tendo sido utilizados nas paredes divisorias dos ateliers; nas galerias do teatro nos espaços de leitura da biblioteca. Frocuroums nas soluçes arquitetonicas sempre respeitar o carater simpless e tosco da fabrica, usando-se portas de madeira lavada luminarias de ferro (panelas pintadas deverde ebanco) edeixando todos os canos a mostran. 
Esta tubulacá aparente evitou cortes nas parectes de tijolos e possibilita facil manutenço As cores utilizadas distinguem suas funcoes que säo as seguntes: vermelho para esgoto incendion amarejo para o som ambienten azul. para a eletricidaden verde para a agua e os fios telefonicos correm por condutores laranjan No setor de escritorios, o preto determina o sistema de emergencia de luzes e prata o ar condicionado.

Os paraleleppedos originais foram levantados e novamente assentados na terra em substituiço a areia que os firmavan para que o mato pudesse crescer entre as frestas as canaletas para escoamento de água na rua central foram feitas de concireto avenariag e depois revestidas de seixosn

Ass tecnicas usadas tambern estáo a vista na obra de marcenarian como no caso dos portoes dos galpóes, de cabretiva macisa ș simpless envernizados "sem acabamento sofisticado ou polimentos n Fodewse dizer que os materiais estão nus, e toda a parte referente k madeira foi trabalhada dentro da propria fabrica. Lina bo fardi. projetou os moveis do teatro, do restaurante e da area de convivencia em madeira clara, vinda do farana como o finus Eldioti. e o Araucaria Brasilienses que, segundo diz, os brasileiros valorizam pouco. 0 sistema de treliçs e utilizado em todas as janelas externas: ern biombos de separaça e nas grandes portas divisoriass principalmente no teatro.

Os espaçs que foram restaurados pela arquiteta se distribuem em gapoes ao longo da rua centrat interna que se inicia na calsada da rua clebia e termina na area do conjunto esportivo. Descendowse essa rua do lado direito esta localizados os seguintes setores: un hall. de entradas onde esta a portaria tenclo ao seu final una sal para a assessoria de jomprensa en subincome por uma pequena escadan os escritorios da administracóo e de parte do corpo tecnicon com salas pintadas de amarelo forten portas bem como todas as madeiras, na cor azul marinhoi a area de convivencian o teatro" separado do teatro por uma rua interna transversaly o gatpa com as oficinas de coriatividade ou ateliersn 
Do outro lado da rua central ha un refeitorjo e acima deste um vestiario para funcionárioss com a garagem ao lado do conjuntọ̣ aposs o canteiro com arbustos; onde esta o totem indicativo dos; setores. e una pequena area cimentada que se chamou de praca do forno, ha a cozinha o restaurante e a cafeteria num mesmo bloco. que esta em frente ao galpa da convivencia a teatro o setor de manutenço com sua marcenarian depósitos almoxarifado localiza... se defronte ds ofitinasis „ 1 )

o espaço de convivencia tem sua área de 4 .700 me abertan sem paredes divisorias p procurando estimular o convivio Fensou-sem num intercabio coletivo facilitado pela horizontalidades aldm de propiciar maior polivalencia e mais facjl manutenghon "Wxo separanos as atividades por salas, salinhas e andares, como habituamentese faz. Integramos os ambientes para que as pessoas se movimentem como se estivessem numa praça pubilican numa rua mu ma comunidade mesmo"s explicou a arquiteta. o piso foi. feito com pedras Goiks e ha um espelho d'água de formato ameboide que segundo Lina Bo Bardin "é uma espécie de rio sao Francisco aqui. dentro servindo de traço de uniso entre areas de funcoss diferentes" " o funcionamento se da por intermedio de bomba de circulaço so suatrutura e de concreto aparentes com seixos de Uberlation em seu leiton

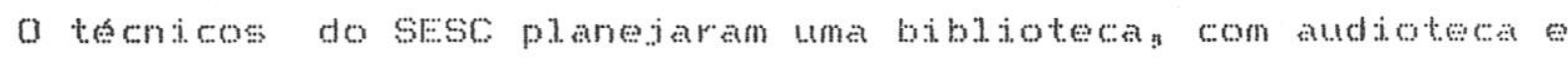
varias outras atividades a a arquteta dispos no espaco seis a a jes de concreto" com bases quadradas e suspensas erm un primeiro nivet. para lejtura, sejs lajes de concreto com bases retangulares que estao acima das de lejtura e foram concebidas para iogos " Ma parede lateral direita da area de convivencia estao localizados os banheirose o centro de criatividade infantila uma grande sala de formato irregular " assoalhada por tabuas de iatoba sobre placas de isopor" para amortecer o impacton

\footnotetext{
(2)a planta apresentada refere-se ao inlcio de funcionanento da fabrica, tendo havido udangas posteriores, cono o local da matricula.
} 

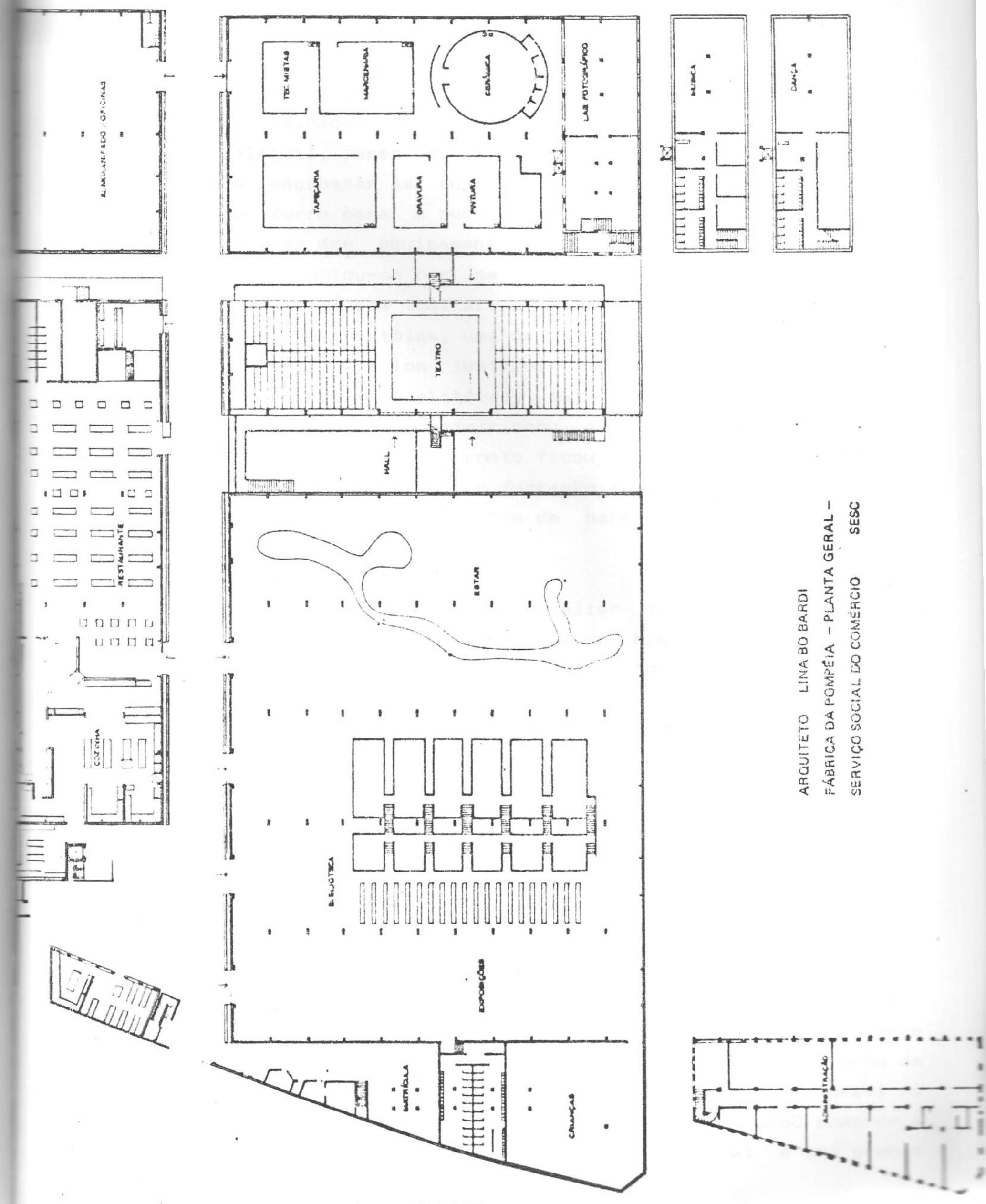
o teatro foi instalado onde havia uma linha de montagen do geladeiras; tendo sido todo construfdon mantendo-se apenas as tesouras do telhado. Fara o engenheiro luis octavio de Carvalho tudo fol dificils porem o teatro foi o mais trabalhoson pois tiveram que engrossar as colunas para fazer as galerias e colocar reforços de ferro para a sustentaço das tesourass que deverian suportar o peso dos equipamentos tecnicos e da tubulaço do ar condicionado. optoume por se realizar un teatro diferente que propiciasse espetaculos teatrais alternativos e shows musicais seu espaço possui duas plateias; uma de frente a outra tendo ao meio o palco formado por modulos justapostos e as galerias laterais de concreto que unem as plateiss totalizando 800 lugares.

carpinteiro chican que confeccionou as cadeiras valoriza muto este trabaho: "Depois de pronto ficou muto bonto. Gracks a Deus, conseguimos vencer". A forraço acustica foi reatizacla com la de vidroe as portas dispoem de barras de fechaduras anti-patnicon

No espaso das oficinas cada atelier foi delimitado por uma parede de 2 metros de alura feita de blocos de concireto com armas de 40 a 100 man sendo o chaso de cimento salpicado de seixos. o antigo monta-cargas foi substitufo por um elevador que dat acesso a dois andares: en cada un deles ha banheiros n uma sala grande outras menoress cujo assoalho de tabuas de ratoba.

O restaurante foi calcado com lajotas de ceramica e as paredes de separacán da cozinha para o sala esto rovestidas de azulejos especialinente concebidos: completadas por enormess vidros que permitem a visazo da cozinha industrial.

A torre da caixa dagua formada por aneis de concreto. necessitou da invenço de un novo sistema de andaimes cue subia internamente pelos seus setenta inetros de altura. Esta torre tornou-se o simbolo do SESC Fabrica da forpeia en num desenho de Lina ko kardin o representada por una chamine exalando filores; as verdadeiras chamines haviam sido demolidas antes do SESC comprar a fabrican outra imagem intimanente ligada no local é una grande 
carranca, escultura feita por artesaos de firapora em madeira de tamborit e pesando 3 toneladas que fica olhando para os visitantes que se aproximan do balcro de informaçes.

A arquiteta usou alguns poucos elementos decorativos: como os azulejose tapecarias reunidos no restauranten sendo que seu trabatho tamben se distingue por uma especial atencto aos pisos. Os azulejos foran concebidos por Fubens Gershman e trazern follhas de bananeiras alusivas a natureza brasileira nas cores amarejo azul. 1embrando os azulejos coloniais portugueses: l..ina Bo Bardi dejxou que seus operários escolhessem as combinacoes aplicassem os azulejos de modo aleatorion resultando jnesperados efeitos de compositaro. Tamberm pernitiu que os operarios que cimentavan o galparo das oficinas dosassem os seixos espalhados pelo piso! no chao dos banheiros foram aplicados cacos e azulejos de cores vivas e variadas, usados na mesma tradiço dos cacos de mámore romanos.

Ass tesouras do restaurante sustentan tecidos en tear e tapecarias feitos em ponto "kilim" com fibras tingidas com corantes naturais, tendo sido trabalhados por mais de dois anos pelo artista mineiro Edmar de Almeidan Os uniformes dos funcionarios tambern foram cuidados pela arquiteda que explicava "Os tecidos sáo o brime o gabardine muto frescose leves. Serventes e faxineiros usarăo un dolmă nordestino de algodá com avental tipo chiness. calsa e camiseta para ofrio. Na cabeça un Iencovermelho botas de couro cru. Tudo praticon boniton popular"

o verde teve tamberm o seu lugary aparecendo en um pequeno jardim suspenso sobre uma caixa d'agua localizada acima do galparo de convivenciag no canteiro com arbustos logo na entrada e ern uma area gramada e com flores violaceas que podeser vista pelos que sobem a administracko. Lina ko kardi. sempre insistiu em que a rua central fosse molhada para nascer a graminha e as flores ininusculas por entre os paralelepipedosy e pendurava floredras feitas com velhas latas cortadas repletas de plantas bem brasiledirasy cono a espada de saro torge. 
Contando com una area inicial de 11.000 man o conjunto esportivo teve sua construço iniciata no final de $1982 a$ a constituldo por un dectin dois prédios para práticas esportivas diversas, a caixa d'apua e uma cascata artificialn o dect: um ripado de madeira que cruza toda a area esportiva e estás sobre un veio d'agua que a prefeitura năo deixou soterrarg sendo utilizado como solarium neste espaço já se realizaram alguns shows com grandes nomes da mús.ica popular brasileiran

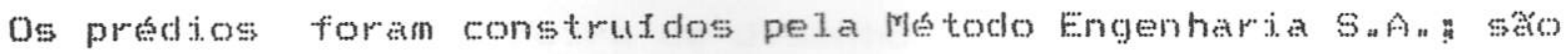
dois enormes blocos de concreto aparente interligados por quatro nfveiss de passarelas -- cada um deles apresentando diferentess 1.igacoes -... que levam aos quatro ginasios poliesportivos n oredio da esquerda 6 mats largo mais baixo e possui cinco pavimentos 0 primeiro a a piscina aquecida (com a dimensáo de $20 \times 30 \mathrm{~m}$ e uma profundidade variavel. entre 0,60 e $1,50 \mathrm{~m}$ ) g que foi forrada com azulejos concebidos por Fubens Gershman (um peixe vermelho em companhia de una estrtia do mar azul). Acima da piscina estacos quatro ginasios n batizados com os nomes das estackes do ano e com as marcacoss das quadras en cores correspondentes (pela ordem" Frimaveramuticor: Veracomes quentes outonomarrom laranda Invernowbancon prata ecinza). o ginasio Frimaveran que primeiro, term una quadra longitudinat con arquibancada, os outros tress duas quadras transversajs para se chegar a elos deverse subir de elevador pelo outro predio. Este possui a alem dos dois elevadores, una escada espiral erm seu joterior e outra externa abriga una lanchonete os vestiarios pequenas salas de ginatica - dança A cada dois de seus andares corresponde um ginasio do prédio da esquerda.

A diferente arquitetura assimilando-se a silos torres que caracteriza o conjunto alude - segundo a arquiteta Lina Bo Bardi. aos Castelos da Umbrian na Italian eas construçeses inglesas dos primordios da revolugáno industrial. 


\subsection{Realizaçôes do CLSFP}

Nos aureos tempos do ClofFy de meados de 1982 a meados de 1984, todos os seus espacos oferectam atividaces culturats que se caracterizaran pela diversidaden Dentre elas podewse citar: destile de Andre Courreges (setembro de 1982) " "T. Encontro nacional. da terceira idade" (setembro de 1982) " comeco do fin do mundo" (Festival. Funk com bandas paulistas de rock pesado -.- outubro de

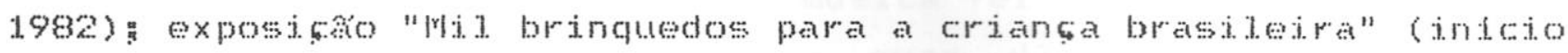
en dezmbro de 1.982) "Feim de desenho animado" (mostra e oficina - março de 1983)" "Semana do fndio" (cheres indtgemas discutindo sobre terras - abrit de 1983) " 60 anos de radido" (mostar de equipanentos e baile com cantores do radio -.. abrit de 1903 ) "Encontros com a cultura portuguesa" (artes comidas roupas festas -... junho de 1983) "Festa new wave" (some animaston com a escolha do oculos mais chocante da noite - julno de 1963$)$ exposiço "Finocchio a... a historia de um boneco jtaliano" (indeio m agosto de 1985)! exposiço de peixes (com repteis peixes curiosos -novembro de 1983)! langamento do discowabum "Folonatises" (com interpretacoes do pianista Arthur loreira Lima -.- janeiro de 1984 ) "Festival gastronomico da cidade" (concurso de pizas maro de 1.984): ciclos de conferencias da sociedade Brasileira para o Frogresso da ciencia -.- skF (março de 1984) a exposicho "Caipiras (capiaus: pau a pique" (intecio erm junho de 1984).

Autores de livros esportivos" polsticose cut turats langaran

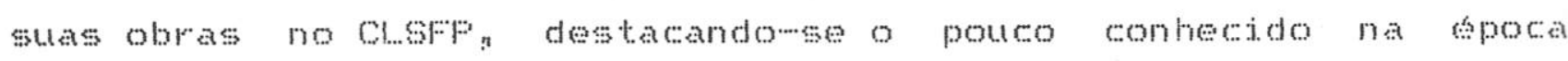
Marcelo Fubens Favan com seu "Feliz Ano velho" p Teotonio Videla com o livro "Frojeto Energencia" "sendo que nesta noite onoo pessoas se reuniran para assistir aos debates. Wa rua centrat eram armadas barracas para fejras -- entre elas as alternativas (com produtos naturats roupase objetos artesanass a as de troca infantil. (de diflicil desenvolvimento "dada a constante interferencia dos pass) - eparastas as mais variacis " 
Certas presenças; tornaramse constantes na fábrican o teatro recebeu algumas vezes os grupos cariocas "Asdrubat trouxe o trombone" e "ranhas e manias" que alén dos espetaculos fizeram oficinas de preparaço de atoresa na dança Ivaldo bertazo escolhera o novo palco para lancar as pesas protagonizadas pelos seus alunos: e sempre un dos interpretes (Arrigo barnaber Itamar Assunçaso) ou dos coniuntos (Fumo, Fremeditando o Breque) representantes da nova faço da musica feita en sao fauto estavam apresentando shows para nostrar suas uitimas criacess. Na choperian os grupos "Magazine" (musica popy com o fdolo Kid Vinit) e "Sossega l...en" (musica caribenha grupo formado para as festas do SESC Fompdia) eram "habitues" g as gafiejras de Frulo moura juntavarn mais de 2500 pessoas por noite. Alguns destes nomes frequentam o cl.sFr ate hoje mas naco com tanta assidudace.

Além das grandes mostras preparadas no espaço do galpáo de exposiçes; pelo menos tres atividades neste perfodo foram elaboradas por una boa parte da equipe que trabalhava no steso Fábrica da Fompeia, principalmente na area das oficinas.

A primeira delas ocorreu antess da inauguraço ofician pois com o cancelamento das duas uitimas semanas da peça "Filhos do silencio" no teatro abriumse a possibilidade de se trabalhar linguagens experimentais: o que resultou na primeira atividade do centro totalinente criada e executada pela equipe de animadorese

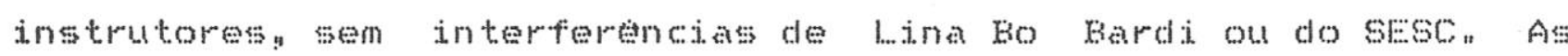
"1.4 noites de performances" ocorreran de 12 a as de jultho de 1982, reunindo mais de vinte grupos de artistas ligados a vangurda $e$ experimentaço; que levaram 300 pessisos por not te do teatro da fabrica: a abertura coube a Fatricio esisson apresentando-se depois concertos de musica eletro-matistican as esculturas sonoras de l.eon Ferrari, trabalnos integrados dos ateliers de fotografiay dansas musica tipografia da fabrican o grupo argentino "Talier de investigationes teatrales" e outras atraçes sendo a finalizacko a cargo de Ivald Granaton artista plastico tido como o precursor da performance no krasil. 
A segunda atuacto coletiva foi a "odisseba na Fomperia" projeto de forias desenvolvido de 3 a 24 de janeiro de 1983 inter igando todas as oficinas numa unica propostan "A terra chata "entao vamos construir um planeta mais interessante" "Var ias etapas se sucederam, vivenciando-se o caos (instrumentos sonoros: manuseados conforme sensaçes produzidas por meio de cores)" procurandowse o desbloqueio e o relaxamento do corpo (experiencias dos corpos pintados e enlameados), conhecendowse espacos (exploraso de labirintos) e recebendowse as majs diversas sensagoess físicas, sendo que o laboratório terminou numa conversa ao redor de uma foguedira quando foi queinado todo o lixo acumuado das diversas experithciasn Em seguidan veio a fase de criatividade: na qual se montou um teatro de sombrs com experitncias de luz e cores, es depois de mutas discussoss, os participantes acabaran se dividindo em quatro grandes gruposs"

0 projeto envolveu os 28 instrutores da fabrica 240 participantes (con idades variando de 14 a 60 anos "sendo a maioria da periferia) : que se reuniram nas noites de segunda a sexta-reira e participaram ao final da festa de encerramento que aconteceu na Fraça da Fepubitica en frente a Colégio Caetano de campos num sabadon dia 5 de fevereiron pela manha o resultado naro foi como se esperava de cenarios extraterrenos naves espaciajs ou bonecos marcianos: acontecendo que cada um dos grupos desenvolveu uma forma para condenser suas ideias: a geodesia cespeite de colmeiay representando un planeta onde o apelo fosse a vida comunturiag como a das abejhas), que era enorme acabou náso dando mujo certo o barco (Jembrando as viagens de Uissses) a lagarta (stimbolo de una metanorfose ajo resultado era os proprios participantes) que lambia quen encontrasse pela frente: o draga (representante da vitalidade e da força), sendo que estas trtes estruturas eram moveis e circulavan pela praça A apresentacko, porern na no agradou ao jomalista Antonio Ooncalves filhon que escreveu na Folha de sao Fauto" "Construir un planeta aternativo no plano imaginario so poderia mesmo estar en fintima conexacom os maquiavedicos projetos de Lazer institucionalizado, cuja pretensagon em tidtima instincian e 
a de sublimar o desejo reativo do individuo ern fungsio de uma

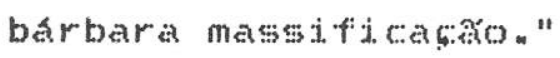

E o terexiro evento foi a reediço das "14 noites performances": que foram apresentadas de 1 a 14 de agoston em comemoraço ao primejo aniversario da fabrican desta vez a proposta baseava colaborasta dos instrutoros das oficinass e na animasaso de uma serje de mitos do imaginario ocidentala o cabares o bairo orientaly a festa a fantasian o ambiente dos cassinos dos circos o publico deveria vivenciar os diversos cidmas montados a cada

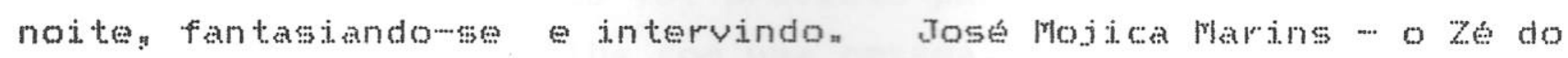
Caixo -..- profeta do terror primários abriu as noitom convidando todos a comparexerem vestidos de preto para sub corimcind de

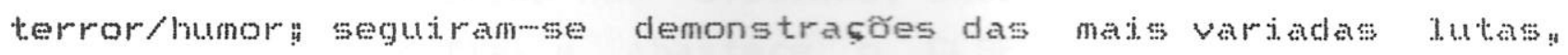
shows de i.lusionismo e magia, exibiçes de hatterofilitimo domadores de leoes hipnoticos tambores africanos sendo tudo

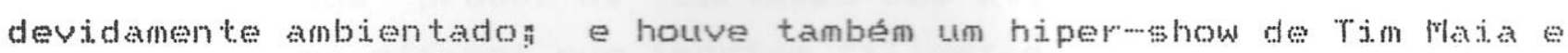
a exibiças en trits telas simultaneas, do ciassico "Napoleon" filmado por Abel. Gance en $1927=$

Alguns programas de televisao foram gravados no teatro do CLSFF" O "Fábrica do som" comecou a ser produzido em marso de 1983, chegando a levar por noite mats de 2000 pessoas aos

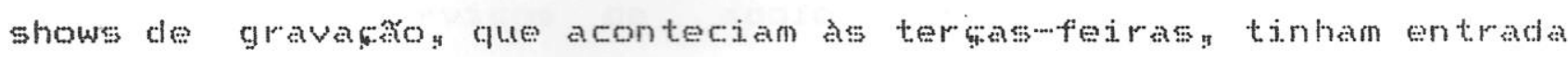
franca e eran comandados por Tadeu Tungle. Fiepresentava encuanto durou, (ate julho de 1984), o cinjec canal aberto do pats para toda una goraço de musicos e por isso recebeu uma larga gama de grupos

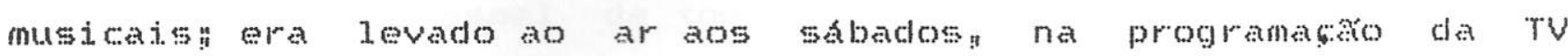
Culturan e suas gravaços tornaram-se pontos de encontro da categoriag sendo que la se podia contratar um interprete ou vender um instmunto. os outros dois progranas seguiran a linha sertanejä "Emporio brasileiro" apresentado por fiolando koldrin

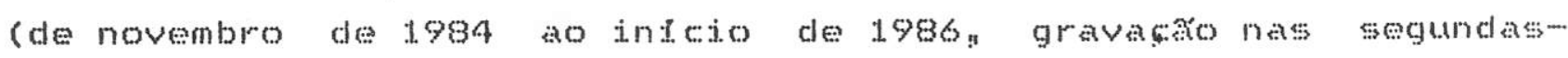
feiras indo a

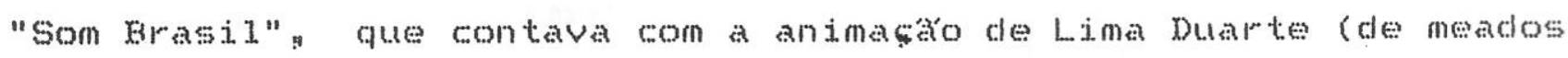


de 1936 a dezenbro de 1989, gravado as tersas wereiras, indo ao ar aos domingos de manha pela TV Globo).

\subsection{Divisôes do CLSFP (z)}

A Secretaria o responsavel pela receptáo e envio de toda correspondencia externa datilografa todos os of cios da unidade 0 gerente $\Leftrightarrow$ linico que tem autonomia para assinar un papel timbrado), cuida do arquivo de documentos administrativos recebidos e emitidos e faz o contato entre o CLSFF, o SESC Central e todas as unidades, informando e enviando os impressos para divulgar ass atividades. Tnicialmente foi previsto para o setor uma secretara geral mas hoje so trabalha com uma pessoa.

A Grafica funciona nas oficinas, onde era anteriormente o atelier de tipografian $e$ abastece o CLSFF de guase todos os impressos distribufdos pela unidade. Dispóe de uma impressora tipografican que produz os cartazes das atividades os avisos de uma maquina off-set que imprime filipetas convites "folhetose a programaça mensat.

\subsubsection{Coordenaçă das Atividades de Apoio e Administrativas}

Esta coordenaça realiza o trabalho de assistencia para a gerencia nos serviços de apoio (como o controle dos bens patrimoniais; a manutenço e a seguraņ̣a) e adminjstrativos s sendo este trabalho processado dentro de un sistema de contabilidade e orçamento subordinado ao SESC Central o qual reune os servictos de tesouraria de pessoal de todas as unidadess A coordenasta chefiada por Francisco Carlos Alves, que idealizou o seu sistema de funcionamenton e e composta por dez setores n num total de 58 funcionarios:

(2) O organograna do CLSFP está na página 146. 
A área de Servicos Administrativos tem a responsabilidade por todos os trabalhos feitos pelos setores, verificando se estat tudo correto no prazon aldm disso providencia as assinaturas para os pagamentos, elabora o orcamento programa estabelece os elos com a programaço a gerencia, faz os contatos com o SESC central.

Em 1.982 o substito do Cl..SFF ultrapassava os 80\% no noteio até se cogitou a cobrang̣a de ingressos para a entrada na fabrica " mas esta possibilidade foi logo rejeitada Hoje esta na módida $70 \%$ ao mes inclundowe os salários nos gastos a a receiten operacional do SESC Fomperia ven dos serviços de alimentaçon do setor de matricula dos cursos nas oficinase no predio esportivon e dos ingressos dos espetáculos do teatro. comenta subsidio que a fabrica recebe é permitido hoje porque consideranse como sua principal missão realizar atividades que levem o nome do SESC aOs mejos de comunicaça de massa.

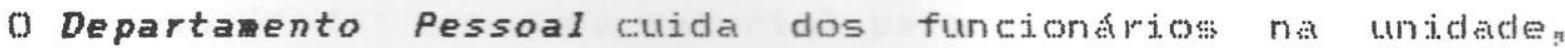
conferindo os cartöes de ponton intercedendo junto aos auxilios beneffoios previstos pelo SESC (assistencia medica cooperativas 1. cenças, adicional produtividade) e prestando as informaçes gerais, alem de preparar os documentos para a selectón de novos funcionarioss.

o setor de Tesouraria e Contas a Pagar verifica a natureza gestumbo dise despesas dentro dos controles ostabelecidos. cuidando para que esteja dentro das normas como a de náso u3.rapassar a autonomia do gerenten pois se isto acontecer fó necessario uma representaço solicitando o gasto ao diretor regionali, alem de processar e conferir todas as despesas de compras, pagamentos de serviços encargos . Esta parte cabe a Contas a Fagar que depois passa a documentaşo a tesourarian a qual faz o fluxo do pagamento atraves de chequess ou dinhejro e realiza a contabilizaça do que ocorreu diariamente no boletim de catixa finat. 
Flanejado para funcionar como uma auditoria interna do Cl..sF" o setor de Controle e custos faz o levantamento fisso dos bens patrimoniasis confere o almoxarifado, fiscaliza os cursos verifica se o que foi consunido compesponde aos tickets enitidos acompana os borderos do teatro festas e bailes" Alem disto apura os custos das atividades dos varios departamentos " confrontando-os com o previstoy e faz o acompanhamento diario das receitas o despesas da unidade.

- setor de Compras busca centralizar todas as compras da unidade! providenciando material para atividades manutensaso de equipamentos o os reparos necessários; a solicitaco of feita pelo setor interessado atraves de un formularjo de autorizasa para gastos, sendo realizada cotaça de preços quando a norma exigen quando a despesa ultrapassa a autonomia da unidade a compra 6 efetuada pelo slisc-wentral.

O Almoxarifado armazena material para todos os departamentos. excetuandowse generos alimenticios. Fornecen conforme requisticas material de expediente, de limpeza, de manutenças de espomtes de copa cozinha Ha um terminal de computador que controla este almoxarjardo $e$ o de generos, registrando entradasy satdas e as enissoses de pedidosn

0 controle da integridade de bens dentro da unjdade tre to pelo setor de Bens Patri ${ }^{\prime}$ niais que realiza periodicanente um inventario fis ico e faz a manutenço de todos os bens patrimoniats cadastrados da undade e tambem os de localizacto de uso (ferraments aparelnos telefonicos)" os bens jmobilizacios (que recebem uma chapinha como cadeiras mesas e maquinario pesado) sao comprados n cadastodos e numerados pela administracko centrat.

o setor de Manutencaso ajuda nas montagens requisitadas pei programaşo e faz a manutenço geral da unidade realizando servicos hidrulicosa eletricosn de pintura de carpintaria responsabididade de manter os elementos defindos por l...na ko bardi. cabe a este setor a comecar pelos movejs de laminado de pinho que 


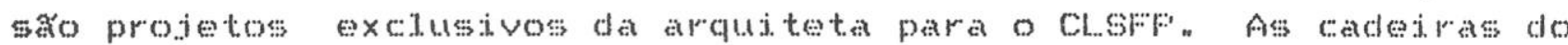
teatro saco periodicamente desmontadas para revisason poren os sofä e poltronas da convivencia estáo batante desgastados pelo uso e por serem deslocados quando o espaço gue ocupan fe requisitaco para a realizacto de atividades a firma do Faran que forneceu os laminados de pinho - os quais foram colados prensados na fabrica - fechou $e$ com a impossibilidade de reposiço acaba-se fazendo apenas reparos nas lonas r rasgadas e rabiscadas por canetasn o espelho d'agua da convivencia esvaziado conforme a necessidade de menovar a agua e limpar os seixos, as tubulaços sáso repintadas em suas coress e cuidase da preservaço das treliças e dos latoes de lixo e de cigaro (pintados de verde e de azuly respectivamenten apelidados de romeu e tulieta) que sao marcas caractersticas do SESC Fabrica da Fompeia están distribudos por toda a unidade mantem a lembranga do que era produzido na antiga fabrica da rabsa. A Manutenço tambem providencia os contratos acompanha a aço de firmas que prestam serviços ao Cloff nas areas de seguractan 1. impeza, ar condicionadon elevadores, refrigeraca e caldeirasn

A Matrfcula localiza-se num balcho em meio a area de convivencia e faz na hora as carteirinhas para os comerciarios cor azul) e usuarios (cor verde) com validade para um ano frara se matricular como comerciário é necessario apresentar a carteira de trabalino registrada por una empresa que faca a arrecadaço para o SESCy o portador da carteira é o titular e seus farili aress sao considerados dependentes. A pessoa ná ligada ao comercio que queira uma carteirinha (que permite a entracla no conjunto esportivo) pode obte-la pagando una taxa anual, valida apenas para - SESC Fabrica da Fompeian

o numero de carteirinhas feitas en um mes varia de 300 a 1200, sendo 80\% de comerciarios (50\% titulares e $30 \%$ dependentes) e o restante de Usuariosn O SESC ná exige numeracro das matriculas. porem o Cl.sFF a faz para melhor controlar a recedita gerada por e1. as . 
A Telefonia e Portaria prestan informacoses sobre a programaso do Cl..SFF e hat um balcáo de atendimento $10 g 0$ apos o portäo de entrada que dispose da programaşo do mesn

\subsubsection{Coordenaçă dos Serviços de Alimentaçăo}

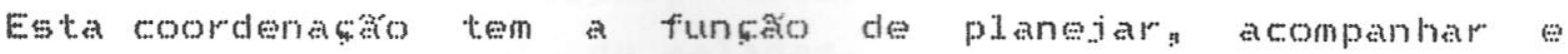
avaliar as atividades de alimentaçăo da unidade p providencitando o suprimento dos materiais necessarios e controlando sua utidizaşo. E chefiada por Helena Yoshico Matsui e divididerse em quatro setoress.

A Secretaria muda, principalmente, do arquivo da documentacko referente ao setor y como notas fiscais e comunicacos internas n

A Contabilidade exerce o controle interno referente ass atividades economicas e financeiras, e encaminha para pagamento at: notas fiscais dos pedidos dos generos e materiais. o controle verifica o numero de atendimentos, faz a avaliaço financeira (relaço receita e despesa) e elabora os mapas de venda e consumo diarioe mensal. o recebimento. a conferencia e a guarda do material de uso e de consumo cabem ao Almoxarifado de Generos "que atende as requisiches para todas as atividades do departanento faz o inventario semanal do estoque.

- Restaurante começou a funcionar en setembro de 1982 por ocasiăo do I Encontro Nacional de Idosos "E constitufto por um grande salá e atraves dos vidros que o separam da cozinha possivei. ver a preparaço da comida no equipanento industriat instalado sob grandes coifas azul-marinhon o mobiliarion construfdo com laminado de pinho base de concreto f formado por 1.9 mesas retangularess cada uma com lugar para 12 pessoas em 4 compridos bancos " localizadas perpendicularmente as paredes de ti.jolos: por 28 mesas quadradas com 4 cadedras, dispostas no centro do saläon que sáo removidas para os bailes noturnoss. 
0 sistema de atendimento कo de bandeja lisan com os pratos quentes servidos num badero de concreto e uma mesa de saldas "self-wervice" "Durante os primeiros meses de funcionamento havia varias opsess; com alimentos naturais e uma farta mesa de firios mas depois as refeicoes foram se restringindo a trivialidacie sendo diarianente servido un prato proteico (carnes bovinass aves" peixes) com arroz feijas acompanhado por refrigerante e sobremesa alem do buffet de saladas. o restaurante fica aberto durante duas horase meia no horario do almoşo e serve 450 refeiços por dia (sendo 180 para funcionários), havendo periodos de alta frequencia (clurante os congelamentos do plano cruzaclo) e de baixa, como atualmente ocorre. o frequentador náo matriculado paga $50 \%$ acima do preso de una refeiço para comerciario sendo que aos domingos e feriados os preços sao acrescidos em 40\%"

A Lanchonete do Conjunto Esportivo e formada por um balcko oval de concreto no seu centro, rodeado por assentos individuais tamberm de concreto. $e$ possui bancos de madeira fixos en toda a extensáo das suas paredes. Esta aberta durante 8 horas por dia apresenta un cardápio restrito "com poucos 1 tens de venda.

o restaurante fecha a tarde e o espaço reabre ao publico ass 19:00 horas cono choperia! servindo lanches aos funcionarios e sanduiches: porsoss" bebidas destiladas e chope a cilientela jovem que a frequentag a partir das 22 woo horas ha apresentacoes musicais" O Cafe/Bar esta num espaço anexo ao restaurante se seve refrigerante agua e cafe somente nos finais de semana. A Bowboniere 6 uma grande caxa vermelha de metal que quando aberta, mostra vitrines com bandejas arredondadas. l..ocalizawse no hall. do teatro e vende chocolates" balas e cigarros "os coqueteis de langamento de livros "as aberturas de exposichess os bailes sao considerados Projetos Especiais" 


\subsubsection{Coordenaçăo da Programaşăo}

A Secretaria cuida da comunicafó joterna e estabelece uma ponte com o servico administrativo para apoiar a producho cultural. Os funcionarios que cuidan dos recursos audiorvisuais pertencem a este setorn sendo necessaria solicitaço por escrito para montagem do equipanento de som a ser usado nas atividadesn

A Divulgacá \& o setor de assessoria de imprensa que envia aos meios de comunicaço a programaço cultural e esportiva do sias

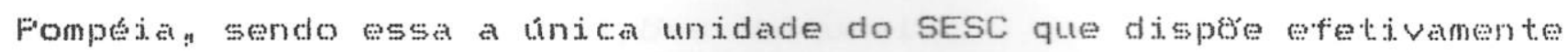
de un setor proprio de divulgato e năo recorre ao st:sc Central para o contato com a imprensan 0 seu trabalho consiste som obter as informaços dos responskeis pelas atividadesn elaborar os releases onvia- los as pessoas encarregadas que podem vir a fazer a

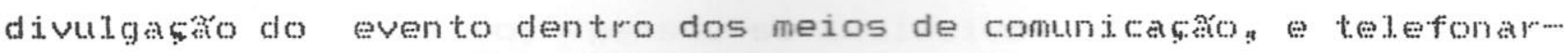
1.hes para insistir na cobertura = Segundo silvio Tareto.

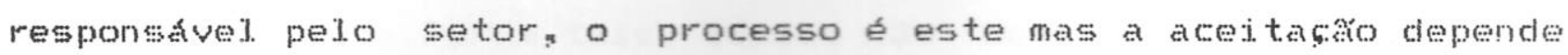
da qualidade do produto cultural. Comenta que o que mais se almeja no SESC Fompeia é o retorno na midia impressa cprincipalinente na Folha de Săo Faulo considerado o jornal da intelectualdade paulistana) e televisivạ o rádio, apesar de sua grande penetraçós $\Leftrightarrow$ pouco visado. Ha un arquivo com as atividados do stso Fompeia quen desde 1982, viraram noticia e os jornais sáo acompanhacos diariamente para mante-1o atualizado. 0 setor reciama equipampntos majs modernos, como un tele-faxy que possue um baixo custog havendo un telex apenas no si:.sc Central.

Alem do setor de divulgaços usase o recurso de contratar pessoas para distribuj cartazes e fi.jipetas ern locatis apropriacos e os convites normalmente no fornato de cartbes postajs. sás

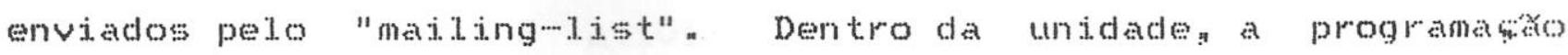
mensal e as filipetas sao distribuidas na portaria es fol hetos normalmentesaco encontrados nos locais das exposiçosen as faixas internas săo estendidas na rua central e no conjunto esportivon con chanadas para os eventos. 


\section{Area de Esportes}

A Area de Esportes e separada dos galpós por un portáo, sendo o acesso exclusivo para matriculados no sesci quando acontecen eventos como a Festa runina e projetos esportivos especiaisa a entrada e liberada a todos o porta dos fundos n que da para a avenida Fompeiag e raramente aberton o que ocorre somente quando ha necessidade de se separar o publico esportivo por ocasiá de alouma atividade especial nos galpoes culturais.

No infeio o nome do conjunto esportivo era "Centro de atividades corporais" pois a intençio foi a de se inovar na area" integrando-se a programaşo cultural já existente com a do novo departamento esportivo: pensouse inctusive ern ter aparelhos para aprendizado de praticas circenses. mas sem a preocupaço acadenica de una escola forem tais idedas na se conoretizarain havendo nesta direça apenas alguns eventos que hoje se desenvolvem esporadicanente.

A Area de Esportes e chefiada por Faulo Jose sajgado Fodrigues: e possue quatro setoress sendo que tres deles sa dedicados as atividades permanentes e atendem a un publico frequente e regutar.

o setor Esporte/Empresa assessora as empresas e os comerciarios matricutados, fazendo as reservas e locacoes das quadras para torneios e campeonatos.

Os Cursos de Técnicas Corporais abrangem nataço a esportes de quadra varias modalidades de ginastican danças e lutas a há tambem programas de mporte atividades fisicas e recreativas para a terceira idade e para jovens. A capacidade e de 2. 500 vagas y com

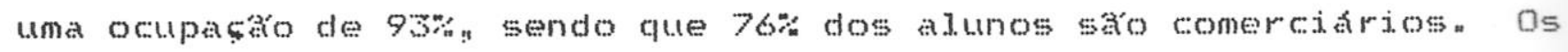
cursos mats procurados sa os de natakso com 1000 alunos ocupando todas as vagas seguindo-se os de ginastica com aparelhos e aerobica, que retinem 635 pessoas n Alguns professoress fazen locacao 
de espaçon cabendo ao SESC 20\% do que arrecadam em suas aulas n como \& o caso da Toga "Taj. Chi Chuan "Kung Fu e danças "Segundo Faulo salgado fiodrigues, ha bons profissionais que acabam recebencio poucon seus cursos năo podem ter um prȩ̣o muto acima daqueless orientados pelos instrutores do SESC, pois isto poderia desprestigiar a mäcomobra interna este limite financeiro foi um dos motivos que impediram os pretendidos cursos de vanguarda para corpo.

A prefertncia de escolha dos cursos cabe aos comerciariose as vagas restantes sa oferecidas aos usuarios na abertura das inscriços formam grandes filas, devido ao bajxo preço dos; cursos -.. Uma auta de Toga no SESC, por exemploy custa menos da metade do que se cobra numa academia. Nos horarios da manha da tarde sempre sobran algumas vagas, porem a noite todas as modalidades ficam completas. A renovaço das mentalidactes deve ser feita na primeira quinzena de cada mess e caso náo ocora a vaga passa a ser oferecida quando houver novas inscriçoes. os cursos saro dados na piscina, num dos ginasiosn e em quatro salas para ginastican danças e lutas, equipadas com espelhos: colchonetes, som e aparelhagens proprias" e localizadas do 80 ao 110 andar do predio da direita.

Ha uma enfermaria de plantáo para urgencias e obrigatorio o exame medico para o uso da piscina e frequencia nos cursos de tecnicas corporais.

A Recreaço Esportiva é feita na piscinan dividida por raiase flutuadores que delimitam espasos permanentes de recreacto e nos ginasios de esporte, sendo emprestado material esportivo para futebol de salaso volej. basquete e outros jogos, como malha" dardos, dama, ping wong e futebol de botăon No espaco da lanchonete sa realizadas exposiçess de fotografias nornalmente em convenio com a revista fracar, e exibidos programas de video.

0s Eventos ocorrem semestramente e procuran trazer alternativas de trabalho com o corpon sendo escolnidos os temase 
depois convidadas as pessoas para debates, aulas abertas demonstracoes. Săo tambon realizadas campanhas echucionats exposicoses cicios de video.

A area de esportes apresenta problemas desde sua inaugurato: sente-se a falta de sanitarios no decte solarium năo foi feito tratamento acustico nos predios, náo ha lugar para se guardar os materiais esportivos: nå ha bebedourose o concreto acentua as altase baixas temperaturas. Na área da piscina ha aloumas dificuldades: ná se tem uma ante-sala e sempre que a porta de acesso of aberta entra un forte ventog no verán com a grande frequencias aumenta-se a quantidade de produtos quimicos para combater os microorganismos, o que causa fortes irritaçes nos olhos e reactes al orgicas as belas portas originais de ferro foram logo corrofdas pelos vapores químicos, tendo sido trocadas por portas de aluminion e a parte elétrica tamberm sofre problemas causados pelos gaseş e ná ha aquecimento centrit as as resistencias dos chuveiros queimam devido ao uso exessivo. Mos ginasios ha vazamento de água por entre as lajess problema presente quando se lavam os pisos: os largos orificios irmeglares que funcionam como janelas eram totalmente abertos e depois colocaran... se trelicias para impedir a safda das bolas que tambem escapam pelas portas corrediçs de metal que abrem os ginasios (para a uti.izactio simutionea das quadras, foram montadas redes no sistema de cortinas). As escadas externas tem parapeitos baixos as escadas de metal internass em espiraly possuen pequeno espaso do circulaşon o que causa congestionamentos e riscos de acidentes.

\section{Area Socio Cultural}

A Area sociomoutural e dividida em tres setoresy destesn a Difusaro cultural subdivide-se en mais trets setores s sendo que o primeito deles. a Equipe de Animaşo bibljoteca. 
A Biblioteca do Cl.sfF foj planejada para aleanar certos objetivos y tendo sido reatizado un estudo posteriormente entregue a Lina ko sardi. para que a arquiteta se orientasse na adequacko dos espacos;

OFrojeto Fibiliotecas SESC, documento que procurava definir o funcionamento das bibliotecas de lazer nas unidades do SESC. afirma que a atuasco destas bibliotecas é expressa pela formula liazer sociomcultural" devendo se oferecer leituras rapidas ageis; 1 eves e fantasiosas que sáo as que os usuários procuram le turas menos 1.igadas as questos profissionais, escolares e sociais s sendo estas apropriadas as bibliotecas de pesquisa e consulta à quats as pessoas se dirigen por obrigacaro. Adianteg o documento diz que as bibliotecas de lazer deverian se caracterizar pela velocidade de

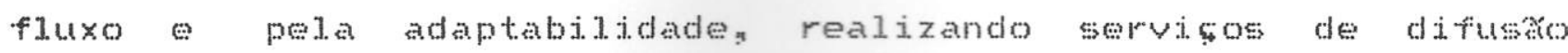
cultural mais dindinicos procurando cultivar o interesse amador para os mais Variados assuntos, mas serm estimular maiores tentativas de ordenamento cientifico e/ou academico. Os locais das bibliotecas deverian ser agradácis e repousantes possibilitando ao individuo seu afastamento do mundo das obrigaçess diarjas lhe dando a oportunidade do relaxamento e do prazer. o que significava colock-10 "en situagro de lazer" para tanto aconselhavase a oferecer, em lugar de livros, un acervo de consuno rapido. constitufdo de un grande numero de revistas jornats gibis outras publicacos atrantes e de caducanento eftmero, com carateristicas de passatempo ou veloz referencian

Ruanto a biblioteca do ClsFF" havia a preocupacao de que ela se tomasse un orgaro de apoio as oficinas a as tecnicos do proprio SESC, sendo especializada en artes e tamben possuindo livros da area esportiva pretendiase priorizar os livros novos aqueles gue demoram para aparecer nas bibliotecas publicas por problemas de processamentos tecnicos g contavawse com a assessoria de Frederico Wasser para a importasta de revistas. A biblioteca coube a Araty Feroni. que a acompanhou desce o planejamento de implantacaso ates o final de 1984: o projeto previa instalaçes de audio e video acoplados " com os suportes de informastes cobrindo, portanto, desde 
o grafico ate as ondas sonoras e magneticas sempre acompanhando o avanco tecnologico atuat. A audioteca iria dispor de uma sesto

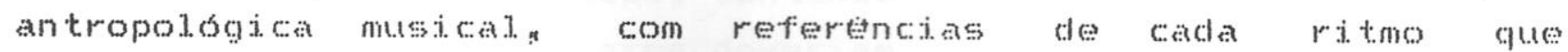
possibilitasse comparacao de linguagens, e pensavase em criar uma central. de informacos culturais da cidade de sáo faulon

o divreto que continha as linhas gerais da undocte referia-so a biblioteca da seguinte maneiraz "o atendimento informa o sentirwse en casa, o encontro de pequenos grupos de interessen o acesso as obras as vezes inacessiveis ao grande publicon esta é a grande tonica deste espaço gerador ilimitadon aberto as novas propostas s sugeridas pelos proprios usuariosn desde que atendam ats exigencias dos mesmos as de um laboratorio de pesquisas cul turaiss"

Fara atingir ostes objetivos, Lina ko kardi fe\% a biblioteca em moldes abertos" concebendo pequenas saletas semil isoladas as seis lajes de concreto suspensas, que funcionam como inhs des 1. i.tura tendo en seu interior una grande nesa de pinho, redonda comunitaria. For entre elas há escadas de acesso as lajes dos jogos de salan que possuem mesas pretas retangulares quadradas: estas lajes retangularos estao paralelanente dispostas as lajes de leitura em un nfvel superior de tal maneira que suas colunas delimitam uma galeria na qual foi instalado o setor de vadeon

As oficinas e o Frojeto Curumim pertencem a ultimo dos tress setores que respondem diretamente a Area sociomcultural. A instalaçon a compra de equipamentose materiatse os sistemas de animaço dos ateliers foram projetados com a colaboracho de especialistas que deverian continuar assessorando os trabajhos de implantasno dos diferentes cursos e atividadesn e desta parte

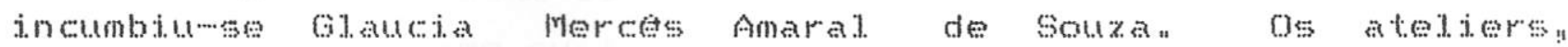
demarcados com paredes de blocos de concreto, eseus respectivos assessores foram os seguintes" ao lado esquerdo de quem entra no

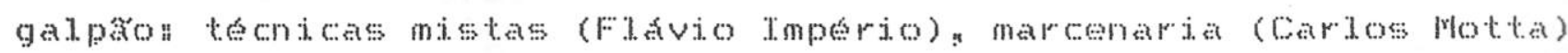

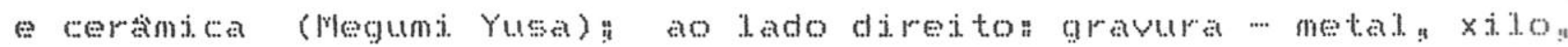
1. to -- e serigrafia (Evandro Carlos dardim), tapesaria e tecelagem 
(Edmar de Almeida) y desenho (Edmar de Almeida) e artes graficas (Frederico Masser) " o laboratorio fotografico foi instalado peia Kodat: numa sala dos fundoss contando com a assessoria de Luiss Hossaka e nos dois andares deverian funcionar musica (conraco

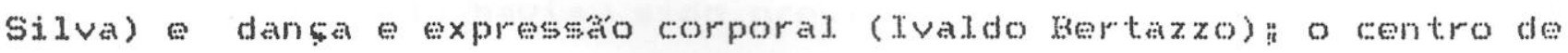
criatividade infantil., na area de convivencias coube a rlo Krugli. As oficinas foram inauguradas com aulas abertas para mostrar como funcionavam o que poderiam oferecer e a ideia era a de que atendessem zooo atunos por mess estando abertas nove horas por dian Forem o projeto das oficinas deveria ser subsidjado e o slisc nấ queria pagar o salario dos assessores, oferecendo- lhes o sistema de cessăo de local. Eles năo se interessaram pela proposta o os unicos que permaneceram ainda que por pouco tempon foram linturo Imperio e conrado silva procurando sistematizar ide ias para todo o espaço dos ateijers atraves da integraço de linguagens n

0 assessores indicaram instrutores-artistas para trabalharem nas oficinas, e mutos deles nato passaram pelo psicotecnico exigido pelo slesc os que foram admitidos em pouco tempo se revoltam contra o baixo pagamento que recebiam pois a instituiço os enquadrou da mesma forma que os demais instrutoreswhoristas das outras unidades n Mitas atividades da fabrica se apoiaram nos instrutores; que colaboravam principalmente nas montagens das exposiços tematicas sendo que as vezes recebiam allom pagamento extra. Quando Miguel Faladino esteve na chefia das oficinas, conseguituse una formula de melhorar o salarjo agregando se aldumas horas de pesquisa segundo eles as oficinas há podiam ser administradas visando se a uma receita.

Maquela fopoca eram oferecidos cursos de pequena duracán para permitir o fiuxo de pessoas, as atividades deverian ser sempre integradas convidavam - se artistas consagrados para as aulas abertas e insistia-se muto no fato de que as oficinas nato tinham a funçăo de formar profissionais. Miguel Faladino conta que em certa epoca Lina Bo fardi. pretendeu deixar de lado as atividacies artusticas e dar espaço as atividades tecnicisa as pequenas 
utilidades do cotidiano, com propostas de bricolage encadernaça on molduras.

Dentre as oficinas, a de tipografia tem uma historia peculiar, pois náo havia sido prevista foi preciso convencer a arquiteta a eliminar a sala de instrutores para dar espaço a ea chamava se inicialmente "Oficina de expressaco grafica" " e pejas idejas de Frederico Masser, deveria atender al necessidade individuat de expressáso e possibilitar que as pessoss se relacionassem de maneira mais consciente com todo o tipo de materiat. impresso e visuat. com que sáo bombardeadas diariamente. Isto atraves do fazer e do questionamento sem aulas teoricas. Umat boa parte dos equipamentos da tipografia vieram da grafica do SEMAC, fechada en 1981, tendo sido transferidos gaveteiros antigos com tipos de madeira chumbon e caixas de clichto da decada de bo. A oficina de tipografia dava aulas e imprimian atraves de suas

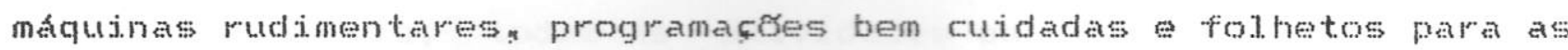
atividades com cores e formas criativas, que passavam sempre pelo crivo de Lina Bo Bardi. Hoje essa oficina năo dát mass aulas transformouse numa grafica mal aparelhada que imprime os informativos do CLSFF" tendo recebido uma pequena impressora ofi. set. -- comprada para auxiljar na epoca o candidato dose fapa dunjor - Uma máquina para dobrar os impressos.

- Iaboratorio fotografico SESC/Kodak demorou para iniciar suas atividades e durante o convenio a Kodak fornecia os produtos quimi-.cose consertava os oito ampliadoress profissionats em coress sendo esse un laboratorio línico na cidade em termos de equipamento para aprendizagenycom a quebra do convenion os ampliadores sáo usados apenas para preto e brancog porque para o trabalho a cores seriat necessario comprar os equipamentos e os reveladores e pagar um laboratorista profissionat "providencias que o $5 E S C$ ná guer toma.

Quanto aos dois andares das oficinas, havia um projeto de se acoplar un estudio a sala de musica, o que acabou náo sendo fed to devido ao preso dos equipanentos, as grandes salas foram utilizadas para ginatica, danga, taj-chi-chuan e outras praticas 
corporais enquanto o predio esportivo estava em construgro. Atualmente os andares săo usados para desenho com modelo vivon poiss essa atividade requer un ambiente fechado nas oficinas de baxo dificid. se obter concentraço, cursos de musica e atividaces da Terceira Idade e do Frojeto Curumin. Fretende-se a implantaço de un gabinete odontologico em todo o segundo andar.

As oficinas que ainda hoje se mantem nos lugares que 1 hess foram destinados saso a de marcenaria (que conta com equipamentos; semi profissionais) 9 a de cersmica (que possui trts fornos eletricos que atingen $1200^{\circ} \mathrm{C}$ e necessitam de muta manutenços a de tapesaria (que dispóe de 40 teares manuais) a a de gravura (com prensas de metal, pedras para litogravura e equipanento de serigrafia) "

En principiog todas as atividades para criansas geradas no CLSFF sao ligadas ao Projeto Curumi :

- SESC vem há muito realizando projetos infantił" como "Super-Ferias": "Cemeio" (Centro de Estudos do Meio)" "Mini-issporte" "Viva o Verde" "Frojoven" e outros. Frocurando sistematizaro atendimento as orianças nas várias unidades de que dispoe no estado de Sao Faulo" foi idealizado o frograma Integrado de Desenvolvimento Infanti.1 - FIDI. Esse projeto cuidadosamente elaborado: de infio estabelece a opço de contar com una citentela prioritaria constituda pelos filhos de comerciarios de renda mais modesta e pelos menores carentes. E frisado que se fugiu deliberadamente de una linha escolarizante pois, por importante que seja ela náse mostra consentanea com a vocaço institucional do SESC, cuja esfera de operaços se situa no dominio do tempo livre e da educasa ná formal. optou-se quando da aplitaço do projeto.

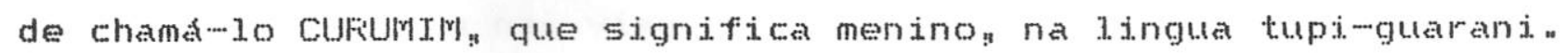

No CisfF o Curumion teve intcio en meados de 1987, tendo sido contratados doze instrutores para trabalhar com as criancas n Em jutho houve a inauguraça oficialn preparandowse uma grande festa com baloes, pipocass gincanas atividades nas oficinas" o bicho 
Faparofia, un ser surrealista imaginado por Tacus a autor de uin 1.juro sobre animas hibridos. Wa fase inicialy a coordenasoso do projeto foi dividida entre as oficinas e o conjunto esportivon mas agora esta subordinada a frea socio-cut tural.

Os grupos de frequencia regular no SESC Fompera trabalham atualmente com tres turmas de crianças de 7 a 9 anos o duas turmas de idades entre 10 e 12 anos, que se encontram nas tardes das tercas quartas e quintas feiras, durante os meses de março abril, maio, junho, agosto setembro, outubro e novembro" A partir dass 15:00 horas e servito o lanche, com um sanduicheg un refrigerante ou suco e una fruta ou yogurte. Cada turma de criansas recebe orientaçoss de una dupla de instrutoresy sendo un com formatro em educaço fistica e outro en artes. A definiço dos trabahos feita pelos instrutores: que procuram levantar os interesses aptidoes comuns entre as crianças de cada grupon

Alem das atividades com os grupos regulares, os instrutores do Curumim atondon as visitas de escolas as sextas feipas quando as crianças passeiam por todo o SESC Fompeiay olham as exposiçess participam de atividades variadas nas areas de artes e praticas esportivas sendo solicitada a presença dos professores para orientar a circulaço de suas crianças. Nos fins de semana o Curumim se abre para o publico visitanten e os instrutores atendem as crianças presentes no perfodo da tarde tentando relacionar as atividades com temas presentes en exposicoes ou eventos apresentados pela unidade. Na epoca das ferias, em julno

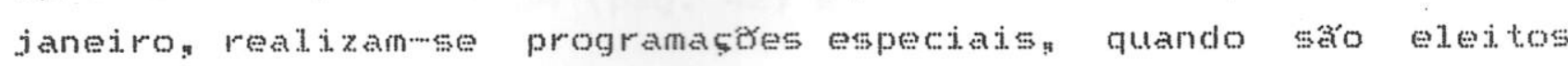
alguns temas especticos como ocorreu na simulacko de um programa de televisaron na escolha dos superwherois de historias em quadrinhos (cujas silhuetas recortadas e pintadas se espalharan pelass oficinas) ou na viagem a Lua com instalacoss espaciais e aparelhos estranhos.

As atividacies habituais dos grupos permanentes do curumin sào de recreaço aquatica, natacas jogos e brincadeiras esportivas e expressaco corporat, na area do conjunto esportivo para o programa 


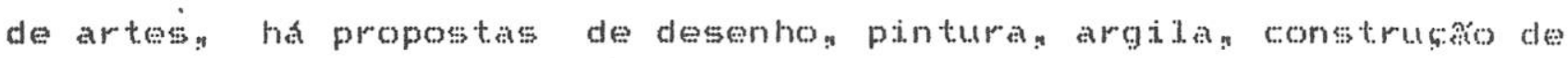
brinquedos, invenşo de historias e montagem de um teatro de

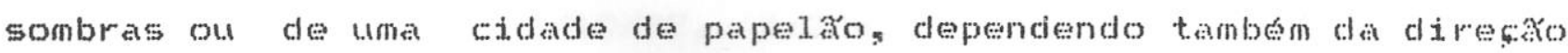

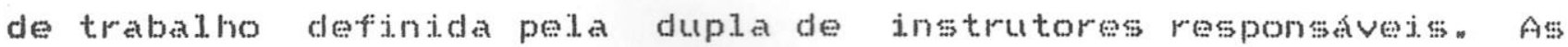

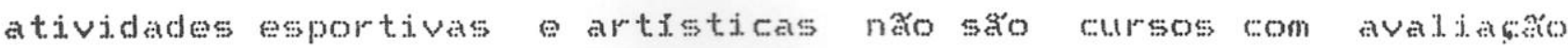
final, como pretendem alguns pais que alimentain a espectativa de un aprendizado mais formal. para seus filhosa ha uma festa para marcar o encerranento do semestre com mostra de trabalibos nas oficinas.

Inicialmente foran realizadas reunibes de esciarenimento com os pais. mas a frequencia era muito baixa e elas foram abandonadam. Os pais ou responsavejes deixam as criangas no local combinado para cada grupo e das $14 n 00$ as 17:30 horas elas estás sob a responsabilidade dos instrutores no final da tarde as pessoas retornam para encontra-las. Juitas das criangas residem nas imediaçes , jndo e voltando sozinhas.

\subsection{Entrevistas e Dados Bibliográficos}

\section{Revistas}

- Casa ciadudia junho/1982 (pag. 7)

- Interview - nr. 53 , setembro/1982

- Isto Eg 7/4/82(pgs. 43 e 44) e 29/9/82 (pgs . 48 a 50$)$ "

- Isto E/Senhor "29/8/84 (pag. 42) e 19/4/89 (pgs. 82 a 85)

- Veja, $14 / 4 / 82$ (pgs. 126 a 129) e 10/11/82 (pag. 89)

\section{Jornais}

- Diario Fopular -... dian $27 / 11 / 84$. 
- 0 Estado de são Faulo - diasa 22/1/82, $20 / 6 / 82,10 / 07 / 82$, $25 / 7 / 82,19 / 8 / 82, \quad 28 / 10 / 82, \quad 5 / 2 / 83, \quad 7 / 8 / 83,19 / 9 / 83, \quad 9 / 9 / 84$, $9 / 4 / 89$.

-... Fin de Semana - dia: $5 / 6 / 82$.

- Folha de Sao Faulo -- dias: 4/1/82, $28 / 1 / 82,11 / 4 / 82,12 / 7 / 82$, $18 / 7 / 82,23 / 7 / 82, \quad 19 / 8 / 82, \quad 14 / 11 / 82,7 / 2 / 83,7 / 8 / 83,1 / 7 / 84$, $9 / 10 / 84$.

- Folha da Tarde - dias: 12/4/82, $26 / 7 / 82,28 / 7 / 83,18 / 8 / 84$ "

- Gazeta Esportiva - dia: $20 / 3 / 81$.

- Gazeta da Lapa - dias: 17/4/82 e 24/4/82.

- o Globo - dian $6 / 7 / 32$ n

- Jornal Faulista - dian $23 / 3 / 82$.

- Jornal. da Lapa - dia 17/4/82.

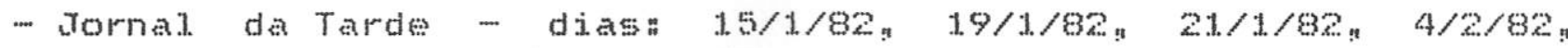
12/4/82, 8/5/82, 10/7/82, $27 / 7 / 82, \quad 19 / 8 / 82, \quad 13 / 9 / 82,4 / 1 / 83$, $11 / 1 / 83,7 / 2 / 83,2 / 5 / 83 ; 23 / 7 / 83 n$

- Metro News - dia: 19/7/82.

- Noticias Fopulares - dia: $31 / 3 / 82$.

- Fede Faulista de Jornais -.. dian $6 / 2 / 82$.

\section{Folhetos e Publicagres do SESC}

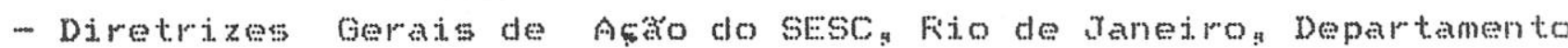
Nacional, 1973.

- Fequixa, Fento -..- Lazer e Aço Comunitarian Sáo Faulon SESC, 1973. 
- Dumazedier: Jofife -- Flanejamento de Lazer no Erasila A Teoria Sociologica da Decisáo (tradn de Fiegina Maria Viejra) săo Faulo. SESC - Celazer, 1980 .

- Centro de Lazer SESC Fabrica da Fompeia , 1.982.

- Cl.sFF - Linhas Gerais da Unidade (distribuiço interna) "1983.

- Gongalves da Gilvag Osvaldo - "Vinte e Cinco Anos de rrabalho Fioneiro" in Fevista da Terceira Idade, SESC - DFSF, 1983.

- Arquitetura para o lazer e a educaçon SESC - Sá Faulo 1989.

- Frogramasa 1.98\% "SESC - Sáo Faulo 1989.

\section{Textos do SESC}

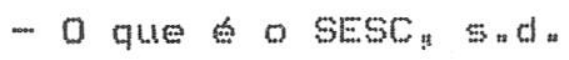

- O SESC - Origens / Frogramas / Organizaçăo \$ \$.

- Frojeto Bibliotecas, SESC - Sao Faulo, 1981.

- Frograma Tntegrado de Desenvolvimento Infantil - FIDI 1986.

- Ferfil do Frequentador do SESC (estudo feito sobre a cidade de Sa Faulo) " Gertncia de Estudos e Desenvolvimento - Gedes: SESC Saัo Faulo! 1986 .

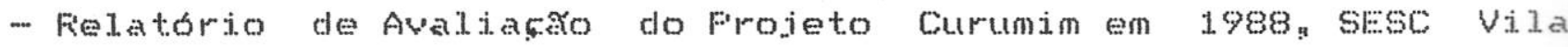
Novan.

- Cultura e Historia do SESC, estudo de Dirceu Noguedra Wagaháas, Fito de Janeiro, 1988.

- Relatório Anual "SESC - Sao Faulo, 1989. 


\section{Estudos sobre o SESC fabrica da Ponpeia}

\section{- Sobre a Restauracao}

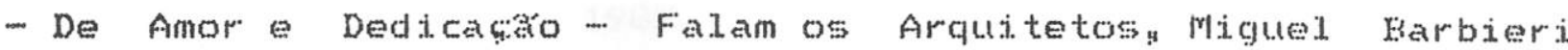
Junior: $s$ d.

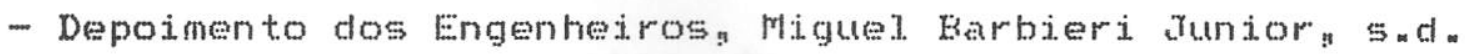

- Depoimento dos Operários niaul Viana de Camargon sonn

- Texto sobre a construçáco da fábrica da Mauser. 5 al.

- Texto sobre a preservaço da fabrica da Fompeia a son

\section{- Celazer}

- Caracteristicas da oferta cultural do Fompeian Máto Damineit. $\mathrm{S}, \mathrm{d}$.

- Falestra sobre o SESC Fabrica da Fompeia Tofre Dumadider.

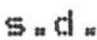

- Quo Vadis "Fompeia? Erivel to Eusto Garcian 5 n.

- Sugestoes para a programago da fompeia gesus Vasquez fereira. 1981."

- A Tradigo Inovadora Erivel to Eusto Garcia "s,

- Uma Fabrica um Marco Cultural, Ërivelto Busto Garcian son

\section{- Gerais}

- Notas sobre as intenctes operacionais do CCD Fompeia, 1981.

- Felatorio do trabalo da comissá de programaço do SESC Fábica da Fompeía, 1982. 


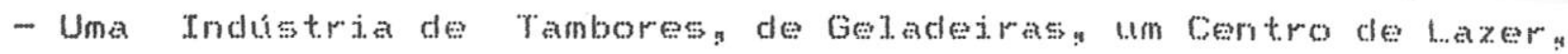
uma Fabrica de Sonhos: 1982.

- Conjunto Esportivo - relatorio de equipamentos servicos do apoio, e programasan $198 \%$ "

- Flano de Frogramasa SESC Fompeia 1990.

- Fesquisas semanats sobre frequencia no clofF" referente aos meses de fevereiro, maio junho de 1990.

\section{- Entrevistas a Funcionarios do CLSFP}

(todas realizadas durante o ano de 1.990)

... Adenor Serranoy Argemiro de Souza Neto e Welington Wagner Andrade - programadores do teatro da choperian of (5/mato)

- Alexandre Suardi. Neto - segurança do teatron OAma (22/junho)

- Antonio Carlos Moraes Frado - coordenador da programa (28/junho)

- Araty Feroni.-. chefe da area de convivencian (2\%junho)

- Eenedito Rocha do Nascimento Filho -.. responsavel peia matricula, CAm (12/junho)

- Dendse Martha - programadora do setor de videon of (so/junho)

- Domingos Barbosa da Focha - gerente do ClofF (29/junho)

- Fabio Malavoglia -- coordenador da programagro de 1982 a 1984 (26/abr.i.1.)

-.- Francisco Carlos Alves - coodenador das atividades de apoio e adininistrativas ( $3 /$ iutho)

-.. Helena Yoshiko Matsui. -. coordenadora dos servichos do a 1. imentasaco $(9 /$ junho) 
- Irene Marques D'Avila - chefe da biblioteca e responsavel. pela Terceira Idade, $C F(9 /$ junho)

- Lucia Vianna Lacourt - instrutora do Frojeto Curumimn CF ( $5 /$ ianeiro)

- Luiz Carjos Zanoli. - diretor do Cl.sFF de setembro de 1980 a julho de $198 \%$ e de outubro de 1985 a agosto de 1986 , (23/julho)

- Miguel. Angel Faladino - responsável pelas oficinas e exposicoss tematicas de 1982 a 1984 (17/maio)

- Newton oliveira cunha - chefe do setor das oficinas: cF (26/maio)

- Paulo Tose Salgado Fodrigues - chefe da Area de Esportes CF (27/junho)

- Silvio Taretto -- chefe do setor de divulgackon CF (9/junho)

- Vera Albuquerque -- professora do laboratorio fotografico, cF (19/maio) 


\section{BIBLIOGRAFIA}

- ANZTEU: DTDIEF El grupo y el inconsciente: lo imaginario grupal (traduccion de Sofia Vidaurazaga), Madrid biblioteca Nuova! 1986.

.... ANZTEU, DIDTEF (org.) Psicoanalisis del genio creador (trachceion de Manue l. Lamana), Buenos Aires, Editorial. Vancu, 1978,

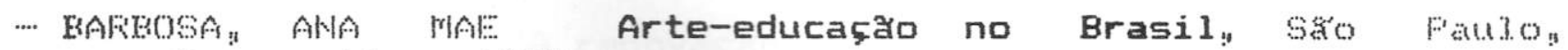
Ferspectiva, 1978.

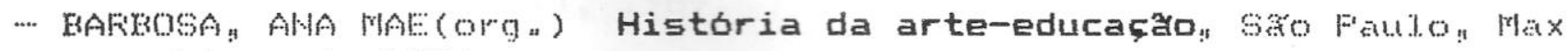
L...inonad, 1.986.

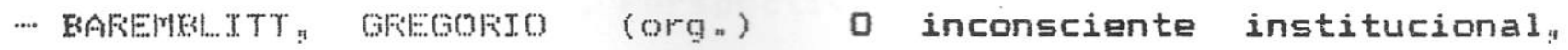
Fetrópolis , Vozes, 1984 .

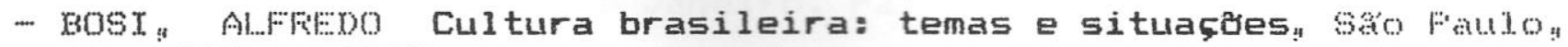
At.ican 198\%"

- BFANDAO CAFl...S FODFTCUES (orgn) o educador vida e morte "Fio de Taneiro: lidicoses Grat; 1985.

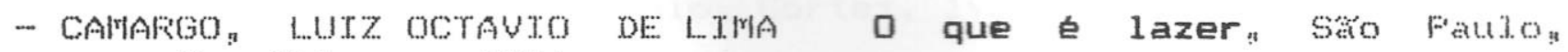
Brasiliense "1986"

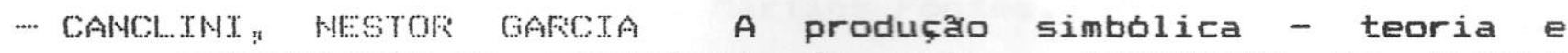
metodologia em sociologia da arte (tracuso de buta Fodrigues), Fío de raneiro, Civilizacto Brasileiran 1979.

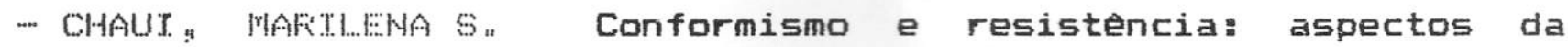
cultura popular no Brasil "Sao Faulo "Brasiliense " 1986 "

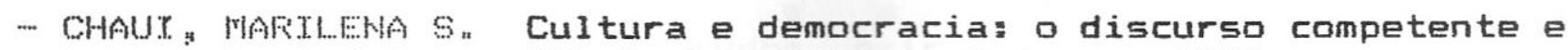
outras falas "Sa Faulo. Editora Foderna " $198 \%$

- COELHO HETrO, MOSE TETXETFA Usos da cultura: politica de aça cultural "Fio de Ganeiro, Faz e Terra, 1986.

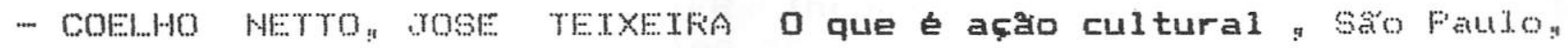
Brasi i. iensen, 1989 .

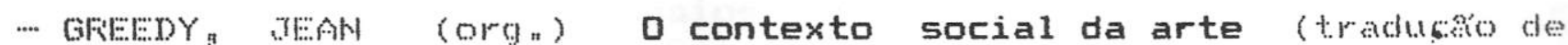
Yvone Alves Velho Sergio Flaksman), Fijo de daneiro zahar, 1975.

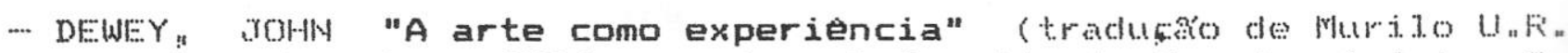
Faes Lerne) "Vida e educaça" (traducho de Antsio s.

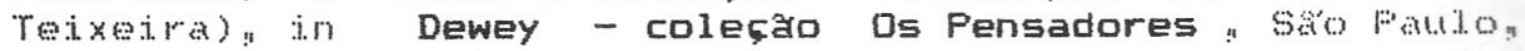
Abrit. Cul turat, 1980. 


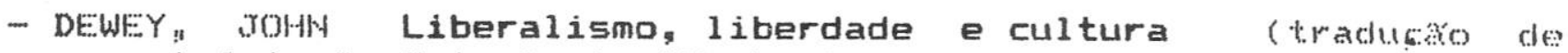

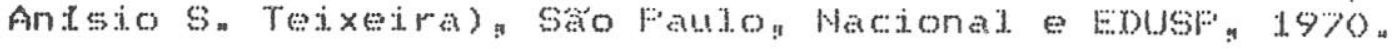

- DFEVITLLON! IEAN Psicologia de los grupos humanos (traduction de Jorge Wieto), Buenos Aires, Ediciones Wueva Vision, 1978"

-.. DUAFTE MUNIOF, TOWO FFANCTSCO Por que arte-educaça? : Campinas. Fapi.us y 1986.

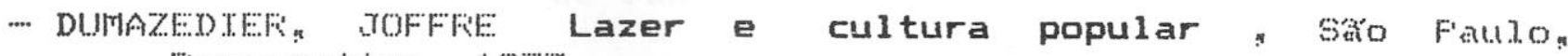
Ferspectiva: 1973 .

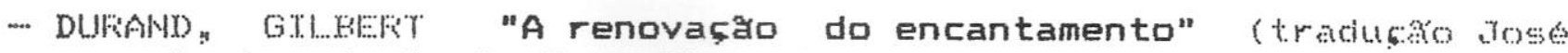
Carlos de Fata Carvalho) gevista da Faculdade de Educaço" Så Faulo, $1.5(1), 1989$.

- ECO, Umefiro Como se faz uma tese (traducho de oilson cesar de Souza) "Sao Faulo, Ferspectiva, 1989.

- FINKTEIKFAUT, AI...TAN A derrota do pensamento (traducho do Monica de Almeida) g Fio de Taneirog Faz e Terrag 1988.

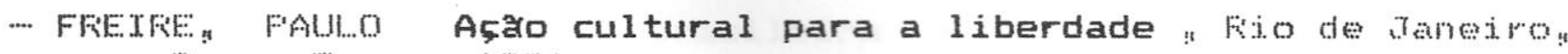
Fazererrag 1981.

-... GIFOUX, HENFY Escola e politica cultural (traducho de Dagmar M "L... Zibas), Sao Faulo" Cortez, 1988.

- HELl. vicrof A ideia de cultura (traducho de Halumi Tateyama Takahashi. "Sa Faulo" Wartins Fontes" 1989 "

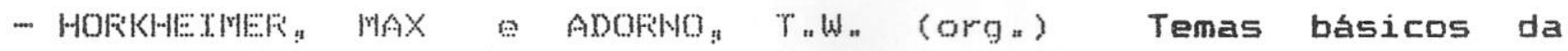
sociologia (traducko de Alvaro Cabrat), Sao Faton Cutrix. 1973 .

... TACOUE: "ELITOT "Sistemas sociais como defesas contra a ansiedade depressiva e a ansiedade persecutória: contribuição aos estudos psicanaliticos dos processos sociais" (trachero de Tose Carlos de Futha Carvalho) an Psychologie Sociale: texte fondamentaux Anglais et Americains "A "Levy (orgn), Faris, Dunod, 1978 "

- KAES: FENE ${ }^{-}$ANZTEU! DTDTEF Inconsciet et culture - Le travail psychanalytigue dans les groupes "Farisn Durod "1979"

- LANGEF" SUSANNE: $K_{n}$ Ensaios filosoficos (trachso de tranir Martinss), Săo Faulo, Cultrix, 1971."

- LAFASSADE "..EOFGES Chaves da sociologia, Fído de Taneiro.

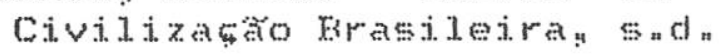

... LAFASSADE, GEOFES Grupos, organizaçes $e$ instituiçBes (traduço de Henrique Werquita), Fio de janedron Francisco A.lves, 1.983 . 
- MAFFESOLI, MCHEL O tempo das tribos (traducho de Maria de

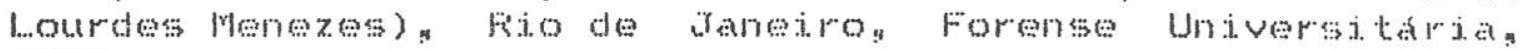
1987 .

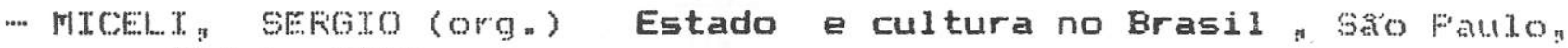
Dife1. 1.984.

... MCEI... SEFGO comparada, Fio de Taneiro, Funate/Finesp/Tdesp. 1985

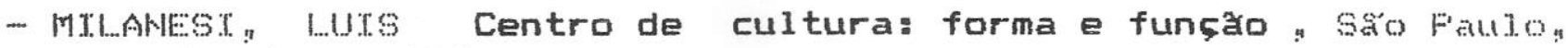
Hucitece 1989 ,

... Moscovtct, SFFGE: Psicologia social I (traciución de David Fosenbaum), Barcejona, Faidos, 1985.

-.. MOFTN, EDOAF Cultura de massas no seculo XX a fíto de Ganeiro, Forense Universitarian 1977"

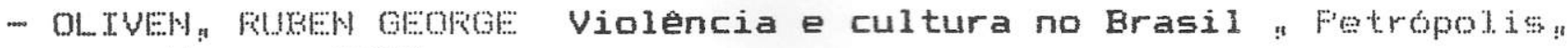
Vozess. $197 \%$.

... OFTIZ, FENATO Cultura brasileira e identidade nacional "săo Faulo, grasidiense, 1985.

... OSTFOWEF" FAYGA Criatividade e processos de criaçă " Fetropolis: Vozess 1978 .

-. FAgEs, MAX A vida afetiva dos grupos - esboço de uma teoria da

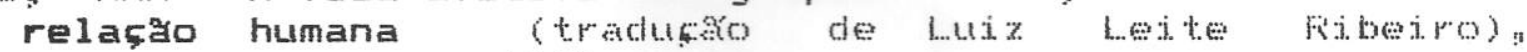
Fetropolis "Vozes, 1982.

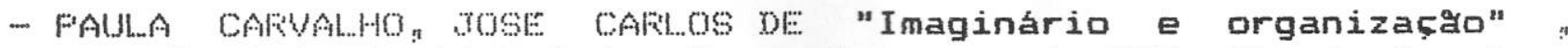
Fevista de Administraço de Empresas da Fov pio de raneiro. $25(01), 1985$,

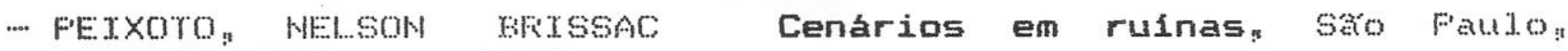
Brasiditionse "1987"

... FEFETEA MAFTA DE: LOUFDES MADFF (coOrd, Arte como processo na educaço "Fio de Taneiro, Funarte, $198 \%$.

- FIATON, GEFGies Educaça e socializaça (traduço de rose Saramago), Lisboa, Moraes liditores, 1970.

.... FOFCHE:

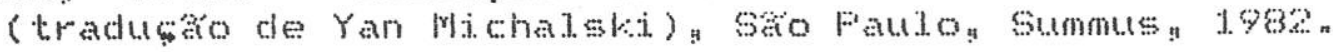

- FFOKOF" DTETEF Coleço grandes cientistas sociais (traducho de Ciro Warcondes Fitho) "Sä Fatilo" Atica " 1986.

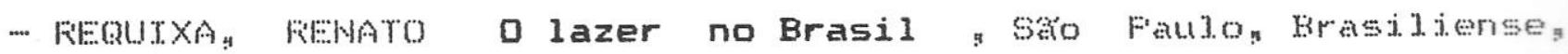
1977. 
- SCHWAFTZMMN STMON Tempos de Capanema a Fio de Taneiro, Faze rerra/Edusp, 1.984,

... SODFE: MllNT.. A verdade seduzida: por um conceito de cultura no Brasil "Río de Taneiro. Codectin "1983"

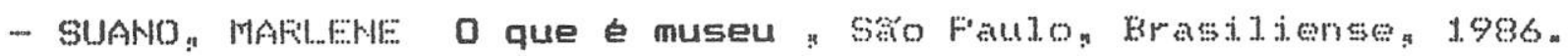


